Autonomy and control of public bodies 
PhD dissertation committee

\section{Promotor:}

Prof. dr N.P. Mol (University of Twente, Enschede)

Assistant promotor:

mrs. dr S. van Thiel (Erasmus University, Rotterdam)

Referee:

prof. dr S.E. Zijlstra (VU University, Amsterdam)

Members:

Prof. dr P.B. Boorsma (University of Twente, Enschede)

mrs Prof. dr N. M. van Gestel (Tilburg University, Tilburg)

Prof. dr G.J. van Helden (University of Groningen, Groningen)

Prof. dr M.A. Heldeweg (University of Twente, Enschede)

Dr K. Verhoest (Catholic University Leuven, Leuven)

ISBN 978--90-365-3193-1

DOI 10.3990/1.9789036531931

cover design: Jo-Ann Snel, www.boekenbent.com

editing: W. Tahil, Elycio Tekst \& Vertaling

Copyright (C) 2011 by Johan A.M. de Kruijf

Printed by WPS, Zutphen

All rights reserved. No part of this publication may be reproduced, stored in a retrieval system or transmitted, in any form or by any means, without the written permission of the author 


\title{
AUTONOMY AND CONTROL OF PUBLIC BODIES \\ LEGAL AND ECONOMIC AUTONOMY AND PARLIAMENTARY CONTROL ON SERVICE PROVISION BY ZBOS.
}

\section{DISSERTATION}

\author{
to obtain \\ the degree of doctor at the University of Twente, \\ on the authority of the Rector Magnificus, \\ prof. dr H. Brinksma, \\ on account of the decision of the graduation committee, \\ to be publicly defended \\ on Thursday June 16, 2011 at 16:45 hours \\ by \\ Johannes Antonius Maria de Kruijf
}

Born on June 25, 1961

Drunen, the Netherlands. 
Promotor: Prof. dr N.P. Mol

Assistant promotor: mw. dr S. van Thiel

Referee: Prof. dr S.E. Zijlstra 


\section{Contents}

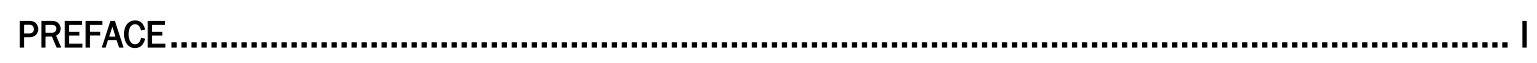

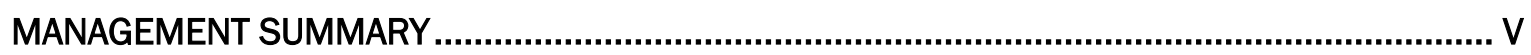

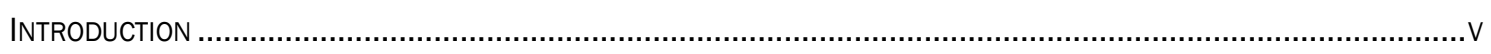

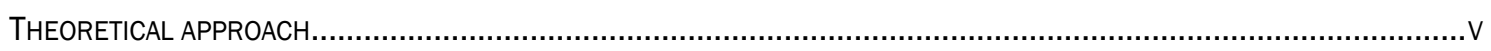

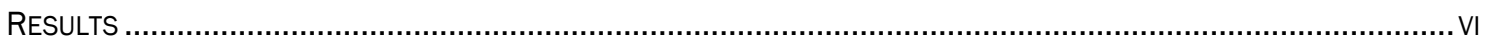

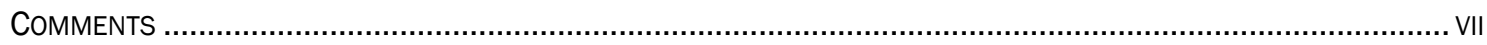

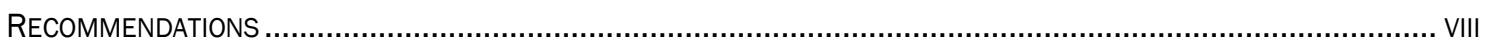

PART A: RESEARCH PROBLEM AND DUTCH INSTITUTIONAL CONTEXT ................................... 1

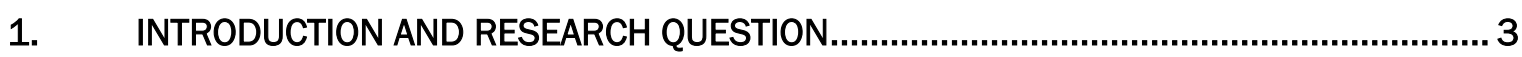

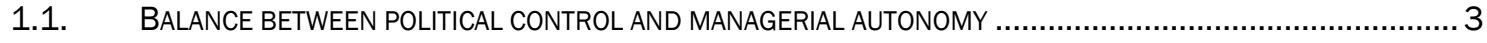

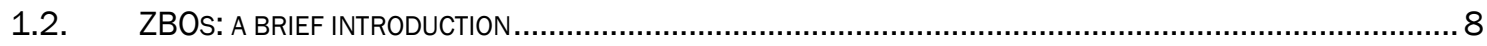

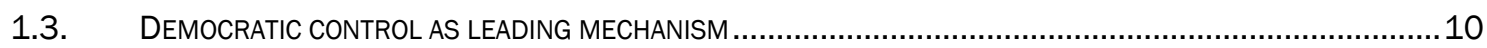

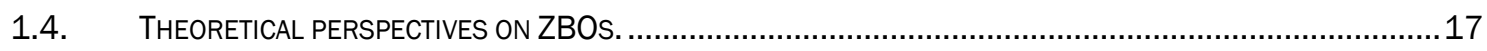

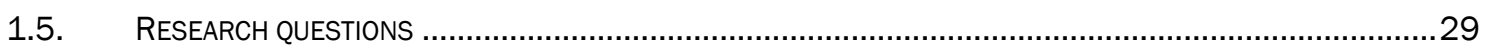

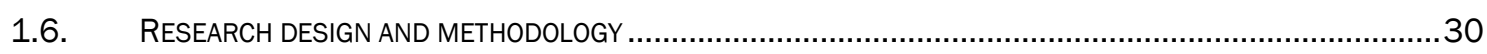

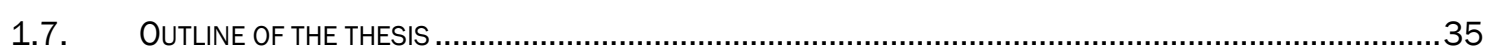

2. ZBOS WITHIN THE FRAMEWORK OF DUTCH CENTRAL GOVERNMENT .........................37

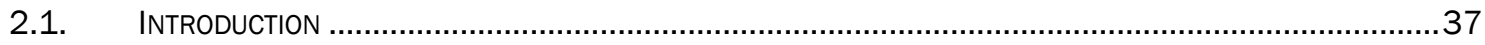

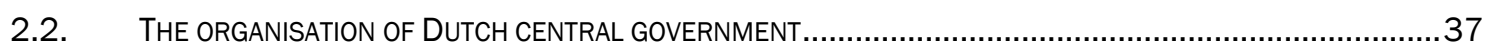

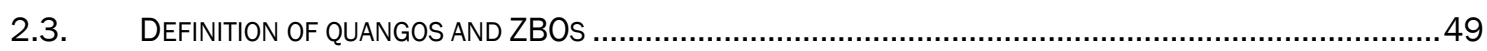

2.4. POSITIONING OF DUTCH ZBOS IN RELATION TO OTHER DUTCH QUANGOS ..............................................52

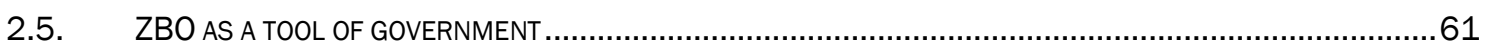

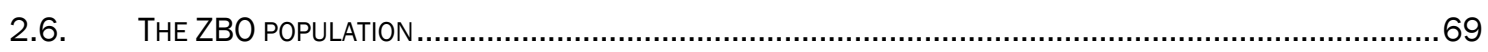

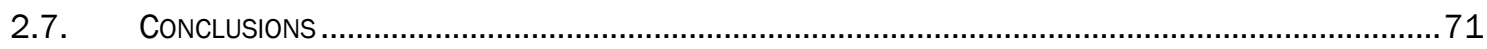

PART B: AUTONOMY AND CONTROL OF ZBOS FROM A LEGAL PERSPECTIVE............................73

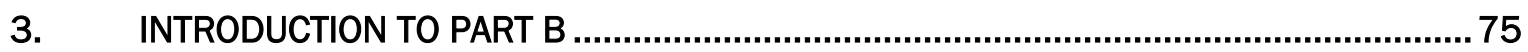

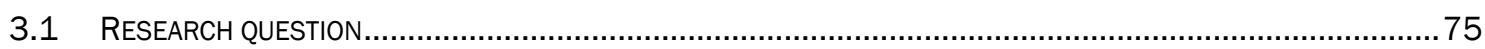

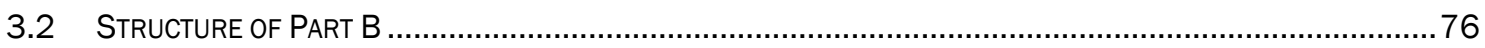

4. BUDGET AUTHORISATION: THE BUDGETING AND ACCOUNTING ACT..........................79

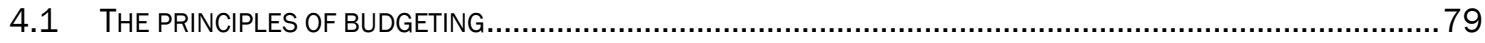

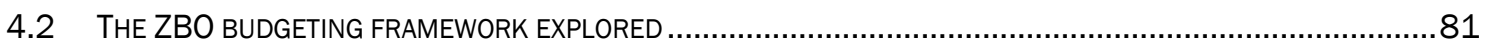

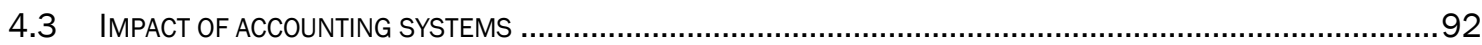

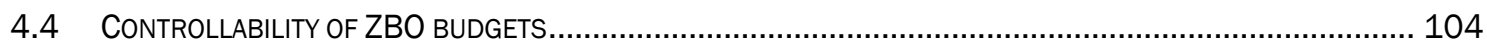

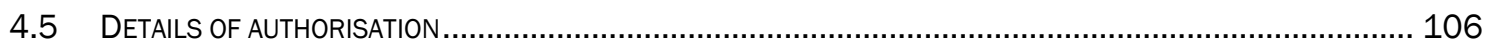

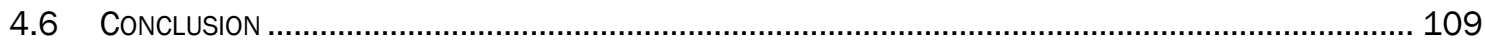




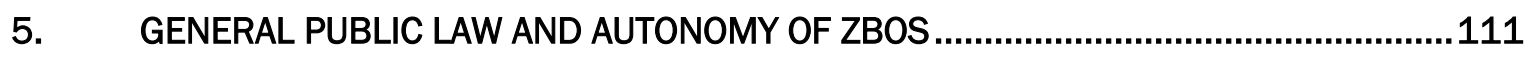

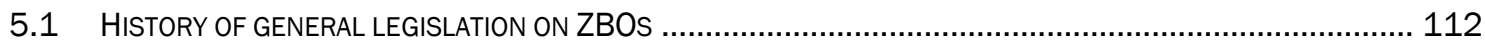

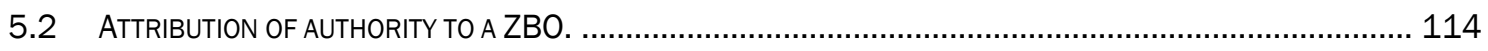

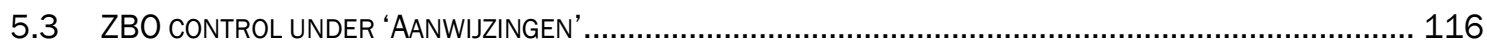

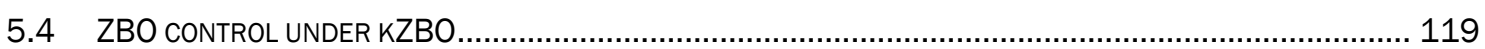

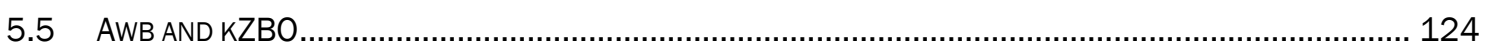

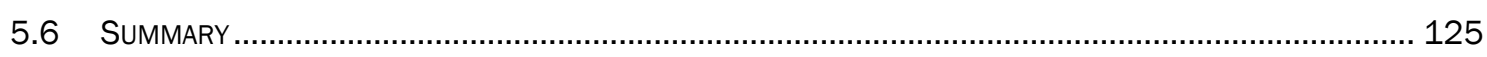

6. AUTONOMY AND MINISTERIAL CONTROL: A CIVIL LAW PERSPECTIVE........................127

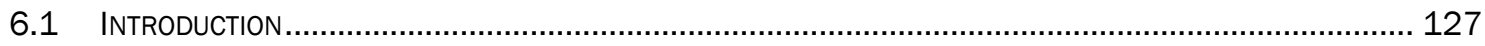

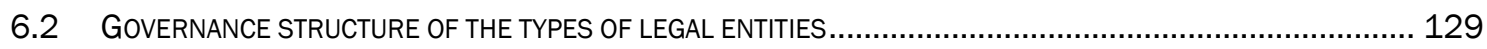

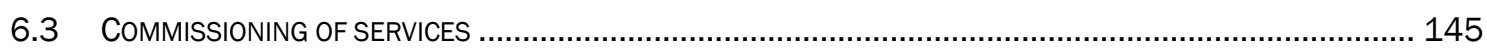

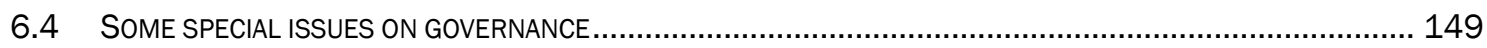

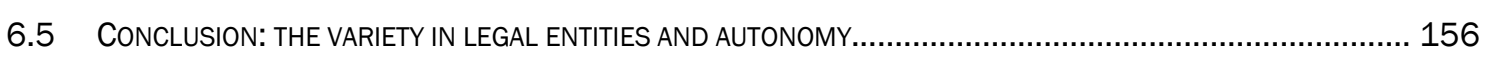

7. THE EFFECT OF LEGAL CONTROL TOOLS ON ZBO AUTONOMY ...............................159

PART C: AUTONOMY AND CONTROL OF ZBOS FROM AN ECONOMIC PERSPECTIVE...............165

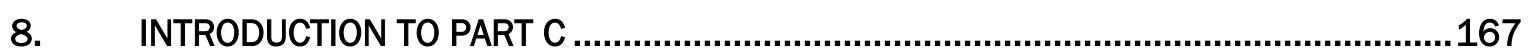

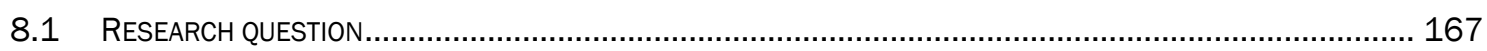

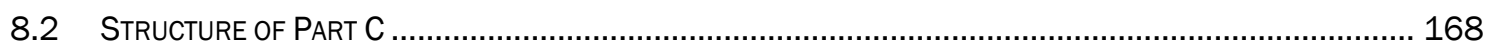

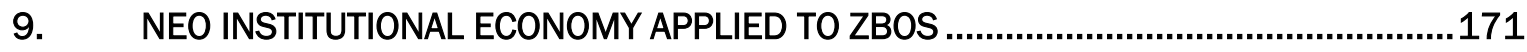

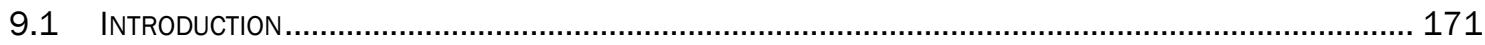

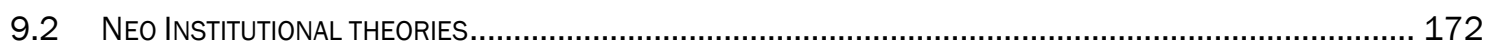

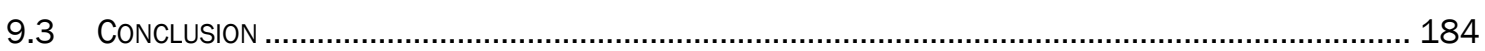

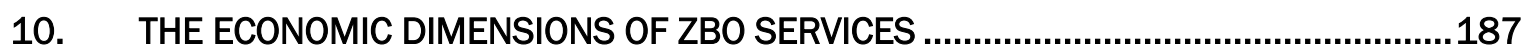

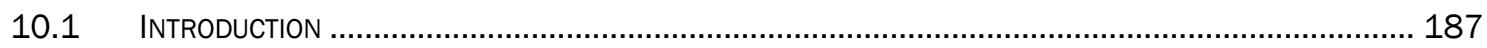

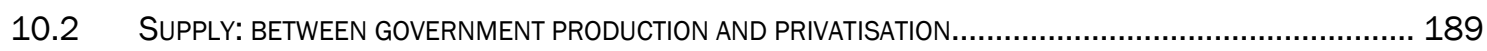

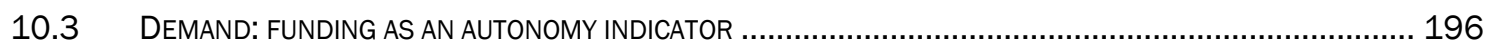

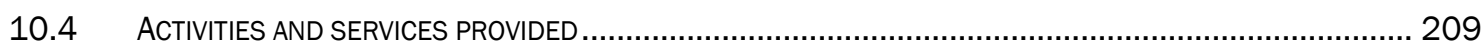

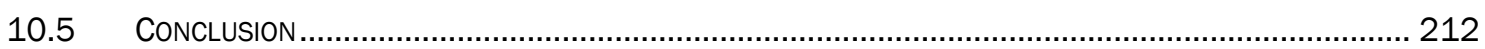

11. CONTROL TOOLS FROM AN ECONOMIC PERSPECTIVE .......................................215

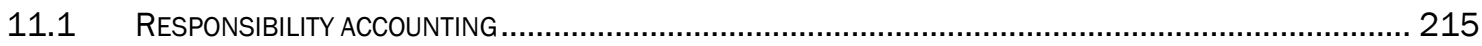

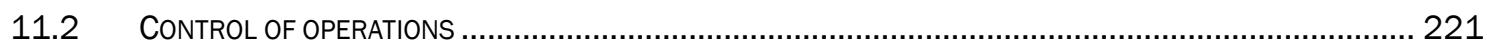

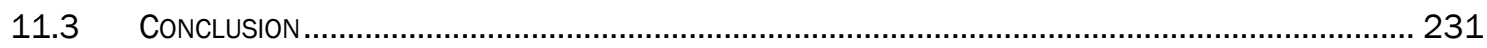

12. IMPACT ON ZBO AUTONOMY FROM AN ECONOMIC PERSPECTIVE ...........................233

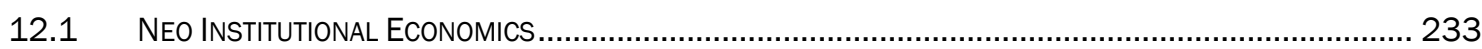

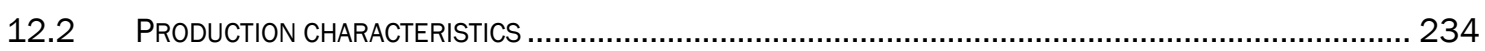

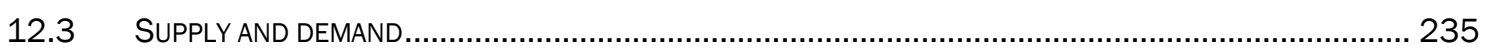

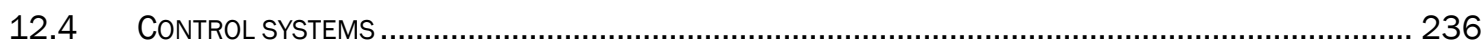

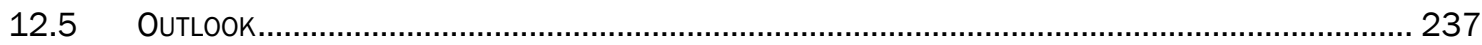


13. INTRODUCTION TO PART D

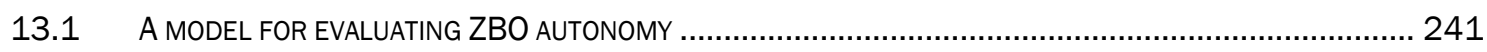

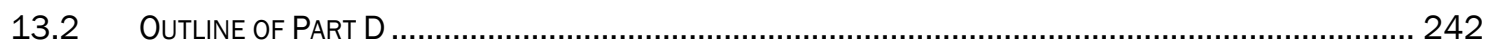

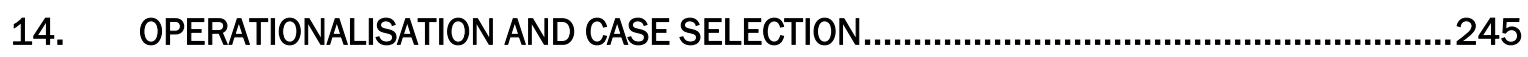

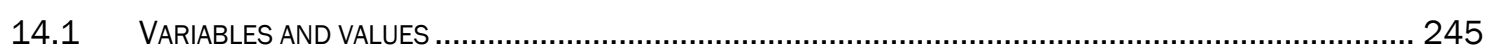

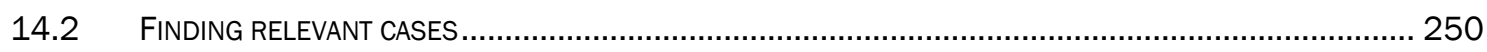

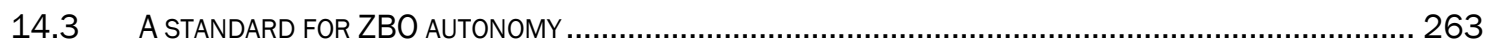

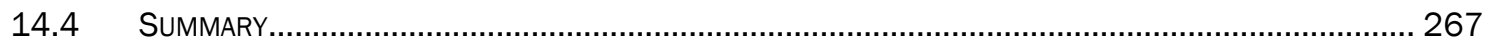

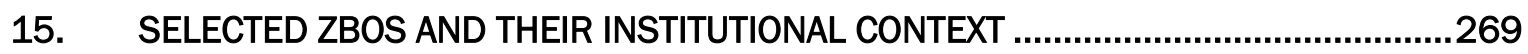

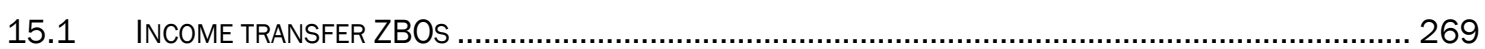

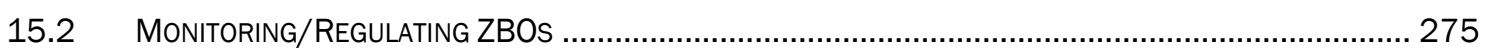

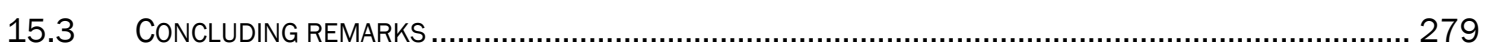

16. FORMAL AND ACTUAL AUTONOMY OF INCOME TRANSFER ZBOS..............................281

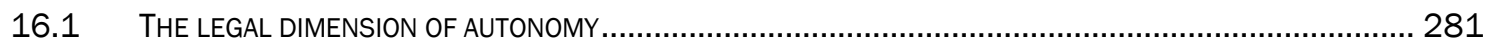

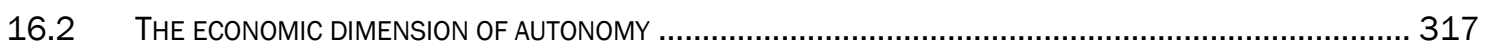

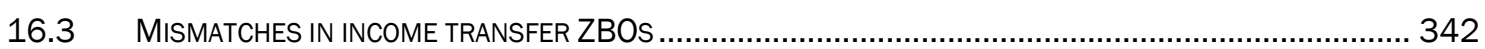

17. FORMAL AND ACTUAL AUTONOMY OF MONITORING ZBOS....................................347

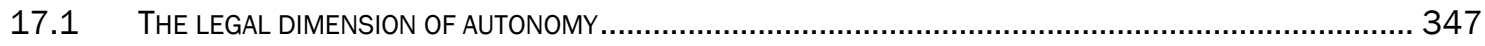

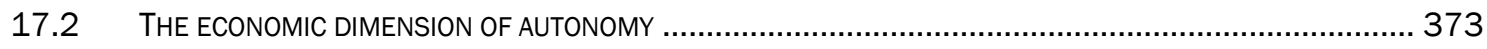

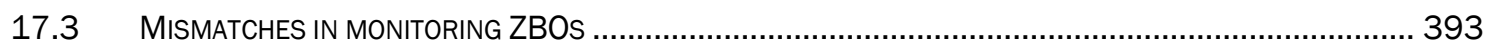

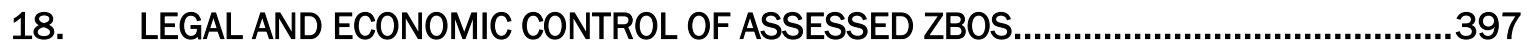

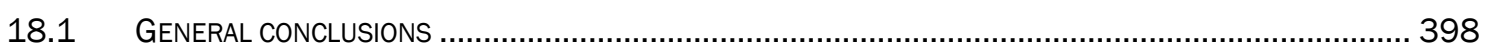

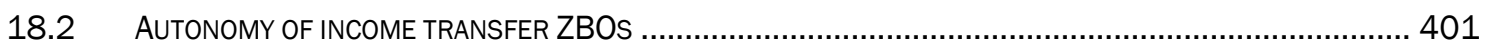

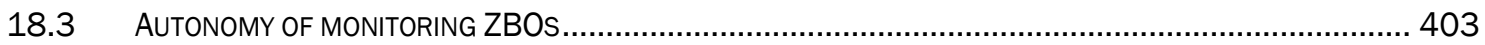

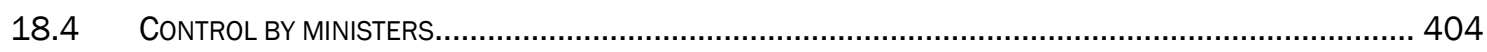

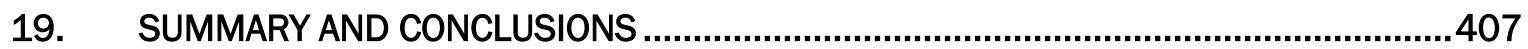

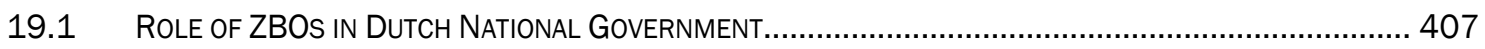

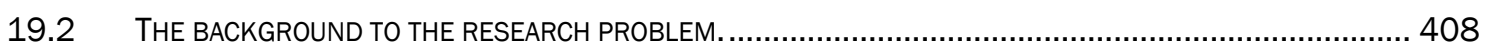

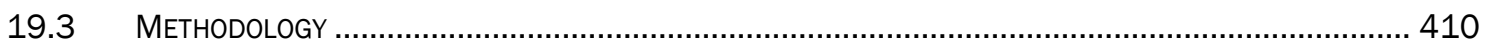

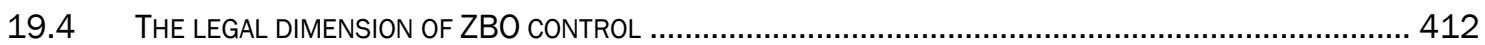

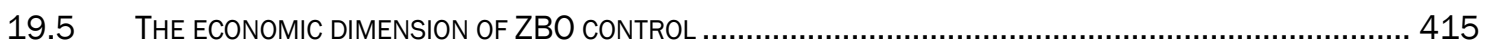

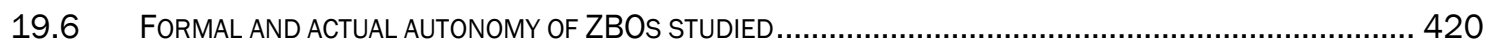

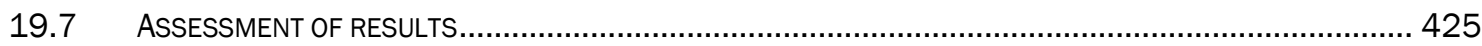

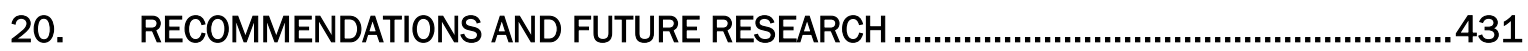

20.1 DEVELOP STANDARD FORMAT FOR INFORMATION PROVISION ON ZBOS ............................................. 431

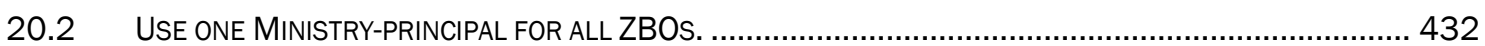

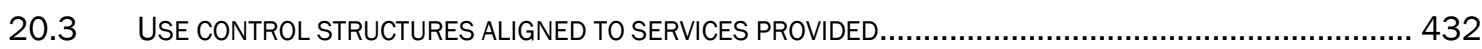

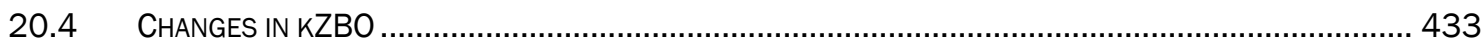

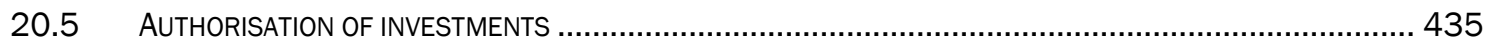

20.6 DEFINE A STANDARD FOR THE LEVEL OF EQUALISATION RESERVES ................................................ 435 


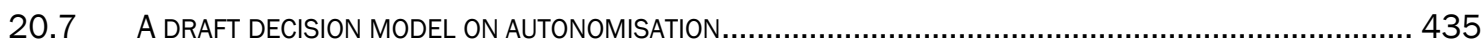

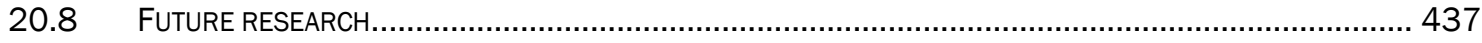

BESTUURLIJKE SAMENVATTING .....................................................................................439

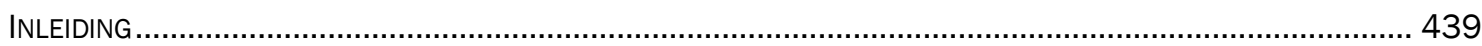

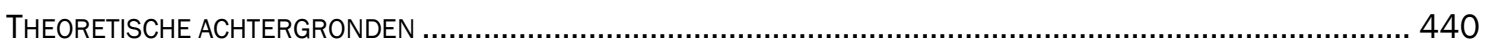

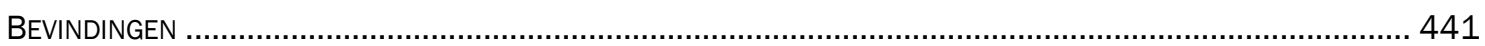

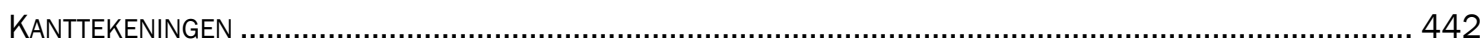

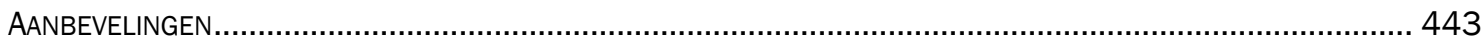

PART E: REFERENCES AND INDICES .............................................................................445

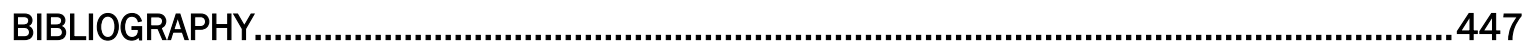

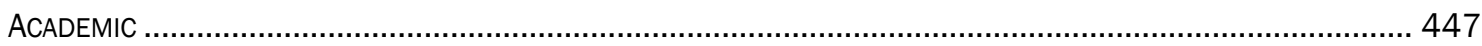

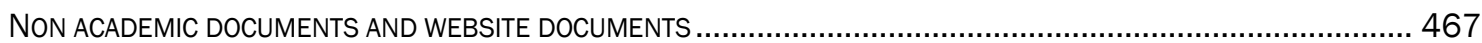

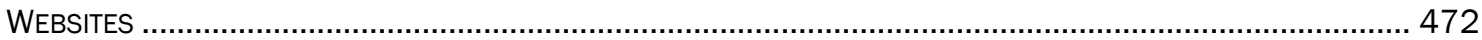

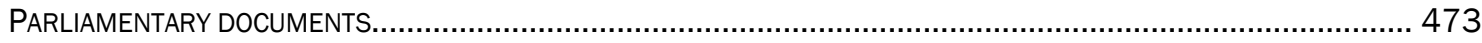

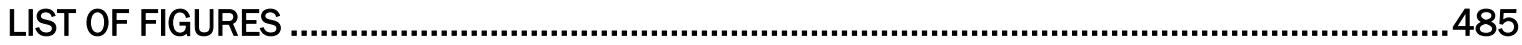

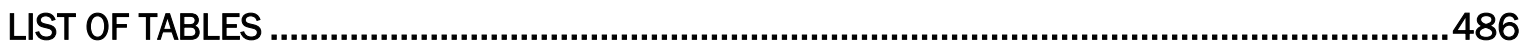

INDEX 488

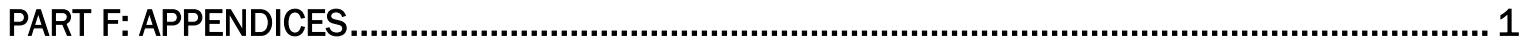

LIST OF ABBREVIATIONS............................................................................................... 2

LIST OF FREQUENTLY USED CONCEPTS............................................................................ 5

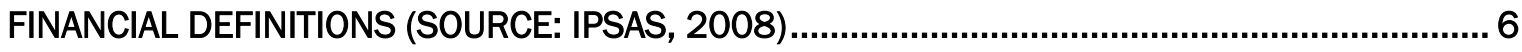

APPENDIX 1A: FULL LIST OF ZBOS AS OF JULY 1, 2007 ................................................. 7

APPENDIX 1B: LEGAL BASIS OF SELECTED ZBOS ........................................................... 18

APPENDIX 2: DOCUMENTS REQUESTED FOR PREPARATION OF INTERVIEWS .......................19

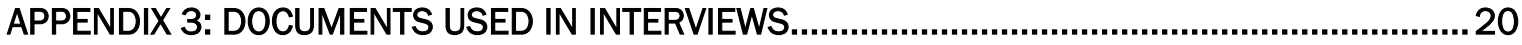

APPENDIX 4: QUESTIONNAIRE ZBOS AND PARENT MINISTRIES ..........................................27

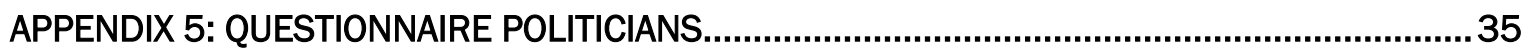

APPENDIX 6: QUESTIONNAIRE GERRITSEN COMMITTEE ................................................... 37

APPENDIX 7: LIST OF INTERVIEWEES.....................................................................................40

APPENDIX 8: RELEVANT PARLIAMENTARY DOCUMENTS ON ZBOS ......................................41

RVR 


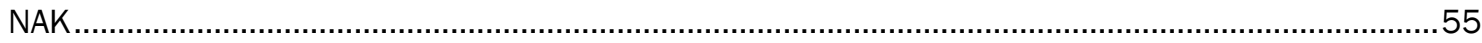

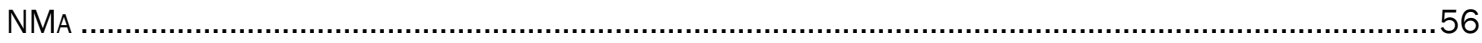

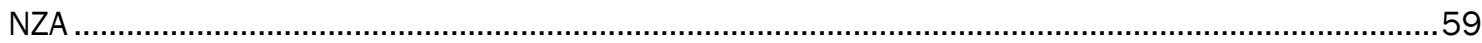

APPENDIX 9: RESPONSIBILITY CENTRE ASSESSMENT ........................................................ 61

APPENDIX 10: COMPARATIVE OVERVIEW OF ACTUAL MISMATCHES...................................6 63

APPENDIX 11: INSTRUCTIONS ON ATTRIBUTING AUTHORITY. ............................................... 71

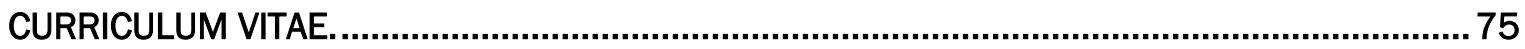




\section{Preface}

On the day I am writing this preface, a national newspaper published a four column article on the bureau for drivers license examinations CBR. It read: CBR nearly bankrupt. ${ }^{1}$ It might be that at the time of the defence of this thesis, it is know what solution has been found to solve CBR's problems. CBR is an institution that fits the definition of the research topic of this study: unilateral authoritative decision making on behalf of government outside central government's hierarchical structure. Politicians and civil servants who might have thought that the implementation as of 2008 of the framework law on ZBOs would lead to a decrease of political attention for the difficult relation between autonomy and control on ZBOs are again faced with the problematic facts.

The study focuses on a particular form of autonomisation on the level of Dutch central government. The idea goes back to my early experiences in the Dutch social security industry which has been transformed from a really arm's length non controlled public service to an industry in which political control seems to be daily routine. Given the enormous amounts of public money spent in the industry, political attention is to be expected, but should it lead to strict control on operations as well?

This PhD study would never have been written if changes in my career and the opportunities that resulted from it had not happened. Some 15 years ago, I restarted studying and changed my professional career in local government to one in the social security industry. Not much later an even more fundamental opportunity emerged, which allowed me to operate both in the academic world of public financial management as well as to continue my practitioner role. The combination of activities allowed observing what happened in organisations beyond the usual daily rush and ultimately led to a research proposal discussed at the Cigar 2003 conference. From that time I spent some of my time on the dissertation, resulting in the publication you are reading right now. Yes, it took a while to write it down, but rest assured that motivation improves if you are not only focusing full time on a PhD study. Practical experience and spending time on other issues allow making progress on the days, weeks or months that are actually used to write the thesis.

Although writing is a personal activity, discussions on the research project are an essential part of completing the project. Dear Nico, your comments have first of all contributed to my knowledge and understanding of neo-institutional economics in the public sector, an issue that was only developing when I started taking university classes. Furthermore, you have contributed to finding a balance between the abstract structure of the study and the attention for the details that can help to illustrate abstract concepts. Dear Sandra, your knowledge on the field of ZBOs and your methodological contributions

\footnotetext{
${ }^{1}$ NRC Handelsblad, January 24, 2011.
} 
helped mapping the field and developing a research strategy that has brought this study beyond a mere case based study. Whether on individual cases or the general theme of controlling arm's length organisations, you were willing to discuss problems and provide directions for solutions to unresolved issues. Dear Sjoerd, you have had the difficult task to fill in a gap in knowledge on legal issues, discussing them with someone who only had some basic education in law. Thank you for spending time on this study even in a time in which you had other things on your mind.

Without the academic support of many at the School of Management and Governance and the Department of Finance and Accounting, this thesis would not be what it has become. I would particularly like to mention prof. dr P.B. Boorsma and dr J.M. Bos who regularly reminded me of my academic duties and were always willing to discuss issues at hand. Of course, the support of Annette, Manon and Jolande for many practical issues was always available whether I was at my Enschede office or somewhere else. The academic world does not end at the campus of the University of Twente. I would like to thank the academics in the Cigar and EIASM networks for their time and comments on drafts and thoughts that ultimately have resulted in this book.

A special word of thanks is needed for all the respondents who were willing to answer my questions on the individual cases. Their contributions are at the heart of the practical empirical findings in this study. I hope that the comparative elements in the book can contribute to a better understanding of control issues and the differences observed between the individual cases.

Let me not forget the colleagues and the management of the UWV control directorate who were faced with a colleague who spent most of his time doing things that were beyond the daily control routines of the organisation. This project has now come to an end allowing for more flexibility in prioritising tasks to be realised. I can't promise to be at my Amsterdam office more regularly but there will be more time available for your questions and UWV issues.

The last part of this preface focuses on my family. My parents made it possible to choose for the unusual lines of education, both in secondary school and later at University. Directly and indirectly they stimulated my interest in politics and public administration which have resulted in sometimes lively discussions. Their support during the years of education has been crucial.

The question most asked at home was "when will this booklet of yours finally be completed?' Lisanne and Mathieu do not know better than having a father who was in his study writing or reading or somewhere outside for meetings and conferences. Only in the weekends and during holidays some spare time remained for family life. They will now be confronted with the results and there will be structurally more time, especially in the weekends. My beloved Frederike, the final word is to you. Having a serious full time job is still not common for Dutch women, whether it is the glass ceiling or other cultural issues that play a role is for a later debate. Fact is that you had to find your way in managing 
your job, and finding time for children as well on all these days that I have spent on doing the job I felt I had to do. We don't know what the future will bring to us, but rest assured, without your backup and support, I would never have finished this project. Therefore, the book is dedicated to you. 


\section{Management summary}

\section{Introduction}

In the last three decades, autonomisation and decentralisation of government services have been important trends. In very general terms, (new) organisations were set at arm's length of government, often based on arguments of improved efficiency. In this study I have assessed a particular Dutch variety of arm's length organisations, Zelfstandige Bestuursorganen (ZBOs), from a legal and economic perspective. The research question in the study is:

\section{Do Parliamentary control tools match the legal and economic operational autonomy attributed to ZBOs?}

The idea is that legal and economic control tools must be aligned to prevent conflicts affecting the autonomy of ZBOs. Furthermore, based on the control tools used, an indication can be given of the actual autonomy in operations of a ZBO. In this management summary, emphasis is on results. A more elaborate summary of the study is given in chapter 19 .

ZBOs are organisations delivering services on behalf of central government. The key feature of ZBO services is delivering unilaterally binding decisions by an organisation outside the hierarchical structure of central government. An example of a ZBO is the land registry office 'Kadaster', whereas the state owned railway company 'Nederlandse Spoorwegen' does not qualify as a ZBO. Depending on counting methods and interpretation of definitions, the number of ZBOs ranges from over 100 to over 600 . I have grouped ZBOs based on government publications to 128 different (groups) of organisations by July 2007, spending some $€ 7$ bln on operations and over $€ 80$ bln on program costs. Total costs of ZBOs are equivalent to some $40 \%$ of total Dutch national government spending.

\section{Theoretical approach}

The arm's length position of ZBOs towards central government raises some problems. On the one hand autonomy is intended; on the other politicians regularly want to reclaim control over these organisations. In some cases, budgets of ZBOs are clearly disclosed in budget documents submitted to Parliament, in other cases budgets are not disclosed at all. This makes it difficult for Parliament to assess operations and performance of ZBOs. After a long debate, initiated by a critical report in 1995 by the Netherlands Court of Audit [NCA], in 2008 a new law - 'Kaderwet Zelfstandige Bestuursorganen' [kZBO] - was implemented that is intended to standardise control measures on ZBOs. The law does not solve the problem of transparency of budgets towards Parliament and does suggest that 
although deviations from the standard are possible, a one size fits all approach for controlling ZBOs is needed.

My study was started during the debate on KZBO and takes a different approach. Earlier studies showed that there is variety between ZBOs, which is based on differences in legal status but also on funding of operations of ZBOs. Based on this knowledge, I have decided to study the legal measures and the economic characteristics of individual ZBOs. Together these dimensions determine the possibilities for planning and control and thus ultimately control of ZBOs by Parliament. If inconsistencies between legal and economic control tools exist, actual control of ZBOs is likely to be problematic and results in unintended increase or decrease of autonomy.

\section{Results}

It is not possible to cover all ZBO cases in the study due to the number of ZBOs that exist. I have selected 11 cases from within two main groups of ZBOs (income transfer and monitoring ZBOs respectively). Based on the theoretical framework, document studies were realised based on legislation and control documents available. Furthermore, interviews with staff of ZBOs and of the relevant principal-ministries were held. The combination of document study and interviews allows assessing not only the formal but also actual control on ZBOs as used on behalf of Parliament.

In developing the theoretical framework, three different general legal perspectives were used: budgeting legislation, general public law including the general control measures available on ZBOs and civil law. The latter is needed because several ZBOs have a civil law status. Furthermore, civil law can be used to describe relations of service provision between two formally independent organisations. The general legal framework is used as a yardstick for the formal measures in individual ZBO cases as reflected in ZBO-case law. Many of the legal measures are mentioned in the current kZBO but still need to be included in ZBO-case law.

From an economic perspective, I have used three lines of theory. First Neoinstitutional economics provides tools to be used in cases where management and ownership of organisations are not in the same hands. Issues such as incentives for management, control tools available to management as well as transaction costs associated with monitoring management are discussed. The second line in economic theory is based on product- and production characteristics. It covers discussions on mass production versus unit production and on measurement of services. The third line of theory covers market characteristics including fully integrated versus fully privatised production, on funding of services delivered and the related topic of the origins of demand and use of services. These economic perspectives are ultimately reflected in a set of possible control tools that fit to the particular characteristics of services of a ZBO. It 
means at least theoretically that differentiation in control of ZBOs is needed from an economic perspective.

When services delivered by ZBOs are similar, one might expect that control tools as designed and actually used are similar as well. Theoretically this means that a set of expected standard controls can be developed and used for assessment. I have tested the hypothesis on six income transfer ZBOs and five monitoring ZBOs. 2 The classification in subgroups of ZBOs was based on the core services delivered by the individual ZBO as found in their annual reports.

The following conclusions and observations were found in this study:

1. After testing designed and actual control tools in eleven cases, in only three cases a match of actual legal and economic control tools is found.

2. In eight cases, emphasis is on legal controls rather than on economic controls.

3. Public law ZBOs are controlled on a more restrictive basis than was expected.

4. Income transfer ZBOs are faced with more restrictive controls than monitoring ZBOs.

5. Ownership and commissioning role are not clearly separated and in some cases ministries act inconsistently.

6. Budgetary control, often based on lump sum budgets prevails over activity based budgetary controls.

7. Performance information is not provided on a consistent basis.

The answer to the research question is thus that in most cases studied here, formally designed and actual control do not match because legal controls restrict the possibilities for control given the economic characteristics of the services delivered by the ZBOs studied here.

\section{Comments}

In a nutshell some comments on the results are given. First, full generalisation of the results to all ZBOs is not possible. However, NAK and FBKVB are ZBOs that are single cases within groups of identical ZBOs. In these two cases, it is likely that the other ZBOs in these clusters will be controlled similarly. Second, based on interviews with some members of Parliament [MPs], it was found that on the one hand information provision is problematic and rather minimal. On the other hand, MPs cannot handle the information overload they are faced with. A more structured approach on information provision on all

2 names in Dutch (see list of abbreviations) Autoriteit Financiële Markten (AFM); Centraal Fonds voor de Volkshuisvesting (CFV); College voor Zorgverzekeringen (CVZ); Fonds Beeldende Kunsten, Vormgeving en Bouwkunst (FBKVB; Nederlandse Algemene Keuringsdienst voor Zaaizaad en Pootgoed (NAK); Nederlandse Mededingingsautoriteit (NMa); Nederlandse Zorgautoriteit (NZA); Raden voor Rechtsbijstand (RvR); Sociale Verzekeringsbank (SVB); Uitvoeringsinstituut Werknemersverzekeringen (UWV); Vervangings- en Participatiefonds (Vf/Pf). 
ZBOs and not only those funded by government would be helpful. Furthermore MPs indicated that except for ZBOs that provide impartial judgement services (such as the market regulators studied here), a different and less restrictive control is needed than for other ZBOs. A last point to be made here is that the analysis is based on ideas of improving public management as expressed in the new public management paradigm. The findings in this study show a great variety in controls applied and raise questions on consistency in creating ZBOs in the Dutch context. It was even observed that in some cases, ministries act inconsistently towards ZBOs they control. It seems that issues such as historic background, culture and complexity also have an impact on how control in particular cases is organised.

\section{Recommendations}

Based on what has been found in this study the following recommendations are worth considering:

1. Develop a standard for information provision on ZBOs.

2. Create one Ministry-principal for all ZBOs.

3. Use control structures aligned to services provided.

4. Change kZBO legislation on multiyear budgets, providing assessed annual reports to Parliament, appointment of PLB boards and some other technical issues.

5. Authorise investments of ZBOs.

6. Define a standard for the level of equalisation reserves.

Finally, from a research perspective it might be worthwhile to focus on political relevance and stability of services provided as a driver for decisions on organisational structure for public service delivery. 
Part A: Research problem and Dutch institutional context 


\section{Introduction and research question}

Around 1990, a number of reorganisations carried out at Dutch central government level resulted in the creation of various forms of quasi autonomous executive organisations as well as privatisations. In this study, I will focus on a particular type of quasi autonomous organisation - 'Zelfstandig Bestuursorgaan' [ZBO].3/4 These organisations provide services on behalf of government but are not under direct control of a minister. This implies that there is a lower level of democratic control on these organisations compared to a traditional government unit.

My objective is to assess the actual autonomy of ZBOs in relation to their political masters from an economic and legal perspective. Are ZBOs really autonomous as their name suggests or is autonomy reduced or even only a matter of window dressing because legal provisions are not consistent with the economic characteristics of the services provided? In several reports, the Netherlands Court of Audit [NCA] 5 has discussed the position of ZBOs in relation to accountability towards minister and Parliament. I will focus on task assignment and control of ZBOs because when no standards are set, a legitimate question would be: "Accountability - to whom and for what?" Basically there is a control relationship between the responsible minister and the ZBO. However, ultimately Parliament is the key democratic institution at the national level and a minister only holds office as long as Parliament has confidence in the minister. This means that ultimately tasks assigned and controls upon ZBOs are subject to decisions in Parliament. Therefore a draft research question for this study is: How does Parliament control ZBOs?

The study is organised into four separate parts. In Part A, the research problem and questions are developed and a general context on ZBOs is given. In Part B, the legal dimension of autonomy is discussed from a general level, ignoring particular measures for individual ZBOs. Part $\mathrm{C}$ focuses on the economic dimensions relevant for autonomy. Finally, in Part D, legal and economic aspects of autonomy are brought together. This results in 1) observed formal legal autonomy; 2) observed actual implementation of legal measures; 3) observed economic characteristics of individual ZBOs and 4) (mis)match between the legal design, economic characteristics and actual control. The answer to the research question will provide indicators for improving legal and economic control tools and thus implicitly improving ZBO accountability to the political system.

\subsection{Balance between political control and managerial autonomy}

Dutch central government traditionally executes most of its activities in ministries, politically led by ministers. The budgets of these ministries are subject to authorisation by

3 ZBO can be translated as Autonomous Authoritative Body.

${ }^{4}$ All translations of Dutch texts are mine, unless otherwise stated.

${ }^{5}$ A comparison of the Dutch NCA to the UK National Audit Office is given in Lonsdale (2007). 
Parliament. ${ }^{6}$ The details of the authorisation process are regulated by the 'Comptabiliteitswet' ([CW] 7; Budgeting and Accounting Act). Even before the first CW was created in 1927, it was recognised that in some cases, a more business oriented model of financial management for government activities might be suitable (Van den Bent, 1989, p. 154-155). The role of Parliament in the authorisation process in these cases was restricted compared to its role of authorising ministry budgets. After World War II, the development of the welfare state and later on, debates on privatisation and autonomisation $^{8}$ of production of government services resulted in the creation of numerous semi-public or semi-private organisations. Each of these at arm's length organisations has different roles and positions in the political system (e.g. Boxum, de Ridder \& Scheltema, 1989, p.1-2; Van Thiel, 2001, p. 5-6).

In 1974, Scheltema coined the concept Zelfstandig Bestuursorgaan. He characterises ZBOs as entities that execute part of the government's authority with some degree of freedom (Scheltema, 1974, p. 4). Scheltema focuses on the tension between autonomy and political control, basically from a legal point of view. In his opinion, full ministerial authority does not match with the intention to manage a civil service unit at arm's length (Scheltema, 1974, p. 13). Scheltema does not consider the financial connection between a minister and a ZBO. When authoritative tasks are carried out, one would expect Parliament to be able to exercise its budget authorisation prerogatives on the same basis as in case of authoritative tasks executed by traditional government units like in this case, ministries. This is based on the rule in public finance which states that when government wishes to achieve objectives by raising taxes and spending funds, this can only be performed after the consent of a democratically elected institution (e.g. Goedhart, 1958, p. 282-283; Schick, 2000, p. 9; Lauth, 2002, p. 43). This principle still holds, but is complicated by the fact that government activities provided by traditional government units such as ministries or cities may be funded by resources other than taxes (e.g. Wagner, 1991). It is also possible that services on behalf of government are provided by other institutions that are not immediately identified as institutions of government. Dutch ZBOs are an example of institutions providing services on behalf of government, which are not part of government. The odd thing in the Dutch budget process is that in some cases, budgets of ZBOs are not included in the budget laws authorised by Parliament. Does this mean there is no control at all or do other measures compensate for this lack of budget authorisation by Parliament?

Take for example the case of the re-organisation of the production of social security services management system, implemented on January 12002 . This social security reorganisation involved, amongst other things, merging five former private companies and one public organisation into one new large ZBO called 'Uitvoeringsvoeringsinstituut

6 I use Parliament when both Tweede Kamer (House of Commons/House of Representatives) and Eerste Kamer (House of Lords/Senate) are meant. Where necessary I refer to the specific House.

7 Acronyms will be indicated between [ ]. A list of acronyms is included in the appendices.

8 Autonomisation is used as a catch all phrase for granting some degree of operational and/or legal autonomy for public service providers other than full privatisation to the market. 
Werknemersverzekeringen' [UWV]. The Ministry of Social Affairs and Employment [minSZW] ${ }^{9}$, budget includes some $€ 34$ million to cover reorganisation costs (Parliament, 2001a, p. 105). Somewhere, almost hidden in an explanatory memorandum (Parliament, 2001 b, p. 151), the actual total operating ${ }^{10}$ costs (€1.8 billion!) of all three social security ZBOs are to be found. In the same explanatory memorandum, social security program costs are presented, totalling $€ 57.2$ billion but this is not immediately related to the organisations that are responsible for distributing program benefits. A Member of Parliament has to invest some time to find the UWV full program budget and the operating cost budget as it is spread over two main categories and a number of programs (Parliament, 2001b, p. 148-150 and p. 182-191). As of 2005, information on individual ZBO operating budgets are presented in an appendix to the ministerial budget document, but in the case of UWV there is still no formal operating cost budget proposal (Parliament, 2004a, p. 225). Although some additional information is disclosed in the 2009 ministerial budget document, this is still essentially the case (Parliament, 2008a, p. 177178).

Some 20 years after Scheltema's remarks, three reports put the issue of controlling ZBOs seriously onto the political agenda. First, in 1989, Cabinet submitted a document to Parliament on 'functional delegation'. In functional delegation one single activity of government is transferred to a separate unit, not fully controlled by Parliament and a minister. With respect to ZBOs in particular, Cabinet stated that ministerial responsibility is restricted to key issues and not to individual decisions. The precise legal context is irrelevant; the key is that authority is transferred (Parliament, 1989, p. 3-4). Second, there was a report by a government appointed committee - the Sint Committee (1994) which analysed the motives for creating ${ }^{11}$ ZBOs. This report was the result of earlier (Sint Committee, 1994, p. 6) debates on autonomisation of central government units.

Around the same time, the NCA published its FY1994 annual report. In this report, the NCA concluded that governance and control of ZBOs was insufficient. The key issue according to the NCA is that a minister has "insufficient powers to be able to carry out his general responsibility for the policy area in which ZBOs operate as well as for the budgets required for the ZBO to execute public tasks" (Parliament, 1995a, p. 4). The Dutch Cabinet ${ }^{12}$ responded that it intended to "restore the political primacy by means of more precise control of executive government units by Cabinet and Parliament" (Parliament, 1995b, p. 1).

\footnotetext{
${ }^{9} \operatorname{minXXX}$ will be used as a general shorthand for all Dutch ministries, see also list of abbreviations.

10 I use 'cost of operations' or 'operating costs' when I address the full scope of costs that are incurred to run the ZBO; the concept of operational costs is only used when expenses excluding investment related expenses (depreciation, interest) are meant.

11 I will use 'creating a unit' when I mean that some organisational unit is set at arm's length of government irrespective of the legal form. I will use 'establishing an entity' when the unit at arm's length is given a separate legal status outside the legal entity 'State'.

12 An elaboration on the Dutch Constitutional setting will be given in chapter 2 .
} 
In the more than 10 years that have elapsed since publication of the NCA-report, several initiatives have been started to improve control and restore political primacy. By the end of 2006, a framework law had passed through Parliament - 'Kaderwet Zelfstandige Bestuursorganen' [kZBO] - in which general measures for creating and controlling ZBOs are laid down. The law is effective for all newly created ZBOs as well as for existing ZBOs if the legislative framework for the individual ZBO explicitly refers to kZBO (kZBO:2a).13 Also at the end of 2006, the NCA presented a new report regarding a larger group of organisations at arm's length of government in which it concluded that improvements have been achieved. There are still accountability and control gaps: public accountability "can be improved" and "information provision towards Parliament requires improvements", especially because "Parliament has insufficient understanding of operations... and on the cash flows and equity of the organisations at arm's length of government" (Parliament, 2006a, p. 9). In early 2007, the Council of Economic Advisors of Parliament [REA] made comments on ZBOs by stating "that there is only a limited overview on the operations of government because authority and responsibilities are not clearly defined" (Parliament, 2007a, p. 3).

Both the NCA and REA opinions indicate that despite all efforts, there is still a problem regarding control of at arm's length government entities ${ }^{14}$ such as ZBOs. On the other hand, managers of at arm's length entities express their feelings that government should not draw back from the path of granting autonomy (Tokmetzis, 2006, p. 5). Although the conclusions of NCA and REA do not cover exactly the same groups of organisations, they are an indication of a problematic situation. The NCA comments seem to focus only on expost control themes on at arm's length entities. REA however, seems to point out that there is still a more fundamental problem regarding control of ZBOs. Following the line of argument given by REA, being held accountable implies that service delivery standards, perhaps merely a fixed budget, exist beforehand. In the example of UWV, I indicated that Parliament does not have the proper information to set these standards in the form of a budget authorisation. In my opinion, this means that what Janse de Jonge (1993, p. 1) referred to as the "most fundamental right of Parliament" is apparently not working properly when applied to entities at arm's length of central government. Without proper authorisation, no expenditure compliance standards can exist. Additionally, the standards for a statement on accountability cannot be set at all without an ex-ante framework.

The problem of balancing autonomy and political control of ZBOs is not just a Dutch issue. Under the labels of Quasi non governmental organisations [Quangos] (e.g. Barker, 1982; Ridley and Wilson, 1995), Public Law Administrations [PLA] and Private Law Bodies [PLB] (OECD, 2002) and Hybrids (e.g. Kickert, 1998; Koppell, 2003) similar

13 References to legislation have the following structure: $Y Y: X . Z ; Y Y=$ acronym of relevant law, $\mathrm{X}=$ relevant article number, $\mathrm{z}=$ relevant sub article number.

14 In some cases arm's length organisations are not separate legal entities but units within an organisation. This is for example the case in executive agencies. 
control issues regarding organisations at arm's length of government are described for many western countries. Greer, Hoggett and Maile (2003, p. 41) refer to the fact that in studying control of organisations at arm's length of government, one should take into account that the context and history of each organisation should be examined to be able to assess actual autonomy and political control. I note here that, although it is not explicitly discussed in the literature, control is about controlling operations and resulting output. Quangos, including ZBOs, are generally used to execute programs as efficiently as possible. The program itself is given. If a program includes income transfers, these are subject to separate control mechanisms which in most cases do not affect the debate on quangos.

The case of UWV described above confirms Greer et al.'s point. Superficially studied, it seems that UWV has quite a lot of autonomy because Parliament does not authorise the budget of the organisation. This is not the case as can be seen from a letter from the Minister of Social Affairs and Employment to Parliament in early 2006, in which he stated that he did not approve the UWV 2006 budget proposal (Parliament, 2006b). This example shows a paradox in the political control of ZBOs. On the one hand no formal budget authorisation by Parliament is realised in a number of cases. On the other hand political intervention by ministers on ZBO managerial decisions do occur, just as if a ZBO is nothing more than a classic government entity under full budgetary scrutiny of Parliament. To put it in even stronger terms, in a debate on organisations at arm's length of government, representatives of both the opposition and the majority demanded transparency on all cash receipts and cash payments ${ }^{15}$ processed by these organisations (Parliament, 2004b).

Hogwood (1995, p. 31) noted that in the UK organisations at arm's length of government sometimes have the power to raise their own funds, resulting in reduced Parliamentary budgetary control. In the Netherlands some ZBOs are also able to raise their own funds. When such funds can be regarded as compulsory contributions, there is a strong similarity to raising taxes, which is regarded as the prerogative of the legislature (for the Dutch case see e.g. Goedhart, 1958, p. 282-293). The rationale behind democratic consent on raising taxes is the compulsory character of taxes, affecting individual's wealth (Lauth, 2002, p. 43). In cases where government provides a service funded by taxes, authorisation by Parliament is required. From a budgeting perspective, providing a compulsory service for which citizens have to pay a fee ${ }^{16}$ rather than having to pay taxes, the effect is actually the same. The effect on someone's wealth is achieved indirectly because the citizen cannot avoid using the service and making the

15 In the Dutch text the words 'inkomsten en uitgaven' are used. I have chosen to use the wording used in the International Public Sector Accounting Standards IPSAS1 and IPSAS: Financial reporting under the cash basis of accounting to provide a uniform definition of financial terms. Using IPSAS here does not mean that these standards are used in the Dutch context. See the financial definition in Appendix 10

16 'Fee' is used to denominate all forms of funding that cannot be regarded as general purpose taxes such as income tax, VAT, corporate tax and local general taxes. An elaboration on fees is given in Part C. 
corresponding payment. Hence, the compulsory nature of either a payment or the use of a service requires a priori consent by the democratically elected institutions.

\subsection{ZBOs: a brief introduction}

\subsubsection{The concept ZBO}

Until now I have used two different concepts for entities that are not fully part of central government. I used the term 'at arm's length entity', which is fairly standard in the international literature (e.g. Flinders, 1999a, p. 4; OECD, 2002, p. 10) and the term 'ZBO'. Generally speaking, ZBOs are a subset of the larger group of entities which are at arm's length of government in the Netherlands (Greve, Flinders and Van Thiel, 1999). The acronym ZBO consists of two concepts. First and foremost, 'Bestuursorgaan', which is a concept from public law that means authoritative body. Without elaborating on details here, a Bestuursorgaan has the power to impose unilateral decisions upon citizens. The second concept is 'Zelfstandig', which may either be translated as autonomous or independent. It is meant to express the idea that the entity is outside the hierarchical structure of central government ministries or in some cases that it may decide on matters between citizens and government impartially. In this study I will use autonomy when I refer to the organisational status of an entity outside the government hierarchy.

I will focus on ZBOs for two reasons. First, ZBOs have authoritative powers that allow them to impose decisions upon citizens. Other groups of entities at arm's length of government perform a task within the public domain which is generally an executive non authoritative - task such as teaching or operating a museum. Having authoritative power implies unilateral decision making on the position of a citizen in a specific case. Such a power requires forms of democratic control that go beyond mere accountability issues as the NCA seems to suggest in its 2006 report (Parliament, 2006a). Second, most of the political debates on attributing autonomy concern ZBOs. The debate has been going on for more than three decades, mainly focusing on ministerial responsibility and ex post accountability. There has been no systematic evaluation of the political control of ZBO operations from creating an entity and attributing operational authority ex ante to operations accountability ex post. ${ }^{17}$ In hindsight one might state that the Sint Committee tried to start that systematic evaluation process but ended up identifying three motives for creating $\mathrm{ZBOs}^{18}$ rather than developing its report further into the control mechanisms required for the three groups of ZBOs.

\subsubsection{Focus on $Z B O$ operations}

In this study the focus is on services provided to the public by ZBOs on behalf of national government. Such services may either be 'pure public goods' or 'impure public goods' (e.g. Hillman, 2003, p. 64-65; Rosen, 2005, p. 56-57). When production is realised within the hierarchically controlled civil service, ministerial responsibility for budgeting and

17 Case based political interventions on operational decisions are not done in the Dutch political setting (Scheltema, 1974, p. 13).

18 The motives were: mass production, impartial judgement and co-operation with third parties. 
monitoring are clear as there is a direct chain of command. However, when a decision is made to transfer production to a unit like a ZBO outside the hierarchical structure , responsibilities become blurred even though the transfer of production was based on a democratic decision. It is the political system that makes this decision, sometimes perhaps for reasons of efficiency; in other cases possibly to guarantee objectivity or because government does not have the specific knowledge (Sint Committee, 1994, p. 13; OECD, 2002, p. 14). After this decision, ZBO management is responsible - given the (program) authority attributed - for actual realisation of the program as efficiently as possible. This also implies that in the relationship between Parliament, minister and ZBO the primary focus will be on quality and efficiency of operations. As the services provided are still regarded as public services rather than market activities, the system of funding the services will not change as a result of using another organisational structure. Using a ZBO only means that production is transferred to an institution that is no longer fully controlled by Parliament and a minister. Essentially, transfer of production does not change the nature of the services and the accompanying system of funding the services. If funding is based on a budget authorisation process, the transfer of production does not automatically require a change in the initial budget authorisation process. Only a fundamental political decision on funding rather than on production may result in a change in the budget authorisation process. Furthermore, a decision on budget authorisation frequency can be made as an expression of the reduced level of political control that was intended when production was transferred to an arm's length organisation.

Zijlstra (2009, p. 43) notes that a ZBO has a double legal entity status. From a public law perspective, the office including attributed powers can be regarded as the legal entity; in a civil law context, the organisation and not the office is the legal entity. The emphasis in this study is the control by Parliament on the organisation, not control of the office which has a delegated or attributed power to issue public law based decisions. It is possible to address the ex ante Parliamentary control of ZBOs at two different levels. First, there is the debate between Parliament and Minister who have to agree on the level of budgets and the objectives to be achieved by the ZBO. At this level the issue is authorisation of budgets and objectives to be achieved. Using a ZBO implies that there is some managerial autonomy in operating the unit. In the Dutch setting, authorisation and appropriation have no separate legal status as in the USA (Janse de Jonge, 1993, p. 149). It would therefore be odd for Parliamentary (budgetary) authorisations to result in detailed Parliamentary appropriations which restrict managerial autonomy. Second, there is the relationship between the minister and the management of the ZBO. Given the authorised budget, the minister is allowed to appropriate money to the ZBO and monitor the use of funds and the resulting performance. The level of detail a minister specifies in commissioning the tasks and corresponding funding for the ZBO of course also has an impact on ZBO managerial autonomy. Given the present Dutch practice of authorising more aggregated budget articles in the law (Minderman, 2003, p. 66), ZBO financial 
autonomy seems to be formally assured. Intervention by a minister in appropriating detailed budgets may have a negative effect on autonomy and therefore needs to be investigated to assess the actual autonomy of individual ZBOs. At the end of a fiscal year the loop is the other way around. The ZBO is accountable to the minister with respect to services delivered and resources used. The minister assesses performance and is held accountable by Parliament for his actions with respect to the ZBO's management given the authorisation framework which was set by Parliament in the legislative and budgetary processes.

Some ZBOs - such as UWV - provide income transfers to people who qualify for a particular income transfer program. These programs are based on a law that has passed Parliament in a separate procedure. It is up to the ZBO to decide upon individual applications and then provide the income transfer. From a program perspective, the transfer should be in compliance with the regulations in the program law. From an operational perspective, management of the ZBO has to assure that compliance is realised and payments are made as efficiently as possible. The ZBO is funded for its processing activities rather than the amount of income transfers provided to applicants. This means that budget authorisation of the ZBO only looks at the amount of money Parliament is willing to spend on the execution of the program, given the requirements in the program (level of compliance, timeliness and the like). Therefore, I can neglect the budget authorisation for the actual income transfers and focus on costs of operations only.

\subsection{Democratic control as leading mechanism}

In this study, the theoretical notions for provision of services are indirectly relevant as they have an impact on the solutions that can be used for specifying and funding the activities of a particular ZBO. I assume that the specific service is regarded as a service that must be provided in the (national) public domain. The study starts with the task assigned to a ZBO and elaborates on economic and legal control tools available to Parliament and minister to ensure that services are provided as efficiently as possible. Therefore I will not discuss the normative choices made by the political system to perform a task in the public domain. To illustrate this I will use the example of Land Registry. In the Netherlands, the Land Registry Office 'Kadaster' was created in the early $19^{\text {th }}$ century as a public service. For decades no one had debated the position of the Kadaster as a public service at the national level subject to budget authorisation and appropriation, despite the fact that citizens have always paid fees for the service. However, in 1994, the Kadaster was given a ZBO status and very soon after that a more efficient organisation with reduced fees came into being (Deelen and Eertink, 2004, p. 118), while still performing its traditional tasks. Kadaster's task is still regarded as a typically public task. The organisation was given more organisational freedom when it was given a ZBO-status and it is no longer included in the budget authorisation and appropriation process. Despite increased organisational freedom, Kadaster is still part of the broader 
public/democratic control system. The control tools that are still used are the key subject of this study, although I will use other cases than Kadaster.

\subsubsection{Authorisation and autonomy}

This study focuses on operational autonomy of ZBOs. A ZBO has to produce services in the public interest, based on a democratic decision that a service has to be provided through government intervention rather than by market forces. It is the government who decides on funding of the organisation, either by taxes or by fees. The specification of services and the type and level of funding will be relevant for actual production and are, from a public finance theory perspective, based on a democratic decision to allocate resources in order to perform a public task. Allocation of a budget is reflected in the authorisation of a law that specifies the level and type of resources to be granted to perform a public task. The other two motives for government intervention - the macroeconomic and the distributive motive - can be ignored. The macro economic motive is not relevant as the resources used for operations of an individual ZBO are too small to have a macro economic impact. Furthermore, the macro-economic motive includes fiscal policy of government as a whole. NCA studies claim that the amount of money spent in entities at arm's length of government is some $€ 120$ billion, just below the level of central government spending (Parliament, 2006a, p. 5). Such an amount of money suggests that a macro-economic impact from ZBO activities can be expected. However, based on the data collected for this study, nearly 95\% of spending within at arm's length entities can be classified as program costs. As the study focuses on control of operations by Parliament, the impact of operating costs are relevant and their impact on fiscal policy and the macro-economic dimension to budget authorisation is, given the amount spent, rather small.

The distributive motive covers income transfers and is related to the programs to be realised. Demand for an income transfer program will determine the level of operations of a ZBO but not the societal impact of the redistribution which is the relevant issue for the distributive motive.

In the classic model, service provision based on authorised budgets is executed by a ministry and under full responsibility of the executive, in the Dutch case a minister. Unspent resources will be available for re-distribution within the political system. Due to the hierarchical structure, direct intervention by Parliament is possible if Parliament calls upon the minister to act. Using a ZBO or another form of quango implies that a specific public task is deliberately - e.g. for organisational reasons - commissioned to an entity at arm's length of government with consequences for the remaining responsibility of the executive (Scheltema, 1974). Direct intervention is no longer possible. From a budget authorisation perspective, the money will be spent within the organisation it has been 
appropriated to, but there is no automatic mechanism ${ }^{19}$ for re-appropriation of unspent money because the money has left the State to be spent within another organisation. ${ }^{20}$ Intervention by Parliament may be based on an ex-ante basis when the organisation is created and tasks are assigned or at the start of a fiscal year by passing a budget law and/or defining service levels. Parliament can also intervene during and after the initial budget authorisation, when performance of the organisation is assessed, be it to decide upon next year's budget or as a result of information on the organisation's operations. Whether interventions by Parliament have an effect can depend on the attribution of the necessary authority to the minister in the process of creating a ZBO for actual interventions. Creating a new legal entity is not automatically a financial authorisation procedure; to some extent it is part of the budget authorisation process, not only because of legislative requirements (CW2001:32-36), but also because it means that Parliament reduces part of its budget authorisation powers and transfers it into the hands of a minister. The fundamental decision on the distribution of authority between minister and ZBO in the legislative process is the foundation of decisions to be made in annual budgetary decisions.

Given the arguments above, purely discussing budget authorisation as the key Parliamentary control tool would deny the broader context in which a production decision for government services and the related decision on the organisation of production by using a government unit or establishing ZBOs as well as other units at arm's length is realised. To discuss this broader context, I will use 'control' of ZBOs rather than the classic concept of 'budget authorisation'.

\subsection{2. $\quad$ Product and market characteristics}

The type of services to be delivered by any publicly funded organisation might have an impact on how resources are allocated. In the case of 'pure public goods' (Cullis and Jones, 1998, p. 50-51; Hillman, 2003, p. 64-65) such as defence, price cannot determine the quantity of the services to be delivered. This is caused by the fact that $a$ pure public good does not allow for exclusion and is non-competitive, which means that the use of the service by a single additional user does not affect quality of or access to the service for other users. The lack of a market requires that government produces the services itself or will commission delivery of the service from a third (public) party such as a ZBO. In that situation a budget allocation is most likely a given amount of money.

At the other end of the spectrum, a market good allows for exclusion and has a competitive character. In principle, no intervention by government is needed, unless the

19 Of course, it is possible that funding is paid on condition that unspent money will be returned, but this requires an action of government.

20 Zijlstra (2009, p. 199) implicitly addresses this issue from another perspective. He notes that from a constitutional perspective ZBOs are nothing more than substructures rather than democratically legitimised organisations. He has a point and the precise legal arrangement of a ZBO will actually determine whether or not an automatic mechanism for re-appropriation mechanism exists. My point here is that the legislature has to consider this beforehand, whereas in the case of a ministry no specific arrangements have to be made. 
government's objective is to create a level playing field for supply and demand. Allocation of production and consumption of services is in this case subject to individual free choice. Government intervention may exist in the form of market or price regulation. In many countries a form of market regulator exists (e.g. Nederlandse Mededingingsautoriteit [NMa] - which is a ZBO; Bundeskartellamt in Germany, Conseil de la Concurrence in France). In general, such organisations are classified as quangos because they are not subordinate to ministerial control for policy independence reasons (OECD, 2002, p. 14). The control mechanisms applied by the market regulators influence the allocation decisions of both consumers and producers. They do not affect the price mechanism as the prime control tool in production and supply, because the market regulator only intervenes in cases of possible mergers or unfair competition by price dumping for instance. The price after regulatory intervention will be different from the price in a perfect market and therefore, demand will be different as well, but this does not change the principle that decisions are made based on the new equilibrium price of the services.

In both cases, political decisions have to be made to spend resources on the authority that is responsible for the market regulation and on the issue of funding these activities. Whether or not the particular authority is a ministerial unit with some autonomy or an autonomous entity, the same budget appropriation questions exist.

Between excludable and rival services, which the market can provide and the "pure public goods" a whole range of services exists which may be subject to the political decision making mechanisms. Both in the case of creating a form of market regulation or in the case of traditional government services, a democratic authority has to decide upon the need for delivering this service and thus the same authority has to have some form of control over the task attributed to the executive unit and the corresponding funding.

\subsubsection{Control by Parliament}

In section 1.3.1, I have argued that budget authorisation by Parliament is in practice an expression of a wider range of control tools available to Parliament in relation to achieving political objectives. From a legal perspective, these control tools are not defined as control tools but can be derived from the powers attributed to Parliament by the constitution (Grondwet; [GW]) or by unwritten law. Basically, one can argue that Parliament has two types of powers for controlling government. The first type of power is related to passing legislation, the second type relates to providing information to Parliament. 'Tweede Kamer' and 'Eerste Kamer' do not have exactly the same powers; the role of 'Eerste Kamer' is limited and regarded as an institution which reviews (chambre de réflexion; Burkens, Kummeling, Vermeulen and Widdershoven, 2001, p. 228) proposals passed by 'Tweede Kamer'. I will mention the key differences in the discussion below.

In the legislative process, Parliament in general is constitutionally co-legislator (GW:81). Van der Pot et al. (2006, p. 632) note that this was done to implement a system 
of checks and balances within the legislative power. Both 'Tweede Kamer' and 'Eerste Kamer' have to approve a proposal for a law, before the law can be signed and published. In the Dutch system, there is no measure made in the case of diverging opinions on legislation between 'Tweede Kamer' and 'Eerste Kamer' (Burkens et al., 2001, p. 229).21 The legislative power of 'Tweede Kamer' is stronger than that of 'Eerste Kamer' because 'Tweede Kamer' has not only the right to accept or reject a proposal, it can also propose amendments (GW:84) or submit a proposal (right of initiative) for a law from its own ranks (GW:82). Van der Pot et al. note (2006, p. 633-638) that only a few proposals for a law are actually submitted by members of Parliament. Furthermore, the role of 'Tweede Kamer' as legislator is changing from debating and considering legislation to debating policy programs, including objectives to be met (and services to be delivered- jdk) as well as active monitoring of Government (Van der Pot et al., 2006, p. 653). As a result, legislation has become the final stage of a process rather than an initial stage and 'Tweede Kamer' is relying on its (ex post) monitoring role rather than its (ex ante) legislative role. The above remarks concern formal legislation, including budget laws and tax laws (Van der Pot et al. 2006, p. 794-800; Kortmann and Bovend'Eert, 2006, p. 91). With respect to lower level legislation, generally decrees, ministerial rulings and policy rules, the role of Parliament is an ex post based rather than ex ante based control. This means that Parliament can discuss the decree or ruling after it has been announced. In the case of conditional decrees only, Parliament can use ex ante control tools by requiring legislation (Van der Pot et al., 2006, p. 678). One of the examples of conditional decrees regards creating at arm's length entities and will be discussed in Part B.

The second type of control tools available to Parliament regards information provision. In this category, the rights of the 'Tweede Kamer' and 'Eerste Kamer' are theoretically similar, only the use of particular instruments may diverge. The first tool available is that of submitting questions to a minister. In formal law this is referred to as the right of information (GW:68). Ministers will generally answer questions, unless national interest prevents them from providing the information requested. A second tool is interpellation, a particular form of questioning on a subject not yet scheduled for discussion. Third and related to questioning and interpellation are motions, in which a proposed opinion of Parliament on a subject, generally the 'Tweede Kamer', is submitted. If a motion passes Parliament, it is an expression of Parliament's desires on the subject towards the relevant minister who will generally give it due attention (Van der Pot et al., 2006, p. 782). A fourth form is a Parliamentary investigation in which politicians and others can be heard but are not required to respond to Parliament's invitation. The last, and scarce, form is using an Parliamentary inquiry (GW:70) in which a particular topic is investigated by a Parliamentary subcommittee that is allowed to summon both politicians and others

21 This means that negotiation as is usual in the budgeting processes in the US House of Representatives and Senate (e.g. Ott and Ott, 1982, p. 136; Janse de Jonge, 1993, p. 47; Schick, 2000, p. 108-110; Wildavsky and Caiden, 2001, p. 104) does not exist. 
involved in the subject under scrutiny and question them under oath. Parliamentary investigations and inquiries are generally based on the initiative of the 'Tweede Kamer' but are tools available to the 'Eerste Kamer' as well although it has not yet been used. (Van der Pot, 2006, p. 783).

Questioning, interpellations and motions are tools that may be used on an ex ante or an ex post basis. Basically they fit the observed tendency for a monitoring role for Parliament (Van der Pot et al., p. 2006, p. 637). As these control tools are relatively easy to use, it is likely that these are tools that will be used when discussing at arm's length organisations as well. Investigations and inquiries are typical ex post control tools meant to evaluate a particular process. Van der Pot et al. (2006, p. 784) mention eight inquiries, one of them on the arm's length organisation of Dutch social security which provided some of the building blocks for the present organisation of social security (Bekke and Van Gestel, 2004, p. 37).

Ultimately, the legal control tools attributed to Parliament are used to assess whether or not Parliament still has confidence in a particular minister or Cabinet as a whole, given the responsibility attributed to a minister in a particular case (see section 2.2.2 below). The role of these control tools is wider than just budgetary control, although the right of budget authorisation still is a strong control tool, which has been used in the past to express a lack of confidence in the Cabinet as well (Van der Pot et al., 2006, p. 634).

Contrary to the legal setting, where control is not defined as a concept, in an economic setting definitions do exist. I will now address control from an economic perspective and after doing so discuss the relations between the legal and the economic perspectives of control.

Merchant (1998, p. 2) starts noting that there is no universally accepted definition. He distinguishes two groups of definitions, one based on 'a simple cybernetic system' and the other encompassing 'all devices managers use to ensure that the behaviour and decisions of people in the organisation are consistent with the organisation's objectives and strategies' (Merchant, 1998, p. 2). Examples of the cybernetic system definitions can be found in for example Drury $(2008$, p. 11) when he refers to the managerial function of control consisting of measurement, reporting and subsequent correction of performance. Similarly, Weetman (2006, p. 10) describes control as a system of information seeking and gathering including accountability and feedback to achieve the organisation's goals. Atrill and McLaney (2009, p. 177) define control as 'compelling events to conform to plan'. Early promoters of the broad definition of control are Ouchi (1977) and Hofstede (1981) referring to different levels of control and required control tools that match types of decisions in organisations. They refer to differences between routine day to day decisions at one end of the spectrum and strategic decisions with ambiguity which require political control, even in private organisations (Hofstede, 1981, p. 197-198). Anthony writes in his foreword to the 9 th edition of his management control systems book 
(Anthony and Govindarajan, 1998, p ix) that back in 1965 he had some clues to behavioural issues with respect to control but that the issue was by far not as important as it is nowadays (end 1990s, jdk). Anthony and Young (2003, p. 3-4) and Merchant (1998, p. 2-3) identify three levels of control. First strategy formulation: setting out the goals and the activities to be realised to achieve these objectives. Second, management control in which, given the defined strategies, decisions are made on how to use resources to meet the strategic targets including systematic assessment of the results. Third, task control focuses on efficient and effective daily operations, including all necessary procedures to achieve production. In a fully unambiguous case where production is based on standard routines, Hofstede's routine controls are a very important instrument for managing the organisation. On the strategic level however, uncertainty prevails and decisions have a political character.

In this study, the focus is on control of ZBO operations at the level of the decision makers, in this case Parliament and ministers. Parliament will set the objectives to be achieved, including the appropriation of resources needed to deliver production and the organisational framework in which production is to be realised. Furthermore, Parliament may set key decision rules for delivery of services, for example a driver's licence may only be issued to a person above the age of 18 . These decisions are at the strategic level. In terms of the legal powers attributed to Parliament they refer to passing legislation including setting standards in the budgeting process. The latter group of decisions by Parliament aims at the managerial level rather than the strategic level because the cyclical budgeting procedures determine each and every year, given the strategic choices, the actual level of production to be delivered.22 Parliament's role in controlling decrees and other lower levels of legislation can be regarded as part of the management control tools because lower level legislation is based on the strategic decisions made before. Parliament's second cluster of legal control tools concern information provision. In economic terms, these control tools primarily focus on the management control level because information provision focuses on what is actually going on in a ZBO's operations. The information provision process can result in reconsidering strategic decisions in Parliament, or in interventions in the daily operations of an organisation in case of unexpected outcomes. However, given the arm's length relation between Parliament/Minister and a ZBO without hierarchical control structures, in general Parliamentary interventions at the operations level will be rare. It is the ZBO's management which was hired to define the actual operational processes to deliver the services and allocate the appropriated resources. They will have to organise processes in line with standards set by Parliament's control tools. A summary of the control tools available to Parliament is given in Table 1.1.

22 For now, I ignore differences in product and market characteristics although they may influence the control tools available to Parliament at a managerial level. 
Table 1.1 Parliamentary control tools at the different control levels

\begin{tabular}{|l|l|l|}
\hline Strategic control & Management control & Task control \\
\hline $\begin{array}{l}\text { Passing law on ZBO tasks and } \\
\text { organisation }\end{array}$ & Passing budget law & - \\
\hline Right of initiative & Discussing decrees & - \\
\hline Amendments & Amendments & - \\
\hline Investigations and inquiries & Questions & Questions \\
\hline
\end{tabular}

Given the control tools available to Parliament, focus in the study will be on the strategic and managerial level rather than on the actual operational level.

\subsection{Theoretical perspectives on ZBOs.}

Using quangos to deliver government services is neither new, nor a specific Dutch issue. The Swedish case is well known for its long history of small central government supported by numerous quangos (Statskontoret, 2001). Zwart (2003, p. 5) claims that the USA was one of the founding fathers of the executive agency ${ }^{23}$ concept that by now has spread all over the world. Early forms of what would in the $21^{\text {st }}$ century be labelled "quango" existed in The Netherlands at the beginning of the 20th century. In the 1950s, many new autonomous organisations were established by government (Van Thiel, 2000, p. 18). It lasted until 1974 when the label "Zelfstandig Bestuursorgaan" or "ZBO" was used in Scheltema's inaugural speech (Scheltema, 1974). A decade later, under growing budgetary pressure, political and academic attention was given to the issue of privatisation (e.g. Boorsma and Mol, 1983) and autonomisation of ministerial units. From around 1990 (Boxum, de Ridder and Scheltema, 1989; Parliament, 1993a, 1993b), more (academic) attention was gradually given to controlling quangos and more specifically ZBOs. At the same time, a new peak in creating ZBOs could be observed (Van Thiel, Leeuw, Siegers \& Flap, 1999, p. 34). The subject became an issue on the political agenda with the 1994 annual report of the NCA (Parliament, 1995a) I have already mentioned in section 1.1.

In the last decade, studies on quangos from an economic, legal, political and managerial perspective have been published. The motives for creating quangos - of which ZBOs are a subgroup - include delegation of public management and improving efficiency (e.g. Hunt, 1995 p. 19; Pollitt and Bouckaert, 2004, p. 6-7). The idea is that delegation of responsibilities gives more leeway for management to use resources in line with actual needs. Delegation of responsibilities is based on neo-institutional theories from both an economic (Thompson, 1993, Ter Bogt, 1998, Verhoest, 2002) and a sociological/political perspective (Dimaggio and Anheier, 1990 p. 152; Osborne and Gaebler, 1992). Van Thiel's conclusion (2000, p. 180) that creating quangos does not automatically or immediately lead to improved efficiency and effectiveness is a warning regarding the

23 Some authors use executive agency (e.g. Hyndman and Eden, 2001; Smullen, 2007, p. 13); others use Government Agency (e.g. Pollitt, Talbot, Caulfield and Smullen, 2004, p. 3). I will use 'executive agency' when an internally autonomised unit is meant and the more general 'agency' if reference is made to any form of agency, not covering the whole range of quangos. 
creation of quangos as a panacea for management and control issues in the public sector. An additional complication with respect to quangos is that the authority related to ownership may be dispersed over several different institutions. This is what the NCA reported in their general reports on two groups of Dutch quangos ${ }^{24}$ (Parliament, 2000a, 2001c, 2002a, 2004b, 2006a). In the following sections I will address some issues related to quangos in general that have been covered in earlier research. I will start with autonomy from a legal and economic perspective and then give some attention to issues that are relevant as background for my study.

\subsubsection{Legal perspective}

From a legal perspective, three lines of issues related to control of ZBOs can be identified in earlier studies. The first issue is the matter of ministerial responsibility. The doctrine is that there is no ministerial responsibility without corresponding ministerial authority (e.g. Scheltema, 1974, Scheltema Committee, 1993, p. 8; Kummeling, Duijkersloot, Minderman, van Schagen \& Zijlstra, 1999, p. 69). Kummeling et al. conclude in their study that ministerial power towards ZBOs is limited compared to ministerial powers within the hierarchical structures of government. Authority given to a ZBO implies that a minister cannot be forced to reverse a decision made by the ZBO unless he has specific authority to do so (Kummeling et al., 1999, p. 69). In a study in the British context (Westminster style democracy), Stone (1995) has developed a framework on responsibility and accountability resulting in different sets of institutional arrangements for public administration. In Stone's model traditional Parliamentary control and the effects it has on ministerial responsibility is contrasted with a judicial review perspective, a constituency accountability perspective, a market accountability perspective and a managerial perspective. The judicial review and constituency accountability are issues that affect individual cases, whereas the other two themes have an effect on the system of government operations. I will not cover the issue of market accountability which is covered in the issue of horizontalisation as referred to in section 1.4.3. When discussing budgetary control of operations, the differences between traditional Parliamentary control and the managerial perspective are the most relevant issues. In the former, compliance with authorised budgets, correct application of legislation in providing services and the resulting strict regulations prevail. In the latter the achievement of objectives is the relevant issue for Parliamentary control. To rephrase Stone's contrast in a budget authorisation context: traditional Parliamentary control is associated with line item budgeting (Anthony and Young, 1999, p. 449; Wildavsky, 2001, p. 139-140; McCaffrey and Jones, 2001, p. 11-12). The management perspective is reflected in program budgeting models such as the 'Planning Programming and Budgeting System' [PPBS] (Schick, 1966), the (US) Government Performance and Results Act [GPRA] (McCaffery and Jones, 2001, p. 310) or the Dutch equivalent 'Van Beleidsbegroting tot

\footnotetext{
${ }^{24}$ More specifically: ZBOs and ‘Rechtspersonen met Wettelijke Taak' [RWT]; see chapter 2.
} 
Beleidsverantwoording25' [VBTB] (see e.g. Boorsma, Maessen \& Schild, 1999) as it is incorporated in the present Dutch CW2001. The essential difference between the two is that in the traditional model ministerial responsibility will imply that on a day to day basis interventions may exist, whereas in the managerial model ministerial responsibility is at the strategic level of achieving goals (Stone, 1995, p 511-514). In the Dutch context, the strategic level responsibility is referred to as system responsibility (Parliament, 2006a, p. 21).

Second, there is the issue of budgeting and budget laws themselves. Why and how has the present central government budgetary framework developed, more specifically with respect to those units that operate outside the traditional hierarchical setting of the ministries? This means that the concept of authorisation and appropriation (e.g. Lyden and Miller, 1982) and the importance of ex ante authorisation (van Braband, 1986) have to be addressed. The work of Minderman (2000) and Janse de Jonge (1993) discusses Dutch budgeting procedures and requirements and the role of Parliament in budget authorisation. In the words of Lüder's contingency model, the institutional arrangements including the legal system have an effect on government accounting reforms (Lüder, 1992) and must therefore also have effects on budgeting as the budgeting framework defines the accounting model that can be used. In Minderman's work, ZBO budgeting procedures are described given the responsibilities attributed to a minister for controlling ZBOs. He concludes that there are sufficient control instruments available regarding ZBOs although these control instruments are not always fully used (Minderman, 2000, p. 206). Minderman refers to annual reports (informally) submitted to Parliament which are hardly used by Members of Parliament [MP]. Minderman neglects two issues that are related to each other. The control instruments available remain within the domain of the executive power - the minister and his staff - rather than in the domain of the legislature. Therefore, Parliament in its role as legislator is not able to assess how ZBOs are performing and using their budgets. Furthermore, Minderman does not discuss whether there is a need for authorisation of ZBO budgets at all. NCA and Cabinet have different opinions on ex post reporting: Cabinet prefers reporting by exception whereas NCA notes that transparent information provision requires aggregated information on operations and performance of ZBOs including reporting on the monitoring role by the respective minister (Parliament, 2007b, p. 14). MPs interviewed in the context of this study note information overload. Reading the full annual reports of ZBOs is time consuming, whereas a summarised statement by a minister is likely to draw attention of Parliament and is in line with NCA's suggestions for improving control of ZBOs. Does that mean that allocating a budget to a ZBO is equivalent to allocating a budget to a ministry which uses that budget to buy services on the private market? If that was the case, all critical reports and studies on ZBOs would be obsolete because in general Parliament will not discuss profits or governance structures of individual contractors. Whether or not authorisation and

\footnotetext{
25 This can be translated as 'from policy budget to policy accountability'
} 
appropriation are described in present law is only one part of the story, there have been substantial changes in Dutch Budgeting Laws throughout the years. Documents such as Antheunissen's (1948) description and explanation of the first 'Comptabiliteitswet' of 1927 [CW1927] or the Simons Committee report (1960) that drafted the 1976 'Comptabiliteitswet' [CW1976] reveal different stages in attitude towards budget authorisation and appropriation for what are now generally labelled as at arm's length organisations.

The third issue is the legal setting in which ZBOs operate. ZBOs should preferably operate within the public law framework (Zijlstra, 2009, p. 9). This notion was for example expressed in the recommendations of the Sint Committee on creating ZBOs (Sint Committee, 1994, p. 22) and confirmed in statements by the Cabinet on kZBO (Parliament, 2005a, p. 6). The fact is that the Dutch government often uses private sector entities to perform public tasks (Peters, 1997; Zijlstra, 1997; Van Wijk, Konijnenbelt and Van der Male, 1999; Schroten, 2000). In other cases ZBOs are part of the 'State' legal entity (Van Wijk et al., 1999, p. 126), which suggests at first glance that they are hierarchically subordinated to the minister. Such differences in legal status may have effects on the authority that is or can be attributed to the minister to control ZBOs. In kZBO some differentiation with respect to financial monitoring by the minister exists between ZBOs created as public law units, public law entities and private law entities. It is not immediately clear how this differentiation affects the role of Parliament in authorising and appropriating budgets.

What is known of the legal framework in which ZBOs operate mainly concerns ministerial responsibility and accountability rather than a discussion on the role of Parliament in controlling ZBOs. In line with the NCA recommendations on improving information provision to the legislature (Parliament, 2006a, p. 9) I will use the concept of ministerial responsibility related to the legal status of specific ZBOs to assess the effects on Parliamentary control of ZBOs.

\subsubsection{Economic perspective}

Secondly, I will address the economic perspective. In this section I will focus on three lines of economic theory: Neo Institutional Economics, providing public goods and financial management. I will discuss the concepts 'principal' and 'agent' which are concepts in Neo-institutional Economics, particularly 'Agency Theory [AT]'. This choice is driven by the fact that these concepts have different meanings when used in an economic or in a public administration perspective. I will follow the economic perspective and elaborate on the differences between this perspective and the public administration perspective.

\subsubsection{Commissioning and funding}

Berle and Means (1932) developed the agency theory from a business environment. In a small business, the owner and manager of the entity is one and the same person, which prevents the problem of information asymmetry. The owner/manager has to deal with his 
clients to whom he has to sell his products and services on demand of the individual client. In larger companies, the information problem arises from the separation between owner and manager. Jensen and Meckling (1976, p. 308) as well as Eggertson (1990, p 40-41) defined an agency relation as a relationship in which the principal delegates some authority to an agent who in turn provides a service on behalf of the principal. This implies that the agent's services to the principal is to organise matters so that the customer, who would previously ask the owner (principal) to deliver the service directly to him no longer asks the owner to do so, but asks his stand-in, the agent. As a result two service relationships are created: one between the principal and the agent (the stand-in relation) and one between the agent and the customer (the purchaser relation). A key point in Jensen and Meckling's and Eggertson's definitions is the principle of delegation of rights or - to put it differently - authority/powers from one person (organisation) to another. These two persons are labelled principal and agent respectively. It is the information problem that exists between these two that is analysed under agency theory. The owner no longer has a relationship with the client: that is left to the manager who is responsible for the operations of the entity. Neelen (1993, p. 65-67) notes that the hierarchical relationship is not necessarily essential for defining principal-agent problems but that positive principal agent theory with respect to problems between or in organisations has led to this focus on delegation of authority.

In the public sector, agency theory has been applied as well (e.g. Moe, 1984; 2006). The analogy to the private sector implies that principal and agent must be regarded in terms of owner and manager. The manager has to make sure that the services provided are delivered within a framework set by the owner. In a business case, the framework will come down to a ROI-indicator. ${ }^{26}$ In a budgeted environment in the public sector, management has to meet the standards set in the budget, eventually including output standards.

Agency theory in the public sector has developed beyond the original separation of ownership and control. Moe (2006, p. 3) and West (1997, p. 599) focus on the hierarchical relationship in which a task is delegated or assigned to an agent. In that case, information problems arise due to the differences in knowledge on the assigned task. In public administration theory, agency theory is broadened towards political control in general (e.g. Waterman \& Meier, 1998, p. 177; Verhoest, 2002, p. 53) and even further to issues of multiple principals (e.g. Waterman \& Meier, 1998, p. 178; Hazeu, 2000 , p 99-100). Koppel (2003, p. 22) points out that few public administration users adhere to the formal meaning of the concepts of principal and agent in the economic context. In his words, "principal-agent theory has become the metaphor of choice for political scientists studying bureaucratic control'. Others are suggesting that agency theory is associated with supply and demand. Waterman and Meier (1998, p. 175) state

\footnotetext{
26 Return on investment
} 
that the economic perspective of agency theory is on 'buyers and sellers'. Similarly, Van Thiel and Pollitt (2007, p. 56) implicitly assume a supply and demand relationship as they state that 'the principal charges the agent in return for a budget'. McGuire (2003), states that 'purchaser-provider arrangements are a variant of the principal-agent model of rational choice', which also suggests 'buyer-seller' relations. Using agency theory to describe supply and demand relations may be the effect of using examples commonly used as 'insurer-insured' or 'doctor-patient' which actually address the moral hazarddimension of information asymmetry rather than a division of powers between two related institutions. In a legal context, Songer, Segal and Cameron (1994, p. 674) indicate that the courts in the USA "...have considered agency "a fiduciary relationship", where the agent has a primary duty to act primarily for the benefit of the principal'. They continue that, in their study on the relationships between different levels of courts, the hierarchical relationship is the most important issue. This resembles the original economic interpretation of principal and agent.

Although there may be a shift in attention from the formal hierarchical structure as a result of adapting agency theory to the public administration field, the emphasis is in my opinion still on the original governance structure. This is emphasised by words like 'control' (e.g. Jensen and Meckling, 1976, p. 309; Fama \& Jensen, 1983a, p. 331-332; West, 1997, p. 600) or 'power' (e.g. Moran, 2008, p. 159).

The different interpretations of the principal-agent concept have to do with convergence in the hierarchical relationship between the political system and the executive power on the one hand and the provision of (impure) public services by the executive on the other. Meier and O'Toole (2006, p. 142) note that in NPM, there are in fact different focuses: on the one hand consumer sovereignty or, in the words of Boorsma and Mol (1983), privatisation of demand, in which choice by citizens is the main issue. On the other hand, there is a focus on reducing the bureaucratic hurdles that prevent management from being creative in delivering services. The client as user of services is not discussed in most public sector principal-agent cases; just as in the private sector analysis of principal agent relations within or between organisations. ${ }^{27}$

The concept client gives rise to another complication in the analysis. First, Fountain (2001) remarked that the focus on privatisation of demand has risks with respect to democratic choices as well, given the focus on the individual. I will focus on the difference between final user and the one who is paying for the service as an analytical tool and not discuss the possible impact on democracy. Second, in a private sector environment, the client directly pays for and receives the goods or services delivered. In a public sector environment, there may be a difference between the one paying for a service and the one who actually receives the service. This difference can best be elaborated upon in the case of an income transfer transaction. Suppose government has decided that a form of

27 Classic examples of private relationships between client (principal) and agent service provider are patient-physician, client-lawyer (e.g. Neelen, 1993, p. 65) 
scholarships should be available to a particular group of students. The decision making process is left to a private entity who, after a tendering procedure, has a monopoly on this decision making process and has to comply with rules set by government. Government is in this case not the owner of the entity, but has commissioned this task to the private entity. As government is not the owner of the private entity, it cannot have the status of the principal as meant by agency theory. Government is also not the one who receives the service; that would be the student who successfully applied for the scholarship. The services government receives are in fact intermediate: it regards the decisions made by the private entity on the applications of all students. Government will pay for these decisions and also fund the scholarships.

The example illustrates that 'client' is an ambiguous concept, as there are in fact two different clients who each receive a different service based on the single application of the individual student. To make a clear distinction between the different roles government and individuals have, I will not use the concept of principal when discussing the role of government towards an individual ZBO. If I do refer to the role of principal as meant in agency theory, I will use the word 'owner' or 'minister-principal'. If government is the entity that assigns a task to an entity outside the hierarchical structure but only receives benefits in terms of intermediate outputs or in terms of general outcomes, I will use 'commissioner'. The concept 'client' is only used for the individual or entity that is the final user of the service provided; in the case of the scholarships this is the individual student who has applied for the scholarship. A final point to be made is that commissioner or client need not be the person who is actually paying for the service delivered. I will use 'funder' to indicate the entity that actually transfers the payment for the service directly to the service provider (i.e. the ZBO). Of course, both in theory and in practice cases exist in which government has multiple roles, but by clearly separating them in the analysis, the different interests involved in these different roles and the impact that has on the relative autonomy of ZBOs can be shown.

\subsubsection{Three economic dimensions.}

Autonomisation is often regarded as a result of Neo Institutional Economic theories (e.g. Ter Bogt, 1998; Kettl, 2002, p. 86-87; Pollitt \& Bouckaert, 2004, 175; Guthrie, Humprhrey, Jones \& Olson, 2005, p. 2). I have already discussed AT, but another related issue has to do with the observation of the NCA on dispersed ownership (e.g. Parliament, 2000a, p. 16). Property Rights Theory [PRT] can provide tools for analysing residual claims (Künneke, 1997): who bears the ultimate operational risk. The ideas of PRT are related to the legal status of a ZBO and the distribution of authority, but have to my knowledge not been discussed in a ZBO context.

From Transaction Costs Theory [TCT] (e.g. Williamson, 1993) it is known that asset specificity - either physical or in terms of knowledge - may lead to mutual dependencies between commissioner and supplier. It will thus also affect Parliament's budget authorisation perspective. 
In the PRT literature that directly refers to ZBOs, Kuiper (1999) focuses on financial supervision, which is basically an element of AT. His proposals address the organisation of supervision and the actual arrangements to be made. Once the legislature has authorised the structure of supervision in the law that creates a ZBO, supervision is a tool that is only available once budgets have been authorised. It therefore does not immediately contribute to a debate on the need of budget authorisation as such.

Plug, Timmerman and Dekker (2004, p. 28) note that supervision is only one of four elements in the relationship between ministry and ZBO. The policy-program is given when discussing ZBO operating costs and therefore, ownership and contract are the remaining themes which are relevant. From the authorisation perspective, the issues are the amount of resources Parliament would like to allocate to execute a specific task. Only when that is given, can negotiations and contracting be performed.

Similarly, ownership suggests control over residual value (see PRT). The role of Parliament from the authorisation perspective would then be that it considers the possibilities to reallocate residual value, which can only be performed if there is a match between the institutional setting - including the distribution of authority - of a ZBO, the tasks attributed to it and the matter of funding.

Finally, Verhoest (2002, p. 117) uses agency theory to develop a model in which controls on results and inputs on the one hand and incentives such as funding and competition on the other hand determine the level of control required. He ultimately suggests that perhaps other variables such as legitimacy are more important in determining the performance than the controls developed from AT (Verhoest, 2002, p. 358). The control models Verhoest tests are meant to predict effectiveness of organisations, which is of course relevant in a performance budgeting environment.

What in my opinion is still missing is the possibility to apply such a control model based neither on the activities of organisations nor on the choice of a specific form of organisation. As a result, Parliament's role in authorising budgets - whether traditional input or performance based budgets - is not sufficiently covered.

A second perspective is public finance theory. This line of theory on providing public services aims at identifying possible solutions for funding and commissioning services provided by ZBOs. The characteristics of a service determine whether or not the service is non-rival and/or non-excludable. As a result, services can be classified as pure public good, impure public good or individual good (e.g. Hillman, 2003, p 64-65; Rosen, 2005; p. 56-57). It is obvious that in the case of a pure public good, the free rider problem prevents commissioning and funding solutions other than government commissioning and funding. Government has to fund and allocate a budget, irrespective of who is actually producing a service. Thus budget authorisation is expected to be a decision of Parliament. Pure public services may be found in case of quasi judicial ZBOs (tribunals) such as 'Commissie Gelijke Behandeling' [CGB] (Equal Treatment Commission). The other extreme is an individual service (e.g. a licence) that allows for user payment for the 
service as well as calculation of cost prices. Services provided by ZBOs will generally have a monopolistic character as they are the result of an exclusive public law based authoritative decision by the ZBO as an office. Hence, from the supply side of the 'market' there may be a lack of efficiency incentives (e.g. IBGroep, 2006, p. 15; Linker, 2006, p. 237). It may thus also have an effect on the (budgetary) controls and authorisation that is needed when Parliament decides that a specific good has to be provided.

In the literature on ZBOs, some classifications on services or activities exist (Sint Committee, 1994; Parliament, 1995a, p. 12; Boxum et al, 1989, p. 48-49; Smullen \& Van Thiel, 2002) but in none of these are the public good characteristics of ZBO-services included. Only in discussions on hybrids (Simon, 1989; Kickert, 1998) does the dichotomy between the task-market environment have a relation to the public good dimension. Using the public good dimension can thus contribute to understanding the relation between controls by Parliament and the provision of services by ZBOs.

The last economic perspective to be mentioned here is based on (micro) business economics. From this perspective, the debate is on the continuity of the organisation or, in the words of Bouma (1982, p. 42), economic independence. This concept has a very straightforward link to autonomy as it is an indicator of the ability of an organisation to cover costs through revenues generated. If not, the organisation will be doomed to disappear. To put it simply: if Parliament is not willing to authorise a ZBO's budget and the ZBO has no other options for generating revenues, it will cease to exist as a result of lack of resources. A ZBO that delivers pure public good can thus never be economically independent, whereas a ZBO that delivers individual services, at least theoretically has opportunities to survive. Zijlstra (1997, p. 213) noted in his dissertation that independence of a ZBO is a function of funding, organisational structure and the authority attributed to the oversight body (i.e. minister). The business economy perspective also has a relation to PRT and legal authority attributed through the concept of responsibility accounting (e.g. Merchant, 1998, p. 305; Anthony \& Young, 1999, p. 12-15). The concepts of economic independence and responsibility accounting have as far as I know not been applied to the domain of quangos in general nor for that of ZBOs. Budget authorisation has an effect on economic independence and responsibility accounting first and foremost while discussing making funds available to a specific entity. It also has an indirect effect by setting the (legal) standards under which the unit has to operate. The concept of responsibility accounting is a reflection of the degrees of freedom available to management of a ZBO and thus by implication a reflection of the responsibilities that have been left at the higher - in this case political - level of the organisation. It is an expression of the link to the authority attributed by Parliament to the minister from an economic rather than a legal perspective. 


\subsubsection{Public Administration perspective}

For the public administration perspective, three groups of studies can be identified. The first group addresses the issue of why and how at arm's length entities were created. The Sint Committee's report (1994) is a document which has tried to set standards for creating ZBOs in the broader context of the privatisation and autonomisation debate. The most important conclusions of this report were that only three motives should allow for creating ZBOs: efficiency in production; impartial judgement or co-operation with third parties outside central government. Similar motives were given in the UK (Wilson, 1995, p. 9). Later government reports such as the Kohnstamm Committee report (2004) recognised this conclusion but noted that given ministerial responsibilities, only the impartiality motive would allow for creating ZBOs. Van Thiel's (2000) study is an example of studies that address the issue of why and how at arm's length organisations were created by politicians. In a later study, an effort was made to find relevant factors within the civil service that may have led to specific choices in autonomisation (Van Thiel, 2006). Similar studies exist for the UK setting (e.g. Ridley \& Wilson, 1995; Flinders \& Smith, 1999) and the USA (e.g. Hammond \& Knott, 1996).

Related to the first group of studies on creating entities at arm's length of government is the cluster of comparative (international) studies. The underlying perspectives vary but they have in common that an analysis is performed based on institutional arrangements in different countries. The study of Greve, Flinders and Van Thiel (1999) is an early example of describing units at arm's length of government from within three different jurisdictions. Another example focusing mainly on the Anglo Saxon world is Nolan (2001). The OECD (2002) and Zwart and Verhey (2003) comparative studies provide general descriptions of positions of arm's length organisations in several countries including economic and legal dimensions of control. These studies are useful as they provide elementary frameworks for analysis of ZBOs. Pollitt and Talbot (2004) provide a comparative study from a public administration, more particularly, Public Management Reform perspective in which they comment on the impact of the organisational changes. Janse de Jonge's (1993) work is a comparative study of (legal) budgeting procedures in the USA, the UK and the Netherlands. This work is useful because it provides a context to assess literature on at arm's length organisations in their national setting. Solutions that may have an effect on controlling at arm's length organisations in one jurisdiction may have other effects in other jurisdictions.

The policy objective and managerial perspectives of units at arm's length of government are covered for example by the works of Pollitt (1990) and Flynn (1993) who study the development of management theories that allow for executing public tasks at arm's length from government. Hood, James, Peters and Scott (2004) and Pollitt, Talbot, Caulfield and Smullen (2004) studied specific policy domains in which at arm's length organisations have been created.

A third group consists of studies that focus on the perspective of changing governance structures (e.g. Kalders, Van Erp \& Peters, 2004; Schillemans \& Bovens, 
2004; Bovens, 2005; Schillemans, 2005). The core of the debate in these studies is that vertical accountability - the accountability from a hierarchically subordinate unit to its principals - can partly be transferred by accountability to other stakeholders, referred to as horizontal accountability.

The first group of studies only explains the existence of autonomous units without creating a link between the characteristics of the services provided and funding of quangos. As a result of that, there has been no discussion whatsoever on the role of the legislature in the budgeting process. That is where my study can fill a gap. I will use the second group of comparative literature mainly to describe the Dutch setting in a broader international perspective when needed to make readers aware of specific institutional and constitutional features. The third group of studies is not interested in the ex ante budgeting process at all and focuses on the ex post accountability and the performance of units at arm's length of government. In my opinion it is not possible to assess the performance of a unit when no clear standards have been set. In the public domain the legislature has the role of defining what services have to be delivered and at what cost. From an economic perspective this is referred to as the allocation and authorisation function of budgeting. Before it is possible to discuss performance, one should be able to assess the allocation and authorisation perspective. I will therefore not address the issue of ex post accountability as a separate issue.

\subsubsection{Organisation and management perspective}

There is very wide literature available on the why and how of New Public Management/Public Management Reforms. The (economic) work of for example Jensen and Meckling (1976), Jensen (1983) and Williamson (1993) as well as Osborne and Gaebler's (1992) sociological approach may be regarded as the theoretical foundation behind present developments in delegated public management. Key issues in this literature include that delegated authority and responsibility generate more responsive government but at the same time create new issues on how to control delegated authority and responsibilities on an operational level. As in the Public Administration literature, authorisation of budgets by the legislature is not an issue.

A specific theme in organisation theory is the phenomenon of hybrid organisations. Hybrid organisations are according to Kickert organisations that have to operate 'businesslike... and efficiently' while performing their public tasks (Kickert, 1998, p. 192). Others describe hybrid organisations as organisations that deliver services both in a (budgeted) task setting as well as in a market setting (In 't Veld, 1995; Meijerink, 2005, p. 19; Simon, 2005, p. 39). In the USA, Koppell defines hybrid organisations as (partly) privately owned entities created by government to realise public policy purposes (Koppell, 2003 , p. 12). Although the definition is not the same as in the Dutch cases, Koppell also discusses organisations that deliver services on behalf of the public as well as the private sector (Koppell, 2003, p. 184). 
A ZBO is not necessarily a hybrid organisation. In most cases when hybrids are discussed, the debate is on organisations that deliver services (e.g. education and health care) in the public domain but without the legal-authoritative character of the services (e.g. licensing) as is required to qualify as a ZBO. A parallel between hybrids and ZBOs can be found in discussions on governance of these institutions. Many debates in the Dutch Parliament as well as in the press are on issues such as remuneration of top management and the level of equity accumulated in such organisations. A Parliamentary committee even reported on the matter of remuneration (Dijkstal Committee, 2004, 2007) and discussions on equity in the public domain emerge regularly (e.g. Tubbing, 2007).

A major issue for hybrid organisations is whether the organisation can manage to deliver services for both the market and the public domain without bias in favour of market production. In the Netherlands, two rather opposed perspectives exist. On the one hand, Simon (1989; 2005, p. 42) is very explicit: a mixture of task and market services in one organisation will ultimately result in a relative disadvantage for one of the domains. In 't Veld (1995) and Meijerink (2005) are more optimistic. They postulate that especially in the not-for-profit domain numerous organisations exist which deliver public services from a private setting where governance and control is different not just in the financial or legal dimension (Meijerink, 2005, p. 31). I do not intend to analyse hybridity of ZBOs in depth, but I cannot neglect it either. Some ZBOs are private legal entities, others do have a mixture of public and private tasks (e.g. Boxum et. al, 1989); the previously mentioned Kadaster generates some sales from international activities (Kadaster, 2007). It is likely that such differences may have an effect on the need for budget authorisation and appropriation in specific cases.

Kickert concludes in his book on hybrid organisations that creating formal autonomy may be misleading. He found that ministerial control seems to be even stronger when an organisation is given formal autonomy as a result of differences in cultural and managerial responsibilities (Kickert, 1998, p. 189.). A few years later the NCA issued a report describing possible control tools for ministries to monitor ZBOs (Parliament, 2001c). Both studies address internal management issues which are relevant for ensuring that information is available to a minister and thus in principle also for Parliament. Such instruments can be the result of responsibility and accountability attributed to a minister, but do not discuss whether ministerial responsibility is required or not. Therefore, I will not follow a similar line of research.

By now, I have superficially discussed four perspectives for studying ZBOs. The economic dimension in particular seems to have had only limited attention despite the indications that this dimension, together with the legal context, does have an impact on Parliamentary control including budget authorisation and appropriation. Parts $\mathrm{B}$ and $\mathrm{C}$ of this study will provide an in depth analysis on the legal and economic dimensions related 
to ex ante control of ZBOs. In the following section, the research questions and the outline of the study will be discussed.

\subsection{Research questions}

Parliament has two ex ante tools to control ZBOs. First Parliament defines the legal framework in which ZBOs have to operate by attributing authority to a minister and assigning tasks to a ZBO. Second, the annual budget process is the key tool by which Parliament is periodically able to allocate resources to a ZBO and implicitly accept priorities and service levels (Minderman, 2002, p. 20-21). In section 1.3, I argued that "ex ante control' represents a wider set of legal and economic instruments for Parliament than the formal budgeting process. There has been no systematic evaluation of the effects of ex ante control by Parliament on the distribution of authority and the impact on budgeting authorisation with respect to ZBOs and, by implication, autonomy on the operations of ZBOs. Therefore, my research problem will focus on these effects as expressed in the following question:

\section{Do Parliamentary control tools match the legal and economic operational autonomy attributed to ZBOs?}

To arrive at an answer, a multidisciplinary study will be performed in which not only the effects of the separate legal and economic dimensions to the problem will be evaluated, but also the effect of arrangements of the separate dimensions on each other. Before I can actually assess the full impact of a set of arrangements, I will need to evaluate three separate descriptive research questions leading to a framework for assessing ZBO autonomy. The first question addresses a description of the field of ZBOs in its institutional context:

How do Dutch ZBOs fit into the institutional context of Dutch central government?

I will not only focus on a description of ZBOs but also provide a brief description of the Dutch institutional setting. By doing so, I aim to create a level playing field for understanding Dutch solutions in an international (comparative) context.

The second question provides a mono-disciplinary approach to autonomy in the Dutch legal context and its impact on Parliamentary control:

Which autonomy indicators can be derived from legal theory and how do they match control of ZBO operations?

Similarly, a question from an economic perspective is needed:

Which autonomy indicators can be derived from economic theory and how do they match control of ZBO operations?

Given the answers to these research questions, an analysis can be performed on the autonomy of individual (groups of) ZBOs. I use the word relative to express that I expect not all ZBOs to have been attributed the same level of autonomy. This is for example based on Linker's (2006, p. 103-104) remarks on differences in control structures of 
ZBOs. On the level of analysis of an individual ZBO, this means that a ZBO can be classified as an entity with high or low autonomy, both in the legal and on the economic dimension. Ideally, there will be a match between the economic and the legal dimension of autonomy, otherwise conflict in controlling a ZBO is built in by design. This is expressed in Figure 1.1. When legal and economic autonomy are aligned in the Parliamentary control systems, only problems that are mainly driven by political considerations rather than actual ZBO operations may remain.

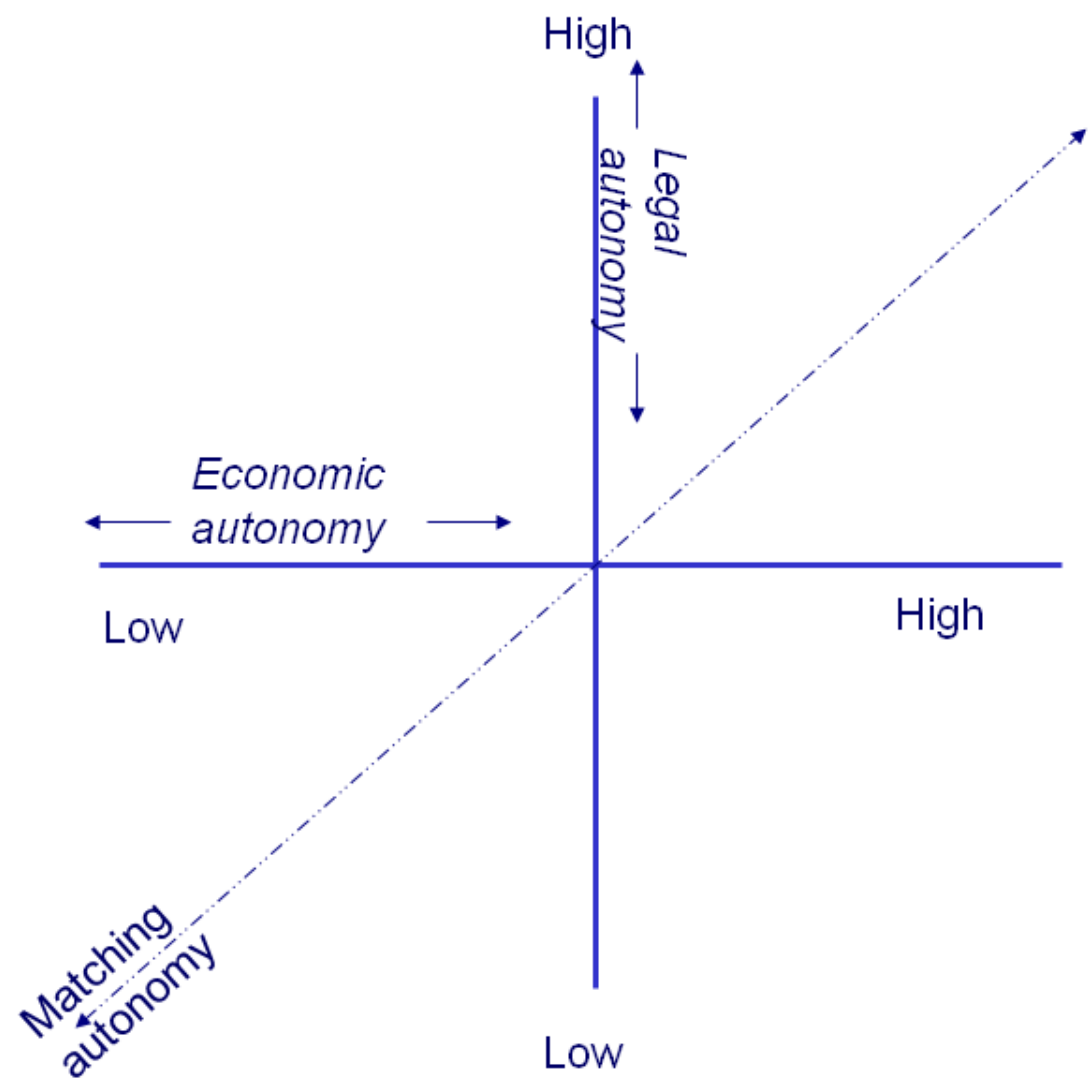

Figure 1.1: Matching of legal and economic autonomy of ZBOs.

The empirical part of this study will address the issue of the (mis)match between Parliament's control tools and the economic and legal autonomy of a ZBO. The question for this part of the study is:

\section{Do Parliament's control tools match the control tools that fit the legal and economic characteristics of ZBO services?}

Given the number of ZBOs, it would be too ambitious to prepare a study that covers all existing cases; therefore I will use a multiple case study approach. Before I give a brief outline of the thesis, I will first address the research methodology in more detail.

\subsection{Research design and methodology}

\subsubsection{Research plan}

The purpose of this study is to evaluate possible mismatches between formally observed and actual practices in Parliamentary control and autonomy of ZBOs. There has been no 
previous research on a multidisciplinary basis of law and economics with respect to ZBOs. Previous mono-disciplinary studies on ZBOs, both in terms of economics and law, do exist (e.g. Kummeling et al. 1999; Kuiper, 1999). Such studies do allow a theoretical basis to be developed that goes beyond the pure exploratory research model (Babbie, 2008, p. 326; Yin, 2009, p. 18) that would be necessary if no knowledge was available at all. The research plan has an inductive rather than a deductive design (Babbie, 2008, p. 57). Furthermore, the research has a descriptive comparative character (Geurts, 1999, p. 153) rather than a testing character. This allows for what Shadish, Cook and Campbell, 2002, p. 501) refer to as theory based evaluations by disclosing expected relationships. It cannot have a testing character due to a lack of a theory on possible causal relationships that determines the autonomy of ZBOs. ${ }^{28}$ The descriptive character of the study is also a result of the fact that there are no normative solutions for controlling ZBOs: as far as general legislation on ZBOs (even in kZBO as of 2008) exists it allows politicians to choose between options or to even fully diverge from these options (Parliament, 2008b).

On a broader level, comparative research is needed due to the differences in institutional settings in each jurisdiction: just copying a solution that seems to be adequate in one jurisdiction may be totally ineffective in another one. A comparative study can provide the context that is needed to understand what is going on in the particular - in this case Dutch national level - jurisdiction. A comparative case study design provides the opportunity for an in depth analysis of controlling individual ZBOs.

In addition to the two formal legal and economic dimensions, controlling a ZBO is based on an interaction between different participants at different levels (ZBO-ministrypolitical level) who might have different opinions on the effect of autonomy on budget authorisation. The case study design allows data to be brought together from this variety of perspectives (Swanborn, 2003, p. 39-40; Yin, 2009; p.18).

\subsubsection{Methodology}

I have chosen to carry out multiple case study research. From a methodological point of view, a multiple case study design allows more powerful conclusions to be reached than a single case study design (Yin, 2009, p. 61). The choice is also driven by the indications, at least in the literature on the legal setting in which ZBOs operate, of a link between reasons for creating ZBOs and the authority attributed to a minister (e.g. Boxum et al., 1989, p. 37-39; Kummeling et al., 1999, p. 65-67). Kuiper (1999, p. 35-39) adds that different control regimes exist, also based on the legal characteristics of ZBOs. A single case study would not reveal such differences. A full survey (Geurts, 1999, p. 152; Babbie, 2008 , p. 270$)$ on the population $(n>100)$ would be more appropriate for an exploratory research design aiming at future in depth research (Yin, 2009, p. 9) or an explanatory design meant for deductive research types (Babbie, 2008, p. 303)

When executing multiple case study research, a major question is how to find relevant cases. Basically, two options exist: a random or a stratified sample. Swanborn (2003, p.

28 See e.g. the variation in autonomy of ZBOs as described in Van Thiel and Yesilkagit (2006). 
59) notes that a random sample is not really suitable for case study designs. A stratified sample from the population is, given the research question for this study, possible because at least some characteristics that might be relevant - such as legal status and services provided - can be observed objectively.

The process for arriving at the stratified sample started by collecting data from the Internet on all ZBOs as listed by minBZK (minBZK, 2007b). The date of data collection, 1 July, 2007 has been used as a benchmark. By doing so, a comparison between the different ZBOs could be made without interference from legislative changes during the empirical part of the research. It does not imply that changes in later legislation were completely ignored; where relevant, reference is made to such changes. The empirical part of the study in terms of data collection and including legislative developments was finally closed on December 31, 2008. The data collection process currently covers what occurred throughout fiscal 2007 concerning oversight and control on ZBOs from all of the ministries. The information search was aimed at finding the ZBO 2006 annual reports and preparing a database of ZBO financial information as well as on the services provided. The data were used to design the case selection model as described in Part $D$ as well as to present the data on ZBOs in general as shown in chapter 2.5.3.

Once the cases were selected, the second stage of the research was started. At this stage, desk research based on ZBO case law and ZBO statutes as of 1 July 2007, documents from fiscal 2007 and 2008 as submitted to Parliament as well as a number of documents from ZBOs and ministries were studied. Finding the latter group of documents was based on a general description of these documents and on own experience. ${ }^{29}$ The list could only include general descriptions as there was no information on the jargon used on ZBOs related to ministries I was less familiar with. Appendix 2 lists the general description of the documents requested and Appendix 3 lists the documents that were actually received and studied at this stage of the study.

Documents in principle only provide formal information on autonomy and authorisation. It is possible that underlying documents reveal something of a mismatch between formal and actual autonomy, particularly when an underlying document seems to have content that diverges from legislation or legislation based decrees.

However, most of the information on actual autonomy can only be retrieved by participating in the budget authorisation and appropriation processes. Along with the general restrictions on participative research such as risk of bias and the effort needed (Yin, 2009, p. 102), in this case it would require more observers to cover both sides ministry and ZBO - of the process. I chose for another complementary research strategy that can reveal actual processes, I decided to interview key officials at both the selected

29 I had the advantage that I am also an employee of a large ZBO, UWV. Although I am not working work in UWV's process of controlling operating costs, I do have knowledge of the outlines of the process of controlling operating costs and the documents that are used in that process. 
ZBOs and the ministries that can be regarded as their owners. These key officials are considered to be the major players in the debates between Parliament and minister. It is possible that this approach also results in some bias, particularly in those cases where the parent ministry 30 is not the only ministry involved in commissioning services towards a single ZBO. I will mention this issue in cases where it appeared to be relevant.

In preparation for the interviews a semi-structured or focused (Yin, 2009, p. 107) questionnaire was designed. This questionnaire aims at identifying both legal and financial arrangements between parent ministry and ZBO based on 9 topics, ranging from attributed authority to planning and control. The questionnaire was used as a tool for the interviews and was not literally followed, partially because some information could be found in documents, partially because a thematic semi-structured interview rather than a strictly structured interview provides opportunities to find information that would not have been revealed if the questionnaire had been followed strictly (Yin, 2009, p. 107). The questionnaire was discussed with the research supervisors and is included in Appendix 4. I did use structured questions on the questionnaire form, but these were meant as a reminder for the interviewer. The interviewee did not see the questionnaire but was informed about the general topics to be addressed in the interview in the letter in which the interview was confirmed.

At the time of most of the interviews in the $2^{\text {nd }}$ quarter 2008, 2007 was the most recently completed fiscal year that could be discussed. Especially with respect to the interviews this choice prevented bias from respondents having to rely on their memory ('poor recall bias'; Yin, 2009, p. 108-109) for issues that had occurred too long ago, since preparation of the 2007 budget may start early in 2006. It also reduced the risk of holding interviews with respondents who had only been recently been assigned to the job and did not know (enough) about what had happened in the past. Of course, the method used also has some disadvantages, because fiscal 2007 was covered fully and fiscal 2008 was only partially covered in the evaluation process. In my opinion, the risk of bias due to an incomplete overview of a fiscal year is relatively low because as long as there are no significant changes in tasks or activities involved as well as no substantial changes in law or statutes, there will be no change in the basic lines of autonomy. Furthermore, budget processes do have an overlap: at the end of fiscal 2007, the budgeting process for 2008 has already been started (Minderman, 2000, p. 88), which allows for inclusion of information on the budgeting process for the next fiscal year. It is unlikely that the interviewees would not mention essential changes in the process if that was the case. By including remarks on particularly recent legal developments (i.e. after 1 July, 2007) based on documents, another provision is made to include the most recent information.

The interviews were held with controllers and/or secretaries of the executive board of the ZBO. These people are supposed to have the most direct relationship with the parent

30 Parent ministry refers to the ministry that is politically managed by the minister responsible for a particular ZBO. 
ministry and should have an overview of the relationship between ministry and ZBO. To prevent a ZBO-bias in the research, account managers and/or controllers within the parent ministry, mostly staff that are directly involved in controlling and monitoring the ZBO, were interviewed as well. In some cases a separation existed between policymakers responsible for the ZBO and controllers. In such cases, a separate interview was held with the policy makers. All interviews were recorded and an interview protocol was presented to the interviewees. The interview protocols were authorised and these authorised protocols have served as input for the empirical section. Theoretically, interviews with civil servants may be biased by politically driven answers. This cannot be fully excluded, but is mitigated by the interviews with ZBO staff and the use of document analysis.

In addition to officials from ZBOs and parent ministries, some other people were interviewed. The reason for this is that in the end, this research project is focused on the issue of democratic control of ZBOs as a group of organisations at arm's length of central government. Finding out what civil servants and ZBO staff think of the governance structure and budgetary control procedures gives insight as to what is going on, but it does not cover the opinions of those who are actually supposed to pass laws and hold ministers to account. That is why I decided to ask (former) Members of Parliament about their opinions on controlling ZBOs. An additional incentive to do so is given by remarks by the NCA (Parliament, 2006a, p 9) concerning the information provided by ministers on at arm's length entities to ensure that Parliament is able to hold a minister accountable for controlling these entities. The questions to Members of Parliament are at a higher level of abstraction, but also aimed to cover the full scope of the research. Similar procedures were used as for the interviews with officials. The questions to Members of Parliament are included in Appendix 5. I have also prepared a set of questions for staff involved in preparing the report that is at the basis of the proposals for implementing a kZBO (Parliament, 2007c). In this interview, emphasis was on exceptions to full implementation of kZBO and the general motivation that is the basis of these exceptions. These questions are included in Appendix 6. Finally, a full list of all interviewees (at a functional level) is included in Appendix 7.

The data generated from documentary analysis as well as from the interviews were supplemented with Parliamentary documents regarding budgetary and intermediate financial information. In the three stages of the budget process: authorisation/appropriation, execution and reporting, Parliament has a direct opportunity to discuss ZBO operations. I searched these documents for fiscal 2007 and 2008 to find references to the ZBOs in the case studies with respect to operations as an additional tool for indications of autonomy. When the interviews revealed that a discussion on a specific ZBO had been held in Parliament on another occasion, these documents were also included in the desk research. A list of key documents used can be found in Appendix 11. 
A final note should be given on data analysis and validity. In general, using both documents and interviews provides a form of data triangulation (Geurts, 1999, p. 98; Yin, 2009 , p. 116) that addresses the ZBO autonomy issue from different perspectives, which is in this case supported by interviewing respondents. Triangulation is also applied on the methodological level by using document analysis along with interviews and in operationalisation (Van Thiel, 2007, p. 118; Yin, 2009, p. 116) by using more than one indicator for the autonomy concept, both from a legal and economic perspective. Although using these different forms of triangulation contributes to the reliability of the results, some bias cannot be fully excluded. Civil servants may have provided politically motivated answers as a result of their position in the process. The guarantee of anonymity for individual respondents is an important tool to reduce the risk of politically driven answers. On the other hand, recording the interviews and preparing an interview protocol might have had the opposite effect. In general my impression was that respondents were willing to share their views with an open mind. Details on data analysis and actual operationalisation will be discussed in section $\mathrm{D}$.

External validity of this research has been ensured by concentrating most of the interviews within a short period of three months in spring 2008 at the final stage of the reporting process on fiscal 2007 . This has contributed to preventing poor recall bias but also to a similar political setting. During this period there was no change in the political climate or political priorities. The ministry of the interior (minBZK) ${ }^{31}$ had just published its letter on the implementation of kZBO (Parliament, 2008b) but there had not yet been a debate in Parliament on this subject.

To some extent the results of this study can be generalised to a larger group of ZBOs: first, if a ZBO in the study is actually part of a cluster, it is very likely that other ZBOs in the cluster will have similar levels of autonomy including mismatches. Second, the stratified sample used allows for an autonomy indication for ZBOs delivering similar tasks. It does not allow for conclusions with respect to ZBOs that provide essentially different types of services. Third, the interviews and documents provided by the ministries reveal some information on the attitude of a ministry towards the ZBOs 'owned' by that ministry. Similar cases are likely to be treated similarly. I should note that this aspect of external validity only holds from the perspective of a ministry, it cannot be concluded that all ZBOs 'owned' by a ministry hold similar attitudes towards that ministry.

\subsection{Outline of the thesis}

The thesis is split up in four parts, each addressing one of the research questions. Part A covers the introduction, research questions and research plan (chapter 1 ) as well as the descriptive research question on the field of ZBOs (chapter 2).

31 I use the name of the ministry as provided on its website. minBZK has tasks similar to the UK Home Office. 
Part B covers the legal dimension of ZBO autonomy. In three chapters, the descriptive research question on autonomy from a legal perspective will be discussed. Each chapter covers a particular domain of legislation. I will start by discussing the legal budgeting framework as this subject is at the heart of the constitutional position of Parliament in authorising budgets. Secondly, I will address issues regarding public law in relation to ZBOs. This will cover general legislation on ZBOs. Thirdly, private law will be reviewed. This is driven by the fact that some ZBOs have a private law based status and thus by definition a different governance structure to those ZBOs that have a public law status.

Part $\mathrm{C}$ covers the economic dimension of ZBO autonomy. In three chapters the descriptive research question on autonomy from the economic perspective will be discussed. This will be done along the lines of Neo-institutional economy, the market as well as product and production characteristics. The last issue regards the actual control tools that follow from service characteristics.

In Part D, the empirical research question is addressed. Here, I will start with a more detailed description of the ZBO field to arrive at a case selection for empirical research. In the actual empirical research chapters, I will describe the individual cases selected and then address autonomy as it has been formally described and materially observed. The last chapters of this part will end with a summary, conclusions and policy recommendations. 


\section{ZBOs within the framework of Dutch central government}

\subsection{Introduction}

Chapter 1 briefly discussed research on quangos and more specifically, ZBOs. I made my case as to why I would specifically like to focus on Parliamentary control in relation to ZBO (relative) autonomy. Before I can address theoretical notions on that issue it is necessary to describe the context of Dutch ZBOs within the framework of Dutch central government. The question that will be addressed in this chapter is:

\section{How do Dutch ZBOs fit into the institutional context of Dutch central government?}

I will start with the last part of the question. Every national jurisdiction has its own characteristics, traditions and regulations. In section 2.2 I will describe in a nutshell how the Dutch government is organised and what roles are given to legislative and executive powers to provide a context for the institutional setting. After the introduction on the Dutch government, more can be said on ZBOs as a tool in implementing government tasks. Sections 2.3 and 2.4 discuss definitions, motives for creating ZBOs and the relationship to the core of central government. In section 2.5.1, internal and external autonomisation of government entities are discussed.

The last part of this chapter will be used to describe ZBOs in more detail. The number of ZBOs that exist at a national level in the Netherlands is an issue that causes confusion. In the literature the number of ZBOs varies between 144 (Parliament, 2008b, p. 1), 17032 (Kohnstamm Committee, 2004, p 19); 430 (Kraan, 2006, p 226), 431 (Van Thiel and Van Buuren, 2001) to 54533 (Parliament, 1995a, p. 10) and 600+ (Van Thiel, 2009). Without elaborating here, it is fair to claim that a definitive answer as to what is to be regarded as a ZBO cannot be given as it is still subject to substantial changes. Section 2.6 addresses the ZBO population and different classifications that may be used to create a more structured view on the population. In the last section (2.7) I will draw some conclusions and define the population studied in the following chapters.

\subsection{The organisation of Dutch central government}

The Netherlands is formally a constitutional democracy which can be classified as a decentralised unitary state (Andeweg and Irwin, 2002, p. 12 and p. 161). Three levels of territorial government exist: central government, provinces on a regional level and local government. Within the framework of central law, regional and local governments have some autonomy to make policy decisions, but the degrees of freedom are limited. In many cases a form of joint government (co-governance; Andeweg and Irwin, 2002, p.

32 In some cases, a ZBO is in fact a group of separate ZBOs each performing the same task within a specified jurisdiction. These groups are counted only once. Example: there are 22 Chambers of Commerce, each with a separate ZBO-status.

з3 162 when corrected for groups of ZBOs 
166) between the central and local level exists in which local government is in fact executing central legislation and receives the necessary funds from central government. Degrees of freedom for local (and regional) government are also restricted by the relatively small opportunities for raising taxes and the amounts of general income transfers from central government (Allers and Elhorst, 2005; p. 499).

ZBOs are a form of functional rather than territorial government (Zijlstra, 2009, p. 199) and are in most cases only affiliated to central government. In the following subsections I will first address the political setting at the national level. After that some notes on legal as well as on government budgeting and accounting traditions will be made. The section will end with some remarks on the reasons for creating forms of functional government at the national level as an introduction to the concept of ZBOs.

\section{Focusing on the national level}

Autonomisation and privatisation are phenomena that can be found at all levels of government. At the sub-national level, at arm's length entities may have been created based on a general law or statute. Examples of these are local public bodies delivering services for a group of municipalities. Statute based arm's length entities exist in different forms as well. Zijlstra (1997, p. 309-386) discussed the possibility of the existence of ZBOs at a local level. His conclusion is that some units of local government may have a status similar to a national ZBO but that the local government act 'Gemeentewet' [GemW] does not allow attributing ZBO status to separate legal entities (Zijlstra, 1997, p. 385). In this study I will only focus on national level ZBOs, which include both separate legal entities as well as units operating within the State legal entity.

\subsubsection{The political setting}

In the Dutch constitutional monarchy, the legislature can be regarded as a joint effort between Parliament, Cabinet and the Monarch, in which the latter's role is limited to giving the final formal consent to laws that have passed through Parliament. This is expressed by the formal definition of Government in the constitution which stipulates that Government consists of the King and the Ministers, followed by the statement that the ministers must be held accountable for acts of government (GW:42). Both 'Tweede Kamer' and Cabinet can propose laws, which have to pass both chambers of Parliament, the 'Tweede Kamer' and 'Eerste Kamer'. In practice, the majority of proposals for legislation are initiated by Cabinet (Van der Pot, Elzinga, De Lange and Hoogers, 2006, p. 632; Kortmann and Bovend'Eert, 2006, p.73).

The political system is based on a representative democracy in which citizens choose the 'Tweede Kamer' and the members of the provincial parliaments elect the 'Eerste Kamer' indirectly. Members of Parliament do not represent a specific constituency, but represent the people as a whole (Van der Pot et al., 2006, p. 537-538; Kortmann and Bovend'Eert, 2006, p.74). The system of representative democracy without electoral thresholds implies that it is extremely unlikely that any party will win an absolute majority. 
Since universal suffrage was introduced in 1918, every Cabinet has been a coalition government, in most cases with Christian Democrat parties as part of the coalition ${ }^{34}$ (Stuurman, 1983, p. 281; Andeweg and Irwin, 2002, p. 110). For decades the political system in the Netherlands has been based on 'accommodation' (Lijphart, 1975, p. 103) and 'pillarisation' (Andeweg and Irwin, 2002, p. 21) in which consensus in the political elite was based on the minimal agreement of fundamentals in the political system (Lijphart, 1975, p. 103). In this system, co-operation between the elites resulted in power sharing (Andeweg \& Irwin, 2002, p. 111). The electorate however, was organised along strictly separate religious and class lines. One can state that since 1980, most Cabinets only had small majorities which is an indication that the idea of power sharing is losing some of its relevance. After the 2002 elections, the idea of power sharing has been heavily discussed and within five years, four different government coalitions have governed, indicating some political instability. Thomassen (2010, p. 39-40) notes that the coalition governments did not face a structured opposition ready to take over government, which resulted in voting for anti-establishment parties and increased instability during the last decade. Despite this instability and change in attitude towards creating coalition governments, the traces of the tradition of organising political influence along religious and class lines is still visible, especially in education and health care, where private organisations that originate from this tradition dominate the provision of public services.

The strong religious and class based influence on politics has of course had an effect on the position of the state in society. Esping Andersen (1990) has developed a model in which he describes three 35 welfare state regimes. In the liberal model, government intervention is at a minimal level. This model applies for countries such as the USA. The social democratic model on the other hand, is aimed at high level equality, leading to widespread intervention in society by government. This model applies to the Scandinavian countries. In the corporatist/conservative model, state intervention does exist but is aimed at maintaining basic differences between social classes. The model is according to Esping Andersen (1990, p. 27) 'typically shaped by the Church'. In his studies he classifies The Netherlands under corporatist countries with substantial influence from social democrat institutions (Esping Andersen (1990, p. 53). ${ }^{36}$ Although the fundamentals still exist, under the influence of new public management [NPM] theories, the Dutch model is changing to a more market based liberal model. Examples of this can be found in competition policy (Parliament, 1997a) which ultimately has resulted in sale of the postal services and power production companies.

\footnotetext{
34 The only exceptions are the two liberal/social democrat coalitions between 1994 and 2002.

35 In his revision of the study (Esping Andersen, 1999) he introduces a fourth - Mediterranean - regime, which can be disregarded here.

36 In the last two decades changes in opinion on the role of government in society can be observed, influenced by neo-liberalism and NPM-programs. Kickert notes that these changes however have not really affected government decision making (Kickert, 2008, p. 135).
} 
The Cabinet (i.e. the ministers) constitutes the executive power. The coalition that is formed after elections builds on a coalition agreement document 'Regeerakkoord', which is more or less a political contract which morally binds coalition parties in the Coalition Majority in the Tweede Kamer to the agreements laid down in the document. Officially the Cabinet is not a partner in the 'Regeerakkoord', but in practice members of the Cabinet are involved in drawing up the agreement (Vis, 1986 p. 8-9). Minderman (2000, p. 144) notes that the 'Regeerakkoord' has become an important document for fiscal policy in the last two decades. It defines the financial targets the Cabinet has to achieve and thus also has an impact on the budget authorisation process.

Ministers are not necessarily recruited from the political system and cannot be both Member of Parliament and minister. This has led to selecting ministers based on experience in the policy domain they will be operating in (Andeweg \& Irwin, 2002, p. 116). Once appointed, a minister can hold his office until the next elections or as long as Parliament does not explicitly state that it has lost confidence in the minister. This rule of confidence is one of the most important soft law rules in the Dutch Government. The Scheltema committee notes that the rule of confidence has a separate function to ministerial responsibility and accountability. When Parliament expresses its loss of confidence in a minister, he is supposed to resign, even in cases where he has explained his actions or if he cannot be held responsible for a certain matter (Scheltema Committee, 1993, p. 12). With respect to the issue of ministerial responsibility, the Scheltema Committee distinguishes between four elements: responsibility for his own acts, responsibility as a member of the Cabinet, responsibility for the King and members of the Royal family and responsibility for the civil service (Scheltema Committee, 1993, p 10). When applied to ZBOs, especially the responsibility for his own acts and that of the civil service are relevant. In short, a minister is responsible for ZBOs given the authority attributed to him in relation to the specific ZBO and his actions towards the ZBO under scrutiny. I will elaborate on these issues in Part B.

The organisation of the civil service is in principle politically neutral. The minister is supported by his personal staff. Senior civil servant staff is not replaced when a new government comes into office. ${ }^{37}$ This is in line with the traditional concept of bureaucracy as meant by Weber, which includes rules bound officials subject to hierarchical structures but independent from the individual who holds office (Weber, 1947, p. 330). The ministries are highly specialised and horizontal coordination between ministries with respect to shared or adjacent policy fields is difficult. The ministries do however have many relationships with outside specialist interest groups which were originally also related to the pillarised movements (Andeweg and Irwin, 2002, p. 208). In relation to ZBOs, the ministry of agriculture has strong affiliations to specialist groups; many ZBOs affiliated to the ministry of agriculture are industry based quality control and certifying

37 At the appointment of heads of ministries and the level immediately below, political affiliation is taken into consideration. This ensures that all major political parties are represented in the civil service. 
institutions. Relationships with external specialist groups are used to coordinate within a policy domain and negotiate a specific result.

The main forum where policy coordination beyond the boundaries of a policy domain can be realised is in the Cabinet and its subcommittees, but even there coordination is the result of negotiation and non-intervention (Van den Berg, 1981, p. 234; Andeweg \& Irwin, 2002, p. 117) rather than from using authority to decide. A result of this method of organising politics is that consensus is an important mechanism for implementing policies. Once consensus is agreed upon, then there is a high level of legitimacy for the results achieved, even when the results themselves are regarded as unpopular (Andeweg \& Irwin, 2002, p. 209). A disadvantage of the system is that when no consensus can be agreed upon, no changes will be realised and the status quo will be continued. The minister has in such cases insufficient power to enforce a change, because there is always the possibility that he will lose a vote of confidence when he proposes changes that are not sufficiently coordinated and prepared with members of the majority parties or agreed upon in the 'Regeerakkoord'. Once a particular policy has been developed including the organisational setting in which it is to be implemented, it is very difficult to change this setting: (re)nationalisation of tasks in the public domain is practically impossible in the Netherlands. ${ }^{38}$ This can be illustrated by critical comments of the "Raad voor het Openbaar Bestuur'39, which stated that managerial and efficiency motives only are no longer sufficient to set up a ZBO (Rob, 2004, p. 11). However, many ZBOs have existed for many years and altering their status as an autonomous entity with ministerial responsibility as the single argument to do so is questionable. Furthermore, there are limits to rational decision making in politics: I refer to Simon's concept of bounded rationality (Simon, 1978, p. 10). Within the Dutch political context with its traditions of coalition agreements and negotiations, the outcome of a debate is often more determined by finding a majority than by the strictly rational arguments that can be found to realise changes in policy or organisation. The ups and downs in the appreciation of the use of ZBOs both in the Netherlands and abroad 40 indicate that popularity of ZBOs may sometimes be discussed but that the phenomenon as such is likely to persist.

A rare example of a case where an unexpected shift in opinion on hiving off or hiving in (In 't Veld, 1995, p. 10; Van Thiel, 2000, p. 9) occurred, is the case of creating UWV. Bekke and Van Gestel (2004, p. 88-93) describe how the political elites became convinced that the proposed privatisation of UWV's predecessors was undesirable. However, making the creation of a public sector based UWV acceptable for one of the majority parties required that 'Arbeidsvoorziening' - the public office operating as an intermediate on the labour market - had to be privatised. Ultimately this plan was implemented and resulted in a mixture of hiving in social security programs to be

38 In particular, nationalisation by fully integrating a separate organisation into departmental structures is unlikely; a softer form - hiving in (In 't Veld, 1995, p. 10) is sometimes carried out.

39 The Rob is an advisory body to central government on governance issues.

40 See Van Thiel's analysis on the creation of Dutch Quangos (Van Thiel, 2000, p 18-20) or Flinders (1999b, p 34) description of ups and downs of quangos in the UK. 
implemented by UWV and privatising of re-integration services formerly delivered by Arbeidsvoorziening, both at the expense of corporatist control by employers and labour unions which had controlled the industry before.

\subsubsection{Ministerial responsibility for organisations}

In this section I will discuss the (political) responsibility attributed to a minister for the organisations he uses to achieve his policy objectives. Three articles of the Dutch Constitution are relevant, regarding government in general, the responsibility of ministers and the creation of legal entities.

First, article 44 of the Dutch Constitution governs the creation of ministries. A Decree is required to create a ministry and it is also stated that a ministry is led by a minister. The internal organisation and tasks attributed to a ministry are also laid down in Decrees. The minister is fully responsible and accountable for all acts and decisions made within the ministerial structure, unless otherwise stated. All ministerial units including executive agencies belong to the internal structure of the ministry. They are fully included under ministerial responsibility. The fact that executive agencies use a separate accounting framework does not alter the ministerial responsibility and hierarchical subordination of an executive agency (e.g. Parliament, 1995c, p 3; Van Oosteroom, 2002, p. 113; Wall \& West, 2002, p 211; Plug et al., 2003, p. 24-25; Minderman, 2003, p. 68-69, Pollitt et al., 2004, p.71).

Second, the full hierarchical subordination of a ministry implies that a minister has full responsibility for both operations as well as policy development in programs and policy effectiveness. Although the minister has full responsibility for operations, the impact of errors by civil servants on the position of a minister is in most cases low. In many cases the minister may not know about errors or cannot prevent errors from occurring. Although he is still fully responsible, the political debate - if any - will then focus on the question of whether the minister is still supported by Parliament on a basis of trust (Scheltema Committee, 1993, p. 11-13). Bovens (2000, p. 12-13) showed that no minister has resigned since 1945 only because of errors committed by civil servants.

This is different for those entities that are not hierarchically subordinated to the minister. The study of the Scheltema Committee stressed that other control instruments are required to ensure that a minister can assess the operations of the at arm's length entity (Scheltema Committee, 1993, p. 72-73). Kummeling et al. (1999, p. 19-20) summarised ministerial accountability into three criteria. First, the minister is accountable as far as authority is attributed to him. Second he can be held accountable for his acts with respect to the at arm's length entity - either public or private - and third, he is responsible and thus accountable for the framework in which the at arm's length entity is operating. The general rules on responsibility and accountability hold for all forms of legal entities executing a task on behalf of the State. 
Third, public legal entities other than ministries must, according to article 134 of the Dutch Constitution, be created by or under the law. When a body is given a separate legal status, this implies that the minister in charge cannot have the same authority that he has with respect to the ministry he is leading. Minderman (2000, p. 182) states that such a reduction of responsibility can only be authorised by law. The inclusion of article 134 of the Dutch Constitution is the formal institutionalisation of this proposition. The wording in the Dutch Constitution is however ambiguous. Holterman (2000, p. 596-597) shows that this section of the Dutch Constitution governs the creation of the Dutch concept of public bodies - 'Openbare lichamen'- in general. He also indicates that the Government intended to change article 134 because it might lead to confusion when a constitutional arrangement on ZBOs was made because 'Openbare Lichamen' covers more than just ZBOs. This change of GW:134 has never been implemented in favour of the development of the formal kZBO-law. ${ }^{41}$ The principle of creating an entity by law however stands: 'Openbare Lichamen' have to be established by law according to the Dutch Constitution (Grondwet; [GW]) and the creation of civil law legal entities by government is governed in $\mathrm{CW}$ for the authorisation procedure and the civil code 'Burgerlijk Wetboek' [BW] for the governance structure of the civil law legal entity. The group of public law ZBOs which is somewhere in between these two groups then also has to be established by law. The tasks, organisation and governance structure (composition of the executive and/or non-executive board, the authorities attributed to the board and the system of monitoring) of public entities must be defined by law. This wording indicates that for every specific public legal entity a law has to pass Parliament.

Passing a law requires that Parliament must be involved in the procedure. According to the Dutch Constitution, the Tweede Kamer can make amendments to a proposal and thus modify the level of control attributed to a minister. The Eerste Kamer can only reject or accept the proposal as it is submitted to them after adoption by the Tweede Kamer. In political terms it is therefore Parliament that ultimately decides to what extent a minister's responsibilities are to be reduced and where Parliament can hold a minister accountable.

One should note here that responsibility, accountability and provision of information are related but not identical. External autonomisation - creating a new (public) legal entity is one form of that concept - and the corresponding reduction in ministerial responsibility does not reduce the obligation of a minister to inform Parliament on request. The minister has to provide information when requested, but at the same time he may state that he does not have the proper instruments (authority) to change any undesired results arising from the actions of a public legal entity. Zijlstra (1997, p. 104) noted that the distinction between accountability and information provision is deliberately

41 See also Zijlstra (2009, p. 208) who refers to a proposal of the 'Raad voor Openbaar Bestuur' [Rob] to include the concept of ZBOs in the constitution in relation to ministerial responsibility rather than under separately legitimised public bodies meant in GW:134. 
included in the Dutch Constitution. He illustrates the difference with a theoretical case in which information reveals undesired policy outcomes for which a minister can be held accountable if he did not use his authority to change the system that led to the undesired result. This example is in line with the conclusion by Kummeling et al. (1999, p. 19-20) of ministerial responsibility as described above, in particular the minister's responsibility for the framework an entity is operating in.

When creating an at arm's length entity, the Dutch Constitution requires a law on creating public legal entities and CW specifies requirements for creating a civil law legal entity by government. The contents of the law or statute formally divide the responsibility between the minister and the (non-) executive board of the entity. The more responsibilities are attributed to the board, the greater the relative autonomy from a minister will be. However, the doctrine of ministerial responsibility also includes the concept of system responsibility for a minister. If the system of which the at arm's length entity is a part does not operate correctly, he is supposed to intervene. In the end that may change the relative autonomy of the entity involved.

\subsubsection{Legal traditions}

The present Dutch legal system is based on the civil law tradition that was adapted from the French system in the early $19^{\text {th }}$ century (Glendon, Gordon \& Osakwe, 1985, p. 54). The core of the civil law tradition is that it is based on written law, whereas the generally Anglo Saxon - common law system is based on case law and legal procedures (Glendon et al., 1985, p. 281). The Dutch legal framework is based on a written constitution and a set of formal and material laws. As for all Member States of the European Union [EU], EU-law is superior to national legislation and rulings from the European Courts can overrule national legislation (Seerden and Stroink, 2002a, p. 347). Dutch law is based on the Constitution and consists of a criminal section - which is not considered here - a civil section, as expressed in the 'Burgerlijk Wetboek' [BW] (Civil Code) and a public section, consisting of general public law, as well as administrative law. Based on the Dutch Constitution, the general public law includes issues such as basic (human) rights, the parliamentary system, the judiciary system and decentralisation (Seerden \& Stroink, 2002b, p. 145). The group of administrative laws can be divided into a more general part which includes for example legal protection of citizens and a more specialised part. The 'Algemene wet bestuursrecht' [Awb] (General Administrative Law) and the 'Comptabiliteitswet' [CW] are important laws in this group. The second group is a more specific part which includes for example the relations between citizens and the state in several policy domains. In this group not only are specific policy domains addressed, but organisational matters concerning the attribution of tasks to entities such as ZBOs are also included. 
An important issue in Dutch public law is that it depends on the matter at hand whether or not a public entity is allowed to use private law. In pure business transactions, such as purchasing goods, civil law prevails. In transactions that are meant to achieve government objectives, private law may be used, unless a public law provides better legal protection and can be used to achieve the same objective (Nicolaï, 1997, p. 320-321; Seerden \& Stroink, 2002b, p. 162-164). The 'Hoge Raad' (Supreme Court of the Netherlands, [HR]) ruled in the Windmill case ${ }^{42}$ that a local government is not allowed to levy private law based fees in a case where public law based fees are possible. Whenever government uses private law, it is not allowed to abuse its powers and must comply with the general principles of proper administration as developed by the Courts and which are by now included in the Awb (Seerden \& Stroink, 2002b, p. 151). When it comes to individual authoritative decisions of a government unit, these are governed by general rules of the Awb and subject to testing by an administrative court.

In cases where (central) government uses units outside the ministerial structure, such as ZBOs, in principle the same administrative rules apply to these units. Central government will in those cases either have attributed powers to the unit directly by law (functional decentralisation; Parliament, 1989) or has delegated existing powers of central government to the unit. The difference is rather formal; intervention in decision making based on the powers that were transferred by central government is in both cases restricted to the powers that remain in the hands of the relevant minister. In the case of delegation, it is comparatively easier to withdraw the transfer of power because the formal law does not have to be changed by Parliament.

\section{Examples of delegating and attributing authority}

In the case of ZBOs which provide certification services, the law states that a minister can delegate the certifying task to one or more ZBOs (e.g. 6 organisations are allowed to certify radio equipment, based on article 10.3 of the 'Telecommunicatiewet').

In the case of RDW, the law has attributed specific tasks to the ZBO (see article 4b 'Wegenverkeerswet') such as issuing motor vehicle registrations and general motor vehicle approvals.

The 'Grondwet' and 'Comptabilititeitswet' (Budgeting and accounting act, [CW]) are the basic laws that govern central government organisation. The 'Grondwet' stipulates in article 44 how ministries have to be created. In article 105 of the 'Grondwet', it is stipulated that a general law covers financial management of central government. This is the basis for the 'Comptabiliteitswet'. In the latter, the use and creation of public and private law units operating at the level of central government is defined. To put it shortly here, it is Parliament which has the ultimate voice on the creation of units other than ministries. The Constitution (GW:120) explicitly states that the judiciary is not allowed to

42 HR 260-01-1990; NJ 1991, 393; AB 1990, 408) 
evaluate whether or not a law is contrary to the constitution or international treaties. This implies that no-one can claim before a court that using a ZBO or any other at arm's length entity for providing government services is illegal.

From a legal perspective, the main issue in this study will be the relationship between Parliament, Minister and the ZBO involved. This means that the relationship between citizens and ZBO, which is governed by the powers available to ZBOs and legal protection as included in the Awb will not be considered. What remains is the division of powers between the Minister and the ZBO as they are described in both the formal law in which powers are attributed to Minister and ZBO and the powers that are delegated from the minister to the ZBO. I will elaborate on this in Part B.

\subsubsection{The budgeting process in Dutch central government}

The present CW2001 covers the budgeting procedures of the ministries and is based on cash and encumbrance (or obligation) accounting in a program oriented setting. It is intended that in budget documents a connection is made between objectives and central government activities and the costs of these activities. Based on CW2001, the Minister of Finance can set rules on the information provided in budget documents by ZBOs, but no direct reference is made to the accounting framework of ZBOs.

Budget proposals for central government are presented on an annual basis by mid September before the start of the fiscal year.43 The Budget proposal consists of a review of the general financial position of the State (national level only) in the so called 'Miljoenennota' (Budget memorandum). This document does not include budget laws; it provides context and indicates the more general ideas of the Cabinet on the financial position of the State. In addition to the 'Miljoenennota', 26 budget laws are proposed for fiscal 2007 by the Cabinet to Parliament. There are budget laws for each separate ministry (13), High Authorities of State (Royal Household, Parliament and the like), Overseas Territories, Treasury and Special Purpose Funds ${ }^{44}$ (8; e.g. grants towards local government). The budgets can include expenditure from ministries to ZBOs. As of 2005, a list of ZBOs is included as an appendix to the budget document. Ministerial budgets for fiscal 2007 amount to some $75+\%$ ( $€ 121$ billion) of total proposed spending. This is some $20 \%$ of GDP. Because ministry responsibilities do not change very often, budgets are fairly comparable over a number of years, even after new elections. ${ }^{45,46}$ Parliament, more specifically the 'Tweede Kamer' discusses and passes the budget laws before the start of the new fiscal year on 1 January. The role of the 'Eerste Kamer' is rather formal because the 'Eerste Kamer' cannot amend budget proposals (GW:84-85). In case budget

43 In the Dutch context, fiscal year = calendar year

44 These funds are not Sovereign Wealth Funds meant for investment but are earmarked program resources on behalf of e.g. local government or infrastructure.

45 Van den Bent's (1989, p. 62) book on budgeting in central government also lists budgets for 13 ministries with more or less the same names as those that exist in 2007.

46 The Balkenende IV government (February 2007-February 2010) made an exception to this rule. Two new budget chapters are presented for fiscal 2008 , reflecting political priorities of coalition members. 
laws do not pass the 'Eerste Kamer' before the start of the fiscal year, provisions exist that allow spending to a certain level.

The budgetary process for Parliament formally starts when the Minister of Finance presents the government's budget proposals for the next fiscal year on the third Tuesday of September t-/-1. This date is mentioned in CW2001:12. In the following few days, Tweede Kamer has the opportunity to discuss the budgets in general. After that, discussions start on each separate budget. In recent years ${ }^{47}$, this has generally lasted until December before all discussions are completed and all budgets have passed the Tweede Kamer. Although, constitutionally, Eerste Kamer has to pass all budgets as well, this is in most cases only a formality due to the lack of right of amendment by Eerste Kamer. Therefore, Eerste Kamer will be neglected in this study (see also Minderman, 2000, p. 19).

CW2001 includes regulations for modifying budgets throughout the fiscal year. Ultimately on June 1, fiscal year 't', the 'Voorjaarsnota' [VJN] (1 ${ }^{\text {st }}$ supplement to the budget) and accompanying proposals for adapting budgets are presented. The proposed modifications may be policy driven, whereas under the 'Najaarsnota' [NJN] (2 ${ }^{\text {nd }}$ supplement to the budget) - which is to be presented before December 1 , ' $\mathrm{t}$ ' - only changes due to accounting differences or errors are allowed. On the $3^{\text {rd }}$ Wednesday in May $t+/+1$, budgets are formally closed under the 'Slotwet' proposals - covering the difference between actual results and budgets as authorised under 'Najaarsnota' - which are submitted together with the Annual Report of the Dutch State. All intermediate budget laws have to pass Parliament as well, finally discharging the ministers for their budgetary responsibilities over fiscal year ' $t$ '. The time line in Figure 2.1 shows all politically relevant moments in the planning and control process of Dutch central government.

\begin{tabular}{|l|l|l|l|l|l|l|}
\hline $\begin{array}{l}\text { December } \\
\mathrm{t}-2\end{array}$ & $\begin{array}{l}\text { September } \\
\mathrm{t}-1\end{array}$ & $\begin{array}{l}\text { October- } \\
\text { December t-1 }\end{array}$ & June t & December t & March t+1 & May t+1 \\
\hline $\begin{array}{l}\text { Instructions } \\
\text { minFin to } \\
\text { ministries }\end{array}$ & $\begin{array}{l}\text { Budget } \\
\text { proposals } \\
\text { to }\end{array}$ & $\begin{array}{l}\text { Tweede Kamer } \\
\text { decides on } \\
\text { budget } \\
\text { proposals }\end{array}$ & $\begin{array}{l}\text { 1st } \\
\text { supplement: } \\
\text { changes in } \\
\text { policy are } \\
\text { proposed }\end{array}$ & $\begin{array}{l}\text { 2nd } \\
\text { supplement: } \\
\text { budgets } \\
\text { changed only } \\
\text { for } \\
\text { accounting } \\
\text { reasons }\end{array}$ & $\begin{array}{l}\text { Audited } \\
\text { reports of } \\
\text { ministries to } \\
\text { minFin and }\end{array}$ & $\begin{array}{l}\text { Annual } \\
\text { report } \\
\text { presented to } \\
\text { Parliament, } \\
\text { including } \\
\text { NCA audit. }\end{array}$ \\
& & & & & & \\
\hline
\end{tabular}

Figure 2.1 Time line of the budget process in Dutch central government.

\subsubsection{Budgeting and accounting traditions}

The Dutch central government traditionally uses a cash accounting system. Outside central government, accrual accounting systems are commonly used, not only in the private sector, but also at the level of local government and many arm's length

47 Further back in history it was not unusual for budget laws to be passed after the start of the fiscal year (Van den Bent, 1989, p. 40; Janse de Jonge, 1993, p. 372 and 471; Warmelink, 1993, p. 164) 
organisations such as ZBOs. In this section, I will provide a context for the application and interpretation of accruals based accounting in line with commercial practices of BW2 in the Netherlands and its possible implications for ZBOs.

Accounting regulations in the Netherlands have a long history in using accruals accounting for enterprises. Sutton (2004, p 164-168) classifies Dutch accounting practices as falling within the Anglo-Saxon tradition of accounting principles, which is different to the Continental European tradition. The Anglo-Saxon tradition is driven by diffuse ownership, separation between tax and book income and common law. The Continental European tradition is more government and tax driven and has relatively little emphasis on equity. With the exception of common law (see 2.2.3), the Dutch BW2 accounting principles comply with the Anglo-Saxon tradition. Nobes and Parker (2004, p 66-69) note that Dutch accounting practices are commercially driven; equity oriented and have room for professional judgement. The difference with UK and US practices is found in the autonomy of professionals. Whereas in UK and US practice professional regulation is preferred, in the Netherlands regulation could be overruled by professional judgement from the accounting profession. Due to globalisation and the efforts of the International Accounting Standards Board [IASB], accounting in the $21^{\text {st }}$ century is regulated by the international financial reporting standards [IFRS] which are applied in the Netherlands as well, reducing the significance of professional judgement.

The context of commercial accounting has had its influence on ideas about government accounting as well. As early as 1916, proposals were made by the Minister of Finance Van Gijn for a 'Comptabiliteitswet' in which accruals budgeting and accounting was included (Goedhart, 1958, p. 249-254; Van der Bij, 1993, p 184).48 It lasted until 1985 before accruals accounting was introduced, but at that stage it was only applied in local and regional government. In 1991, the Ministry of Finance proposed creating executive agencies which would have to use accruals budgeting and accounting (Ministerie van Financiën, 1991, p. 58). The first executive agencies were created in 1994 and used accruals budgeting and accounting from the start. In the case of ZBOs there is no uniform accounting framework, the general rule is that those ZBOs with a separate legal status use accruals accounting as far as possible in line with the BW2framework (Staatscourant, 1995, instruction 124p; as of now, I will use the word 'Aanwijzingen' [AW1996], when I refer to this decree). Where transition from cash to accruals based budgeting and accounting for existing ZBOs was regarded as necessary, it was implemented in the 1990s, in most cases related to other changes in the formal law on the ZBO.

Despite the long history of application of accruals accounting in The Netherlands, the country is not in the frontline of government accounting reform. Lüder and Jones (2003, p. 47-48) explain this by the relatively weak position of the Minister of Finance due to the

48 The Netherlands was not the first country in which accruals accounting for government was discussed. Goedhart mentions that Italy introduced accruals in 1886 (Goedhart, 1958, p. 288). 
process of decision making as described in section 2.2.1 and the lack of a central accounting agency that supports a transition to accruals accounting.

Lüder and Jones's analysis is partially correct. Te Velde (2007, p. 16-17) notes that the role of the minister of Finance has changed in the last two decades. Te Velde points at the role of the Minister of Finance in the domain of fiscal policy. When it comes to a matter such as changing an accounting system, this does have elements of fiscal policy (Van Schaik, 2007) but the bottom line is an organisational matter in which many hurdles can be created (see e.g. Robinson, 2002; Hepworth, 2003; Mol \& De Kruijf, 2004). Introduction of accrual based budgeting and accounting for national government was considered around 2000 (Parliament, 2000b, p. 83 - 88) but was quietly deleted from the political agenda. In 2003, the NCA made a new effort to put the issue on the political agenda (Parliament, 2003a). Despite critical comments from Parliament, the Cabinet was not convinced to continue the 2000 initiatives to use accruals accounting (Dees, Neelissen and Steenhoek, 2004).

By 2007, a pilot project by the Ministry of Agriculture [minLNV] was agreed upon as a result of pressure from both Parliament as well as from the accounting industry (Van Schaik, 2007, p. 8). Cabinet reconfirmed its position on government accruals accounting at the end of the pilot project. The main argument provided was that the introduction of another accounting system would not resolve problems with providing policy - outcome information (Parliament, 2008c, p. 12). For this study it is particularly relevant that consolidation 49 of ZBOs in the financial statement of minLNV - as would be required under IPSAS $6^{50}$ - was not realised due to the additional complexity it would generate for the pilot project (Parliament, 2008c, p. 4).

\subsection{Definition of quangos and ZBOs}

This study is on a specific Dutch group of units at arm's length of government, ZBOs. In the literature, quasi non-governmental organisation - quango (Barker, 1982, p. 4) ${ }^{51}$ - is often used to describe the whole group of at arm's length entities. I have already noted that in the political context of the Netherlands, tasks in the public domain were performed by private entities, organised along the lines of the various social groups. In the Swedish case, using at arm's length entities to achieve public goals has a more than 200 year history (Larsson, 2002, p. 181). In more recent years, under the influence of demand for more efficiency in the public domain, the concept of using entities at arm's length of government has spread over many countries (e.g. OECD, 2005, p. 110-112; Pollitt, 2007).

The quango concept is a catch all concept for all kinds of organisations somewhere in between private entities and government units (Forward, 1976, p. 50; Ridley \& Wilson,

49 In short: consolidation means that the separate financial statements of individual legal entities are integrated into one financial statement for the holding company. See Part C for further elaboration.

50 International Public Sector Accounting Standard no 6 on Consolidation

51 Historically, Quango is based on a classification on a scale of public to private service provision in which quasi government and quasi non-government units were separated in an effort to separate public from private organisations (Barker, 1982, p. 13). 
1995; Koppell, 2003, p. 16; Smith, 2004). Barker has emphasised that the negative aspect 'non' in the acronym is actually inadequate, as the organisations are more affiliated to government than to the public sector as a whole, despite their independent legal status (Barker, 1982, p. 4). In definitions of the quango concept, factors on spending public money (Flinders, 1999a, p. 4) and (hierarchical) independence (from bureaucracy) (Flinders, 1999a, p. 4; Van Thiel, 2000, p. 5; Koppell, 2003, p. 16-17, Talbot, 2004, p. 5) are shared issues. Some (Ridley \& Wilson, 1995, p. 4-5; Greve et al. 1999 , p. 142) include entities at the sub-national level in the quango definition, but this only holds for the general concept.

\begin{tabular}{|l|l|l|l|l|l|}
\hline & \multicolumn{4}{|c|}{ QUANGOS } & \\
\hline & \multicolumn{3}{|c|}{ not subject to ministerial hierarchy } & \multicolumn{2}{l|}{ subject to ministerial hierarchy } \\
\hline $\begin{array}{l}\text { private } \\
\text { companies }\end{array}$ & $\begin{array}{l}\text { state } \\
\text { enterprises }\end{array}$ & $\begin{array}{l}\text { voluntaries and } \\
\text { charities }\end{array}$ & public body & $\begin{array}{l}\text { executive } \\
\text { agency }\end{array}$ & unit of ministry \\
\hline
\end{tabular}

Figure 2.2: Different types of organisations for delivering government services. Adapted from Van Thiel $(2000$, p. 8)

Figure 2.2 shows the group of quangos which is divided into four subgroups: state enterprises, voluntaries/charities, public bodies and government agencies (Flinders, 1999a; Greve et al., 1999, van Thiel, 2000). Flinders (1999b, p. 29-30) notes that creating quangos has to do with reducing the span of control of central government's bureaucracy and the limitations of government to execute tasks independent of political control. This argument is more or less in line with the Dutch debate on separation of core and non-core activities of departments as mentioned in the Kadaster example before.

I will now focus on the specific subgroup of Public Bodies from Figure 2.2 as an introduction to the definition of the Dutch variety, ZBOs. Barker (1982, p. 4) noted that organisations under the UK label Non-Departmental Public Body [NDPB], although it suggests independence in fact are a form of arm's length controlled government institutions providing services to the public. Similarly, Talbot (2004, p. 6) emphasises the non-departmental (italics jdk) rather than non-governmental aspect of the NDPB concept.

In the UK, the government uses the concept of Non Departmental Public Bodies, which is according to Hogwood (1995, p. 30) a "pragmatic labelling focusing mainly on a set of bodies to which government makes appointments and is inconsistently applied'. In France, the 'etablissements publics administratifs' are identified as organisations under public law and subject to the jurisdiction of administrative courts. Together with autonomous administrative authorities, which are part of the State entity but operate independently from government, they form a group of entities performing public tasks at arm's length of government (Rochet, Cabane \& Formery, 2002, p. 74-77). Their legal status does not allow them to be included under either government enterprises or voluntary organisations. They cannot be included under the concept of executive agencies as they are not subject to ministerial hierarchy. 
In an OECD-report (2002, p. 11), Public Bodies are negatively defined as not being part of the vertically integrated ministries, but still part of government. Therefore all definitions in fact emphasise a government rather than private affiliation. The OECD document specifically excludes state enterprises from their definition, which is an indication that the quango definition is broader than the usual Public Body definitions. Another important distinction to be made here is the 'hybrid concept', as used in the USA (Moe, 2002, p. 250-254). In a US context hybridity only refers to private organisations that may have some relation to federal government, whereas in a Dutch context, hybridity suggests a mixture of tasks and market activities within one organisation, irrespective of legal status (In 't Veld, 1995; Kickert, 1998; Hazeu, 2004, Meijerink, 2005). These authors basically accept the existence of hybrid organisations. Despite that they do see some risks related to for instance prioritising private tasks over public tasks and distortion of competition (e.g. Meijerink, 2005, p. 19-20). The opinion of these authors is strongly debated by Simon $(1989,2005)$. In his opinion a combination of market oriented production and task (budget) driven activities within one organisation should be avoided. He claims that in cases where government is commissioning services within the framework of a quasi market rather than a competitive market, traditional budgetary controls must be maintained. If not, there is substantial risk of losing control of both the entity that is delivering the services as well as the quality and quantity of the services themselves. I will avoid the normative discussion raised by Simon, but the fact that all authors see some issues in the relation between government and hybrid entity implies that I will have to take that into account in this study.

In the Dutch literature, there also is no unambiguous definition of the ZBO concept. Scheltema (1974, p. 4) identifies them as entities executing central government tasks with some discretion. He did not mention the lack of hierarchical subordination as was done later by the Sint Committee (1994, p. 24) and the NCA (Parliament, 1995a, p. 7-8). Academic literature also recognised the lack of hierarchical subordination (Boxum et al., 1989, p. 16; Kummeling et al., 1999, p. 24; Kraan, 2006, p. 28). As a result of the nonhierarchical relationship, ministerial responsibility is also limited (Scheltema Committee, 1993; Sint Committee; 1994). The services provided by ZBOs are regarded as executive (Sint Committee, 1994) or administrative (Boxum et al., 1989) public tasks, which implies that some authority has been attributed to the ZBO (e.g. Kummeling et al., 1999, p. 24).

Kraan (2006, p. 228) noted that ZBOs can be distinguished from executive agencies not only by the difference in hierarchical subordination of the latter, but also by the lack of ministerial authority to give instructions in individual cases processed by ZBOs and the option for ZBOs to use civil law when the minister intends to claim (part of) the ZBO's equity. These differences are according to Kraan of only minor importance, in the case of both executive agencies and ZBOs there is no residual claimant or competition, and as a result of that, economic incentives are relatively low. Kraan's implicit assumption seems to be that all ZBOs whether based on public or private law, have similar public controls. I 
disagree with this point of view. He is right when referring to the large public law based ZBOs and those private law based ZBOs that were created by government. However, a number of ZBOs - notably certifying institutions - only have a ZBO status for a specific task and operate in a competitive market. They do perform authoritative public tasks, but ministerial control is generally on quality control rather than on budgetary controls. This latter group of ZBOs is often neglected in debates on ZBOs.

Dutch administrative law allows both public law and private law units to execute administrative public tasks. This has been the case historically and is still continued practice under kZBO. It should be noted that there is a strong emphasis on using a public law based legal status if a new ZBO is to be created (AW2008). In some cases, a ZBO does not have a separate legal status but is still part of the legal entity State. This primarily concerns small ZBOs which operate at arm's length of government mostly for reasons of what is labelled as policy independence (OECD, 2002, p. 14) or impartial judgement (Sint Committee, 1994, p. 13).

A formal definition of a ZBO was given in AW1996 and by now under kZBO. The essential difference between the two definitions is 'attribution of public authority' as it is included in the kZBO definition. It is precisely this change in definition that is contested from a constitutional perspective, because it also implies that without public authority a public law entity is not subject to KZBO, leaving an open end in the legal framework of public law entities (Zijlstra, 2009, p. 196-197). The full definition (kZBO:1) is as follows: 'a public body at the level of central government that has been attributed public authority by or under the law and which is not hierarchically subordinated to a minister'. I will follow that definition in general, but will mainly discuss the concept of ZBO based on two characteristics: 'authority to decide unilaterally' ('bestuursbesluit') and 'not hierarchically subordinated'. This choice is driven by the fact that the formal definition of kZBO had not yet been implemented in 2007 and the register of minBZK followed the old AW1996 definition. The two characteristics position ZBOs on the quango scale. If there is no authority for unilateral decisions the unit is, in the words of Greve et al. (1999, p. 142), a voluntary/charity organisation or a (semi) privatised organisation. If the organisation can be classified as hierarchically subordinate to a minister, it is either an executive agency or a unit within a ministry.

\subsection{Positioning of Dutch ZBOs in relation to other Dutch quangos}

\subsubsection{Use of ZBOs for policy realisation}

Before the issue of efficiency was on the political agenda, the role of non governmental actors in decision making and policy execution was already an issue in Dutch government, due to the traditions of pillarisation. Van Thiel mentions that one of the reasons for creating quangos - which includes ZBOs - could be that it gives the opportunity to let interest groups participate in policy execution, e.g. by giving them positions in the quango boards (Van Thiel, 2000, p 169). In more than a quarter of the cases (Van Thiel, 2000, p. 8) where politicians gave a motive for creating a quango, the 
motive of self-regulation is mentioned. The Parliamentary Inquiry Committee on social security concluded in 1993 that organised employers and labour were able to influence the cost of social security programs and there was insufficient supervision to prevent this (Bannink, 2004, p. 153). Ultimately the conclusions of the Parliamentary Inquiry Committee have led to reforms in the social security domain resulting in the exclusion of organised employers and labour from policy execution. The participation motive based on traditional corporatist structures loses relevance. The Gerritsen Committee (2008, p. 20) explicitly suggested that board members in a participation type ZBO must be able to act independently from their stakeholders. If not, transfer of activities to the particular organisation must be considered according to the Gerritsen Committee.

As of the 1980s, the issue of financial distress and as a result, reconsideration of the position of government in society was put on the political agenda. In a report on privatisation of government units, the suggestion was made to either outsource activities performed by Kadaster or to restructure units of ministries into a state enterprise (Parliament, 1982, p. 91). It lasted another 12 years before Kadaster was actually autonomised, but now under a ZBO-label. The outsourcing argument was the intended separation between core activities and non-core activities of ministries (Parliament, 1993a, p. 3). By autonomising, efficiency improvement was expected. The motivation to create a new public legal entity was the typical public character of the services provided by Kadaster.

The example of Kadaster is illustrative but only one in a sequence of reconsideration of the organisation of the civil service at the national level. This process had started with forms of delegated operational control 'zelfbeheer' and the creation of executive agencies (e.g. Kuiper, 1999, p. 20-21). This process continued for another decade in which some 200 (Van Thiel and Van Buuren, 2001) new ZBOs were created and some 300 were dissolved. After the year 2000, there have been some changes, but the discussion on kZBO between 2002 and 2006 resulted in a political reluctance to create ZBOs. If ZBOs were created, the main motive was no longer the participation motive; emphasis is on impartial judgement and to a lesser extent rule driven provision of services, often referred to as the efficiency motive (Gerritsen Committee, 2008, p. 1718). The latter option is only used if other solutions are inadequate (see AW2008:124a).

\subsubsection{Privatisation and autonomisation}

The ideas from New Public Management have led to a vast array of organisations, each with different names, status and authorities. Like other governments, Dutch government has used several forms of autonomisation, originally labelled privatisation (Boorsma and Mol, 1983; Kuiper, 1999, p. 8). Later on, a distinction was made between 'pure' privatisation indicating a full transfer of tasks and responsibilities to the private sector ${ }^{52}$ and autonomisation. The concept of autonomisation implies that there is some remaining

52 Of course when government commissions services from such a privatised organisation, the commissioning would be part of the ministerial responsibility. 
ministerial responsibility. In the debate on autonomisation a distinction is made between 'internal autonomisation' on the one hand and 'external autonomisation' on the other. The concept of internal autonomisation is used when entities are given more degrees of management freedom but the entity still remains within the hierarchical structure of central government (Mol, 1998, p. 67; Kickert, 1998, p. 35; Kummeling et al., 1999, p. 22). Internal autonomisation started with degrees of freedom on specific budgets within the framework of the cash accounting system in the early 1980s (Verbaan, 1983), and evolved - based on a government report in 1991 (Mininisterie van Financiën, 1991) to the creation of what is now known as executive agencies 'Agentschappen' 53 with substantial degrees of freedom to operate and to use an accruals budgeting and accounting system. External autonomisation refers to those cases where there is some remaining ministerial responsibility, but the organisation involved is no longer part of the hierarchical structure of a ministry as is the case with ZBOs.

Greve et al. (1999) prepared a continuum in which different groups of quangos were included. In an adapted form, this table was also used by Van Thiel (2000, p. 7-8). I will use the idea of this table as well but again with some modifications. One of the problems with the original tables was that public authority was not included. Furthermore, legal status and funding are mentioned only marginally, whereas these issues are major topics in this study. I have modified the table in a way that so that the basic (sub)groups of quangos can be identified. The classification is mainly adapted by using the 'hybrid' concept (In 't Veld, 1995); the separation of public law and private law based ZBOs as used by the OECD (OECD, 2002) and the typical Dutch concept of 'Rechtspersoon met Wettelijke Taak' [RWT] (Legal entity with statutory task; Kummeling \& Duijkersloot, 2003, p. 82).

\begin{tabular}{|c|c|c|c|c|c|c|}
\hline \multicolumn{5}{|c|}{ No hierarchical subordination } & \multicolumn{2}{|l|}{ Hierarchical } \\
\hline & & & PUBLIC & ODY & & \\
\hline \multirow{8}{*}{$\begin{array}{l}\text { STATE } \\
\text { OWNED } \\
\text { ENTERPRISE }\end{array}$} & \multirow{9}{*}{$\begin{array}{l}\text { VOLUNTARY / } \\
\text { CHARITY } \\
\text { ORGANISTION }\end{array}$} & \multirow{8}{*}{$\begin{array}{l}\text { Non-ZBO } \\
\text { RWTs }\end{array}$} & & Other public bodies & \multirow{8}{*}{$\begin{array}{l}\text { EXECUTIVE } \\
\text { AGENCY }\end{array}$} & \multirow[t]{10}{*}{ MINISTRY } \\
\hline & & & & & & \\
\hline & & & Hybrid & PLA-legal entity & & \\
\hline & & & PLB & PLA-State & & \\
\hline & & & Hybrid & PLA-legal entity & & \\
\hline & & & & Hybrid & & \\
\hline & & & & & & \\
\hline & & & & & & \\
\hline & & \multirow{2}{*}{\multicolumn{3}{|c|}{ Other Quangos }} & & \\
\hline \multirow[t]{2}{*}{ Legend: } & ALL ZBOs & & & & ANGO & \\
\hline & \multicolumn{6}{|c|}{ PLA: Public LAW Administration; PLB: Private Law Body } \\
\hline
\end{tabular}

Figure 2.3: Different types of ZBOs within the quango spectrum Adapted from Van Thiel (2000, p. 8).

53 The formal name is 'Baten-lastendiensten' (accruals accounting units) to emphasize that the only relevant distinction from other units of ministries is the accounting system 
Figure 2.3 provides an overview of the different groups of ZBOs that can be identified both within the spectrum of Public Bodies as well as in the broader quango spectrum. I will elaborate on each of these different subgroups in the following subsections.

\subsubsection{State owned enterprises}

The first group of quangos is 'state owned enterprises'. Originally, this concept covered three groups of organisations, each with a separate status (Van den Bent, 1989, p. 152154). The most important ones were companies 'Staatsbedrijven' that were operated like private companies, including an accrual budgeting and accounting system but regarded as companies performing a specific public task. The former Postal and Telecom Company is an example of this group, which is now fully privatised. In the Netherlands, the last 'Staatsbedrijf' at the national level, Royal Dutch Mint, was transferred into a private company in 1994. The second group consisted of organisational units within central government that were allowed to operate like a company but remained subject to most of the rules of the cash accounting system of the $\mathrm{CW}$. With the introduction of executive agencies, this form of managing government units was obsolete. The third group consists of private companies ('Staatsdeelnemingen') in which the Dutch state owns a majority or all shares and thus has full control over the company. This is the group which Van Thiel $(2000$, p. 6) refers to in her study. This group of some 30 companies (Parliament, 2006c, p. 55-56) includes 'NV Nederlandsche Spoorwegen' [NS] (National Railways), NV Nederlandse Gasunie' - the national gas transport infrastructure company - and most of the airports. The Dutch State holds a minority interest in some 25 other private companies, implying that it does not fully control these companies.

Government involvement in state owned enterprises is related to legal and economic ownership of the organisation rather than the involvement in the production process. State enterprises are governed by the principles of supply and demand in their operational activities; the government may have influence through voting rights or having appointed members on the board of the organisation.

There is a thin line between a state enterprise and privatisation. One can argue that at the moment when a ministerial entity is reorganised into a private company, this change would qualify as privatisation. From a legal point of view this can be justified as the organisation is no longer subject to public law. From an economic point of view this can be debated because as long as government holds the majority of shares (and thus voting rights) actual control is not in private hands. If the Dutch State were to follow IPSAS accounting standards, this would be expressed by the consolidation of the financial data of state enterprises in the financial statements of the State (Van Schaik, 2008; De Kruijf, 2009).

In some cases, using a state owned enterprise may be regarded as a step in the process of transition of a unit from a government controlled unit to a market controlled 
entity (Pollitt and Bouckaert, 2004, p. 97). ${ }^{4}$ In other cases, such as for example DNB, it is however hard to imagine that government will ever sell its shares to third parties.

\subsubsection{Voluntary or Charity organisations}

'Private law voluntary or charity organisations' may perform a public task and are generally funded by donations and sometimes subsidies from (national) government. Their main relation to government is that they may perform a task that is in the general public interest and therefore sponsored or funded by government. Examples given by Van Thiel are the Salvation Army and the Red Cross, which operate in several countries. ${ }^{55}$ The initiative for establishment of private law voluntary or charity organisations will generally be found in the private sector. The entities that have now merged into the previously mentioned UWV have roots that fit into the characteristics of voluntary and charity organisations (Bannink, 2004, p. 19).

It is possible that Dutch central government has a role in establishing these organisations. Examples can be found in some New Zealand trusts (OECD, 2002, p. 137) and Canadian foundations (OECD, 2002, p. 66). In the Dutch case, Dalhuisen (2004; see also Parliament, 2005b) has shown that CW2001 allows ministerial involvement in establishing such organisations - sometimes referred to as "public' foundations (Van der Burg, 1986; Schroten, 2000) - ranging from granting financial facilities to direct involvement by taking the initiative to establish such an organisation.

As is the case with state owned enterprises, in several cases Dutch central government has attributed authoritative tasks to organisations that at a first glance seem to be voluntary organisations. Examples are the funds supporting art, affiliated to the ministry of education, culture, science [minOCW] and the mortgage guarantee fund affiliated to the ministry of housing, spatial planning and environment [minVROM]. The organisations mentioned are classified as ZBOs. Although it is recognised that using voluntary organisations is undesirable from a governance point of view (Parliament, $2005 a$, p. 6), the fact is that some seemingly voluntary organisations do act as ZBOs and that there are no indications that government is intending to reposition these organisations in the near future.

\subsubsection{Public Bodies}

In the Dutch case ZBOs are regarded as the 'public body' type of quango. In section 2.3 on the definition of ZBOs, I have already mentioned that two criteria are relevant for identifying ZBOs. These criteria are authoritative power and not being hierarchically subordinated to a minister. In the description Van Thiel (2000, p. 5-6) uses in her study, water boards are included as public bodies. However, water boards are a group of entities that have a specific constitutional position (GW:133) in the Dutch public sector. They are

\footnotetext{
54 I will neglect the stake the State has taken in banks as a result of the financial crisis of 2008.

55 Although partially sponsored by government, these examples are not the best examples to be found as they operate independently from government. Better examples are social housing associations and hospitals, both private organisations which are at least in the Netherlands still strongly regulated by government.
} 
functionally decentralised bodies like ZBOs, but their board is democratically elected rather than appointed by the minister. A second problem with using 'Public Bodies' in the Dutch context is that, literally translated, a public body is an 'Openbaar Lichaam', an entity that is mentioned in the Dutch Constitution (GW:134). Examples of 'Openbare Lichamen' are the former 'Openbaar Lichaam Zuidelijke IJsselmeerpolders', now part of the province of Flevoland and 'NIVRA', the organisation of chartered accountants. In Dutch studies on ZBOs both 'water boards' as well as 'Openbare Lichamen are generally excluded (see e.g. Boxum et al., 1989, p. 16) although they would qualify under the public body type of quango. From a legal perspective, GW:134 generates confusion even in the courts, but according to Zijlstra, the constitutionally relevant distinction between Public Bodies as meant in GW:134 and a ZBO is found in the direct democratic legitimisation of Public Bodies. Legitimisation of a ZBO is indirect and based on authority delegated by Parliament (Zijlstra, 2009, p. 63).

ZBOs do not have a standard legal format. I will mention some highlights in legal structure here; details will be elaborated on in Part B. There is a group of ZBOs that is at first glance not hierarchically independent from a minister because they are units within the legal entity State and use ministerial facilities. A well known example is the 'Kiesraad', which operates from within minBZK. A second remark is that both public and private law based ZBOs exist. I have mentioned above that some private organisations are regarded as ZBOs, but the main rule is that a ZBO has a public legal status (KZBO:4).

The OECD (2002, p. 19) makes a distinction between private and public law based public bodies. Public law based bodies, both units of the entity State as well as separate legal entities, are referred to as 'Public Law Administrations' [PLA], whereas private law based bodies are referred to as 'Private Law Bodies' [PLB]. I will follow this distinction whenever necessary because it is clear cut and in the Dutch kZBO-law, a similar distinction is made with respect to ministerial authority towards the two groups.

In principle, ZBOs operate exclusively in the public domain, given their authoritative tasks and irrespective of their legal status (e.g. the PLB 'Autoriteit Financiële Markten' [AFM] (Netherlands Authority for the financial markets). In some cases however the activities performed can be used for market purposes as well and when political consent is given, market operations are allowed.

A last remark to be made here is that ZBOs do not have to operate exclusively on behalf of government. The hybridity concept has been discussed in more detail in section 2.3. A classification of ZBOs along the lines of 'hybrid' - 'non-hybrid' can complete the overview of different groups of ZBOs.

To summarise, the quango group of public bodies seems to be larger than the group of Dutch ZBOs. For this reason I will avoid using the concept 'Public Body'. ZBOs can be a unit within the legal entity State or they have a separate legal status, either public [PLA] or private law [PLB] based. Finally, some ZBOs may have hybrid characteristics implying 
that only part of their activities have an authoritative public character. I will refer to ZBO when studying the whole group or use PLA and PLB when referring to a specific subgroup.

\subsubsection{Executive Agencies}

After discussing Public Bodies, all subgroups of quangos are in fact discussed. The acronym quango includes the words 'non-governmental'. As Barker (1982, p. 4) put it, 'non-governmental' actually suggests 'non-ministerial'. Lack of hierarchical relationships is what binds the three types of entities described above. It also distinguishes them from the executive agency type of quango which is still subject to hierarchy within the ministry.

An executive agency is an internally autonomised unit within a central government ministry. The minister who is responsible has the opportunity to give operational instructions to any unit within the ministry, including the executive agencies. Although this is the formal position of executive agencies, Pollitt, Talbot, Caulfield and Smullen (2004, p.9) state that executive agencies "have a greater autonomy than the normal [emphasis in original] divisions and directorates in the core of a ministry'. The Dutch form of executive agencies - 'agentschappen' -were introduced in the mid 1990s after a government report (Ministerie van Financiën, 1991) was issued on improving public management (see e.g. Van Oosteroom \& Soons, 2002, p. 19 and Van Oosteroom, 2002). Unlike ZBOs, 'agentschappen' are a well defined group which is easily identifiable in budget documents of central government. In fiscal 2007, 39 'agentschappen' are listed with total costs of operations of some €9.2 billion (Parliament, 2006d, p. 83-84).

Although executive agencies differ in their hierarchical relationship from other quangos, there is some justification to include them within the quango concept. In many cases, quangos were created to reduce ministerial overload (Flinders, 1999b, p. 30), give management more responsibilities and to focus on results rather than on money spent (Statskontoret, 2001). These motives hold for executive agencies in general and the Dutch 'agentschappen' as well.

Executive agencies are not an explicit object of this study. In principle, their budgets are authorised by Parliament and included in government budgets. In the Netherlands, executive agencies are a relatively new way of implementing public tasks, and are in some cases very close to what some ZBOs do. The Dutch government notes that in situations where large numbers of executive administrative decisions are made, an executive agency may very well be an alternative to ZBOs (Parliament, 2005a, p. 5).56 In effect, a letter from minOCW announces the merger of an executive agency and a ZBO as of 1 January, 2010. One of the motives given for this merger is that '...ministerial responsibility requires that operations of the ZBO should be under closer scrutiny of the minister...' (Parliament, 2007d, p. 1) In the literature (e.g. Berenschot, 2002, p. 40; Mol and de Kruijf, 2003 p. 561; Mol and de Kruijf, 2004), indications are given that performance and control of executive agencies is not always as was expected. Because

56 The Gerritsen Committee suggested that creating new rule driven ZBOs was no longer necessary given the opportunity to create an executive agency (Gerritsen Committee, 2008, p. 19) 
of the supposed similarity and remarks in the literature on executive agencies, I will use what is known about executive agency management in the assessment of ZBOs whenever that may be relevant.

\subsubsection{Quangos and the Netherlands Court of Audit}

When the NCA published its first report on ZBOs in 1995, discussions were restricted to those entities that did have an authoritative task at central government level. In 2000, a first report in a series on quangos was delivered by the NCA (Parliament, 2000a). The report discussed not only ZBOs but also other entities that deliver services 'funded by central government contributions or fees that are charged by or under the law' (Parliament, 2000a, p. 16). In the Dutch jargon, the groups of entities that are included under this definition of the NCA are labelled 'Rechtspersonen met wettelijke taken' [RWT] (Legal entities with statutory tasks; Kummeling and Duijkersloot, 2003, p. 82). RWTs perform tasks on behalf of central government, either at central level or at a local level, but these tasks need not have an authoritative status as is the case with ZBOs. The largest groups of RWTs are primary and secondary schools. This group comprises some 1,600 school boards out of 1,900 RWTs (Parliament, 2006e, p. 15), down from some 2,700 school boards some 6 years earlier (Parliament, 2000a). School boards can also be classified as voluntary organisations receiving public funds to perform their tasks.

The concept of quango might be applied to describe the group of RWTs, but is not fully correct either, especially as the NCA includes some public utilities (postal services and power supply) which are regarded as entities outside government control by the relevant ministries (Parliament, 2004c, p. 167). In their 5th study on RWTs (Parliament, 2007b, p. 12), the discussion seems to be closed. The majority of organisations discussed in 2004 are no longer regarded as RWTs.

The RWT concept creates greater confusion compared to international discussions as there are other organisations which can qualify as quangos from an international perspective. For example, social housing associations ${ }^{57}$ (SHAs) which operate nearly $40 \%$ of Dutch housing (Hazeu; 2004, p. 188) are not included in the definition of an RWT, but they could also be classified as quangos as their assets are still subject to indirect control by the Minister of Housing. ${ }^{58}$ Following the same line of reasoning of the NCA for public utilities, one could also argue that SHAs are entities that have a statutory task as price regulation still exists for homes with below market rate rents. Similarly, hospitals are not included in the RWT definition, although they are tightly controlled by government regulated fees and budgets. Van Thiel and Yesilkagit (2006) have done a survey on governance of Dutch quangos. In that study, it can be observed that for comparative reasons it was necessary to include organisations which in the Netherlands are regarded as entities that have their own democratic governance structure and are regarded as

57 In this case 'association' does not refer to a specific legal status, SHAs are in most cases actually foundations rather than associations.

58 Equity in excess of the actual SHA needs can only be used within the sector, a topic which is still heavily debated in Parliament (Vrom-raad, 2003; Parliament, 2007e, p. 46) 
neither RWT nor ZBO. However in the political debates governance discussions are in general mostly limited to the RWT or ZBO concept only.

In 1999 Kummeling et al. presented a diagram showing the main groups of entities in the Dutch public sector that could be identified. This diagram was used to draw a distinction between RWTs and ZBOs. I have modified this diagram to give an overview of the complexity of the whole quango field at the Dutch national level. Figure 2.4 shows that it is hard to identify the individual status of an organisation which performs tasks in the public domain.

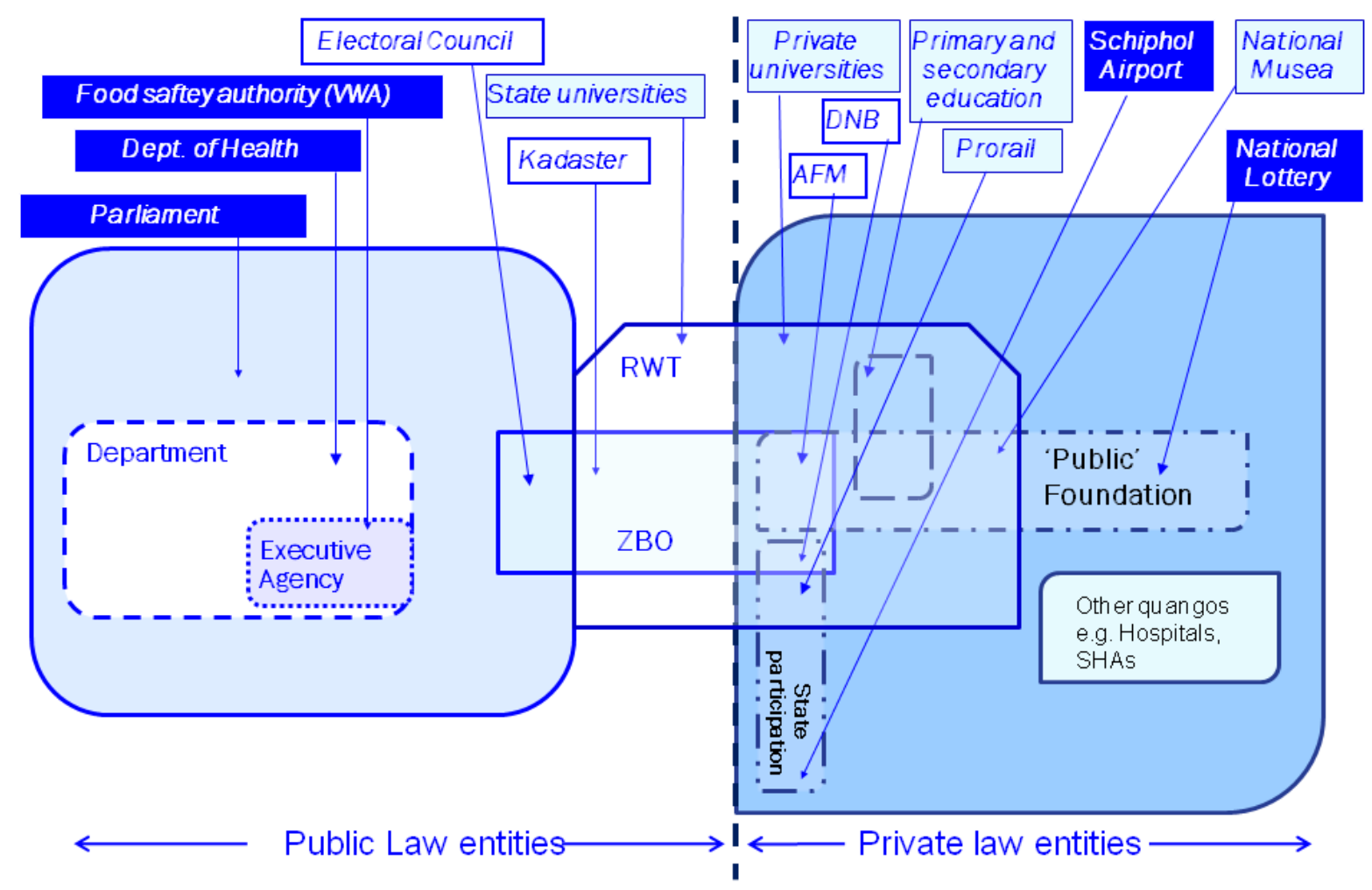

Figure 2.4: National level quangos in the Netherlands. Adapted from Kummeling et al. (1999, p. 26)

As discussed in the subsections on the different types of quangos, the diagram also shows that ZBOs do not need to be public law entities. Some may have private law entity status with an authoritative task, possibly along with fully privately operated tasks. The example of the Kiesraad (Dutch Electoral Council) also indicates that ZBO-status does not require separate legal entity status.

In this section, the different forms of quangos that exist in the Dutch context were briefly discussed. I pointed out that from an organisational point of view executive agencies 
('Agentschappen') are clearly separated from the three other forms of quangos - state owned enterprises, voluntary/charity organisations and public bodies.

Studying Dutch units at arm's length of government is a complex matter. There are numerous organisations in the field with very different characteristics. One can take a snapshot right now, but be assured that a new one a year later will show different results.

Using the internationally widely used concept of the quango seems to be helpful for creating analytical structures. Readers should however be aware of the complications that arise in the Dutch case as a result of the introduction of the RWT concept by the NCA. Furthermore, ZBOs are only a - although substantial - subgroup of the public body concept within the quango debate.

\subsection{Z Z Z Z as a tool of government}

Up to this point, the ZBO concept has been described. The last step in this chapter is to provide a framework that can be used for classifications within the group of ZBOs as a whole, to be used in empirical section $D$. I will discuss four elements: motives for creating ZBOs, the emphasis on ZBO operations (section 2.5.1), and the complexity of the role of a minister in relation to ZBO operations (section 2.5.2). Finally, some remarks are made on services delivered by ZBOs (section 2.5.3), which is related to the discussion on the economic characteristics of services and the possibilities for funding as was generally discussed in section 1.4.2.

The first motive is impartial judgement, which was a motive for creating ZBOs before cost-efficiency in government really became an issue on the political agenda. This motive refers to two different types of decision making. Government may not be able to make an impartial decision because of the lack of specific knowledge and expertise in the relevant policy domain. By using a ZBO, it is possible to organise the required knowledge and to reinforce the legitimacy of the decision making processes (Scheltema, 1974, p. 10; Boxum et al., 1989, p. 21; OECD, 2002, p. 14). Examples of this kind of ZBO are the Dutch Statistical Office 'Centraal Bureau voor de Statistiek' [CBS] and the Medicines Evaluation Board 'College Beoordeling Geneesmiddelen'[CGB-MEB]. Impartial judgement is also needed in those cases where government itself may be a party in the decision making process (Boxum et al., 1989, p. 28; OECD, 2002, p. 14; Gerritsen Committee, 2008). Often, this motive is related to quasi-judicial themes as is the case with the 'Kiesraad' (Electoral Council) and the 'College Bescherming Persoonsgegevens' [CBP] (Dutch Data Protection Authority).

The second motive for creating ZBOs is the result of New Public Management/Public Management Reform theory and its preceding discussions on privatisation of government activities. Traditional government entities are subject to full bureaucratic control mechanisms that may not provide sufficient flexibility (see e.g. Osborne \& Gaebler, 1992, p. 11-12; Pollitt and Bouckaert, 2004, p. 61-63). The idea is that administrative tasks might be performed more efficiently and effectively outside the hierarchically controlled 
bureaucracy. An additional argument for this motive is found in ministerial responsibility: a minister cannot be held accountable for any error in operations deep down in an organisation. This argument is more generalised in the problem of 'span of control' (Scheltema, 1974, p.11; Scheltema Committee, 1993, p. 45-47; Flinders, 1999, p. 29). Under the new kZBO framework, support for this motive is diminishing (Gerritsen Committee, 2008, p. 19).

The third motive for creating Dutch ZBOs is strongly related to the political history of the Netherlands. The Sint Committee states that ZBOs may be used in 'specific policy domains in which it is thought to be desirable that groups in society have direct (co-) responsibility for governance and administration (Sint Committee, 1994, p. 13). Van Thiel notes that this motive was particularly important in the growth of ZBOs in the 1950s (Van Thiel, 2000, p. 9). Flinders (1999b, p. 29) and the OECD (2002, p. 14-15) also refer to this motive as a tool for citizen involvement or other levels of government in decision making processes. Examples of ZBOs that were created based on this motive are the Kamers van Koophandel [KvK] (Chambers of Commerce) and the former social security benefit organisations that have been merged into the present UWV. In this latter case, one can also observe another development with respect to Dutch ZBOs, which is 'hiving in' (In 't Veld, 1995, p. 10; Kohnstamm Committee, 2004, p. 17), meaning that central government is formalising former private tasks into the domain of public law.

Given these three motives, some indications on the services provided by a ZBO can be derived. In all cases there is some form of unilateral decision to be made; however, the nature of that decision is different. When impartial judgement is needed, the decision has a relatively high 'knowledge' character which is to some extent close to the ruling of a judge. In the efficiency case, decisions are rule driven and relatively straightforward; only the public nature of the decision results in the political choice not to privatise the service. The participation motive results in decisions which are the most difficult to describe. A key issue is that some peer group is apparently required to be involved in the decision making process as part of legitimising the decision. These differences have an impact on ex ante budgetary control because it allows for differentiation in funding. This will be developed in Part C.

\subsubsection{Policy Objectives, Commissioning and Ownership}

A decision to create a ZBO implies that the task assigned to the entity requires some form of control by Minister and Parliament. In this section I will address the distinction between the commissioning and ownership roles of ministers because these different roles imply different control tools. To do so, I will elaborate on the policy objectives to be achieved through the operations performed by a ZBO.

Analytically, the creation of a ZBO can be split up into two different decisions. First, there is the public task that has to be performed. Second, an organisation(al) unit is set up to perform this specific program task. These two decisions imply different governance 
issues in the relationship between Parliament and Minister. Decision making on delivering a public task assumes that Parliament and Minister set the framework under which the entity may come to decisions. This framework requires a precise specification of the kind of decisions a unit is allowed to make as well as a choice on how the activities resulting in decisions are to be funded. It is Parliament - in collaboration with the Minister - which sets these specifications, may assess the outcomes ${ }^{59}$ and possibly alter the original specifications. In some cases, there may be a financial link to the desired outcomes when Parliament and the Government agree to use income transfer to achieve the outcomes. In such a case Parliament and Government have two strings to pull: one through the policy program requirements in the law and one through the level of income transfers that are made available to achieve the outcomes. Changing the level of income transfers may have an effect on the level and kind of activities of the unit that actually executes the task as attributed to it by law. What is stated here with respect to ZBOs generally holds for fully hierarchically subordinated units of government as well. The major difference is found in the organisational setting in which service is realised.

The second issue is the decision to use a unit that operates within the hierarchical structure of central government, at arm's length of central government or perhaps further decentralised to local government or even privatised. Whatever form is chosen, to some extent the unit will be held accountable for the performance of the program task attributed to it or the services it provides. Without doubt, accountability demands will be stronger when a unit is closer to central government. Zijlstra $(1997$, p. 6) noted that in Dutch public law there is relatively little attention paid to the organisational structure under which public tasks are performed. That is why he tried to develop a normative framework on the organisation of ZBO public task execution. Whether Zijlstra's or another framework is used, the governance structure of a specific ZBO can deviate from that framework. Differences can be the result of either formal divergence from a framework or as a result of historic developments and arrangements that already existed before the framework became a standard. For example, in the Kadaster case, the organisation was able to create a new separate legal entity, which was not in line with the political opinions on the services to be provided by Kadaster, Kadata BV, (Deelen \& Eertink, 2004, p. 119). As a result, Kadata was dissolved and its activities were again continued by the ZBO Kadaster. Furthermore, formal governance structures as reflected in the legal status of an entity can be overruled by actual controls imposed by the political system on a specific ZBO.

As discussed in section 1.4.2.1, service delivery and thus ZBO operations are determined by commissioning and funding once the program has been defined. The political question regarding operations of a ZBO is not one of the outcomes of the program to be executed, but one of outputs and continuity of the organisation. Outputs are related to the

\footnotetext{
59 I use outcomes in terms of effects as the result of outputs or production (See e.g. Hoogerwerf, 1982,
} p.53; Pollitt and Bouckaert, 2004, p. 118-119; Kettl, 2008, p. 378) 
production delivered to government in its role as commissioner of services on behalf of the general interest. Continuity of the organisation regards the ownership relationship between government and the ZBO as well as the authority on operations attributed to ZBO management. If financial resources are insufficient, theoretically the ZBO will face illiquidity and insolvency. When looking at the issue of output, Government - and through Government, Parliament - is acting as a commissioner in a quasi market who desires best value for the services to be delivered. In this role, the minister who represents Government as a contract party will have to monitor whether the output as requested in an implicit or explicit Service Level Agreement (SLA)60 is actually delivered according to the specifications. In case of under performance, reassessment of the SLA is needed, leading to questions as to how and whether or not to continue the use of this specific ZBO to achieve the desired output. Second, and related to the desired level of output, there is the matter of funding the output. At arm's length entities - especially those which have legal entity status - have to ensure that their financial continuity61 is guaranteed. The financial continuity issue is the link to the debate on authority to control ZBOs. One question is whether the costs of the entities' operations are in line with the financial resources available. A second question in this respect is whether the performance of the entity is on such a level that the SLA is met. If not, the commissioner theoretically has the option to find another service provider or will impose incentives/controls (e.g. fines) that will stimulate the service provider to deliver in accordance with the SLA specifications. Both these questions determine whether the financial position of the ZBO will enable the organisation to perform its tasks without additional financial support from the bodies controlling the entity.

When studying ZBO autonomy from a legal structure and governance perspective, it is the issue of continuity that is the most important one. If Government and Parliament intend to continue to classify the task executed by the ZBO as a public task under the same conditions, the remaining issue is that of assessing the performance of the entity from both the commissioner and the owner perspective. From the commissioner perspective, the ultimate question is whether you get what you have paid for and the price is not too high. From the owner perspective, the question is whether revenues generated by the entity are sufficient so that there is no need - either in the short or long term - to allocate additional resources to the entity to prevent it from financial collapse.

\subsubsection{Multiple roles of a minister}

A problem with ZBOs is that program objectives, commissioning and ownership are in many cases interwoven and get mixed up. By using the analytical tool of separation between programs to be realised and operations to be managed, it is possible to focus entirely on the organisational structure of ZBOs and assess the formal and actual autonomy attributed by or under the law to a ZBO. Managing operations has a direct

60 In Dutch sometimes indicated as Service Niveau Overeenkomst (SNO)

${ }^{61}$ As opposed to program continuity, which is ultimately under the discretionary power of Parliament 
relation to the continuity and ownership perspective as it aims at the delivery of agreed upon services as efficiently as possible. The analytical tool of separating program objectives and managing operations was implicitly used in the Sint Committee report where it stated that the creation of ZBOs would only be possible in an environment in which policy objectives appear to be relatively stable (Sint Committee, 1994, p. 14). Van Leerdam (1999, p. 185-186) arrived at a similar conclusion from a transaction cost approach. He stated that unambiguous policy goals lead to more balanced provision of services in the course of time. According to Leerdam lack of ambiguity leads to improved (ex-post) accountability and as a result creates a balanced basis for delegation of authority.

The NCA (Parliament 2006a, p. 9) notes in its $5^{\text {th }}$ report on (ex post) accountability of at arm's length entities that there is insufficient information provided to Parliament to assess "the full cash flows and equities of RWTs" 62 which includes program costs as well. This remark by the NCA seems to be a mix of the owner and commissioner perspective. It is based on a statement regarding a budget for all RWTs of over $€ 100$ billion $^{63}$ and is related to performance information including 'outcomes' (Parliament, 2006a, p. 13). Having noticed this, my second comment would be that I do not fully agree with the NCA comment as it ignores the essential difference between decisions on program costs and costs of operations when assessing ZBO performance. Under my assumption of executing a program under steady conditions, a discussion on program costs is irrelevant in assessing ZBO autonomy. In fact, this remark holds for government units which process program costs as well. The essential difference is that in a ZBO case, operations are in fact outside the full hierarchical control of Parliament and Minister.

In those cases where programs are an element in the public debate based on the inclusion of that program in a ministerial budget document, the debate on effectiveness of the program as well as its costs should be held in a policy debate setting rather than in the setting of assessing the performance of the ZBO from the customer and ownership perspective. This is also in line with the remarks of the Scheltema committee (1993, p. 62) which states: 'By reducing the full authority of a minister to the core ministry, the responsibility for policy tasks is emphasised and incrementalism is prevented'. The responsibility for policy tasks will also be reflected in monitoring ZBOs which consists of 'assessing the quality of operations' and second 'the feedback from operations to policy making' (Scheltema Committee, 1993, p. 63). The minister is, in his role as (quasi) owner of the ZBO, responsible for the continuity of the organisation and the issue of customer satisfaction. His role is comparable to that of a shareholder ${ }^{64}$ who is interested in the

62 Note that the NCA report is on RWTs, which is a broader population than ZBOs alone, see Figure 2.4.

63 Some $€ 20$ bln program costs refers to cure budgets which are only regarded as part of RWT not ZBO budgets.

64 Actually, one can argue that the minister is only the shareholder spokesman. It is the legislature Parliament and Cabinet which decide to create a ZBO, so the legislature should formally be regarded as shareholder of an entity. For matters of convenience in writing, I regard the minister as shareholder. Reallocation of residual claims is however a matter for the legislature. 
financial targets set for the entity. From this comparison it also follows that the governance structure in the relationship between minister as (quasi) owner and ZBO is basically ex post. The minister and the entity do not have a formal hierarchical relation, which prevents the minister from giving direct instructions.

In the ex post assessment of entity performance, the owner can require strategic or tactical changes in entity operations. Measuring the formal and actual distance between government and ZBO can from the ownership perspective be realised by assessing to what extent the minister has been given more authority than the authority available to a regular shareholder. Full autonomy would exist when the minister (and Parliament) has similar influence on the operations of a ZBO to a shareholder in a company where nobody has a controlling share in the organisation. On the ownership dimension only, Figure 2.5 shows a decreasing level of autonomy. Note that this is an analytical tool only; I am not suggesting that non-controlling interests are a normative model for the ownership relationship between Government and ZBO, only that it can be used to assess the arm's length position of ZBOs amongst each other. The tool cannot be used as precisely as it can be in a BW2 context where the controlling number of shares can be assessed objectively. The legal measures laid down in ZBO case law are likely to disclose the scope of control by a minister, ranging from no control to full control.

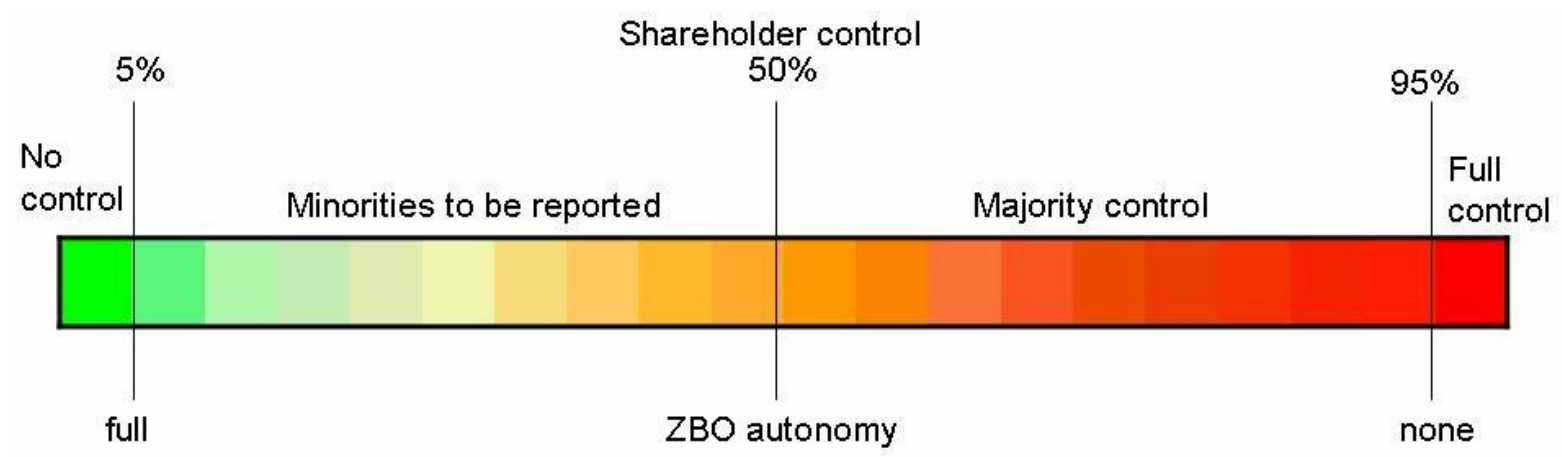

Figure 2.5: Autonomy from a BW2-shareholder perspective

The Scheltema Committee's statement on 'assessing quality of operations' (1993, p. 63) is also an indicator for the commissioner perspective. The question would then be whether the specifications set beforehand in a SLA or similar contract document, which are part of the budget authorisation and appropriation process and the use of the appropriated budgets was in line with the standards set. As indicated above, it is difficult enough to distinguish between assessing the role of a minister as (quasi) owner or as commissioner acting on behalf of Parliament. Matters are even more complicated because the structure of ministerial budgets under CW2001, often makes it difficult to draw a distinction between programs and operations. Budgets are allocated based on policy programs as expressed in the ministerial budget documents that are submitted to Parliament. Unlike practices in the UK, where management of a Non Departmental Public 
Body may be called to account by Parliament (OECD, 2002, p. 237)65, budgeting and accounting procedures for Dutch ZBOs are the responsibility of the minister. In the Netherlands, only annual reports from ZBOs have to be sent to Parliament (kZBO:18.2). Hence, budget authorisation can only be based on the ministerial budget documents submitted to Parliament.

To summarise, a policy program may be executed by several forms of organisational structures, from a ministerial unit or an entity at arm's length such as a ZBO or perhaps even further decentralised to local institutions. The assessment of the program must be at least analytically - separated from the assessment of the entity that is executing the program. Altering the program of course affects the operations of the entity involved, but the aim is primarily effectiveness rather than efficiency of the program. In this study, the programs to be realised are not discussed. The emphasis is on operations that are a result of the program specifications. Given the program specifications, a quasi contract relation emerges on service delivery (commissioning) and the continuity of the organisation (ownership) providing the services.

When assessing an organisation that is responsible for operating a program, the focus is on how the organisation is run and how continuity of the entity is affected as a result of operations. This is the ownership perspective of control. Appropriating resources to a unit implies that some kind of service is to be delivered by that unit. The roles of Parliament and Minister in this case are based on the perspective of commissioning a task and expecting a certain level of quality to be delivered. The ownership and commissioning perspective can be used to find indicators for autonomy in operations. This analysis of the multiple roles of Minister and Parliament will be used in the theoretical discussion on ZBO autonomy from both a legal and economic perspective.

\subsubsection{Classification of $Z B O$ services}

Bouckaert and Peters (2004, p. 38-43) provide a classification of services to be delivered by autonomous organisations. Bouckaert and Peters identify 7 groups of activities ranging from implementation of policies through direct services or income transfers to quasi judicial services and policy advice. In a paper on executive agencies, Pollitt, Bathgate, Caulfield, Smullen \& Talbot (2001, p. 282) note that an international comparison is difficult due to differences in size and functions of agencies. A draft paper by Van Thiel and CRIPO-team (2009) shows based on a survey of 21 countries that the organisation of 25 different public services is widely spread over different types of legal entities ranging from traditional government units to private organisations. A very general classification as provided by Bouckaert and Peters may therefore also be helpful for a general impression of ZBO functions, but it will improve understanding of the specific national context to stay as close to national classifications as possible. 65 This UK practice allows to separate accountability regarding operations (managerial responsibility) and
programs (political responsibility) 
In the Dutch context, the NCA classified 11 types of services in its first report on ZBOs in 1995 (Parliament, 1995a, p. 12). In the context of a classification of executive agencies the NCA classification was reduced to 6 types of services by Smullen and Van Thiel (2002, p. 40-41). Smullen and Van Thiel made an association with diversification of governance and control of executive agencies, suggesting that different types of activities require different control tools. Although less diversified, the classification is in fact an aggregation of the previous items defined by the NCA and can therefore also be applied to ZBOs. This is generally confirmed by the Cobra research findings (Van Thiel \& Yesilkagit, 2006, p. 12-13) in which distributing and collecting money, auditing and information provision are the top three tasks mentioned by ZBOs. In Table 2.1, the classifications by Bouckaert and Peters, the NCA and Smullen and Van Thiel are presented.

Table 2.1: Classification of activities of autonomous entities

\begin{tabular}{|c|c|c|c|}
\hline $\begin{array}{l}\text { Bouckaert and Peters } \\
\text { (2004) }\end{array}$ & NCA (1995) & Smullen and Van Thiel (2002) & This study \\
\hline $\begin{array}{l}\text { Implementation: } \\
\text { Direct service delivery }\end{array}$ & $\begin{array}{l}\text { Licensing } \\
\text { Other unilateral decisions } \\
\text { Registration }\end{array}$ & $\begin{array}{l}\text { Stewardship (assets and data) } \\
\text { Licensing. }\end{array}$ & $\begin{array}{l}\text { 1. Stewardship } \\
\text { (assets and data) } \\
\text { 5. Licensing }\end{array}$ \\
\hline $\begin{array}{l}\text { Implementation: } \\
\text { Transfer of funds }\end{array}$ & $\begin{array}{l}\text { Income transfers } \\
\text { Collecting fees/taxes }\end{array}$ & $\begin{array}{l}\text { Income transfers } \\
+ \text { collecting fees/taxes }\end{array}$ & $\begin{array}{l}\text { 2. Income transfers } \\
\text { (inward and } \\
\text { outward) }\end{array}$ \\
\hline Regulation & $\begin{array}{l}\text { Monitor } \\
\text { Quality control } \\
\text { Issuing decrees }\end{array}$ & Monitor/control & $\begin{array}{l}\text { 3. Monitor + Quality } \\
\text { control }\end{array}$ \\
\hline $\begin{array}{l}\text { Advice and policy } \\
\text { development }\end{array}$ & $x x$ & Not applicable on ZBOs & $x x$ \\
\hline $\begin{array}{l}\text { Information: } \\
\text { Collection and } \\
\text { dissemination }\end{array}$ & $x x$ & $\mathrm{xx}$ & $\mathrm{xX}$ \\
\hline Research & Research & $\begin{array}{l}\text { Research/Education/Informat } \\
\text { ion }\end{array}$ & $\begin{array}{l}\text { 4. Research + } \\
\text { education } \\
\text { (examination) + } \\
\text { information } \\
\text { (dissemination) + } \\
\text { impartial judgement } \\
\text { (tribunals) }\end{array}$ \\
\hline $\begin{array}{l}\text { Tribunals and public } \\
\text { enquiries }\end{array}$ & $\begin{array}{l}\text { Not mentioned, included } \\
\text { under policy advice }\end{array}$ & Not mentioned & $\begin{array}{l}\text { included in } 4 \\
\text { Research }\end{array}$ \\
\hline \multirow[t]{2}{*}{ Representation } & Not applicable on ZBOs & Not applicable on ZBOs & \\
\hline & $\begin{array}{l}\text { Policy advice, educate, } \\
\text { stewardship } \\
\text { (assets/data) }\end{array}$ & Others & \\
\hline
\end{tabular}

I will use the Smullen and Van Thiel classification as a key classification in this study. The classification is comprehensive and more up to date than the NCA-classification. In the latter, the policy advice option existed, which was later excluded from the ZBO-definition. In the NCA classification, no distinction is made between decisions that can be regarded as impartial decisions and rule driven decisions as is the case in the Bouckaert and Peters classification. In Smullen and Van Thiel's classification, tribunal activities are not mentioned because such activities are not assigned to executive agencies. Given the 
relevance of tribunals for ZBOs, I have included tribunal-activities under the 'Research' label as it is, like research, an activity that is supposed to be realised in a value free setting allowing for impartial conclusions. My classification allows segregation between rule driven decisions (Stewardship, Income Transfers and Licensing) on the one hand and tasks based on impartial decision making (Monitoring and Research) on the other.

\subsection{The ZBO population}

As indicated earlier in this chapter, the number of ZBOs varies, depending on when they are counted as well as on the definitions used. In 2005, minBZK created an Internet register of all units that are regarded as a ZBO (Parliament, 2005a, p.1). This register is regularly updated. An earlier paper list was presented by the Ministry of Finance in 2002 (Ministerie van Financiën [minFin], 2002) and the NCA included a list of what were at that time regarded as ZBOs in their 1995 report on ZBOs (Parliament, 1995a). In this study I will use the list of ZBOs as it was available on July 1, 2007 from the Ministry of the Interior's website (MinBZK, 2007b). The July 2007-register included 145 entries, which include some entries that indicate a group of similar entities and other entities listed separately. Examples are the separately listed 'art funds' whereas the territorially devolved separate legal entities KvK (Chamber of Commerce) are mentioned as 1 item. After rearranging all items that can be regarded as a group, 128 items remain. Details of this rearrangement are disclosed in Appendix 1.

Compared to the previous lists that were available, the most remarkable change in the July 2007 list is the omission of the regional police forces. Apparently police forces are not regarded as units that are part of central government although the Minister of the Interior still has an arm's length role in controlling them. As a result, police forces are not subject to the framework law on public bodies (kZBO) that passed through Parliament by the end of 2006. I will follow the most recent classification of ZBOs for practical reasons. This study is not intended to discuss whether an entity should or should not be included within a specific definition of ZBOs. The study addresses the characteristics of organisations and the implications they have on the authorisation and control framework for an individual ZBO. The characteristics described in this study might however, be useful for other entities that operate at arm's length of government; whatever label they may have.

Table 2.2: ZBOs subject to kZBO based on data minBZK

\begin{tabular}{|c|c|c|c|c|c|}
\hline & under kZBO & not kZBO & $\begin{array}{l}\text { not listed January } \\
2008\end{array}$ & $\begin{array}{l}\text { included in } \\
\text { groups }\end{array}$ & totals \\
\hline July 2007 list & 56 & 51 & 21 & - & 128 \\
\hline January 2008 list & 59 & 66 & - & 19 & 144 \\
\hline
\end{tabular}

In January 2008, minBZK sent a letter to Parliament (Parliament, 2008b) in which she summarised the effects on individual ZBOs of the implementation of kZBO. Again, the list of ZBOs was different from the July 2007 list. Because the July 2007 list is no longer publicly available and the 2008 minBZK list is an officially published document, I have disclosed the aggregated data of both lists in Table 2.2. The letter of minBZK splits ZBOs 
in two clusters: a cluster subject to kZBO and a cluster that will not be subject to kZBO, but governed differently. In the following paragraphs, I will provide some data on the clusters of ZBOs in which a link is made between the July 2007 list used in this study and the list provided by minBZK.

The three newly listed ZBOs that are subject to kZBO appear to be very small entities66; I will not cover them in the remainder of the study. Which ZBOs are classified as subject to $\mathrm{kZBO}$ can be derived from Appendix 1. Most ZBOs that do not fully comply are regarded as "part-time ZBOs by minBZK (Parliament, 2008b), indicating a hybrid role with a relatively small ZBO function. Another reason that is given is reconsideration of the role of the ZBO in the near future.

At this stage of the study, data on the number of ZBOs that are listed by government is basically sufficient. I will only give the numbers of ZBOs classified as to their legal status in Table 2.3. All other details on the population needed for the empirical part of this study will be given in Part D.

Table 2.3 below shows the variety of ZBOs by the different types of legal status that exists. Even those ZBOs that are subject to kZBO show a variety in legal status. The variety in legal status is accepted by minBZK, otherwise the reconsideration argument mentioned above would have been used as well. Thus in the budget authorisation process, one has to take into account the different forms of legal entities that exist.

Table 2.3: Number of ZBOs by legal entity and subject to kZBO

\begin{tabular}{|l|r|r|r|r|}
\hline & $\begin{array}{l}\text { Part of legal entity } \\
\text { State }\end{array}$ & Public legal entity & Private legal entity & Totals \\
\hline ZBOs under kZBO & 12 & 26 & 18 & 56 \\
\hline $\begin{array}{l}\text { ZBOs not under } \\
\text { kZBO }\end{array}$ & 26 & 9 & 55 & 72 \\
\hline Totals & 38 & 35 & 57 & 128 \\
\hline
\end{tabular}

In Figure 2.4, the complexity of the use of quangos at the national level in the Netherlands has been illustrated. In absolute numbers, RWTs outnumber all other quangos, due to the fact that the RWT concept includes some 1,600 school boards operating at local or regional levels. However, when the different groups of Quangos ${ }^{67}$ are presented at a similar level in which entities performing the same task in separate jurisdictions are treated as being part of a group, ZBOs become a more prominent group of quangos, both in numbers as well as financially.

66 These three entities are: Stichting VAMEX (minVW); a committee on exam standards for accountants and a group of registration committees for medical professionals.

67 Quangos meant here are State participations, ZBOs, executive agencies and RWTs which do not qualify as ZBOs. 
Table 2.4: Relevance of types of quangos 2007

\begin{tabular}{|l|r|r|r|r|}
\hline & $\begin{array}{l}\text { State } \\
\text { participation* }\end{array}$ & $\begin{array}{l}\text { RWT, not } \\
\text { ZBOs** }\end{array}$ & ZBOs & $\begin{array}{l}\text { Executive } \\
\text { agencies }\end{array}$ \\
\hline Number of items & 21 & 22 & 128 & 39 \\
\hline Estimated operating budget 2007 & n.a. & $€ 8$ B & $€ 7 \mathrm{~B}$ & $€ 9 \mathrm{~B}$ \\
\hline $\begin{array}{l}\text { * Excluding 3 State participations that either have the status of RWT or ZBO } \\
\text { ** excluding the education sector }\end{array}$ \\
\hline
\end{tabular}

The RWT group includes an estimated operating budget of some €21 billion for educational institutions from primary education to university education. Of the remaining $€ 8$ billion, some $€ 3.5$ billion is spent by police forces; another $€ 1.5$ billion by the railway infrastructure company and some $€ 0.75$ billion by public broadcasting organisations. This implies that after excluding the education sector, some $70 \%$ of RWT-resources are spent within the three largest entities.

Estimated operating budgets of ZBOs add up to some $€ 7 \mathrm{~B}$ (own calculations). The three largest budgets are those of UWV (€1.8 B); TNO (research institute; €0.6 B) and academic hospitals (€0.5 B for ZBO activities). The latter two are in fact only partial ZBOs. Runners up and full ZBOs are COA (housing asylum seekers; €0.5 B) and CWI (employment front office; in 2009 merged with UWV: €0.4 B). With respect to the executive agencies, the three largest units are DJI (prison service; €2.1 B); 'Rijkswaterstaat' (infrastructure management; $€ 1.9$ B) and RGD (real estate management $€ 1.3 \mathrm{~B})$.

\subsection{Conclusions}

In this chapter, I have discussed the environment in which Dutch ZBOs operate. The question in this chapter was:

\section{How do Dutch ZBOs fit into the institutional context of Dutch central government?}

The Netherlands is a decentralised unitary Monarchy in which political majorities are based on participation of several political parties in government. Ministers must act in line with the authority attributed to them, both with respect to ministries which are fully controlled by the minister, as well as for ministerial responsibility with respect to ZBOs (and quangos in general). The history of coalition building and accommodation and pillarisation has had a substantial role in the development of central government. One of the results, dating from at least the 1950s, but even prior to that, was that public tasks were executed by entities that are now labelled ZBOs.

ZBOs are a Dutch form of organising production in the public domain at national level. They are the result of private initiatives that were 'hived in' later on, or - mainly after 1980 - the result of new ideas on managing the public sector and using entities at arm's length of government. In the literature, four groups of entities at arm's length of government are identified: state owned enterprises, charity/voluntary organisations, public bodies and executive agencies. ZBOs can be classified as a form of the public body 
concept: not within the hierarchical structure of central government but executing authoritative public tasks on behalf of central government.

The purpose of this study is to assess ZBO autonomy from a legal and economic perspective in relation to Parliament's ex ante control tools. From that perspective, ZBOs can be split into two groups: those that do have a separate legal status and those that do not. The latter group is part of the legal entity State and from a budgetary perspective subject to the same rules as ministries. Their autonomy is mainly based on political non intervention rather than on efficiency driven reasons. The group that does have a separate legal status is subject to other rules, which are basically case specific. In addition to the legal status of a ZBO, the type of services to be provided has an impact on the alignment of legal and economic dimensions of autonomy. Five types of services emerge from the literature: stewardship, income transfer, monitoring, research and finally licensing services provided by individual ZBOs. In the following chapter I will start elaborating on the relevant legal dimensions. 


\section{Part B: Autonomy and control of ZBOs from a legal perspective}




\section{Introduction to Part B}

\subsection{Research question}

In the previous chapters, the research problem for this study was given. The research problem is as follows:

\section{Do Parliamentary control tools match the legal and economic operational autonomy attributed to ZBOs?}

I have also given some indications of the institutional context in which ZBOs operate at Dutch central government level. Furthermore some remarks were made on the literature regarding entities at arm's length from government. ZBOs are a form of quango outside the hierarchical structure of government but still relatively close to government, given the authoritative nature of the task attributed to a ZBO. As a result Parliamentary involvement with ZBOs is likely to be stronger than for the voluntary/charity sector or state participation group of quangos.

The research question focuses on two dimensions of autonomy that affect Parliamentary control of ZBOs: the legal and the economic dimension. In Part B of this study, I will address the legal autonomy dimension for ZBO operation. The research question addressed in Part $B$ is:

\section{Which autonomy indicators can be derived from legal theory and how do they match control of ZBO operations?}

In Dutch law, the concept of autonomy itself does not exist. Autonomy is reflected in the concept of delegation (Awb:10.13) which refers to full transfer of authority to another entity under the responsibility of that entity. Delegation does not allow transfer of responsibilities to a subordinate body or person (Awb:10.14).68,69 Although full responsibility suggests autonomy, the extent to which autonomy is actually given will depend on the type of authority and the aggregated areas of responsibility issued. Therefore, I have to construct a set of indicators that allow me to determine to what extent a ZBO can be regarded as having formal and actual autonomy from the classic hierarchical structures of government. The attribution of delegated authority by Parliament and the corresponding budget authorisation process are the most important control tools for Parliament to allocate resources. This basically holds true for all government funded activities. For national government activities which are not government funded, other forms of authorisation - passing relevant laws - have to be used. Depending on the level of autonomy that is actually given to ZBOs, the

68 By July 2009, arrangements on attribution of authority were included in Awb10:22-23, which also refers to transfer of decision making.

69 A mandate, as meant in Awb10:1 refers to a transfer of a decision on behalf of a public office, which means that there is no separate decision making autonomy. 
authorisation principle results in a set of control tools which a minister needs to be able to use to fulfil his responsibilities towards Parliament.

The remainder of the introduction consists of a short introduction on the legal dimensions to be assessed in order to answer the research question (section 3.2 ). I note that when I use examples to illustrate an issue being discussed, I will refer to ZBOs that are not included in the cases studies in Part D.

\subsection{Structure of Part B}

The analysis on the autonomy of ZBOs attributed or derived from the law can be performed along two thematic lines. These are responsibility and authority on the one hand and budget authorisation on the other. These two thematic lines are spread over several parts of the Dutch legislative framework. The budget authorisation issue is covered in the legal financial framework for the public sector; in the case of ZBOs, the part that covers the national level. The authority and responsibility issue with respect to ZBOs is influenced by the comments of the NCA in 1995 and the political pressure that resulted from it. This part is covered in three groups of legislation: general public law, ZBO-case law and civil law. In the end, the NCA comments resulted in a general law on distribution of responsibility for ZBOs, the framework law on ZBOs [kZBO].

The research question for this part of the study focuses on autonomy indicators from a legal perspective. This is the basis for finding autonomy indicators. The Dutch legal framework consists of International Law, Civil Law, Public Law and Criminal Law. I can ignore Criminal Law and International Law as not being relevant to the organisational issue of using ZBOs for provision of government services. Civil Law is relevant, because at least some ZBOs are created under Private Law rather than Public Law.

The underlying research sub-questions in Part B address the autonomy indicators to be derived from the legal financial framework, general public law and the civil law framework respectively. 

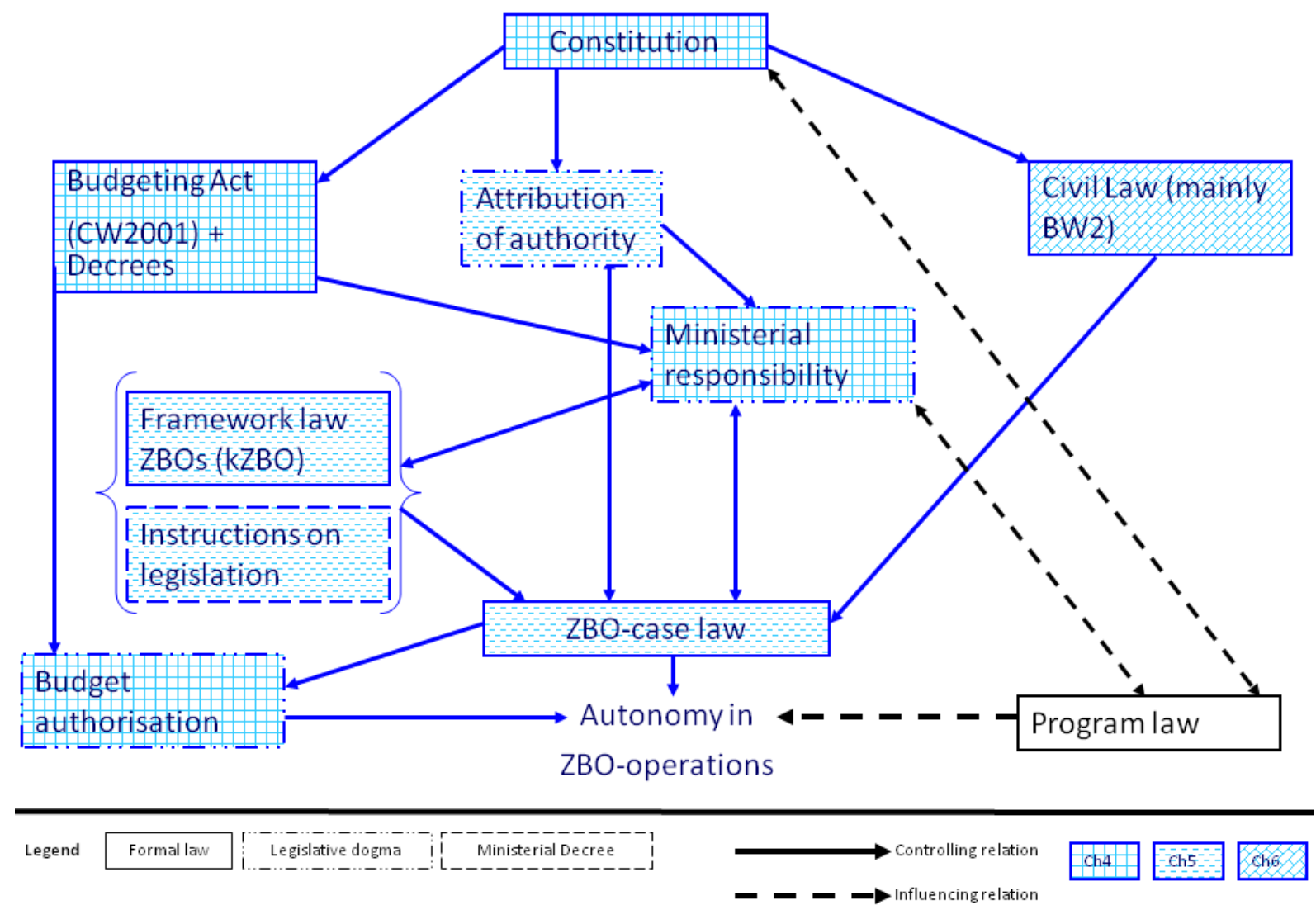

Figure 3.1: Most important legislation influencing autonomy of ZBOs

Figure 3.1 provides an overview of the most relevant parts of legislation that affect the relationship between government and ZBO. Civil law defines all legal entities that exist in the Netherlands. At first glance it would be sensible to start my analysis from the Civil Law perspective. However, the emphasis in the study as a whole is on the relationship between Parliament, Minister and the ZBO executing a public task. Therefore, I will start with a discussion on Public Law. Without attribution or delegation of authority and the subsequent spending authorisation, government cannot execute its tasks, unless the activities are funded otherwise. In that case, Parliament has authorised the attribution of responsibilities to the minister and the (non) executive board of a ZBO. The restrictions in budget law and possibly any exceptions made to these restrictions in ZBO laws, determine the (relative) autonomy of ZBO management towards Parliament and minister. In principle, the legal framework including budget authorisation should result in a (matching) set of control tools which a minister requires to be able to fulfil his responsibilities to Parliament.

I will not consider the issue of case specific judicial supervision by administrative courts. Although relevant to citizens appealing against decisions, a judgement in an individual case does not in principle affect the governance relationship between ZBO and Parliament or minister. Therefore, the organisation of judicial supervision can be ignored although the outcome of that supervision may be an element in the assessment of the 
performance of the ZBO by the minister, or an element in the discussion between Parliament and minister on ministerial responsibility.

In this theoretical part of the study, the emphasis is on the factors included in the legal context. Each element of the law will have an emphasis which either leans towards autonomy or towards government control. By assessing all elements it is possible to state a theoretical position of (legal) autonomy for ZBOs at a general level. Actual autonomy can only be assessed when case law is included in the evaluation, but that will be discussed in Part D. The results of this assessment can then be compared with elements which determine the autonomy of individual ZBOs from an economic perspective (Part C), which is the basis for an answer to the match in design of ZBOs. A final statement on the (relative) autonomy of ZBOs requires that not only does a match in design exist, but also the material position of the ZBO is in line with the design. The material position can be assessed by the question of whether parties behave according to the design or whether the actual governing structure is tighter or looser than was intended in the design. The match of design at an individual ZBO level to its material position is covered in the empirical Part D.

The structure of Part B is as follows. Chapter 4 addresses the relevant budget authorisation legislation. In Chapter 5 the emphasis is on specific public laws that govern general measures on ZBOs, including the framework on attribution of responsibility. In Part B I will not discuss individual laws under which ZBOs were created: that issue is to be discussed in the empirical part $D$ of the study. Chapter 6 focuses on autonomy indicators from a Civil law perspective. Finally chapter 7 provides an answer to the research question and summarises the elements which determine autonomy from a legal perspective. 


\section{Budget authorisation: The budgeting and accounting act}

\subsection{The principles of budgeting}

Production of services is in general controlled by the market mechanism. Supply and demand ultimately determine the level of actual production. However, in the case of a deficiency in the market-mechanism, another control system has to be used to determine the desired level of production. The classic example is policing. Since nobody is prepared to pay voluntarily for the service, it will only be performed when at some level an authoritative power imposes a tax on all citizens to pay for police services. Such a tax will ideally be imposed by a democratically legitimised body. On the one hand, that body will impose the tax; on the other hand it will use a budgetary control tool - authorisation - to match expenditure on policing with the aggregate level of taxes. In the authorisation process, rules and regulations can be set which have impact on the degrees of freedom available to top and middle management of at arm's length entities. This section explores the general impact of budget authorisation on the operations of these entities.

Theory mentions a variety of budgeting functions, which I will reduce here to three main public budgeting functions: 'allocation', 'authorisation' and 'stabilisation or macroeconomic' functions (Musgrave, 1959, p. 7-9; Musgrave \& Musgrave, 1973, p. 10; Boorsma, 1982, p. 323-325; Dolman, 1987, p. 147; Van den Bent, 1989, p. 25; Heun, 1989, p. 272-282; Wildavsky \& Caiden, 2001, p. 1-5; Minderman, 2003, p. 13-14).70 The choices made by the political system with respect to allocation and stabilisation are finally expressed in the authorisation procedures through the legislature. Allocation of budgets indicates Parliamentary preferences on the direction of spending. Gray, Jenkins and Segsworth $(1993$, p. 6) have stated that at its most basic level, the budgetary process acts as a mechanism for integrating different interests into the regular procedures of the political process and by doing so realising political efficiency.

Authorisation in relation to budgeting should be regarded as the formal decision by the legislature to spend government resources. Appropriation is the related consent to incur obligations and to make payments (Lyden \& Miller, 1982, p. 408). In the US context, authorisation focuses on passing program laws, but not the funding of these programs. The funds related to the program are passed in separate appropriations, after the program law has been passed. Both authorisation and appropriation are the prerogative of Congress (Ott \& Ott, 1982, p. 79-83). This difference between authorisation and

70 This study focuses on operations of ZBOs. This means that I am studying the activities of ZBOs which are directed to generate a certain output and outcome. From the perspective of ministerial responsibility for ZBOs the stabilisation function can be neglected as this function aims at using programs to actively or passively redistribute income within the economy. When a ZBO is involved in redistribution, this is a matter of production, not one of stabilising the economy which is politically determined. From a legal perspective the stabilisation function is subordinate to the other budgeting functions. In the Netherlands the EMU requirement is the only legal framework that influences budgetary decisions from a stabilisation perspective. 
appropriation (Janse de Jonge, 1993, p. 149) is a typical issue in the American budgeting system. ${ }^{71}$ In the Netherlands, the distinction does not exist as clearly as in the American system. This is due to the fact that the program laws that have been passed by Parliament do not require annual adoption as is the case in the USA (see also Heun, 1989 , p. 89). Parliament has the right to change a program law and by doing so affects the budget required to execute that specific law. The result is that once the budget has been adopted, the role of the legislature ends and the executive - i.e. the minister takes over.

In the Netherlands and also in other European countries, budget authorisation has no external effect on citizens or legal entities (Heun, 1989, p. 165-171; Van der Bij, 1993, p. 13-15; Mulder, 1995, p. 26; Minderman, 2003, p. 20). No one can claim a right based on an available budget but government cannot claim that budgetary limits do not allow for payment if an applicant for a government contribution has fulfilled the legal requirements to receive the grant. In the USA the authorised budget is a strict spending limit and no spending is allowed above the authorised budget. A government shut down as may occur in the USA (Schick, 2000, p. 4; Joyce \& Meyers, 2001, p. 6) cannot happen in the Netherlands.

Once the budget laws have passed through Parliament, the minister has the formal right to distribute the appropriated funds to the entities that actually execute a specific program. The distribution of money will be realised by the ministry under full ministerial responsibility. The actual entity that executes the program can be the ministry, a ZBO or any other organisation outside the ministry. Of course, the budget law may have restrictions by specifying an organisation that should receive the resources.

The Dutch budgeting and accounting act $(\mathrm{CW})$ is the main document in which budgeting procedures are described. I will start by describing CW and its relevance for ZBOs (section 4.2). After that, I will focus on authorisation procedures, accounting details and the effects of CW on budgeting for ZBOs.

Depending on the level of detail in the budget laws, the minister is free to distribute the monies appropriated. This distribution of funds is a ministerial responsibility for which he is accountable to Parliament. The authorisation issue in budgeting is dominated by two themes. First, what is to be authorised: a level of spending or a level of costs? In other words: is there an authorisation in terms of cash or in terms of resources/accruals (section 4.3). The second theme is the subject of authorisation and the level of detail of authorisation. What are the degrees of freedom for management and what has been controlled ex ante by the legislature? This will be discussed in sections 4.3.2.2 and 4.5 respectively. The chapter ends with a summary of findings.

71 I use the comparison with the American budgeting system as much of the general budgeting literature in English refers to the US system. By doing so, I stress some of the differences that exist in budgeting systems. 


\subsection{The ZBO budgeting framework explored}

Before the 1994 NCA annual report (Parliament, 1995a), relatively little attention was paid to ZBO governance issues. The NCA noted that as a result of this low political attention, a wide variety of ZBO governance measures existed and furthermore that ministers did not have the appropriate tools to control ZBOs. The immediate effect of the NCA report was a motion passed by Parliament (Parliament, 1995c) to prepare a legal framework in which ZBO governance had to be arranged. At that time, $\mathrm{CW}$ did not include any explicit regulations on ZBOs. In the following sub-sections, I will address the measures in CW for creating arm's length organisations, including ZBOs, the planning and control measures that are relevant for Parliamentary decision making and finally, the issue of funding ZBOs by resources other than government budgets.

\subsubsection{Comptabiliteitswet and creating arm's length organisations}

The budgeting process is generally defined in the Constitution (GW:105.1-105.3). by stating that the government submits annual budgets to Parliament and that the income and expenditure statement has to be approved by the NCA before they are presented to Parliament. In GW:105.4 the requirement that a law must be passed to govern central government operational and financial management. This law is the 'Comptabiliteitswet' [CW]. The general features of CW are that it describes the format of the budgets including the cash-commitments accounting system to be used by the ministries. Second, CW describes requirements on administration and daily financial operations and third, the authority and competences of the NCA are described.

$\mathrm{CW}$ includes some articles on the relationship with arm's length organisations. These articles focus on executive agencies as well as private law based entities, which include PLB type ZBOs. I will not consider executive agencies and focus on creating legal entities under CW. Many ZBOs are however public law based entities (PLAs). Public law entities are not separately discussed in CW. In BW2:1 $1 a^{72}$, it is stipulated that a public law entity is created by law. This is a reference to case law in which the organisation and - in the case of ZBOs - offices of the public law entity are described. Ten Berge \& Zijlstra (2000, p. 10) emphasise that from a constitutional perspective, a PLA is part of the public body State even though it has the right to use assets and is accountable for its civil law acts from a civil law perspective ${ }^{73}$. Formal measures on creating a law as well as on creating a PLA are laid down in the Constitution (GW:81-89) and in "Aanwijzingen voor de regelgeving", a decree which includes general instructions for legislation. Particularly with respect to ZBOs, as of 2008 the legislation creation framework is supplemented by kZBO on the organisational arrangements for ZBOs. I will discuss the decree in more detail in Chapter 5.

72 References to BW will have this style 'BWX:y.z, to be read as BW, book X, article y, sub article $\mathrm{z}$.

73 See also Ten Berge \& Zijlstra (2000, p. 21) in which reference is made to the full legal private law capacity of a PLA based on BW2:5 and BW3:32. 
CW has changed several times in the course of time. For the purpose of this study four CW phases are relevant. First, I will discuss CW1927 as effective from about 1950. This law oversees the creation of private law entities in the 1950s, according to Van Thiel (2000, p.18-19) a period during which many decisions on ZBOs were made. Article 89a of CW1927 was introduced to define the exact position of government regarding third party liabilities of legal entities in which government participated. Antheunissen (1948, p. 167) shows that this CW 1927 article was of only very limited scope since it was aimed at those entities for which no general third party liability rules existed. In modern phrasing, the clause is directed at civil law ZBOs or state owned companies which are materially governed by a minister. In 1956, the Simons Committee was asked to investigate the need to revise CW1927. With respect to creating legal entities by government, the committee acknowledged that the civil code ${ }^{74}$ already made a provision for creating public law legal entities by law. The Committee advised including an explicit requirement for creating civil law entities by or under the law (Simons Committee, 1960, p. 192). In their draft of the new CW, they referred directly to article 89a of CW 1927. In the debates on the proposed new CW, the requirement was made more restrictive; a civil law entity could only be established by law. The option to use an instrument - such as a Decree that is available to a minister without prior authorisation by Parliament was removed (Ministerie van Financiën, 2003, p. 166; CW1976-I:40.1).75 This restriction was motivated by the desire to give Parliament the explicit power to consider prior to the establishment of the entity whether the political role of Parliament was secured. Parliament also considered whether sufficient control instruments were available to monitor the activities of the civil law entity. The period governed by the CW1976 version can be divided into two parts. From 1976 till 1995 (CW1976-I) regulations on creating private legal entities were stricter than from 1995 until and including fiscal 2001 (CW1976-II). ${ }^{76}$ Before the 6th revision of CW1976 in 1995, as already mentioned, a law was required if a minister wanted to create a private legal entity (CW1976-I:40). As of 1995 the procedure changed from explicit authorisation to restricted implicit consent. A minister has to notify both Houses of Parliament that he intends to participate in establishing a private legal entity. This procedure is called 'voorhang-procedure'. In the debate regarding the change of the procedure, both the Raad van State [RvS]; (Council of State) ${ }^{77}$ and members of Parliament commented that the change would be constitutionally inappropriate because prior approval on creating a private entity would be required in those cases where government was acting on behalf of the general interest. Furthermore an a priori test of the effects of establishing a private entity on the political function of Parliament would be required (Parliament, 1994a, p. 7). The government replied that the procedure to create

74 The civil code was under revision in 1956. The Simons committee referred to the proposed version of the Civil code. In 2006 this requirement was codified under BW2:1.2

75 After $4^{\text {th }}$ modification of CW1976: article 29

76 CW1976-I refers to versions before the $6^{\text {th }}$ revision in 1995, CW1976-II refers to the later versions

77 A High Authority of State that has to be consulted on every proposal for a law (Dutch Constitution, article 73) 
civil law entities based on a law, led in some cases to the use of puppets that formally created the legal entity on behalf of a minister. The proposal to change the procedure implies according to the minister that such evasion of legal requirements can be prevented (Parliament, 1994b). Furthermore, the Minister of Finance claimed that deregulation and a need to speed up processes make the change in the law necessary (Parliament, 1994c, p. 15). Parliament still has the option to require that a law is submitted in which the proposal for establishing a private legal entity is included. The difference between CW1976-I and CW1976-II may be relevant in those cases were private legal entities were established, initially without the status of a ZBO but which are regarded as being ZBOs by the administrative court (Kloosterman, Winter, Noordam \& De Ridder, 2002, p. 60) or when a ZBO is created without proposing a law as in the case of the Jewish Humanitarian Fund (Parliament, 2000c). Parliament ultimately agreed with the government's proposal with only a minor change. In the original proposal implicit consent was given after 14 days. This was changed to 30 days to bring the proposal in line with a similar procedure for the creation of executive agencies (Parliament, 1995d)

The fourth and last version of CW is the present CW2001, which regarding the creation of private legal entities is equivalent to the preceding version CW1976-II.78 The present measures in CW2001 cover notification when a private law entity is created, whereas creating a public law entity is covered in the constitutional procedures and from a civil law perspective described in BW2:1a. To summarise, Table 4.1 provides an overview of the different stages of CW for creating legal entities and ZBOs.

Table 4.1: Requirements on creating private entities and ZBOs in CW.

\begin{tabular}{|l|l|l|l|l|}
\hline & $\begin{array}{l}\text { CW 1927 } \\
\text { (As of 1934) }\end{array}$ & CW 1976-I & $\begin{array}{l}\text { CW 1976-II } \\
\text { (as of 1995) }\end{array}$ & CW 2001 \\
\hline $\begin{array}{l}\text { On private entities } \\
\text { includes PLBs }\end{array}$ & $\begin{array}{l}\text { Art 89a: } \\
\text { 3rd party liability }\end{array}$ & $\begin{array}{l}\text { Art 40.1: } \\
\text { Explicit } \\
\text { parliamentary } \\
\text { consent. } \\
\text { Law on private } \\
\text { entity required }\end{array}$ & $\begin{array}{l}\text { Art 29: } \\
\text { Notification } \\
\text { required; option to } \\
\text { use a law. Law } \\
\text { required if } \\
\text { Parliament } \\
\text { demands it }\end{array}$ & $\begin{array}{l}\text { Art 34 } \\
\text { required; option to } \\
\text { use a law. Law } \\
\text { required if } \\
\text { Parliament } \\
\text { demands it }\end{array}$ \\
\hline On PLAs & No requirements & No requirements & No requirements & No requirements \\
\hline
\end{tabular}

Before notifying Parliament, the minister has to consult the NCA and obtain the consent of the entire Cabinet (CW2001:34.1 and 34.2). This implies that any plan to create a private legal entity has to have the consent of the Minister of Finance before it can be implemented. I do not consider the role of the other members of the Cabinet as they will generally have a policy of non-intervention in cases which do not immediately affect their policy field (e.g. Van den Berg, 1981, p. 234). If Parliament does not require additional information within 30 days after notification, the minister can create the entity. If Parliament does require additional information two possible outcomes may occur. First,

78 See article 34, CW2001 
the information provided is sufficient for Parliament. In that case the minister can create the entity. Second, Parliament expresses the opinion that authorisation by law is required for a specific proposal. In that case, the minister has to comply with the procedures of a proposal for a law, which results in a considerable delay. To my knowledge, there are no cases between 1995 and 2009 where Parliament required a law for creating a private legal entity, neither a PLB, nor any other form of private legal entity. Of course that does not mean that no private law entities were created at all, but this was carried out on the basis of the notification procedure only.

\subsubsection{Planning \& Control under CW}

In Part A, I have briefly indicated that between September ' $\mathrm{t} \%$ ' ' and December ' $\mathrm{t} \%$ 1', Parliament (i.e. Tweede Kamer) discusses and passes the budget laws of the ministries including government funding of ZBOs. Actually the procedure starts with a document presented to the ministers in December ' $\mathrm{t} \% 2$ ' in which the regulations for preparing the budget for fiscal year ' $t$ ' are included. The Minister of Finance has the power to issue a set of standards for preparing budgets under article 18 CW 2001. These standards include only one instruction on ZBOs, which is the authority to set rules on the information with respect to ZBOs (and RWTs) to be included in the ministries' budget documents. In practice, this has resulted in the requirement to submit an appendix which presents proposed (realised) spending from a ministerial budget. It is up to the minister who is responsible for the ZBO organisation how to include relevant budget information for specific ZBOs into the ministries budget proposals. There are no general regulations on changing ZBO budgets, unless the ZBO is funded from a ministerial budget. In that case, the implicit policy is that budget overruns can be included in the relevant budget article. In fact, that results in authorisation for the minister to use the additional resources, not a direct authorisation towards a ZBO. Only at the end of the fiscal year, in the annual reports, is information on all ZBOs and the level of government funding they received further disclosed. The internal procedures of individual ZBOs are governed by the regulations in ZBO-case law, which can include regulations on (the timing of) approval of ZBO budget documents and annual reports by the minister.

If a ZBO's budget is included in the budgets of a ministry, Parliament has the same rights as for other parts of the ministry budget. In my opinion, given studies on reallocated budgets on the initiative of Parliament (e.g. Warmelink, 1993, p. 171-185), it is very unlikely that Parliament will change a ZBO budget proposal. If Parliament does decide to do so, the change is likely to refer to the program to be carried out by the ZBO rather than strictly based on decisions on its operations, given Minderman's explanation of budget reallocation by Parliament. 


\section{Parliament's influence on proposed budgets.}

Minderman (2000, p. 44) emphasises that the role of Parliament in the Dutch system is to legitimise the plans to be implemented by the government by - amongst other issues passing the budgetary laws. However the actual influence of Parliament on budget levels or the direction of spending is low. Many authors have shown that the actual changes in proposed budgets as a result of amendments submitted in Parliament are only very minor, both in number as well as in the amount of money reallocated (e.g. Warmelink, 1993, p. 171-185; Van der Bij, 1993, p. 87-89). Warmelink shows data for five ministries whose budgets were amended on average between $0.0 \%$ and $0.34 \%$ in the 1980 s. Warmelink claims that the small impact is due to the fact that budgets are prepared by the ministries and that Parliament neither has time nor knowledge to develop alternatives to the proposals submitted. Another part of the explanation is shared by Warmelink (1993, p. 187) and Minderman (2000, p. 103) by stating that in practice the coalition agreement as concluded after an election is the basic document for allocating resources to policy objectives. The coalition majority in Parliament is politically committed to this agreement and only in the event of urgent political issues may reallocation of resources be needed.

\subsubsection{CW regulations relevant for $Z B O S$}

In this section, I will discuss the regulations in CW that are relevant for ZBOs and the impact of these regulations on autonomy in operations. I will start with the general budgeting procedures, then discuss information provision and finally discuss other relevant parts of the CW regulations. I will use CW 1976-II as a benchmark in this section. The CW1976-II regulations on ZBOs are essentially transferred to CW2001 (Minderman, 2002; Van der Dussen, 2002), whereas older regulation were more stringent, particularly for creating legal entities. Minderman (2000, p. 180-183) indicates that (ex ante) financial control of ZBOs is based on CW1976-II:17 on the one hand and articles CW1976-II:57, 59, 66 and 79 on the other hand, which cover ex post controls based on the authority attributed to the NCA. The latter articles are beyond the scope of this study.

Ex ante control of ZBOs is not explicitly covered in the CW. CW1976-II:1779 refers to ministerial responsibility for compliance, efficiency and effectiveness with respect to the budgets attributed to him. CW1976-II:17 holds for ZBOs with legal entity status. Budgetary control of ZBOs without legal status is covered under the standard regulations for ministries in CW2001:1 and CW 2001:4. Minderman (2000, p. 183-184) notes that CW1976-II:17 implies that the minister is at least responsible for control and distribution of government budgets and the conditions for efficient and effective organisation of independent entities - amongst them ZBOs (jdk). In those cases where specified government budgets for ZBOs are authorised and appropriated in budget legislation,

${ }^{79}$ CW1976-I: basically article 25 , but in other words. 
Parliament has had an active role in the decision appropriating a specific level of budget to a minister with the intention that it is to be distributed to that specific ZBO.

In the formal setting, the budget law is not regarded as externally binding legislation. When a ZBO is not part of the State legal entity, the Parliamentary decision has no immediate effect on the ZBO. The minister has two formal options so that the ZBO complies with the budget that was appropriated by Parliament. The first option would be to pass a law governing the financial relationship between minister and ZBO. This option would be rather inefficient, as it will only transpose what has already been decided for the relationship between Parliament and minister. Furthermore, such a law has to be adopted every year. The second option is to agree upon a budget document or a civil law contract/SLA which specifies exactly what services are to be delivered by the ZBO. Verhoest (2002, p. 60) shows that such an option is possible but generates additional sometimes hidden (jdk) - costs in terms of monitoring or bonding costs.

Besides these two formal options, the minister has the material option to use incentives such as informal pressure or postponing and prioritising delivery of services to make the ZBO comply with the desired level of spending. Whatever option the minister uses, Parliament has no option other than to accept the actual level of use of resources by a ZBO since as a result of this reduced authority the minister is not in the hierarchical position to instruct the ZBO to comply with the budget level that was appropriated. The lack of a hierarchical relationship might be overruled in those cases where other legal instruments exist, e.g. if laid down in the legislation regarding a specific ZBO. This will be discussed in chapter 5.

The minister can be held accountable by Parliament for the efforts made to have the ZBO comply with Parliament's intentions. This is part of his responsibility for his own acts towards the ZBO in question (Kummeling et al., 1999, p. 19). The legal status of the SLA will be discussed in chapter 6 . From a budgeting perspective, the SLA is only an explanatory note when it is included in the budget documents. In other cases it has no direct impact on the relationship between authorisation in Parliament and actual budget appropriation for the ZBO. If Parliament is dissatisfied with the performance of a ZBO related to the SLA or other performance documents, then Parliament has to hold the minister accountable for his efforts to encourage the ZBO to comply with the performance document.

In the present CW2001, the contents of CW1976-II:17 are split up into four new articles (CW2001:19-22), in which a clear distinction is made between efficiency, effectiveness and compliance. The purpose of the new articles is similar to the old ones. According to Minderman (2000, p. 184) it is generally accepted that ministerial responsibility also refers to monitoring the operations of independent entities.

Two other, more general remarks on budgetary control should be made here. First, the rules of fiscal discipline - an appendix to the Coalition agreement, covering procedures in case of budget overruns - require that budgetary overspending in a ministry budget is generally compensated for by other items in the ministry's budget. If a 
minister has an excess expenditure problem, he may choose to apply general budget cuts throughout the whole of the ministry's budget. Such a budget cut may also affect ZBOs that are directly or indirectly funded from within the budget of a ministry. The impact on ZBO operations will depend on the specifications in the SLA. Second, and more recently, a general report on the future structure of central government particularly focuses on the staff levels in ministries and ZBOs. In this report, a claim on staff reduction in ZBOs is mentioned (Parliament, 2007f, p 33-34). This claim has impact on 35 ZBOs. ${ }^{80}$ Although comments are made that ZBO operations cannot be directly influenced by a minister, he is urged to prepare implementation plans for staff reduction that also cover the ZBOs listed in the document. These 35 ZBOs are thus in effect less autonomous than those which were not listed in the document.

The second issue to be addressed is information provision. Minderman's comment that ministerial responsibility includes monitoring the operations of arm's length entities implies that relevant information has to be available to allow monitoring. In the present CW2001 a provision for this has explicitly been included. Article CW2001:44a81 requires that information on (non-financial) performance of all ZBOs and other legal entities that are funded by fees (RWTs) is submitted to the minister who is responsible for the specific entity and not Parliament (jdk). Such performance information may include information as required in the specific law on an entity as well as information that is agreed upon between minister and ZBO in whatever format (Parliament, 2002c). The fact that information is provided to the minister implies that Parliament has deprived itself of the direct opportunity to use such information in budget and accounting documents.

Another new issue in CW2001 is described in article 18.4. In this article it is explicitly stated that the Minister of Finance can set standards regarding the information on ZBOs and RWTs to be included in a ministry's budget proposal. The origin of this article lies in an amendment proposed in the debate on kZBO (Parliament, 2002d) that was meant to obtain financial information on all ZBOs. The Minister of Finance accepted the proposal but included it in CW2001 because he thought this amendment would fit better in CW2001 (Parliament, 2002e, p. 4-5). The Minister of Finance listed the information that should be included in the budget documents and annual reports of the ministries in the explanatory notes to CW2001:18.4. Table 4.2 shows the information required as of fiscal 2004 according to these explanatory notes:

80 The number of 35 ZBOs is based on a selection by minBZK of all ZBOs with staff over 50 FTE and 'fulltime' ZBOs. For other ZBOs, no targets are set under this specific program (Parliament, 2007f, p. 43)

81 The wording of article $44 \mathrm{a}$ is not completely clear. It only states 'our minister' where all other articles within CW2001 use either 'our minister of finance' or 'our minister in question' when a specific minister is meant. From the explanatory memorandum (Parliament, 2002c, p. 2) it can be concluded that 'our minister in question' is meant 
Table 4.2: Information on all ZBOs to be included in budgets of ministries and annual reports (Source: Parliament, 2002e, p. 4-5)

\begin{tabular}{|l|l|l|}
\hline & Budget document & Annual report \\
\hline List of all ZBOs and RWTs & Yes & Yes \\
\hline Related policy article & For each entity separately & For each entity separately \\
\hline (Estimate) of government contribution & For each entity separately & - -- \\
\hline Actual government contribution & -- & For each entity separately \\
\hline $\begin{array}{l}\text { When applicable: } \\
\text { Explanation of use of authority by the } \\
\text { minister on: }\end{array}$ & \multicolumn{2}{|l}{} \\
\hline Approval of fees & -- & Yes \\
\hline Approval of budget document & -- & Yes \\
\hline Approval of annual report & -- & Yes \\
\hline $\begin{array}{l}\text { Report on structure of assets and } \\
\text { liabilities }\end{array}$ & -- & For each entity separately \\
\hline
\end{tabular}

From the control perspective the explanation on the use of authority is especially relevant. This information is supposed to disclose how a minister has used his authority and thus how the relative autonomy of a ZBO can be assessed on this specific item. However provision of non-financial information on ZBOs in budget documents or annual reports is not mentioned. When Parliament requires that information, there are two options: one is voluntary disclosure by either the entity or the minister or by using the right of information as stated in article 68 of the Dutch Constitution. This is an indication of the level of autonomy of a specific ZBO. Article CW2001:18.4 requires information on ZBOs to be provided by the minister; it does not state rules on actual control of ZBOs.

Finally, at a more detailed control level, CW2001 introduces some regulations with respect to liquidity and debt management. These regulations are related to the allowed level of EMU-debt. Their origin lies in an NCA-report on the desired level of general equity in RWTs (Parliament, 2000e and Parliament, 2001d). These regulations may be relevant for ZBOs as long as they have a separate legal status. Article CW2001:44 stipulates that the Minister of Finance can set rules for providing information by those entities that according to the European System of Accounts are included in the General Government sector. Article CW2001:45 gives the Minister of Finance the power to require that specific legal entities deposit their cash in an account at the Treasury. A Decree on this was issued in $2004^{82}$ and affects a number of ZBOs. Article 46 prohibits obtaining cash with the single purpose of reinvesting it to obtain additional resources. Articles 48, 49 and 49a provide opportunities for the group of legal entities defined in article 45 to borrow money from the Treasury. With respect to the assessment of ZBO autonomy, those ZBOs who are not subject to one or more of articles 44 to 4983 have relatively more autonomy than those who are subject to those articles. Table 4.3 summarises the effects of $\mathrm{CW}$ regulations on the autonomy of ZBOs.

\footnotetext{
82 Aanwijzingsbesluit rechtspersonen met beperkte kasbeheerfunctie

83 With exception of article $44 a$, which regulates non-financial information provision.
} 
Table 4.3: CW2001 and effect on autonomy of operations of ZBOs

\begin{tabular}{|l|l|l|}
\hline Regulation & Contents & Effect on ZBO autonomy \\
\hline CW2001:1 and 4 & Describes details of ministry's budgets & $\begin{array}{l}\text { Holds for ZBOs part of the legal entity } \\
\text { State; financial autonomy equals } \\
\text { autonomy of units of ministries }\end{array}$ \\
\hline CW2001:44 & $\begin{array}{l}\text { Authority minFin on setting rules related } \\
\text { to EMU-debt }\end{array}$ & $\begin{array}{l}\text { Reduces autonomy, but holds for all } \\
\text { 'full-time' ZBOs }\end{array}$ \\
\hline CW2001:18d & $\begin{array}{l}\text { Information provision in budgetary } \\
\text { documents of ministries }\end{array}$ & No effect \\
\hline CW2001:44a & $\begin{array}{l}\text { Information provision non-financial } \\
\text { information to the minister }\end{array}$ & $\begin{array}{l}\text { No effect } \\
\text { the State }\end{array}$ \\
\hline CW2001:45.1 & $\begin{array}{l}\text { Requirement treasury management by management with restrictions } \\
\text { on using financial instruments }\end{array}$ & $\begin{array}{l}\text { Reduces autonomy (less than under } \\
\text { 45.1) }\end{array}$ \\
\hline CW2001:45.2 & $\begin{array}{l}\text { Restrictions on borrowing } \\
\text { CW2001:46 }\end{array}$ & $\begin{array}{l}\text { Reduces autonomy except for } \\
\text { competitive ZBOs }\end{array}$ \\
\hline CW2001:48 -49a & Options to borrow at minFin & No effect \\
\hline CW2001:91 & $\begin{array}{l}\text { Nuditing level equals that of } \\
\text { ministries, } \\
\text { Reduces autonomy compared to a } \\
\text { 'standard' legal entity. }\end{array}$ \\
\hline $\begin{array}{l}\text { Rules on fiscal } \\
\text { discipline }\end{array}$ & $\begin{array}{l}\text { Overspending by a ministry is to be } \\
\text { internally compensated }\end{array}$ & $\begin{array}{l}\text { Pressure on not overspending } \\
\text { authorised level of resources on the } \\
\text { government funded part of ZBO } \\
\text { activities; reduces autonomy. }\end{array}$ \\
\hline
\end{tabular}

As of fiscal 2002, CW2001 is applicable for all units within the State as well as the legal entities - including ZBOs - to which reference is made in the law. This implies that a uniform presentation should be available in the ministry's budget documents. However, in those cases where under earlier laws ZBOs or other legal entities were established, there may be some exceptions to the CW2001 rules. Whether that is the case will be studied in empirical Part D.

\subsubsection{Price control by Parliament?}

The discussion in the previous section is relevant for ZBOs which are funded directly by government. This means that the ZBO budget is included in the budget proposal sent to Parliament. A number of ZBOs are not (fully) funded from contributions by ministries but by some form of (compulsory) fee. I will elaborate on different fees in Part $\mathrm{C}$, but in this section I will address the legal dimension of funding activities through fees. In short, a distinction can be made between authority biased fees which resemble taxes and market biased fees - not market based as there is no real market for ZBO services - that resemble prices. For example Goedhart (1958, p. 77), mentions retributions as an example of fees for authoritative services and public prices for non-authoritative services delivered directly to individuals.

The Dutch Constitution states in article 104 that taxes must be levied by law and that non-tax charges by the Dutch State ('het Rijk') have to be based on the law. According to Janse de Jonge (2000, p. 500), in both cases the level of the fee or the tax rate has to be 
included in the law, but according to him this is not always the case. The result is that the influence of Parliament on charges levied by ZBOs is reduced in favour of the minister who is allowed to issue a Decree on fees.

Janse de Jonge (2000, p 499-500) also indicates that the wording chosen in article 104 of the Constitution is based on an amendment in Parliament, which intended to minimise delegation in fiscal matters by requiring a formal law and implicitly allows some delegation for other charges. The wording 'het Rijk' is in the constitution the opposite to local and regional governments and public bodies. This suggests that at arm's length entities should also be considered under the concept of the Dutch State and therefore that charges imposed by ZBOs should also be defined by law.

\section{Taxes in the law and charges based on the law}

To illustrate the difference in legislative treatment of taxes and charges, I refer to income tax on the one hand and premiums levied for unemployment benefits (WW) on the other. In article 2.10 of the law on income tax, the tax brackets are directly included. The premiums levied for WW is based on the law funding social security insurance (Wet financiering Sociale Verzekeringen; WFSV). Article 27 of this law stipulates that the premium is set in a ministerial Decree rather than in the law.

If the fee charged by the ZBO qualifies as authority biased, their strong resemblance to taxes would suggest that delegation is not desirable. In the case of a market biased charge, some form of delegation might exist, although according to Janse de Jonge the level of charges should also be formally included in the law.

Wattel (1995, p. 193-194) notes that it is odd that delegation is formally minimised with respect to taxation, whereas in the case of other sources of government income, which are according to Wattel similar to taxes as far as citizens are concerned, delegation is allowed. Wattel suggests that a formal law on taxation should at least include a description of what is subject to taxation, the fundamentals and yardsticks for levying them as well as the structure of the tax brackets imposed. According to Wattel, GW:104 should be reconsidered to allow a form of delegation (Wattel, 1995, p. 221). In terms of autonomy, I would argue that the less the criteria mentioned by Wattel are included in a formal ZBO(case) law, the more ex-ante autonomy is given to the ZBO for calculating the fee. Secondly, the standards proposed by Wattel reduce the arguments a minister can formally use in disapproving a fees proposal. That effectively also results in more autonomy for the ZBO.

Wattel's proposal seems to be interesting, but at the local level, regulations on imposing taxes seem to be stricter and more in line with the Constitution than central government practice. In the Gemeentewet (Law on local government [GemW]), a provision is made for local taxes. Local taxes have to be separately authorised in a local decree along with the local government budget authorisation. Such a local decree has to be explicitly approved by the City Council rather than issued by the executive (alderman) 
and then possibly discussed by the City Council. Gemeentewet specifies that the decree must include the subject as well as object of taxation, the fundamentals, tax brackets, date of effectiveness as well as other relevant information regarding levying (GemW:217). This strongly resembles the criteria used by Wattel. In the local government decrees not only do those resources that traditionally qualify as taxes need to be included but also the levies charged for services provided by local government (GemW:220 and GemW:229).

\section{Regulations on ZBO fees: an example.}

RDW-fees are imposed for example for the motor-vehicle registration issued when someone buys a new car. This is comparable to issuing of passports by local authorities.

Article 48 of Wegenverkeerswet 1994 [WVW1994] (Law on traffic regulation) covers issuance of a registration document. In Article 4q WVW1994, the requirements for determining the fees for issuing a registration document are given. These requirements specify the costs of the activities which are to be included in the fee imposed. The fee needs to be related to the costs of the activities performed. The fee will be announced in a ministerial decree but determined by RDW according to article $4 \mathrm{~b} .1 \mathrm{n}$. In Wattel's terms, anyone who asks for registration of a vehicle would be subject to this (article 48); fundamentals are covered by "a relation to costs of tasks". There is neither an indication for a yardstick nor for tax brackets in the law. I think it might be claimed that even the fundamentals are not solid, because a relation to costs of tasks leaves degrees of freedom compared to an imperative that 'estimated revenue does not exceed estimated expenses' as is stated in GemW229b on determining fees for services.

Regulations on ZBO fees are included in or based on ZBO-case laws rather than in general laws as each case will have to be assessed separately. In kZBO, there is a reference to specifying revenues in ZBO budgets, but there is no all encompassing reference made to fees similar to taxes and the way they should be decided upon. Given the remarks of Wattel and local government legislation, that seems to be an omission. An exception could be made in cases where the charge is based on market competition such as is the case for a number of monitoring ZBOs. Such a procedure would also match with the authority the NCA has for assessing the operations of all entities that are funded by some form of fees (CW2001:91).

\subsubsection{Summary}

In this section, the ZBO budgeting framework has been explored. First, I have elaborated on the creation of legal entities, including ZBOs and concluded that the constitution oversees creating public law entities, supplemented by full civil law capacity under BW2. CW oversees creation of private law entities, which means that Parliament has the authority to require legislation if the government wants to set up a private law entity. Secondly, planning \& control under $\mathrm{CW}$ was discussed. Formal budgeting rules only bind 
government, not a separate legal entity. This means that a minister can use contract based agreements or informal control tools to manage ZBO budget levels and not the formal legislative procedure in Parliament. The information arrangement included in $\mathrm{CW}$ allows for monitoring by a minister and therefore for him to fulfil his responsibility towards Parliament. Furthermore, some operational arrangements on treasury management exist which reduce ZBO autonomy when applicable. The third point made is that not all ZBOs are fully government funded. Although the constitution seems to require that all fees levied have to be included in the law, there are indications that this does not hold. This practice raises questions to say the least, since at the local level regulations require that any fees charged by local government are explicitly authorised by the City Council. As many of the activities performed by ZBOs that are funded by direct contributions from citizens are similar to services local governments provide, I would plead for a similar form of decision making for the fees charged by ZBOs.

\subsection{Impact of accounting systems}

In this section I will address the relevance of the use of the two main accounting systems (cash and accruals) from the constitutional perspective of budget authorisation. I will start with a general assessment of these two accounting systems (subsection 4.3.1). After that, I will focus on the position of ZBOs when using a particular accounting system (subsection 4.3.2). The section continues with a discussion on accountability and the supposed need for aggregated information on ZBOs (subsection 4.3.3). The section is concluded by a summary on the use of accounting systems (subsection 4.3.4).

\subsubsection{Authorisation: cash or accruals?}

Originally, all government activities were organised into entities hierarchically subordinated to a minister, implying that both the legislature and the minister had full control on budgets. Authorisation of budgets was based on expenditures. The background for this accounting method is the economic argument that government only consumes income, whereas a private company aims at generating income (Mol, 1998, p. 24). Government income is primarily derived from taxes, which are generally budgeted and accounted for in terms of cash receipts. The origins of taxation go back to the system for funding the expenditure of the Monarch and ensuring a balance between his estimated expenditure for both government services and the Monarch's household and the taxation level required to cover that expenditure (Grapperhaus, 1989, p. 43-46; Van der Bij, 1993, p. 1-2). This principle of budgeting and tax accounting on a cash basis holds for those entities that in theory have unlimited opportunities for raising revenue. On the central government level in the Netherlands, this traditional relationship between expenditure and tax income still holds (Mol \& De Kruijf, 2003, p. 547-548).84 Measurement and regulations on expenditure are rather straightforward; the actual date

84 In the western world, mainly countries such as the UK, Australia and New Zealand have introduced forms of accruals accounting for central government (e.g. Guthrie, 1998; Robinson, 1998). 
of a cash flow determines whether or not certain expenditure is subject to fiscal year $A$ or B.

In the last few decades, several countries have started to convert their budgeting procedures into forms of accruals budgeting (e.g. Guthrie, 1998, Carnegie and West, 2003, Likierman, 2003). International accounting organisations and also the OECD and IMF recommend introducing accrual based budgeting and accounting for government entities in many other countries. As of 2000, the International Public Sector Accounting Standards Board [IPSASB] has been working on a set of international public sector accounting standards [IPSASes]. These standards are also based on accruals budgeting and accounting principles, derived from the commercial International Accounting Standards [IAS]. Some standards only exist under IPSAS because issues such as nonexchange revenues ${ }^{85}$ are not covered in commercial accounting (Christiaens, Reyniers and Rollé, 2010, p. 540). Accrual standards are more complex than cash standards and are not relevant for the core of Dutch central government. They can be relevant for arm's length entities such as ZBOs because these entities do not have an unlimited opportunity to raise taxes.

To my knowledge the economic literature gives no reasons to favour accruals budgeting from an authorisation perspective. In the IPSASB handbook, the objective is described as serving the public interest by developing high quality public sector financial reporting (italics JdK) standards (IPSASB, 2007, p. 16). This wording indicates that emphasis is on ex post reporting, which is also expressed by the fact that budgeting is one of the last IPSASes in the structure of the IPSASB-project.

In the legislative discussions on spending resources by government, it is not the ex post accountability issue that is most important, but the ex ante control of the proposed levels of spending. Schick (2002, p. 18) mentioned that the appropriations process is the expression of the original fiscal power of legislation above the executive. In his view budgeting emerged as a result of insufficient fiscal control over the executive. Schick's argument is independent from the accounting framework and implies that budgetary reform has no effect on the distribution of power between legislature and executive. Another comment in this respect was made by Perrin (1998, p. 10) who stated that in public budgeting ex ante disclosure remains more relevant than the ex post disclosure. For purposes of ex ante disclosure, Perrin states that cash disclosures are better suited. Traditional budgets are, according to Perrin, often rather detailed to express the primacy of the legislature for control of spending. The shift in focus towards output and outcome together with delegating responsibility to operational managers has led to more global budgets, giving management leeway at a micro level to achieve the goals desired by the legislature. Delegation of responsibility in the public sector is relatively independent of budgeting and accounting frameworks, as most production in government entities is

\footnotetext{
85 This refers to revenues for which no direct service is delivered such as social security premiums.
} 
strongly related to the use of staff and not on the use of any kind of assets (investments), resulting in accounting statements where expenditure nearly equals expenses. In the Dutch case, it is estimated that $97 \%$ of expenditure equals expenses (Mol \& De Kruijf, 2003, p. 552; Parliament, 2008c, p. 5), which is an empirical confirmation of Perrin's analysis.

According to Likierman (2003, p. 45) accruals imply that a shift can be made from an input to output focus. This suggests that accrual budgeting may be helpful in assessing the allocation function of budgeting. Likierman refers to the British model of Resource Accounting and Budgeting (RAB), which should provide better information for management and reduce the 'perverse effects of annuality', which is associated with traditional budgeting methods. A well known example of this is the training budget, which is often spent at the end of the fiscal year to prevent budget cuts the following year. The Australian model of Accrual Output Budgeting (AOB) (Robinson, 2002, p. 18) goes even further; the basic idea is that government purchases from agencies in an environment that attempts to simulate a competitive market. This model has parallels to the Dutch case because government budgets are not externally binding. Therefore, ex ante control of arm's length entities' budgets resembles contract relations rather than full budgetary control relations. In the private sector, the direct link between expenses, revenues and outputs makes the use of accrual accounting logical. For budgeting however, financial targets need not to be set in terms of accruals, investments will be presented as a level of expenditure and in a company a budget may be set in terms of return on investment [ROI] instead of expenditure levels as I already mentioned.

\subsubsection{ZBOs and accounting systems}

ZBOs, unlike central government, do not have unlimited scope to raise taxes. Their income is derived from contributions from central government or other parties, which have to be matched to expenses in order to ensure the continuity of the activities of the entity. This implies that in accounting terms it is necessary to match ZBO revenues and expenses within a fiscal year. However it does not immediately imply that ZBO budgeting also has to be defined in terms of accruals. Accruals budgeting and accounting is required for PLB-type ZBOs, given the fact that they follow the civil law accounting regime. However the accounting regime for a PLA-type ZBO is determined by the relevant ZBO case law.

\subsubsection{Accruals accounting used by ZBOs}

The case-laws on most ZBOs as well as kZBO ( $\mathrm{kZBO}: 35$ ) include the requirement that ZBOs have to use an accruals accounting system for financial reporting purposes. ${ }^{86}$ There is one exception to this rule and that regards PLA type ZBOs which are part of the State and therefore use the cash accounting system as required for ministries under CW2001. Whether or not accruals accounting is effectively used by ZBOs is discussed in Part D of

86 Article 35 kZBO states: as far as possible in line with BW2, section 9 (accounting regulations for companies, jdk), implying that accruals accounting is not fully in line with commercial accounting. 
this study. For now it is sufficient to state that overall a form of accruals accounting is applied. In the explanatory memorandum to kZBO (Parliament, 2000d), no reference is made as to why ZBOs should use an accruals accounting system or the impact that may have on funding relationships and ministerial control of ZBOs. There is some logic behind the choice to require use of accruals accounting systems, since legal entity ZBOs are separate entities that do not have unlimited access to taxation or other resources. As a result a continuous flow of financial resources to a ZBO cannot be guaranteed. ZBOs must therefore be regarded as organisations that are required just as private companies are to match revenues and expenses as well as account for changes in the value of assets (Mol \& de Kruijf, 2004). Some authors claim that such a matching process can also be fulfilled in a cash accounting system (e.g. Berens, Bücker \& Finken, 1998; Günther \& Schill, 2000; Monsen, 2001), but the public sector accounting mainstream is convinced that accruals accounting is preferable as can be concluded from the effort devoted to the IPSAS-project.

In general, a distinction can be made between authorisations of a budget without connection to production - a traditional line item fixed budget - or a budget which has a connection to production and is at least theoretically flexible (Wildavsky, 2001; p. 139141). This distinction was one of the arguments for introducing an accruals system of accounting for executive agencies (Van Oosteroom \& Soons, 2002, p. 23), with a separate operations budget and investment budget (CW2001:11.3).

The same arguments can be applied to ZBO budgets. If the ZBO budget has no connection with production and can be regarded as a fixed budget, authorisation is straightforward: the budget is approved by Parliament and will result in a cash flow to the ZBO irrespective of the accounting system used. The second possibility is that a ZBO's budget is based on a flexible, production oriented allocation. Here, two options can be identified: budget authorisation and funding on completed products or authorisation and funding based on activities. In the first case, authorisation will imply payment for a completed product regardless of the budget period in which a service was started. This is similar to the matching principle in accruals accounting. The result for the ZBO is authorised and funded on expenses rather than on expenditure. When products are paid for, the ZBO's budget could be in terms of resources/accruals but if a ministry's budget is authorised and funds the ZBO, the result might be that expenditure control in the ministry will be disrupted if there are divergences in the ZBO's actual production. When activities are funded, each separate step in a process is paid for and in most cases this will lead to the same result in terms of expenses and expenditures. This means that ZBO budget authorisation can be on expenditure basis when activities are funded.

The fact that no procedure exists is not only remarkable, it might even result in a risk of uncontrollable budgets. The rationale for a separate authorisation for investments is based on the fact that Parliamentary decision making is based on avoidable costs rather 
than on full cost calculations. Once an investment is decided upon and expenditure is made, there is no possibility to change the level of expenses related to the investment until a decision to discontinue is made (Mol \& De Kruijf, 2003, p. 551). Controlling the level of investment expenditure for executive agencies as well as for ZBOs prevents undesired increases in the level of future expenses for the services delivered. This also implies that Parliament has to authorise investment budgets in expenditure terms. It does not necessarily mean that individual assets have to be authorised. By using an investment budget it will be possible to give management freedom to invest based on what the organisation actually requires. This solution parallels the trend to authorise more general budgets and simultaneously delegate responsibility.

\section{The impact of authorisation of a ministry's cash budgets for operations of a ZBO that uses accruals budgeting and accounting.}

The example given below uses fictional data, but is based on problems described in an earlier study (Mol \& de Kruijf, 2002, p. 100). A ZBO 'X' provides income transfers which are based on an initial decision using estimates and a final decision more than a year later when the applicant's fiscal data is definitively available. The decision is then made in two stages: one in year ' $t$ ' and one in year ' $t+1$ '. Suppose the initial decision has operational costs of $€ 1,000$ and the final decision has operational costs of $€ 500$. In both stages, $€ 100$ is included as depreciation costs for an IT system.

In an activities funded context, the ZBO charges $€ 1,000$ in year ' $\mathrm{t}$ ' and $€ 500$ in year ' $t+1$ '. The ZBO receives these amounts from the commissioning ministry. In a completed product funded setting, the completed product will be charged, i.e. at the final stage in ' $t+1$ '. On the ZBO ' $X$ ' balance sheet, at the end of year ' $t$ ' under current assets the amount of $€ 1,000$ will be included as unfinished product. Payment of $€ 1,500$ in ' $t+1$ 'for the finished product will complete the transaction, including a reduction in 'unfinished product' on the balance sheet by $€ 1,000$.

In the cash based budget authorisation processes in Parliament, both the ' $\mathrm{t}$ ' as well as the ' $t+1$ ' budget will be approved. In the activities funded setting, budgets will be $€ 1,000$ and $€ 500$ respectively. In the product funded context, budgets will be $€ 0$ and $€ 1,500$.

Now suppose that Parliament imposes a budget cut for year ' $t+1$ ' of $20 \%$, without reducing the production level required from the $\mathrm{ZBO}$ in the activities funded setting. As a result, the ministry will pay only $€ 400$ for the second stage of the activity. The ZBO however has $€ 100$ of unavoidable costs - depreciation - which means that only €300 remains to cover the costs of staff and materials rather than the original $€ 400$. In effect a budget cut is required of $25 \%$.

The ZBO management is able to reduce staff and materials costs in ' $t+1$ ' to $€ 350$. Because all original requests that were submitted in year ' $t$ ' have to be processed in 
' $t+1$ ', the effect will be that at the end of fiscal ' $t+1$ ' Parliament has to approve the additional costs of $€ 50$ (€350-/- €300) for each decision. If they do not approve, the additional $€ 50$ will be transferred to the ZBO's balance sheet as receivables and will affect the remaining budget available in ' $t+2$ '. In that case the ZBO will have spent the money and needs to borrow the additional cash from the bank, because the commissioning ministry is not allowed to pay. If ZBO ' $X$ ' is not allowed to borrow money, the effect will be that production has to match cash available and that means that 1 in 9 cases cannot be handled in ' $t+1$ '. The unlucky applicant has to wait till ' $t+2$ ' until a final decision is made.

The budget cut has an even more severe effect on available resources in the completed product funding context. The budget cut results in a cash flow in ' $t+1$ ' of $€ 1,200(80 \%$ of $€ 1,500)$. The first $€ 1,000$ is needed to cover expenses made in ' $t$ ', leaving $€ 200$ in ' $t+1$ '. That amount must be used to cover both depreciation and other expenses in ' $t+1$ '. Effectively that means that instead of the original $€ 400$, only $€ 100$ remains for expenses other than depreciation.

A last point to be made regards the claims by accruals accounting supporters that balance sheet information is relevant to the budgeting process. Wildavsky's (1992) and Chan's (2003) analysis with respect to output and outcome control that budgeting morals also have to change applies here. Behn (2002, p. 107) arrives at a similar conclusion from the public administration perspective. He notes that vagueness in objectives is politically rational. Thus a focus on performance can only be ex post but without having a yardstick based on set standards. As a result, an emphasis on financial performance will continue to exist. Ex post - balance sheet - information will only be useful when the information is applied in the ex ante budgeting procedure for the next budget cycle. This is relevant because investment finance is raised directly or indirectly from the financial markets. In general, Dutch ZBOs do not enter the financial markets, making the motive of informing investors (italics jdk) about the financial position of the ZBO obsolete. This remark typically holds in the Dutch context. Under IPSAS 6, consolidation of financial ZBO statements might be required, but as financing is - due to CW 2001:45-46 - already included in the State's financial statements, such an action would not have additional value. This might be different in other jurisdictions. Only when financing is the responsibility of the ZBO itself, in combination with a demand driven form of funding, could the (financial) risk profile of the ZBO be an issue for investors.

The idea that a ZBO balance sheet is not relevant for investors does not make the balance sheet obsolete at all. When a ZBO is funded by government, a relatively weak financial position may lead to additional future claims on the government budget because the level of reserves might not be adequate to cover losses on operations. This argument indicates that Wildavky's and Chan's arguments also hold for information on ZBOs. Furthermore profit from operations can result in amounts of equity higher than 
politically desired or statutory levels. Drawing a parallel to the right shareholders have to determine what a company is allowed to do with surplus equity, the Government has, from an allocation perspective, the duty to assess how surpluses may be used in an economically efficient way. Therefore, Parliament as budgetary legislator should have the right to reallocate surplus equity. Finally, depending on the way production is funded, it can be relevant to have an overview of receivables to prevent the problems illustrated in the text box on page 96 on the differences in accounting systems. At the local level, the most recent version of the 'Besluit Begroting en Verantwoording' [Local Government Accounting Regulations] (BBV:27) explicitly requires that allocating surpluses is separated from determining the financial results of operations. The surplus equity of a ZBO is not presently subject to Parliamentary control. CW2001 does not provide any rules; ZBO-case laws may do so. In kZBO:33 a provision is made which allows ZBOs to create an equalisation reserve. However the level of this reserve is not specified. Where no political control of surplus equity exists, the ZBO can be regarded as relatively more autonomous than a ZBO that does have rules on surplus equity.

\subsubsection{The mismatch between government and ZBO accounting systems.}

I have mentioned that there are no rules for creating a ZBO except for passing a law in the case of PLAs or reporting it to Parliament in the case of PLBs. As ZBOs and executive agencies are close to each other on the scale of autonomisation, it is interesting to compare the requirements for internal autonomisation with those for the closest form of external autonomisation. One of the rules for creating an executive agency is that before a proposal is submitted to Parliament, a number of financial processes have to be tested. This includes preparing a cost price model as a basis for funding the executive agency; be it on a mere billable hours basis rather than a cost price basis for services delivered (Ridderbos, Zweers, Biemold, Jonker \& Van Veen, 2005, p. 44-45). Regulations also require that efficiency incentives are included in the system and that an opening balance sheet is prepared (MinFin, 2007a). The whole procedure is rather formal, strict and tests whether a government unit is prepared for internal autonomisation. ${ }^{87} \mathrm{It}$ is to say the least remarkable that in the case of creating a ZBO, none of these requirements are stated in law, neither in CW2001, nor in kZBO nor in ministerial decrees. In one of the most recent case laws (Zorgverzekeringswet [ZVW]; law on health insurance) in which the ZBO CVZ is (re)established, reference is only made to past experience and a statement that 'budgeting is an appropriate tool to control the level of operating costs for the tasks to be executed and the output/outcome to be delivered' (Parliament, 2004d, p. 165).

In short, it is remarkable that there are no regulations on testing whether a ZBO is ready to use accruals accounting when needed.

\subsubsection{Financial accountability and accounting standards}

The developments in international public sector accounting and the growing use of accruals budgeting and accounting do of course also affect the position of Dutch public

87 As of 2008, the procedures have been changed and are less severe (Mookhoek, 2008). 
sector entities. The Dutch State does not intend to fully adhere to IPSAS standards (Parliament, 2008c, p. 9). However, it is recognised that financial information on ZBOs should be improved (Parliament, 2004e, p. 2). The NCA emphasises the relevance of information on the aggregated financial position of RWTs, which includes most ZBOs (Parliament, 2007b, p. 15).

In the private sector, financial information on companies is provided at the level of the holding company rather than at the level of the individual companies that have a separate legal status but are part of a larger group of companies within the holding company. These so called 'consolidated financial statements' presented by the holding company provide all relevant (ex post) information on the holding company and its subsidiaries. Consolidation in the private sector is regulated by the IFRS and is also covered in the Dutch BW2. Some Anglo Saxon countries such as New Zealand, Australia and the United Kingdom are working on the introduction of what is called 'Whole of Government Accounts' [WGA] (Chow, Humphrey \& Moll, 2007). This WGA concept is a form of consolidation in which all units of government (at all levels) are regarded as part of one holding company. The claim for aggregated information as proposed by the Dutch NCA resembles the ideas of consolidated information. Therefore it is interesting to study the relevance of consolidation with respect to ZBOs. As no Dutch public sector consolidation regulations exist, the issue can only be studied from standards that exist elsewhere. Because an international standard has been developed under IPSAS, I will follow the requirements laid down in that standard. The IPSAS 6 standard on consolidation is supported by some Dutch authors. For example Van Schaik (2008) claims that as a result of the creation of executive agencies and ZBOs, the scope of the ministry's financial statements has been reduced.

In the evaluation of the application of accruals accounting at minLNV, it was concluded that consolidation of ZBOs in the ministry's documents would result in 'significantly more complexity' than in the case of only consolidating executive agencies (Parliament, 2008c, p. 4). The reason for this seems to be found in the consolidation technique and accounting policies rather than in the question of whether or not to consolidate one or another entity as the Finance Minister does not discuss the principle of applying consolidation on ZBOs in his letter to Parliament. In this section, I will argue that consolidation of ZBOs is not useful at all for the most important ZBO stakeholders.

\subsubsection{The concept of consolidation}

When summarising issues on consolidation and segmentation one can discuss two issues: (a) what is to be consolidated or segmented and (b) which accounting policies and procedures should be used when a consolidated financial statement including relevant segmentation is to be presented. I will focus mainly on the first issue: whether or not consolidation and segmentation can contribute to improving provision of information on ZBOs to Parliament. I will not discuss consolidation within the financial statements of a ZBO, which might be required under BW2 if the ZBO is a holding entity in which several 
legal entities exist. The second issue on accounting policies is a matter of technique which is not immediately relevant for stakeholders.

In IPSAS 6 and 18 consolidation and segmentation of Government Business Enterprises [GBE] that would qualify as controlling entities are excluded. In general this means that 'State enterprises' as discussed in Part A are excluded. It implicitly indicates that ZBOs in general might be included under the IPSAS standards.

The basic consolidation rule in IPSAS 6 is that a controlling entity using accruals accounting has to present a consolidated statement unless, to put it simply, the entity itself is controlled by another entity or there are no financial instruments of the entity being traded on a public market (IPSAS 6:15-16). The second basic rule is that all controlled entities except those which are only temporarily controlled need to be consolidated (IPSAS 6:20-21). In both rules, the key word is 'control' which is defined as 'the power to govern the financial and operating policies of another entity so as to benefit from its activities' (IPSAS 6:7). This power to govern has to be 'presently exercisable' although the controlling entity may choose not to exercise its power (IPSAS 6:30-32). The concept of 'power to govern' is operationalised in (potential) voting power over operations and financial decisions and implies that the controlling entity is able to benefit from this voting power on the other entity. In IPSAS 6:39-40 criteria are given under which power to govern is presumed or likely to exist. Table 4.4 gives a brief overview:

Table 4.4: Summary of control indicators under IPSAS 6

\begin{tabular}{|l|l|l|}
\hline & Presumed control* & Indicators of control \\
\hline Power & $\begin{array}{l}\text { Majority voting rights } \\
\text { Appointment majority of board }\end{array}$ & $\begin{array}{l}\text { Ability to veto budgets } \\
\text { Ability to veto/modify decisions } \\
\text { Ability to approve hiring of senior staff } \\
\text { Holding 'golden share' }\end{array}$ \\
\hline Benefit & $\begin{array}{l}\text { Dissolve entity and claim residual value } \\
\text { Extract distributions of assets }\end{array}$ & $\begin{array}{l}\text { (In)direct title to net assets with ongoing } \\
\text { right to access net assets } \\
\text { Right to significant level of net assets in } \\
\text { case of liquidation/distribution } \\
\end{array}$ \\
& \multicolumn{2}{|l}{$\begin{array}{l}\text { Direct to co-operate } \\
\text { Exposed to residual liabilities }\end{array}$} \\
\hline * Control by “holding' entity, in the case of ZBOs to be read as the Dutch State when applicable.
\end{tabular}

The remainder of IPSAS 6 is dedicated to the consolidation technique as well as to what items are to be disclosed. In short this comes down to using the same reporting dates, uniform accounting policies and using equity method, at cost or as financial instruments (IPSAS6:58).

Applied to the Dutch context, the simple answer on consolidation would be that the Dutch State does not have to consolidate controlled entities because it does not qualify under the accrual accounting criterion. The Dutch State does qualify under the 'financial instruments' criterion because it issues bonds on the public market. The financial statements of the Dutch State include the 'Staatsbalans'; the balance sheet of the State. It includes information on State participations in share issuing companies as well as 
some information on current ZBO and executive agency assets and debts. The document is confusing, because only partial information is given: not all assets or liabilities are included (Van Schaik, 2007) which also holds for information on ZBOs. For example, infrastructure assets are not included and the same holds for the liabilities of the State's old age pension plan AOW (1st pillar old age pension plan, see Boot, 2008). It can thus not be regarded as a consolidated statement, but does include some forms of information on legal entities other than the State.

The fact that the Dutch State does provide some information on other legal entities in its financial statements is also an indication that providing such information is regarded as relevant. Therefore, it is reasonable not to consider the formal answer to the consolidation question and assess the possibility and impact of consolidation as if the Dutch State is using an accruals system of accounting. A more pragmatic approach is to assess the impact of a single consolidated statement for all State controlled entities that do use accruals accounting along with the ministry's cash based financial statement. By doing this, it is possible to assess whether applying IPSAS 6 on consolidation would result in improved information for stakeholders.

If an assessment of the relationship between two or more legal entities concludes that consolidation is required the issue of segmentation also becomes automatically relevant (Van Offeren, 2002, p. 6). The core function of segmentation is to provide information on the activities of the consolidated entities in different (program) lines or geographical regions. Without consolidation, there is often no need for segmentation unless the individual company is operating in different markets, for example two countries with different economic fundamentals. According to IPSAS 18, a segment is a 'distinguishable activity or group of activities of an entity' for which separate financial information is useful to evaluate past performance or to have a basis for making future resource allocation decisions (IPSAS 18:9). Where the issue of the need for consolidation can be discussed based on more or less objective criteria, segmentation is more a matter of judgement according to IPSAS 18:15. This gives management more degrees of freedom to choose their segmentation basis, as long as it is consistent over time. Segmented information must cover segment revenues and expenses as well as assets and liabilities which can either directly or reasonably be attributed to the specific segment. Segment information does not include interest and dividends, results from sales of assets, taxes and head office expenses (IPSAS 18:27). Under segment-revenues external revenues have to be separated from transactions between segments as well as from revenues generated by budget appropriation.

\subsubsection{State as controlling entity over ZBOs}

The question of actual control by the State of ZBOs is to be answered from the criteria laid down in IPSAS 6. Under the assumption that Parliament needs to have information on all ZBOs rather than on only a part of the population, consolidation of financial data is only useful if all ZBOs were required to be consolidated. In the case of at least two 
subgroups of ZBOs, there is doubt whether the requirements are met. First, for PLB type ZBOs, the group of 'part-time' ZBOs (Parliament, 2008b) will not pass the IPSAS criteria because they are basically commercial entities with only a small ZBO task. The State (in fact the minister) has no control on any of the indicators stated in Table 4.4. The second group for which the IPSAS criteria can be discussed are the PLB type ZBOs that have foundation legal status. Here, the power criterion is met, based on kZBO:24 which allows the minister to intervene in cases of negligence. Foundations that only provide unilateral authoritative services (kZBO:37) are subject to the same criteria as PLA type ZBOs having a separate legal status, including having an equalisation reserve that allows compensating for differences between budgeted and actual results over a number of years. This means that the minister at least has indirect access to the assets of the entity because he is not obliged to compensate for operational losses in a particular year. In the case of hybrid (foundation type) ZBOs ${ }^{88}$, these rules do not apply.

Therefore, I can conclude that in the case of PLB type ZBOs, it is not always certain that consolidation is required. Furthermore, ZBOs that are not subject to kZBO are likely to have more degrees of freedom; otherwise they would have been included.89 Thus, consolidation requirements applied to ZBOs would result in partial consolidation rather than full consolidation. This might generate confusion rather than transparency in information provision on ZBOs.

A second point to be made is based on problems regarding authorisation and the twin-brother of consolidation, which is segmentation. When searching for possible improvements to the information provided in Dutch State budget documents and annual reports, two information levels have to be distinguished. First, from an investor perspective, the Dutch State as a whole is relevant. This would ideally be achieved by consolidated statements in the Budget Memorandum as well as the financial statements of the Dutch State. From a political authorisation perspective however, it is not the Budget Memorandum or the financial statements of the Dutch State that are relevant, but the individual budget proposals of ministries for which an individual minister can be held accountable.

The most relevant information for investors, EMU debt and EMU deficit are discussed extensively in the Budget Memorandum. This information is based on the projected consolidated information based on ESA95 (the accounting system used for statistical purposes within the EU) which includes what could be labelled as 'Whole of Government', thus including the financial position of ZBOs. The EMU-deficit and EMU-debt aggregation level is based on three main budgetary themes: State, Local governments and Social Security funds. From a political control perspective such a classification is a prime concern. This implies that the most relevant information for investors - aggregate State

88 Foundation ZBOs that provide both authoritative and non-authoritative services.

89 Some ZBOs are in fact only temporary excluded from kZBO due to 'reconsidering their position' (Parliament, 2008d). 
debt - already covers debt of ZBOs because given CW2001:45-46 ZBOs are generally financed by the Dutch State.

The second perspective, based on authorisation in Parliament cannot be solved by a consolidated statement alone, because it violates what Goedhart labels as the "specificity principle in budgeting' (Goedhart, 1958, p. 304). Under this principle, authorisation of a consolidated statement would imply that in fact all ZBO budgets and investments would be authorised in one large budget article. As a result, government would have all formal flexibility to reallocate budgets at will, which conflicts with the allocation principle in budgeting. The result would be that in fact segmentation along the lines of the individual ZBOs is needed to reveal the really relevant policy decision making information and then disclosure of information for individual ZBOs would be a starting point again. Given the remarks of the NCA on organisational information provision with respect to RWTs and ZBOs (Parliament, 2006a, p. 53), an organisational (sub)classification along the lines of Ministries, Government Agencies and RWT/ZBOs might be a suggestion. To prevent information overload, the information to be directly submitted to Parliament in budget documents and annual ministry statements should be on a relatively high level of aggregation. This can be done realistically, because kZBO:18.2 already requires that ZBO annual reports of ZBOs to be submitted to Parliament.90 I note that in general annual reports will include financial statements, but the wording of kZBO:18.2 and kZBO:34 allow financial statements not to be submitted to Parliament. This is in my opinion an omission in the kZBO legislation because it would directly give feedback on resources used by the ZBO based on Parliament's decision to attribute authority and resources to the ZBO. One of the prime motives for consolidation in the private sector is that the financial statements of individual subsidiaries need not to be publicly disclosed, a problem that with respect to ZBOs is thus covered in kZBO and makes consolidation at least less necessary if not obsolete.

Consolidation of ZBO information in the State's financial documents is thus problematic. First, only some of the ZBOs would be included. Second, consolidation would violate the budget authorisation principle, which can only be solved by providing segmented (in fact individual) information on ZBOs. Third, from an investor perspective, the key issue - ZBO debt - is included in the State debt which means that the key information on trading financial instruments on a public market (IPSAS6:IN8) is already available in the data on EMU debt provided by the Dutch State. Therefore, consolidation of ZBO-information at the level of the State as a whole does not contribute to the providing relevant information to stakeholders including Parliament.

Because ZBO annual reports are sent to Parliament directly under kZBO, it is possible that a form of aggregated information with respect to ZBOs is provided in ministry budget

90 In chapter 5, I will discuss the requirement to submit annual reports to Parliament. 
documents. This might contribute to solving the remarks made by the NCA on the lack of financial information on ZBOs provided to Parliament.

\subsubsection{Conclusion on accounting systems}

Most ZBOs are separate legal entities which unlike central government do not have unlimited scope to raise revenues. Therefore, the use of an accruals accounting system is more or less required from a perspective of matching revenues and expenses. Two main remarks can be made. First accruals accounting systems are not the best solution for ex ante control. This leads to problems in aligning budgets appropriated by a minister on behalf of Parliament and the actual operations of a ZBO. Second, it is remarkable that no procedure exists to assess whether or not a (potential) ZBO is ready to use an accruals accounting system as is performed for executive agencies. Related to this issue is the fact that the ex ante control of investments - which has also been implemented for executive agencies - does not apply to ZBOs. This might have an impact on the total costs of ZBOs in the future.

Along with these two general remarks, I have addressed the issue of financial accountability. The NCA has indicated that insufficient financial information on ZBOs is provided to Parliament. Under international public sector (accruals) accounting rules, a consolidation regulation exists which might allow ex post information provision to be improved. I have shown that consolidation does not contribute to transparency for two reasons. First: in general financing of ZBOs is provided by central government and included in the State's financial position, more particularly the EMU-debt. Second, a full consolidated statement of all ZBOs would result in a level of information aggregation which does not support information transparency to Parliament. Consolidation would automatically call for its twin-brother, segmentation, and is likely to result in the individual financial statement of each ZBO as the 'market' in which each ZBO operates is entirely different. As kZBO requires individual ZBO annual reports to be submitted to Parliament, consolidation would be a solution to a non-existing problem. However, the wording of kZBO can be improved to ensure that full financial statements including statements of accounts and balance sheet information are submitted to Parliament.

\subsection{Controllability of ZBO budgets}

Budgetary reforms over the last three decades suggest that Parliament focuses on output and outcome rather than just on the level of expenditure (e.g. Wildavsky, 1992, p. 597; Potter, 2001, p. 84). As indicated in Part A, one of the reasons for creating ZBOs was to create flexible administrative units at arm's length of government. In these organisations, output can at least be measured, which means that some form of price and volume numbers can be used to prepare a budget. If in these situations Parliament adhered to the traditional lump sum based authorisation process, it would ignore the intended flexibility of the ZBO budget. In this section, I will address the impact of using a combination of ex ante control tools by Parliament on the controllability of ZBO budgets. 
In general, Parliament has three control tools available that determine the budget of a ZBO both in the short term and in the long term. In section 4.3, I have discussed why Parliament has to consider controlling ZBO investment budgets. In short, if investments are not controlled, in the long run prices cannot be controlled under an accruals accounting system as applied by ZBOs. The other two control mechanisms available to Parliament are price and volume control.

If the ZBO's budget is funded by government and Parliament is able to determine the maximum level of services to be delivered by a ZBO, a form of volume control exists. Such a volume control can however only exist if the services provided by the ZBO are not open for any application, because a basic budgetary rule is that government budgets are not externally binding. Furthermore Parliament can authorise the cost price of the service to be provided by the ZBO. This type of control is relatively strong as a cost price as such does have an impact on the total budget to be authorised. If Parliament is able to control both volume and price of the ZBO services, one can argue that this results in a case of full budgetary control. If Parliament has neither the opportunity to control price or volume, the ZBO budget is beyond Parliamentary control.

The price control issue is of particular relevance if a ZBO is not funded by government but by citizens. The services provided by a ZBO have an authoritative character, which generally implies that a market mechanism to determine prices is not available. Price control (i.e. authorisation) by Parliament is then the substitute mechanism to determine allocation of resources, just as is the case when taxes are charged. Price control on ZBOs would also be in line with the constitutional idea that charges (i.e. prices) levied by government institutions have to be based on the law.

\begin{tabular}{|c|c|c|c|c|c|c|c|c|c|}
\hline & & 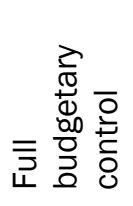 & 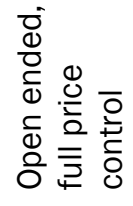 & 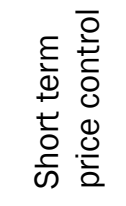 & 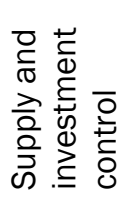 & 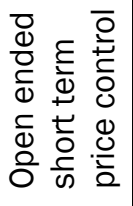 & 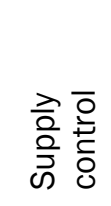 & 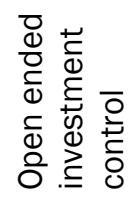 & 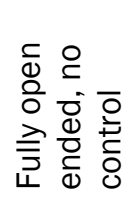 \\
\hline $\begin{array}{l}\text { Discretionary } \\
\text { (lump sum) } \\
\text { budget }\end{array}$ & Expenditure & Yes & $\begin{array}{l}\text { Not } \\
\text { appli- } \\
\text { cable }\end{array}$ & n.a. & n.a. & n.a. & n.a. & n.a. & n.a. \\
\hline \multirow{3}{*}{$\begin{array}{l}\text { Activity/ } \\
\text { product } \\
\text { based budget }\end{array}$} & $\begin{array}{l}\text { Level of } \\
\text { production }\end{array}$ & Yes & No & Yes & Yes & No & Yes & No & No \\
\hline & Cost price & Yes & Yes & Yes & No & Yes & No & No & No \\
\hline & $\begin{array}{l}\text { Investment } \\
\text { budget }\end{array}$ & Yes & Yes & No & Yes & No & No & Yes & No \\
\hline & & \multicolumn{8}{|l|}{ High } \\
\hline
\end{tabular}

Figure 4.1: Effect of authorisation of different types of budgets on controllability of the ZBO budget

One can summarise the effects of authorisation of different forms of budgets as follows. The basic classic form of authorisation is a discretionary line-item or lump sum budget. It only sets an expenditure level and focuses on compliance. No other criteria are set. Under modern budgeting models, in which output has a role in the level of budgeting, the level of control depends on what has been authorised by Parliament. When production is 
maximised, cost-prices are determined by Parliament (or minister on behalf of Parliament) and an investment budget is given, the control level is similar to that of the classic budgeting process. However, when one or more of the three control items are not authorised, degrees of freedom for management will result, depending on what is actually authorised by Parliament. Figure 4.1 summarises the options that exist. The classification of these different options is mine.

\subsection{Details of authorisation}

Traditional authorisation of budgets is based on line item expenditure based budgets. Applied to ZBOs, Parliament would authorise a budget for individual ZBOs - or even more detailed into cost categories - as these would be separately listed in the budget proposals (Anthony \& Young, 2003, p. 492). Although it is recognised that (annual) line-item budgeting may lead to inefficiencies (e.g. Jones \& McCaffery, 2005, p. 338), it is still used to some extent. From an autonomy perspective, the more detailed a budget is, the fewer the degrees of freedom available to management. I will now address the level of detail found in the budgets of Dutch ministries and analyse the effects on autonomy and transparency of that level of detail for ZBO budgets.

\subsubsection{Development of line item budgeting}

The budget of a Dutch ministry consists of a number of articles; each of them can be regarded as a form of a line item. In Table 4.5, an example is given of the development of the level of aggregation in these line items over the last 30 years.

Table 4.5: Line items in the budget law of minVROM in nominal amounts (own calculations)

\begin{tabular}{|c|c|c|c|c|c|}
\hline & Fiscal Year & $\begin{array}{l}\text { Operating } \\
\text { expenditure }\end{array}$ & $\begin{array}{l}\text { Program } \\
\text { expenditure }\end{array}$ & Accruals Expenses & \begin{tabular}{|l} 
Investment \\
expenditure*
\end{tabular} \\
\hline \multirow{4}{*}{ Number of items } & 1976 & 29 & 45 & $\mathrm{X}$ & $5 * *$ \\
\hline & 1986 & 21 & 91 & $X$ & $\underline{X}$ \\
\hline & 1996 & 11 & 29 & $10 * * *$ & $\underline{X}$ \\
\hline & 2006 & $\mathrm{X}$ & 15 & 2 & 1 \\
\hline \multirow{4}{*}{$\begin{array}{l}\text { Average amount } \\
\text { in €'000s }\end{array}$} & 1976 & 7,555 & 30,731 & $\mathrm{X}$ & 93,279 \\
\hline & 1986 & 14,300 & 51,705 & $X$ & $\mathrm{X}$ \\
\hline & 1996 & 23,181 & 101,135 & 64,185 & $\underline{X}$ \\
\hline & 2006 & $\mathrm{X}$ & 227,765 & 618,697 & 726,941 \\
\hline \multirow{4}{*}{$\begin{array}{l}\text { Minimum amount } \\
\text { in €'000s }\end{array}$} & 1976 & 3 & 15 & $\bar{X}$ & 9,484 \\
\hline & 1986 & 95 & 45 & $X$ & $\mathrm{X}$ \\
\hline & 1996 & 28 & 11 & 2,168 & $\underline{x}$ \\
\hline & 2006 & $\mathrm{X}$ & 1,818 & 4,333 & 726,941 \\
\hline \multicolumn{6}{|c|}{$\begin{array}{l}\text { * } 1976 \text { was the last fiscal year in which a separate capital budget was used. With the introduction of } \\
\text { government agencies, investments by those agencies are again authorised separately. } \\
* * \text { Lending for housing was discontinued in the early 1990s-and would give large distortions in this } \\
\text { comparison. Therefore it is excluded for all budgets. } \\
\star * * \text { In } 1996 \text { preparations were made to establish an executive agency. This was done by separating the } \\
\text { budget for the future executive agency from the main budget of minVROM, however still on an expenditure } \\
\text { basis. }\end{array}$} \\
\hline
\end{tabular}

Compared to some 30 years ago, the level of aggregation of line item budgets in the Netherlands has shifted to a more abstract and general level as is shown by the example in Table 4.5. One aspect of this aggregation is that program and operations costs are no 
longer legally separate budgets. Particularly in the case of budgets to be authorised for and distributed to ZBOs this may have negative effects for Parliament, as it may no longer recognise what budgets are intended for a program and what parts are intended for ZBO operations related to the program or the remaining monitoring functions within the ministry. In some cases, it is not even possible to recognise the budgets of individual ZBOs at all. In those cases Parliament may require information from the minister on the ZBO's budget. When the minister informs Parliament of the actual distribution of funds by means of a letter, Parliament will not be able to change the choices of the minister by changing the budget law because there was no law proposed. In those cases where Parliament disagrees with the minister on the distribution of funds, there are only two possibilities. Parliament - more specifically Tweede Kamer - can use its right of initiative and propose a budget law themselves. Janse de Jonge $(1993$, p. 5) indicated that Parliament has not used this instrument.91 The other option is for Parliament to use political pressure with the ultimate sanction of dismissing the minister in order to distribute funds in accordance with the will of Parliament (Janse de Jonge, 1993, p. 5). Such political pressure may result in a change of the budget law on the initiative of the minister in the regular intermediate budget procedures in spring and autumn. However, that would be an odd procedure, given the fact that executive agency budgets are not amended throughout a fiscal year. Effectively, it would imply that a ZBO has less autonomy relative to an executive agency, despite the fact that only the latter has a hierarchical relationship to the minister.

\subsubsection{Content of authorisation}

From a constitutional point of view, Minderman (2003, p. 21) claims that only what is directly described in the budget law is authorised. All other information is explanatory notes which cannot be amended. This implies that the content of a SLA is a matter between the minister and the ZBO which cannot be included in a law. At present four possibilities in authorising and distributing operating budgets for ZBOs may occur as a result of the change in the level of aggregation of budgets. First, the ZBO only has an operating budget and is separately visible in the proposed budget law for a ministry (e.g. CBS, Budget 2006, minEZ, article 9). In this case, Parliament can theoretically authorise and amend the budget of the ZBO directly. Second, the ZBO is funded from ministry budgets, but performs activities within several policy programs. The budgeting system will then present the costs of the operational activities over several line items, resulting in a lack of overview on the grand total available for the specific ZBO (e.g. IBGroep, minOCW) ${ }^{92}$, in most cases as part of a larger budget. There is no separate authorisation by Parliament for the ZBO's budget either in total or for parts of the ZBO's budget. An amendment in the budget law can in such a case only affect the total of the line item and the minister can distribute funds at will, including an option not to distribute funds. The

91 To my knowledge Tweede Kamer had not done so between 1993 and 2008

92 As of 2005, a compulsory appendix to the budget law has to be provided in which total government payments to ZBOs and RWTs have to be listed for each entity. 
explanatory notes provide Parliament with some information on the costs of the operations of the ZBO with respect to a certain program. Third, the operating budget of a ZBO is aggregated within a larger group of operating budgets. Then the difference between budget authorisation and distribution is most noticeable as it is the minister who actually decides what level of budgets are to be distributed to each individual ZBO and the explanatory notes do not reveal the separate budgets for individual ZBOs (e.g. CBP and CGB, Budget 2006, minBZK, article 1). When Parliament wants to influence the budget of a specific ZBO in the second or third case, it may use the right to amend the budget but simultaneously has to specify the budget to be authorised for the specific ZBO. The last option is that only a part of or even no budget is included in the ministry's budget law. In that case no overview is available with respect to the level of spending of the ZBO and no budget law is passed for that specific ZBO. This implies that there has to be another source of income for the ZBO in order to cover the costs of operations. An example of this is RDW (minVW), which is funded by direct charges on citizens for services delivered. In cases where no formal budget authorisation exists, laws other than the budget law may however regulate the level of charges to be imposed upon users of the ZBO service. Such case law has, to be authorised by Parliament in the same way as all other laws. Generally, such a regulation will be included in the law creating the entity, which means that the influence of Parliament is minimised after the entity has been created. Table 4.6 summarises the effects of the different ways of including ZBO budgets on the roles of Parliament and minister in the budgetary process.

Table 4.6: Influence of Parliament on ZBO budgets as stated by law.

\begin{tabular}{|l|l|l|l|}
\hline $\begin{array}{l}\text { Effect } \\
\text { Inclusion } \\
\text { Of ZBO budget } \\
\text { in Budget law }\end{array}$ & $\begin{array}{l}\text { Influence of } \\
\text { Parliament }\end{array}$ & Transparency & Ministerial role \\
\hline Separate article & Full authorisation & Fully disclosed & $\begin{array}{l}\text { Appropriation according } \\
\text { to law }\end{array}$ \\
\hline $\begin{array}{l}\text { Split up over several } \\
\text { articles }\end{array}$ & $\begin{array}{l}\text { Fragmented } \\
\text { authorisation }\end{array}$ & Needs consolidation & $\begin{array}{l}\text { Appropriation at will } \\
\text { within framework of } \\
\text { separate budget articles }\end{array}$ \\
\hline In larger budget & $\begin{array}{l}\text { Indirect, outside } \\
\text { budgetary } \\
\text { procedures }\end{array}$ & $\begin{array}{l}\text { Disclosure at best in } \\
\text { explanatory notes }\end{array}$ & $\begin{array}{l}\text { Appropriation at will } \\
\text { within framework of } \\
\text { larger budget }\end{array}$ \\
\hline Not included & No budgetary role & No disclosure & $\begin{array}{l}\text { Ministerial } \\
\text { consent/approval of } \\
\text { fees }\end{array}$ \\
\hline
\end{tabular}

Due to the lack of external impact towards third parties, authorisation of budgets which are intended to be used by ZBOs may have different results with respect to set spending limits. First, ZBOs that are part of the legal Entity State are not formally external parties and therefore the spending limit is a critical issue in the relationship between the minister and the ZBO. In these cases, the minister in fact has the hierarchical power to force the ZBO to comply with budget limits. This conflicts with the ZBO's intended status of an autonomous entity. Second, for those ZBOs which have a separate legal status, it is possible to ignore the spending limits as authorised by Parliament and appropriated by 
the minister. A minister has to ensure that a ZBO with a separate legal status controls its budget and respects the spending limits. An instrument to do so may be found by using specific reserves which allow overspending to be compensated for with previous years' savings. Such an instrument has to be included in the law, because it is a breach of the fundamentals of Parliamentary control over allocation of (unspent) budgets. Third, there is a group of ZBOs that is not directly funded through budgets as authorised by Parliament, but through separate direct charges on citizens. In those cases, some form of control on either the full budget or the level of charges must be included in a law when the charges levied strongly resemble a compulsory contribution for government activities. If not, this would mean a breach of the legitimising role of Parliament in requiring compulsory contributions from citizens. From the autonomy perspective, one can claim that for cases where ZBO budgets are not included in the budget authorisation processes in Parliament these ZBOs have more relative autonomy than those ZBOs whose budgets are specifically authorised.

\subsection{Conclusion}

In this chapter, the legislation on Dutch Central Government budgeting process is discussed. Parliament passes budget laws which has no external effect outside the legal entity State. This means that Parliament can never directly control the level of budgets in a ZBO that has a separate legal status. However, the concept of ministerial responsibility and accountability mean that Parliament can hold the minister accountable for his decisions with respect to appropriation of budgets to entities - such as ZBOs - outside the State. The constitution and budgeting legislation do include some regulations that can be used as indicators for ZBO autonomy.

First, I have discussed the CW regulations with respect to ZBOs: essentially the only requirement to disclose information is in budget documents and ministry annual reports as well arrangements on treasury management. An important omission seems to be authorisation of fees charged by ZBOs. Following the lines of the Dutch constitution and practice at the local government level, a case can be made that Parliament should approve ZBO fees.

Second, accruals budgeting and accounting was discussed. In principle accruals budgeting and accounting does not contribute to ex ante control of ZBO budgets, except in some cases of demand driven production as well as for investment authorisation. The issue of demand driven production is based on control of (cost) prices, production volumes and investments. If these three variables are ex ante controlled by Parliament, the result is a traditional fixed budget to be complied with. At the other end of the spectrum, a full open ended budget exists when Parliament authorises none of the variables. In between a variety of control levels exist in which differentiation between short term and long term control can be made.

The last point discussed looks at the level of detail in control. Dutch practice in the last three decades shows an increase in aggregation of budgets, resulting in less 
Parliamentary control on parts of budgets. As a result, only when a ZBO budget is explicitly and fully disclosed in a ministry's budget does Parliament have the possibility of direct control. Partially disclosed budgets, budgets of ZBOs split up over several budget articles as well as ZBO budgets not included in ministry budgets reduce transparency and as a result the power of Parliament to influence these budgets. 


\section{General Public law and autonomy of ZBOs}

In this chapter I will address general public legislation on ZBOs and the impact this legislation has on the (relative) autonomy of ZBOs. Public law legislation on ZBOs is divided into three groups. The general level of legislation comprises framework legislation on structuring ZBOs and legislation on general principles of public administration. The latter holds for any government entity - at arm's length or within a ministry's hierarchy executing an authoritative task (Goorden, 1997, p. 73-74). Within the law on general principles of public administration (Awb), two issues are relevant for ZBOs from an operations perspective. First, the already mentioned issue of delegation in section 10.1.2 Awb (see chapter 3) and second, Awb includes regulations on subsidies in section 4.2 Awb. The second group of legislation is ZBO case law. These laws generally cover the organisational structure, distribution of authority between ZBO and minister, as well as the tasks assigned to or the program to be executed by an individual ZBO. The last group of legislation covers ZBO-programs. ZBO case law may include a specification of activities to be performed on a general level, operationalised in other legislation or in decrees (see text box on page 111). In other cases, a full program law is defined which includes a separate chapter on the organisation of the ZBO. If so, I will only focus on the organisational arrangements of the ZBO and not consider the program contents of that law. A similar law can exist for a unit within the hierarchical structure of a ministry or for an executive agency. This chapter focuses on the ZBO framework law and addresses the Awb delegation and subsidising regulations.

\section{ZBO case law and program law.}

Public law ZBOs are created by or in the law. When a separate law is used, this law is referred to in this study as a ZBO case law. When a law is used in which the activities performed by the ZBO are the main contents, such a law is referred to as a program law. Private law ZBOs are created by statutes and their ZBO-task is defined by a program law.

An example of a ZBO case law is on IBGroep. This ZBO ${ }^{93}$ provides several forms of income transfer in the education field and has registration and examination responsibilities. The ZBO case law in this case is the 'Wet verzelfstandiging informatiseringsbank' (Law on autonomisation of IB-Group). The title of the law in this case even indicates that it is a ZBO case law rather than a program law. Relevant program laws are mentioned in the ZBO case law (article 3): e.g. Wet op de studiefinanciering (Law on Student benefits) and 'Algemene wet erkenning EG-hoger onderwijsdiplomas' (Law on accepting EU-higher education degrees). The ZBO case law also includes the system for funding IBGroep: article 11 deals with operating costs, article 13 covers program costs.

${ }^{93}$ As of 1-1-2010, IBGroep has merged with an executive agency and lost its ZBO status. 
An example of a program law which creates a ZBO is the 'Kieswet' (Law on elections). In this law the existence of the 'Kiesraad' (Electoral Council) is mentioned (article A1). Its role in the election process is defined in articles $F$ and $G$ under which the 'Kiesraad' is attributed the authority to decide upon the admittance of political parties to general elections, given the rules laid down in the law.

An example of a program law under which a private law ZBO is authorised to decide upon a particular issue is the 'Wet houdende vaststelling regeling ten aanzien van de Stichting tot verzorging en afwikkeling van pensioensaangelegenheden gewezen overheidspersoneel van Indonesië' (Pensions law for former government staff in Indonesia), in which the ZBO 'Stichting Administratie Indische Pensioenen'94 is authorised to provide income transfers for widows of former Dutch government and military staff in the Dutch East Indies.

The structure of the chapter is as follows. I will start with a short introduction on the history of public law in relation to ZBOs. Secondly, a short discussion on authority and responsibility is given from the perspective of the authority to be attributed to either the minister or ZBO. Then I will address the key features of the two frameworks that are relevant for ZBOs. These frameworks are 'Aanwijzingen voor de regelgeving 1996' and, as of 2008 the framework law on ZBOs 'Kaderwet Zelfstandige Bestuursorganen'. Then, I will address delegation and subsidising concepts in Awb. Finally, I will compare the frameworks and assess the impact they have on ZBO autonomy, either individually or as a group.

\subsection{History of general legislation on ZBOs}

In 1992, Cabinet presented a fully revised framework on general legislation with the objective of standardising the structure of legislation and decrees. These 'Aanwijzingen voor de regelgeving' (General Instructions on Legislation) [Aanwijzingen; AW] are internally binding instructions on the preparation of legislation, without direct effect on amongst other things - ZBOs (AW1996:4). They cover the basic rules for all new legislation (Borman, 1993, p. XVI). Eijlander and Voermans (2000, p. 374-375) note that Aanwijzingen have the characteristics of an order to civil servants but have the impact of an evaluation framework for assessing legislation proposals by the Council of State and sometimes even in Parliament. Furthermore a motivated exception to AW can be claimed on the basis of AW1996:5.

The comments on control of ZBOs in the NCA 1994 fiscal report led to a motion in Parliament in which the Cabinet was asked to develop a dedicated framework law for ZBOs, to be effective as of 1997 (Parliament, 1995c). The Cabinet first solved the problem of a more structured legislative process on ZBOs by introducing a new section in 'Aanwijzingen' as of January 1, 1996. Although the new section in 'Aanwijzingen' structures the creation of ZBOs, this only applies to new ZBOs. However many ZBOs were

94 Note that this foundation was created on the basis of CW1927:89a. 
already in existence before 1995. These older ZBOs were, according to the Dutch Constitution and $\mathrm{CW}$, established by law but the authority and responsibilities available to the minister may not be the same as those stated in 'Aanwijzingen'. Many older ZBOs have been merged or reorganised in recent years (Van Thiel en Yesilkagit, 2006, p. 10). These new entities have also had to apply 'Aanwijzingen' rules. The precise requirements can differ from case to case and it is here that 'Aanwijzingen' has most of its added value. Aanwijzingen 1996 was used as the framework to assess all known ZBOs based on the 1995 NCA report. This initiated reconsideration of the role of ZBOs in the structure of national government (Parliament, 1995b; Parliament, 1997a) in what was labelled as 're-introducing primacy of political authority' (herstel van het primaat van de politiek). The instructions lay down the procedure for establishing a ZBO as well as the specific controls that may be applicable in a specific situation. Depending on what controls are ultimately included in the law or statute that establishes the ZBO, one can analyse the degrees of freedom and the remaining ministerial responsibility with respect to that specific ZBO.

In September 2000 a proposal for the new ZBO framework law [KZBO] as meant in the 1995 motion of Parliament was submitted to Parliament. The Tweede Kamer passed the bill in March 2002. After the May 2002 general elections, the new Cabinet stated in August 2002 that it would review its opinion on the proposal of kZBO and as a result, debates in the Eerste Kamer were suspended (Parliament, 2005c). In 2005, discussions were reopened and the law was adopted by the Eerste Kamer on October 31, 2006. kZBO consists of both compulsory measures as well as optional measures which theoretically still allow for differentiation and tailor made measures. As with 'Aanwijzingen', kZBO can only be applied to new ZBOs. To include as many existing ZBOs as possible under the new law, article (KZBO:42) states that within a year of kZBO coming into effect, a list of ZBOs to which KZBO will be applied must be made available. This indicates the start of a process to change legislation for those ZBOs that are on the list and for which kZBO rules are not fully met. A weakness in the transition process with respect to PLB ZBOs under KZBO is that changing a private law statute cannot simply be enforced by Parliament and a minister. This problem may particularly arise when a minister does not have a final word in changing statutes - an optional issue under AW1996. Dalhuisen (2004, p. 145) indicated that in only $60 \%$ of all ZBO foundations does the minister have the final say on changing the statute, implying that in the other cases either there is no possibility of changing the statute or that the minister needs cooperation of the board of the foundation to change the statute.

Based on the data set used in this study (see Part A) it appears that only some $20 \%$ of ZBOs will have to fully comply with kZBO and some $25 \%$ have to partially comply with kZBO. All other ZBOs are either to be reconsidered or discontinued (34) are no longer mentioned by minBZK (21) or are not relevant under the kZBO framework. Table 5.1 shows the distribution of compliance with kZBO as proposed by government (Parliament, 2008b). 
Table 5.1: ZBOs by legal status listed in this study to be included under kZBO (source: Parliament, 2008b)

\begin{tabular}{|l|r|r|r|r|}
\hline & \multicolumn{1}{|l|}{ State } & \multicolumn{1}{l|}{ Public } & \multicolumn{1}{l|}{ Private } & \multicolumn{1}{l|}{ Total } \\
\hline kZBO & 12 & 26 & 18 & 56 \\
\hline Not kZBO & 16 & 8 & 27 & 51 \\
\hline Not mentioned & 10 & 1 & 10 & 21 \\
\hline Total & 38 & 35 & 55 & 128 \\
\hline
\end{tabular}

Based on cabinet's decision, 56 ZBOs will be subject to the new framework. The other 72 ZBOs will be subject to older standards if they were created after 1995 or had their statutes revised after 1996. If no changes in statute were made after 1995, there has been no standardisation of regulations. Absence of standardisation does not imply absence of control mechanisms for Parliament and minister: the only way to find the control mechanisms is to fully assess the individual statutes.

\section{$5.2 \quad$ Attribution of authority to a ZBO.}

From a political point of view, establishment of a ZBO by law implies that both Houses of Parliament have to give their consent. This implies that Parliament also agrees to the reduction of ministerial responsibility. The differences between the authority and responsibilities attributed to and/or executed by ministers with respect to ZBOs create confusion and different degrees of real autonomy for ZBOs. After the conclusions of the NCA in 1995 several studies were performed on these authority and responsibility differences (Zijlstra, 1997; Boxum, 1997, Leerdam, 1999; Kuiper, 1999; Kummeling et al., 1999; Minderman, 2000; Dalhuisen, 2004; Van Thiel, 2006). Zijlstra notes that autonomy of an entity is determined by the lack of another entity to direct operations of that authority. Autonomy is a relative concept, but if a hierarchical relationship, a mandate relationship or the power to give instructions in individual cases exists, an organisation is subordinate to the other organisation (Zijlstra, 1997, p. 76-77). A hierarchical relationship with a minister is by definition excluded for ZBOs. The other two elements could be included by law but are unlikely given the intentions to create an arm's length organisation. As a result, variations in autonomy for different ZBOs are based on the actual authority attributed to the entity. Some of these authors (Kummeling et al., 1999; Minderman, 2000; Dalhuisen, 2004) tried to classify authority into different categories, others tried to explain why this authority was given (Van Thiel, 2006). The categorisation of authority as identified by Kummeling et al. (1999, p. 39) includes four groups: cyclical powers, information based powers, other (governance) powers and normative powers. In this study normative authority is relatively unimportant. Normative measures aim to standardise programs rather than ZBO operations. I regard such measures as part of the specifications of services to be delivered. As long as the ZBO can deliver according to these specifications, the actual operational processes can remain a black box for the commissioning ministry. The other three categories of authoritative power have a more immediate effect on operations: they all have to do with transparency 
in operations, with interventions on available resources or managerial decisions. When assessing relative autonomy of ZBOs, these three categories will be emphasised.

Kummeling et al. (1999, p. 53-59) emphasise the differences in the authority attributed to a minister from the wording the legislature uses to do this. Full authority and responsibility is expressed by attributing decisive power or determining power ('vaststellen') to the minister. In that case the minister can accept a proposal but is also able to change the proposal or even to reject it. Authority is relatively restricted when the minister only has power to approve ('goedkeuren') a proposal. In that case, the minister can only accept or reject the proposal. Approval can be used before a proposal becomes effective or afterwards. In the latter case, it will lead to annulling a decision made by the entity that had to obtain approval for its decision from the minister. In the context of local government oversight Bolkestein and Van der Wel (1959, p. 28) noted that approval is a necessary condition before a local government decision can become effective. Kummeling et al. note (1999, p. 55) that disapproval of an annual report does not have a direct legal effect, but might lead to resignation of the board that submitted the annual report. Often, the power to (dis)approve is restricted in law by stating under what conditions a minister is allowed to reject a proposal. In that case the legislature uses the following wording: 'approval can only be withheld when the decision is contrary to the law or the general interest' (e.g. GemW:85.3; kZBO:29.2). A third expression used in the context of attributing power is consent ('instemmen'). In this case, the power of the minister is even more formally restricted.

In the literature I did not find any definition of the consent concept. In general the discussion is on 'to approve' or 'to decide'. Visser (1986) gave an example of consent in the contemporary version of GemW: the provincial authorities could send a message of consent on receiving a local government decree in which sanctions were included. This suggests that rejection of the decree by the provincial authorities was not possible. Similarly, a minister can give a negative opinion on a decision or proposal but lacks the authority to disapprove and thus annul the decision. In the explanatory memorandum to the third part of the Awb-legislation, reference is made to the concept of consent. Based on comments on an earlier draft of the proposed legislation Cabinet argues that consent suggests that the monitoring public body would consent to a proposal only if it accepts full accountability as if the decision was made by the monitoring public body itself. Furthermore, according to the explanatory memorandum approval is related to relationships between public bodies that do not operate under the hierarchical responsibility of the monitoring public body. In terms of ZBOs, this is the case as ministerial responsibility is reduced and not hierarchical (Parliament, 1994d, p. 185). I note that the consent option still exists, but that the legislature has indicated in his legislative instructions on attributing authoritative powers that using a word such as consent should be avoided (Borman, 1993, p. 112). 
In the following two sections I will discuss standardisation under 'Aanwijzingen' and kZBO respectively. The discussion on AW1996 is needed because the empirical part of the study was performed during the intermediate period when the legislation had not yet been aligned with kZBO.

\subsection{ZBO control under 'Aanwijzingen'}

The 'Aanwijzingen' decree starts with a definition of a ZBO. This states that a ZBO is 'an authoritative body at the level of central government, which is not hierarchically subordinated to a minister and which is not an advisory board...'(AW1996:124a). In the following two articles, the organisational form and the reasons for creating a ZBO are determined. The leading principle is that a ZBO is to be created under public law and based on one of the three listed motives: 'impartial judgement', 'rule based decision making' or 'participation with third parties'. Although the principle that a ZBO has status under public law is not politically discussed, the organisational form is open. The fact is that many ZBOs have civil law status and that even after 1995 new civil law ZBOs were created. ${ }^{95} \mathrm{~A}$ ZBO can either be a unit within a larger structure or a separate legal entity. This follows from the words 'organisational form' in AW1996:124b.1 which is different from the word 'organisation' that is used in AW1996:124b.2 for civil law ZBOs. Moreover, in AW1996:124h it is explicitly stated that 'when attributing legal status is desired', which clearly shows that a ZBO may have a separate legal status but does not need to have one. The Dutch Electoral Council is an example of an entity that has no separate legal status but does have the status of a ZBO. In general, only small units that require the status of ZBO will not have a separate public legal entity status.

In general, all other arrangements being equal, not having separate legal status implies having relatively less autonomy in operations compared to other ZBOs. This is because operational processes and operational control have to fit in to the system of the larger entity under which the ZBO unit is operating. In specific cases, autonomy actually depends on the authority attributed and the control procedures applied. 'Aanwijzingen' continues with a list of legislative instructions which includes areas of authority that can or must be attributed to the minister responsible for the ZBO. The list of authority areas to be attributed to the minister is more restricted for PLBs than for PLAs. This implies that a PLA has less autonomy than a PLB. Again, case law and actual control practices ultimately determine ZBO autonomy. In Appendix 10 a full specification of the regulations in 'Aanwijzingen' is given, including an indication of whether or not the regulation affects operations of the ZBO and thus possibly its autonomy. Table 5.2 below, only shows the items in 'Aanwijzingen' which affect autonomy of operations of ZBOs.

The table shows that about half of the instructions in 'Aanwijzingen' are optional. This means that Minister and Parliament may or may not include the issue in the ZBO case law. The other half is compulsory, but the instructions only require a measure to be included in the ZBO case law. In theory, Parliament and minister can agree not to include

\footnotetext{
95 e.g. Stichting Nidos, established in 2005
} 
a measure in the ZBO case law. Formal autonomy of a ZBO can therefore only be assessed by studying the individual ZBO case-laws.

Table 5.2: Authority issues having impact on autonomy as mentioned in 'Aanwijzingen' as of 1996

\begin{tabular}{|c|c|c|c|}
\hline Issue & $\begin{array}{l}\text { Article } x \\
\text { AW1996 }\end{array}$ & Applicability & $\begin{array}{l}\text { Option }(\mathrm{O}) \text { or } \\
\text { compulsory }(\mathrm{C})\end{array}$ \\
\hline \multicolumn{4}{|l|}{ Cyclical issues } \\
\hline Approval of fees by minister & 1241.3 & All & $\mathrm{C}$ \\
\hline Including funding method in the law & $\begin{array}{l}124 n .1 / \\
1241.2\end{array}$ & PLA & $\mathrm{C}$ \\
\hline ZBO Board decides upon the budget & 1240.1 & PLA & $\mathrm{C}$ \\
\hline Consent with budget and multiyear forecast by minister & 1241.4 & PLA & $\mathrm{C}$ \\
\hline Minister can set rules on structure of budget, & 124 p.2 & PLA & 0 \\
\hline \multicolumn{4}{|l|}{ Information issues } \\
\hline ZBO submits annual report to minister & 124s.1 & All & $\mathrm{C}$ \\
\hline General right of inquiry for minister & $124 \mathrm{t}$ & All & C \\
\hline Requirements on statement of accounts & $124 p .1$ & PLA & $\mathrm{C}$ \\
\hline $\begin{array}{l}\text { Requirement that ZBO-case law determines financial } \\
\text { oversight }\end{array}$ & 1240.2 & PLA & C \\
\hline Specifications of annual report included in ZBO-case law & 124s.2 & PLA & 0 \\
\hline $\begin{array}{l}\text { Minister can set rules on structure statement of accounts } \\
\text { and auditing }\end{array}$ & 124p.2 & PLA & $\mathrm{O}$ \\
\hline \multicolumn{4}{|l|}{ Other (governance) issues } \\
\hline $\begin{array}{l}\text { Law must include relation and authority attributed to minister } \\
\text { and board }\end{array}$ & $\begin{array}{l}124 I .1 / \\
124 I .2\end{array}$ & All & C \\
\hline Appointment in governance structures other than Board & $124 \mathrm{i} .4$ & PLA & C \\
\hline (Re)appointment and dismissal of board & $124 \mathrm{i} .1$ & PLA & $\mathrm{C}$ \\
\hline Structure of board & $124 \mathrm{i} .1$ & PLA & $\mathrm{C}$ \\
\hline $\begin{array}{l}\text { Defining relationship between different bodies in governance } \\
\text { structure }\end{array}$ & $124 j$ & PLA & C \\
\hline Approval of internal governance statute by minister & 1241.4 & PLA & $\mathrm{C}$ \\
\hline Appointment of members of interest groups & $124 i .3$ & All & 0 \\
\hline Approval, suspension or reversal of ZBO-decisions & $1241.5 c$ & All & 0 \\
\hline Intervention by minister in case of negligence & $124 \mathrm{~m}$ & All & 0 \\
\hline $\begin{array}{l}\text { Requirement that ZBO case law determines ministerial } \\
\text { consent to private law based decisions (e.g. statutes, lease, } \\
\text { borrowing) }\end{array}$ & 1240.3 & PLA & 0 \\
\hline \multicolumn{4}{|l|}{ Normative issues } \\
\hline Task description & $124 g$ & All & $\mathrm{C}$ \\
\hline Prohibition to appoint civil servants in board & $124 i .2$ & All & $\mathrm{C}$ \\
\hline $\begin{array}{l}\text { Change of legislation when insufficient authority appears to } \\
\text { be attributed to minister }\end{array}$ & $124 I .7$ & All & $\mathrm{C}$ \\
\hline Conditions for issuing operational instructions by ZBO & $124 f$ & All & 0 \\
\hline Approval by minister of other authoritative decisions by ZBO & 1241.5 & All & 0 \\
\hline $\begin{array}{l}\text { Minister decides on general instructions on tasks and other } \\
\text { listed issues }\end{array}$ & $\begin{array}{l}1241.5 a / \\
1241.5 b\end{array}$ & All & 0 \\
\hline Measures on appointing staff & $124 u$ & PLA & 0 \\
\hline Measures on transfer of legal disputes & $124 w$ & PLA & 0 \\
\hline Measures on transfer of liabilities to new legal entity & $124 v$ & PLA & 0 \\
\hline
\end{tabular}

The table also indicates that the compulsory normative issues with impact on the autonomy of ZBOs hold for all ZBOs. As a result, relative autonomy of ZBOs is hardly affected; only the optional normative issues may result in differences. In the three other categories, the emphasis is on PLA's: relatively few issues hold for all ZBOs. Furthermore, 
authority issues aimed at PLAs are mainly compulsory requirements. Thus, PLA case laws drawn up under AW1996 are likely to have stronger control tools thanthose for other ZBOs.

Some remarks can be made on specific articles in AW1996. Article AW1996:1240.3 leads to some confusion. The article only applies to PLAs (according to AW1996:124b.3). In the explanatory notes, changing of statutes is mentioned as an example of a private law based action that might be subject to ex ante permission by the minister. However, a statute is only relevant in a PLB setting; a PLA is based on a law, not a statute. Furthermore, the article is not restricted to types of private law actions, which theoretically means that any action might need ex ante permission from the minister.

The introduction of kZBO did not make the ZBO section in 'Aanwijzingen' obsolete. As of August 2008, the section has been reduced to a set of instructions that standardise the phrasing in individual ZBO laws and the procedures on changing ZBO-legislation. Such instructions had been included in 'Aanwijzingen' in 1996, but were surrounded by instructions that aimed at the contents of ZBO legislation. One instruction that does affect autonomy and is still included in AW2008 has changed. This instruction (AW1996:124j; AW2008:124f) allows PLA authority to be distributed amongst different bodies. The text of the instruction has been changed to emphasise that it only holds for PLAs. In AW1996:124b, it had been arranged that only a limited number of instructions were applicable for PLBs. As the differentiation between public law based and private law based ZBOs has been transferred to kZBO, the wording of AW2008:124f had to be adapted as well. More relevant however is that three different cases are mentioned in the explanatory notes to AW2008:124f: an executive board and a non-executive board, a non-executive board and an executive director and an executive board and a user / client panel. These cases are not restrictive: the wording is 'one can think of...' ('gedacht kan worden aan...'). Compared to the AW1996:124j instruction, the AW2008 instruction is extended by the latter two options. This means that solutions other than the three mentioned are also possible.

A final remark can be made on ministerial responsibility, more particularly on system responsibility as described by Kummeling et al. (1999, p. 19-20). In the case of ZBOs, this element of responsibility is institutionalised; 'Aanwijzingen' requires that in the event of insufficient authority a minister has to change the legal framework in order to acquire the authority he needs (Aanwijzingen:124l.7). The adapted 'Aanwijzingen 2008' does not include the contents of the former AW1996:124I.7. As a result, the system responsibility for monitoring ZBOs is now implicitly assumed rather than explicitly given in the legislative frameworks on ZBOs. 


\subsection{ZBO control under kZBO}

The remarks on lack of ministerial control made by the NCA and the Sint Committee in 1995 initially led to a fast and practical solution through the adoption of 'Aanwijzingen'. This lasted till the end of 2006 before the Framework law (kZBO) had passed through Parliament.

Goorden (1997, p. 110-111) mentioned a list of minimum requirements that should be included in the new framework law. These five requirements were: general right of inquiry, cognisance of the annual report and financial statements; approval or decision making on budgets and fees, ability to give general instructions and the appointment and dismissal of the board. According to Goorden another 6 issues had to be considered when developing the new framework law. These were: funding, arrangements for secondary or commercial activities, incompatibility in the functions of board members, annulling and negligence provisions, evaluation and finally remuneration of the (non) executive board. Goorden's requirements can be used to assess the differences between AW1996 and kZBO measures.

\subsubsection{Legal status of $k Z B O$}

The legal impact of kZBO and 'Aanwijzingen' is different. As mentioned, AW1996 generally only has an internal effect on ministers and civil servants and sometimes serves as an assessment framework for new legislation. The framework law kZBO has an external effect as a law generally addresses anyone whom it may affect. Ten Berge \& Zijlstra (2000, p. 83-84) note that the general legislative rule is that 'lex specialis' (i.e. case law), overrules general legislation. In this case kZBO can be overruled by other rules in case law. If deviations from the general law are deliberately meant, the standard wording '..in afwijking van..' (contrary to) is to be used. This holds for legislation in general.

Applied to the kZBO-framework, two cases exist. First, a new ZBO is created after kZBO came into effect. The kZBO generally holds for all compulsorily worded kZBO articles and those optional articles which are explicitly mentioned in ZBO case law. Provisions that run contrary to KZBO also have to be mentioned explicitly. Secondly, in the case of an existing ZBO, kZBO must be explicitly made effective first in the case law, possibly by excluding some compulsorily worded kZBO measures. What has been covered in kZBO does not need to be repeated in the case law once kZBO has been made effective. The optional measures do not hold; here the old wording in the case law can be used unless another measure has been implemented.

In both cases, new (adopted) legislation has to pass through Parliament before legislation actually becomes effective and Parliament can therefore discuss possible measures which run contrary to kZBO.

\subsubsection{Contents of $k Z B O$}

A key concept under KZBO is that the law requires a ZBO to be based on public law, unless 'it is particularly relevant for the public interest' to use a private law solution. 
There have to be 'sufficient' safeguards included in the statutes of a PLB to ensure that the public ZBO tasks can be separated from the other tasks of the private entity (kZBO:4). In the initial proposal, this article as well as article kZBO:3 on the motives for creating a ZBO (impartial judgement, rule driven task execution and participation of third parties), were not included. Both articles were included in kZBO only after amendments from Tweede Kamer were accepted. Article kZBO:4 was motivated by standardising the legal status of ZBOs, which was in line with the general idea of kZBO (Parliament, 2002f). An amendment that proposed to extend this rule to a priori approval by minBZK was included in modified form in article kZBO:6 (Parliament, 2002g). Article kZBO:3 was included (Parliament, 2002d) as an assurance that only these three categories of reasons were sufficient to create a ZBO. The article is identical to the text used in AW1996:124c. In kZBO, a requirement is included that ZBO annual reports must be submitted to Parliament. Again, it was Tweede Kamer which managed to include an amendment to KZBO with this requirement, which is stronger than the previous measure in which these documents were submitted to Parliament on request or on a voluntary basis directly from a ZBO (Parliament, 2002h). It should be noted that the wording of the article does not cover the intentions of MPs. In the debate on kZBO, several MPs made a link between annual reports and financial statements (Parliament, 2002i, p. 3533-3535). The text of kZBO:18 only refers to an annual report, not financial statements. The latter have to be approved by the 'parent' minister based on kZBO:34 in which a clear distinction between the annual report and annual accounts/financial statements is made.

Another amendment (Parliament, 2002j) that was included in kZBO is in kZBO:21. This allows a minister to issue general instructions. The measure included in kZBO is restricted to policy rules on the task of a ZBO only, whereas AW1996:124I.5 also includes rules on a limited list of issues in the ZBO-case law. At present a similar measure is included in AWb:10.16.

The content of kZBO has similarities with the original 'Aanwijzingen'. Some new issues on authority are also included. Table 5.3 gives an overview of the issues which impact ZBO operations that are included in the new law.

Compared to AW1996, it appears that many of the issues included in ZBO laws are now compulsory and hold for all ZBOs that are subject to the new law. Only a few issues are particularly relevant for a specific group of ZBOs. At first glance, kZBO suggests much stronger control tools than those used before. Compared to Goorden's (1997, p. 110111) proposals, three issues have been solved differently. First, a minister has to approve annual reports rather than having knowledge of the contents but formally restricted to the annual report and not annual accounts. This is a stronger measure compared to Goorden's proposal. Two issues are less strict than Goorden's proposal: the minister only 
approves budgets and fees; the executive board decides. The other one is the lack of an explicit rule on secondary or commercial activities.

Table 5.3: Authority issues impacting autonomy as mentioned in kZBO

\begin{tabular}{|c|c|c|c|}
\hline & Art x kZBO & Applicability & $\begin{array}{l}\text { Option }(0) \\
\text { or } \\
\text { compulsory } \\
\text { (C) }\end{array}$ \\
\hline \multicolumn{4}{|l|}{ Cyclical issues } \\
\hline Approval of fees by minister & 17 & All & C \\
\hline Consent with budget and multiyear forecast by minister & $\begin{array}{l}\text { 29: approval } \\
\text { except } \\
\text { multiyear } \\
\text { forecast }\end{array}$ & All & $\mathrm{C}$ \\
\hline $\begin{array}{l}\text { Report on substantial differences between budgeted and } \\
\text { actual expenditure }\end{array}$ & 30 & All & C \\
\hline Creating equalisation reserve & 33 & All & C \\
\hline ZBO board decides upon the budget & $\begin{array}{l}26, \text { by } \\
\text { implication } 29\end{array}$ & All & C \\
\hline Minister can set rules on budget structure & $\begin{array}{l}27[\mathrm{C}] \\
28[\mathrm{C}]\end{array}$ & All & 0 \\
\hline \multicolumn{4}{|l|}{ Information issues } \\
\hline ZBO submits annual report to minister and Parliament & 18 & All & C \\
\hline General right of inquiry for minister & 20 & All & $\mathrm{C}$ \\
\hline Requirement for approval of statement of accounts & 34 & All & C \\
\hline $\begin{array}{l}\text { Minister can set rules on structure of statement of } \\
\text { accounts and auditing }\end{array}$ & $35[\mathrm{C}]$ & All & 0 \\
\hline $\begin{array}{l}\text { Requirement to separate accounts for ZBO activities and } \\
\text { non-ZBO activities }\end{array}$ & 38 & PLB & C \\
\hline \multicolumn{4}{|l|}{ Other (governance) issues } \\
\hline $\begin{array}{l}\text { Defining relationship between different bodies in } \\
\text { governance structure }\end{array}$ & 7 & All & C \\
\hline Ex ante approval by minister for mandates to the ZBO & 8 & All & $\mathrm{C}$ \\
\hline $\begin{array}{l}\text { Requirement that ZBO-case law determines ministerial } \\
\text { consent to private law based decisions (e.g. statutes, } \\
\text { lease, borrowing) }\end{array}$ & $\begin{array}{l}\text { 32, limitative } \\
\text { list }\end{array}$ & All & 0 \\
\hline Intervention by minister in case of negligence & 23 & $\begin{array}{l}\text { All + inform } \\
\text { Parliament }\end{array}$ & $\begin{array}{l}\text { Yes, directly } \\
\text { based on } \\
\text { kZBO }\end{array}$ \\
\hline Approval, suspension or reversal of ZBO-decisions & 22 & $\begin{array}{l}\text { All, only } \\
\text { annulment }\end{array}$ & 0 \\
\hline Approval of internal governance statute by minister & 11 & PLA & $\mathrm{C}$ \\
\hline (Re)appointment and dismissal of board & 12 & PLA & C \\
\hline Rules on Board member secondary jobs & 13 & PLA & $\mathrm{C}$ \\
\hline Minister decides on Board member remuneration & 14 & PLA & $\mathrm{C}$ \\
\hline \multicolumn{4}{|l|}{ Normative issues } \\
\hline Prohibition on appointing civil servants to board & 9 & All & $\mathrm{C}$ \\
\hline Decide upon ZBOs to be subject to kZBO & 42 & All & $\mathrm{C}$ \\
\hline ZBO staff are subordinated to board, not minister & 16 & PLA & $\mathrm{C}$ \\
\hline Applicability of rules for PLBs & $36 ; 37$ & PLB & C \\
\hline Data protection requirement & 41 & All & 0 \\
\hline Rules on appointing staff & 15 & PLA & 0 \\
\hline Minister decides on general instructions on tasks & 21 & All & 0 \\
\hline
\end{tabular}

In a letter on hybrid status in the public sector, Cabinet announced an assessment of whether or not rules on secondary activities had to be included in kZBO as well as 
assessing the need for changes in individual ZBO case laws (Parliament, 1997b, p. 7). Since no rules have been included in $\mathrm{kZBO}$, the issue is left to the ZBO case law, implying that minister and Parliament are 'free' to decide on this topic.

In AW1996:1240.3, a provision is made which suggests that private law transactions by PLBs - at least changes in statutes - should be approved by the minister. Under kZBO, a similar article is included in the law (KZBO:32) but this article applies to all ZBOs and restricts ex ante permission to a limited list of actions. In effect, this means that theoretical autonomy under kZBO on private law actions is greater than under AW1996. Another relevant difference between AW1996 and kZBO is found in an instruction to the minister to acquire relevant authority if an omission in the system of responsibilities is discovered. This requirement is not explicitly included in kZBO. Basically, kZBO is meant to specify what is to be regulated in the laws or statutes of individual ZBOs. From that perspective, it is logical that this element of 'Aanwijzingen' is not included in kZBO.

Before I discuss implementation of $k Z B O$, one issue that has no immediate impact on autonomy from a legal perspective must be discussed. In kZBO:14, it is stated that the minister decides the remuneration of the ZBO Executive Board members. In the explanatory memorandum to KZBO (Parliament, 2000d, p. 24) the text suggests that remuneration is based on a standard system, because no performance related remuneration is mentioned. This is however not explicitly excluded. Furthermore, it is expected that ZBOs will publish the total amount of remuneration of the board in line with civil law (Parliament, 2000d, p. 13). In 2006, a specific law was introduced - Wet Openbaarheid uit publieke middelen gefinancierde topinkomens (law on publication of high level remuneration for publicly funded activities [WOPT]) - which required any public sector remuneration which exceeds that of a minister to be disclosed in the institution's annual report. This law holds for ZBOs as well. The issue is relevant given the political debates on remuneration (Dijkstal Committee, 2004; 2007) and because the remuneration structure may affect autonomy from an economic perspective. ${ }^{96}$ Given the political attention to this issue and its relevance from an economic perspective, I will include an assessment of remuneration decisions and compliance with WOPT in the empirical part of the study.

\subsection{3 kZBO implementation}

The reader is reminded that kZBO only applies to ZBOs created after the law was implemented in February 2007. A transition arrangement for existing ZBOs is included in the law. In order to accommodate the transition process, a committee of ministry representatives (Parliament, 2007c; Gerritsen committee, 2008) assessed proposals to modify present ZBO case laws to comply with kZBO. The committee took the position that basically each ministry had to comply or explain itself when a deviation from kZBO was desired. In its report, the committee discussed five groups of issues that required special

96 Incentives as performance related remuneration are mentioned in neo-institutional economics as a control tool (Moe, 1984, p. 756. See also Part C.) 
attention by cabinet. Three of them need some attention here, because they have particular relevance for the relative autonomy of ZBOs. A fourth - appointment of staff also has an impact. The committee advises continuing the existing arrangements on this point to avoid transition costs (Gerritsen Committee, 2008, p. 33). As a result, the relative autonomy of individual ZBOs is not affected by the issue of appointing staff. I now will discuss the relevant issues.

The first item is the appointment of a 'non-executive board' or an 'advisory board'. Under AW1996:124i.4, PLAs may have a governance structure consisting of an executive board as well as a non-executive board. Goorden noticed in 1997 that there is a strong resemblance between private sector arrangements on two tier boards and the public sector arrangements (Goorden, 1997, p. 209). He notes that the essential difference is that along with the responsibilities of the (two tier) board, there is a process of accountability towards the minister. Dalhuisen (2004, p. 62) indicates that issues on appointing and dismissing the executive board of a foundation are deliberately not included in the proposed kZBO. The Cabinet argued that the Dutch civil code gives sufficient scope to deal with appointments and dismissals and additional measures in kZBO might conflict with the civil code (Parliament, 2000d, p.7; Dalhuisen, 2004, p. 62). In the kZBO-proposal as it was finally concluded by the Dutch Senate (Parliament, 2000f; Parliament, 2002b), no explicit reference is made to appointments to the non-executive boards of foundations. However in the explanatory remarks to the original kZBO proposal, the minister leaves the option open to include a rule on appointments in a specific law or in the civil law ZBO statutes (Parliament, 2000d, p. 23). By August 2007, the Minister of Justice published a proposal on a 'Maatschappelijke Ondernemingen' law for consultation with relevant organisations, based on a policy advise by the Wijffels Committee (2006). ${ }^{97}$ This idea is similar to that of Community Interest Companies in the UK [CIC] (Masson, 2005) or Public Interest Company (Birchall, 2002; Maltby, 2003). The Dutch variety of a $\mathrm{CIC}$ is a private legal entity aimed at achieving a goal on behalf of society and parallel to the general interest, where profits are not distributed but used to achieve the goal of the entity. However a CIC is not the same as a ZBO, because qualifying as a $\mathrm{CIC}$ does not require an authoritative task. ${ }^{98}$ In the minJus proposal, a regulation (proposed $\mathrm{BW} 2: 307 \mathrm{i}$ ) is included that the board of a $\mathrm{CIC}$ is appointed by the non-executive board; in specific cases based on a binding nomination by relevant interest groups. Such a solution could overcome the comments made on not including appointment regulations for PLBs in kZBO. Some authors (De Ru, Burggraaf \& Spaans, 2005; Baarsma \& Theeuwes, 2008; Wolfson, 2008, Jongsma, 2008) have expressed their doubts whether a CIC in Dutch law really has additional value. Without the CICproposal, appointments to boards of foundation-ZBOs are not structurally governed by general law. Another point is that at the political level, there seems to be doubt on the usefulness of creating a non-executive board in the ZBO governance structure. In its

\footnotetext{
97 See also Pijls (2006).

98 The idea of the Dutch CIC is based on governance issues in health, education and social housing.
} 
report on the assessment of the proposals by ministries, the Gerritsen Committee observes a tendency to attribute authority to non-executive boards (articles kZBO11-14, kZBO:20) rather than to the minister. The committee proposed that cabinet should not attribute authority that ought to be attributed to minister or executive board to a nonexecutive board (Gerritsen Committee, 2008, p. 24). The opinion of the Gerritsen Committee reflects the shift in (political) opinions on the use of non-executive boards. Although the Committee prepared this proposal, the subsequent new AW2008:124f does allow degrees of freedom to create a non-executive board.

Second, the exemption from the authority of a minister to reverse decisions of a ZBO was discussed. This exemption (KZBO:22) is the most frequently claimed exemption (18 cases). In most cases, it regards quasi-judicial entities, where a ministerial intervention would be undesirable. However, in the case of the Art-funds, Parliament explicitly states that it should not intervene with funding for art. This is expressed in the letter of minOCW (Parliament, 2008d, p. 3) by stating that the exemption only holds for 'decisions that are based on the activities performed by the funds', implying that the exemption from the authority to reverse a decision only refers to program decisions. Operational decisions of the Art funds are supposed to be part of the ministerial authority attributed to him under kZBO:22. However, having said this, by mid 2008 discussions emerged in the media (e.g. NRC, 2008) and in Parliament (Parliament, 2008e) on the distribution of funds towards individual organisations. This is an indication that, despite restricted responsibility for the minister on this topic, the Parliamentary right of inquiry and political pressure may affect the formal position of the minister towards a ZBO.

The last item discussed by the Gerritsen Committee was on creating an equalisation reserve. In four cases, an exception is made to the standard that a ZBO has an equalisation reserve (KZBO:33). The idea of an equalisation reserve is that differences between actual expenditure and budgeted expenditure can be compensated for over a number of years. By not allowing an equalisation reserve, the ZBO is actually fully controlled as a budgetary entity, which has affects absolute and relative autonomy. The discussion is remarkable given the fact that a similar equalisation reserve arrangement also exists for executive agencies which are formally fully subject to ministerial control.

\section{$5.5 \quad$ Awb and kZBO}

As stated before, Awb governs general administrative issues with respect to all government bodies. In most cases, it regards the relationship between citizen and public body, including appeal procedures. I will not consider that as it does not affect general control of ZBO operations.

Two issues are relevant from an operations perspective. First, Awb, chapter 10 governs the relationship between public bodies including issues such as attribution and delegation of authority. These can be classified under Kummeling et al.'s (1999, p. 39) normative measures. The main issues are transfer of responsibility, issuing policy rules as well as approval, suspension and annulling of decisions by a public body. Most of these 
issues are also made explicit in kZBO. Second, the section on providing subsidies to legal entities should be mentioned (Awb4:58-80). In AW1996:n.2 it is suggested that reference be made to Awb to allow monitoring ZBO use of resources. The specific measures on structurally subsidising legal entities include the procedures to apply for a subsidy and the subsection on applicant obligations include measures on asset control similar to kZBO:32 (Awb4:71) and measures on equalisation reserves (Awb4:72; kZBO:33). The difference in the measures is that under kZBO:33, a compulsory measure is laid down whereas Awb4:72 is only optional. Furthermore, both optional asset control measures are not exactly the same. Awb4:71h covers an measure on conjunction of fees and subsidies and Awb4:71i covers dissolution of a legal entity. As under kZBO, the parent minister needs to approve fees, so the impact of Awb4:71h is low. Not including Awb4:71 i in the kZBO-framework seems to be an omission; the explanatory notes to kZBO (Parliament, 2000d, p. 31) only refer to the previous measures in AW1996.

\subsection{Summary}

A direct comparison between the authority issues which impact ZBO operations between AW1996 and kZBO regulations shows that kZBO is in theory a more restrictive model. Many more requirements have to be included in ZBO case laws or ZBO-statutes. This means that more authority is attributed to the minister and thus ZBO executive board autonomy is reduced.

Both kZBO and AW1996 have left degrees of freedom in attributing authority to minister and ZBO. By the end of 2008, the legislative process on adapting ZBO case laws to the KZBO framework had not yet been completed. Formal testing of autonomy based on kZBO is not yet possible. However, all ministers have indicated the proposed deviations to kZBO for individual ZBOs under their responsibility and these were assessed by the Gerritsen Committee. The exceptions to kZBO in individual cases are therefore likely to be accepted, unless Parliament intervenes. This does allow formal ZBO autonomy to be assessed under the new regime. In my opinion, such an assessment provides a better view on the position of a ZBO than a retrospective assessment only.

Along with the KZBO and AW measures, a third set of measures has to be kept in mind. Awb governs a number of normative measures which are mostly also covered in kZBO. The measures on subsidising legal entities (chapter $4.2 \mathrm{Awb}$ ) may have an impact on ZBOs as at least in AW1996 reference was made to these measures.

In the following chapter, attention shifts from the public law dimension to the private law dimension. Up to this point, ministerial authority and responsibility have been discussed. Secondly, the general legislative processes with respect to budgeting as well as developments in the history of ZBOs have been described. Third, the chapter on framework legislation showed the theoretical options for distributing authority between the minister and the board of a ZBO. 
The private law dimension will address in more detail the different legal entities and the impact of private law issues such as contracting on ZBO operations. 


\section{Autonomy and ministerial control: a civil law perspective}

\subsection{Introduction}

The two previous chapters discussed (relative) autonomy indicators and their impact on Parliamentary control from a public law perspective. Relevant indicators found were the level of detail in budgeting and the distribution of authority as actually laid down in the individual ZBO case laws. This chapter will address the indicators that can be derived from a private law perspective. Again, a general analysis will be performed which at this stage does not assess the actual rules in the ZBO case laws or statutes. Statements and conclusions therefore only reflect on general civil law rules. Creating a ZBO under a private law based organisational structure is not excluded although public law states that ZBOs are preferably created under public law. Whatever form of legal entity is used all forms are, unless stated otherwise, regulated under civil law. This follows from article 1 , book 2 of the Dutch civil code (BW2:1). Of course, as most ZBOs have public law based case law; this overrules the civil code with respect to the contents of that public case law under the principle that lex specialis overrides lex generalis. What is not included in the public case law is governed by the civil code as far as it concerns the acts of a ZBO as a legal entity rather than a public body (Ten Berge \& Zijlstra, 2000, p.21), although even then the principles of good public governance have to be met (Nicolaï et al., 1997, p. 247). Therefore, this chapter discusses ZBOs from a civil law perspective.

The attribution and distribution of authority towards a single ZBO is given in the requirements of public law but has to fit in with statutes that are also governed by private law for PLBs. For PLAs, the same holds as far as financial controls allow autonomous operation (Ten Berge \& Zijlstra, 2000, p. 39) and authority to participate in private law transactions is given (ibid., p. 46). When discussing organisations and the governance structure of organisations, two main themes emerge. First, there is an ownership-control discussion because creating a separate legal entity outside central government implies that some of the hierarchical controls used within central government cannot be used. Ownership of ZBOs may sometimes be similar to that in the private sector (shares held by government), but in other cases there are no shares and only a form of quasi-ownership exists, based on rules set in the formal statute (Law) ${ }^{99}$ of the ZBO. In a private company, ownership implies access to residual value and determining the strategy of the organisation. In a public law setting one can distinguish between controls on tasks assigned to an organisation including system-responsibility (Kummeling et al., 1999, p. 19-20). The other part refers to responsibility for the organisation as an entity or unit, which is in a civil law context referred to as the continuity issue. It should be noted that continuity of a PLA is guaranteed as long as it is not dissolved by law (Ten Berge \&

\footnotetext{
99 Public ZBOs are created by ZBO-case Law, Private Law ZBOs are created by a statute; the attribution of a
} ZBO task to a PLB is either done by or under the law. 
Zijlstra, 2000, p. 57 and p. 95-96). If net equity of a PLA is negative, the organisation is technically bankrupt, generating a problem for the Minister-Principal responsible for the organisation.

In the case of ZBOs which have public legal entity status (PLA), different individual governance structures may exist as a result of historical developments. As a result, ZBO case laws have to be studied individually to arrive at a conclusion on (relative) autonomy for PLAs. In the case of PLBs, Civil law (BW2:3) gives three (relevant) different formats for private law entities, each having different characteristics when studied from an ownership-control perspective. These forms are (limited liability) corporations, foundations and associations. Within these formats, statutes can vary as well, implying that classifying private law entities along the lines of formats alone is not sufficient to arrive at a conclusion of (relative) autonomy for private law ZBOs. In theory, it might very well be that the statute of a private law ZBO includes restrictions that result in a position in which that specific ZBO is less autonomous from an operations perspective than a public law ZBO. It is therefore necessary to study separately both the legal format and the owner controls for each type of entity.

The second problem to be discussed is related to the tasks assigned to the ZBO. The lack of hierarchical relationship between ZBO and the minister results in a relationship between two separate legal entities. ${ }^{100}$ This relationship is expressed in a form of "quasi contracting' to define the production for the new fiscal year. Both parties depend on each other for delivering services as most ZBOs have been assigned a unique task. A discussion on the specifications of the task to be commissioned will resemble a contract relationship between two fully independent organisations. Therefore, I will study the commissioning process from a civil law perspective to find indicators that may result in differences in (relative) autonomy (Lane, 2000, p. 149-155; Greve, 2008, p. 167-168). The commissioning issue is not fully equal to pure private law contract relationships since the minister can have authoritative powers that may overrule such negotiations. Goorden (1997, p. 79) suggested that ZBOs should be subject to the section on subsidies in Awb as well as in AW1996 (see section 5.4) to describe the relation between the entity and the minister. In my opinion, this is an incorrect proposition as ZBO operations are activities delivered on behalf of central government which are similar to the provision of services to government. The ZBO produces the service at government request, given the specifications that are set in the program laws. As a result, the financial relationship between ZBO and government has more resemblance to a contract relationship in terms of funding in exchange for services rendered rather than an income transfer (grant) relationship in which there is no need for direct service delivery. In more economic terms, the relationship between minister and ZBO is basically one on commissioning and funding (see section 6.3 for more details). Ensuring proper decision making on grants as laid down in Awb is therefore not relevant. The fact that an authorised budget is the basis

100 Except in case of ZBOs without separate legal status. 
of this contract relationship is irrelevant because a budget does not formally have an external effect outside the hierarchical structure of the State (e.g. Van der Bij, 1993, p. 13-15). The statutory power to (dis)approve budgets is one of the most powerful tools available, but Van Wijk (1998, p. 15) mentions for example that a concession - in this case to be interpreted as the quasi contract - or grant terms can be used by a minister to influence entity behaviour. While commissioning of public services ultimately aims at outcomes delivered, the main objective with respect to ownership-control is the operational output and financial results in terms of residual income realised by the organisation on behalf of its owners. I recall that this operational relationship is at the heart of this study.

I will start this chapter by describing the variety of legal structures that exist under civil law in section 6.2. This includes a discussion on the two possible formats for PLAs as well as the three major different formats ${ }^{101}$ for PLBs that can be derived from BW2:3. Given the formats, including rules that are described in the public law frameworks 'Aanwijzingen' and kZBO, a ZBO case law or a private law statute ultimately determines the actual autonomy of an individual ZBO. Section 6.3 focuses on service provision by ZBOs and the 'contract relationship' that will emerge when someone submits a request to a ZBO to provide the service that may only be provided by the ZBO. In section 6.4 , I will address controlling property rights in ZBOs which have separate legal status as well as the relevance of the internal governance structure of a ZBO with a separate legal status on the relative autonomy towards minister and Parliament. The chapter concludes with a short summary of findings in section 6.5. After these conclusions, a short intermediate chapter will focus on the overall results on the legal perspective of ZBO control and the implications for empirical research.

\subsection{Governance structure of the types of legal entities}

Civil law states that "a body, to which a public task is assigned, only has the status of a separate legal entity when that status has explicitly been attributed by or under the law' (BW2.1.2). This legal status is generally confirmed by the phrase: 'Entity $X$ is a legal entity'. ${ }^{102}$ There is no definition of ZBOs in civil law; they are described in public law. This implies that all ZBOs must fit into the framework of civil law as defined by BW2:1 and BW2:3. There are basically two options. First, the ZBO is part of the legal Entity State. Second, the entity has a separate legal status as defined in BW2:1 (public law entity) or BW2:3 (civil law entity).

When a ZBO is part of the legal entity State, autonomy as a result of legal status under the civil code does not exist. In that case, autonomy can only be enlarged by making special provisions in ZBO case law. Creating a separate public law based legal

\footnotetext{
101 Formally BW2:3 describes 6 forms but two of them - co-operation and mutual assurance company - are not relevant at all and one - limited company - is basically a variety of a share-issuing company.

102 For example, article 2, section 2 of 'Wet verzelfstandiging informatiseringsbank' explicitly attributes the status of legal entity to IBGroep.
} 
entity also implies a form of enlarged autonomy from the State. If not, there would be no argument for creating a separate legal entity at all. Enlarged autonomy implies that the legislature deliberately loosens its control systems which may affect the budget authorisation process. In the case of a ZBO with separate legal status under civil law, the opposite occurs. The initial autonomy of the entity due to its separate legal status can only be reduced as a result of the provisions in the law or statute.

The discussion in this chapter is on autonomy of legal entities from a civil law perspective and starts with some general remarks. The discussion on autonomy seems odd, as BW2:5 explicitly states that a legal entity has, under civil law, the same rights as a natural person, unless otherwise stated. Without restrictions as meant by "unless otherwise stated", the entity is entitled to full control as well as full benefits from the assets available to the entity. This means that in principle, a legal entity is autonomous. The autonomy of the entity can be reduced as a result of legal or statutory measures. In a pure civil law context between companies, the most common form of reduction of autonomy is found in a corporate holding structure in which the autonomy of a subsidiary company is reduced by the control systems - at least a majority voting right - available to the holding company.

In the context of a ZBO, the impact is more complex. In the case of a PLA, autonomy is described in the distribution of authority between Minister-Principal and the (executive) board of the entity on managerial issues ${ }^{103}$ as well as on the authority attributed or delegated to management on civil law transactions under the general condition that the use of the attributed or delegated authority does not conflict with public law (BW3:14). The fact that the measures to carry out private law transactions are based on attribution or delegation of authority to the (executive) board of a PLA implies that whether or not the transaction scope is restricted depends on the characteristics of that authority. I refer to the options of Awb4:71.1 and kZBO:32 on ex ante control of particular civil law transactions by the Minister-Principal (see also Ten Berge \& Zijlstra, 2000, p. 48). With respect to a PLB, a standard framework on authority is provided in BW2. These measures are reflected in the minimum set of controls from a governance perspective. Parliament and Minister-Principal can reduce the operational authority of the (executive) board by requiring additional controls in the statutes, setting standards on authority in the relevant program law or by including conditions for qualification as a PLB service provider in a program law. In all cases, this means an increase of public controls and decreased autonomy for a PLB. To what extent autonomy is actually diminished depends on the individual provisions.

Autonomy indicators will be analysed along the lines of the control tools available to (quasi) owners of the legal entity. The idea is that control tools not attributed to the

103 Even then, public law may be relevant, for example with respect to the legal status of staff under public law. 
(quasi) owner of the organisation are available to the (management of the) legal entity. As will be shown, it is not possible to refer to ownership of entities in all cases. In fact, only for those entities where shares are (publicly) issued is it possible to refer to ownership in the basic sense of BW5:1, where ownership is described as the most encompassing right' a (legal) person may have on an asset.

When an entity has issued shares, the shareholders are the residual claimants to all assets of the entity in the event of liquidation. Shareholders, or at least the majority of shareholders, can alter the legal position of the entity when appropriate (BW2:107a). In the case of the legal entity State there are no residual claimants. Neither Cabinet nor Parliament is able to alter the legal position of the State without consent of the other party due to the constitutional requirement 104 that they are jointly responsible for legislation. More or less the same holds for all other entities that are established by law. In associations there is no explicit ownership relation either, the majority of members has the right to alter the legal position of the entity (BW2:42.1). In foundations, where there are no members, the statutes determine how control is organised, and specify how remaining assets will be distributed in the event of liquidation. As the original founders of the entity cannot distribute the remaining assets amongst themselves (BW2:285.3), they are not equivalent to the residual claimants of enterprises that issue shares.

In the following subsections, I will discuss the different forms of legal entities that exist. For each type of entity, I will describe the effect of using that form of legal entity on ministerial responsibility and ex ante control including budget authorisation. I will start by describing the legal entities that typically have a public sector character (PLA). These are the State on the one hand and ZBOs with the status of public legal entity on the other. The description of the other forms of legal entities which includes PLBs is then continued along the lines of the relative share in the number of ZBOs that have private legal entity status. The description given here has to be read from the perspective of control of operations of the entity, assuming that the legal entity is only operating in a public sector environment. ${ }^{105}$ Program control of ZBOs is by definition a public law rule and does not generally affect the position the minister has as (quasi) owner of the entity and the budgets that are made available for operations of the entity.

\subsubsection{Public legal entities}

In this section the two forms of public legal entities that exist at national level will be discussed. Zijlstra (1997, p. 6) noted that in general little attention is given to the organisational structure of ZBOs. I will start with the legal entity Dutch State (6.2.1.1). After that other public legal entities at the national level will be discussed (section 6.2.1.2).

\footnotetext{
104 Article 81 Dutch Constitution

105 Hybrids as meant by Meijerink (2005), operating public as well as private tasks are neglected here because hybridity does not affect the status of a legal entity.
} 


\subsubsection{Legal entity 'State'}

The formal definition in the Dutch Constitution of the legal entity State is that the State consists of Government - i.e. King and Ministers - and High Authorities of State. From an operational perspective, ministers are - given the budget authorisation by Parliament responsible for controlling ZBOs that are part of the legal entity State. The Dutch Constitution also defines that a Minister is the head of a ministry. The organisational entity ministry however is based on hierarchical structures and ministerial accountability holds 'for all activities within the civil service' (Scheltema, 1993). Therefore, ministries are administrative structures within the framework of the State. The fact that a ministry does not have a separate legal status implies that all civil legal acts are based on mandates from the holding legal entity - i.e. the State - and that the State can be held fully accountable for any transaction or behaviour that is based on bipartisan consent or on civil law. Several 'Hoge Raad' decisions have led to this present opinion on the relation between public entities and private parties (e.g. Landsmeer-rulings ${ }^{106}$ ). Figure 6.1shows the general structure of the Dutch State.

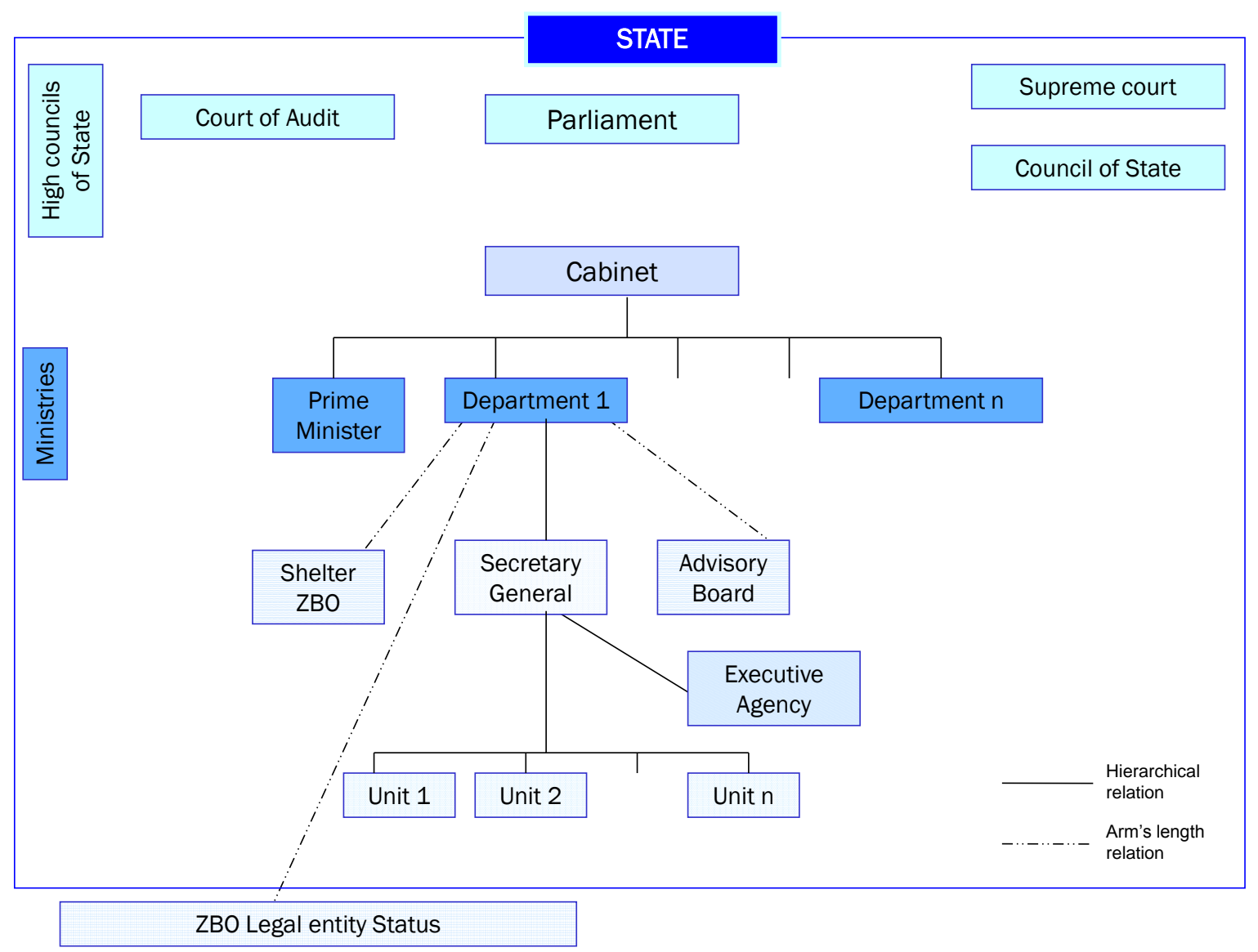

Figure 6.1: Organisation of the Dutch State

106 HR, 4 January 1963, NJ 1964, 202, 203, 204 
A ministry consists of a set of hierarchical units and may also include two specific forms of units: a) the executive agency ['Agentschap'] and b) dedicated units that operate independently on a particular policy issue (for example ZBOs or Advisory Boards). Executive agencies are a sub-structure within a ministry with a separate system of administration. Article 10, section 1 of CW2001 explicitly states that executive agencies are 'a unit of a ministry'. The creation of an executive agency does not require a specific law but only a Cabinet decision. If Parliament does not object, the executive agency will be created. This means that the requirement BW2:1.2 - the establishment by formal law - is not met and therefore executive agencies do not have a separate legal status. In civil law, executive agencies have a position equal to that of a ministry.

Matters become more complex because there are ZBOs that do not have a separate legal status. The tasks of such units are attributed under public law, but they operate within the framework of another entity - either public or private - depending on the task attributed. ZBOs without a separate legal status are in most cases relatively small organisational units for which it is not efficient to create separate legal status. They often qualify as 'quasi judicial' - impartial - autonomous units such as the Dutch Electoral Council or the Dutch Data Protection Authority (CBP). ${ }^{107}$ When such a ZBO is operating within the framework of the Dutch State, legal provisions exist that guarantee the necessary autonomy from full ministerial control, particularly safeguarding the impartial role of the unit. Minderman (2000, p.76) stated that a minister is fully accountable to Parliament if no restrictions on a minister's authority are given and, given authority attributed to a minister, he cannot be held accountable outside the scope of his authority. If specific responsibility is attributed to a minister, then accountability ends outside the borders of the given responsibility. From a formal civil law point of view however, it is the legal entity under whose framework the ZBO operates that can be held accountable for civil transactions or behaviour. In a civil dispute regarding a ZBO without legal status, operating within a ministry, such an entity would be represented by the State. In that case it would follow that the minister can still be held accountable for decisions or behaviour of an entity which was deliberately set at arm's length. With some imagination one might state that ZBOs without legal status can find shelter within the ministry led by the Minister who has portfolio responsibility for the specific ZBO. In these cases public law will specify to what extent the minister can be held accountable for the acts of such 'Shelter' ZBOs. Without specific restrictions on decisions based on civil law for the management of the 'Shelter ZBO' a minister does not have an ex ante opportunity to intervene. Operations of Shelter ZBOs as well as budget authorisation fully comply with $\mathrm{CW}$ regulations. In theory, this also means that Parliament has full (budgetary) control on these Shelter ZBOs. The decision making autonomy of a Shelter ZBO might generate some risk in the budget appropriation process as the minister's scope to intervene in

\footnotetext{
107 The Dutch Electoral Council consists of 7 members and has a staff of 10 people (Kiesraad, 2006); CBP
} has 3 members and a staff of some 80 people. 
decisions is limited. He might not be able to prevent a decision that can ultimately lead to a civil law claim affecting the appropriated budget. This may also hold for operational decisions made by the Shelter ZBO unless the minister has arranged for some form of ex ante control on the Shelter ZBO's operational decisions. An ex post opportunity to intervene would not prevent a legal ruling and the consequences thereof; it might however give the minister the opportunity to dismiss management of the 'Shelter ZBO' for reasons of mismanagement ${ }^{108}$.

Another complication in the relation between a Shelter ZBO and the minister is the appointment of staff. When staff for the Shelter ZBO are recruited from the civil servants of the parent ministry and perhaps assigned on a secondment basis, staff formally has a legal status equal to that of all other staff in the ministry. This implies that a minister has the power to control staff and thus overrule decisions made by the board of the Shelter ZBO. To prevent such interventions, the law under which the Shelter ZBO is created should have an article on the relationship between appointed staff of the Shelter ZBO in relation to other staff in the ministry.

\subsubsection{Public legal entity other than State}

The second group of public legal entities does have a separate legal status. As mentioned before, the Dutch civil code recognises public legal entities as equal to a natural person (BW2:5) with respect to property law, under the condition that proper authority is attributed to the PLA. All other legal requirements and restrictions with respect to creation, operational behaviour and dissolving a public legal entity can only be laid down in public law. This follows from article BW2:1.3 which stipulates that of all general regulations on creation and dissolution of legal entities, public legal entities are equal to other legal entities and natural persons with respect to property issues unless stated otherwise in the case law. If a PLA is unable to comply with its civil law based liabilities due to inefficient production or highly risky operations, it would technically be classified as bankrupt. Formally, bankruptcy is not possible, not only given BW2:1.3, but also because a PLA can only cease to exist if its legal entity status is withdrawn by law under BW2:1.1 (Ten Berge \& Zijlstra, 2000, p. 57). If the law under which the entity was created is withdrawn or changed, the consequences might be that the public legal entity ceases to exist. Such changes do occur from time to time; in 2002, the ZBO 'CTSV'109 was merged with a unit within minSZW into a new executive agency. Although a public legal entity ZBO has autonomous legal status under civil law, the restricted application of civil law to property issues only means that autonomy can only be studied by comparing the law on the specific ZBO with general public law instructions and the degrees of autonomy that are attributed to private legal entities in civil law. This has been discussed in the previous two chapters.

108 Of course the minister must have the authority to do so, see AW1996:124c:1.

109 CTSV [Dutch: College van Toezicht Sociale Verzekeringen] had a compliance and policy monitoring role in social security. 
To describe a public legal entity ZBO more generally, I would like to draw an analogy with strictly private legal entities. For fiscal and financial accounting purposes the concepts of parent companies, subsidiaries and group companies ${ }^{110}$ exist. These concepts have to do with control of entities and are used to show the financial interest or prevent double taxation in the private sector. Although exact definitions in national and international law may differ, the essential issue is that a subsidiary is controlled by a parent entity when either by voting rights (shares) or another instrument of influence the parent entity ultimately decides what will happen to the subsidiary. The IPSASB project to standardise international public sector accounting rules has adapted the private sector control concept for public sector purposes by introducing 'benefit' and 'control' criteria in IPSAS6:38-42. A strict interpretation of IPSAS6 is likely to include ZBOs under entities to be consolidated at the national level (Van Schaik, 2008; De Kruijf, 2009) ${ }^{111}$ and from this perspective would be similar to a subsidiary company.

In daily operations, both a subsidiary company and a public legal entity ZBO can decide for themselves how to manage the entity, implying a substantial level of autonomy. They both have their own identity, unlike franchise or branch entities which adopt the identity of the parent company, as for example observed with McDonalds, where the level of autonomy is far more restricted.112 However, when it comes to strategic decisions with respect to the subsidiary, final consent from the parent company will be needed. This final consent is governed by the general rules of civil law ${ }^{113}$ and internal implicit or explicit rules issued by the parent company. In public law this final consent on strategic discussions is supposed to be formalised in the law by which the "public legal entity ZBO' was created as BW2 does not regulate anything more than the status of the legal entity for the ZBO. Whether the specific public law actually has regulated final approval remains to be seen. Public law ('Aanwijzingen' and kZBO) only stipulates that the specific law regulates and ministerial consent is required for these civil legal acts. ${ }^{114}$ Based on this parallel to parent and subsidiary companies in the private sector, I would like to label public legal entity ZBOs as 'Subsidiary ZBOs'. This shorthand phrase distinguishes them from the 'Shelter ZBOs' which have no separate legal status on the one hand and the civil law ZBOs on the other, which I will discuss in the following sections.

Just as in the case of Shelter ZBOs, ministerial authority determines responsibility and accountability with respect to Subsidiary ZBOs. From an operations perspective the minister may in most cases have ex ante and / or ex post authority on budgets or other

110 BW2:24a and BW2:24b, BW2:405-406; EC Directive of 23 July 1990 90/435/EEC, and IPSAS 6; the word division would not be appropriate as it is not mentioned in relevant civil law.

111 I ignore the discussion on decision making relevance for consolidation of ZBOs in ministerial annual reports (De Kruijf, 2009)

112 The introduction of a corporate identity style for Dutch national government as of 2007 affects ministries and executive agencies but not ZBOs.

113 In the Netherlands Title 1 of Book 2 BW

${ }^{114}$ AW1996:1240.3; kZBO:32 
(financial) decisions, based on the responsibilities attributed to him by Parliament. When ex ante authority exists that goes beyond a general consent on the budget towards interventions in operational decisions with budgetary effects, one might come to the conclusion that the ZBO is in operational terms actually run as a hierarchical subordinate unit. If a minister does not have the power to intervene in operational decisions that have financial effects, the principle of budget authorisation and appropriation loses some of its power as the minister can be confronted with ex post financial claims. The position of Subsidiary ZBOs in civil law implies that the civil behaviour of the subsidiary ZBO will reflect on the assets of the entity. Lawsuits and damages will have to be funded from the assets of the entity rather than from the assets of the State as is the case with Shelter ZBOs. Lawsuits based on a decision as a public office are covered in Awb:8.73.1 and Awb:8.75.3. The latter article states that the court decides which entity is liable for compensation. However the ultimate effect of a lawsuit and the resulting damages to be paid may be similar to that of a Shelter ZBO.

BW2:19 specifies the cases in which a legal entity can be dissolved, including dissolution as a result of bankruptcy. This article is not applicable to public law legal entities (BW2:5). If a Shelter ZBO is technically bankrupt, the fact that the entity can only be dissolved by law also implies that an institution of last resort must exist which guarantees all liabilities of the Subsidiary ZBO. Due to the (national) public character of the Subsidiary ZBO, there can only be one institution that can act as the institution of last resort. Of course, that is the State as represented by the Minister-Principal who can be held accountable for the operations ${ }^{115}$ of that specific Subsidiary ZBO. This is another parallel to the parent-subsidiary construction in civil law, in which it is stipulated that a company ' $A$ ' that is fully accountable for the liabilities of another company ' $\mathrm{B}$ ' is regarded as the parent company of 'B' (BW2:24a.2). Under kZBO:32g, an optional provision is made that requires ministerial consent before the Subsidiary ZBO can file for bankruptcy or postponement of payments. Given the remarks made before, one can discuss whether kZBO:32g is relevant at all for PLAs; the sub-article is in my opinion only relevant in relation to kZBO:37 which stipulates that the provisions of kZBO:26-35 also apply to PLBs.

In some cases, Subsidiary ZBOs are allowed to execute tasks in a market setting (In 't Veld, 1995; Kickert, 1998; Meijerink, 2005). Like civil law entities that are basically operating for the market and are granted the privilege to execute a ZBO task, Subsidiary ZBOs can use a part of their skills and knowledge for market purposes as well. However, before they are allowed to exploit their skills in the free market, explicit consent by their political 'owner' might be required. An example of this form of hybridity is found at Kadaster where in 1996 a separate private legal entity Kadata was established to

115 One might argue that liabilities which are the result of issues in a particular program not part of the responsibility of the Minister-Principal, the claim might be politically transferred to the relevant minister responsible, given the specific responsibility for the program budget. 
perform commercial activities with respect to information provision (Deelen \& Eertink, 2004, p. 118-119). This was later discontinued.

The intermediate conclusion of the two previous sections is that there are two forms of public ZBOs. The essential difference between the Shelter ZBO and the Subsidiary ZBO from a civil law perspective is that the Shelter ZBO has no legal status and all consequences of civil acts immediately affect the State, whereas in the case of a Subsidiary ZBO the effect is primarily on the assets of the ZBO itself. Ministerial accountability for both types strongly depends on what is regulated in public law rather than in civil law. Creating a ZBO under public law implies increasing autonomy compared to the classic hierarchical structure of government. The financial impact of ex post claims on the two different types of PLAs is different. As a result, public legal status may be regarded as a separate autonomy indicator.

\subsubsection{Civil law entities}

Civil legal entities exist in three categories: a first group which is based on membership control (associations), a second group which is based on shareholder control (PLC and Ltd) and a third group in which control is attributed to specified people or entities by statutory agreements (foundations). The most commonly used form of civil law ZBO is the foundation, governed by statutory agreements. The remaining civil law ZBOs are in most cases shareholder governed and only very rarely is a membership governed ZBO used. Given the frequency of using foundations as ZBOs, I will start the analysis with this group rather than following the contents of the civil code.

\section{Legal entities.}

In the Netherlands, some 200,000 private law legal entities existed on January 1, 2006 (CBS, 2008; own calculations). Some 16\% of these legal entities were operating activities that are regarded as being public domain (government, health, education, culture). The majority of these entities use the foundation form (9\%); the rest are mainly organised as limited liability companies.

The foundation legal entity is widely used, both in the public domain and in the private domain. In the public domain organisations such as hospitals, housing 'associations' and school boards generally have the legal status of a foundation. In the private domain, charities and lobby groups use this form of organisation. Because there are no financial or membership requirements, there is hardly any threshold to establish a foundation. In the ZBO domain, 55 (clusters of) entities (total ZBO population 128 (clusters of) entities) are regarded as private law based entities. Of these 55, $32(58 \%)$ have the legal form of a foundation. 


\subsubsection{Foundations}

The first group of private entities is the group where control is attributed to specific people without issuing shares. In this group one form of legal entity exists, the foundation (Stichting). ${ }^{116}$ According to the civil code a foundation is "an entity that is created by a legal act without members and aims to achieve its statutory goals with a dedicated capital'. A foundation is not allowed to distribute income amongst board or founders, nor to anyone else unless these transfers have an idealistic or social purpose (BW2:285.3). The civil code does not specify the governance structure of a foundation; the only requirement is that procedures for appointing and dismissing members of the board are included in the statutes of the entity (BW2:286.4c). Ownership of foundations is not explicitly regulated as no shares exist and there are no members that may control the board. The main governance document of a foundation is the statute, in which regulations on the board are specified. The basic rule is that the board or trustees represent the foundation. However it is possible that a person who is not a trustee is a legal representative of the foundation (BW2:292.4), when this is included in the statute. In general this regulation aims at creating a non executive board whose members may be able to represent the entity to third parties (Schreuder, 1994, p. 215). The person(s) or entities - which can include government - that created the foundation also determined the statute and can therefore indirectly legally or economically influence board decisions. Therefore, the constituting parties of a foundation may be regarded as the "owners" of the foundation. ${ }^{117}$ As a result of BW2:285.3, there are no residual claimants on the equity of a foundation. In other words, there are no real owners of the entity either bearing the ultimate risk of bankruptcy of a foundation, nor for surpluses that may be accumulated by the foundation. Technically speaking, this means that a minister as representative of the State bears no financial risks when a foundation executing a ZBO task and established under some sort of government support fails. However, as in the case of a public legal entity in financial difficulties, a minister will consider, ideally after consulting Parliament, whether or not to continue supporting the foundation. The options will be similar to the case of a public legal entity ZBO, implying that he can either transfer tasks to another ZBO or financially support the foundation in difficulties.

The statute must include a goal or a procedure to distribute remaining assets in case of dissolution of the foundation. The lack of performance or efficiency incentives that are associated with residual claimants however may result in managerial behaviour that is similar to that of a regular ministerial unit (Kraan, 2006, p. 228) due to the absence of cost efficiency incentives and a tendency to improve labour conditions. In principle, once a foundation has been created, all powers are attributed to the board. Unless provisions have been made for external independent monitoring nobody can influence or dismiss a

116 The minister of Justice has developed a proposal for a change in BW2 to create a new form of legal entity 'maatschappelijke onderneming' which is very similar to foundations (Ministerie van Justitie, 2007, Parliament, 2009a). A similar form: Public interest company exists in the UK (Maltby, 2003)

117 This holds particularly when changes of statutes are to be approved by the founding fathers; if not, the foundation's board can be regarded as the 'owner'. 
board. This results on the one hand in an attractive form for a single purpose legal entity. On the other hand, it creates a governance gap when public objectives are to be achieved by a foundation.

Dalhuisen (2004, p. 25) has analysed foundations based on questions asked by Parliament (Parliament, 2003a) on either directly or indirectly creating foundations by ministers and their position in the public domain (ZBO or not). At the heart of this analysis is the way a foundation is established. Three forms are identified. First, the minister is the only party involved in establishing a foundation. This seems to be equivalent to Dijk and Van der Ploeg's (1997, p. 39) requirement for a government entity to establish it but it is not. Dijk and Van der Ploeg's definition also allows local governments to establish foundations and in theory an entity at arm's length of central government can also establish a foundation. When the minister is the only party involved in establishing a foundation, he has full control of the contents of the foundation's statutes. This form of establishing a foundation will be classified as 'government establishment'. The second option is that a minister, together with other public or private parties is involved in establishing the foundation. Such an option may be used for forms of co-operation between the minister and other parties. This form will be classified as "participatory establishment'. In both these cases the minister can at least partly be regarded as the owner of the foundation. In the third case, the minister will not be regarded as the owner of a foundation. When a minister takes action to have a foundation established, other legal entities are the actual founders of the specific entity and the minister is only facilitating the initiative of those other legal entities. Therefore, this form of establishment of a foundation will be classified as 'facilitating establishment'. Depending on the role a minister has had in establishing the foundation (government establishment, participatory establishment or facilitating establishment), the influence of a minister in controlling the foundation is expected to decline as his involvement in the contents of the statutes will decline. Thus a 'government established' foundation is expected to have less autonomy than a 'facilitating establishment' foundation. Of course, actual attribution or delegation of authority in individual cases is leading; but if Parliamentary and ministerial control are required, creating a government established foundation seems to be preferable over a form of facilitated establishment of a foundation. The model Dalhuisen uses is a more detailed version of Schreuder's criterion and was used by minFin in a report on foundations to Parliament (Parliament, 2005b). Because the key objective of this study is to focus on the control of operations and the risk associated with operations, I prefer to follow Dalhuisen's line of classifying foundations as a general indicator for autonomy.

Government entities often use the legal concept of the foundation to organise a specific public but not necessarily authoritative task. Literature suggests that in such cases, at least some provisions for political control are made. Political control can be realised either at the foundation creation stage or at the stage of foundation operations. Van der 
Burg (1986) introduced the concept of 'government foundation' to indicate the relevance of the concept in the public sector. There is no legal entity 'government foundation'; the concept refers to the influence government has on the legal entity foundation. Schroten (2000, p. 34-35) operationalises the definition of a government foundation by relating influence to the authority of a minister to appoint the majority of the (non) executive board, which is a more formal approach to influence. Given the legal requirement that appointment procedures must be included in the statute of the foundation and the fact that the constituting parties determine the contents of the statutes, this implies that the minister was involved in creating the foundation. The only other option would be that the statute of the foundation has been changed, but the civil code only allows a change in the statutes when this is explicitly included in the original statute (BW2:293). When the option of changing the statute of a foundation is included in the original statute, this may be a risk for a minister. Once the foundation has been created, it is up to the executive board to propose changes. Without forms of influence - actually some right of approval by a minister on these changes, the minister may lose control of the foundation. Foundations whose statutes do not include ex ante control tools for a minister thus have more autonomy than foundations for which control measures have been implemented.

Dijk and Van der Ploeg (1997, p. 39) choose a government foundation definition that overlaps with the Schroten's. Their definition consists of two parts: a government entity has established the foundation or the foundation has a role in performing a public task. The first part of the definition is close to Schroten's as one may assume that when a government entity establishes a foundation, it is likely - but not required - to include a role for the minister in the appointment of the board of the foundation. This part of Dijk and Van der Ploeg's definition is rather objective; the civil code requires that the foundation's constituting entities are registered (BW2:289). The second part of the definition is however ambiguous. One can disagree as to what exactly constitutes a public task. This is also a reason why Schroten did not choose this criterion (Schroten, 2000, p. 34). Schreuder (1994, p. 216) prefers a definition of government influence as 'controlling operations' rather than influence through creating the foundation or controlling the structure of the organisation. Influence can then be measured by including approval rights ${ }^{118}$ in the statute with respect to information, general instructions, budgets and annual reports (Schreuder, 1994, p. 243-245).

The use of foundations - as of now Foundation ZBOs - as a legal structure to which an authoritative public task has been assigned is an exception to the basic rule of establishing ZBOs within the framework of public law. It will for example be used when specific knowledge that is available in the private domain must be used (AW1996:124b; kZBO:3.2). Dalhuisen's study showed that of the 336 foundations he identified, 176 had a 'facilitating establishment' status, of which 18 also have ZBO status (Dalhuisen, 2004,

118 Determining rights are more far reaching than approval rights; determining includes changing of a proposal (Kummeling et al., 1999, p. 53). 
p. 119-129). There might have been historical reasons to use a foundation rather than a public law entity. For example, ZBOs operating in the domain of quality assurance in the agricultural industry were established as foundations without any government involvement long before the idea of ZBOs existed and will be subject to all aspects of kZBO (Parliament, 2008b). In more general terms, motives for creating private law legal entities include increased autonomy, creating a private law entity is faster than passing legislation and allows more co-operation with private parties (Ten Berge \& Zijlstra, 2000, p. 250). Each of these arguments can be contested, but the fact is that the instrument for creating private law entities such as foundations is still used.

Given the different forms of involvement in establishing foundations, it is likely that in a case where 'government creation' of the foundation occurs, it will be more likely that a minister will be actively involved in finding a solution if the foundation ZBO is in financial difficulties. As a result of that involvement, it will also be likely that the minister will monitor the operations of a 'government created' foundation more closely than a 'facilitated creation' of a foundation. This closer monitoring will in the end affect the autonomy of a foundation to which a ZBO task has been attributed.

\subsubsection{Corporations}

The second group of private entities is the group of corporations based on shareholder control. This group consists of two types of entities. The Naamloze Vennootschap (NV) is the Dutch equivalent of a PLC company. Shares in a NV are transferable without restriction and shareholders can neither be held accountable for the acts of the NV nor can they be required to compensate for losses of the NV (BW2:64.1). The Besloten Vennootschap (BV) is the Dutch equivalent of a limited (Ltd) company. Shares in a BV cannot be transferred freely and no stock certificates are issued (BW2:175.2). ${ }^{119}$ From a governance perspective, NVs and BVs are treated similarly. In both cases, the general assembly of shareholders has control with respect to appointment, remuneration and dismissal of the board of directors or executive board, unless this power is (partly) attributed to a non-executive board. The general shareholder assembly also appoints, remunerates and dismisses the non-executive board (BW2:142 and BW2:144). As a result of the role of the general assembly, strategy and control of a corporation are in the hands of the executive board as managerial unit. The owners - i.e. the shareholders can only express their views on an ex post basis by discharging or dismissing the board, based on the policies realised.

A minister has three options to attribute ZBO tasks to companies. First he can create a company on his own initiative. The classic form of this option is to use companies in which the State holds all shares - mostly former State Enterprises - to execute a specific ZBO task. A second option is to create a new company or to buy an existing company to which a ZBO task is attributed. Such a company may be fully government owned, as is the

119 I will only make references to relevant articles of the Civil Code with respect to the NV, unless substantial differences exist between NV and BV. 
case with TenneT, which was created by electricity producing companies as the electricity network manager. TenneT was sold to the State in 2001 (Parliament, 2006c, p. 35) and was attributed a part-time ZBO task. ${ }^{120}$ It may also be that the State jointly creates a new company with third parties and attributes ZBO-tasks to such a new company. An example of this was the former NV SCG ${ }^{121}$, which as of January 2005 has been merged with an executive agency. The last option is that government attributes a ZBO-task to a fully private company. This option may be used when the ZBO-task is related to other operations in a commercial branch such as is the case with certification institutions. This holds for CAK (Centraal Administratiekantoor B.V.), a limited liability company which is ultimately owned by health insurance companies. CAK is responsible for collecting user contributions for some care arrangements. I will label the shareholder controlled ZBOs as 'Enterprise ZBOs'.

The influence of the minister on the operations of a company which has been attributed ZBO tasks depends primarily on his influence on the entity's governance structure. The civil code specifies the scope for influence by those who own shares. In principle each share is attributed the same value and ownership rights. There are a number of options for changing the ownership rights based on the possession of shares. First, corporation statutes may include specific regulations on voting rights that may alter the balance of power between shareholders (BW2:92.1). Second, special rights attributed to specific forms of shares (BW2:92.3) may for example exist as "golden shares", which give veto power to the owner of that share (Sołtysiński, 2005, Parliament, 2006c). Third, registered shares may be issued which may not be sold without prior consent (BW2:86).

Another option for changing the relative position of shareholders is when the statute specifies specific requirements for executive board or non-executive board appointments. The most important instruments for changing the balance of power amongst members of a (non) executive board who are equal in principle are the attribution of additional voting rights to a specific member (BW2:140.4) and the possibility to specify requirements for appointing members (BW2:142.1).

In those cases where the minister has (jointly) created the company he has had the opportunity to influence governance structures by defining his position in the statute through one of the options mentioned above. In other cases he can buy influence by participating in a privately created company. However the official policy of the Minister of Finance until December 2007 was that the State will secure public interest by public policy instruments or concessions and contracts rather than private ownership by the State (Parliament, 2006c, p. 36). In December 2007, there was a slight change in policy, in which it is acknowledged that private ownership by the State might be complementary to concessions and regulations (Parliament, 2007g, p. 3). In both cases however, the

\footnotetext{
120 Income transfers and environmental quality assurance with respect to electricity production.

121 NV SCG [Dutch: Service Centrum Grond] was operating on funding and coordinating soil decontamination.
} 
option of buying influence is hence a rather theoretical one. When it is not possible or desirable to use civil law control instruments on companies, the State has the power to use public law instruments. The State can only attribute ZBO tasks to entities by issuing a (public) law. This law can not only specify the tasks attributed to the private entity but may also be used to specify the supervision and accountability requirements that may safeguard the appropriate use of public powers by a private entity.

An Enterprise ZBO is likely to incorporate public and market oriented tasks within one organisation. I use the term 'likely' to mean that the whole idea of using a shareholder company to perform a task suggests that the main operations of the entity are market oriented. An example of an Enterprise ZBO providing public tasks without any competition is the Dutch Central Bank DNB; the ZBO-status of notaries or health insurance companies includes competition on services, some of which have an authoritative character. Another clear example is the TenneT case where the ZBO task is only a relative small income transfer and quality assurance' activity related to TenneT's network management tasks. According to Zijlstra (1997, p. 232), only the fact that specialised knowledge is available in the entity allows a company to be used to execute a ZBO task. When a company is used to perform a public task, this requires additional assurances that the minister can be held accountable for the operations of the ZBO. Such assurances will be found in public law rather than in the statute of the entity.

\subsubsection{Membership based entities}

The most common membership private entities are associations (Vereniging). This form is defined as a legal entity with members and a specific objective (BW2:26). An association is not allowed to distribute profits amongst its members; hence the entity is a not-forprofit institution. The objective of an association can be material or immaterial, such as a sports association or an association of a specific group of professionals. Members of the association elect and dismiss the board. The exact governance rules are at the discretion of the members of the entity; the only requirement is that a general assembly is consulted and formal control is ultimately in the hands of the members of the entity. Two special forms of associations exist: one is the cooperative society, which aims at distributing material goods amongst its members; the other is the mutual insurance company that aims to organise a form of insurance (e.g. health, funeral etc.) for its members. As both the cooperative society and the mutual insurance company are association sub-groups, they are also not allowed to generate profits.

If a minister wants to use an association as the entity for attributing ZBO status, he has to consider carefully how he would like to influence the association operations. Without specific statutory measures, the minister has equal voting rights like any other member of the association. In order to obtain special rights under civil law, the minister has to convince the other members of the association that a special position is appropriate and can be granted. Such agreements are in theory most likely to be established when the minister is one of the founders of the association. 
The complexity resulting from the influence of the general assembly makes it unlikely that a minister will deliberately establish an association to which the status of ZBO is attributed. It is possible that a minister will use an association ${ }^{122}$ to perform a ZBO task in the context of a larger set of private tasks that are operated by the association. In that case, governance and control become more complex because the entity under scrutiny is a hybrid entity operating both market and public domain activities. ${ }^{123}$ I will label these ZBOs as Association ZBOs.

By now, I have discussed all forms of legal entities that exist under Dutch civil law. Table 6.1 gives a summary of these forms and the degree of autonomy that can be derived from their basic legal status. Three indicators are used to arrive at a conclusion on the autonomy of a ZBO under different types of legal entities. First, the degree of influence a minister (and Parliament) has on the statutes of a specific type of unit under the assumption that Parliament is willing to assign a ZBO task to a unit. Second, the influence the minister has ex ante on the level of operating costs the unit will charge for realising the assigned ZBO task. The third indicator refers to the effect overspending or a negative equity has on budget authorisation. The arguments only hold with respect to the general characteristics of the type of legal entity discussed. Actual influence and autonomy must be derived from the relevant case laws or statutes of the respective entity. It might very well be that in a particular case a private law entity has autonomy similar to that of a public law entity given for example budgetary controls on operations.

Table 6.1: Expected government influence and impact of financial risk for different types of legal entities

\begin{tabular}{|c|c|c|c|}
\hline & $\begin{array}{l}\text { Influence on } \\
\text { Statutes/ZBO- } \\
\text { case laws }\end{array}$ & $\begin{array}{l}\text { Ex ante budgetary } \\
\text { control on ZBO- } \\
\text { task }\end{array}$ & $\begin{array}{l}\text { Likeliness of budgetary claim in } \\
\text { case of overspending or negative } \\
\text { equity }\end{array}$ \\
\hline Ministry & $++/++\star)$ & $++/++$ & $++/++$ \\
\hline Executive Agency & $++/++$ & $++/++$ & $++/++$ \\
\hline Shelter ZBO & $++/++$ & $++/++$ & $++/++$ \\
\hline Subsidiary ZBO & $++/++$ & $++/++$ & $+/+$ \\
\hline \multicolumn{4}{|l|}{ Foundation ZBO } \\
\hline Government established & $+/+$ & $+/+$ & $+/-$ \\
\hline Participatory establishment & $+/+$ & $+/-$ & $-1-$ \\
\hline Facilitating Establishment & $+/-$ & $+/-$ & $--/--$ \\
\hline Fully Private Establishment & $--/--$ & $-/-$ & $--/--$ \\
\hline Enterprise ZBO & $-/-$ & $-/-$ & $--/--$ \\
\hline Association ZBO & $--/--$ & $--/--$ & $--/--$ \\
\hline
\end{tabular}

Up to now, I have discussed the formal aspects of organisational forms within Dutch civil law. The different types of organisational forms have different impacts on the autonomy of the entity towards the minister. Therefore, the legal status as such is only a general

\footnotetext{
122 An example is ANWB whose ZBO task is to issue navigation licences for recreational purposes.

123 I refer to Simon $(1989,2005)$ who concluded that using hybrids lead to underperformance in both public or private tasks.
} 
autonomy indicator. One can summarise that a Shelter ZBO has limited autonomy, whereas a Foundation ZBO has substantial autonomy, particularly when the statutes of the latter attribute only limited authority to the Minister-Principal.

\subsection{Commissioning of services}

Assigning a public task by law only provides the authority to deliver public services by an individual ZBO. The ZBO case law or statute cannot provide the specifications for annual production to be delivered because that would imply that the law has to be changed every year to determine the budget and the level of services to be provided. Thus other arrangements on commissioning services (see Part $A$ for a discussion on the use of commissioning) must exist to allow production by a ZBO, particularly when the minister is funding the services provided by the ZBO. When two separate legal entities are involved in commissioning and providing services, civil law governs the relationship between these two entities. The basic rule in civil law is that an agreement between two parties governs the commissioning and supply of goods and services. The supplying entity has the obligation to deliver the service, whereas the commissioner has the obligation to pay for the service. If one of the parties fails to deliver, the other party is entitled to claim compensation (BW6:58 and BW6:74). These general principles hold regardless of the type of goods or services to be delivered. In the case of providing services, the contract may have the form of what is called a Service Level Agreement [SLA]. Essentially a SLA is also a bilateral agreement between two parties, that can exist in a market setting (e.g. computer services; Jander (1999)) as well as in a public setting. From a civil law perspective, the legal position of a contract specifying the delivery of $x$ goods at $y$ price per unit is not different from a Service Level Agreement which stipulates what activities will be performed at what quality by the delivering entity. The specification in a SLA on prices charged and performance delivered can be negotiated similarly to a contract in which physical goods are to be supplied. The difference is that in the case of service provision, there will probably be more disputes on the compliance with the SLA. Problems with SLA compliance have a different character than traditional contracts, which is due to the problem of measurability and not because of the mere existence of the agreement.

The idea of SLAs has been copied by the public sector (e.g. Domberger, 1998, p. 13; Linker, 2006, p. 113) and is based on earlier ideas in economic theory such as contract management (e.g. Van Leerdam, 1999, p. 20; Pollitt \& Bouckaert, 2004, p. 84). These ideas can also be used for creating an internal market within the hierarchical structure of government (Van Oosteroom, 2002, p. 116) or to let the internal service provider compete with the market (Domberger, 1998, p. 13; Sclar, 2000, p. 65-66). In these cases, the economic measures for contracting prevail over the legal measures.

Linker illustrated (2006, p. 100) that contract management is also used in relations with ZBOs. As ZBOs are in general hierarchically independent, the contract relationship between minister and ZBO is at first glance similar to a regular civil law contract. The mutual authority based relationship between minister and ZBO reduces the contract 
relationship to a relationship that has elements of the idea of contract management in a hierarchical structure as well. To distinguish the contract relationship between minister and ZBO from conventional civil law contracts, I will refer to them as 'quasi contracts'.

Another relevant issue is that a minister can have two roles with respect to the ZBO. He can be the owner which means he has ownership-control responsibility towards the specific ZBO in his portfolio, including the authority to decide which services are to be delivered. Furthermore, he will be commissioner as far as he requires services under the quasi contract with the ZBO. A minister who has both roles is labelled here as a MinisterPrincipal, whereas a minister who merely has the commissioner role is indicated as 'minister'. Due to the authoritative powers attributed to a minister, it might be that the balance of power in the SLA is biased in favour of the commissioning entity. Should that be the case, one can argue that again the relative autonomy of the ZBO compared to other ZBOs with the same civil law legal status will be reduced.

When studying quasi contract ZBO relationships, three issues have to be addressed. First, who is commissioning. Second, how can the quasi contracts be characterised. Third, what are the consequences of a failure by one of the parties to comply with his obligations? Under civil law, commissioning is in principle a matter between two equivalent parties, voluntarily agreeing upon the delivery of services. The commissioning party requires some service and is willing to pay a certain amount of money. The contractor is at the same time obliged to deliver the service to the commissioner at the specified price. In a public sector setting, the voluntary character of the agreement may be discussed. Furthermore, commissioning and receiving the service to be delivered may not be in the same hands as the activities of a public sector unit and may be aimed at parties others than those who are commissioning and funding the activity.

The analysis presented here is mainly from a theoretical civil law perspective on the relationship between State and ZBO under the assumption of a bilateral contract. The relation between the two is however primarily based on public law and that is the environment in which most disputes will be settled. Specifically in those cases where the 'quasi contract' can be regarded as a unilaterally imposed set of performance specifications, one can study that relationship more conveniently from a principal-agent perspective than from a civil law perspective. I will discuss the (economic) principal-agent theory in detail in Part C. However an analysis from a civil law perspective assuming two equal parties is still useful as it shows that the roles of commissioning and supply of services may have different effects on parties involved in the commissioning relationship. Furthermore, the concept of 'principal' may not be applicable to the role of the State, particularly when a citizen is applying and paying for the service delivered by a ZBO. 
A ZBO has been assigned a task by law. ${ }^{124}$ This suggests that supply must be realised by the ZBO under the framework of the law. The commissioner of a specific service to be delivered by a ZBO cannot be identified immediately. One can argue that the State is commissioning for specific services as there is a relation between the law as defined by the legislature and the service that has to be delivered by the ZBO. In this section I assume that the executive - i.e. the minister - is the proper authority to commission a task.

Analytically it is possible to identify three different relationships regarding commissioning and supply of ZBO services. The first relationship to be identified is that the State commissions and is the final user of the service. Such a position exists for example in those cases where monitoring activities are performed by a ZBO on behalf of the State. In this case, there is a single relation between commissioner and supplier as only two parties are involved in the production and delivery of the service which completes the quasi contract. There will be a financial transaction between the State and the ZBO related to the delivery of the services. The second possible relationship is that the State commissions a task from a ZBO, funds the task but actual demand is exercised by a third party: a citizen or a legal entity. From a civil law perspective, there will still be a quasi contractual relation between State and ZBO. This quasi contractual relation is however similar to the conditional contract of BW6:21 and has the character of a suspending condition. Delivery of the service is suspended until a specific condition is met. In most cases the condition will be that someone applies for the ZBO service. The financial transaction will remain within the State-ZBO relationship. If an applicant for a service does not qualify for that service, there is no civil law obligation for the commissioner to require the service to be delivered. Depending on the quasi contract specifications, there might be a quasi contractual obligation for the commissioner to pay for the activities that have led to the refusal to deliver the service that was applied for. The third relation is the one in which the State has authorised the ZBO to deliver a specific service but funding originates from the individual that requests the service. In this case two different quasi contract relationships exist. The first one regards the demand from an individual who is paying for the service. This relationship resembles a traditional civil law contract relation. The second - 'quasi contract' - relationship is the one in which the State specifies the quality of the service to be delivered given the authority attributed to the ZBO. This relationship has quasi contract characteristic because it only determines the services that can be delivered by the ZBO. In Figure 6.2, an overview is given of the forms of commissioning relationships that may exist in public service delivery. The case of the 'free market' contracting model is illustrated for the sake of completeness. It should also be noted here, that although the model uses the concept 'citizen' this should be interpreted as both individual citizens and private legal entities

124 In exceptional cases like CAK, the ZBO-task seems to be based on a mandate given by other ZBOs, only recently formalised by law (Parliament, 2008f, p. 14). 
that apply for a certain service from a ZBO. An example of this is a real estate broker asking for information from Kadaster on a specific real estate object.

\begin{tabular}{|c|c|c|c|c|c|}
\hline & \multicolumn{5}{|c|}{ LEADING PARTY IN EACH STAGE OF CONTRACTING } \\
\hline \multirow{5}{*}{ 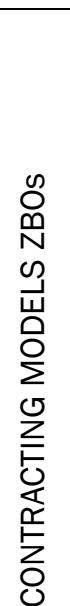 } & & $\begin{array}{l}\text { DEFINING } \\
\text { PRODUCT } \\
\text { SPECIFICATIONS }\end{array}$ & COMMISSIONING & FUNDING & FINAL USER \\
\hline & FULL STATE & $\begin{array}{l}\text { MINISTER- } \\
\text { principal }\end{array}$ & MINISTER & MINISTER & MINISTER \\
\hline & CITIZENS'S REQUEST & $\begin{array}{l}\text { MINISTER- } \\
\text { principal }\end{array}$ & MINISTER & MINISTER & CITIZEN \\
\hline & CITIZEN'S DEMAND & $\begin{array}{l}\text { MINISTER- } \\
\text { principal }\end{array}$ & CITIZEN & CITIZEN & CITIZEN \\
\hline & FREE MARKET & CITIZEN & CITIZEN & CITIZEN & CITIZEN \\
\hline
\end{tabular}

Figure 6.2: Contracting models and distribution of prime responsibility.

In addition to the analysis of the parties involved in the quasi contract relationship, it is also possible to study what the consequences of a breach of the "contractual relationship" between different parties may be. The analysis discussed below is theoretical; I did not find any ZBO cases which have led to an actual intervention from the judicial system. ${ }^{125} \mathrm{~A}$ breach of contract in terms of civil law requires that two legal entities (persons) must be involved. This means that in the quasi contract relationship between a Shelter ZBO and the State no civil law violation can exist, due to the fact that a Shelter ZBO is part of the legal entity State; hence there is only one legal entity involved. If claims or sanctions of whatever kind have to be applied, this must be based on public law as civil law has no instruments available. In all other cases, a different conclusion will result. The remaining types of ZBOs can be divided into public law based Subsidiary ZBOs and civil law types - Enterprise, Foundation and Association ZBOs. Despite its separate legal status the category of Subsidiary ZBOs has a direct relationship to the State. In such cases, a breach of quasi contract may occur, but it is very likely - given the specific relationship between the two entities - that a dispute will be settled without intervention from the judicial system. Civil law ZBOs may settle disputes in court. However, whether this will happen or not will depend on the contents of the specific statute of the entity and the actual governing influence of the State upon the entity. Given the characteristics of the three groups of civil law ZBOs it seems that it is more likely that civil law claims may result in the event of a breach of quasi contract between State and Enterprise ZBO than with a government established Foundation ZBO. The case of civil law ZBOs also includes the possibility that a real breach of contract may occur. That would occur if government

125 In the USZO case, discussion on quality of services was related to possible annulment of contracts (Parliament, 1997c, p. 1723). 
decided that a specific civil law ZBO was to lose its contract to perform the authoritative task assigned to it (Parliament, 1997c). Possible intervention by the judicial system is therefore also an indication of the relative autonomy of a specific ZBO.

Whatever the reason for a breach of contract, there may be an effect - due to the compensation to be paid - on the budgets that have to be made available to (dis)continue a task assigned to a ZBO. ${ }^{126}$ From this perspective the Parliamentary control functions of the legislature are at stake and the Minister-principal can be held accountable for his acts with respect to the ZBO. This section has argued that the effects of a breach of contract may differ. In some cases citizens may be involved, in others there is only an internal government dispute and in a third category a dispute on performance and contracts may lead to explicit financial claims.

The differences between commissioning and final user are an indicator of the degree of Parliamentary (budgetary) control (and as a result the relative autonomy of an entity) which government has in the contract relationship with a specific ZBO. One may assume that if a citizen is the final user and direct funder 127 of the service delivered by the ZBO, the degree of (budgetary) control for minister and thus Parliament is different from the case in which government is both commissioner and final user. It is thus relevant to assess who is actually commissioning the service to be delivered. The analysis given above also reveals who is in what case entitled to claim compliance with a "contractual relationship'.

\subsection{Some special issues on governance}

At the end of the discussion on the civil law legal setting in which ZBOs operate, some attention is given to three special issues that can affect relative autonomy of ZBOs and the process of Parliamentary controls on ZBOs. These three items are property rights, (financial) claims for compensation as a result of a ZBO's activities and governance structures other than traditional hierarchical relationships.

\subsubsection{Property rights and effect on control}

Ownership is described as the most encompassing right a (legal) person may have (BW5:1.1). The owner has full control over a specific property item to the exclusion of anyone else, at least as long as this control does not conflict with the law.

Private and public legal entities share one important characteristic: they are regarded as equal to a natural person with respect to property legislation issues unless a specific law states otherwise (BW2:5). This means that a legal entity controls all assets of the entity and can use, sale, mortgage or pawn them whenever and however the entity likes if no restrictions are set in case law or statutes. Controlling the assets of an entity implies that one can decide to transfer assets to another entity but also that assets are being

\footnotetext{
${ }^{126}$ As of 2010, a law on paying penalties in case of untimely decision making may affect a ZBO's financial position.

127 Because the citizens directly pays fees for the service delivered.
} 
sold and thus effectively reducing the production capacity of the organisation. Sale of assets by a public legal entity would have the same effect and as a result, the public task that was assigned to the entity can no longer be (fully) realised. Without additional specific regulations, this would mean that a minister is not able to control a public legal entity. The restrictions imposed upon a (public) legal entity on controlling assets will determine the remaining degrees of management freedom on operational and strategic decisions. Conversely, purchasing new assets may affect the full cost price of a service and thus indirectly affect the required budget level. This means that ex ante control of investments is in line with Parliament's right of budget authorisation.

The property right rule seems to be unambiguous, but it is not, as there are options to attribute partial rights to property which may change the position of the original owner in relation to those who own the partial rights to a specific item of property.

Huijgen (1995) has written on the distinction between legal ownership and economic ownership. While in the case of legal ownership, full control on property exists as it is meant in BW5:1.1, economic ownership implies a division of a property right amongst more than one owner. In his definition (Huijgen, 1995, p. 12), economic ownership exists when a separation between control and interest with respect to specific goods occurs, based on a binding legal contract and where all positive and negative benefits with respect to the interest in the good will have an impact on the assets of the economic owner. Economic ownership was originally a concept used for fiscal motives, but it can also be used to conceal actual control of goods (Huijgen, 1995, p. 72-73). When economic and legal ownership are to be separated, a contract based on civil law has to describe the exact relationship of the economic and legal owner towards each other to prevent future disputes on the control of the specific asset attributed to each party. A separation of ownership may be realised for tangible assets such as real estate - for example a partial sale of the user right for an office block - but it may also be used to attribute specific rights to shares in an entity. A model often used in the Netherlands was that of creating an entity that has the legal ownership of shares as part of a take-over protection scheme. This entity may issue certificates of shares to the free market, which bear all economic benefits and risks. The legal owner however still has the voting rights attached to the original shares and has control on the entity. Selling the voting rights would lead to a transfer of control of the entity. An example of this was found at Grolsch NV - a listed brewery - before it was sold to SAB-Miller in 2008.

From the perspective of ministerial responsibility and accountability, allowing entities to have full control of their assets may lead to opportunities to transfer control (partially) - such as voting rights or financing assets by a mortgage - to other entities, leaving a minister with political or financial risks without appropriate tools to at least reduce operational risks. Therefore, it seems to be appropriate that a minister has to give final consent for major decisions which affect control based on civil law within organisations. In public law, particularly in 'Aanwijzingen', some regulations are included that can affect 
the autonomy of legal entities on property decisions. These regulations are: a) the requirement to approve fees (AW1996:124.I.3), b) consent on the budget (AW1996:124.I.4) and c) the option to give ex ante consent to private law based decisions (AW1996:124.03). 128

The topic is also covered in $\mathrm{kZBO}: 32$, and is here explicitly extended to all ZBOs with a separate legal status. The provision in $\mathrm{kZBO}$ is also optional; the minister has the right to include the rule in ZBO case law, but is not required to do so. For private law based ZBOs, the option only holds when the ZBO exclusively performs public tasks and is not a hybrid entity (kZBO:37). Finally, I note here that in the economic literature the issue of property control is referred to as 'property rights theory'. The economic perspective will be discussed in Part $\mathrm{C}$.

The conclusion of this subsection is that a separate legal entity holds all rights on the assets of the entity. From a budgetary perspective, ex ante control on investments can prevent unexpected rises in fees in the future. Ex ante control on transfer of (partial) property rights prevents financial losses or risks arising for the minister controlling the ZBO. Both AW1996 and kZBO include some measures for ex ante control on property, although some of these control tools are merely optional.

\subsubsection{Third party liabilities and effect on control}

If an act of government results in damages for individuals, the individual has a possibility to claim compensation from government (Schueler, 1997, p. 710-720). Because ZBOs are not part of core central government and some of them are even private law entities, it is useful to elaborate on the possibility and impact of claims for compensation as a result of an act of a ZBO.

The general rule in the event of unlawful behaviour by an entity is that the entity will be required to pay third party damages that are the result of the unlawful act (BW6:162). In a strictly civil setting, third party liability will be imposed upon the legal owner. If legal and economic ownership are separated, the legal owner can claim upon the economic owner when third party liability is caused by an act of the economic owner. In a holding company and fully owned subsidiary structure, third party liability may be transferred to the holding company in those cases where it is clear that the holding company gave an instruction for the behaviour that has led to the third party liability (De Kluiver, 1998, p. 91). Although for foundations no formal ownership relationship exists, De Kluiver states that based on BW 2:291 - "the board governs except in case of restrictions included in the statute' - an entity or person that has given instructions to the foundation can be held liable for damages towards third parties. De Kluiver concludes that the civil code regulations on unlawful acts and third party liability may be also applied to all entities that are controlled by government (De Kluiver, 1998, p. 99).

${ }^{128}$ And in Awb with respect to subsidising organisations. 
For those entities controlled by government that have public authority, there is also a public law regulation which implies that whatever the legal form an entity has, unlawful acts may lead to payment of damages. Peters as well as Maeijer state that private law entities providing a government service must in general - due to BW3:14 - comply with the principles of good government as stated in Awb:3.1 (Peters, 1992, p. 981; Maeijer, 1997, p. 10). ${ }^{129}$ Article $8: 73 \mathrm{AWb}$ states that the administrative court can name the entity that will have to pay for third party liability. De Kluiver (1998, p. 88-89) indicates that this section of $\mathrm{AWb}$ primarily aims at those cases where administrative decisions are made in units that do not have separate legal status. However, according to him, it may also be applied to units that do have separate legal status, especially in those cases where budgets or net assets are insufficient to pay the damages. In that case the legal entity that controls or funds the entity in question might very well be ordered to pay the compensation.

Maeijer reviews the history of CW which until CW1976 included an article (CW1927:89a) which if a private law entity was created, required a provision on government liability to be included in the law constituting the new private law legal entity (Maeijer, 1997, p. 21). This article was deleted in the new CW1976, as it would only be relevant if government accepted liability (Parliament, 1963, p. 37). According to Maeijer, this argument is incorrect; as far as government controls a private law entity, liability will ultimately be transferred to government (Maeijer, 1997, p. 22). Based on Maeijer's arguments on liability for private law entities which are controlled by a public office, it seems likely that the relevant public office - the minister - will be held liable. The case of a private law entity controlled by a public office is in my opinion different from the case of a relationship between two public offices at different independent levels of government as mentioned by Ten Berge \& Zijlstra (2000, p.51). They refer to a case between national government and local government in which it was ruled that the State has no liability for the acts of local government, even in the case of co-government.130 The essential difference is that co-government does not include a control relation as is the case in a private law entity providing services ultimately controlled by the State.

Applied to ZBOs this means that along the lines of civil law, third party liabilities may influence the position of a minister when it is clear that ministerial instructions have led to the unlawful behaviour. Along the lines of public law, the administrative court may order the minister to pay compensation. In the end such a compensation payment affects the financial position of the State and thus has an effect on the right of budget appropriation by Parliament. Although the minister is not responsible for the unlawful act, he can be held accountable. Depending on the remaining authority of the minister

129 Maeijer refers to Stichting Silicose Oud-Mijnwerkers, a private law entity in which despite direct control by a minister on operations, the approval of the program plan by the minister implied that a public task was realised.

130 Co-government is a form of cooperation between central and local government: central government sets the legal framework and generally funds activities, local government has some delegated authority and is responsible for actual implementation of a program. 
(Scheltema Committee, 1993, p. 11), he may directly intervene to mitigate the effects of the claim or intervene indirectly to prevent claims in the future. In either case, accountability will then refer to the actions the minister has initiated and not the claim itself. Although this conclusion is an indication of relative autonomy, it will not be included in the assessment of relative autonomy of ZBOs. There are two reasons not to consider this issue. First, when a ZBO is government funded, it is very likely that in the end the budget appropriated by the minister will be affected by claims. This means that the indication 'government funding' also covers risks of third party liabilities. Secondly, the powers attributed to a minister to intervene are included in the ZBO case law or ZBO statute. The unlawful behaviour can thus be reduced to the authority attributed to the minister and thus to his (lack of) responsibility (Heuvelhof, Ringeling, Van Sluis \& Van Thiel, 2001, p. 51-53). That again is also an indicator of relative autonomy that has been recognised as relevant for assessing relative autonomy before. As a result, there are two indicators available that cover the problem of third party compensation in relation to relative ZBO autonomy.

\subsubsection{Horizontal and diagonal governance structures.}

So far, the relevant factors in the governance structure between minister and ZBO have been discussed. Although the minister and Parliament are important stakeholders when studying the governance structure of ZBOs, other parties may also be stakeholders. Ultimately establishment of ZBOs is nothing more than an organisational form to provide government services to third parties. When other stakeholders are particularly relevant, the legislature has two solutions to include these stakeholders in the ZBO decision making or monitoring processes. First, there is the possibility of incorporating these other stakeholders into the board of the ZBO. This has been formalised in AW1996:124b.2 and kZBO:3.1. In that case they actively participate in governing the ZBO. I will focus here on the other solution which may be regarded as a substitute for formal democratic control: creating a participatory structure in which no authority on operations is given to stakeholders. Stakeholders are attributed a right to actively monitor and comment on the (quality of) operations of the ZBO. Minderman (2000:173) refers to Meijerink, who claims that it is possible that citizens claim more influence on the use of resources by autonomised entities. In a more general context, several authors suggest that forms of horizontal or diagonal governance structures may replace or be additional to the traditional vertical governance structures (e.g. Newman, 2003, p. 210, Schillemans \& Bovens, 2004, p. 29; Goddard \& Manion, 2004; Blomgren Bingham, Nabatchi \& O'Leary, 2005; OECD, 2005, p. 85). When a minister or Parliament wants such other forms of governance structures to be used, this implies that arrangements must be made. Like all other measures with respect to governance structure, such measures are to be included in the law. For the purpose of this study, this means that commonly used horizontal or diagonal governance structures must be listed as far as they are not already listed as options in the laws and instructions mentioned above. 
Schillemans and Bovens (2004, p. 29) identify horizontal accountability relationships by which they mean those relationships where entities negotiate on the basis of equality rather than from a traditional hierarchical structure between the entities. Schillemans and Bovens also indicate that along with a vertical and horizontal accountability relationship, there may be a diagonal accountability relationship. In a diagonal accountability relationship, the entity under scrutiny is not monitored by either the minister as principal or the parties that have an interest in the entity, but by a third impartial party who reports to the stakeholders. From the perspective of this study, in which the minister must be able to be held accountable by Parliament, it is not the contents of these horizontal and diagonal accountability relationships that are relevant. The minister has to allow or even stimulate or formalise the existence of such horizontal and diagonal accountability structures and can be held accountable by Parliament with respect to his responses on the findings of parties involved in horizontal or diagonal accountability. When the minister responsible for a ZBO includes forms of horizontal or diagonal accountability structures within the statute or law establishing the ZBO, this is an indication that the minister intends to give the entity more autonomy than an entity that ceteris paribus does not have horizontal or diagonal accountability structures. In this context, Trappenburg, Schillemans and Van de Bovenkamp (2009, p. 195) note that with respect to ZBOs, board members indicate that forms of horizontal accountability can contribute to legitimising the organisation as well as to possibly improving the organisation.

In their study on horizontal accountability of ZBO's, Schillemans and Bovens (2004) list four groups of institutionalised structures that may be used to improve horizontal accountability. Forms of institutionalisation can be a non-executive board, customerpanels and the like, structured reviews and assessments and an Ombudsman function (Schillemans, 2005, p. 29). Besides these formalised structures, ZBO's may have set up several other forms of dialogue with stakeholders, which are classified as unstructured by Schillemans. Amongst these unstructured forms are actively publishing information such as annual reports, benchmark reports and the like and internally organised stakeholder dialogue in advisory boards of any kind. I have mentioned before that kZBO does not refer to the use of non-executive boards. In AW2008, the explanatory notes do mention the possibility of using a non-executive board (AW2008:124f). The Gerritsen Committee (2008, p. 24) stated that it does not actively support the use of non-executive boards because they may interfere with ministerial or managerial responsibilities. AW2008:124f stipulates that if the ZBO governance structure consists of more elements than just an executive board this structure should be included in the ZBO case law. If so, the responsibilities of the different governance structure elements have to be specified. When not included in the law consulting or advisory boards may be created on the initiative of ZBOs themselves. If so, they have no formal legal status.

Bouckaert and Van Dooren (2003, p. 134) use another typology to indicate accountability relations, specifically with respect to performance indicators. This typology 
aims more at all accountability relationships from within the organisation upward to the ultimate political accountability towards citizens. Bouckaert and Van Dooren note that the accountability relationship from government to citizens has been unilateral in most cases. According to them an accountability relationship may be more effective when citizens are involved in defining for example performance indicators. At this point they implicitly make a link between the horizontal forms of accountability without further elaboration.

For the purpose of this study in which the accountability relationship between minister and Parliament based on budget authorisation is the core issue, horizontal forms of accountability may be relevant when they are institutionalised. Parliament may transfer part of its accountability relationship to third (delegated) parties under the assumption that operations and operational monitoring and control may be better served at a lower institutional level. If so, the remaining political responsibility will be the minimal system responsibility for the framework in which a ZBO operates. The question remains whether a horizontal accountability relationship can replace the traditional vertical relation, especially when central government is commissioning tasks from ZBOs where demand actually originates from within the ministry's structure rather than directly from citizens. In other words: horizontal accountability might be a (partial) substitute for vertical accountability relationships in those cases where citizens can actually influence production from the ZBO involved. This will generally be the case when the ZBO performs a task that can be qualified as an individual service to an individual citizen who has to pay for that service. In many cases, such a relationship will not exist and then horizontal accountability may be useful as an instrument to report on the quality of ZBO operations to the minister. The minister will then have to take responsibility and act upon the findings. By then there is again a vertical accountability relationship between ZBO, minister and Parliament. In its review on their RWT-project, the NCA stresses that vertical accountability remains an important issue. The NCA emphasises the relevance of ministerial system responsibility which is not fully accounted for. Furthermore, the level of information provided to Parliament based on management by exception reports can still be improved and there is insufficient information to Parliament on fee funded RWTs (Parliament, 2009b, p. 8-9).

The NCA emphasised the relevance of vertical accountability. In his thesis, Schillemans concluded that the impact of horizontal accountability is rather limited (Schillemans, 2007, p. 268-269) and that his findings are in line with other studies. He notes that as a relatively light form of accountability horizontal accountability can be executed at low cost. It can provide useful information for other stakeholders (ibid., p. 270). In this respect, he explicitly refers to the visitation procedures of 'Handvestgroep'; a group of ZBOs and executive agencies which assess each other's performance and disclose results publicly.

The conclusion of this section on vertical and horizontal accountability relationships is that horizontal accountability relationships can only work on condition that individually 
paid services are delivered. Then they can replace vertical relations from a budget authorisation perspective. In other cases, it will at best be an additional tool generating input for a minister to act on his responsibilities.

In this section, three issues were addressed. First, from a perspective of (legal) property rights, ex ante approval of asset related transactions of ZBOs is relevant to prevent the ZBO 'escaping' the governance structure. Second, both civil law and public law have provisions that may result in claims towards a minister in the event of unlawful behaviour of a ZBO. I will ignore that issue because it is strongly associated to other indicators for ZBO relative autonomy. Finally, it is possible to use forms other than traditional vertical accountability. In the case of institutionalised horizontal accountability this may especially have an effect on relative autonomy of ZBOs.

\subsection{Conclusion: the variety in legal entities and autonomy.}

In this chapter I have discussed several forms of legal entities that may be used to carry out ZBO tasks and the way a minister can control the operations of these entities from a civil law perspective. National level public legal entities are either part of the legal entity State or have separate legal entity status. A ZBO that is part of the legal entity State has no formal status and is - from the perspective of civil law - equal to any other unit of the State such as a ministry. This means that the State is owner and liable for the acts of the unit. I have labelled these ZBO's as 'Shelter ZBOs'. The second option is a public law ZBO, which are labelled as 'Subsidiary ZBOs'. Such an entity is created by a specific public law - ZBO case law - in which the minister has the opportunity to specify responsibility and accountability relationships between the Subsidiary ZBO and himself.

Civil law ZBOs may exist in three forms. The largest number of civil law ZBOs are foundations (Foundation ZBOs). The extent to which a minister can influence operations of the entity depends on the exact regulations in the statute of the Foundation ZBO which are influenced by the type and number of parties that were involved in its establishment. With respect to Enterprise ZBOs, powers are similar to those for foundations as long as a Minister-Principal holds a relevant portion of the shares or can make provisions in legislation - or at the start of a company - in the statutes. With respect to the last group, Association ZBOs, the governance structure does not allow for a privileged position by a minister. Only in cases where the minister was involved in creating an Enterprise ZBO can he influence the statutes and create a position in which he has more direct influence than might be expected from his share in the Enterprise. It should be noted however, that Association ZBOs and Enterprise ZBOs are relatively rare. Furthermore, government policy with respect to Enterprise ZBOs no longer allows a special position (e.g. golden share, Parliament, 2006c, p. 38).

Secondly, relative autonomy is influenced by the quasi contract relationship that exists between ministers and ZBOs. I have identified four different quasi contract relationships, from full state commissioning, funding and using services to a full free 
market model in which government no longer intervenes, implying a declining influence of the minister (on behalf of Parliament) as attributor of a ZBO task.

Finally, the Civil Code does not specify regulations for public law entities except for use of assets and liabilities. The civil acts of a Subsidiary ZBO will affect the assets of the entity immediately. A minister who has not intervened ex ante on this control of assets has not reduced the autonomy of the Subsidiary ZBO. In the end the budgetary effects of that choice may have a negative impact on Parliament's authorisation functions. In terms of responsibility however, the minister can only be held accountable for not regulating asset control, rather than for the behaviour of management.

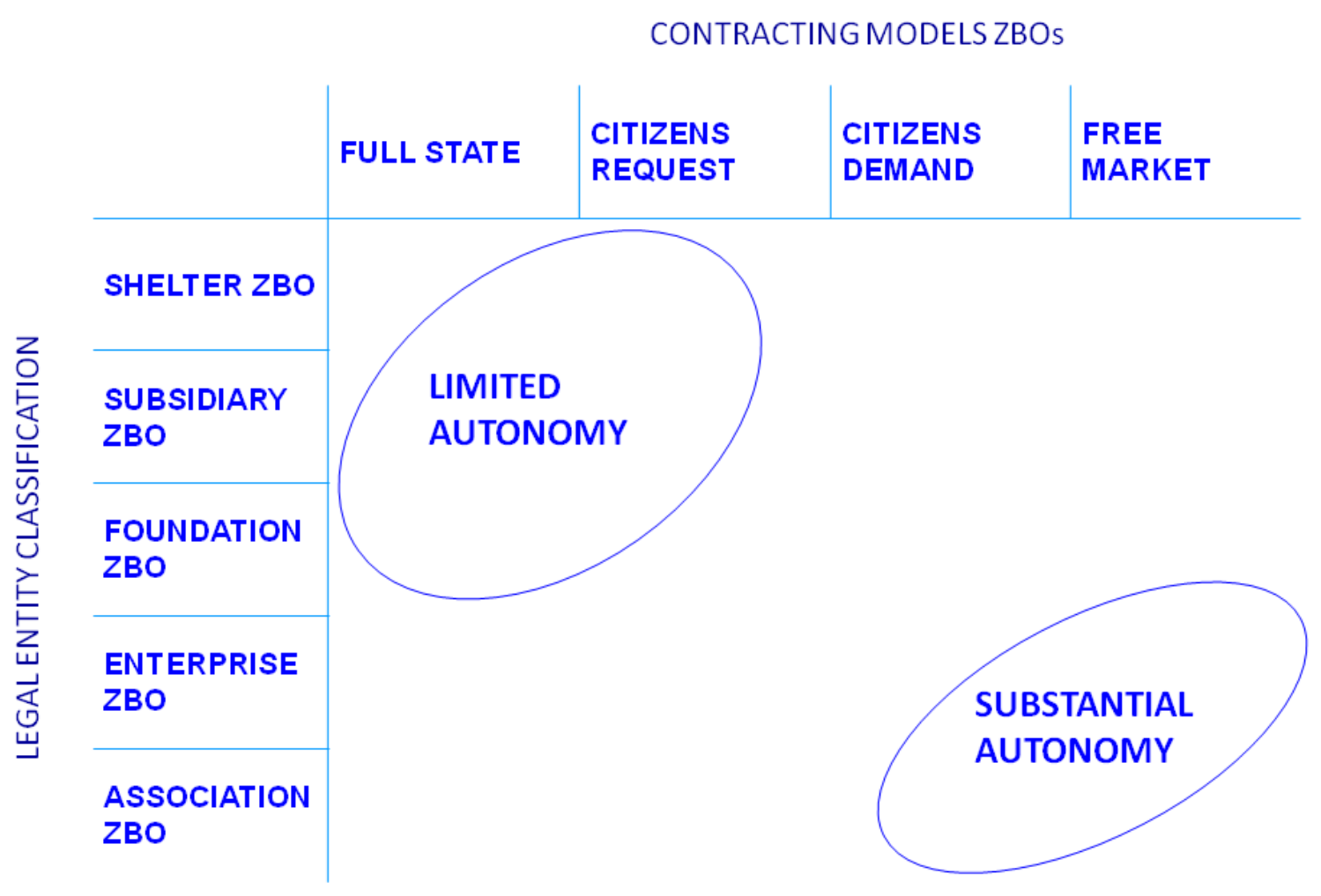

Figure 6.3: Legal forms of ZBOs, contract relations and expected autonomy

Based on the relative autonomy that can be derived from the basic legal status of the ZBO and the main characteristics of commissioning services, Figure 6.3 provides an overview of the level of ZBO autonomy in a civil law context. This classification is only an indication, specifically for ZBOs having a public legal status as well as for Foundation ZBOs. Under public law, additional measures may exist that do affect the relative autonomy of one or another ZBO. 


\section{The effect of legal control tools on ZBO autonomy}

In this part, I have focused on relative autonomy indicators from a legal perspective. The concept of autonomy is not explicitly used in Dutch legislation. Autonomy is included in the concepts of delegation, attribution and mandate (Awb, chapter 10). Mandates only cover decision making on behalf of a public office; the other two imply a separate authority to decide, given a legal framework. As the concepts are very general, further implementation is delegated and attributed authority has to be realised. This is done by evaluating the general legal framework on ZBOs, at this stage only on a general level. This part of the study focuses on identifying autonomy indicators and the impact including or excluding a particular authority issue has on autonomy of operations. Therefore, I shall only focus on autonomy indicators derived from the existing general legal framework and not consider case laws. ZBO case law will be discussed in Part D and by then $a$ relationship to the discussion in Part $\mathrm{B}$ can be made.

The research question in this part of the study was:

\section{Which autonomy indicators can be derived from legal theory and how do they match control of ZBO operations?}

Key issues in the legal framework are ministerial responsibility and the controls for Parliament to decide upon distribution of authority for ZBO case laws and budget authorisation. I recall that the concept of ministerial responsibility with respect to entities outside the hierarchical structure of a ministry includes three elements: a.) responsibility for authority attributed to the minister, b.) system responsibility which means that the minister is supposed to monitor and intervene when the setting in which a public task is to be performed does not achieve the desired output or outcome and c.) his individual acts towards an entity outside the hierarchical structure. From the perspective of ZBO autonomy, the first two responsibilities are the most relevant.

The legislation that is relevant for control of ZBOs' operations mainly consists of three groups of legislation: a) budgeting and accounting (CW); b) public law framework legislation on ZBOs (AW1996, AW2008 and kZBO) as well as the relevant ZBO case laws. Finally, c) civil law is discussed particularly with respect to legal entities and contract relations. These three main themes are addressed here.

I note that most parts of general administrative law (Awb) regard processes on programs but some elements also concern ZBO operations. When studying control of a ZBO as an organisation, they are of minor relevance as most Awb regulations regard ZBOs as a public office in their relation to individual citizens.

Parliament's influence on ZBO operations is performed during the process of creating a ZBO and the corresponding attribution or delegation of authority as well as by the ex ante control tools laid down in the ZBO budgeting procedures. From a budgeting perspective, 
constitutional arrangements imply that budgets authorised by Parliament have no external effect and that only the spending levels as included in the budget law have a binding legal status between Parliament and Minister. Thus, Parliament can only indirectly influence spending levels within a ZBO. In ministry budget documents, the level of aggregation of ZBO budgets varies from full disclosure of grand total budgets in a separate budget section to no disclosure at all. From a budgeting perspective, the full disclosure option would be preferable although Parliament has - at least theoretically the power to set spending limits by separating out a ZBO budget for the minister. The effect of the aggregation level on the autonomy of a ZBO is relatively low because Dutch budget laws no longer distinguish separate budgets for groups of operating costs. That does not however exclude the possibility that at the lower level of distributing funds from minister to ZBO specific groups of operating costs may be earmarked. If earmarking is carried out, that would in practice have a negative effect on autonomy, at least compared to cases without earmarked budgets.

Second, in CW2001 and its predecessors very little attention is given to ZBOs. What has been regulated is that the establishment of civil law ZBOs has to be proposed to Parliament and if Parliament requests it, a law has to be passed to implement establishment of the entity. Public law ZBOs (PLAs) are created and dissolved under the regular legislative framework for adopting legislation. Two other issues are regulated under CW2001. One is the specification of the non-financial information required in ministry budget documents which has no effect on autonomy. The other is the possibility that a ZBO has to pool its treasury function within the treasury function of the Ministry of Finance. When a ZBO is obliged to pool its treasury function that is an indication that the (relative) autonomy of the entity is lower than for those cases where a ZBO does not have this obligation. The treasury pooling itself affects the freedom to use financial assets but in principle does not immediately affect ZBO operations, which indicates that the effect on operational autonomy will be low.

Third, two financial elements affecting budget authorisation and appropriation might be covered in ZBO case law and also affect autonomy. First, when the budget of a ZBO is based on fees rather than appropriation by the minister, tax law theory suggests that criteria should be set for calculating such fees. If not, this means that the ZBO has more autonomy in their funding than if strict regulation existed. Secondly, the (accumulated) difference between budgeted and actual financial result leads to equity on the ZBO's balance sheet. When no provisions have been stipulated, the equity is at the free disposal of ZBO management rather than at the disposal of Parliament for possible reallocation. I note that this is not a normative statement, merely an indicator for relative autonomy given to the ZBO's management.

A final remark is that from the literature I concluded that from an authorisation perspective, ZBO budgets and investments levels can best be based on an expenditure based budgeting system. This does not imply that the ZBO itself must also use an expenditure based system; if the entity has to ensure its continuity, then an accruals 
based budgeting and accounting system will be required. Two issues with respect to accruals budgeting and accounting need attention here. First, it is remarkable that no procedures exist to assess whether a ZBO is capable of using accruals budgeting and accounting. Second, accruals accounting allows consolidating financial information of more than one legal entity. I have shown that consolidation of the financial statements of all ZBOs to the level of the Dutch State does not solve problems on information provision to stakeholders such as Parliament and investors.

The purely budgetary perspective thus allows for several options of control with different levels of impact on operational autonomy of a ZBO.

The second line of theory looks at the attribution and distribution of authority to minister and ZBO. In general, the attribution of authority is regulated in the framework legislation on creating ZBOs (originally AW1996, by the end of 2008 kZBO and AW2008) and is ultimately reflected in the ZBO case law (PLA) or ZBO Statutes (PLB). Parliament has ex ante influence on the attribution of authority by 1.) modifying the framework legislation and 2.) including elements mentioned in the framework legislation in the ZBO case law. The influence of Parliament on ZBO statutes (PLB) is more passive. Only if Parliament explicitly requires a law to be passed before creating a private law based entity, is Parliament likely to influence the statutes.

From a legal perspective, autonomy is a relative concept. If a minister can instruct an entity on acts in individual cases, the entity is subordinate to the minister; in other cases some degrees of autonomy exist. This means that depending on the authority attributed to the ZBO board, different levels of authority can be observed. I have argued that cyclical and governance measures are particularly relevant when assessing autonomy once a ZBO has been created. Two lines of impact on autonomy can be discussed generally. First, several framework legislation (AW1996, kZBO) measures have an optional character. Not including them in ZBO case law means that the executive board of the ZBO has degrees of freedom. If however the optional measures are included, this generally means that authority is attributed to a minister at the expense of the executive board. Second, kZBO is a general law. If Parliament and minister decide to exclude some measures stipulated in KZBO from a specific ZBO case law, this implies that more autonomy is given to the executive board of the ZBO. The main exception to this general rule is kZBO:33 on creating an equalisation reserve. If not allowed, dependency on budgetary measures by Parliament increases.

The new framework law kZBO came into effect in 2008. The law has to be implemented by changing individual ZBO case law or statutes. The proposals that existed by the end of 2008 create a distinction between ZBOs that will be subject to kZBO and those that will not. Ceteris paribus, from a legal perspective, this means that those ZBOs which are subject to $k Z B O$ will have less relative autonomy than those which are not subject to kZBO. 
The conclusion on attribution of authority in general is that framework legislation still allows for variety, affecting autonomy negatively if optional authority measures are included in ZBO case law. In most cases, autonomy is affected positively if an exception is made, including an exception to a compulsory measure in kZBO.

The third line of theory to be discussed looks at civil law. ZBOs operate in a mixed public and private law setting; therefore a civil law perspective must also be discussed. First, ZBOs exist in different civil law legal formats. Basically the public law ZBO legal entity (PLA) is the format that allows for most control by the legislature, thus having a relatively low level of autonomy. Under kZBO, more controls are laid down for PLAs than for PLBs, although the kZBO measures for both groups are the same in terms of financial controls. The key from a civil law perspective is found in the governance structure. In a PLA setting, requirements on appointment and the role of the (non) executive board are explicitly included. With respect to PLBs, the key measures are found in BW2. It is up to the legislature to influence PLB statutes, either by requiring additional controls in statutes, standard setting in program laws or including conditions in a program law to qualify as a PLB.

In the case of share based PLBs, it is possible to generate direct control by having a majority of voting rights. In the case of foundations, the most common type of PLB, control must be implemented by statutes and program law. In principle a minister has the most scope to control a foundation if he is actively involved in creating the entity. In fact in that case only Parliament has a theoretical say in the decision. If a minister only supports creating a foundation, controls have to be implemented in legislation, often afterwards. Whatever arrangement is used, both formal and actual autonomy still depends on the authority attributed to the minister in the individual statutes of the PLB.

Second, based on civil law concepts, I have developed a model consisting of different 'quasi (service level) contracts' between minister and ZBO. At this level, from a public law perspective regarded as the appropriation stage of budgeting, the influence of Parliament is ex post rather than ex ante. Depending on who is commissioning, funding and using the services, the quasi contract forms have different impacts on a ZBO. From that perspective, individual demand from citizens for ZBO services provides relatively more opportunities for autonomy than in those cases where demand is directly driven and commissioned from within the State. The use of 'quasi contracts' which include performance agreements between minister and ZBO does not alter the budgeting system as such because 'quasi contract' documents are not part of the budget authorisation. According to the literature performance information as well as financial information from annual reports, including possible effects of third party liabilities should be used in future budgeting processes. At the same time the literature indicates that such options are seldom used. In this study, the actual use of ex post information in future budgeting procedures can be used as an indication for autonomy: the less information is debated, the more autonomy may exist for the entity under scrutiny. 
Third, a ZBO with separate legal status has the same position under civil law as a natural person, unless the law - in a PLA case - states otherwise. In cases of changing statutes, damages and financial distress, this may have an impact on Parliamentary and ministerial (financial) control of ZBOs. Civil law allows restricting the freedom of decision making by ZBO management in these cases, for example in changing a statute. If so, the relative autonomy of a ZBO declines compared to cases where no arrangements have been made.

Finally, governance structures need not to be only vertical or top down. The literature suggests that forms of horizontal accountability can be a partial substitute for traditional vertical accountability. Some forms of horizontal accountability may be institutionalised in the law by which the ZBO was established. The value of horizontal accountability measures will probably depend on the party commissioning the ZBO activities. When government is commissioning and funding activities on behalf of ministers and departments, horizontal (democratic) accountability measures are likely to be less important than in cases where commissioning originates from citizens.

With respect to civil law, the conclusion is that the variety of legal entities alone suggests different levels of autonomy and also results in different types of risks with respect to the financial position of a particular type of ZBO. Another important aspect is that an analysis of 'quasi-contract' relations shows that differentiation of control is possible. The key issue with respect to contracting is that a declining relevance of political influence can be observed. If that is the case, the other measures for distributing authority should be in line with the actual type of 'quasi-contracting' form to end up with a match between authority and operations of a ZBO.

Table 7.1: Indicators affecting relative autonomy of ZBOs from a legal perspective.

\begin{tabular}{|l|l|l|}
\hline Budgeting law & General ZBO law \& ZBO case law & Private law \\
\hline $\begin{array}{l}\text { Budget types: } \\
\text { Full budgetary control to fully } \\
\text { open ended without control } \\
\text { (section 4.4) }\end{array}$ & Inclusion under kZBO (section 5.1) & $\begin{array}{l}\text { Type of legal entity used } \\
\text { (section 6.2) }\end{array}$ \\
\hline $\begin{array}{l}\text { Aggregation level of budgets: } \\
\begin{array}{l}\text { Separate article to not } \\
\text { included in budgets at all } \\
\text { (section 4.5) }\end{array}\end{array}$ & $\begin{array}{l}\text { Actual authority elements attributed to } \\
\text { the minister (sections 5.3; 5.4) }\end{array}$ & $\begin{array}{l}\text { Contracting model used to } \\
\text { assign annual service level } \\
\text { (section 6.3) }\end{array}$ \\
\hline $\begin{array}{l}\text { Treasury and investment } \\
\text { restrictions (section 4.2.3) }\end{array}$ & $\begin{array}{l}\text { Level of detail in criteria for calculating } \\
\text { fees (section 4.2.4) }\end{array}$ & $\begin{array}{l}\text { Existence of provisions on } \\
\text { property rights and third party } \\
\text { liabilities (sections 6.4.1; } \\
\text { 6.4.2) }\end{array}$ \\
\hline & $\begin{array}{l}\text { Reallocation of excess equity (section } \\
\text { 4.3.2.1) }\end{array}$ & $\begin{array}{l}\text { Use and relevance of } \\
\text { structures (section 6.4.3) }\end{array}$ \\
\hline
\end{tabular}

This part of the study focused on ZBO relative autonomy indicators from a legal perspective. I have summarised the main indicators found in Table 7.1. However one must be aware that only studying the formal attribution of authority may be misleading. Actual behaviour by a minister may result in either stricter control than formally described 
or a higher degree of management freedom. The actual autonomy related to the attribution of authority of a minister must therefore be assessed on an individual basis of actual behaviour. This will be tested in the empirical part of the study.

Before I can evaluate actual autonomy, I will focus on the economic dimension of ZBO autonomy in Part $\mathrm{C}$ of this study. 
Part C: Autonomy and control of ZBOs from an economic perspective 


\section{Introduction to Part C}

\subsection{Research question}

In the previous part, the characteristics determining (relative) autonomy from a legal perspective were discussed. Indicators that affect (relative) autonomy of ZBOs were identified from budgeting law, public law as well as from private law. In this part of the study, the emphasis is on the economic dimension of relative autonomy. The research question in this chapter is:

\section{Which autonomy indicators can be derived from economic theory and how do they match control of ZBO operations?}

The relation between ZBO and government is one of organising production at arm's length. From an economic perspective, that means that the focus is on the ZBO as an organisation rather than as a public office. Key control tools are desired levels of production and operating resources required. These control tools can be related to the product and market characteristics of the services delivered.

The concept of autonomy is discussed in economic theory. Bouma's concept of economic independence is a description of organisational autonomy from an income generation perspective. According to Bouma, economic independence refers to the possibility that an organisation is able to assure its near term continuity by covering all its costs out of revenues (Bouma, 1982, p. 41). This definition creates a dichotomy: either the entity is economically independent or it is not. Authors like Anthony and Young (1999, p. 301) and Merchant (1998, p. 305) refer to the responsibilities for costs and revenues as well as assets and liabilities within an organisation. (Economic) responsibilities can be regarded as autonomy indicators from an empirical perspective but can also be used normatively. Given a particular (desired) level of autonomy, a specific set of economic responsibilities has to be given to management under the condition that product and market characteristics allow that level of autonomy. In general, management can be regarded as managing an autonomous organisation if the organisation can be classified as an investment centre. Anthony and Young (1999, p. 301) note that on a higher level - what could be labelled the owner-manager differentiation as identified by Berle and Means $(1932 / 2009)$ - the organisation as a whole is regarded as a responsibility centre without differentiation. Even in that case, a classification as an investment centre with responsibility for return on assets is an indication for autonomy of the organisation. A key feature of autonomisation of a ZBO is that there is still an arm's length relationship with government. This implies that autonomy as meant by Bouma is not likely to be the most common position of ZBOs. In the previous Part B on the legal setting, distribution of authority was discussed as a key element in determining autonomy and levels of control 
by Parliament and minister. From an empirical perspective, Anthony and Young note that investment centre classifications in government and not-for-profit bodies (which includes ZBOs) are not common.

Problems arise in an arm's length relationship from a mixture of ministerial roles (on behalf of Parliament) as owner-principal as well as commissioner within one organisation on the one hand and a separation between ownership and management on the other. These problems are extensively described in Neo Institutional Economics. This theoretical framework can be used to identify the different roles and interests in the relationship between a minister who is politically responsible for a ZBO and the ZBO management which is actually responsible for daily operations given the framework set by the owner.

The neo-institutional framework is a tool for analysing the relevant instruments that allow controlling relations between a minister as owner and management of ZBOs as the agent which is ideally working in the interest of the owner. It does not directly provide an answer to the control issues that result from the economic characteristics of the services delivered by a ZBO. The economic characteristics of the services ultimately determine the options available for planning and control tools within the organisation, ranging from political control on an abstract strategic level to routine control for well described and repetitive services (Hofstede, 1981, p. 196). I will develop a set of indicators based on the economic characteristics of the services provided to be able to determine autonomy of ZBO operations from an economic perspective.

\subsection{Structure of Part C}

A ZBO produces its services in an environment in which owner and management are not one and the same. Neo Institutional Economics [NIE] provides a framework that allows the relationship between owner and management to be classified. The issues addressed in NIE therefore have an impact on the formal planning and control structure. The result is a planning and control system that is determined by the (relative) autonomy of a ZBO from the traditional hierarchy.

Because the formal budget authorisation process is an important annual ex ante Parliamentary control tool, it is useful to start an economic analysis by identifying the product characteristics of the services provided by a ZBO. These product characteristics determine the possible options for budget authorisation ranging from a traditional line item budget to an activity based budget. Whether or not a particular (more sophisticated) form of budgeting is chosen is mainly a political preference. An activity based budget is however useless unless measurable production can be identified.

In general, an analysis of an entity's autonomy in relation to the market in which the entity operates is determined by product characteristics on the one hand and market characteristics on the other. In a pure market setting, Adam Smith's invisible hand controls the market for services. In a public finance setting however, product characteristics determine whether political allocation is inevitable (pure public goods; e.g. Hillman, 2003, p. 64), is politically preferable (impure public goods) or can be left to the 
power of the market (market goods). Product characteristics have an impact on demand for the particular services including the possible variations in funding of services.

Another matter is how production is organised. Theoretically, production can be fully controlled by the political system or can - at the other extreme - be left to the power of competitive markets. These extremes in production settings are an indication that a variety of organisational production settings can be used. The contracting models as discussed in Part B reflect the options to find a match between production structure and demand for a particular public service. From this match between product characteristics and the possible market settings available, a ZBO autonomy framework can be derived which results in a planning and control system that is theoretically aligned with the underlying economic characteristics of the services to be delivered.

The planning and control system to be used in a specific economic context can be derived from the autonomy framework which is based on product and market characteristics as well as the controls that are available within the framework of neoinstitutional economy. The actual operationalisation under attribution of authority based on the concept of responsibility accounting (e.g. Lapsley, 1994) and the accounting system used as part of the whole planning and control model reflect the actual autonomy of a ZBO from an economic perspective. Figure 8.1 gives a brief overview of the economic dimensions with an impact on autonomy.

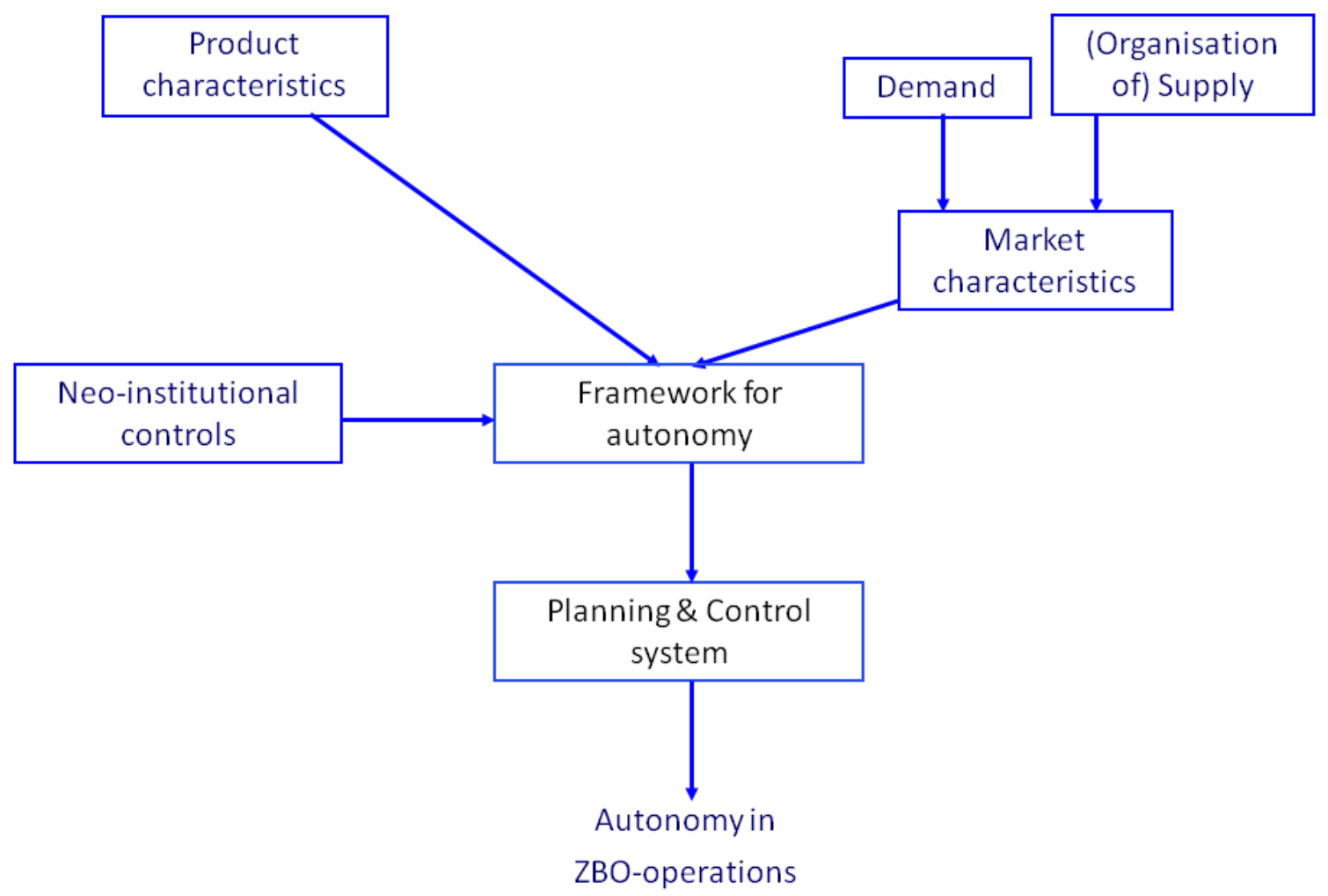

Figure 8.1: Economic issues with an impact on autonomy of ZBO operations 
The outline of Part $\mathrm{C}$ is as follows: Chapter 9 starts with a discussion on neo-institutional economics. Chapter 10 discusses various economic dimensions of services provided and starts with the organisation of supply (section 10.2). In section 10.3, demand is discussed including an elaboration on the difference between funding and financing (section 10.3.2), the theory of public goods (section 10.3.3) and the various forms of funding that can be identified (section 10.3.4). In section 10.4, I will focus on product and production characteristics and the impact they have on control tools that can be used for the various forms of services delivered by ZBOs that were identified in Part A. The theoretical options that exist on transferring supply and demand responsibility from public control to private control have an effect on the planning and control system as well. In chapter 11, I will discuss the control tools that might be used given the product and market characteristics of the services delivered. Section 11.1 discusses responsibility accounting as the main reflection of control given product and production characteristics. In section 11.2 a discussion on operational control tools available in relation to ministerial responsibility is provided. Part $C$ is concluded with a short summarising chapter. 


\section{Neo institutional economy applied to ZBOs}

\section{$9.1 \quad$ Introduction}

Distribution of power and authority can be discussed from a legal perspective as was done in Part B, but it also has an economic dimension. Berle and Means (1932) showed that when a separation between ownership and management exist, agency losses can occur due to unaligned interests between management and owners of a private organisation (Berle and Means, 1932/2009, p. 7). Coase (1937) noted that within an organisation, market price as a coordination mechanism is replaced by hierarchy, based on the differences in transaction costs when purchasing the service/commodity on the market compared to organising services by a hierarchical control mechanism. The ideas of Berle and Means as well as Coase are at the basis of what is now labelled Neo Institutional Economics (NIE).

Neo Institutional Economics contests rational choice models and the assumption of the availability of full information for decisions to be taken (Eggertsson, 1990, p. 7-8). The two main issues covered in NIE are the transaction costs that have to be incurred to gather the relevant information to make decisions (Williamson, 1973) and the concept of property rights which provide owners of these rights some form of control on the assets to be used (Furubotn \& Pejovich, 1972). A third part of NIE is agency theory [AT], which discusses the relationship between principals and agents based on what is labelled information asymmetry. Agency theory is regarded as a linchpin (Mol, Verbon and De Vries, 1997, p. 8) between the two basic theories or as a derivative from transaction cost theory [TCT] (Eggertsson, 1990, p. 40) as it requires specific measures and thus costs to cover the differences in information between two contracting individuals or entities (Jensen \& Meckling, 1976). Authors like Niskanen (1968) claim that bureaucrats - in this case ZBO management - tend to maximise budgets at the expense of political principals. NIE can be applied to private sector units - which were the prime objects of Coase and Berle and Means - but also to the public domain (e.g. Furubotn \& Pejovich (1972) in former Yugoslavia or, applied to the Dutch context, Künneke $(1991,1997)$, Künneke and Manders (1997) and Ter Bogt, (1998)).

In Part A, I have already discussed the relationship between ZBO and government from a NIE perspective. I explained why I use 'owner' and 'commissioner' as two separate concepts that are relevant in assigning tasks to ZBOs. The 'owner' of an entity refers to the principal in AT whereas the supplying entity and its management can be regarded as the agent. The separation of owner and commissioner is particularly relevant when demand is driven by individuals rather than government.

In this chapter, I will elaborate on the impact of the three main lines of theory under NIE on the autonomy of ZBOs. I will start with TCT (subsection 9.2.1), then focus on PRT 
(subsection 9.2.2) and finally address AT (subsection 9.2.3). The last section (9.3) summarises the most important aspects of NIE that affect ZBO autonomy.

\subsection{Neo Institutional theories}

\subsubsection{Transaction costs theory and relative autonomy of ZBOs}

The theory of transaction costs is based on the view that costs of individual transactions determine whether or not a particular service or commodity is produced within the organisation or purchased on the market. The idea is that not only are actual service production costs relevant but also the costs for the transactions required to generate actual production (Douma \& Schreuder, 1998, p. 124). In a more empirically based setting, the concept of Total Cost of Ownership (Wouters, Anderson \& Wynstra, 2005) attempts to calculate the costs of purchasing and using outsourced services within an organisation.

In TCT, rational behaviour in decision making is contested. Williamson (1973) noted that individuals have limited capacity to assess available information. Simon (1978, p. 10) notes that bounded rationality results in decisions which are driven by an implicit assumption of the additional effort needed to acquire the necessary information for a more complete assessment of the alternatives available. Furthermore, in decision making, some elements of self interest or opportunistic behaviour may exist. This can result in differences between the interest of the individual and the interest of an organisation as a whole. As a result, organisations should - according to Williamson (1990, p. 12) - organise their transactions 'so as to economise on bounded rationality while simultaneously safeguarding transactions against the hazards of opportunism'.

Williamson (1973) argues that the problems of bounded rationality and opportunistic behaviour are less severe in relatively uncomplicated organisational structures. If this is not the case, three elements influence the intra- and inter-organisational contracting relations. The most important element is 'asset specificity' which refers to the access to technology and knowledge with respect to certain production processes on the market. Asset specificity is classified into six groups which affect governance structure within the organisation (site specificity, human asset specificity and temporal specificity), or the arrangement in the market contract (physical asset specificity and dedicated asset specificity). The last item is brand capital, related to the reputation of the organisation (Lohtia, Brooks \& Krapfel, 1994, p. 262). Whatever the type of asset specificity, the key argument is that when asset specificity is low, technology and knowledge are readily available in the market and the organisation has the ability to choose an efficient provider of the commodity or service to be delivered. If, however, asset specificity is high, only one or a few providers can deliver the commodity or service and the organisation that needs the services will be depending on that particular provider. That might be an argument to have the relevant technology to produce the service within the organisation rather than purchasing it on the market. From an empirical perspective, Sclar (2000) 
noted that once an outsourcing decision has been made, it may be very difficult to reverse such a decision due to asset specificity.

The second element in TCT is uncertainty, which is strongly related to the problem of bounded rationality (Douma \& Schreuder, 1998, p. 131) and to changes in the environment. As an effect, uncertainty may result in continuous discussions on the contents of contracts (Epstein \& O'Halloran, 1999, p 38). Van Genugten (2008, p. 212) has split uncertainty in a public sector setting into two different aspects: 1 ) environmental uncertainty based upon political sensitivity and technical and policy changes with respect to the public service and 2) behavioural uncertainty which is related to the possibility to measure production of services.

The last element is the frequency of transactions (Williamson, 1973; Tijdink, 1998, p. 44; Van Leerdam, 1999, p. 104). Van Leerdam (1999, p. 104) and Van Helden (1997, p. 41) note on the frequency of transactions that it may be that if similar transactions appear frequently, this allows a tailor made governance structure to be created for these similar transactions as the cost of the governance structure can be spread over a number of transactions. It also implies that if a transaction has a low frequency (incidental cases), the organisation will be better off by using a rather uncomplicated market transaction (Van Genugten, 2008, p. 39).

Theoretically, application of TCT results in particular forms of organisation structures ranging from unitary (or hierarchical) to multi-divisional or semi-autonomous self governing models (Van Leerdam, 1999, p. 110), depending on the characteristics of the three main elements of TCT. Bokkes (1989, p. 203) commented that TCT has a strong theoretical emphasis and that many assumptions have to be made in order to apply or test the theory. Similar comments are made by Van Helden (1997, p. 50) when he notes that TCT should be extended to provide improved explanations for autonomisation. These theoretical comments are confirmed by empirical studies on autonomisation in the Netherlands.

Ter Bogt (1999) states that for the 6 cases of autonomisation he studied, the choices made on and the degree of autonomy cannot be explained from an asset specificity perspective. He even emphasises that although NIE principles are relevant in autonomisation discussions, other perspectives such as public administration or sociology are needed to explain choices made in autonomisation. Van Thiel (2006) noted in a study on styles of creating Dutch quangos that the managerial style - which is closest to the concepts of NPM and aspects of NIE (jdk) - is hardly used for creating Dutch quangos. Van Leerdam (1999, p. 195-196) argues that from a transaction cost perspective, an ideal type ZBO has more delegated powers, greater autonomy, greater opportunities for participation by third parties and less scope for intervention by political principals than an ideal type executive agency. He notes that these ideal types cannot be used as deterministic models but are an indication of the direction of the choice for an organisational form in the event of autonomisation. Van Genugten's contribution is that 
she found that even in an - at first glance rather uncomplicated - issue such as household waste collection, uncertainty is an important factor and has an impact on the level of transaction costs to be made. As a result, Van Genugten raises questions on using hybrid forms of governance structures (implying arm's length organisations, jdk) for the provision of public services (Van Genugten, 2008, p. 207-208). The comments made above indicate that TCT does not provide an explanation for autonomisation. The elements identified in TCT do suggest that they may restrict or extend the possibilities for arm's length control. Underlying product characteristics may also have an impact on the TCT elements, which will be discussed in section 10.4 .

In this section, TCT and its impact on autonomy was discussed. Transaction costs theory aims at identifying all costs involved in producing and organising production of a service. Due to bounded rationality and opportunistic behaviour, arrangements have to be made to find a governance structure that covers the risks implied in asset specificity, uncertainty and frequency of transactions. The theory is considered to be weak in explaining why a particular form of autonomisation will emerge. It can however be used to estimate the impact on autonomy in the relationship between ZBO and minister by assessing each of the individual elements. Asset specificity is expected to affect autonomy positively and can result in additional monitoring tools used by the commissioner in order to reduce this effect, whereas high (environmental) uncertainty and high frequency of transactions are expected to affect autonomy negatively.

\subsubsection{Property rights theory and relative autonomy of ZBOs}

The second line of theory in NIE is property rights theory (PRT). In PRT, the emphasis is on ownership and control of property. The concept of property in property rights theory is broader than the traditional legal interpretation of ownership of property. Eggertson (1990, p. 38) states that property rights are regarded as undiminished when there are no restrictions on individual rights to use, earn income from and exchange assets. Under the property right concept an individual is not allowed to cause physical damage to someone else's resources. Künneke (1997, p. 31) even gives an example of air pollution that can be covered under property rights although it initially did not exist as a property right at all.

Furubotn and Pejovich (1972) state that three elements are relevant in PRT. First, individuals pursue their own interest rather than the organisation's interest. Second, property rights have a variety of forms that have a different impact on the distribution of the organisation's residual income. Third, transaction costs exist and are greater than zero. The first two PRT items are the main ones of relevance for ZBOs. Pursuing own interests holds in any organisation. The issue of residual income is relevant in terms of controlling resources generated from services delivered on behalf of government. The transaction cost issue is reflected in the monitoring costs discussed in section 9.2.1 on TCT. These elements result in an emphasis on maximising utility with a focus on the individuals within the organisation rather than a focus on the organisational level. 
Property rights theory assumes rational behaviour of individuals as can be derived from the claim that 'the crucial task for the property rights approach is to show that the content of property rights affects the allocation and use of resources in specific and predictable ways' (Furubotn \& Pejovich, 1972, p. 1139, italics in original; see also Van Leerdam, 1999, p. 89).

Property rights theory is based on the idea that property rights are not necessarily controlled by one individual or entity. The theory identifies three different forms of property rights with a decreasing level of control on the particular asset. ${ }^{131}$

The most encompassing property right is the 'abusus' right which means that the owner is allowed to realise any transaction with respect to the specific asset ranging from use to changing or selling it. At the other end of the spectrum is the 'usus' right. The owner of a usus right is only allowed to use the asset and cannot claim any residual value. In the 'usus fructus' case, the owner of this right is allowed to use the asset and can also claim some residual value from the asset. However, he is supposed to maintain the asset (or its value, jdk) in the present state because he is using someone else's resources (see e.g. Furubotn \& Pejovich, 1972, p. 1155 on Yugoslavia). Künneke (1997, p. 26-29) describes the impact of property rights with respect to autonomised government organisations. If all residual income has to be transferred to the owner (i.e. government), this means that the autonomous organisation has no interest in improving the efficiency of the organisation. Having access to a share in residual income implies that the organisation has an incentive to realise efficiency gains. As a result it allows the autonomised organisation to guarantee continuity of the organisation or, in Bouma's (1982, p. 42) words, its economic independence. Theoretically, efficiency improvement is most stimulated if the autonomised organisation has full access to residual income. However, Künneke (1997, p. 26) notes that substantial aggregated amounts of residual income or equity may also result in inefficient behaviour.

A second issue with respect to autonomisation is the contents of the abusus rights attributed to the organisation. In the case of a Shelter ZBO without separate legal status, no abusus rights exist at all. In the case of a Subsidiary ZBO, abusus rights might cover some assets, but sale of a Subsidiary ZBO is a political rather than a managerial decision. For PLBs, there is no full abusus right in the (Dutch) public sector as there are restrictions on selling shares in public companies. An abusus right may however also be attributed by means of access to capital markets (Künneke, 1991, p. 135-142). Basically access to the capital markets holds for separate legal entities, i.e. Subsidiary ZBOs and PLBs if no legal restrictions are set. Borrowing on the capital market means that the organisation provides some form of collateral to the lender to ensure it will pay back the borrowed amounts of money. Providing collateral can be regarded as an incentive for the borrowing

131 Hart and Moore (1990, p. 1150) note that it is unclear what authority or control on human assets actually means. In their study they focused on tangible assets, but they suspect that the argument also holds for intangibles such as goodwill. 
organisation to at least stabilise or improve efficiency. If not, the value of the collateral provided may decline and, as a result, capital markets may no longer be willing to lend money. Without free access to the capital markets or if access to the capital markets is guaranteed, the efficiency incentive for the borrowing entity is less strong.

A third issue with respect to autonomisation is the possibility of shared property rights. If this is the case, the problems identified by Berle and Means (1932/2009, p. 53) on separation of ownership and management emerge. Particularly in a public sector context, Künneke (1997, p. 29) notes that when separate democratic institutions share property rights, the democratic decision making procedures will result in compromises not fully in line with the original objectives of individual owners. This allows the management of the autonomised organisation to avoid responsibility (shirking, see e.g. Flynn, 2007, p. 127) by supporting a compromise that best fits its own objectives. At the national level one formal democratic institution exists. The risk of shirking responsibility is still realistic on the national level as well in those cases where the Minister-Principal of a particular ZBO has to deal with other Ministers-Commissioners and possible conflicts emerge.

Property rights theory provides a perspective on the possibilities for autonomisation and improved efficiency. As long as services provided are measurable, autonomisation seems to be possible. To prevent from shirking in such cases, attribution of abusus rights either with respect to access to residual income or free access to the capital market are relevant issues for improving efficiency in organisations. This implies that from a PRT perspective, an increase in autonomy is expected to result in improved service delivery efficiency. Particularly in the setting of separate democratic institutions or more generally multiple public sector commissioners, there is an additional risk in shirking due to the fact that compromises have to be made that allow management to follow their own interests.

Economic autonomisation in a government setting is according to Künneke (1997, p. 22) a restructuring of the property rights controlled by government in a way that the characteristics of private control of property rights will have a stronger impact on operations. Property rights theory can be used to explain autonomisation (Van Leerdam, 1999, p. 93). The main tools for implementing autonomisation are found in attributing 'abusus' or at least 'usus fructus' rights. A mere 'usus' right suggests that the entity that has attributed the usus right will have made provisions to assure that the assets made available to the usus rights holder are properly taken care of. In the other two cases, there is less need to do so as usus fructus and abusus imply that some of the funds generated are at the disposal of the owner of the relevant right.

Theory also indicates that there are restrictions depending on the characteristics of the services provided (Blankart, 1986, p. 351), on the possibilities of identifying and enforcing property rights and in the distribution of property rights amongst economic 
actors (Künneke, 1997, p. 32-33). Some ZBOs seem to provide services that can be qualified under Blankart's 'trust'-type. If that is the case, attribution of property rights is not likely to improve efficiency of the organisation. However compared to government units that provide similar services, autonomy is greater due to the assigned property rights but it is not likely that this will have an impact on budget authorisation processes.

Applied to ZBOs it is not the explanation as to why the organisation was autonomised that is at stake in PRT, but the impact the attribution of a particular set of property rights has on efficiency and autonomy of the organisation. This affects the production structure that is used in the organisation. I will start with the abusus concept. PRT argues that providing abusus rights to an autonomised organisation will contribute to more efficiency. Abusus rights basically consist of two elements: right to use parts of residual income for the organisation and the right to sell or change assets. If these rights are institutionalised in the setting of a particular ZBO, this means that the organisation has more degrees of freedom to use resources than an organisation that does not have such rights. A particular form of abusus is the right of free access to the capital market. Künneke (1997, p. 27) claims that this can improve the efficiency of an organisation in similar ways as when direct access to residual income is available. In an organisation such as a ZBO that is funded by government, this may not be completely true. Economic theory assumes that a State can borrow on the capital market at a risk free interest rate (e.g. Bodie, Kane \& Marcus, 1996, p. 125; Pike \& Neale, 2006, p. 16). This still holds for the Dutch State. ${ }^{132}$ Borrowing on the capital market for any other entity, including arm's length organisations, will not be performed at that risk free rate, but at a substantially higher level. ${ }^{133}$ These additional costs will have to be covered either by efficiency gains or by additional budgets. Therefore, free access to the capital markets might negatively affect efficiency gains or residual income in budgeted organisations. Compared to ZBOs that are only allowed to borrow from government, the autonomy of a ZBO that borrows from the capital markets may be wider, but at the expense of higher budgets.

Another issue that should be considered when assessing abusus rights is that such rights can have negative effects when granted inadequately. When full abusus rights on transfer of assets exist, undesired outcomes cannot be reversed as long as the abusus right is not violated. This may mean that residual income realised from sale of assets may be fully at the disposal of management at the expense of the public sector. That this is not only a theoretical issue can be shown from the GAK/ASZ case in which an originally public domain ICT unit was transferred to a private law entity and ultimately sold. An abusus right was attributed, resulting in a donation of publicly funded assets to a private

132 In a Eurozone context, one can argue that the risk free interest rate is the lowest interest rate that is offered on the market for government bonds, actually German Bunds. Spreads between Dutch Government Bonds and German Bunds are in general very low, effectively resulting in as good as risk free interest rates for the Dutch State as well. See also Mann (1999) on the US.

133 In the Netherlands, the mutual assurance fund for the health sector (WFZ) notes that borrowing for hospitals on the capital market resulted in risk premiums of 100-150 basis points (WFZ, 2009). 
company. At the time of the attribution of the abusus right no one realised the impact of this decision. When the sale was completed, it appeared that the revenues could no longer be used in the public sector (Parliament, 2000g; CTSV, 2000). In hindsight, a usus fructus measure would have been a better solution given the original public funding of the ICT-unit. Abusus rights may not be complete for reasons such as that shown by this example. Depending on the level of the restrictions, the relative autonomy of a particular ZBO may then be relatively low compared to a case where abusus rights exist. I refer to kZBO:32 and CW2001:45 which can impose restrictions on property rights transactions as well as access to capital markets as tools to manage risks of abusus rights.

If only a usus fructus right is assigned, relative autonomy of a particular ZBO is lower than in case of abusus rights. In principle usus fructus rights mean that a form of access to residual income is granted in order to improve efficiency. As Eggertson (1990, p. 38) noted, any regulation that restricts the behaviour of economic actors implies the attribution of property rights. Given the context in which ZBOs operate, particularly the variation in regulations due to options in the legal framework kZBO, differences arise in attributed property rights and thus in the relative autonomy. The key issues on variation in regulations were discussed in Part $B$.

A last point to be made is the issue of shared ownership. If shared ownership exists, management has more degrees of freedom (Künneke, 1997, p. 28-29). This issue is relevant for those ZBOs that can be regarded as hybrids or part of a larger private law based unit. In those cases, restrictions are imposed upon the organisation by government for the ZBO activities to be realised and by the other (group) of owners that are responsible for the market activities of the organisation in which the ZBO-activities are performed. Thus, if shared ownership can be identified, this is an indicator of relatively greater autonomy for that particular ZBO.

\subsection{3 $\quad A T$ and political control of ZBOs}

In Agency theory, the organisation is studied from the perspective that ownership and management are not controlled by one single person and that the control relationship between owner and management is covered in contractual terms. Jensen and Meckling (1976, p. 308) define an agency relationship as 'a contract under which one or more persons engage (the principal(s)) another person (the agent) to perform some service on their behalf. This involves delegating some decision making authority to the agent'. As explained in Part A, I have chosen to substitute 'principal' by 'owner' to be able to make a distinction between the theoretical residual claimant and the person(s) generating demand for services of the agent. Under AT, the main assumptions are that owner and manager have different objectives and utility functions as well as different access to information regarding the organisations (Van Leerdam, 1999, p. 95). Despite these differences, owner and agent both benefit from mutual co-operation because the owner can use the agent's specialised knowledge and skills as long as the agent receives 
appropriate incentives and rewards for his services (Moe, 1984, p. 756; Petersen, 1993, p. 278).

Agency theory has two main lines (Jensen, 1983, p. 334-335): one is labelled 'principal-agent' literature and focuses on contract, uncertainty and information structures. In the principal-agent literature, risk and welfare effects related to the contractual equilibrium between owner/principal and agent are discussed. The principalagent literature focuses on optimal solutions for the problems that arise from information asymmetry and diverging interests. The other line of theory is the positive agency theory. It emphasises the effects of the contracting environment and the control tools applied within the principal agent relationship. In positive agency theory, it is not the optimisation problem that is the key issue, but the operational tools used to manage and monitor the relationship between owner/principal and agent. For the purpose of this study, positive agency theory is more relevant. The problem is not on an optimal distribution of welfare effects, but on the control tools available once the decision to separate ownership and management has been made by creating an arm's length organisation like a ZBO and the subsequent use of these control tools. The remaining issue then is how to make arrangements that cover the problems which emerge from a separation of ownership and management and the consequences this has for ZBO autonomy.

\subsubsection{Information asymmetry}

If full transparency on the organisation's operations existed, agency problems would not arise. However, the organisation has to cope with information asymmetry between owner and management, as expressed by issues such as uncertainty, problems in measurement and programmability (Eisenhardt, 1989, p. 61-62).

The problems of information asymmetry and unaligned interests of owners and managers (agents) of an organisation in private companies can partly be mitigated based on market mechanisms in the stock market. Agents (managers) of listed companies know that inefficient behaviour might result in take-overs or mergers and that their reputation might be at stake (Eggertson, 1990, p. 134-135).

In not-for-profit organisations, there is no residual income to be distributed to owners, which means that the market mechanisms that contribute to controlling the owner-agent problem do not exist (Fama \& Jensen, 1983b, p. 318-321). As a result, control mechanisms such as sale and merger do not exist and the monitoring and bonding elements in the contract between owner and agent become more important. Several authors (Moe 1984, p. 765; Garner, 1996, p. 87; Bouckaert, 1998, p. 141-142) discuss the fact that the governance systems in a public sector setting are essentially different from those in the private sector. Neelen $(1997$, p. 70$)$ distinguishes three forms of control mechanisms: control by persuasion, by incentives and by directives and or authority. In a bureaucratic public sector setting, directives and authority are important because public sector organisations operate in a complex environment in which many interests have to be managed and accounted for. 
The complexity of the public sector is also caused by the objectives to be realised by policy instruments and the objectives to be realised when running an organisation. Verhoest states that when government as principal - he implies commissioner as the discussion is on policy objectives, jdk - only sets standards at a strategic policy level, for example by only setting outcome standards, the agent has far more degrees of freedom compared to the case in which government sets operations standards within the agent's organisation (Verhoest, 2002, p. 36-37). Standards for both policy instruments and operational instruments can be set at different levels of the organisation. The key issues are presented in Table 9.1.

Table 9.1: Levels of policy and operational control of an executive central government organisation (Source: Verhoest, 2002, p. 37)

\begin{tabular}{|l|l|l|}
\hline Level & Policy control & Managerial control \\
\hline Strategic & $\begin{array}{l}\text { Effect control } \\
\text { Objectives and effects } \\
\text { Standards, compliance and evaluation/ } \\
\text { adjustment }\end{array}$ & $\begin{array}{l}\text { Input control } \\
\text { General rules, principles and volume of input } \\
\text { resources } \\
\text { Standards, compliance and evaluation/ } \\
\text { adjustment }\end{array}$ \\
\hline Tactic & $\begin{array}{l}\text { Output control } \\
\text { Policy tools and performance }\end{array}$ & $\begin{array}{l}\text { Input control } \\
\text { Specific rules, procedures for each category } \\
\text { of input resources } \\
\text { Standards, compliance and evaluation/ } \\
\text { adjustment }\end{array}$ \\
\hline Operational & $\begin{array}{l}\text { Standards, compliance and evaluation/ } \\
\text { adjustment }\end{array}$ & $\begin{array}{l}\text { Input control } \\
\text { Individual decisions regarding use of input } \\
\text { resources } \\
\text { Standards, compliance and evaluation/ } \\
\text { adjustment }\end{array}$ \\
\hline Source: Verhoest, 2002, p. 37 & $\begin{array}{l}\text { Standards, compliance and evaluation/ } \\
\text { adjustment }\end{array}$ & \\
\hline
\end{tabular}

No matter at what level the standards are set, problems of information asymmetry will exist. Verhoest (2002, p. 66) identified five characteristics of public sector organisations that explain why the information asymmetry problem in a public sector setting results in less efficient and effective operations. These issues are a.) multiple hierarchy of principals; b.) multiple conflicting and ambiguous policy objectives; c.) difficulties in performance measurement; d.) no clear relation between funding and organisational performance and e.) relatively low level of autonomy compared to the private sector setting. Despite these differences, quasi contracting based on AT can contribute to improved performance by public sector organisations (Verhoest, 2002, p. 76). In his model, Verhoest (2002, p. 76-77) identifies four main actors ${ }^{134}$ governing the operations of an autonomised government unit. In addition to the agent (i.e. the autonomised unit), a central principal/commissioner - the minister who is responsible for the content of the activities of the agent - and two horizontal principals/owners exist. The latter are the minister of finance with respect to financing and budgeting issues and the minister responsible for the civil service. Whether or not the governance setting under which the

134 Verhoest's model neglects other stakeholders that may have an interest in the public sector such as private commissioners for the services of the organisation. These may to some extent also behave as principals, for example when an advisory board of stakeholders can monitor the operations of the agent. 
agent operates is successful depends according to Verhoest (2002, p.76-77) on four factors: a.) degree of operational autonomy of the agent; b.) level of coordination between the principals ${ }^{135}$; c.) management of information asymmetry and d.) goal alignment between principal and agent. Mitigating the principal - agent problem by means of quasi contracting has to address each of these elements. Regarding the degrees of operational autonomy, this will be reflected in the input controls laid down at the different levels of operations. Such controls will often be formalised in laws and decrees. Information asymmetry and goal alignment can be mitigated by solutions from quasi contracting by monitoring and bonding agreements. From the agent's perspective, the level of coordination between the principals is a black box; ideally some general rules cover the arrangements between central principal/ commissioner and the horizontal principals/ owners. In that case, both the principals and the agent know the authority limitations of all parties involved, although some ambiguity may continue to exist.

\subsubsection{Monitoring and bonding}

Eisenhardt (1989, p. 62-63) claims that some of the information asymmetry problems can be overcome for long term relationships between owner and agent because it is likely that in the long run the owner will learn from the behaviour of the agent.

In the contractual relationship between owner and agent, several tools can be used to reduce the risks that arise from information asymmetry. From the owner perspective, monitoring the activities of the agent can be realised by using several tools, including auditing, formal control systems, budget restrictions and an incentive compensation system (Jensen \& Meckling, 1976, p. 323). Not all of these control tools are suitable for each and every organisation. From the agent's perspective, bonding activities can be part of the contractual relationship. Control by bonding can be realised by contractual guarantees on auditing, limitations on the agent's decision making power and bonding against possible malfeasance by the agent (Jensen \& Meckling, 1976, p. 325).

Whether monitoring or bonding activities are performed, they all can be expressed as expenses that will negatively affect the residual income of the organisation. Along with monitoring and bonding costs, a third cost category exists, which is the result of the fact that practice will always deviate from maximal utility for the owner of the organisation (Jensen \& Meckling, 1976, p. 308). The loss incurred as a result of these decisions is labelled 'residual loss'. In an ideal contract, in Jensen's (1983) terms part of the principal agent literature, the mixture of monitoring and bonding costs on the one hand and residual loss on the other result in a situation in which total agency costs are minimal. If few monitoring and bonding activities are performed, the degree of freedom for the agent will be relatively large. This results in high residual losses for the owner. On the other hand, if monitoring and bonding is strict, the degree of freedom for the agent is low and

135 Co-ordination between principals should be read as co-ordination between owner(s) and commissioners. These two groups have diverging interests, and co-ordination between principals in subgroups is what can be performed here. 
as a consequence, residual loss is low. Both the owner and the agent have found an optimal solution if the sum of all agency costs is minimal, which means that a trade off between the ex ante monitoring and bonding activities and the ex post residual losses has to be found.

\subsubsection{Operational control and information asymmetry}

Under the assumption that policy control is given in this study, it is possible to focus on the operational control issues that result from information asymmetry, more specifically monitoring and bonding arrangements and their possible impact on ZBOs. I will follow the classification of arrangements given by Jensen and Meckling (1976). Auditing implies that the processes and reports of the agent are reviewed and, if possible certified. A first option is to include arrangements for certifying public accounts. That provides information on financial data but not on non financial outputs or outcomes. Schillemans and Bovens (2004) and Schillemans (2005) identify a second option: diagonal monitoring, which means that a separate institution monitors the agent's performance on behalf of a minister with respect to the minister's system responsibility. This is another solution than using a non-executive board which primarily monitors the continuity of the arm's length organisation on behalf of the owner. Applied to the Dutch case, inspections and or policy monitoring institutions exist that are allowed to review the performance of an individual agent. An example of diagonal monitoring is the Public Safety Inspectorate (Inspectie voor Openbare orde en veiligheid [IOOV]) which monitors the quality of services provided by police forces and other emergency services.

Formal control systems can have the characteristics of behaviour and or performance controls. Such controls may be applied to more than one single agent and might be relevant in case of multiple principals. Regulations that cover standards for a group of agents - like kZBO - which are meant to align the interests of the different principals, can be classified under formal controls as well. Reporting can be included in the formal control system, but also be part of the voluntary bonding arrangement by the agent. The level of detail and frequency of reporting, both on financial as well as non financial indicators should match the economic characteristics of services provided and the autonomy that follows from these economic characteristics. High reporting frequency implies stricter supervision by the principals than in case of low frequency reporting. Product and market characteristics may require a high frequency of reporting. If not, it is a reflection of a mismatch between autonomy derived from economic characteristics and actual control practices. Therefore, reporting frequency can be regarded as a relevant indicator for (relative) autonomy. Formal control may also include the governance structure at the institutional level. The appointment of the executive board of the agent, as well as the existence of a non-executive or an advisory board appointed by the principal may be part of the formal control structure. In terms of control, selection processes for members of these boards can be regarded as a form of Ouchi's (1979) social controls. One of the roles of non-executive or advisory boards might be to fill a gap in democratic legitimisation of the agent particularly when users or commissioners of the 
agency's services are involved (Cornforth, 2003, p. 13; Locke, Begum \& Robson, 2003, p. 63) and an effect of such boards might therefore be that there is less need for control from the owner/principal. The task assigned to a non-executive board may also be an indication of (relative) autonomy. If the non-executive board focuses on compliance with regulations, the board has a bias towards the principal, whereas in the case of focus on performance and strategy, emphasis is biased towards the agent and the users of the agent's services (Cornforth, 2003, p. 14). If no non-executive or advisory boards exist, then the only relation that remains is that between owner and agents, which provides for more direct intervention by the owner of the autonomised organisation.

Budgetary controls can have a variety of forms, from pure input based controls on operational issues to only limited price controls. The variety of budgetary issues has been discussed in Part B and will be discussed from an economic perspective in section 11.2.1. Similarly, in section 9.2.2 on residual income from a property right perspective, access to residual income was described as a tool for management to improve efficiency in the organisation. Management is in that case allowed to use part of the residual income at its own discretion which can be regarded as a form of an incentive. Other incentives may be found in the personal rewards and penalties for management (Arrow, 1985, p. 47-48; Fama \& Jensen, 1983b, p. 302-303; Bouma \& van Helden, 1994, p. 4446; Verhoest, 2002, p. 60).

In a public sector setting, most other bonding controls will be included in the monitoring part of the contract as well due to the more rule driven perspective in the public sector compared to the private sector. The voluntary decision to use external auditors (Jensen \& Meckling, 1976, p. 325) is often included in the legal framework as is the case with controls against malfeasance. I refer to the discussion on AW1996 and kZBO in Part B for examples of these forms of arrangements. A particular form of bonding control is the imposition of fines if contractual targets are not achieved (Bouma \& Van Helden, 1994, p. 46-47). If this occurs for a particular ZBO, it would mean that forms of contractual arrangements, rather than formal regulation, are regarded as an important management incentive. One might conclude that if contractual fines in the owner - agent relationship exist, this allows for more autonomy than if agency costs are mainly based on monitoring activities.

If persuasion and incentives (Neelen, 1997, p. 69-72) are used, implicit degrees of freedom exist because the agent has scope to act on persuasive actions or incentives. If directives and authority are used, the agent has less choice and is thus less autonomous than under the other two governance models. In many cases of autonomisation, a mixture of these governance tools is used. In the ZBO case, Part B has discussed the variety of directives that can exist in the law. However, within directives, degrees of freedom exist as well. Neelen claims that autonomisation as expressed in directives can be found in two trends: one is the emphasis on output rather than input and process type controls; the other is that controls focus on procedures rather than on the contents of 
operations (Neelen, 1997, p. 71). From the perspective of this study, this means that indicators for relative autonomy can be found in the existence of persuasion and incentive based control mechanisms as well as in the characteristics of the directives. Autonomy may however be negatively affected if monitoring procedures such as reporting have a relatively high frequency. The same holds if monitoring procedures have an emphasis on vertical accountability rather than horizontal or diagonal accountability.

\subsection{Conclusion}

In this chapter the three lines of Neo Institutional Economics were discussed. In all cases, there is a problem with respect to achieving efficient production of services due to a separation between ownership and management.

The main question is how the conflicting interests between owner and manager can be overcome. Property rights theory emphasises the distribution of access to (intangible) assets within the organisation and argues that management has additional incentives to perform efficiently if few restrictions on access to the assets of the organisation (abususrights) exist. Access to assets has three basic forms: access to residual income, access to the capital market and rights to sell or change assets. All three forms of abusus rights may, to some extent, be relevant for ZBOs and affect autonomy. It should however be noted that inadequately attributed property rights are in principle not reversible in case of undesired outcomes because these rights are included in the arrangements. Property rights can only be reconsidered after the event but at the expense of losses incurred by the owner of the organisation. If only usus fructus or usus rights are attributed to ZBO's management, autonomy is relatively low compared to when abusus rights exist.

The other two lines of theory focus on the transactions between owner and management of the organisation. In transaction cost theory, uncertainty is an important issue and allows for opportunistic behaviour by management. However, the most important issue in TCT is the impact of asset specificity on arriving at efficient transactions. If the commissioner of services strongly depends on assets only available from the supplier, efficient transactions would result in integrating both entities, whereas in case of low asset specificity, market competition exists and there is no immediate need to integrate both entities. Whether or not integration is the most efficient solution also depends on the level of uncertainty and frequency of transactions. From the perspective of ZBO autonomy, given the existence of a ZBO as a separate legal entity, asset specificity has a positive impact on autonomy, although it can be expected that the commissioning entity will use additional monitoring tools to reduce this.

Agency theory specifically focuses on the information asymmetry problem and divergence of interest between owner and agent. In order to manage this problem, a balance between monitoring tools and efficiency loss as a result of the information problem has to be found, resulting in a solution in which total costs of the agency problem can be minimised. Increasing autonomy will result, according to this theory, in an increase in efficiency losses, whereas reduced autonomy by intensive monitoring will 
reduce efficiency losses although at the expense of increased monitoring costs. Basically three types of controls can be used: persuasion, incentives and directives. Both incentives and directives allow for relative autonomy of ZBO management as these control tools include an element of choice. Directives however affect autonomy negatively as they tend to enforce compliance and thus restrict management's choices.

Tijdink, (1998, p. 53) notes that the three lines of NIE-theory have become 'separate islands of knowledge' and that there may be contradictions between these thee lines. Whereas PRT states that management autonomy including free (re)allocation of assets and claims on residual value will enhance efficiency, AT stresses that the separation of management and ownership of an organisation requires additional control tools to prevent management creating inefficiencies at the expense of the owners. Tijdink (1998, p. 63) concluded that the common denominator in this apparent contradiction are the incentives for management. From the perspective of budget authorisation and ex ante controls in general, three incentives are relevant. First, the degrees of freedom in (re)allocating assets given to a ZBO, second the issue of residual claims as reflected in remuneration of management and access to residual income, and third the control mechanisms related to operations. All these elements may be used as indicators to analyse relative autonomy of ZBOs. 


\section{The economic dimensions of ZBO services}

\subsection{Introduction}

By definition, a ZBO produces public services based on unilateral binding decisions. From a perspective of democratic legitimacy, public services are produced by government institutions. The traditional production setting for public services has been contested under the influence of NIE theories (Behn, 2001, p. 22; Lane, 2000, p. 143; Hood, 2004, p. 17). Lane (2000, p. 156) notes that a key point in public sector reform is to set up a model that stimulates productivity and effectiveness by trying to use competitive factors rather than authority factors in the system of resource allocation. This means that methods based on hierarchy and compliance to the allocation decisions of the political principals is transferred to an (internal) privatisation model based on supply and demand. He refers to internal privatisation as a method of generating competition between bureaus within the hierarchy. Particularly when production can be transferred to entities outside government, there might be an additional stimulus to decide rationally on supply of services (Lane, 2000, p. 158).

In the classic system of providing government services, compliance with a democratically authorised decision on levels of supply is realised based on the allocation of resources for production. Demand is an implicit factor as the same Parliament which decides upon the allocation of resources is supposed to represent the preferences in aggregate demand for services. As a result, government controls both demand and supply by the process of budget authorisation in Parliament and the acts of the executive (minister) based on that decision. By introducing 'market'-prices instead of general taxes or competition between suppliers, control mechanisms on either demand or supply or possibly a combination of the two are introduced, which allows for a control approach that has less emphasis on compliance than on matching demand with supply.

Boorsma and Mol (1983) were among the first to introduce a distinction between privatisation of demand and privatisation of supply. Privatisation of supply implies that the organisational setting under which services are produced is no longer controlled by government which means that there is another (non-government) legal entity that produces the government services. ${ }^{136}$ ZBOs are a particular way of organising production outside the immediate control of the hierarchical government structure. The analysis of privatisation of supply can be used to assess the position of a ZBO in terms of (relative) autonomy from the perspective of production. Simultaneously, if funding of a ZBO is not necessarily based on direct allocation of resources from government, an analysis of demand for ZBO services is also required.

136 I note that in a legal context, Maeijer referred to privatisation as any form of creating an entity with a separate legal status; cases in which the organisation's setting is what is labelled as PLA in this study are forms of autonomisation (Maeijers, 1997, p. 5). In this part of the text, legal setting as such is not the core issue. 
Lane (2000, p. 157) notes that improved efficiency on providing public services can theoretically be realised both from a demand and a supply perspective. In his opinion, actual public sector reforms have a bias towards supply because it is difficult to reveal the real price individuals are willing to pay for public services. From a supply perspective, it is possible to let organisations - even within a hierarchical structure - compete to win production contracts. As a result cost efficiency of production will be a core issue. Although not made explicit by Lane, the compulsory character of a public service might be one of the underlying reasons for problems in measuring demand. Whether or not a particular public service must be qualified as a compulsory service depends on the market characteristics of the service which is known in public finance as the debate on public goods and market goods (e.g. Hillman, 2003, p. 63-65). From the perspective of this study, the variety in demand forms resulting from an analysis on public goods and market goods allows for an analytical perspective with respect to controlling services delivered by ZBOs.

In Part A, it was shown that in most cases, ZBOs are not privatised but actually autonomised, resulting in reduced government responsibility rather than no responsibility. In Boorsma and Mol's model, real (economic) privatisation implies that government is neither involved in supply nor in demand and the market determines whether or not a particular service is to be provided.

ZBOs do not operate in a competitive market; they are assigned to provide a particular service by the political system. Thus real (economic) privatisation is not relevant in ZBO cases. In section 10.2, I will address the issue of control of supply by government. Furthermore, the role of the organisation in the provision of government services is discussed by analysing the position of the organisation in the production chain.

Privatisation of demand implies a shift from taxation towards pricing which can contribute to more transparency on demand for services. Such a shift can only be realised if the services delivered allow forms of pricing. Theory on public goods and market goods provides conceptual answers based on funding possibilities for services. The political system will ultimately decide whether the theoretical solutions available will be used as part of controlling demand for public services. It seems obvious that when general taxes are used, privatisation of demand is not possible and the traditional hierarchical allocation of resources and the corresponding compliance will prevail. In section 10.3, I will address the impact of the variety of fees related to the public good concept that can be used to fund ZBO services. Each of these forms may have a different impact on the possibility of shifting governance models from compliance control to matching of supply and demand.

Market dimensions are not the only relevant issues to discuss with respect to controlling production of public services. Although public services provided by ZBOs all have a unilaterally binding character; the production process may vary due to the underlying characteristics of the services. I will discuss these underlying characteristics in 
section 10.4. Finally, section 10.5 provides a conclusion on the market settings in which ZBOs provide their services.

\subsection{Supply: between government production and privatisation.}

\subsubsection{Privatisation and decentralisation}

As noted before, real (economic) privatisation does not apply to ZBOs. Therefore, privatisation of supply and demand is studied separately. In the case of privatisation of supply, the concept of outsourcing (Kok, 2003; Von Weizsäcker, Young \& Finger, 2005) and contracting (out) are often referred to in the literature (Kettl, 1993; Domberger, 1998; Guttman, 2003; Greve, 2008).

\section{Examples of provision of public services.}

Grant provision in relation to ZBOs is hard to find. One of the few examples is 'Stichting Patiëntenfonds' that was created in 1996 after it was concluded that the services to be supplied could not be carried out within the framework of public law (Parliament, 1996a, p. 12).

Regulated provision seems to be a more common form for supply of services by ZBOs. The regulated provision type can particularly be found in monitoring and research type ZBOs. An example is 'Centraal Bureau Rijvaardigheidsbewijzen' [CBR], responsible for driving licence examination. Government has specified the requirements in the law and CBR plans the examination based on the demand from individual citizens who pay fully for the service. The CBR case is an example of an institution operating as a monopolist. Part-time quality assurance ZBOs in particular operate in a competitive setting. The best known example is the periodic motor vehicle test APK performed by licensed car dealers and service stations.

The most common form of service provision is found in contract provision. This form exists in a wide variety of cases, ranging from the Kiesraad (Dutch Electoral Council) which receives an input based lump sum for its activities to IBGroep which is paid on a cost price basis by MinOCW to provide income transfers.

A more fundamental analysis of the various forms of organising supply was developed by Boorsma and Mol (1983). They identified five different settings for production of government services. In a later study, Bokkes (1989, p. 10) prefers to use service provision rather than service production. His argument is that provision better reflects the actual relationship because a consolidated market does not have the character of a market in economic and legal terms. As this argument also holds for what may be called quasi markets in relationships between two public entities, I will adapt Boorsma and Mol's model by using Bokkes' concept of service provision when referring to interorganisational transactions within the public sector. The key features of the forms of provision of public services are disclosed in Table 10.1. 
Table 10.1: Forms of provision of public services (source: Boorsma \& Mol, 1983)

\begin{tabular}{|l|c|c|c|c|c|}
\hline & $\begin{array}{l}\text { Consolidated } \\
\text { provision }\end{array}$ & $\begin{array}{l}\text { Contract } \\
\text { provision }\end{array}$ & $\begin{array}{l}\text { Grant } \\
\text { provision }\end{array}$ & $\begin{array}{l}\text { Regulated } \\
\text { provision }\end{array}$ & $\begin{array}{l}\text { Private } \\
\text { provision }\end{array}$ \\
\hline Government plans & $\mathrm{X}$ & $\mathrm{X}$ & - & $\mathrm{X}$ & - \\
\hline Government funds & $\mathrm{X}$ & $\mathrm{X}$ & $\mathrm{X}$ & - & - \\
\hline Government produces & $\mathrm{X}$ & - & - & - & - \\
\hline
\end{tabular}

The other and related concepts like outsourcing and contracting out will be included in the more in depth discussion on Boorsma and Mol's analysis. The section is concluded with an analysis of the impact of the various forms of service supply on ZBO autonomy.

\subsubsection{Traditional government provision and full market provision}

In the traditional case, government controls the full process of supply by (1) planning the level and quality of production, (2) funding it by general taxes and (3) actually producing the service. This form of government provision of services is labelled "consolidated provision' by Boorsma and Mol, which means that at the national level, the service is provided by the traditional structure of ministries. ${ }^{137}$ Consolidated provision is at one end of the scale, including full control of service provision by government. At the other end of the scale government has no role whatsoever in the process of delivering services. This form is labelled 'private provision' and is either a traditional market provision of services or a service that has been fully privatised as with the former State postal and telecom services (Parliament, 2006f, p. 4; Parliament 2007g, p. 3).

Consolidated provision and private provision are not an adequate description of the relationship between ZBO and Parliament and minister. Neither Boorsma and Mol nor Bokkes explicitly specify the concept 'government'. From the examples they provide, the implicit assumption can be derived that government is regarded as a single entity at a territorial level. As ZBOs are in most but not all cases separate legal entities, they do not seem to be included in the concept of government as meant by Boorsma and Mol. This means that consolidated provision is not relevant for ZBOs under the assumption that they can be regarded as units operating separately from the government hierarchical command structure. ${ }^{138}$ In principle, the same holds for private provision because the tasks assigned to ZBOs are determined by government decisions. Only if the ZBO is allowed to provide market services alongside the authoritative services specified by government may the private provision model be relevant.

In the following subsections, I will discuss the three forms of service provision that exist between consolidated and private provision of services. These forms can be applied to at least the ZBOs that have a separate legal status. I will also use it for the 'Shelter ZBOs' because these units were created to operate outside the hierarchical command

${ }^{137}$ At the time Boorsma and Mol's work was published, executive agencies did not exist in the Netherlands. I would argue with the present knowledge that as executive agencies are in most cases funded by central government, these executive agencies can also be classified under 'consolidated provision'

138 Only in case of Shelter ZBOs which have no separate legal status there is a case to be made for consolidated provision. 
structure of the ministries and the main reason that they do not have a separate legal status is because of the size of the unit.

\subsubsection{Contract provision}

Closest to traditional consolidated provision is the case in which only actual provision of services is left to the market. Government still controls services' funding and planning. An example of this is found when government outsources household waste collection (Van Genugten, 2008) or hires specific knowledge from the private sector that it cannot organise by itself. The concept of contract provision is often referred to in particular in concepts as contracting out and outsourcing.

Contracting out is according to Domberger (1998, p. 12) 'the design and implementation of contractual relationships between purchasers and suppliers'. Contracting out is possible if the market is contestable, implying that costs of entry and exit to the market are low. If not, government should produce the services itself (Vining \& Weimer, 1990). Others (e.g. Kee \& Robbins, 2003; Gregory, 2004) use cost benefit criteria for decision making on contracting out, but Vining and Weimer's concept is more elegant as it fundamentally raises the question of whether or not a specific service can be produced in a market setting.

Kok (2002, p. 2) describes outsourcing as purchasing a service that was formerly produced within its own organisation. In Von Weizsäcker et al.'s (2005, p. 6-7) definition, outsourcing is related to transfer of production to private actors. The contracting definition of Vining and Weimer provides an indication when to use third parties, whereas Kok's and Von Weizsäcker et al.'s definitions emphasise the organisational structure as such.

The concept of 'actively hiving off' as used by Boorsma and Mol (1983, p. 24) is close to outsourcing, but where outsourcing ceases to be performed if demand ceases, hiving off implies that supply of services is to be continued under some form of government control, only at arm's length of the government hierarchy. Boorsma and Mol's argument implicitly includes elements of the contestability issue also mentioned by Vining and Weimer. Apparently there must be some reason not to transfer production to the market and such a reason could be problematic market access.

In the contract provision case, supply is left to an entity outside hierarchical government but demand is still driven by government. Strictly speaking, contract provision of services means that the production of services is realised by entities not controlled by government. In this study, I use the characteristic elements 'funding by government' and 'planning by government' as identified by Boorsma and Mol (1983) to identify the relationship between the ZBO and the commissioning ministry. The actual form of commissioning by a ministry is not necessarily a contract as is the case when government purchases the service in a competitive market as meant by Vining and Weimer (1990). The contract provision concept can refer to two different forms of service provision. One is the option for government to use a particular service provider to deliver a case specific 
service, for example an ICT project or temporary staff. This option is often associated with outsourcing (e.g. Kok, 2003). The other option is that government wants to provide or use a particular service for a long period of time and uses a tendering procedure (Ashworth, 2002 p. 319; Arrowsmith, 2003, p. 2) to find a service provider in the market. A ZBO is generally created to deliver a service for a long period of time; hence the contract provision concept for a ZBO has parallels to experience from tendering procedures rather than from outsourcing procedures.

Contract provision may result in risks in controlling the services delivered. Sclar (2000, p. 3-15) refers to mutual dependencies between supplier and the commissioning organisation. This can for example be caused by the specialised technology or knowledge used to deliver the service. Another complicating factor is information asymmetry that is the result of the separation between production and commissioning of services. In a ZBO context, there is no competition for the production of services, which means that the potential benefit of market competition is not realised. That does not mean that no efficiency gains are possible, but that these are caused by other conditions, for example improved flexibility in the organisation compared to "consolidated government production'. Another point to be made is that total cost reductions might not be as high as expected due to the additional monitoring that is required with respect to the services delivered. Nijkamp and Ubbels (1998) note in the context of infrastructure projects, that changing the project leads to substantial transaction costs. The issue of transaction costs is likely to hold for ZBOs as well when the task assigned is substantially changed or other issues regarding uncertainty affect operations. As noted in chapter 9, high levels of transaction costs and or uncertainty might be an argument not to autonomise production.

Bokkes (1989, p. 14-15) identified several sub-forms of contract provision, each of which includes the key factors of planning and funding service provision by government. Two of these forms ${ }^{139}$ seem to be relevant when studying ZBOs because they can be associated with the discussion on motives for creating a ZBO. 'Special contract provision' refers to the case in which government does not have the skills and knowledge to provide the service themselves. Special contract provision can be associated with the 'impartial judgement', 'expertise' and 'participation of third parties' motives as mentioned by Boxum et al. (1989, p. 37-38). The second option is 'strategic contract provision'. In Bokkes' analysis, more flexibility is generated within the organisation by deliberately understaffing it. As a result, external staff is required. In the 1980s, budgetary rules were rather strict and did not allow for flexibility (see e.g. Scheltema Committee, 1993, p. 54). Indirectly the 'strategic contract provision' can be related to the debates on separation between policy preparation and policy execution and the role of ministries in the organisational structure of government. This debate has led to the creation of executive

139 The other forms are 'regular capacity based contract provision' meant to be able to handle temporary high demand and 'enforced capacity based contract provision', which refers to the case when unexpected factors influence production levels. 
agencies and the second peak in creating ZBOs in the early 1990s (Van Thiel, Leeuw, Siegers \& Flap, 1999, p. 34). The inflexibility argument in hiring staff to ministries no longer holds; in 1998 questions were raised in Parliament on the level of spending on hired staff in government (Parliament, 1998a) and Cabinet imposed restrictions on hiring temporary staff in 2003 (Parliament, 2003b p. 66). An extended interpretation of 'strategic contract provision', given the development of ZBOs, would be that the efficiency argument 140 for creating ZBOs that was regarded as increasingly important under the influence of fiscal distress and new public management theories is a version of 'strategic contract provision'.

\subsubsection{Grant provision}

In the 'grant provision' case, government's role is reduced to (partial) funding. Actual production and planning ${ }^{141}$ are realised outside the government hierarchy. An example is found in public education which is for the most part funded by government but organised outside the government structure.

According to Boorsma and $\mathrm{Mol}$ (1983, p. 26) the grant provision case requires a government role in funding of the service delivered to citizens. The service may be provided for free or at a fee below cost price and the difference between total costs and fee charged is paid for by government. Grant provision may have two forms. First, government can provide a start-up grant to create an entity that is supposed to provide particular services to the market and then leaves it to the market to accept the services. An example of a start-up grant in the Netherlands is found in the case of the (former ZBO) re-integration company Kliq (Parliament, 2003b, p. 3). The end result of this start-up grant was that Kliq did not survive in its market. The other option is for government to provide a structural grant to the organisation. This is what happens in the case of for example public libraries and in education. The grant provision model is more or less ambiguous. Boorsma and $\mathrm{Mol}(1983$, p. 27) note that receiving a grant often implies that conditions set by government have to be met in order to receive the grant. They only refer to mixing up regulation and grant provision, but in the example of the libraries given before, one might claim that the specification of services by government actually results in a contract relationship. In the Dutch public library case, revenues from sources other than government are generally so small that government nearly funds the entire service. It might also be that an organisation provides a number of services, some of which are funded by citizens and others are funded by government. In that case, grant provision holds for the government funded services and the organisation has elements of hybridity including the risks of cross subsidisation and production bias as mentioned by Simon (1989 and 2005).

140 Boxum et al. noted in their study (1989 p. 39) that the efficiency issue was at that time at best a secondary argument for autonomisation.

141 Bokkes, (1989, p. 14-15) noted that grant provision applies some level of planning by government due to the often included conditions for receiving the grant. 


\subsubsection{Regulated provision}

Finally some short notes on regulated provision are made. Regulated provision of services refers to the case in which government plans service provision but leaves production, funding and distribution to the private market. This form of service provision implies that government specifies the service requirements but leaves all other issues to the market. An example can be found in quality or safety assurance requirements that are laid down in the market. The private market will provide the service; if not, the product is not allowed on the market or penalties will be awarded if the requirements are violated. Government's role is then to monitor the specifications set and can include licensing organisations to deliver a service. In that case, the market setting exists but only organisations that have complied with ex ante controls set by government can enter the market.

\subsubsection{Impact of types of service provision on autonomy of ZBOs}

By now, all five forms of service provision for government services have been discussed. If a ZBO is used as a service provider, consolidated provision and market provision are not relevant. This leaves three options: contract provision, grant provision and regulated provision. In more general terms, the literature uses outsourcing (e.g. Kok, 2003; Von Weiszäcker et al., 2005) if government is no longer fully in control of service provision. The outsourcing concept is ambiguous as some use it only in relation to private provision of services (Von Weiszäcker et al., 2005) whereas others use outsourcing irrespective of the organisational structures (Kok, 2003). Furthermore, the concept of contracting out (Domberger, 1998) is not fully acceptable either for ZBOs because that would suggest that competition is possible. Therefore, I prefer to use the differentiation developed by Boorsma and Mol using three intermediate stages between full government provision and full market provision.

When assessing the contract provision, grant provision and regulated provision possibilities for the different types of ZBOs, the following options are possible. Contract provision is relevant for both PLAs and PLBs. Given the fact that government both plans and funds, the politically expressed proposition to only use PLBs as an option of last resort (AW1996:124b.2; kZBO:4.2 ), it seems likely that contract provision in general will be realised by PLAs rather than PLBs. In case of grant provision, the opposite seems to be plausible, particularly in the case of structural grants which are meant to cover the difference between fees generated from demand and total costs of supplying the service. Furthermore, a start-up grant for a PLA is unlikely given the legislative procedure that is required to create a PLA. Regulated provision is likely to exist for both PLAs as well as PLBs; from a supply perspective there seems to be no specific criterion to choose either the PLA or the PLB form. Finally, free market provision with respect to supply of ZBO services does not apply, irrespective of the legal status of a ZBO. If the ZBO provides multiple services it is possible that some services have a free market-supply character, because they do not qualify as an authoritative task. In that case the ZBO has a hybrid 
character which is primarily possible in relation to PLBs fulfilling a minor ZBO function only.

As in all analysis factors in this study, service provision is studied from the perspective of a single service provided by a ZBO, unless otherwise stated. This means that when an analysis is made from the perspective of supply of services, one has to be aware that sales generated by government are only one element in classifying a ZBO. When a ZBO provides more than one service, it is possible that different supply relationships exist for each of these services.

Having different supply relations within a single ZBO may result in conflicting interests, not only from a perspective of planning and prioritising production. In Simon's strategic function typology (Simon, 1989, 2005) a differentiation is made between market and non-market services. His analysis has a relationship to the market services - (im)pure public services discussion (see section 10.3.3) because non-market services are in Simon's perspective to be controlled by a governing body external to the producing organisation (Simon, 2005, p. 39) whereas in a market setting, the organisation producing services is fully responsible for continuity. In other words, in a task organisation, allocation of resources and desired levels of production are based on external decisions (similar to those that are needed to determine the provision of public goods), whereas in a market organisation, production is purely a result of matching supply and demand. Simon claims that if an organisation is operating on the two fundamentally different markets, in the end control will be based on the commonly used tools for one of the two markets at the expense of controls for the other market. ${ }^{142}$ Simon's analysis has a practical relevance when studying the turnover breakdown of an organisation. He claims that if market-based turnover increases to over $10 \%$ of total turnover of an organisation, managerial problems will arise due to the differences in required control systems (Simon, 2005, p. 41).

Finally, I will discuss the impact of the various forms of service provision on ZBO autonomy. Contract provision has the lowest level of autonomy because government sets production standards and funds the activities. This means that budgets have to be authorised by Parliament. Next on the scale would be the case in which structural grants are provided, due to the required budget authorisation process, but also because it is likely that some non financial requirements are set in relation to the grants to be received. Regulated provision is close to the structural grant case but has more degrees of freedom because funding is generated from citizens. A start-up grant case means that government is willing to help the organisation to get started, but then leaves it to the market. In terms of autonomy, that is relatively close to the last option of private service provision which is fully autonomous from government intervention. Table 10.2

\footnotetext{
142 In a task environment, controls will tend to compliance which affects flexibility in a (commercial) market setting and the other way round.
} 
summarises the expected position of ZBO types in relation to supply and autonomy from Parliament and minister.

Table 10.2: Different supply models per ZBO type

\begin{tabular}{|l|l|l|l|l|c|c|}
\hline Autonomy & Low & \multicolumn{2}{|l|}{ High } \\
\hline Supply & $\begin{array}{l}\text { Consolidated } \\
\text { provision }\end{array}$ & $\begin{array}{l}\text { Contract } \\
\text { provision }\end{array}$ & $\begin{array}{l}\text { Structural } \\
\text { grant } \\
\text { provision }\end{array}$ & $\begin{array}{l}\text { Regulated } \\
\text { provision }\end{array}$ & $\begin{array}{l}\text { Start-up grant } \\
\text { provision }\end{array}$ & $\begin{array}{l}\text { Private } \\
\text { provision }\end{array}$ \\
\hline PLA & 0 & +++ & + & ++ & 0 & 0 \\
\hline PLB & 0 & ++ & ++ & ++ & + & $*$ \\
\hline $\begin{array}{l}\text { Legend: } \\
\text { O: not applicable; +: may exist; ++ likely to exist; +++ highly likely to exist * only in hybrid ZBOs }\end{array}$ \\
\hline
\end{tabular}

In this subsection, it was shown that using ZBOs for the production of services can be regarded as a form of privatisation of supply. The hierarchical structure of government no longer controls the full production process which means that there is no case of 'consolidated production'. Government's role is reduced to planning and/or funding the services produced. Using a ZBO for a single service cannot be classified as a form of 'pure privatisation' because government still has control over at least one element in the production process.

\subsection{Demand: funding as an autonomy indicator}

\subsubsection{Introduction}

Provision of government services is based on two factors. The first is the desire to provide a particular service such as security. The second element is the actual production of the service. In the previous section, supply was discussed. In this section the emphasis is on demand and in particular the possibilities for privatising demand. The key issue in this section is funding of public services as an expression of demand generated. Whether or not demand can be privatised depends on the market characteristics of a service which can be analysed from theory on public goods. If a service is classified as a public good, it means that the possibilities for generating demand are different from services that can be classified as market goods. I recall that in the legal section, I have classified demand into four categories based on contract relationships, ranging from full state demand to free market demand. Full state demand may be an indication that a particular service qualifies as a public good. Using a market categorisation is meant to identify relevant players in the market; not to define the level of aggregate demand. When different (groups) of individuals can be identified as generating demand, it is possible to assess a range of forms of funding of services, ranging from general taxation if demand is fully generated by the State to market prices if demand is fully individually driven.

The debate on funding government services is not new. In Medieval Europe personal services between lord and vassal were the basis of protection and other (public) services. With the revival of the financial system, the growth of cities and the development of mercenary armies, there was a need to fund public services by financial resources instead of by personal services (Grapperhaus, 1989, p. 11). This development was reinforced by the collective interests of those who paid the contributions to the lord. $A$ 
fine Dutch example of this basic concept of funding is the contribution to a regional water board which had - and still has - the task of protecting citizens in their jurisdiction from flooding. It was only after the end of the Feudal system that general forms of taxation were introduced and the role of contributions for public services was reduced. This resulted in funding of goods and services either on the basis of private prices and supply or public supply funded by taxation. In modern times, the need to fund public supply through taxation is contested, both on ideological grounds and with economic arguments. The core of the economic argument lies in the problems that result from the ex ante governance system, requiring rationality and full information in order to be able to plan production. The critique on the ex ante governance system, reinforced by fiscal distress in many countries particularly from the 1980s onwards and changes in technology to pay for government services led to reassessment of funding of public services. For example, several Dutch local governments nowadays charge citizens per unit of household waste collected rather than based on a standard price per household (Dekkers, 2007; Van Genugten, 2008).

I will start with a short description of differences between funding, financing and subsidising. These three forms of cash payments to an organisation have different impacts on the supply of and demand for services (section 10.3.2). The next step focuses on market characteristics of services provided by discussing the public good concept in section 10.3.3. In section 10.3.4, this is followed by a general description of prices and taxes as an introduction to the several forms of funding that are used in the public sector. Finally, section 10.4 provides a summary of the impact of the market for ZBO services on autonomy.

\subsubsection{Funding, Financing and Subsidising}

Once the infrastructure in terms of assets is available, an organisation can produce and will be paid for the production delivered. This basic model holds for all producing entities, be it traditional government or a private company. The resources used to set up the infrastructure of an organisation is generally referred to as financing, whereas the resources that are generated from operations by means of sale of production is labelled revenue or funding. In the following subsections, I will elaborate on the differences between funding, financing and subsidising as different types of resources for an organisation.

\subsubsection{Funding}

Mol (2008, p. 258-259) identifies two main cash flows to and from an organisation. The primary cash flows have to do with the operations of the organisation - in the words of Bhimani, Horngren, Datar and Foster (2008, p. 475) the operating budgets - consisting of incoming cash flows related to production. In this section, emphasis is on the incoming cash flow from operations. In a commercial setting, these incoming cash flows are labelled as revenues. Bhimani et al (2008, p. 944) refer to them as an '...inflow of assets received in exchange for products or services provided to customers.' Horngren, Sundem, 
Stratton, Burgstahler and Schatzberg (2011, p. 640) state that revenues are increases in ownership claims arising from the delivery of goods and services. The IPSASB defined revenues in IPSAS1 as "gross inflow of economic benefits or service potential during the reporting period when these inflows result in an increase in net assets/equity, other than increases relating to contributions from owners.' All these definitions have the common feature of affecting the aggregated equity of an organisation. They differ in scope as the IPSAS definition does not have an immediate relationship to a reciprocal transaction delivery of services - as do the other definitions mentioned. In more general terms, revenues reflect the relationship between the actual cost of production (expenses), including matching the costs of using assets to the transfer of a good or service to the commissioner who will use the goods delivered. Ultimately, it is the cash payment for a service delivered.

From the IPSAS definition, it can be derived that a reciprocal transaction is not always required in a public sector environment. Revenue in a public sector setting does not even need to be voluntary and can be regarded as a contribution paid by the commissioner in this case not necessarily user - of a service to cover costs incurred. As the concept revenue is used differently in public and private sector settings, I will use funding rather than revenues when I refer to a payment either made in exchange for a directly delivered public service or as a (partial) compensation for indirectly delivered public services. By making a distinction between directly and indirectly delivered public services, there is no requirement for a direct exchange or claim on a particular service by the one who is funding the service. Two examples illustrate the difference. Supplying a passport to an individual results in a direct exchange of funding and service, if the individual receiving the passport actually pays for it. Funding of a monitoring institution results in delivery of services to society as a whole. Those who actually pay the monitoring institution have no claim on a particular individual service from the monitoring institution; they merely compensate the monitoring institution for incurred costs.

In a public sector environment funding is a contribution by the commissioner and not necessarily the user of a service. Furthermore, it does not always reflect the price a commissioner is willing to pay for a service as is the case in a market setting. The choices made in the process of calculating full cost recovery determine the sources of funding as a combination of (cost) price and - when desired - contributions from government budget. The result of this combination is reflected in the income statement of the organisation delivering the service (IPSAS1:7). ${ }^{143}$ In a market setting, commissioner and user of a service are in general the same individual or entity which is also a relevant distinction in the public sector. Funding can be considered to be equal to prices if the consumer has a choice in a market between different suppliers or has the option not to consume the service. In most ZBO cases a pure pricing system is unlikely because at least one of these two conditions is not met. Only under the accruals accounting system

143 The income statement shows the expenses and revenues that have lead to the profit or loss reported. 
can the concept of financing be used to express the relationship between the financial resources used to obtain the necessary assets for (government) production.

\subsubsection{Financing}

Whereas funding is related to (in)direct service delivery, financing is related to the resources used to cover capital expenditures (e.g. Brealy and Myers, 1991, p, 287; Groot \& Van Helden, 2003, p. 105). Financing of capital expenditures comes in two forms. The first form is equity, the risk-bearing capital in the organisation, provided by the owners or shareholders. The second form is long and short term debts, the relatively low-risk capital usually provided by banks and suppliers. In the public sector, equity is a complicated concept, as there is in many cases no owner who can claim a share of risk-bearing capital and residual income. Equity in this case is a result from the accumulated 'profits' and 'losses', in some cases reinforced by voluntary cash payments (gifts) from stakeholders. In the IPSAS standards, equity is described as 'net assets/equity', the residual interest in the assets of the entity after deducting all its liabilities (IPSAS1:7).

Financing is relevant from a perspective of having access to cash flows that allow an infrastructure needed for operations to be set up. In a commercial setting, an entity will need access to the capital markets when raising financing is required. In a public sector setting, more particularly ZBOs, it will depend on the particular arrangements made. Financing can be realised by borrowing from the State, grants from the State, access to the capital markets by either issuing bonds or generating equity from the capital market as well as from accumulated positive results from operations. Given the legal measures (CW2001:45) direct access to capital markets is currently excluded for most ZBOs.

\subsubsection{Subsidies}

A last concept to be discussed is a subsidy. A subsidy can be described as a financial contribution by someone who is not necessarily using a service of the entity that is granted the financial contribution (see e.g. Mol, 1998, p. 224). In more general macroeconomic terms, subsidising is referred to as income transfers (see e.g. Goedhart, 1958, p. 52; Eijgelshoven, Nentjes \& Van Velthoven, 1996, p. 288-289). Eijgelshoven et al. refer to two types of income transfers. First, restricted income transfers are meant to be spent on a particular project or activity, which might include buying assets. Second, unrestricted income transfers are fully at the disposal of the receiving entity. A subsidy is generally given on an objectively assessable basis and may be accompanied by reporting and spending conditions independent of demand for services. In a subsidy case, the user of the service provided is not the same as the one who has transferred the cash flow. If a link to demand for services is relevant, there is a case of reciprocity between provider of the cash payment and the receiving party which demands that the receiving party does deliver to or on behalf of the provider. To be clearer an example may be helpful. Central government can require that entrance to higher education must be given to anyone who has the relevant qualifications. The individual in question may be made responsible for funding (part of) the education program. If they are unable to pay, government may 
decide to grant a subsidy to the individual to make it possible for them to participate in the relevant courses. Another solution is to subsidise or fund the institution providing higher education to allow the institution to reduce the fees charged to individuals to participate in the program. In this example, the individual is the final user of the service whereas commissioning and funding are performed under the responsibility of the minister of education, resulting in a citizen's request contract form.

A last point to be made is that if government provides the risk bearing capital in the form of a voluntary cash payment without any corresponding service delivered by the receiving organisation, that cash payment can be regarded as a (start-up) subsidy. Depending on possible restrictions set when the subsidy is granted, the receiving organisation is basically allowed to use the payment at its own discretion.

The difference between funding and subsidy is relevant for two reasons. Funding has a relation to supply and demand and the options that may exist to privatise demand. Subsidising can lower the fee charged to a user of the service and as a result can have an impact on the level of demand. Subsidising does not affect the options for privatising demand because it does not affect the characteristics of the service to be provided. Furthermore as a result of their production processes, 'income transfer' ZBOs provide cash payments that have the character of a subsidy (grant). ${ }^{144}$ When assessing the position of such an autonomised organisation, the cash flow generated with respect to the distributed subsidies is not relevant for the costs of the production process and should be excluded.

\subsubsection{Public Services}

In a market setting a service is provided to an individual in exchange for payment. No other individual than the one who has demanded the service and has paid for it, has the right to have the benefits of that service. In a public setting, the opposite is true. An individual can demand a service, be willing to pay for it but cannot exclude others from having the same benefits without simultaneously paying for the service. Classic public goods/services (Cullis \& Jones, 1998, p. 50; Hillman, 2003, p. 63-65; Rosen, 2005, p. 55-58) have the characteristic of being non-excludable and non-rival. Rosen (2005, p. 58) states that whether or not a service is regarded as a public service depends on market conditions and technology and may vary over time. Furthermore, public services need not necessarily be produced by government. In the case of household waste collection (Van Genugten, 2008), government can hire private firms to actually do the work. Government also has the option to charge citizens by means of a general tax, but it is also possible that government permits citizens to pay on the basis of the quantity of waste produced by the citizen.

Production of a public service will in most cases have a monopolistic character; there is only one provider who is allowed to deliver the service. To simulate a market setting, a

144 In the example of higher education, in the present (2009) Dutch system, the 'grant' actually is a mixture of subsidy and financing. 
tendering procedure can be used to select the most efficient provider. This provider will then be allowed to provide the service for a specified period of time, after which a new tendering procedure is started.

If either non-excludability or non-rivalness can be contested, the service is regarded as an impure public service. Depending on the characteristics of the service, government can regulate access to the service by pricing or other requirements resulting in thresholds to have access to a market. Take for example a toll road. By using a fee, government can try to influence levels of congestion, thus influencing demand. The same tool may also have an effect on the supply of transport services: suppose taxis have to pay the fee just like private individuals in their own cars. The fee charged from the taxi driver may result in a hurdle for access in the taxi market if the fee cannot be priced into the taxi service. As a result, supply of taxis will fall until reduced supply allows taxi fares to rise to a level that covers the fees imposed upon the taxi driver.

In case of impure non-rival services, the marginal costs of providing the service to an additional individual are zero. Alternatively the costs of excluding an individual can be excessively high, resulting in a practical obstacle to exclude an individual. In the first case, one can argue that the supply side perspective seems to be leading: the producer is indifferent how many individuals are using the service. Actual service delivery is still based on demand for services. This implies that funding of the service has a tax based characteristic in order to avoid free rider problems (Cullis \& Jones, 1998, p. 48). In the case of non-excludability, demand is the problem: it is not possible to influence demand by supply driven tools because it is expected that the costs incurred to implement thresholds are too high. If both non-excludability and non-rivalness can be overcome, a publicly provided service actually has the character of a market service. An example of this is found in publicly provided housing: excludability and rivalness exists by charging rents and leasing the house to a single tenant. In Table 10.3 a summary of the variety of (im)pure public services is given.

Table 10.3: Pure and impure public services

\begin{tabular}{|l|c|c|c|c|}
\hline & Pure public service & $\begin{array}{l}\text { Impure supply } \\
\text { driven public } \\
\text { service }\end{array}$ & $\begin{array}{l}\text { Impure demand } \\
\text { driven public } \\
\text { service }\end{array}$ & Market service \\
\hline Non-excludable & $\mathrm{Y}$ & $\mathrm{Y}$ & - & - \\
\hline Non-rival & $\mathrm{Y}$ & - & $\mathrm{y}$ & - \\
\hline
\end{tabular}

In this study, it is not the impact on demand and supply of (impure) public services that is under scrutiny. The emphasis is on the production of these services on behalf of government by a ZBO. The definition of a ZBO includes ZBO services being characterised by a unilateral decision on behalf of government. This suggests that ZBO services can be characterised as either pure or impure public services. However, a ZBO may even provide authoritative public services that can be characterised as market services rather than as im(pure) public services. The 'RDW' case already mentioned in Part A is an example of this. Motor vehicle registration is a service that is performed solely for a single 
user/owner of the car. No one else has a claim at the same time on that particular registration; hence the service has an excludable and rival character.

The key distinction in services provided from a control perspective is between market services, which allow control under Smith's invisible hand and (im)pure public services for which a form of budgetary control is required. The relevance of the distinction between pure and demand driven impure public services on the one hand and impure supply driven and market public services on the other is found in the theoretical possibilities for funding alternatives. A traditional and a non rival public service can only be funded by taxes given the free rider problem implied by the characteristics of the service and thus requires a democratically based allocation mechanism. In case of demand driven impure as well as market public services funding may be realised by forms of contributions from users as price can be used to discriminate between users. This has an impact on controls including the budget authorisation process and the ex post controls to be used by Parliament to monitor the activities of the various ZBOs.

\subsubsection{Privatisation of demand}

In this section, I discuss the possibilities of changing funding from general taxation into forms of funding that have a relation to particular services delivered by government. Lane (2000, p. 157) refers to privatisation of demand as a tool that '..strengthens the willingness of individuals to pay.' I will start with a general elaboration on privatisation of demand and then focus on the two key forms that can be identified, authority biased funding and market biased funding. The section is concluded by providing an overview of the various (sub)types of funding that were identified.

\subsubsection{General theory}

In the case of private service provision, funding a service is based on a (cost)price that is immediately related to an individually identifiable service (Mol, 1998, p. 147). Pricing is the financial reflection of a clearing market for supply and demand of services, under the conditions of open competition and full information available to all parties.

Prices imply that the services have an excludable and rival character. In case of a pure public good, these characteristics do not exist and thus some other form of funding has to be found, generally referred to as taxes. A tax can be defined as a forced transfer of money (or payment in kind) to government without compensation in return. Being enforced however does not affect the fact that citizens in a democratic society have chosen in freedom to accept that taxation influences their control of individual income and property (Grapperhaus, 1989, p. 11). The allocation mechanism used in the political system is an expression of the ex ante governance model for the distribution of taxfunded services provided by the (democratically elected) government.

As indicated, fiscal motives and technology have led to a change in thinking on funding of government services. The theoretical notions on using privatised funding are very generally provided by Stiglitz (2000, p. 457-475) when he claims that a good tax system 
should not interfere with the allocation of resources. Bohley (1980, p. 917) mentions three motives for non-tax government income. First he mentions the issue of efficiency, both Pareto-efficiency as well as cost-efficiency. Second, non-tax income gives opportunities to decentralise decision making whereas taxation demands central allocation decisions. He even notes that it might be possible for some services to be paid for by (small) specific groups, who have a special interest in that service, while if the service had been funded by taxes, the service would not be provided at all. Such a case exists when the majority of tax-payers have no interest in the service demanded by the group for which the service is relevant. Finally, non-tax income can be used as a tool for economic interventions (e.g. using environmental levies).

To these rational motives another, less rational motive can be added. The California 1978 Proposition 13 was the expression of a trend in the USA to limit the level of taxation. Actually it was the first initiative that restricted the ability of local governments to raise taxes. Thus government had two options, either reduce spending or find other ways of funding their activities. Anderson (1991, p. 13) shows that public opinion would accept other sources of funding above general raises in taxation. These developments have resulted in a revival of forms of charging for public services. The idea of using charges is not limited to the USA alone. The Thatcher administration in the UK strongly focused on privatisation and charging and Canada, Australia and New Zealand are also known examples of countries using charges (Blair Consulting Group, 1999; GPOC, 2002). In the Dutch context, forms of non-tax prices can traditionally be found at the local level, in the (former) State enterprises and more recently also in entities at arm's length of central government.

Using charges instead of taxes also has disadvantages as Bennet and DiLorenzo (1983) show. They find that there is a substantial risk that without adequate control mechanisms the budget of non-tax funded public organisations will rise at the expense of the users of government services. ${ }^{145}$ Implicitly this is a plea for budgetary control of privately funded government services and thus a plea for a form of ex ante control as well.

By introducing a form of prices to be charged for individual services, rather than using general taxes, funding is transferred to those individuals that use a particular government service. ${ }^{146}$ The process of changing the funding basis of services is labelled privatisation of demand (Boorsma \& Mol, 1983). Unlike the variety of options described under privatisation of supply, privatisation of demand exists as one single option: to let (groups of) individuals pay for the service either by market prices or by (full cost covering) contributions. By privatising demand, a shift towards ex post oriented governance

145 Of course monopolists in general have an incentive to raise prices at the expense of consumers. In an open market, there is always a possibility of a new competitor contesting the monopolist's position. This does not hold in a regulated market as is the case with ZBOs.

${ }^{146} \mathrm{~A}$ voucher giving access to a particular service can also be regarded as a form of creating demand for a service. However, it ultimately results in funding by government which has issued the voucher. 
systems is expected especially when market prices can be used. In the case of privatisation of demand, the individual can match demand to individual preferences and thus can indirectly influence the level of production. In the end this may lead to more efficient production and a withdrawal of the budget mechanism in favour of the market mechanism (adapted from Boorsma \& Mol, 1983, p. 22-23). When the market mechanism takes over, democratic control of production is - from the perspective of demand - no longer required. Thus, using other forms of funding rather than traditional general taxation may have an impact on service provider autonomy. When contributions are used, there is no pure market mechanism. There is still an immediate link between use of service and payment generated which does not exist in cases where general taxation forms the basis of funding a service.

The literature suggests numerous labels for the prices to be paid for the delivery of government services, ranging from contributions (e.g. Pierson, 1913) to prices (e.g. Bohley, 1980). All of these labels have their specific characteristics and are related to the commissioning perspective - the contracting models - as described in Part $\mathrm{B}$. The classification of types of funding is relevant because from a legal perspective, taxes can only imposed by law, whereas for other forms of fees no general regulations exist. This means that in the latter case, democratic control by Parliament is at least reduced. The classification of fees as a form of taxes or otherwise is thus relevant, not only from a formal perspective, but also because it is an indication of the autonomy of the organisation that charges fees. An elaboration on the variety of forms of privatised funding is therefore necessary.

The formal distinction in legislation between taxes and prices requires all forms of citizen funding to be classified on the basis of this distinction, because classification as a tax has a different impact on autonomy than classification as a price. Given the context of demand and supply that is at the heart of the analysis in this section, I will categorise fees under two groups that have (a) an authority bias - suggesting a tax resemblance or (b) a market bias suggesting that individual demand and supply are relevant for the payment of fees by citizens.

\subsubsection{Authority biased funding}

Public services which still have a non-excludable character need not to be paid for by general taxation. In a US context, Buchanan (1991, p. 159), claims that earmarked taxes have some relation to services provided. According to this author the fact that earmarked taxes exist is based on constitutional restrictions on the imposition of taxes in general. Similarly, Anderson (1991, p. 15-17) makes a link to compulsory services of government for which earmarked taxes are used to 'reimburse government for the costs of the provision of the service'. In practice, the relation between actual costs and earmarked taxes paid is weak. Musgrave (1959, p. 178) mentions earmarking of taxes as a tool in the allocation branch of government and later adds that (earmarked) taxes are compulsory and do not result in a liability for government as is the case when a price is 
charged (Musgrave \& Musgrave, 1989, p. 211-212). In a Dutch context, real147 earmarked taxes are hard to find. A good example is probably the levy imposed by water boards used for flood protection.

In Taylor's (1961, p. 250-254) classification, an opening is made to differentiate in the domain of compulsory payments. Taylor separates administrative revenues that are related to authoritative decisions made by government from taxation, implying that a form of reciprocity may also apply for authoritative services. In German and Dutch literature, this distinction is developed even further. Authors like Goedhart (1958), Mol (1998) and Grossekettler (2000) make a distinction between 'retributions' for authoritative services - for example a passport - which have a reciprocal character and a 'levy' - see the case of the water boards above - in the case of an individual service without a direct reciprocal liability by government. Mol (1998, p. 145-146) notes that the difference between retributions and levies is not very large and merely institutional, which means that in case of levies a public law decision has to be made to set the level of the charge. This is not required in case of retributions. In both cases, the services provided have a kind of reciprocal character. Neumark (1961, p. 323-334) did not make the distinction and labelled all authoritative individual transfers as levies. Whether or not the distinction retribution/levy is used, recovery of total costs seems to be the limit for the level of the retribution to be paid because the service provided is characterised by a partial individual benefit as well as a benefit to society as a whole (Goedhart, 1958, p. 83). Mol (1998, p. 149) notes that for Dutch local governments this rule was institutionalised in $1990 .{ }^{148}$

The word 'levy' or 'contribution'149 is however also used in the context of non reciprocal services for a particular group of users rather than related to an individual user. Pierson (1913, p. 578) distinguishes these levies from 'prices'/'user charges' for two reasons. The first reason is the lack of individual access to a benefit, the other that such contributions do not affect individual demand. Goedhart (1975, p. 126-127) identifies two kinds of contributions. The first is related to quasi-collective services such as social insurance premiums, the other is related to 'betterment-taxes' or 'special assessments' 150 which are charged as an instrument to recover private benefits as a result of public improvements, especially in infrastructure. In the latter case, the relationship to government production is rather weak; there is no liability from government towards the contributors. The private benefit is in many cases the result of side effects of public decisions; whereas quasi-collective services are intended to provide benefit towards those who pay the contributions. Freeman and Shoulders classify the

\footnotetext{
147 In the Netherlands a road tax is charged on owners of motor vehicles. Although the name suggests that there is a link to road maintenance costs, the revenues actually form part of government general funding in its fiscal revenues plan rather than dedicated income in relation to the department of infrastructure's budget.

148 In fact the rule has been re-institutionalised. Pierson (1913, p. 406) noted that before $1897 \mathrm{GW}$ had a similarly strong requirement.

149 In German the word is 'Beitrag'; Pierson (1913, p. 578) refers to this word when discussing contributions.

150 in Dutch: baatbelasting; article 222 GemW.
} 
special assessments under taxes which can be paid during a longer period (Freeman \& Shoulders, 2000, p. 267). In Anglo Saxon literature, these charges on a particular group of beneficiaries do not seem to be of much interest, the only reference I found was in Freeman and Shoulders (2000, p. 197 and p. 722) who use the word 'contribution' for voluntary non reciprocal transactions to government or non government not-for-profits. This is an essentially different approach: the Dutch and German interpretation implies a compulsory rather than a voluntary payment made by a particular group.

\subsubsection{Market biased funding}

Funding of government services based on the provision of services towards society as a whole is generally recognised as taxes. At the other end of the scale, when government provides services to individuals, these payments are generally referred to as '(public) prices' (e.g. Goedhart, 1958, p. 77) or 'user charges' (e.g. Anderson, 1991, p. 15), or more generally, fees. In general, funding of (reciprocal) services that are provided based on citizen demand is also labelled as prices (Pierson, 1913, p. 404-407; Goedhart, 1958, p. 77; Mol, 1998, p. 146-147). Van de Kar, cited in Groenendijk (1998, p. 155) makes a slightly different distinction when he refers to the voluntary character of the reciprocal service. If the reciprocal service provided is compulsory (e.g. local government restructuring a shopping area), then Van de Kar uses benefit tax rather than price. A similar distinction is found in Musgrave and Musgrave (1989, p. 211-212) although they label a voluntary payment as a user charge. Groenendijk classifies Van de Kar's distinction as inadequate because the voluntary character of a government service can be disputed. In Groenendijk's opinion, as long as demand is generated by citizens, payment by citizens qualifies as prices.

The demand driven character of prices/user charges is emphasised by authors like Hillman (2003) who mention the option of using a service as a distinctive feature. Mills (1987, p. 767-768) states that the only distinction between a (market) price and a user charge is supply by government rather than by private institutions. The OECD (1998) seems to have an ambiguous approach. On the one hand, they state that the "legal authority' for charging must be clearly defined (OECD, 1998, p. 7), suggesting an authoritative rather than a reciprocal relation between payment and service. On the other hand, the examples given by the OECD range from road pricing and medical service pricing to charging for fire fighting, which almost covers all areas of government. A user charge in an OECD context is thus anything that is not classified as a general tax.

Other concepts that are used for reciprocal services are 'quid pro quo payments' (Reed \& Swan, 1990, p. 77-83) for any reciprocal government service. Reed and Swan use 'user fees' for cases where government provides business like services such as public utilities or health services. Taylor (1961, p. 250-254) uses 'commercial revenues' for payments having a direct relation between receiving a commodity or service and a corresponding payment, distinguishing them from 'administrative revenues' and taxes. Although Groves and Bish (1973, p. 304-318) reserve 'price' for public utility charges and 'fees' for payments regarding privileges or rights given by government, their approach is 
still based on freedom of choice and thus on demand driven supply. Neumark (1961, p. 323-334) differentiates between prices if the supplying organisation's objective is to at least recover full costs. He uses 'tax prices' if prices should not exceed full costs. However, in both cases demand is still optional. Neumark's distinction has an impact on the budgetary procedures as well. Prices can be budgeted on a net income basis suggesting economic independence of the organisation as illustrated by Neumark's examples of public utilities and government enterprises. Tax prices should, in Neumark's opinion be budgeted on a gross basis because of the normative claim that the tax price should not exceed - and is often actually below - full costs.

In general, one can conclude that prices and user charges are concepts used in relation to demand driven reciprocal commodities and services provided by government. An important point was made by Neumark, when he claimed that if funding does not exceed full costs, gross budgeting is required. This results in a dichotomy of market biased funding: tax prices if only recovery of costs is allowed and prices if funding can be based on a cost plus basis.

\subsubsection{Impact of privatisation of demand}

The analysis presented above is based on the various types of charges that exist, not on the underlying cost calculations that are needed to determine the level of the charge to be claimed from citizens. When studying funding of an individual ZBO, cost calculation will be an issue if the ZBO produces more than one single service and has a variety of funding sources. In that case, the attribution of costs towards the different services is subject to arbitrary choices. This might even be more relevant in those cases where the different services are funded from different sources. In such cases there are risks of cross subsidisation, which may have an effect on demand, resulting in inefficient allocations. Cross subsidisation is especially relevant when an organisation provides services based on both reciprocal demand driven services as well as non authoritative services. Essentially, this has been discussed from the hybridity perspective by authors like In 't Veld (1995) and Simon (1989, 2005). In effect, that means that budgetary controls on authoritative services can be avoided at the expense of the reciprocal services to be delivered. This is possible because in most cases, the reciprocal services will still be provided in a monopolistic setting rather than a competitive setting. If that is the case, using adapted forms of ex ante governance tools such as setting price limits might prevent abuse by the monopolistic supplier of the services. 
By now it is possible to identify the main forms of funding that may be used in the public sector in general. Table 10.4 provides an overview of the variety that exists.

Table 10.4: Concepts and classification of forms of funding in the public sector

\begin{tabular}{|c|c|c|}
\hline & Type of charge & Characteristics \\
\hline \multirow{3}{*}{ 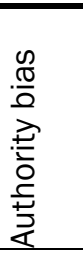 } & Tax & $\begin{array}{l}\text { Sovereign task, Non reciprocal, All Subjects, Unilaterally determined, } \\
\text { Gross Budgeting }\end{array}$ \\
\hline & Contribution & $\begin{array}{l}\text { Sovereign task, Non reciprocal, Group of Subjects, Unilaterally } \\
\text { determined, maximum recovery of full costs, Gross Budgeting }\end{array}$ \\
\hline & Levy & $\begin{array}{l}\text { Sovereign task, Non reciprocal, Individuals, Unilaterally determined, } \\
\text { maximum recovery of full costs, Gross Budgeting }\end{array}$ \\
\hline \multirow{2}{*}{ 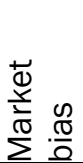 } & Tax Price & $\begin{array}{l}\text { Demand driven, Reciprocal, Individuals, Unilaterally determined, } \\
\text { recovery of full costs + allowed, Gross budgeting }\end{array}$ \\
\hline & Price & $\begin{array}{l}\text { Demand driven, Reciprocal, Individuals, Market controlled, at least } \\
\text { recovery of full costs, Net Budgeting }\end{array}$ \\
\hline
\end{tabular}

Two main criteria are relevant in this study: if funding is based on demand driven criteria, this is an indication for a market bias - not a market base as there is no real market for ZBO services - in the determination of the level of funding for the services. Second, there is a distinction between forms of funding that should cover full costs as a maximum and those for which full costs plus a profit151 is allowed. In the latter case, the organisation charging these forms of funding is in theory economically independent and thus has relatively more autonomy than entities that are only allowed to cover full costs. From a neo-institutional perspective, it means that a residual income is available and that arrangements have to be made on the use or distribution of the residual income. Furthermore, from a transaction cost perspective, one can argue that if market biased funding can be used, demand ultimately determines production and monitoring can focus on the distribution of residual income rather than compliance to costs and production levels. That means that transaction costs may be relatively low.

If only recovery of full costs is allowed, Neumark's statement that in that case budgets should be based on gross budgets is relevant as an indication for an ex ante control tool with respect to the services delivered. Monitoring in this case is likely to be more restrictive due to lack of transparency on demand which allows management to use the information gap between owner and agent of the organisation. That will lead to increased transaction costs. Basically authority biased funding means implies that no structural residual income is available. As a result, no property rights arrangements need to be made with respect to residual income.

From the perspective of autonomy of ZBOs, funding can be based on two main sources: 1) authority biased privatised funding which still requires an ex ante control tool and 2) demand driven market biased funding which allows for relatively more autonomy. As the tasks assigned to ZBOs have an authoritative character, an ex ante control tool will likely dominate the field. Particular attention is needed for the case where a mixture of market biased funding and authoritative funding exists.

151 Or theoretical compensation for additional value received from using the public service (Pierson, 1913) 


\subsection{Activities and services provided}

In the previous sections, focus was on the market for public services. Demand and supply may result in different forms of determining control of production levels. The actual production process that emerges from supply and demand is affected by characteristics of the services to be provided. This has an impact on possibilities for control as well.

In their conclusions on a study of executive agencies, Pollitt et al. (2004, p 265) note that it is extraordinary that '...some texts can discuss particular organisational structures and processes at length without ever specifying the particular activities to which they are supposed to apply'. I share their opinion that one cannot understand control of entities at arm's length of government without knowing what particular activities are performed by these organisations. In the case of ZBOs, the authoritative character of services provided is given by definition, but that does not give any clues to the activities that have to be performed to deliver these services. At first glance, one might argue that the definition also implies that there is a relation to the theory of public goods because government is the only institution that can impose unilateral decisions upon individuals as discussed before.

Pollitt et al.'s comment is reflected in debates on the types of services delivered by ZBOs. Smullen \& Van Thiel (2002) made a classification of five main groups of services each with different characteristics (see Part A) which will be used in this study as well. To give an example, a decision on income transfers differs from a production process perspective from a research based decision. In this subsection, I will address the impact of differences in product characteristics when commissioning services. Emphasis is not on the different contract relations that are possible, but on the contents of the production contract needed to specify the production of a particular service.

Controlling an organisation is a function of the production process in the organisation. Woodward (1965) identified three core types of production processes: mass production, unit production and process production. Mass production refers to standardised production of goods and services ready to be sold on demand, although in the case of services, production actually starts on demand. The mass production dimension is based on the standard procedure needed to deliver on demand rather than being delivered from stock in the case of goods. Unit production refers to custom made products and services based on the specifications or requirements of individual customers, including cases in which production is performed in small series produced to specific demand. Process production is related to continuous flow production, typically related to chemical processes. The control structure of these types of organisations is different. As process production is a typical industrial process, often found in chemical industries, it can be ignored here.

Mintzberg $(1979$, p. 253) notes that mass production processes are characterised by high levels of regulation and impersonal controls whereas unit production and its varieties have less regulated controls. Applied to organisations in the public sector, 
Kickert (1998, p. 91) differentiates between mass and serial production 152 on the one hand and unit production on the other. He does not make unit production explicit as such but uses two separate groups of service providers that can be regarded as having the characteristics of unit production. These two groups are professional autonomous entities such as R\&D units and higher education on the one hand and monitoring entities that focus on the compliance with legislation on the other hand. In both cases, a high level of professionalism is required and output cannot be strongly regulated. Kickert elaborates on the latter group by diversifying them into units with a relatively high level of policybased control (R\&D and higher education) to units (compliance) for which policy based control is not desired for reasons of impartiality (Kickert, 1998, p. 142-150).

Some 10 years before, Wilson observed that organisations could be classified along lines of measurability of outputs and outcomes (Wilson, 1989, p. 158-171). He argued that the four types of organisations identified require different forms of management control. Particularly in procedural and coping organisations, the lack of homogeneous outputs results in higher levels of degrees of freedom for staff (Wilson, 1989, p. 171).

Wilson's classification has a relation to Kickert's classification. In general, one can argue that in the case of mass production of rule based decision making, outputs and outcomes can be expected to be observable, whereas in professional organisations, there can be a debate on whether or not outputs or outcomes can be observable. To illustrate the point from a ZBO perspective, the aforementioned 'RDW' delivers observable rule based registrations, whereas the CBP is at best classified as a procedural organisation issuing rulings based on the professional assessment of legislation. From a transaction cost theory perspective, one can argue that RDW's decisions are of high frequency with low levels of uncertainty allowing for reduced transaction costs. In the CBP case, frequency is low, but specialised knowledge - asset specificity - may require close monitoring of operations although without intervening in the impartial character of the quasi judicial arrangement.

A weak point in Wilson's typology is that output and outcome are characteristics within a similar dimension: without production no outcomes will be achieved except for the outcomes that were already achieved without intervention. The typology does allow for internal management control in terms of capabilities needed for internal controls (see Ouchi, 1979 and Hofstede, 1981). From a production perspective the model contributes to the commissioning process because it splits the commissioning process in two subgroups. In one group, identifiable production is commissioned that allows well described service specifications. In the other group, production cannot be clearly identified, which means that it is hard to provide adequate services specifications. As a result, next to the service specification, additional control arrangements are needed that align the interests of commissioner and service provider. In chapter 11 , I will discuss a

152 In the original concept, series production is a subgroup of unit production. 
similar model that provides a relation towards budgeting and financial control even in cases where production cannot be precisely specified.

Output observable?

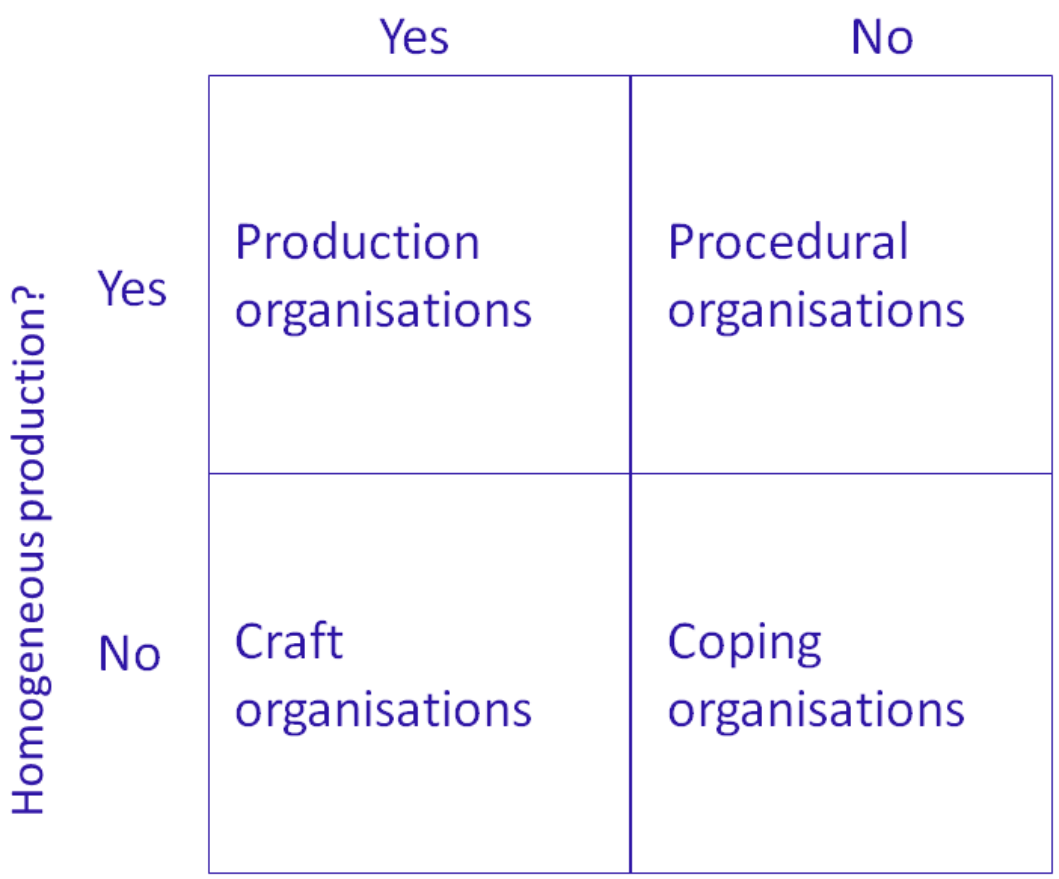

Figure 10.1: Type of organisation by characteristics of tasks (source: Wilson, 1989, p. 158-171)

Another form of classification that is closely related to Kickert's one is given by Abma and Noordegraaf (2003) who distinguish 'routine' and 'non-routine' production in organisations. This distinction is made in a context of ambiguous organisational goals and the possibility to respond to services delivered by consumers. This results in a matrix in which a one-sided interaction is opposed to a two-sided interaction. In the latter case, the service is a 'negotiated outcome' of the interaction between producers and consumers. The model is attractive when studying the whole range of quangos, but in the case of ZBOs, the concept of a two-sided interaction is missing due to the unilateral authority attributed to a ZBO. As a result, only the routine - non-routine scale remains, which strongly resembles the mass production organisation - professional organisation scale already discussed. Yet another slightly different classification that resembles the mass production - professional organisation dichotomy is found in Smullen and Van Thiel (2002, p. 39), who use ‘output production' versus ‘expertise production'.

In Part A, I have distinguished 5 different types of services provided by ZBOs. The attractiveness of that classification can also be illustrated when it is compared to the mass production - professional unit production dichotomy as discussed above. In general, it is possible to claim that 'stewardship', 'income transfers' and 'licensing' 
activities have a strong rule driven, routine character. In these cases frequency and uncertainty are relevant aspects from a transaction cost perspective. Furthermore it allows for output based directives as well as incentives as described under positive agency theory. Stewardship and licensing services may be related to very specific activities, which are basically rule driven but have to be processed based on individual unique - in terms of not similar to another case - demand which results in a classification of series or even unit production. An in depth analysis of product specifications is needed to understand the production processes in these cases. Only after doing so a statement on an expected control system can be given. 'Monitoring' and 'research' activities tend to have a professional 'non-routine' character, including issues on asset specificity and control by persuasion rather than by incentives and authority. In some cases, similarities in monitoring and research activities may allow for series production as well. The different forms of production are illustrated in Table 10.5.

Table 10.5: Production characteristics of ZBO services

\begin{tabular}{|l|c|c|c|c|c|}
\hline & Stewardship & $\begin{array}{l}\text { Income } \\
\text { transfer }\end{array}$ & Monitor & Research & Licensing \\
\hline Mass Production & $\mathrm{X}$ & $\mathrm{X}$ & & & $\mathrm{X}$ \\
\hline $\begin{array}{l}\text { Series } \\
\text { Production }\end{array}$ & $\mathrm{X}$ & & $\mathrm{X}$ & $\mathrm{X}$ & $\mathrm{X}$ \\
\hline $\begin{array}{l}\text { Professional unit } \\
\text { production }\end{array}$ & $\mathrm{X}$ & & $\mathrm{X}$ & $\mathrm{X}$ & $\mathrm{X}$ \\
\hline
\end{tabular}

Within the main types of ZBO services, it is possible to identify sub-groups that may be more similar to each other than to the population of the group as a whole (Smullen \& Van Thiel, 2002, p. 41). Such sub-groups will allow for a separate classification in production types whereas within the group as a whole, several production options are possible. An example from the research cluster is found in differences between quasi judicial services and training activities. These differences can be used to derive separate external control standards for each of these subgroups of services.

\subsection{Conclusion}

In this chapter economic dimensions of ZBO services were studied. I started by analysing supply. Provision of services can be organised in five different forms, ranging from consolidated provision by government to private provision in which government no longer has a role in the provisions of services. In the case of ZBOs, the three varieties in between are the most relevant options. In the contract provision model, government funds and plans production, reducing the demand side of services to a relatively subordinate matter. Contract provision thus has strong government controls which are an indication of relatively low levels of autonomy given the tasks assigned to ZBOs. Actual autonomy within the contract provision framework may still vary due to the differences in funding, ranging from lump sum budgets to individual service based payments.

In the grant provision case, government only (partially) funds services. Although government does not plan the services, it can use its power related to grant provision to 
specify requirements for the quality of services to be delivered. The relevance of demand in the grant provision case is higher compared to the contract provision model, but the autonomy for the ZBO providing the service will still depend on the requirements government imposes upon the use of the grants. When service provision options are combined with the demand forms as identified in Part $\mathrm{B}$, the following options result:

Table 10.6: Relation between demand and provision of services

\begin{tabular}{|l|l|l|c|c|c|c|c|}
\hline & Role citizen & Funding & $\begin{array}{l}\text { Consolidated } \\
\text { provision }\end{array}$ & $\begin{array}{l}\text { Contract } \\
\text { provision }\end{array}$ & $\begin{array}{l}\text { Grant } \\
\text { provision }\end{array}$ & $\begin{array}{l}\text { Regulated } \\
\text { provision }\end{array}$ & $\begin{array}{l}\text { Private } \\
\text { provision }\end{array}$ \\
\hline $\begin{array}{l}\text { Full state } \\
\text { demand }\end{array}$ & user & Taxes & $\mathrm{X}$ & $\mathrm{X}$ & & & \\
\hline $\begin{array}{l}\text { Citizens } \\
\text { request }\end{array}$ & user & $\begin{array}{l}\text { Authority } \\
\text { bias }\end{array}$ & $\mathrm{X}$ & $\mathrm{X}$ & $\mathrm{X}$ & & \\
\hline $\begin{array}{l}\text { Citizens } \\
\text { demand }\end{array}$ & $\begin{array}{l}\text { user/ } \\
\text { commissioner }\end{array}$ & $\begin{array}{l}\text { Market } \\
\text { bias }\end{array}$ & & & $\mathrm{X}$ & $\mathrm{X}$ & \\
\hline $\begin{array}{l}\text { Free } \\
\text { market } \\
\text { demand }\end{array}$ & $\begin{array}{l}\text { commissioner/ } \\
\text { consumer }\end{array}$ & Price & & & & & $X$ \\
\hline
\end{tabular}

The model in Table 10.6 holds for those cases where service provision is based on a single contract relation for a single type of demand. If multiple contract relations exist, conflicts of interest may emerge which is particularly relevant if the main features of contract relations are essentially different. Simon $(1989,2005)$ noted that service provision based on a mixture of task and market services will result in a control system that fits only one of the two types of services at the expense of control for other services. Applied to this study, it means that if revenues are generated from different services, additional attention for control arrangements is needed.

The second issue discussed in this chapter is funding from a demand perspective. If citizens pay for a service, there are several funding options. Two main types can be identified: market biased forms of funding which are strongly demand driven and allow for recovery of full costs or full costs plus profit. The other group consists of authority biased fees, used for non-reciprocal services and for which recovery of full costs is regarded as the maximum level of the fee to be charged. ZBOs that can use market biased fees have a relatively higher level of autonomy than those that can only use authority biased fees.

By definition, contract provision and consolidated provision of services imply that funding is realised by taxes because government funds and plans production. If government does not fully fund services, citizens must pay for at least part of the services. In a grant provision case, funding can either be authority biased or market biased depending on the question of whether or not the citizen can be regarded as commissioner of the service. In regulated and private provision cases, market biased funding can be used, resulting in tax prices in case of regulated provision and market prices if no government intervention exists at all.

From a neo-institutional perspective, authority biased fees can be associated with relatively high transaction costs as management has to comply with rules rather than 
being stimulated by incentives. In case of market biased fees, a structural residual income is theoretically allowed which means that incentive arrangements on behalf of management can be made. Furthermore, demand is more transparent and allows for relatively unsophisticated control tools reducing transaction costs.

Not only has supply and demand impact on the control tools needed for delivering ZBO services. Product characteristics have an effect on how production can be organised and what types of control tools are needed to manage production. If relatively simple control tools can be used, that means that autonomy of the organisation can increase compared to a similar type of organisation in which complex control tools are needed. From a production process perspective, two issues were found relevant. First production processes range from (standardised) mass production to professional unit production. Mass production can be controlled on rules whereas in case of professional unit production skills and competences of individuals are important. The latter ones are more difficult to control from a commissioner perspective. Second, possibilities for control are influenced by possibilities to measure production outputs and outcomes. If it is hard to measure production, again it will require additional control tools compared to a case that does allow measurement.

The knowledge on the variety in control given the production characteristics can be applied on ZBOs. Literature suggests that not all public services are similar. In general this is insufficiently accounted for in debates on controlling arm's length organisations (Pollitt, 2004, p. 265). I will use a categorisation of five types of ZBO services based on earlier studies on Dutch arm's length organisations. On a very general level, income transfer, stewardship and licensing services allow for mass production. In the latter two cases, a case based assessment is needed because complexity might result in unit based production as well. Particularly monitoring and research services are produced in a complex setting and need control tools in line with complexity. That means that from a comparative perspective these two categories of services generate higher levels of transaction costs as services allow for mass production.

By now, the economic dimension of service provision by ZBOs has been discussed. In the following chapter, I can elaborate on the control tools available to cope with the different production and market characteristics. 


\section{Control tools from an economic perspective}

In the previous chapters, the economic framework was discussed by analysing NIE theories, product characteristics and the market aspects of ZBO services. This chapter will discuss the control tools that are available from an economic perspective, given the theoretical framework previously discussed. I will start with an elaboration on responsibility centres which reflects the basis distribution of responsibilities within an organisation given the economic characteristics of the services delivered. First, the responsibility accounting concept is explained (section 11.1) including modifications for application in a public sector environment. After the description of the general economic control tools amiable, I will focus on operation control issues in relation to ministerial responsibility in section 11.2. The chapter is concluded with a summary of tools available.

\section{$11.1 \quad$ Responsibility accounting}

In an economic context, responsibility accounting is the framework in which autonomy of an organisation/entity is reflected and which ultimately determines the control tools available for management to achieve the organisation's objectives.

In private organisations with a divisional structure, financial responsibility is attributed in relation to what an individual manager can control. The idea of attributed economic responsibility is labelled responsibility accounting (e.g. Anthony and Young, 1999, p. 1315). Autonomisation of a public sector organisation essentially means from an economic perspective that a new organisation is created which is theoretically fully responsible for its operations. The management of the autonomised organisation is required to manage operations in a way that allows at least a structural balance between revenue and expenses. If not, the organisation would not be able to continue its operations in the long run and would not be economically independent (Bouma, 1982).

Like in a private organisation, economic control for a public sector manager can be restricted due to characteristics of products and production as well as by financial targets set by the owner of the organisation. This means that it is likely that a responsibility accounting model may also be applied in a public sector setting. Depending on the responsibilities that are derived from the economic environment of the (public sector) organisation, high levels of responsibility imply high levels of autonomy. If low levels of responsibility are found, autonomy is reduced and also suggests high levels of control by the organisation.

\subsubsection{Responsibility accounting: the main concept}

A first step in assessing the degree of managerial autonomy of autonomised government units is to characterise these units in line with the concept of responsibility accounting based on the authority attributed to the executive board. Generally, in responsibility accounting (Lapsley, 1994; Mol, 1997; Merchant 1998; Mol, 2006; Drury, 2008, p. 395396), the question is to what extent a specific manager may be held responsible and accountable for the financial performance of the organisation he or she is managing. 
Lapsley as well as Mol discuss responsibility accounting in a public sector context, which implies that it is likely that responsibility accounting can be used in the ZBO-context of this study.

Responsibility accounting identifies four specific groups of financial responsibility. The most comprehensive of these types is the 'investment centre', in which case the manager is fully responsible for all aspects - including decisions on (dis)investments - of financial control of the organisation he is managing. In an investment centre, the performance assessment bottom line is the return on investment [ROI]. An investment centre type of responsibility centre is only possible in a classic market setting because only in that setting it is possible to assess performance of an organisation purely on production and sales and in terms of profit and ROI. The most restricted form of a responsibility centre is the expense centre, more precisely, the 'discretionary expense centre' (Drury, 2008, p. 395). Drury describes the discretionary expense centre as an entity "where output cannot be measured in financial terms and there are no clearly observable relationships between inputs and the outputs'. According to Drury, a Research \& Development [R\&D] unit is a typical example of such a discretionary expense centre. Control of discretionary expense centres is, according to Drury, aimed at making expenses adhere to budgeted expenses and ensuring that assigned tasks are successfully accomplished. In public sector terms, adherence would be referred to as compliance with the standards set by the powers that have made decisions to allocate resources. The description of a discretionary expense centre thus has a resemblance to the traditional control methods used in government entities, including budget authorisation. The line item budget as traditionally used in many governments (e.g. Anthony \& Young, 1999, p. 449) is a form of budgeting that resembles control in a discretionary expense centre because the focus is on controlling the level of a single part of the budget and does not look at balance sheet issues.

In between the two extremes of responsibility accounting, two other types and a major subtype of responsibility accounting exist. First, a 'profit centre' is very close to an investment centre. The main difference between the two is the lack of authority to decide on the investments of an entity by a profit centre manager. This means that someone else at a higher level in the governance structure decides upon investments. According to Merchant (1998, p. 305) a profit centre's goal is 'normally' to break-even with budgeted profit and profits higher than budgeted are not desirable. A profit centre exists, like an investment centre, basically in a market setting. In a public sector environment and market biased funding one can argue that an organisation can be classified as a profit centre, although structural profit will be close to zero.

The second responsibility centre, a 'revenue centre', is closer to a discretionary expense centre. Management of a revenue centre is accountable for generating revenue such as a sales department for example. A more elaborate form of a revenue centre also holds management accountable for the costs incurred while generating revenues, but not 
for the costs incurred for the production of the output that actually makes it possible to generate the revenues.

Finally, a major responsibility centre subtype is a subcategory of the expense centre, for which I have already discussed the discretionary expense centre. In a standard cost centre, the manager is held accountable for the costs of production where output can be measured and a required inputs per unit specification is available. Control is based on variance analyses of the budgeted costs per product unit and the cost of production actually incurred. Although a standard cost centre is useful for production entities, there may be complications in setting standards when services rather than commodities are produced. Drury $(2008$, p. 395$)$ recognises that in a standard cost centre additional - nonfinancial - controls have to be used in view of service delivery quality characteristics. Mol $(1988,1989,2006)$ has discussed control in budgeted organisations and refers to additional non financial control tools to be used. I will discuss this model in section 11.2.1.

\subsubsection{Control objects in responsibility centres}

The four basic types of responsibility centre are theoretical models. Merchant (1998, p. 306) indicates that it is possible that although a manager is held accountable according to a specific type of responsibility centre, some of the responsibilities that are characteristic given the type of responsibility centre are excluded. He identifies four different subtypes of profit centre, from gross margin to complete profit centres with a growing level of management responsibilities. To assess the specific position of an entity in the classification of responsibility centres, Merchant operationalises the classification by using several aspects of the income statement and balance sheet which are part of management's responsibility in each of the responsibility centre types. Table 11.1 shows the indicators which Merchant used.

In my opinion Merchant's operationalisation is not completely adequate. He recognises that in a revenue centre, some cost control elements may also be needed as well. What he does not mention is the relevance of some balance sheet items for profit centres. In a profit centre, management has to earn revenue by selling goods on the market. In a traditional setting when payment and transfer of commodities and services occur simultaneously, this is a logical step. However, nowadays many commodities and services are delivered before payment is made, which results in 'accounts receivable' and 'accounts payable' when supplies are not paid for immediately. If profit centre management is only held accountable for items in the statement of accounts, this might give them an incentive to generate revenues without critically assessing whether the cash flow that is supposed to follow will actually be received or paid. This can very easily be prevented by giving a profit centre manager the responsibility for the working capital of the entity. 
Table 11.1: Elements of responsibility attributed to management

\begin{tabular}{|c|c|c|c|c|c|c|c|c|}
\hline & 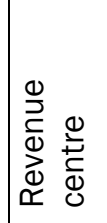 & 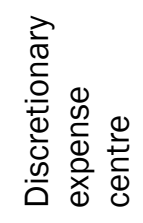 & 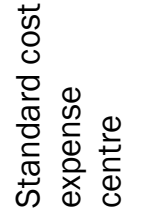 & 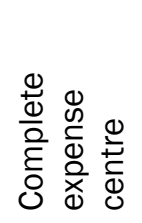 & 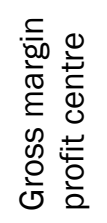 & 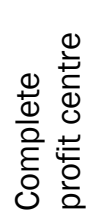 & 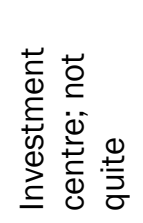 & 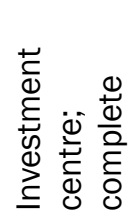 \\
\hline \multicolumn{9}{|l|}{ INCOME STATEMENT } \\
\hline Revenue & $\mathrm{X}$ & & & & $X$ & $X$ & $x$ & $\mathrm{X}$ \\
\hline Cost of goods sold & & & $x$ & $x$ & $X$ & $X$ & $x$ & $x$ \\
\hline Gross margin & & & & & $X$ & $x$ & $x$ & $x$ \\
\hline $\begin{array}{l}\text { Advertising \& } \\
\text { Promotion }\end{array}$ & & $X$ & & $X$ & & $X$ & $x$ & $x$ \\
\hline$R \& D$ & & $X$ & & $X$ & & $X$ & $X$ & $X$ \\
\hline Profit & & & & & & $x$ & $x$ & $x$ \\
\hline Profit after tax & & & & & & $x$ & $x$ & $x$ \\
\hline \multicolumn{9}{|l|}{ BALANCE SHEET } \\
\hline Fixed assets & & & & & & & $X$ & $x$ \\
\hline Working capital & & & & & & & $X$ & $\mathrm{X}$ \\
\hline Debt & & & & & & & $X$ & $X$ \\
\hline ROA & & & & & & & & $X$ \\
\hline
\end{tabular}

Assessment of responsibility centres can be performed from two perspectives. First, assessing formal responsibilities attributed to management based on legislation and instructions provide the 'soll' position. Second, assessing actual controls applied in the organisation is a bottom up approach for the 'ist' position. Depending on information available one of these or both perspectives can be used to arrive at a conclusion on the responsibility centre type of a particular organisation.

\subsubsection{Responsibility accounting in a public sector setting}

To classify public sector entities in terms of responsibility accounting on a similar basis, the operationalisation has to fit in a public sector context. An important difference from private sector entities is that some public sector entities may be in charge of distributing resources to third parties. Such income transfers from the distributive branch of government are then core business of the entity. These income transfers - or more general program costs - are not part of the operational control system of the entity and will not be considered. ${ }^{153}$ When assessing the type of responsibility centre it is in general sufficient to assess control of operating costs and revenues as these are the resources that can be influenced by the management of the organisation.

The fundamental idea of responsibility centres does not change: it still refers to the relevant items in financial statements which can be regarded as part of the control

153 Of course, program costs will be included in a planning and control system as well but essentially the management of the organisation handling program cost cannot intervene in the cash flow of program costs. 
responsibility of the entity's management. ${ }^{154}$ In 5 cases, adjustments have to be made. First, 'profit after tax' may be excluded as in general only for profit entities are subject to corporation tax. Central government may own some profit entities, mostly former state enterprises, but these organisations are generally not ZBOs and thus outside the scope of this study. Second, public sector entities in general aim at recovering costs through their funding, resulting in a positive or negative income at the end of the fiscal year, often at the disposal of political superiors. Therefore I prefer to use 'net income' rather than 'profit' as the latter suggests that surpluses are fully within control of management and (non-) executive board of the entity. This is in line with IPSAS definitions. Third, it would be better to use 'costs of output delivered' instead of 'costs of goods sold' as in many cases, public sector output is not actually sold but subject to a budgetary decision or a service level agreement. In these cases, it might not be possible to identify individual outputs. If no relation between costs and revenues can be identified, 'costs of activities' is a more appropriate description and costs will in most cases equal expenditure. Fourth, with respect to Merchant's element of 'advertising and promotion' I chose 'provision of information' as the relevant counterpart in a public sector setting. Marketing to acquire new customers only exists if public sector entities can compete with either market entities or amongst each other. Most public sector entities however have well defined monopolistic tasks where competition is excluded. ${ }^{155}$ In these cases, communication to final users (clients/consumers) aims at giving information on programs and tasks performed by the entity. Communication is then aimed at informing those who are entitled to use a government program how to apply for it. Fifth, for 'research and development' I substituted 'autonomous product development' using similar reasoning. $R \& D$ refers to development of new products with the aim of selling those new products to a market. When an autonomised government unit is entitled ${ }^{156}$ to develop and implement new products or services that may be regarded as similar to $R \& D$ as meant in a commercial setting. The modified scheme is presented in Table 11.2. The rows in Table 11.2 specify the items of information from which managerial responsibilities may be inferred. On the one hand, all-inclusive responsibilities may be attributed when performance can be unambiguously assessed in terms of 'return on assets' (ROA). This performance indicator will then encompass all values created and consumed by the autonomised government unit, thus measuring both efficiency and effectiveness of its production. On the other hand, accounting information restricted to income statement elements only will imply that constraints on managerial responsibility are set.

154 I refer to De Kruijf and Mol, (2007a and 2007b) for earlier versions of an elaboration on public sector responsibility centres.

155 I note here that in case of hybrids - organisations with market and public tasks - this might be slightly different, as advertising and competition for market activities may be relevant. Some ZBOs are regarded as hybrids (e.g. Meijerink, 2005).

156 This means that the entity is authorised by the political system to develop new products. For example Kadaster has been allowed to develop new products as offshoots from their registration tasks. 
Table 11.2: Elements of responsibility attributed to public sector management

\begin{tabular}{|c|c|c|c|c|c|c|c|c|}
\hline & 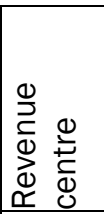 & 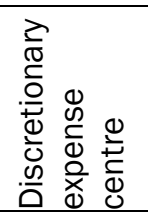 & 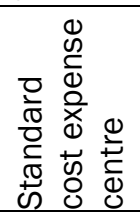 & 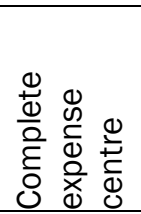 & 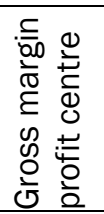 & 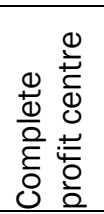 & 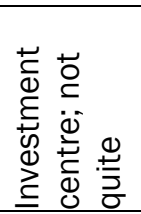 & 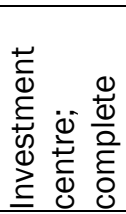 \\
\hline \multicolumn{9}{|l|}{ INCOME STATEMENT } \\
\hline Revenue & $\mathrm{X}$ & & & & $x$ & $\mathrm{X}$ & $\mathrm{X}$ & $\mathrm{X}$ \\
\hline $\begin{array}{l}\text { Cost of output } \\
\text { delivered }\end{array}$ & & $x$ & $x$ & $x$ & $X$ & $\mathrm{x}$ & $x$ & $x$ \\
\hline Cost of activities & & $\mathrm{X}$ & & & & & & \\
\hline Gross margin & & & & & $\mathrm{X}$ & $\mathrm{X}$ & $\mathrm{X}$ & $\mathrm{X}$ \\
\hline Information provision & & & & $\mathrm{X}$ & & $x$ & $\mathrm{X}$ & $\mathrm{X}$ \\
\hline $\begin{array}{l}\text { Autonomous product } \\
\text { development }\end{array}$ & & & & & & $\mathrm{X}$ & $\mathrm{x}$ & $X$ \\
\hline Net income & & & & & & $\mathrm{X}$ & $X$ & $\mathrm{X}$ \\
\hline \multicolumn{9}{|l|}{ BALANCE SHEET } \\
\hline Fixed assets & & & & & & & $\mathrm{X}$ & $\mathrm{X}$ \\
\hline Working capital & & & & & $\mathrm{X}$ & $\mathrm{X}$ & $\mathrm{X}$ & $\mathrm{X}$ \\
\hline Debt & & & & & & & $\mathrm{X}$ & $\mathrm{x}$ \\
\hline $\mathrm{ROA}$ & & & & & & & & $\mathrm{x}$ \\
\hline
\end{tabular}

In the application of Table 11.2, the proposition is that, given the heterogeneity of autonomised government units, the differences in responsibility for results should be reflected in their accountability documents. Whether or not there is a match between the descriptions given in legislation and instructions including the reflection of this attributed authority in annual reports and the actually perceived responsibilities within the planning and control system will be discussed in the empirical Part D of this study. I note here that previous research has shown that inconsistencies may arise here (Mol \& De Kruijf, 2004).

In a market setting, demand and supply control the provision of services and theoretically allow for investment centre type of organisations. This holds at least in those cases where a direct relation between owner and organisation exists. ${ }^{157}$ In a public sector setting, demand and supply are not necessarily related. As a result, the allocation decision is not generated by the market but by an authority. If that is the case, then emphasis will be on cost control rather than on profit-related controls. In the discussion above, I have indicated that several forms of cost centres exist. The differences between these cost centres are related to possibilities for measurement of services. In the following subsection, I will discuss cost control and measurement of production in cost centres in more detail.

157 A direct relation between owner and organisation may exist in case there is no principal agent relation but also in a principal agent relation in an organisation where the agent has a direct like to the shareholding principals. 


\subsection{Control of operations}

In the previous section, responsibility accounting was discussed as the framework of control on organisations given the economic characteristics of the services delivered. In this section, focus is on control tools on an operational level from a direct financial control perspective. Furthermore, some comments are made on the possible restrictions on autonomy that result from using particular accounting systems (section 11.2.2). In the last section 11.2.3, I will discuss the control tools mentioned in neo-institutional economics and their impact on autonomy of arm's length organisations.

\subsubsection{Performance information, production and ministerial responsibility.}

If production of services can be matched with sales and revenues, financial controls are basically sufficient for assessment of performance of the organisation. In such a case, return on investment (or profit) is the key indicator showing whether or not management has fulfilled its task assigned. Of course, present profit is not an indication for good performance in the future. Development of control systems such as balanced scorecards (Kaplan \& Norton, 1996) are meant to extend corporate performance beyond traditional financial performance. However, from a perspective of financial responsibility the first indicator for performance is profit realised.

\subsubsection{Budget typology}

If performance measurement in terms of profit cannot be realised due to a lack of relation between revenues and expenses, additional control tools have to be used. Essentially the debate is then on (budgeted) cost centre organisations. In section 10.4, I have already mentioned Wilson's (1989) framework in which he attempts to differentiate control on the basis of measurable output and outcome. Wilson's typology is an indication for production types and the related control instruments. The typology does not provide an immediate link to financial control and responsibility centres. At around the same time, Mol $(1988 ; 1989)$ defined a classification in which measurable output and homogeneity are the relevant variables to address ex ante (budgetary) control based on cost calculations for production of services that qualify as (im)pure public services and thus need a form of budgetary control. If production is homogeneous, it is possible to standardise the production process. This standardisation allows for a relation between costs and production based on (empirical) evidence (Mol, 1989, p. 375). If output is measurable, it is also possible to set an output standard for production. These standards are to be set by the institution allocating resources. In the case of ZBOs that would ultimately be Parliament. The two variables can be combined and result in a matrix labelled the 'budget typology'. The four options in the budget typology are as follows. If output can be measured and cost standards are possible, a budget can be developed based on costs per unit and production volume which is labelled an 'output budget'. If output is not measurable and no cost standards exist, no standards for control at all can be set and control falls back to the classic government type of 'input budget', in its most extreme form set up as line item budgets for each cost category. In between two other 
options exist, classified as 'task' budget and 'process' budget. In these two cases additional, mostly non-financial control tools are needed to manage operations of an organisation. Figure 11.1 gives an overview of this control model.

Performance standard possible

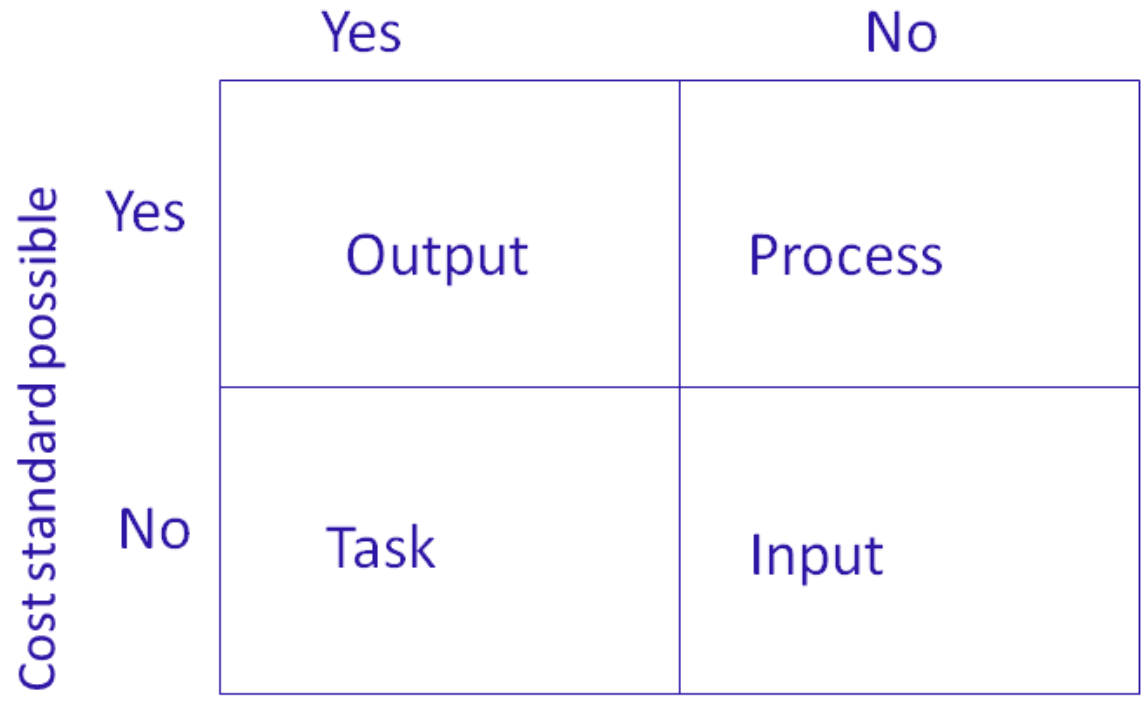

Figure 11.1: Budget typology (Mol, 1989)

In a mass production setting, one will theoretically expect that experience enables both cost standards as well as performance standards to be determined, thus resulting in an output budget. In professional unit production settings, a cost standard in terms of input used for a single unit of production is not possible. ${ }^{158}$ This means that the budget control type is at best a task budget or even an input budget.

The classification of ZBO activities as discussed in Part A resulted in three groups of activities that are likely to be qualified as mass production. In some cases, series production or even unit production may exist as well for stewardship and licensing services. From a budgetary perspective, stewardship and licensing are expected to have a linear relation between ZBO budget and the operating budget; in the third - income transfers - the relationship is regressive due to the program budgets to be spent (Dunleavy, 1991, p. 181-188). At least in the income transfer cases a performance standard in terms of measurable production can be given and the required input is known. The stewardship and licensing category may face some issues with respect to measurable output, for example what is the output of managing a data warehouse? ${ }^{159}$ But even in this case, a cost standard for data entry can be derived. Controlling (and authorising) a budget by Parliament is different for monitoring and research type ZBOs.

158 Of course, one can calculate a cost price based on an hourly labour rate by an employee, but that is not a cost standard which has a direct relationship to the service delivered. The essential point is that the time needed to deliver a service varies and cannot be calculated in advance.

159 The key part of the service is that for a particular stewardship service, the key activity to perform this service is homogeneous from a perspective of a task assigned. If multiple tasks are assigned, homogeneity is at stake but not for the demand based on the individual service. 
Their budget function is also linear, but mainly due to the fact that the level of staff rather than the demand for services determines the cost function. Monitoring and research type ZBOs may be classified as task budget type organisations if their production can be compared to ex ante set performance standards. In other cases they will only be classified as input budget type organisations. In all cases, the actual type of production is a determinant for budgetary control possibilities. Mass production (in a research case for example blood sample testing) will generally allow for an output type of budget, whereas unit production (a research document) will perhaps allow for a performance standard, but it is unlikely to calculate a real cost standard given the fact that each unit is unique.

In the process and task budget cases, non-financial performance indicators may be used as additional control tools to assess the performance of an organisation, for example in terms of quality of services delivered. Such control tools are part of the actual planning and control system and will be discussed in the following section. If an input budget is the only solution, the result is that the key control tool will be compliance.

Mol's budget typology can be applied to a single purpose activity unit, but also allows diversification within an organisation if different activities are realised. I recall that the ZBO activities classification was based on the main tasks of ZBOs as originally identified by the NCA. So, if a ZBO performs more than one activity, the budget typology model should be applied separately for each individual activity.

\subsubsection{Performance information}

The non-financial performance information that is needed in case of cost centre control and problems with performance measurement can be included in a SLA or other documents describing desired services of a ZBO. Non-financial information can be generated independently from the financial accounting system used. An indication of this is the evaluation of the application of accruals accounting at minLNV, which concluded that the focus should be on providing non-financial policy information to Parliament (Parliament, 2008c, p. 3). This conclusion on the information provided in a ministry's budget document also implicitly concerns the information provided by ZBOs.

Although poor performance in the public sector does not have an immediate effect on the capital market as is the case in the private sector, dysfunctional behaviour can occur. From an organisational (administrative) control level, the literature indicates several problems. Olson, Humphrey and Guthrie (2001, p. 513) and Van Thiel and Leeuw (2002, p. 269) mention the risk of a 'tunnel vision', focusing on the targets set and neglecting or under performing on services which are not specifically included in a contract or SLA. A second risk when using financial performance indicators is that the organisation focuses totally on its own performance with negative effects in other parts of the policy chain (Van Thiel \& Leeuw, 2002, p. 272). Financial performance management may also have a negative effect on staff; the focus on numbers may force them into a bureaucratic system without scope for professional judgement. In many cases, non-financial performance indicators are a better fit for responsibility at lower levels in the organisation. It is also indicated that non-financial information will be available more quickly than financial 
information (e.g. Groot \& Van Helden, 2003, p. 84), thus allowing for earlier adjustments in production processes.

At the political control level, performance assessment is of course influenced by the issues at the organisational level, but some other issues are relevant as well. Potter (2001, p. 79) discusses the effects of differences in interpreting results, implying that whatever data are used, expressing performance in numbers may suggest reliable data despite the world that is behind the numbers. In the Dutch context, the NCA has warned that the quality of information provided to government by third parties - including ZBOs is not always assured (Parliament, 2004f, p. 40). Lee and Burns (2000) show that performance measurement is not developing progressively, they observe deterioration in the budgeting process in several US-states. A possible explanation for this phenomenon is a certain maturation of the budgeting process in which failures of the past may lead to some reluctance to introduce new, and often expensive, budgeting processes. On the other hand, according to them the process of budget reform is more or less a one-way street. It is unlikely that sophisticated computer systems will be replaced with systems that provide less information (Lee \& Burns, 2000, p. 52). Thus, once a certain accounting system has been chosen, developments will tend to broaden and deepen the system, resulting in more focus on numbers instead of the effects of programs implemented. The remarks made on the evaluation of the present Dutch budgeting system (Parliament, 2005 d, p. 18) show that a smart combination of financial data and objectives may contribute to political control on budgeting. To put it more strongly, another conclusion in the study is that too much technical and financial data is included in budgets and annual reports. What is however not yet realised is that budget cuts are translated into a corresponding adjustment in the objectives. Here is a link to the remarks of Robinson (2003, p. 23-24) on not matching funding to actual production, despite claims of improved control under the new (Australian) accruals accounting system and Behn (2002) who states that politicians are not always willing to accept performance measurement as a control instrument. Van Meerkerk (2008, p. 94) indicated for example for the Dutch Media Authority (Commissariaat voor de Media) that despite an increase in assigned tasks, staff levels have been held constant at some 50 people rather than being related to the increased level of services.

Performance measurement might lead to focusing on political choices and not on the behaviour of the administrative system and may lead to a decline in political support from citizens. Several authors (Wildavsky, 1992, p. 597; Behn, 2002, Robinson, 2003, Mol \& De Kruijf, 2004) have indicated that although the public sector adheres to the use of nonfinancial performance measures, in many cases actual control remains under classic budgetary control mechanisms. This is partly due to political constraints such as unwillingness to accept responsibility for performance (Wildavsky, 1992; Behn 2002), but also due to insufficient matching of objectives to control instruments (Mol \& De Kruijf, 2004). 
Mol's budget typology allows for differentiation in controlling organisations that are subject to budget authorisation processes. In some cases, cost controls can be used; in others, performance based controls are available as a supplement to the traditional budget authorisation process. Non financial control tools can be categorised based on an elementary production process model including input, throughput, output and outcomes. In an output budget case, outputs of production and possibly outcomes can be measured and assessed. If production is not homogeneous or performance standards cannot be set, in most cases it will be possible to use process indicators such as for example decision processing time. This type of indicators may be used as additional control tools in process budget or task budget type organisations. In any case, resource use input indicators can be used, but in an input type model, it is the only control tool that is readily available. The type of performance indicator disclosed in budget documents and annual reports provides clues to the level of control in an organisation. If input indicators are only used in a setting that allows for an output budget from a production perspective, that can be regarded as a sign that control is probably not aligned to production characteristics. It must be noted that the literature also suggests that the use of non-financial information although regarded as relevant - is not always picked up by politicians for several reasons. I refer to the work of Behn (2002) as an example of such practices which includes arguments like the lack of political usefulness of performance indicators. Performance indicators only can thus not serve as hard evidence for a particular control model.

\subsubsection{Ministerial responsibility}

From a perspective of ministerial responsibility for ZBOs, including and controlling nonfinancial information on production is relevant. Parliament even emphasised the relevance of including non-financial information by the amendment to include a separate section CW2001:44a in which the minister is required to gather non-financial information from ZBOs. Parliament also has the opportunity to find the information in the annual reports of ZBOs, as these have to be submitted to Parliament under kZBO, again based on an amendment in legislation (Parliament, 2002h). As there is no fixed format on the contents of the annual reports of ZBOs, what information is actually provided depends on the willingness of the ZBO's management as well as on any pressure from the minister to whom management is accountable. The ultimate question that remains is whether or not both minister and Parliament are willing to use differentiation in controlling ZBOs as can be derived from Mol's model. The question on information provision as such can be elaborated upon by studying the data provided by ZBOs; the latter question can only be addressed indirectly by looking for questions regarding operations and budgets of ZBOs in Parliament.

\subsubsection{Control and accounting systems}

Responsibility accounting describes in financial terms the distribution of responsibility between principal and agent. In an investment centre type organisation, full responsibility 
is in the hands of management (agent) and owners (principals) only are entitled to residual income. In a cost centre type organisation, responsibility of management is restricted to expenses or even expenditure and owners have set these restrictions. A cost centre type organisation thus has less autonomy than an investment type organisation.

A full assessment of responsibility accounting requires that information on operations as well as on financial position of the organisation is available. In a commercial setting this is no fundamental problem because the principle of accruing income based on results from operations is at the heart of the organisation. In accounting terms, accruals accounting systems must be used to be able to measure the financial position of an organisation. Balance sheet and statement of accounts provide all relevant information. In a traditional public service setting, not accrual of income is at the heart of operations but the effects that can be generated by spending money in the general interest (Wildavsky, 2001, p. 139-140; McCaffrey \& Jones, 2001, p. 2; Mol, 2008, p. 30). This is reflected in the traditional cash accounting system.

If a pure cash accounting system is used, balance sheet information is missing which makes it impossible to identify profit and investment centres. In the Dutch setting, the cash accounting system used by central government includes a quasi balance sheet position on working capital which would theoretically also enable a profit centre to be identified. This means that Shelter ZBOs can at best qualify as profit centres whereas all legal entity ZBOs, either PLA or PLB, can theoretically be classified as an investment centre.

The accounting system used does not only have an impact on the power to hold a manager accountable from a responsibility centre perspective, it also has some other economic implications. First, there is a problem with respect to control budgets on a flexible rather than a fixed basis. When output related budgets are created based on volume and cost per unit, it should not be relevant for the commissioner how the supplier achieves his production. Additional controls along with controls based on volume and price may directly affect the power to carry through production. Given that perspective, one can wonder whether gridlocks expenditure levels or even on detailed issues such as number of staff or externally hired staff fit into accruals based accounting systems. However, in practice there is evidence that these types of more detailed controls are used (Parliament, 2007f).

A second point to be made has to do with funding of ZBOs. In those cases where authoritative services are provided which are paid for by levies or contributions, the general rule is that revenues should not exceed expenses (see section 10.3.3). This can be realised on an ex ante basis only. On an ex post basis, actual demand is likely to deviate from estimated demand and costs might have changed as well. Therefore, it is unlikely that revenues will match expenses on an ex post basis. Using an accruals accounting basis provides a transparent solution for reporting surplus revenues and when necessary returning the surplus to contributors. A similar solution can be used to stabilise levies and contributions over a number of years. Surplus or deficit revenues are 
included in the balance sheet and can be compensated for in the following fiscal year(s). This allows for a relatively stable level of the levy or contribution to be charged each year.

A final point to be mentioned is the effect of changes in demand. Cash outflow control on operational costs (i.e. cost prices) by the ministry may interfere with demand from applicants for services because the ZBO does not have sufficient production resources. This may result in two solutions: first, closing down the unit that is actually processing the applications, at the expense of applicants. This is what has happened in some cases (Mol \& De Kruijf, 2002, p. 100). The other solution is that the ZBO continues to provide services and the operating costs will rise as a result of that. At the end of the fiscal year, the unpaid part of the activities realised will be transferred to the balance sheet under 'receivables'. To cover the cash outflows realised, it is not unlikely that the ZBO has had to borrow money from the treasury to pay for their compulsory cash outflows. Although from an authorisation point of view, formal cash outflow at the level of a ministry complies with Parliamentary decisions including those on the level of the (EMU) deficit; through the backdoor, the actual EMU deficit will - ceteris paribus - have risen due to the need for the ZBO to at least pay its staff wages. Furthermore, future expenses will rise due to the additional interest payments to be made to treasury.

In the cash accounting system, basically income spending is measured and there is no difference between income generating assets and consumed goods. Under the condition that cash payments must be equal to cash receipts, there are no such issues as riskbearing capital or long term debts. Financing under a cash accounting system only exists if government is allowed to spend more than is generated from tax receipts based on for example the golden balanced budget rule (e.g. Pierson, 1913, p. 674; Goedhart, 1958, p. 250). ${ }^{160}$ Furthermore, in a cash accounting system it is difficult to determine full costs of services as the costs of using the productive assets available are not reflected in the system. Matching income and expenditure then means that the total payments for use of services - rather than consumers paying a price - should on an ex ante basis be equal to total expenditure. Whether this issue is really relevant also depends on the assets used for production. I indicated before that only a minor part of total central government expenditure is related to productive (fixed) assets such as machines or real estate. If low levels of fixed assets are found in ZBO financial statements that would indicate that there is no substantial difference between expenses and expenditures but also that from a control perspective, management actually only controls expenses/expenditures. That would be an indication for a classification as a cost centre rather than a profit or investment centre.

The (additional) expenditure controls imposed by the ministry may either undermine production or indirectly total spending limits of the State which conflicts with the

160 This rule on government deficits states that government is only allowed to borrow money for investments and operational costs including interest should be covered by tax receipts. 
authorisation function of Parliament. The issues mentioned above all have an impact on ZBO autonomy or on the authorised budgets of individual ZBOs. Therefore, it is relevant to assess whether one or more of these issues are part of the arrangements between minister and ZBO management.

\subsubsection{Neo institutional theory and control}

In this subsection, I will address the relevance of NIE control tools on the operations of ZBOs. I will start with the relation between control and transaction costs, followed by a discussion on property rights and agency theory.

\subsubsection{Transaction costs and controls}

Several elements in NIE theories provide control instruments which allow using provision of services in settings other than traditional consolidated service provision. In TCT theory, elements of control are based on the impact of transaction costs. Van Leerdam (1999, p. 184) notes that delegation and the possibility to describe ex ante decision rules can reduce decision making costs. The literature suggests that TCT cannot be used to explain the reasons for a form of autonomisation, the core elements of the theory may contribute to the analyses of control of individual organisations in relation to product characteristics. I will discuss all three elements of TCT and their impact on control separately.

I will start with the issue of frequency of transactions. The services that are provided by ZBOs have a repetitive character and are based on a legal framework in which the activities of the ZBO are described. The rule driven character of impartial judgement is based on an individual assessment of a case and leads to tailor made decisions. When the rule driven character is based on processing large numbers of similar cases, it is the decision making rule that determines the actual service delivered. In the latter case, frequency of transactions will allow for a reduction in process transaction costs. Therefore, a high level of transactions alone is insufficient to arrive at a conclusion on control. High level of frequency allows creating a separate organisational structure which can be monitored more strictly than is done in infrequent market transactions.

The second element is uncertainty. At first glance, this element seems to be irrelevant for 'mass production' (rule driven) ZBOs. However, the rules are determined by the political system and if there is a political need for frequent changes 161 in the rules implying changes in the institutional settings for operations (Van Leerdam, 1999, p. 104), uncertainty in operations is generated. This may also negatively impact the issue of autonomy because new rules require new arrangements on services to be provided including the corresponding monitoring and control systems (Van Genugten, 2008, p. 207-208). The same holds if a system of mass production is changed on an incidental basis, for example when provision of services is transferred to another organisation or a fundamentally new production process such as an IT system is required. During such a transition phase, additional controls may be needed. As long as product specification

${ }^{161}$ Such changes are independent from the frequency of transactions to be delivered by the agent (ZBO). 
remains constant, close monitoring means that the autonomy of the organisation is reduced compared to cases where close monitoring is not required.

In professional type ZBOs, uncertainty is a relevant element in individual decision making but expected to have no additional impact on the operations of the organisation. In this case uncertainty does not affect the key operational processes to be performed on delivering services as an organisational issue but is based on the contents of the case to be processed and affects the 'verdict' of the ZBO as an office. Of course, uncertainty can have an impact on decision processing time but that is implied in the professional decision making as it is part of the regular control processes within a professional organisation. This means that uncertainty is not expected to change the control relationship with Parliament and minister.

The third element is asset specificity. ZBOs provide services rather than commodities which mean that not all types of asset specificity as identified by Lohtia et al. (1994) are relevant. In particular site specificity is likely to be irrelevant. Production of services can be realised from nearly any office available. ${ }^{162}$ This also holds for 'brand specificity' because ZBO services have an authoritative character rather than a competitive character which is relevant for brand specificity. However, if the reputation of a ZBO is subject to discussion, brand specificity may be an issue at the political level and result in impact on autonomy through interventions. Physical and dedicated asset specificity in a ZBO are generally based on the availability of production related ICT systems rather than machines and other equipment. For monitoring or research type ZBOs, physical equipment can be relevant as well. If these forms of asset specificity exist, this means that the ZBO is likely to have some negotiating power with the commissioning ministry, which implies that additional control tools might be required to mitigate this negotiating power. Again this is an issue that is likely to exist in the 'mass production' type ZBOs and not in professional driven ZBOs. Indirect indicators of asset specificity can be found in the balance sheet by focusing on the level of fixed assets available to the organisation, as discussed in subsection 11.2.2.

The most important asset of ZBOs - and any service organisation - is the human capital available in the organisation. In this case, asset specificity is primarily relevant for professional type ZBOs, because they rely on the knowledge of their staff for decision making. This holds particularly for quasi judicial tribunal and research type ZBOs. As a result, human capital can generate some autonomy from government control for these organisations. In the mass production ZBOs, in some cases temporal specificity may be relevant, particularly in case of changes in the services to be provided. However, if that is the case, the uncertainty element in production is the driving force behind the position of the organisation and is likely to result in an increase in use of control tools.

162 There might be a need to spread the delivery of services regionally. All an organisation needs to deliver the service is an office. This is essentially different from industries that depend on particular forms of physical infrastructure such as for example water infrastructure in relation to power plants. 


\subsubsection{Property rights, agency theory and control}

In general, the responsibility centre type of organisation is also an indication for property rights control, at least in terms of the difference between user rights on the one hand and usus fructus and abusus rights on the other. Usus fructus and abusus rights will be found in profit or investment centres; if a cost centre is identified, that is an indication of a usus right because in a cost centre responsibility for assets is not an issue for management. In some cases, property rights cannot be enforced due to deficient control or access mechanisms such as public roads. This point has a relationship to the product and market characteristics of services to be delivered. In these cases, funding is achieved by taxation. Enforcement of property rights is according to Künneke (1997, p. 30) related to the ability to measure economic performance. He refers to Blankart (1986, p. 350), who made a classification of government services based on a previous classification by Nelson (1970, p. 312). Blankart identifies three groups of goods: inspection goods, which are immediately observable and measurable, experience goods for which quality issues exist and trust goods for which measurability as well as quality cannot be assessed. Only inspection and experience goods are likely to be provided outside a consolidated service provision context according to Blankart (1986, p. 351) because property rights can be assigned to these goods/services. Furthermore, Blankart's classification has a relationship to a differentiation between pure and impure public goods which is also discussed in section 10.3.3. Trust goods seem to resemble pure public goods as they cannot be attributed to a single individual whereas experience and inspection goods seem to allow for some form of individualisation which results in a qualification as an impure public good. This differentiation thus has an impact on the scope for privatising demand by using forms of funding other than taxes.

Blankart (1986) noted that trust goods cannot be measured. This implies that performance based incentives cannot be used in such organisations. On the level of the organisation, Ouchi and Maguire $(1975)$ and Ouchi $(1977$; 1979) identify three forms of control contracts that may be applied in different forms of organisations. Behaviour control is possible when production is transparent and programmable. In that case, information asymmetry is low. If production is more complex, performance controls may be useful. However, performance controls have their own risk profiles: once performance targets are contracted, management can shirk by focusing only on the stated targets and neglecting all other issues (e.g. Eisenhardt, 1989; Van Thiel \& Leeuw, 2002). Furthermore, performance measurement is not equally suited for different services. If no measurement at all is possible, the two controls described above cannot be used adequately and the third solution, clan or social control, is needed. As is the case with Blankart's models, clan and social controls are likely to be applied for pure public goods, whereas behavioural controls can be applied for impure public goods which allow for measurement of services. Whenever clan and social controls are needed, control is not on production but on the human input that is required to carry out production: people's skills and capabilities. The result is that mechanical production controls and price-volume 
SLAs cannot be applied in these organisations. In these cases funding can only be based on an authority biased funding type due to the lack of reciprocal services. From a budgeting perspective, the analysis of Blankart is included in the issues on performance measurement as discussed in relation to Mol's budget typology.

\subsection{Conclusion}

In this chapter, I have discussed control tools that are available given production and market characteristics of services.

Responsibility accounting is a reflection of the financial control tools that result from product, production and market characteristics for market as well as budgeted organisations. In a market setting, profit and investment centre types of responsibility accounting are possible. These focus primarily on overall financial results in terms of profit or return on investment. Cost centre types of responsibility centres can be found anywhere and have a prime focus on cost control. Cost centres range from compliance control (discretionary cost centres) to lump sum control (complete cost centres). The responsibility accounting model originates from divisionalised private organisations but can, with some modifications, be applied in a public sector environment as well.

If an organisation is budgeted rather than depending on market based sales, it is still possible to differentiate control based on characteristics of services delivered. Mol's budget typology differentiates budgeted organisations in four types of control groups ranging from output budget types in the case of homogeneous production and defined performance standards to a traditional input budget for which compliance measures only can be used. The idea is that additional non financial control tools can be used to manage budgeted organisations in which an output based budget is not possible.

Based on these two theoretical concepts, some remarks were made on particular control instruments that can be derived from them and can be applied in assessing autonomy. From responsibility centres, the financial control elements can be identified which is part of the control set of a particular type of responsibility centre type. Particular attention is needed for levels of fixed assets within an organisation, the impact of cash flows and possible expenditure levels set in the arrangements between ZBO and commissioner as well as equalisation reserves intended to create stable levels of fees. From the budget typology model, homogeneity and possibilities for performance standards in general are relevant. It must be noted that on an analytical level performance standards may exist but that they are not applied in practice. A reason for not using performance standards is that politicians may not like using them. Absence of (non financial) performance indicators can therefore not be used as a single indicator for autonomy of an organisation and has to be assessed within the wider context of control tools applied. 


\section{Impact on ZBO autonomy from an economic perspective}

After the legal dimensions of autonomy were discussed in Part B, in this part the emphasis is on the impact of economic dimensions on relative autonomy. The research question in this chapter is:

\section{Which autonomy indicators can be derived from economic theory and how do they match control of ZBO operations?}

In the following four subsections, I will summarise the findings for each of the lines of economic theory that were studied.

\subsection{Neo Institutional Economics}

Under Neo institutional Economics [NIE] theories, it is not individual production and supply and demand that are relevant but the institutional arrangements that assure that production can be carried out as efficiently as possible. The core issue of NIE is on the risks and economic impact of the unaligned interests between owners and managers of an organisation when these roles are in the hands of different individuals or institutions.

I have discussed three main lines of NIE and its impact on ZBO autonomy. From the perspective of the property rights theory [PRT], the idea is that efficient production will be stimulated if management of the organisation has a relatively low level of restrictions on its operational choices. This is operationalised under the 'abusus rights' concept which means that management has access to all assets of the organisation and can use them as efficiently as possible. Full abusus rights attributed to ZBO management may have negative impact on efficiency for society as well. This holds particularly when no arrangements are made on distributing residual income and if the ZBO has free access to the capital markets. In the latter case, the additional costs incurred due to the fact that a ZBO has to borrow at an interest rate above the risk free rate. These are only compensated for if efficiency gains exceed the additional costs. Under PRT, the more restrictive the measures governing the relationship between ZBO and government are, the lower the autonomy for ZBO management.

From a transaction cost perspective [TCT], the theoretical discussion is on the balance between integrating and outsourcing activities as methods to arrive at the most efficient production solution. Three factors determine finding optimal solutions. Asset specificity is an indicator for the mutual dependency between supply and demand. High levels of asset specificity are an argument for integrated production, whereas low asset specificity allows for services to be purchased on the market. The other relevant factors are uncertainty and frequency of transactions. If uncertainty is high, that is again an argument for integrated production because monitoring outsourced activities would be costly. Low frequency, finally, is an argument for outsourcing production because it would be too costly to organise incidental production within your own organisation. From the perspective of ZBO autonomy, high levels of uncertainty and high frequency will result in a tendency for integration of production, which means that - given that a ZBO is organised 
separately from government - more controls can be expected. In case of asset specificity, it depends on the particular character of asset specificity. In principle asset specificity provides ZBO management with negotiating power. This can be mitigated by additional government control measures.

The last part of NIE is agency theory [AT]. Here, information asymmetry is the key issue. The mismatch in information between owner and manager of the organisation allows for shirking by management. AT discusses the control tools that can be used to reduce the effects of shirking. In particular, control tools based on persuasion and incentives allow such risks to be reduced without fully reducing discretionary powers for management. If such tools are used, relative ZBO autonomy is greater than if the option of control by directives is used. Alignment of interest is in that case based on compliance rather than efficiency.

\subsection{Production characteristics}

After the discussion on the impact of NIE theories on institutional arrangements in general, I have focused on the economic dimensions related to control of services production by ZBOs. First, I have paid attention to the characteristics of production processes. Production forms in a public sector setting may be characterised by mass, series or unit production. If mass production is possible, standardisation is an important element enabling measurement based control tools. Mass production implies standardised procedures whereas in the case of unit production, services are delivered based on exact individual demand specifications. In that case other control tools are required, often related to staff quality and knowledge. Such control tools have a relatively strong internal emphasis and will be affected by the budgetary restrictions as set by the commissioning organisation. In series production, some standardisation exists, but in each case specifications are matched to particular demand, requiring more flexible control tools than used in mass production environments. In the relation between commissioner and ZBO this will also imply more emphasis on budgetary controls in relation to performance standards.

Next to the discussion on production type, the characteristics of the services delivered are important as well. Control tools for services that cannot be measured are different, more complex and often non-financial. That results in different control types in the internal management process and generates problems of information asymmetry between principal and agent.

The key conclusion of the product characteristics analysis is that using one standard control approach does not contribute to adequate control of ZBOs. From an autonomy perspective, mass production allows for an increase in autonomy once the standards for production have been set. In series and unit production, autonomy is different and cannot be based on procedures but on control of staff and budgets. 


\subsection{Supply and demand}

A third line of theory is based on supply and demand for services. Although mass production activities allow for more autonomy than individual services, autonomy also depends on the question of the origin of demand. If services are actually commissioned and used by government ${ }^{163}$ only - which is the case for pure public goods - then there is essentially no difference from a demand perspective between production in a hierarchical structure and production in a ZBO structure. In both cases there is hardly any scope to let people pay for services in any way other than by general taxes. This is different when demand is generated from individual citizens, who might then be required to pay for the service as individually delivered to them. Funding by citizens can be performed in two main ways. In a mass production setting, individual pricing is also possible. In combination with demand from individual citizens this results in market biased - biased, not based because no real market for ZBO services exists - funding and relatively greater autonomy for a ZBO compared to the case where demand is generated from groups of citizens or based on citizen requests. In the latter case, funding tends to be more authority biased and can for example be carried out under forms of pay as you go systems.

It is not only the demand side of the 'market' that allows for variation in autonomy, but the supply side as well. Traditional government production is performed in a hierarchical setting in which planning, production and funding of services are all in the hands of government. The direct opposite of this production setting is private provision of services, in which government has no production role at all. Privatisation of demand means that at least one element of the provision of services is separated from government hierarchy and transferred to the market. Three different forms of privatisation of demand were discussed: contract, grant and regulated provision of services. Each of these solutions has an impact on (relative) autonomy. Contract provision has relatively low autonomy because government still funds and plans service provision, whereas regulated provision has relatively high autonomy because funding is performed by citizens. In the case of start up subsidies - a form of grant provision autonomy will even be greater because the government only intervenes when setting up the ZBO and afterwards full provision of services is left to the market mechanism. Bringing together the forms of demand as identified in Part $B$ and the various forms of service provision services results in the possibilities as described in Table 12.1.

163 In this case as representative of society as a whole. 
Table 12.1: Relation between demand and provision of services

\begin{tabular}{|l|c|c|c|c|c|}
\hline & $\begin{array}{l}\text { Consolidated } \\
\text { provision }\end{array}$ & $\begin{array}{l}\text { Contract } \\
\text { provision }\end{array}$ & Grant provision & $\begin{array}{l}\text { Regulated } \\
\text { provision }\end{array}$ & $\begin{array}{l}\text { Private } \\
\text { provision }\end{array}$ \\
\hline $\begin{array}{l}\text { Full state } \\
\text { demand }\end{array}$ & $\mathrm{X}$ & $\mathrm{X}$ & & & \\
\hline $\begin{array}{l}\text { Citizens } \\
\text { request }\end{array}$ & $\mathrm{X}$ & $\mathrm{X}$ & & & \\
\hline $\begin{array}{l}\text { Citizens } \\
\text { demand }\end{array}$ & & & $\mathrm{x}$ & $\mathrm{X}$ & \\
\hline $\begin{array}{l}\text { Free market } \\
\text { demand }\end{array}$ & & & & & $\mathrm{X}$ \\
\hline
\end{tabular}

The table shows that in contract provision, the State is still in the lead and the role of citizens is relatively restricted. In grant provision and regulated provision, demand is generated from citizens which allows for a shift in control towards a more market based system than in a contract provision case.

\subsection{Control systems}

The differences in production as well as in supply and demand can be reflected in the control systems applied in particular cases. Responsibility accounting and responsibility centres are an expression of the level of financial controls needed in a particular organisation and can be used in a private as well as in a public setting. In very general terms, responsibility accounting types range from pure compliance based controls to controls on return on investment only. In terms of autonomy they range from (hierarchical) subordination to full autonomy.

In cases where production characteristics do not allow for use of market mechanisms, Mol's budget typology is based on control determined by the measurability of services and homogeneity of production. If homogeneous production for which outputs can be measured exists, then control can be based on output levels. If on the contrary neither homogeneity nor measurability exists, only input based controls can be used. The input control type of services also implies that funding is controlled on an input based level with an emphasis on authorisation and compliance.

The product classification of ZBO services as discussed in Part A can now be related to budgeting characteristics. Rule driven, mass production services (stewardship, income transfer and licensing) at least enable cost standards to be identified. Licensing and income transfers are also likely to qualify as homogeneous production. Therefore, these services can be controlled with an 'output type' budget. In general, cost standards cannot be used with respect to the other two types of services (monitoring and research). Furthermore, production of these two types of services may not be homogeneous, creating additional control problems. In the end, this will at best result in a task budget but a traditional input budget is very likely.

From the autonomy perspective, output based budgets allow for more autonomy than input based budgets. In general this means that mass production services would have more autonomy than ZBOs that produces individual services. 
Responsibility accounting and budget typology require the use of financial and nonfinancial control tools in line with the economic characteristics of the organisation and the services delivered. Issues that need particular attention include asset controls as well as restrictions on expenditure levels. Non financial indicators can theoretically be used as well. In that case, one has to be aware that from a political perspective, disclosing such indicators is not always preferred. Drawing conclusions on autonomy based only on the existence or absence of particular types of non financial indicators is therefore not possible and should be related to the use of financial control tools as well.

\subsection{Outlook}

As shown above, economic theory can have impact on the relative autonomy of a ZBO. Some tools such as full government demand and supply have a negative impact on autonomy; other such as nearly full abusus rights has a strong positive impact on autonomy, but at a certain cost. In Table 12.2 I have summarised indicators affecting the relative autonomy of ZBOs. At this level, it is not possible to indicate the impact on autonomy as could be performed in the legal setting where including a rule generally implies restricted autonomy. Economic control tools can increase or decrease autonomy. In the operationalisation of specific control tools in Part D, I will include indications on the impact of individual control tools on autonomy.

Table 12.2: Indicators affecting relative autonomy of ZBOs from an economic perspective

\begin{tabular}{|l|l|}
\hline Product characteristics & Market characteristics \\
\hline $\begin{array}{l}\text { 1. Mass production vs. professional unit } \\
\text { production }\end{array}$ & 1. Service provision options \\
\hline 2. Measurability of services & $\begin{array}{l}\text { 2a. Pure public services vs. market services } \\
\text { 2b. Options in funding }\end{array}$ \\
\hline & 3. Product regulation restrictions \\
\hline & 4. Commissioner \\
\hline
\end{tabular}

Based on the different product and market characteristics, the elements of neo institutional economy can be used to cover the relation between government and the arm's length organisation. Main issues from NIE for this study are access to assets (PRT), asset specificity (TCT) and incentives and frequency of monitoring (AT).

As the discussion on the economic dimension has been concluded, it is now time to merge what has been learned from legal and economic theory. In Part D, I will develop a model that can be used to evaluate ZBO autonomy in both dimensions. The final stage of the research will be an empirical assessment of this model. 


\section{Part D: Matching control from legal and economic perspectives}




\section{Introduction to Part D}

\subsection{A model for evaluating ZBO autonomy}

In the previous two parts, the legal and economic dimensions that affect ZBO autonomy have been discussed. I have assumed that the political intention to request the provision of a service is a given and that the service to be provided is as such not an issue. Furthermore, the political system has chosen to deliver the service in the institutional setting of a ZBO and not otherwise. If a service is to be provided by a ZBO, actual decisions are based on two main issues. First, the governance structure affecting control and autonomy is determined by the legal form as well as the conditions included in the statute of the ZBO. Second, the specifications and characteristics of the services to be provided ultimately determine the planning and control system under which the service can be provided. In this part of the study, the final research question will be addressed. This question is:

\section{Do Parliament's control tools match the control tools that fit the legal and economic characteristics of ZBO services?}

The legal structure was discussed in Part B. Based on the procedures in budget law, Parliament decides upon the main governance structure of the ZBO, given the various forms of legal entities that exist under civil law. Implicitly, this decision includes the consideration to provide a service through an organisation at arm's length of government. The requirements in general public law, including 'Aanwijzingen' and kZBO as well as the ideas from neo-institutional economic theory164 as discussed in Part $\mathrm{C}$ determine the distribution of authority between Parliament and minister on the one hand and ZBO management on the other, resulting in the governance structure as laid down in the ZBOcase laws. This is one line of arrangements affecting formal autonomy of a ZBO, which can either be reinforced or mitigated by the actual use of authority regarding the ZBO's operations.

From an economic perspective - discussed in Part C - the services to be delivered may be regarded as a starting point. Market based questions on funding; producing and commissioning together with product characteristics determine the planning and control options as identified under the concept of budget typology. Planning and control is also influenced by the budget authorisation process as laid down in the budget laws. Again, NIE is also relevant, particularly the issues on the balance in transaction costs and the issue of information asymmetry that has to be managed within the planning and control process. A strict or loose P\&C system in the relationship between the political owners of the organisation and its management ultimately affects the relative autonomy of a ZBO. In individual cases, the mismatch between the cash based accounting systems of commissioning ministries and the accruals based accounting systems of ZBOs may also

${ }^{164}$ And of course the broader NPM philosophy that is excluded here. 
have an impact on ZBO autonomy The key issues here are investment decisions and production levels that can be realised within the ZBO.

The objective in this part of the study is to assess whether or not the economic and legal measures on individual ZBOs match each other on two levels. First, is there a match on a conceptual theoretical level given the legal arrangements of the ZBO and the services it produces? In other words, are the formal ex ante control tools available to Parliament and ZBO management in line with the economic characteristics of the services provided? Second, is the actual use of the control tools in line with the legal provisions made and the observed economic characteristics? The answer to these questions can be visualised by plotting the results of these two questions in Figure 13.1.

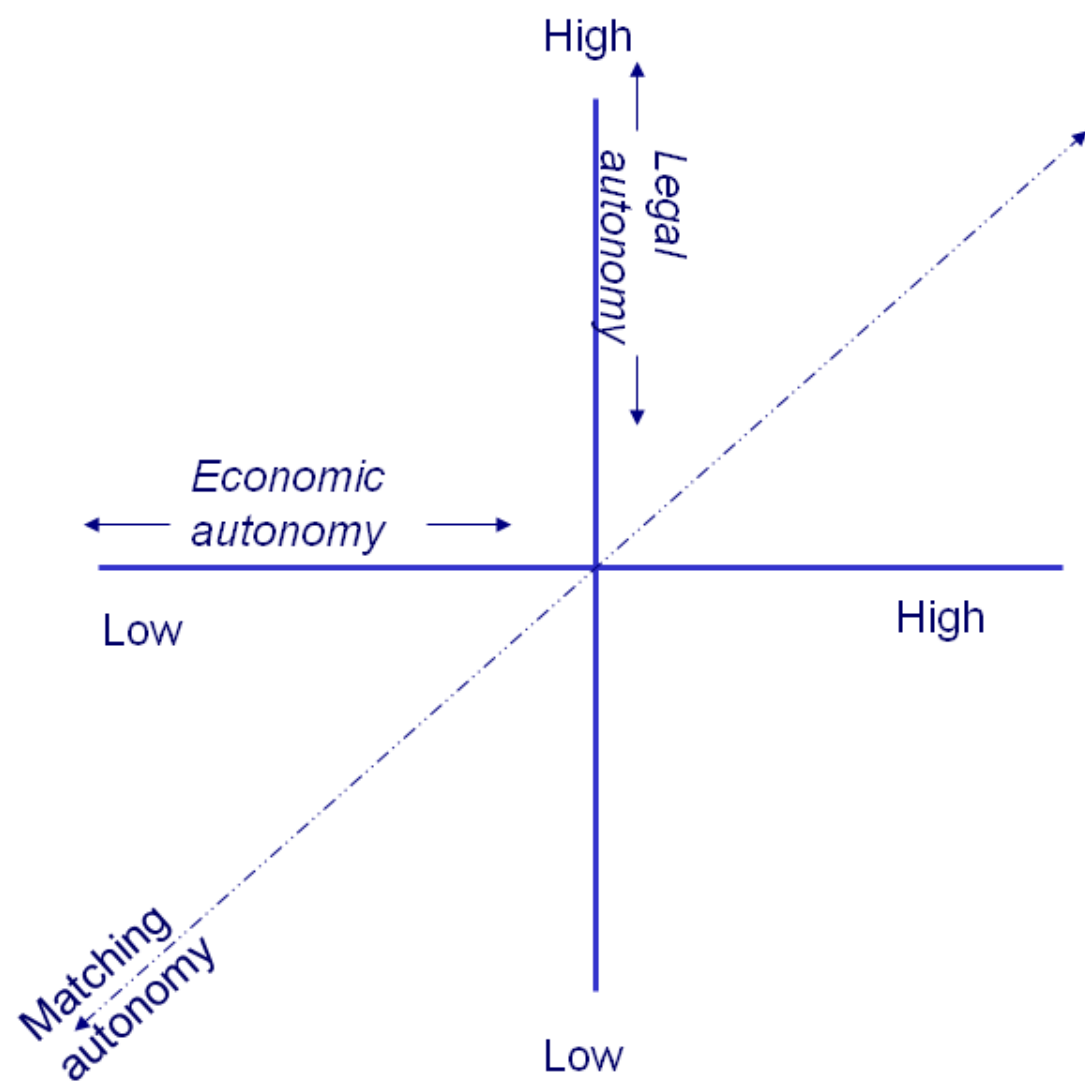

Figure 13.1: Matching of legal and economic autonomy of ZBOs.

If the results fall on the diagonal line in the diagram, autonomy alignment is observed. If the observed autonomy determinants are found above the diagonal line, the legal setting provides more autonomy than the economic characteristics of the services provided would allow and management faces relatively low levels of control. Below the diagonal line, the legal framework restricts management operations given the economic characteristics of the services.

\subsection{Outline of Part D}

The structure of the empirical Part D of this study is as follows. In chapter 14 , I will focus on the implementation of the indicators used as well as on the case selection. The 
subsequent chapter 15 discusses the key features of each of the selected ZBOs as a reference for services provided and the individual institutional setting. Chapters 16 and 17 assess formal and observed autonomy of Income Transfer and Monitoring ZBOS respectively from both legal and economic perspectives for each of the cases to arrive at a conclusion on matching of legal and economic autonomy. After discussing the autonomy of each individual ZBO, I will give some comments on relative autonomy of the ZBOs studied, compared to their peers. Chapter 18 presents the conclusions from the assessment of autonomy on the cases studied. Finally, chapter 19 provides a summary and conclusions of the study as a whole. 


\section{Operationalisation and case selection}

In this chapter, I will discuss three issues. I will start with a discussion on the operationalisation indicators for autonomy as discussed in Parts $B$ and $C$ (section 14.1). In Part A, I have reviewed the execution of a multiple case study research program using a stratified sample. Section 14.2 discusses how the stratified sample was prepared. Once variables have been operationalised and cases have been selected, a standard for the relevant subgroups of ZBOs can be prepared which allows assessing formal and actual autonomy in section 14.3.

\subsection{Variables and values}

In Parts B and C, some indicators have been discussed at the level of values of an operationalised variable. Other elements as discussed in Parts $B$ and $C$ have to be developed further into measurable variables. I will discuss here some of the variables that were developed into separate variables. A description of all values for each of the variables would require a level of detail that would not contribute to the readability of the text of this chapter. Full details of variables and values are disclosed in the appendices in Part F.

In this section, I will start with a discussion of the variables that emerge from the legal perspective (Table 14.1). First, the legal form of the entity is evaluated. This is rather straightforward, except for the foundation type of ZBO, where the involvement of the minister can vary from actively creating the foundation to only supporting creation of the foundation. Data on creation of foundations are retrieved from Dalhuisen (2004) and Parliament (2005b). Second, the authority of the minister is assessed. Some elements of authority are compulsory both under 'Aanwijzingen' and kZBO. I have chosen to classify the elements of authority into four subgroups based on Kummeling et al. (1989 p. 39), each having a different impact on the (relative) autonomy of the ZBO. All formal authority indicators can be derived from legislation and mandates and are disclosed in Table 14.1. Legal entity and attributed authority cover the legal dimension of this study. ZBOs provide different types of services assigned by law. These services were identified in Part A based on similarities between services. Theoretically from both a legal and economic perspective one would expect similar services to be controlled in a similar way. These five groups of services are classified as stewardship, income transfer, monitoring, research, and licensing. I will use the groups as control variables, allowing a comparison between ZBOs that provide similar services. 
Table 14.1: Legal variables, values and their impact on autonomy.

\begin{tabular}{|l|l|l|l|l|}
\hline Theme & Variable & Values/measurement method & Main sources & Impact on autonomy \\
\hline Legal entity & Legal entity & $\begin{array}{l}\text { Listing in increasing autonomy: } \\
\text { State, PLA, PLB-foundation, PLB- } \\
\text { Company }\end{array}$ & $\begin{array}{l}\text { ZBO-case } \\
\text { law/statute }\end{array}$ & $\begin{array}{l}\text { Used as control } \\
\text { variable. }\end{array}$ \\
\hline Authority & $\begin{array}{l}\text { Normative } \\
\text { authority }\end{array}$ & $\begin{array}{l}\text { Number of normative issues in } \\
\text { ZBO case law deviating from } \\
\text { kZBO. }\end{array}$ & $\begin{array}{l}\text { Document } \\
\text { study, } \\
\text { interviews }\end{array}$ & $\begin{array}{l}\text { Counting absolute } \\
\text { number: positive } \\
\text { effect }+/+1 ; \text { negative } \\
\text { effect }-/-1\end{array}$ \\
\hline & $\begin{array}{l}\text { Information } \\
\text { provision }\end{array}$ & $\begin{array}{l}\text { Number of normative issues in } \\
\text { ZBO case law deviating from } \\
\text { kZBO. }\end{array}$ & $\begin{array}{l}\text { Document } \\
\text { study, } \\
\text { interviews }\end{array}$ & $\begin{array}{l}\text { Counting absolute } \\
\text { number: positive } \\
\text { effect }+/+1 ; \text { negative } \\
\text { effect }-/-1\end{array}$ \\
\hline & $\begin{array}{l}\text { Governance } \\
\text { measures }\end{array}$ & $\begin{array}{l}\text { Number of normative issues in } \\
\text { ZBO case law deviating from } \\
\text { kZBO. }\end{array}$ & $\begin{array}{l}\text { Document } \\
\text { study, } \\
\text { interviews }\end{array}$ & $\begin{array}{l}\text { Counting absolute } \\
\text { number: positive } \\
\text { effect }+/+1 ; \text { negative } \\
\text { effect }-/-1\end{array}$ \\
\hline & $\begin{array}{l}\text { Cyclical } \\
\text { authority }\end{array}$ & $\begin{array}{l}\text { Number of normative issues in } \\
\text { ZBO case law deviating from } \\
\text { kZBO. }\end{array}$ & $\begin{array}{l}\text { Document } \\
\text { study, } \\
\text { interviews }\end{array}$ & $\begin{array}{l}\text { Counting absolute } \\
\text { number: positive } \\
\text { effect }+/+1 ; \text { negative } \\
\text { effect }-/-1\end{array}$ \\
\hline
\end{tabular}

Table 14.2 shows the economic dimensions used in this study and the impact on autonomy. The economic dimensions are categorised into three groups of variables, service specifications, market dimensions and planning \& control elements. The first economic dimension is product characteristics which mainly concerns a discussion on identifying (im)pure public goods.

The second main economic theme is covered under the 'market dimension' issue. From a demand perspective, the first variable to be analysed is the source and method of funding. Three elements contribute to autonomy measurement from a funding perspective. First, the percentage of actual government funding as measured based on data in ZBO fiscal 2006 annual reports. Second, if government funds a ZBO by means of a lump sum budget, this is an indicator for a lower level of autonomy compared to when government funds it at an activity (production-based) level. The type of funding is derived from documents as well as from interviews. Third, if funding is to some extent private, a market biased funding allows for greater levels of autonomy than an authority biased type of private funding.

Along with the method of funding, actual commissioning is also an indicator for the level of autonomy of a ZBO. The four commissioning types - Full state, Citizens request, Citizens demand, Free market - are indicators for an increasing level of autonomy because the role of a citizen in the commissioning process increases at the expense of control by Parliament. 
Table 14.2: Economic variables, values and impact on autonomy

\begin{tabular}{|c|c|c|c|c|}
\hline Theme & Variable & Values/measurement method & Main sources & $\begin{array}{l}\text { Impact on } \\
\text { autonomy }\end{array}$ \\
\hline \multirow[t]{2}{*}{$\begin{array}{l}\text { Service } \\
\text { specifications }\end{array}$} & $\begin{array}{l}\text { Product } \\
\text { characteristics }\end{array}$ & $\begin{array}{l}\text { Pure public goods, impure } \\
\text { supply driven public goods, } \\
\text { impure demand driven public } \\
\text { goods, market goods. Based } \\
\text { on assessment of rivalry and } \\
\text { excludability of service } \\
\text { delivered. }\end{array}$ & Document study & $\begin{array}{l}\text { pure public good, } \\
\text { low autonomy }\end{array}$ \\
\hline & $\begin{array}{l}\text { Activities } \\
\text { realised }\end{array}$ & $\begin{array}{l}\text { Main task assigned classified } \\
\text { on the basis of Table } 2.1 \text {, Part } \\
\text { A. } \\
\text { Main task identified based on } \\
\text { ZBO-case law, production } \\
\text { volume and/or revenues, } \\
\text { derived from } 2006 \text { annual } \\
\text { reports. }\end{array}$ & $\begin{array}{l}\text { ZBO-case law } \\
\text { Document study }\end{array}$ & $\begin{array}{l}\text { Used as control } \\
\text { variable }\end{array}$ \\
\hline \multirow[t]{3}{*}{$\begin{array}{l}\text { Market: } \\
\text { demand }\end{array}$} & Funding & $\begin{array}{l}\text { Percentage of funding } \\
\text { generated from central } \\
\text { government } \\
\text { Form of budget authorisation } \\
\text { by Parliament: lump sum or } \\
\text { activity based type of charges } \\
\text { used in the case of private } \\
\text { funding (Table } 11.3 \text { Part C). }\end{array}$ & Document study & $\begin{array}{l}\text { high percentage: } \\
\text { low autonomy; } \\
\text { market biased } \\
\text { funding high } \\
\text { autonomy, } \\
\text { authority biased } \\
\text { funding low } \\
\text { autonomy } \\
\text { lump sum: low } \\
\text { autonomy }\end{array}$ \\
\hline & Commissioning & $\begin{array}{l}\text { Commissioner for main task } \\
\text { assigned to ZBO. }\end{array}$ & Interviews & $\begin{array}{l}\text { In increasing order } \\
\text { of autonomy: } \\
\text { State } \\
\text { commissioning; } \\
\text { Citizens request } \\
\text { Citizens demand } \\
\text { Free market }\end{array}$ \\
\hline & & $\begin{array}{l}\text { Demand dependency; } \\
\text { Percentage funding by largest } \\
\text { commissioner. }\end{array}$ & $\begin{array}{l}\text { Interviews, } \\
\text { Document study }\end{array}$ & $\begin{array}{l}\text { In increasing order } \\
\text { of autonomy: } \\
\text { Ministry, } \\
\text { Multiple ministries } \\
\text { Mixture } \\
\text { Others }\end{array}$ \\
\hline \multirow[t]{3}{*}{$\begin{array}{l}\text { Market: } \\
\text { supply }\end{array}$} & Competitors & $\begin{array}{l}\text { Existence of service provision } \\
\text { competitors. }\end{array}$ & Interviews & $\begin{array}{l}\text { If competition } \\
\text { possible high } \\
\text { autonomy }\end{array}$ \\
\hline & $\begin{array}{l}\text { Production and } \\
\text { Budget } \\
\text { typology }\end{array}$ & $\begin{array}{l}\text { Homogeneous production and } \\
\text { measurable outputs as } \\
\text { reflected in possibilities for } \\
\text { planning \& control. }\end{array}$ & $\begin{array}{l}\text { Document study, } \\
\text { interviews }\end{array}$ & $\begin{array}{l}\text { In declining order } \\
\text { of autonomy: } \\
\text { Output budget, } \\
\text { process budget, } \\
\text { task budget, input } \\
\text { budget. }\end{array}$ \\
\hline & $\begin{array}{l}\text { Production } \\
\text { form }\end{array}$ & $\begin{array}{l}\text { Role of government in } \\
\text { planning, producing and } \\
\text { funding of services. }\end{array}$ & Document study & $\begin{array}{l}\text { Declining order of } \\
\text { autonomy: } \\
\text { Contract, grant } \\
\text { and regulated } \\
\text { provision }\end{array}$ \\
\hline
\end{tabular}


Table 14.3: Economic variables, values and impact on autonomy (continued)

\begin{tabular}{|c|c|c|c|c|}
\hline Theme & Variable & Values/measurement method & Main sources & $\begin{array}{l}\text { Impact on } \\
\text { autonomy }\end{array}$ \\
\hline \multirow[t]{4}{*}{$\begin{array}{l}\text { Planning \& } \\
\text { Control }\end{array}$} & $\begin{array}{l}\text { Responsibility } \\
\text { accounting }\end{array}$ & $\begin{array}{l}\text { Classification based on Part C, } \\
\text { Table } 12.3 \text {. Sources: ZBO-case } \\
\text { law, interviews and annual } \\
\text { reports. Key question: is } \\
\text { responsibility for each item in } \\
\text { the table attributed to } \\
\text { management? }\end{array}$ & $\begin{array}{l}\text { Document study, } \\
\text { interviews }\end{array}$ & $\begin{array}{l}\text { Discretionary cost } \\
\text { centre: low } \\
\text { autonomy, } \\
\text { Investment centre } \\
\text { high autonomy. }\end{array}$ \\
\hline & $\begin{array}{l}\text { Financial data } \\
\text { disclosed }\end{array}$ & $\begin{array}{l}\text { Disclosure to Parliament of } \\
\text { data in a ministry's budget } \\
\text { report (table } 4.2 \text { Part B) } \\
\text { Disclosure of and } \\
\text { authorisation of ZBO budget } \\
\text { in policy articles (Table } 4.6 \\
\text { Part B) } \\
\text { Accounting system (cash vs. } \\
\text { accruals). }\end{array}$ & Document study & $\begin{array}{l}\text { More items } \\
\text { disclosed, lower } \\
\text { autonomy } \\
\text { Separate budget } \\
\text { article, lower } \\
\text { autonomy } \\
\text { Determines type of } \\
\text { information to be } \\
\text { disclosed }\end{array}$ \\
\hline & $\begin{array}{l}\text { Performance } \\
\text { indicators } \\
\text { disclosed }\end{array}$ & $\begin{array}{l}\text { Measures on performance } \\
\text { information to minister and } \\
\text { parliament: frequency and } \\
\text { description of items to be } \\
\text { disclosed. }\end{array}$ & $\begin{array}{l}\text { Document study, } \\
\text { interviews }\end{array}$ & $\begin{array}{l}\text { High frequency } \\
\text { and large number } \\
\text { of items: low } \\
\text { autonomy }\end{array}$ \\
\hline & $\begin{array}{l}\text { Political } \\
\text { debate }\end{array}$ & $\begin{array}{l}\text { Discussion/questions on ZBO } \\
\text { operating budget in process of } \\
\text { authorising a ministry's budget } \\
\text { document, annual report and } \\
\text { intermediate reports. } \\
\text { Separate documents } \\
\text { published on ZBO operations } \\
\text { during fiscal years. } \\
\text { Data sources: fiscal years } \\
2007 \text { and } 2008 \text {. }\end{array}$ & Document study & $\begin{array}{l}\text { High number } \\
\text { indicates high } \\
\text { political attention } \\
\text { and likely less } \\
\text { autonomy. }\end{array}$ \\
\hline
\end{tabular}

From the supply perspective, existence of competition is an indicator for (relative) autonomy. Data on competition was derived from the interviews by asking whether or not new tasks or tasks not assigned by the principal ministry165 were assigned after the commissioning ministry considered alternative providers. Another indicator is found in regulations. If a minister has the power to assign a ZBO task to organisations by decree rather than by law, this gives him discretionary power in assigning a task. The supply perspective also includes the production typology variable by Wilson (1989) which is reflected in the possibilities for planning and control tools in Mol's (1989) budget typology. This variable has four values, ranging from output budgets to input budgets in a declining order of autonomy. Determining the type of budget that fits the major activity of the ZBO is done by assessing whether or not mass production exists (homogeneity) and whether or not outputs can be measured in terms of decisions made or tangible assets delivered. Task descriptions in legislation and the interviews are the main sources for determining the classification under the budget typology. A final issue from supply of

165 For example a ZBO has as minister principal minSZW and also provides services for minVWS. The question then is what has led to the decision to assigning minVWS' task to a ZBO related to minSZW? 
services is found in the government production role: government has a relative direct control in contract provision through commissioning compared to cases where government only plays a role as a market regulator prescribing some level of quality with respect to services supplied. In assessing the production form, it should be noted that only the relationship between government and ZBO must be assessed, not the impact of the interventions on society. This may be relevant when the ZBO has a monitoring or quasi judicial role resulting in societal regulation by the ZBO.

The third and last main economic theme to be discussed is at the Planning \& Control level. Planning and control can be theoretically derived from product characteristics and market dimensions. The result is a particular form of responsibility centre type. To observe (mis)matches between planning and control derived from observed economic characteristics and actual planning and control as applied at the managerial level, several indicators are used. The first issue under P\&C concerns the level of detail in the data disclosed to Parliament in ZBO or ministry documents. When more items are disclosed, this is an indication that there is a perceived need to be accountable to the political system ${ }^{166}$ as opposed to when only a few items or summarised statements are given. Full financial statements may be an indicator of a higher level of transparency. However if only simple financial statements without notes are presented, this might be regarded as an indicator of perceived autonomy from minister and Parliament. Disclosure cannot be regarded as a separate indicator, it must be related to the accounting system used (accruals vs. cash based) and the level of ZBO budget detail in ministry budget documents and financial statements. Explicit listing of a ZBO budget in a budget law implies less autonomy compared to implicit listing or no listing at all.

The same holds for performance information. High levels of performance information at least suggest that accountability is high on the agenda and that the ZBO is aware of its role in society. Measurement standards can be found in regulations on information provision of a particular ZBO: high frequency and a high level of detail in the prescribed information provision are indicators for relatively low levels of autonomy.

Finally, the political significance of a ZBO's operations can be measured. High numbers of documents submitted to Parliament, debates in Parliament as well as questions asked by members of Parliament on a ZBO's operations all suggest that a particular ZBO is less autonomous than a ZBO that receives hardly any Parliamentary scrutiny. To measure Parliament's interest in a ZBO's operations, I will use data from fiscal 2007 and 2008. Covering two years reduces the risk of measuring a coincidental event rather that a structural attitude towards a particular ZBO. Measuring Parliament's attention is based on two types of information: one on the operations of the ZBO in general, the other on case based remarks. The general remarks are the main information item to be measured; if case based remarks concern more than a single case, these

166 If information is disclosed in publicly available ZBO annual reports, this also holds for accountability towards society as well. 
remarks may be an indication that the operations of a ZBO are also subject to tighter Parliamentary scrutiny.

Up to this point the research model, research methods and relevant variables have been discussed. I have focused on ZBOs in general, sometimes illustrated by some case based examples. The number of ZBOs is too large to carry out a full study at the level of detail implied by the variables identified. In the following section, I will discuss the case selection that will serve as the basis for the actual empirical analysis.

\subsection{Finding relevant cases}

\subsubsection{The ZBO population classified}

In Part A, a general description of ZBOs and their position relative to other Dutch quangos was given. The basic population in this study is the modified list (see Appendix 1) disclosed by minBZK, which includes 128 ZBOs. The purpose of the present section is to describe the population in more detail to arrive at a selection of ZBO cases to be studied in detail using the research model and basic research methodology described in Part $A$.

An assessment of ZBO characteristics in both legal and economic terms is time consuming. In general, a random sample of a population will provide a good representation of the population (Shadish, Cook \& Campbell, 2002, p. 23; Babbie, 2008, p. 207) to draw general conclusions. Because the population is relatively small and is divided between two main groups of legal entities (PLAs and PLBs) as well as five main types of services, a random sample is not likely to disclose meaningful data on possible (mis)matches between economic and legal autonomy. Therefore, I have chosen to prepare a stratified sample of the population.

A single solution for a stratified case selection would be to study all ZBOs that are under one government ministry. However, Van Thiel (2006) showed that different policy sectors in the Netherlands have different styles of quango creation. Using a selection based on ministries might not contribute to knowledge which is an argument for not following that strategy. More important is that such a selection ignores the legaleconomic perspective which is at the core of this study. Therefore, I chose to look for criteria that allow for selection but are not affected by a particular governance structure in one part of central government. As the theoretical framework uses two dimensions for the governance structure, I will discuss a number of criteria that do allow for a 'governance-neutral' case selection.

In January 2008, minBZK sent a letter to Parliament in which the minister summarised which ZBOs would be subject to the new kZBO (Parliament, 2008b). As a result, in the future one group of ZBOs will be subject to a more or less standardised 167 legal format and another group will not. In the descriptions below, I will use this political fact to split the population as a whole into these two groups. The criteria discussed below are applied to the population as a whole, unless otherwise stated. After presenting a

167 Deviations are allowed, see discussion on kZBO in Part B. 
more detailed overview of the population as a whole in section 14.2 .2 , it is possible to prepare a stratified case selection for detailed research purposes in section 14.2.3.

\subsubsection{An elaborated overview of the ZBO population}

The basic list of ZBOs used is a modified version of the register published on the Internet by minBZK on July 1,2007 . The modification has to do with grouping individual ZBOs that perform similar activities either in competition or in separate jurisdictions. An example is the 'Kamers van Koophandel' [KvK]: 20 separate legal entities operating regionally. For this study they are treated as one entity. Although formally KvKs are all separate legal entities, there is no reason to suppose that at the Parliamentary and ministerial level that these entities will be treated differently with respect to control. After modifying the minBZK-register, a list of 128 ZBO-items resulted. The total number of single entity ZBOs that were identified is 98. In 21 groups, another 296 separate entities could be identified. Data on the actual number of two public law ZBO-groups as well as seven private law ZBO-groups were not found. All are non-kZBO entities, the private ones operating in competition. Data on for example bailiffs and notaries are therefore missing. Table 14.4 discloses the distribution of these ZBOs over public and private law entities as well as whether or not they are to be subject to kZBO.

Table 14.4: Unique ZBOs and ZBOs aggregated to group level by legal status

\begin{tabular}{|c|c|c|c|c|c|c|}
\hline & \multicolumn{2}{|c|}{ Subject to kZBO $(n=56)$} & \multicolumn{3}{|c|}{ Not subject to kZBO $(n=72)$} & Totals \\
\hline & $\begin{array}{l}\text { Unique } \\
\text { ZBOs }\end{array}$ & \# groups & $\begin{array}{l}\text { Unique } \\
\text { ZBOs }\end{array}$ & \# groups & \# groups & \\
\hline $\begin{array}{l}\text { Public law } \\
\text { entity }\end{array}$ & 34 & $4(90) *$ & 30 & $3(23)$ & $2 * *$ & $73(113+p m)$ \\
\hline $\begin{array}{l}\text { Private law } \\
\text { entity }\end{array}$ & 13 & $5(30)$ & 21 & 9 (153) & $7 * *$ & $55(183+p m)$ \\
\hline Totals & 47 & $9(120)$ & 51 & $12(176)$ & $9(\mathrm{pm})$ & $128(296+p m)$ \\
\hline
\end{tabular}

Five groups of ZBOs are mentioned here in more detail. First, in the public law (kZBO) domain, two groups cover 79 entities. These groups are the previously mentioned 'Kamers van Koophandel' and the 'Huurcommissies'. The latter is a group of 59 units for which a merger proposal into a single ZBO board has been submitted to Parliament (Parliament, 2007h; Parliament, 2009c). In the private law domain, the most important group is the health insurance group of 65 private entities responsible for care service payments. This group is not included under kZBO due to intended restructuring of these ZBOs (Parliament, 2008b; 2008f). Another large group is also in the medical sector: 33 committees have authority to decide on medical/ethical matters. Finally, I mention 23 entities in the field of workplace safety, which compete with each other. These three groups cover some $80 \%$ of the non-kZBO entities that are put into groups. The number of unique ZBOs is divided nearly evenly between ZBOs subject to kZBO and those which are not. 
The research problem addresses the impact on autonomy of a ZBO given the economic and legal characteristics of ZBOs. When classifying ZBOs given this research problem, the most obvious classification would be to look at money spent by the ZBOs. Finding the relevant data for ZBOs started by systematically searching for 2006 ZBO annual reports on their websites and if necessary requesting a copy of the annual report. I looked for the annual report in particular; because that is the information that should be available to Parliament under kZBO and it is also included in the governance code developed by a number of ZBOs (Handvestgroep publiek verantwoorden, 2005). I found 55 unique annual reports (fiscal 2006) as well as reports from individual ZBOs that are included in 6 different ZBO groups. The annual reports from ZBOs, budgetary documents, ministry annual reports as well as the minBZK register are the sources on which the description of the population in this section is based. In general, the information is sufficient to classify a ZBO on the items described below. Where information was not sufficient for a classification, assumptions had to be made. These assumptions are as follows:

- With the exception of 'Kamers van Koophandel'168, it is assumed that public law ZBOs for which no financial information is available are classified as publicly funded. Private law ZBOs for which no information is available are classified as privately funded.

- ZBOs, part of the legal entity State for which no financial information is available are classified as having operating budgets below $€ 1$ million. This holds especially for those ZBOs which have the word 'committee' in their name (e.g. Committees on Exams).

- When staff numbers rather than financial data are known, I have assumed that 1 FTE staff is equivalent to $€ 120,000$ operating costs. ${ }^{169}$

- Classification of tasks is based on descriptions in the minBZK register

When no further information is available, responsibility centre classification results in cost-centre type classification for public law ZBOs and profit-centre type classification for private law ZBOs.

The information available allowed 95 ZBOs to be classified based on (estimated) operating revenues. In Figure 14.1, the distribution on the availability of information is given.

168 Kamers van Koophandel are public law ZBOs funded by fees. This can be derived both from law and the annual reports of individual Kamers van Koophandel that do provide annual reports with financial information.

169 The average operating costs/FTE of 53 ZBOs where both absolute numbers of staff and operating costs are available is $€ 122,861$ 
kZBO-entities $(n=56)$

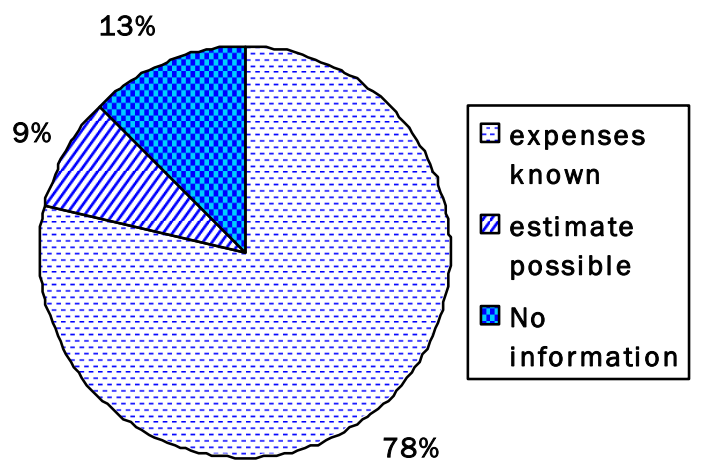

Non kZBO- entities $(n=72)$

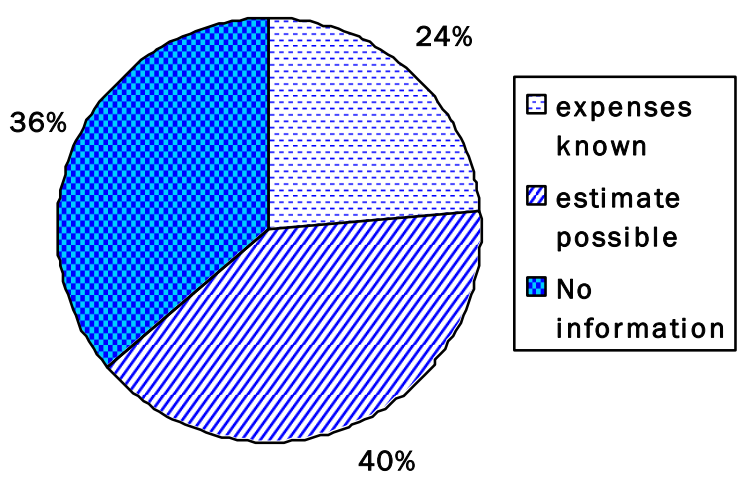

Figure 14.1: Percentage of ZBOs for which (estimated) operating revenues in fiscal 2006 are available

A large majority of the ZBOs subject to $\mathrm{kZBO}$ provide financial information on operating expenses. Even for non-kZBO entities, some two thirds enable at least an estimate of operating expenses to be made. On the aggregate level, financial information for nearly $75 \%$ of all the ZBOs in this study is available. In many cases where information is not available, this concerns private law part-time and commercially operating ZBOs. One can also conclude that ZBO transparency to the citizenry is not provided in $20 \%$ of kZBO cases and in nearly $80 \%$ of non-kZBO cases. These are high numbers but are based on fiscal 2006 data, which is prior to formal implementation of kZBO.

The data available reveal that ZBO operating revenues are widely spread. The largest ZBO (UWV) had operating expenses of some $€ 1.8$ billion; the smallest ones spent less than $€ 1$ million. ZBOs that are part of the State legal entity use cash accounting and therefore only report cash payments, while public and private law legal entities use accruals accounting and thus report in expenses. Because there is a difference in accounting systems, I have assumed that the assets of cash accounting based units are relatively small and do not substantially affect the level of expenses. This assumption allows the data to be aggregated as presented in Table 14.5.

Table 14.5: (Estimated) operating expenses/cash payments of ZBOs in fiscal 2006

\begin{tabular}{|c|c|c|c|c|c|c|}
\hline \multirow[b]{2}{*}{ Legal status $\downarrow$} & \multicolumn{5}{|c|}{ Operating expenses in $€ *$ million $\rightarrow$} & \multirow[t]{2}{*}{ Total } \\
\hline & $<1$ & $1-10$ & $10-100$ & $>100$ & $\begin{array}{l}\text { No data } \\
\text { available }\end{array}$ & \\
\hline \multicolumn{7}{|l|}{ Public } \\
\hline kZBO & 4 & 15 & 8 & 10 & 1 & 38 \\
\hline not kZBO & 23 & 4 & 3 & 5 & 0 & 35 \\
\hline \multicolumn{7}{|l|}{ Private } \\
\hline kZBO & 3 & 1 & 8 & 0 & 6 & 18 \\
\hline not kZBO & 1 & 8 & 0 & 2 & 26 & 37 \\
\hline Total & 31 & 28 & 19 & 17 & 33 & 128 \\
\hline
\end{tabular}


Although the data is based on the 2006 annual reports, the data reflect the level of expenses in more recent years as well. Only 1 ZBO was found with revenues between $€ 90 \mathrm{M}$ and $€ 110 \mathrm{M}$ and none in the range between $€ 9 \mathrm{M}$ and $€ 11 \mathrm{M}$. Therefore, the classification is in my opinion robust: if services to be provided are not changed, substantial changes over $10 \%$ of revenues from operations are unlikely.

\section{Increasing and decreasing expenses.}

A case of increasing expenses is found with the RDW: 2006: €165 M; 2007: €179 M; 2008: $€ 190 \mathrm{M}$.

A case of decreasing expenses is found for the COA: 2006: €503 M; 2007: €459 M; 2008: €472 M.

In both cases the changes do not affect the classification as presented in Table 14.5.

Data on ZBOs with operating budgets over $€ 10 \mathrm{M}$ are reliable: in only three group cases an estimate had to be made due to the fact that not all ZBOs within these groups provided their financial information. Overall, some $70 \%$ of the ZBOs with operating expenses over $€ 10 \mathrm{M}$ will be subject to kZBO. All other ZBOs with revenues from operations over $€ 10 \mathrm{M}$ were classified based on data from their annual reports.

It must be emphasised that Table 14.5 only provides data on operating budgets. The annual reports of the ZBOs that provide income transfers such as in health or State pensions also provide information on the program costs. The total amount of program costs distributed by ZBOs is an estimated $€ 80$ billion - some $40 \%$ of net central government controlled expenditure (own calculations, based on ZBO and Parliament data, 2007i, p 33-35) This is distributed by three ZBOs (CVZ, UWV and SVB) with some $€$ 2.2 billion operating expenses.

A second form of classification is based on staff numbers. Most ZBO activities are likely to be services rather than physical goods. As a result, the level of tangible assets will be relatively low and thus there will be a strong relationship between the level of operating costs and the number of staff employed. Therefore, I did not prepare staff number estimates for those ZBOs where no staff data was available. As a result, the number of ZBOs for which no staff data are available is high compared to the number of ZBOs for which no operating budget (estimate) is available. The lack of data is an empirical indication in line with the REA observation that nobody actually knows the number of civil servants employed (Parliament, 2007a, p. 3). The estimate by REA of 56,000 staff (Parliament, 2007a, p. 4) seems plausible given estimates on numbers of staff in executive agencies (Kraan, 2006, p. 226) which amount to some 65,000. Except for one (grouped) ZBO, data on all major ZBO staff numbers were found in my study. These numbers amount to some 47,000 for fiscal 2006 . The data that was available is summarised in Table 14.6. 
Table 14.6: Staff numbers and operating expenses per ZBO 2006

\begin{tabular}{|c|c|c|c|c|c|}
\hline & Staff in abs & olute numbers $\rightarrow$ & & & Total \\
\hline Operating expenses in $€ \downarrow$ & $<100$ & $100-999$ & $>=1000$ & No data & \\
\hline$<=€ 10 \mathrm{M}$ & 28 & 0 & 0 & 31 & 59 \\
\hline$€ 10-100$ M Public & 3 & 15 & 0 & 1 & 19 \\
\hline$>€ 100 \mathrm{M}$ & 0 & 4 & 12 & 1 & 17 \\
\hline Not known & 1 & 0 & 0 & 32 & 33 \\
\hline Total & 32 & 19 & 12 & 65 & 128 \\
\hline
\end{tabular}

After eliminating missing cases, the correlation between operating revenues and staff numbers is high. A selection based on staff numbers therefore does not contribute to improved case selection if operating expenses have already been used.

From a Parliamentary authorisation point of view, the objective to be met by authorising resources for a specific program has become more relevant, at least since the introduction of CW2001. This will also hold for ZBOs, at least for those that are government funded. Only focusing on resources when selecting cases would therefore ignore the differences that exist in the objectives to be achieved by ZBOs. A possible solution to create a match might be a classification based on motives for creating ZBOs as developed by Boxum et al. (1989). However, a reason for creating an entity is not an indication for operations within the entity as such. It can be an indication for a desired level of (non)-intervention by Parliament and thus for ZBO autonomy, especially when the motive for creating a ZBO is to deliver impartial judgements. As a result, the degree of intervention in operating budgets and expenses might vary between ZBOs.

In Part C, I have elaborated on the development of a classification for the activities performed by ZBOs, resulting in five different groups of activities. This classification is another approach for a link between authorised resources and objectives to be achieved at a general level. The attractiveness of this classification is reinforced by the fact that it also allows a distinction to be drawn between mass production activities and unit production, which has a link to the homogeneity element in the budget typology variable of the research model. More generally, differences in services provided are an important factor in determining the economic dimensions of ZBO autonomy. Therefore, I have chosen to use this classification as a prime classification for ZBOs in this study, along with the legal entity variable. 
Table 14.7: Classification of ZBOs by main tasks of the entity

\begin{tabular}{|c|c|c|c|c|c|c|c|}
\hline & \multicolumn{5}{|l|}{ Main task $\rightarrow$} & \multirow[b]{2}{*}{ Others } & \multirow[t]{2}{*}{ Total } \\
\hline Entity $\downarrow$ & Stewardship & $\begin{array}{l}\text { Income } \\
\text { Transfers }\end{array}$ & $\begin{array}{l}\text { Monitoring/ } \\
\text { Auditing }\end{array}$ & $\begin{array}{l}\text { Research/ } \\
\text { Information }\end{array}$ & $\begin{array}{l}\text { Licensing/ } \\
\text { Registration }\end{array}$ & & \\
\hline \multicolumn{8}{|l|}{ Public } \\
\hline kZBO & 3 & 11 & 8 & 9 & 7 & 0 & 38 \\
\hline not kZBO & 8 & 6 & 0 & 15 & 4 & 2 & 35 \\
\hline \multicolumn{8}{|l|}{ Private } \\
\hline kZBO & 3 & 5 & 5 & 2 & 3 & 0 & 18 \\
\hline not kZBO & 1 & 13 & 11 & 8 & 3 & 1 & 37 \\
\hline Total & 15 & 35 & 24 & 34 & 17 & 3 & 128 \\
\hline
\end{tabular}

Table 14.7 shows which tasks are primarily performed by the ZBOs as mentioned in the modified minBZK-list. In some cases, there are more tasks that cannot be classified within the same group of tasks. An example of this is organising exams by IBGroep, which is a task in the licensing domain rather than in the income distribution domain that covers the main activity of IBGroep. In principle, I have not considered such differences and classified ZBOs according to their most important tasks. If a ZBO actually provides two essentially different tasks, this will emerge in the case study evaluation and will be addressed there. Theoretically, this might mean that it is possible that control of that ZBO should then be split up over these two different types of activities.

The category 'others' includes the ZBO-task of the academic hospitals, a group of ZBOs whose tasks had been classified as non authoritative before kZBO was implemented.

Given the classification in tasks and using only the information 170 disclosed on ZBO operating revenues, an overview of financial relevance can be made.

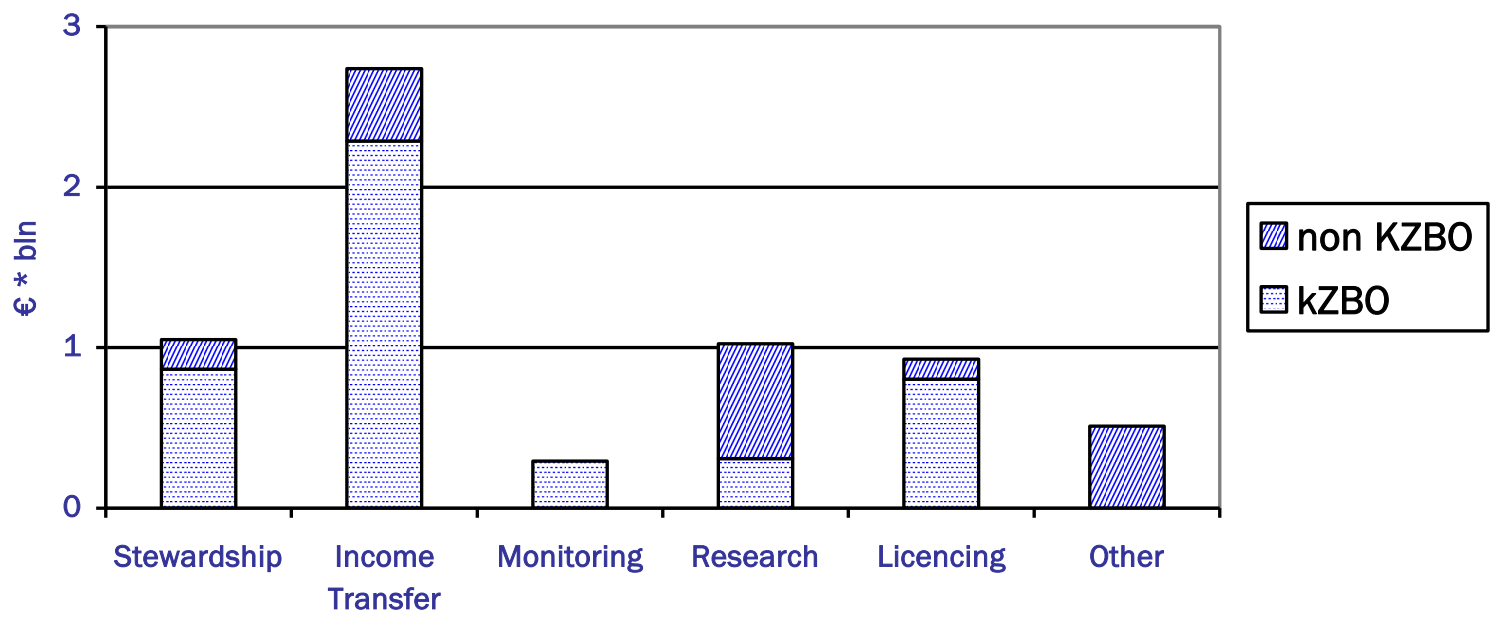

Figure 14.2: Cumulative disclosed 2006 ZBO operating revenues by task group $(n=60)$

\footnotetext{
170 Includes both kZBO and non-kZBO entities which have actually disclosed their financial information. See also Figure 14.1.
} 
Figure 14.2 shows that the operating revenues of the 'income-transfer' group is by far the largest. After eliminating UWV (€1.8 billion), total operating revenues are some $€ 0.9$ billion, which is comparable to the revenues levels of three other task groups. The total revenues covered by these 60 (groups) of ZBOs amounts to $€ 6.4$ billion. An estimate of total revenues for all 128 ZBOs identified is some $€ 6.7$ billion. The difference is mainly caused by the KvK cluster (estimate $€ 200$ million) and certifying institutions in the agricultural sector (estimated at $€ 70$ million). A last remark to be made is that the revenue in the 'Other' category is the contribution of minOCW with respect to the tasks of the academic hospitals. The financial information on the most relevant entities is therefore available for further research.

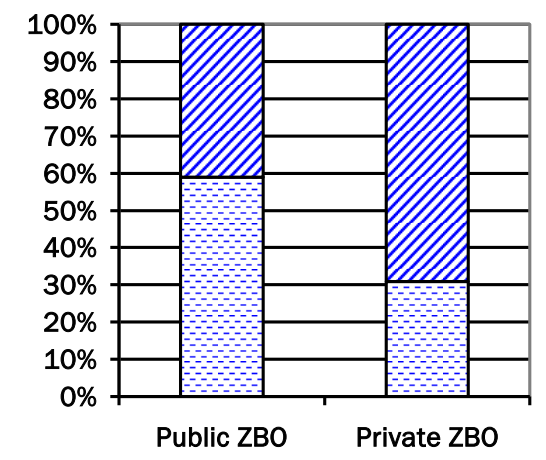

G Funding known $\square$ Funding not known

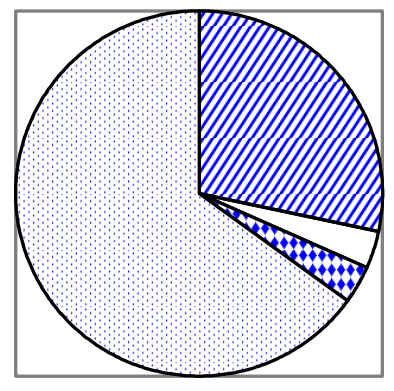

D0-25\% taxes $\square 26-50 \%$ taxes 51-75\% taxes $\square>75 \%$ taxes

Figure 14.3: Ex ante knowledge on sources of funding $(n=128)$

Figure 14.4: Sources of funding of ZBOs $(n=60)$

The level of revenues is one thing; the matter of funding is another which directly affects budget authorisation by minister and Parliament. Funding data can be derived from information in the annual report as well, by looking to the main sources of income of an entity. In a number of cases, more than one source of income was disclosed in annual reports. Therefore, I had to make an arbitrary choice on what would be regarded as ministerial (authority biased or tax) funding or market biased (fee) funding. Under authority biased (tax) funding, I have aggregated all sources of income generated from public entities.171 If a ZBO is funded by more than one ministry, it may have more autonomy than when funded by only one ministry, but both sources of funding are still subject to Parliamentary authorisation. 2006 data on all ZBO show that information on the source of funding for $68 \mathrm{ZBOs} \mathrm{(53 \% )} \mathrm{is} \mathrm{not} \mathrm{directly} \mathrm{available} \mathrm{from} \mathrm{ZBO} \mathrm{or} \mathrm{ministry}$ annual reports. The distribution of knowledge on funding public and private ZBOs is presented in Figure 14.3. The lack of knowledge is partly explained by ZBO clusters where no aggregated information for all ZBOs is available. Another explanation is found in

\footnotetext{
171 Public entities includes Principal-Ministry, other ministries, local and regional governments and other publicly funded entities irrespective of their legal status.
} 
monitoring and research ZBOs that have a private legal status and in most of the cases only have a partial ZBO-task assigned.

Of the 60 (groups of) ZBOs for which funding is known, the distribution of fees is as shown in Figure 14.4. This means that some $60 \%$ of these ZBOs are more than $75 \%$ tax (authority biased) funded and the other $40 \%$ less than that percentage. Partial private funding is thus relevant for ZBOs and the number of cases found enables private funding to be used as a selection criterion for the case studies.

\subsubsection{Selecting cases}

From a budget authorisation point of view, a selection of ZBOs with substantial budgets is most relevant. Furthermore, legal entity and source of funding have been identified as relevant classifications. Finally, a political fact is that a division exists between ZBOs that are subject to KZBO or not, which is supposed to have an effect on political control on ZBOs. In Figure 14.5, the variables mentioned are brought together. Data from 95 of the 128 ZBOs in this study enable a classification on all variables mentioned. The 33 ZBOs that cannot be classified are assumed to be publicly funded in case of public law ZBOs (PLA) and as privately funded in case of private law ZBOs (PLB). In my opinion this is fair, given the fact that most of the public law entities are only small committees operating from within the framework of a ministry. With respect to the private law entities, most of them only have a partial ZBO task along with the commercial activities carried out by these organisations. I have presented them separately in Figure 14.5. 
Private funding bias ( $\geq 25 \%)$

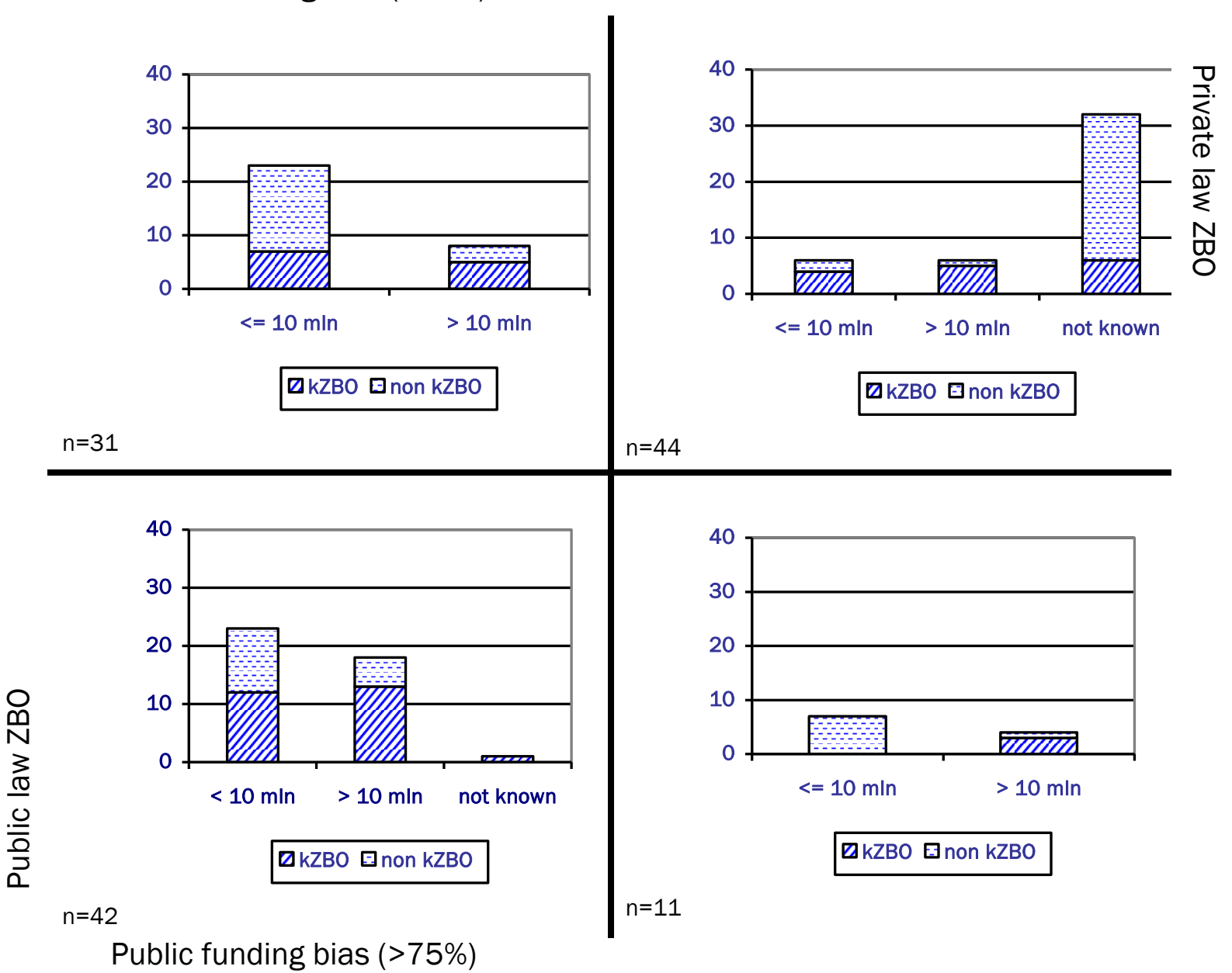

Figure 14.5: (Estimated) revenues, legal entity type and source of funding $(n=128)$

Given the political attention on kZBO-type ZBOs, it seems plausible to focus on this group of ZBOs only. However, doing so might result in unwanted bias in the study. The letter from minBZK (Parliament, 2008b) on implementation of kZBO discloses not only which ZBOs will or will not be subject to KZBO, but also the main reason for the choices made by the Cabinet. Figure 14.6 gives details on reasons why ZBOs will not be subject to kZBO. The most interesting reasons when preparing a case selection are those ZBOs which are no longer listed and those which are excluded from ZBO-status in general. Discontinuing or reconsidering an organisation is in my opinion a reason to exclude entities from case selection because studying such ZBOs has less impact on future decision making than those cases where activities are to be continued. A study on actual reasons for discontinuing or reconsidering might be worthwhile but is outside the scope of my research question. 


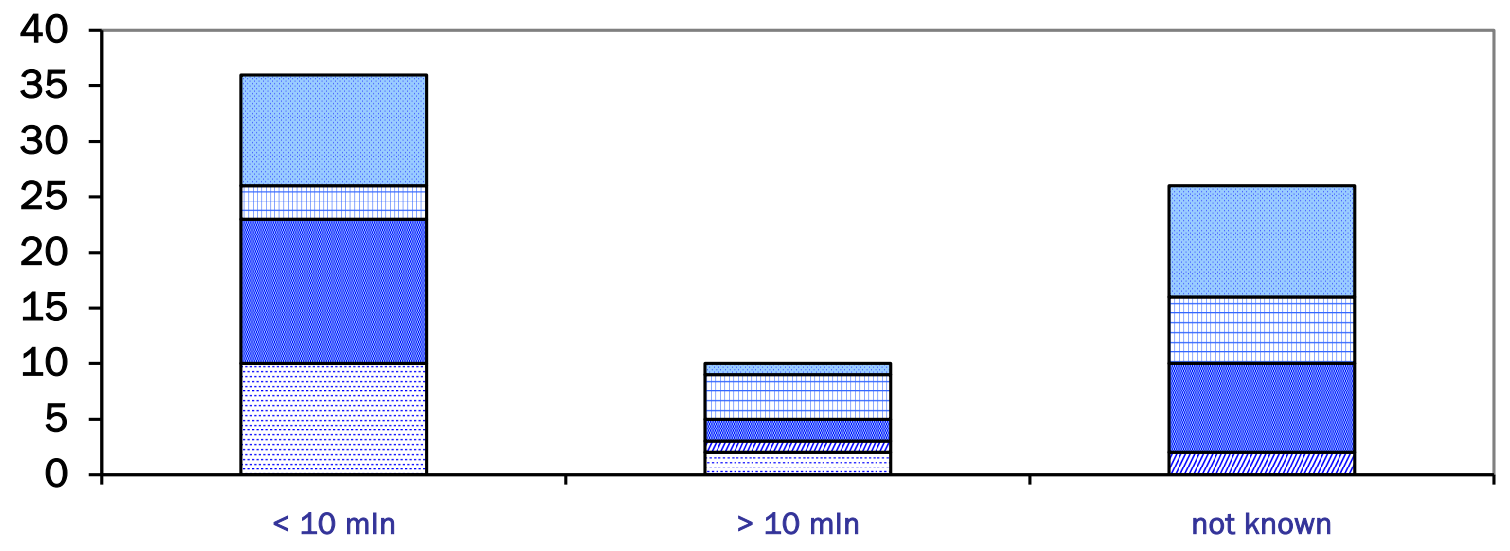

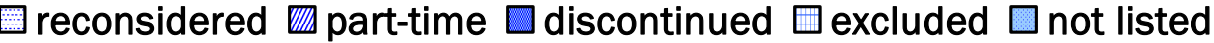

Figure 14.6: Financial relevance and proposals regarding ZBOs not subject to kZBO ( $n=72$, adapted from Parliament, 2008b)

All but one of the 5 cases over $€ 10 \mathrm{M}$ that are 'excluded' or 'not listed' are subject to minOCW. This covers the public academic hospitals (not listed), the Royal Netherlands Academy of Arts and Sciences, the Royal Library, and TNO, an institute for scientific research. The fifth case is Staatsbosbeheer (SBB). Four of the case that were excluded from kZBO have budgets over $€ 100 \mathrm{M}$ and were excluded, according to minBZK due to a lack of authoritative powers. The public academic hospitals only have a small (examination) ZBO-task similar to other academic institutions. When listed, they would probably have qualified as a part-time ZBO. TNO, the academic hospitals and SBB earn substantial parts of their income from 'market' activities; the other two are largely funded by ministry budgets.

The above analysis shows that most ZBOs that are not subject to kZBO, are not really relevant from the three other perspectives. Only four ZBOs in the non-kZBO group might be worthwhile due to relatively large expenses. However, I will not include these in the case study because the group is too small and diversified. The actual case selection is derived from ZBOs that will be subject to kZBO only. As a result the population is reduced from 128 cases to 56 cases (see Figure 14.1). I have indicated that funding, tasks assigned and legal status are ex ante indicators for differences in ZBO autonomy. As a result, differences in ZBO autonomy from a control perspective can be expected when these criteria are used for case selection.

By now, the final stage of case selection can be realised. The group of 56 ZBOs includes 7 units for which no financial information is available or can be estimated. These 7 seem to be small and will also be excluded from further selection. For details, I refer to Appendix 1. I will start with providing details on legal status and funding of the remaining 49 ZBOs. 
\# entities per task cluster

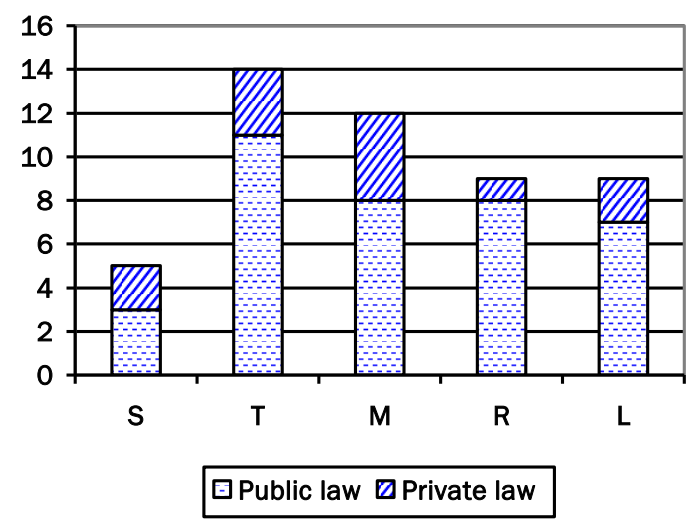

Source of funding

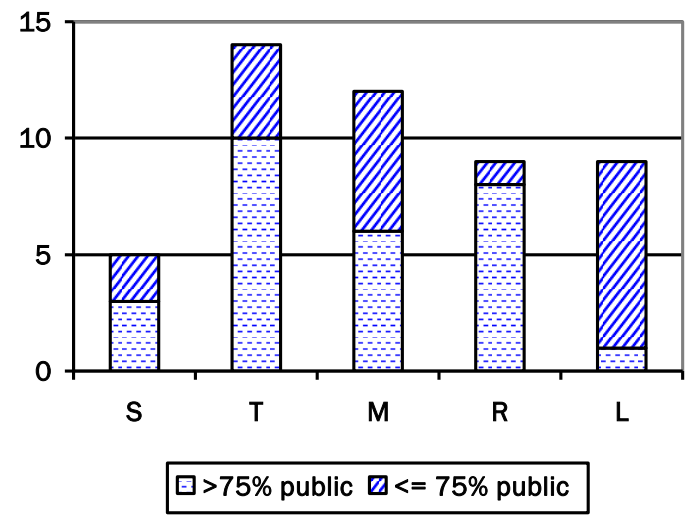

S: Stewardship; T: Income Transfers; M: Monitoring; R: Research; L: Licensing

Figure 14.7: Legal status and sources of funding of ZBOs under the kZBO-framework $(n=49)$

Figure 14.7 shows that more than half of the selected cases are classified as either 'income transfer' or 'monitoring' organisations. There is both a fair diversity of legal status as well as sources of funding for these two groups. In the 'research' group, a nonresponse risk exists given the fact that only 1 ZBO is a private law entity. Similarly, in the 'licensing' group, the risk of non-response is on the funding selection criterion. Furthermore, particularly for the 'licensing' group, earlier studies exist that cover some of the issues discussed in this study (e.g. Kickert, 1998; Mol \& de Kruijf, 2002; Deelen \& Eertink, 2004). Therefore, I decided to study ZBOs that are classified as 'income transfer' or 'monitoring'. Figure 14.8 shows that the chosen classes 'Income Transfer' and 'Monitoring' do indeed enable cases to be selected based both on funding characteristics and legal status.

\begin{tabular}{|c|c|c|c|c|c|c|c|c|c|c|}
\hline & \multicolumn{9}{|l|}{ Public law ZBOs } & \multicolumn{3}{l|}{ Private Law ZBOs } \\
\hline $\begin{array}{l}\geq 25 \% \\
\text { private } \\
\text { funding }\end{array}$ & 1 & 3 & 2 & 0 & 6 & 1 & 1 & 4 & 1 & 2 \\
\hline $\begin{array}{l}<25 \% \\
\text { private } \\
\text { funding }\end{array}$ & 2 & 8 & 6 & 8 & 1 & 1 & 2 & 0 & 0 & 0 \\
\hline
\end{tabular}

Figure 14.8: Distribution of kZBO units based on ex ante classifications $(n=49)$

Initially, I have selected 7 'income transfer' type ZBOs and 5 'monitoring' type ZBOs. It appeared that one private law monitoring type ZBO was not willing to participate in the case studies. I did not search for a replacement, because I had managed to find two private law monitoring ZBOs. Figure 14.9 discloses the selected cases. 


\begin{tabular}{|c|c|c|c|c|c|c|}
\hline & \multirow[t]{2}{*}{$\begin{array}{l}\text { Steward- } \\
\text { ship }\end{array}$} & \multirow[t]{2}{*}{ Income Transfers } & \multirow{2}{*}{$\begin{array}{l}\text { Monitoring } \\
\text { Nederlandse } \\
\text { Mededingsingsautoriteit } \\
\text { (NMa) }\end{array}$} & \multirow[t]{2}{*}{ Research } & \multirow[t]{2}{*}{ Licensing } \\
\hline & $\begin{array}{l}\geq 25 \% \\
\text { private } \\
\text { funding }\end{array}$ & & & & & \\
\hline 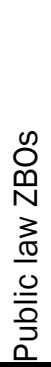 & $\begin{array}{l}<25 \% \\
\text { private } \\
\text { funding }\end{array}$ & & $\begin{array}{l}\text { College voor } \\
\text { Zorgverzekeringen (CVZ) } \\
\text { Uitvoeringsinstituut } \\
\text { werknemersverzekeringen } \\
\text { (UWV) } \\
\text { Sociale Verzekeringsbank } \\
\text { (SVB) } \\
\text { Raden voor Rechtsbijstand } \\
\text { (RvR) }\end{array}$ & $\begin{array}{l}\text { Centraal Fonds voor de } \\
\text { Volkshuisvesting (CFV) } \\
\text { Nederlandse } \\
\text { Zorgautoriteit (NZA) }\end{array}$ & & \\
\hline & $\begin{array}{l}\geq 25 \% \\
\text { private } \\
\text { funding }\end{array}$ & & & $\begin{array}{l}\text { Stichting Autoriteit } \\
\text { financiële markten } \\
\text { (AFM) } \\
\text { Stichting Nederlandse } \\
\text { algemene } \\
\text { keuringsdienst voor } \\
\text { zaaizaad en pootgoed } \\
\text { van landbouwgewassen } \\
\text { (NAK) }\end{array}$ & & \\
\hline 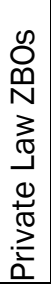 & $\begin{array}{l}<25 \% \\
\text { private } \\
\text { funding }\end{array}$ & & $\begin{array}{l}\text { Stichting Fonds voor de } \\
\text { Beeldende Kunsten, } \\
\text { Vormgeving en Bouwkunst } \\
\text { (FBKVB) } \\
\text { Stichting } \\
\text { Vervangingsfonds/Stichting } \\
\text { Participatiefonds (Vf/Pf) }\end{array}$ & & & \\
\hline
\end{tabular}

Figure 14.9: ZBOs participating in the case studies

Case selection was not random; UWV, SVB and CVZ have large program expenditures which makes them politically relevant not only from an operational budget perspective. In total, the 'income transfer' ZBOs are controlled by 5 different principal-ministries, which gives scope to describe the differences between ministries. In the 'monitoring' class; some players are again more or less comparable to each other: NMa, NZA and AFM all cover competition monitoring and regulation on markets. Nak is one out of a group of ZBOs, all controlled by one principal-ministry which means that it can be expected that it is representative for the position of the other ZBOs within the group. The financial relevance of cases selected is particularly high for the 'income transfer' group: operating revenues in 2006 amount to $€ 2.2$ billion ( $80 \%$ of estimated revenues). In the 'monitoring' group, operating revenues amount to $€ 133$ million (33\% of estimated revenues). The 11 cases to be studied, all have to comply with kZBO although in some cases, exceptions to full compliance exist (Parliament, 2008b). During actual case studies it appeared that CFV's key task had shifted from income transfers to monitoring. This change is accounted for in Figure 14.9 and all following texts. From a research perspective, there was no reason to exclude CFV as CFV was still in one of the two selected service provision categories. 


\subsection{A standard for ZBO autonomy}

The last step is to develop a standard for assessment of expected ZBO autonomy given the variables described above and the ZBOs selected. From a legal perspective, a formal standard can be derived for ZBOs given the kZBO framework and the provisions of ZBO case law. Actual ZBO autonomy is based on practices observed and on interpretation of the case law in practice. From an economic perspective, there is no formal standard to be set. It is only possible to derive an expected level of autonomy from the economic characteristics of the services provided by a particular ZBO. Actual autonomy is then the observed level of autonomy based on the economic behaviour of owner, commissioner and agent. Therefore, I will use 'formal autonomy' only from a legal perspective and discuss 'expected autonomy' from an economic perspective. Both are compared to the actually observed autonomy as can be derived from behaviour of all parties involved in carrying out the ZBO's activities.

Monitoring and income transfer ZBOs provide essentially different services. Monitoring is likely to be qualified as a pure public good, whereas income transfer is an impure demand driven public good. In both cases, it is likely that PLA-type ZBOs are used given the political preferences which state that a PLB-type ZBO is only used in exceptional circumstances.

Therefore in my opinion a full assessment of formal and actual autonomy based on authority has a bias towards cyclical and governance arrangements because one can argue that these two authority issues enable a minister-principal to intervene in the daily operations of a ZBO. Normative measures are mainly relevant in the start up phase of the ZBO and then determine a certain level of autonomy. I will include the normative measure on for appointment of staff because a deviation from the general rule for appointing civil servants generates additional autonomy - for example on staff remuneration.

Information measures are relevant from a transparency perspective and may result in questions from Parliament. So, if information measures exist, the individual ZBO is more vulnerable to external intervention than if no such measure exists. This of course is only a relative argument. Politicians may ask any question they like and it is up to the minister to decide whether he feels responsible for the issue at hand.

The legal variables to be assessed were divided into four subgroups. I will use the standard regulation as described in KZBO as the assessment reference point as this enables us to see whether existing regulations in 2008 were already in line with the new requirements. As all ZBOs selected are subject to kZBO, using this reference point will not affect assessing autonomy for individual cases or when cases are compared.

In the economic dimension, product characteristics, market planning and control are the key issues. Due to the differences in the services provided, the expected standard 
measures for the two types of ZBOs vary on issues such as funding, type of production, budgetary control and performance information. Income transfer ZBOs are expected to provide mass production services enabling activity based budgeting and output measurement. Demand is generated from citizens' request in a contract based production form. Transparency towards Parliament would suggest that the budget of a ZBO is disclosed as a single item (line item ${ }^{172}$ ) within a budget article of the proposed ministry budget law. The structure of Dutch government suggests that each department will operate its own income transfer institutions without mutual competition. Given the citizen request form of demand, emphasis is on cost control rather than on profit or investment centre type control. A minimum standard would be a standard cost centre given the production characteristics. ZBOs are expected to use accruals accounting, but given the knowledge on the relationship between expenses and expenditures (see Part $\mathrm{C}$ on accruals accounting) and the production characteristics, low levels of fixed assets are expected to be managed. I will use an (arbitrary) $10 \%$ of balance sheet total as an indicator for this. Given kZBO, one might expect that feedback is given to Parliament on the minister-principal approvals on budgets, fees and annual reports, although fees are supposed not to be used within an income transfer setting. Because income transfers are related to sometimes substantial program costs, it might be expected that production feedback to a minister-commissioner is in line with the regular reporting frequency of ministries to Parliament. More frequent reporting would result in a position that is similar to that of hierarchical subordinate units rather than of at arm's length units. Finally, related to the production characteristics, output is measurable which allows for output based performance indicators in budget documents and annual reports.

Monitoring ZBOs differ from income transfer ZBOs in several ways. Furthermore, not all monitoring ZBOs deliver similar services. In the sample, four market regulators and a quality assurance organisation are included. The latter provides mass production services, whereas in the other cases, unit production is at the heart of the production process. These differences have an impact on control. I will discuss the market regulators first. First, production is individual or at best series based rather than mass production based. Cost standards cannot be set, which only leaves options for detailed budgeting or lump sum budgeting. Given the intended impartiality of monitoring ZBOs, lump sum budgeting and complete cost centre responsibilities are to be expected. Production is not homogeneous, which means that no cost standards are possible, but output can be observed, resulting in task budgets. Monitoring ZBOs of the market regulator type are supposed to operate impartially, which also suggests that once the budget has been approved, there is no need to report until the end of the fiscal year. Finally, performance indicators are difficult to disclose on an ex ante basis, but at the end of a fiscal year actual process indicators can be provided. I have included the items discussed in Table 14.8 below. A quality assurance ZBO is characterised by mass production with power to

172 Thus line item in this case means: budget ZBO $\mathrm{x}$ is disclosed, as a total budget. 
control production generated by citizen's demand. As a result, a profit centre and funding outside government may be expected. From a legal perspective, kZBO does not include relevant differentiations from standards based on impartiality which are similar to those of market regulator ZBOs.

Standards for the other three types of ZBOs can be derived on a similar basis, again taking into account the differences in production environments. I will discuss them shortly below. First, 'stewardship ZBOs': in this case, the essential difference is found in how activities are measured. It is likely that stewardship does not always allow for output to be measured because no real services are delivered. Stewardship services do allow for citizen contributions because citizens might have a direct stake in the activities of the stewardship ZBO and are asked for an authority biased contribution. Therefore, government funding is expected to be partial, which also means that the budget is not fully disclosed in the ministry's budget document. Government will have a regulating influence in production rather than a contract relation although one can argue that authority biased funding actually means the government only recovers some of its expenses from citizens who have an interest in the stewardship service. As part of the funding is based on government contributions, it is likely that frequency of reporting is in line with reporting by ministries to Parliament given the direct financial interest of the State. The expected mixture of government and citizen funding implies that the stewardship ZBO has to manage revenues as well. A profit centre type of responsibility is plausible, particularly when government contributions can be set relatively low.

Second, research ZBOs: due to the impartiality issue their role is very similar to monitoring ZBOs. The main exception is that government funding is likely to have a 'grant' type character rather than a 'contract' based character to stress the impartiality objective.

The last group of ZBOs are the 'licensing' type. Here, there is a direct relationship between service provision and individual benefit, which means that market biased funding can be used. This means that funding can be fully private, including the impact on budget disclosure and reporting to Parliament. Production is government regulated rather than contract based. Given the funding possibilities, a profit centre type of responsibility centre is a minimum level and an investment centre type responsibility can be used, particularly in the case of a PLB type of ZBO. A full overview of the standards set is presented in Table 14.8 . 
Table 14.8: Expected standard measures determining ZBO autonomy

\begin{tabular}{|c|c|c|c|c|c|}
\hline Variable & $\begin{array}{l}\text { Income } \\
\text { transfer ZBOs }\end{array}$ & $\begin{array}{l}\text { Monitoring } \\
\text { ZBOs* }\end{array}$ & $\begin{array}{l}\text { Stewardship } \\
\text { ZBOs* }\end{array}$ & $\begin{array}{l}\text { Research } \\
\text { ZBOs* }\end{array}$ & $\begin{array}{l}\text { Licensing } \\
\text { ZBOs* }\end{array}$ \\
\hline \multicolumn{6}{|l|}{ Governance issues } \\
\hline $\begin{array}{l}\text { Ex ante approval mandates } \\
\text { (kZBO:8) }\end{array}$ & Yes & Yes & Yes & Yes & Yes \\
\hline Approval kZBO:32 transactions & No & No & No & No & No \\
\hline $\begin{array}{l}\text { Intervention in case of } \\
\text { negligence (kZBO:11) }\end{array}$ & Yes & Yes & Yes & Yes & Yes \\
\hline $\begin{array}{l}\text { Nullification of decisions } \\
(\mathrm{kZBO}: 22)\end{array}$ & Yes & No & Yes & No & Yes \\
\hline $\begin{array}{l}\text { Approval governance statute } \\
\text { (kZBO:11) }\end{array}$ & Yes & Yes & Yes & Yes & Yes \\
\hline $\begin{array}{l}\text { Appointment executive board } \\
\text { (kZBO:12) }\end{array}$ & Yes & Yes & Yes & Yes & Yes \\
\hline $\begin{array}{l}\text { Provision on secondary jobs } \\
\text { executive board members } \\
\text { (kZBO:13) }\end{array}$ & Yes & Yes & Yes & Yes & Yes \\
\hline \multicolumn{6}{|l|}{ Cyclical issues } \\
\hline $\begin{array}{l}\text { Approval of budgets/fees } \\
\text { (kZBO:17; 24) }\end{array}$ & Yes & Yes & Yes & Yes & Yes \\
\hline $\begin{array}{l}\text { Reporting on substantial } \\
\text { differences budget and results } \\
\text { (kZBO:30) }\end{array}$ & Yes & Yes & Yes & Yes & Yes \\
\hline $\begin{array}{l}\text { Creation of equalisation reserve } \\
\text { (kZBO:33) }\end{array}$ & Yes & Yes & Yes & Yes & Yes \\
\hline $\begin{array}{l}\text { Rules on budget structure given } \\
\text { (kZBO:27-28) }\end{array}$ & Yes & Yes & Yes & Yes & Yes \\
\hline \multicolumn{6}{|l|}{ Market dimension } \\
\hline Source of funding & $\begin{array}{l}100 \% \\
\text { government }\end{array}$ & $\begin{array}{l}100 \% \\
\text { government }\end{array}$ & $\begin{array}{l}<100 \% \\
\text { government }\end{array}$ & $\begin{array}{l}100 \% \\
\text { government }\end{array}$ & $\begin{array}{l}100 \% \\
\text { private }\end{array}$ \\
\hline Production type & Mass & Individual & Mass & Individual & Mass \\
\hline Budget funding & Activity based & Lump sum & $\begin{array}{l}\text { Activity } \\
\text { based }\end{array}$ & Lump sum & $\begin{array}{l}\text { Activity } \\
\text { based }\end{array}$ \\
\hline Budget typology & Output & Task & Process & Task & Output \\
\hline Production form & Contract & Contract & Regulated & Grant & Regulated \\
\hline Commissioning & Request & Government & Demand & Government & Request \\
\hline Demand dependency & 1 department & $\begin{array}{l}1 \\
\text { department }\end{array}$ & $\begin{array}{l}1 \\
\text { department }\end{array}$ & $\begin{array}{l}\text { multiple } \\
\text { departments }\end{array}$ & $\begin{array}{l}1 \\
\text { department }\end{array}$ \\
\hline Competition & No & No & Yes & Yes & Yes \\
\hline \multicolumn{6}{|l|}{ Planning \& control } \\
\hline Responsibility centre type & $\begin{array}{l}\text { Standard cost } \\
\text { centre }\end{array}$ & $\begin{array}{l}\text { Complete } \\
\text { cost centre }\end{array}$ & Profit centre & $\begin{array}{l}\text { Complete } \\
\text { cost centre }\end{array}$ & $\begin{array}{l}\text { Investment } \\
\text { centre }\end{array}$ \\
\hline$\%$ fixed assets & $<10 \%$ & $<10 \%$ & $>10 \%$ & $>10 \%$ & $<10 \%$ \\
\hline Budget disclosure & Line item & Line item & Partial & Line item & Not \\
\hline $\begin{array}{l}\text { Budget instruction by Minister- } \\
\text { Principal }\end{array}$ & Yes & No & Yes & No & No \\
\hline $\begin{array}{l}\text { Approval budget documents } \\
\text { mentioned to Parliament }\end{array}$ & Yes & Yes & Yes & Yes & Yes \\
\hline $\begin{array}{l}\text { Approval fees mentioned to } \\
\text { Parliament }\end{array}$ & Not applicable & $\begin{array}{l}\text { Not } \\
\text { applicable }\end{array}$ & Yes & $\begin{array}{l}\text { Not } \\
\text { applicable }\end{array}$ & Yes \\
\hline $\begin{array}{l}\text { Approval annual report } \\
\text { mentioned to Parliament }\end{array}$ & Yes & Yes & Yes & Yes & Yes \\
\hline $\begin{array}{l}\text { Frequency of reporting to } \\
\text { minister }\end{array}$ & $\begin{array}{l}\text { Parliament's } \\
\text { frequency }\end{array}$ & Annually & $\begin{array}{l}\text { Parliament's } \\
\text { frequency }\end{array}$ & Annually & Annually \\
\hline Ex ante performance indicators & $\begin{array}{l}\text { Output } \\
\text { indicators }\end{array}$ & Not available & $\begin{array}{l}\text { Process } \\
\text { indicators }\end{array}$ & Not available & $\begin{array}{l}\text { Output } \\
\text { indicators }\end{array}$ \\
\hline Ex post performance indicators & $\begin{array}{l}\text { Output } \\
\text { indicators }\end{array}$ & $\begin{array}{l}\text { Process } \\
\text { indicators }\end{array}$ & $\begin{array}{l}\text { Process } \\
\text { indicators }\end{array}$ & $\begin{array}{l}\text { Process } \\
\text { indicators }\end{array}$ & $\begin{array}{l}\text { Output } \\
\text { indicators }\end{array}$ \\
\hline
\end{tabular}


Based on the full list of elements to be assessed, expected differences in the legal position of ZBOs are minimal. This is of course the effect of using kZBO as a framework which intends to create a standard for ZBOs. The essential difference is in the approval of decisions (KZBO:22) which does not fit with impartial judgement type ZBOs. The financial transaction measures in kZBO:32 are optional measures, which implies that from a kZBO perspective, the standard does not include such measures. Otherwise the wording of KZBO: would have been compulsory. If a ZBO of a particular type is controlled in line with the expected values of the variables, this would mean that legal and economic autonomy of the ZBO are aligned. In the actual assessment, I will label this position as the neutral or matching position (see Figure 13.1). This will enable any deviations found to be assessed. Each deviation has the same weight in the assessment, because attributing weights to individual items would generate discussions on the relevance of items which cannot be objectively assessed. Positive and negative deviations are added up within the economic or legal dimension. Actual assessment of the impact of a particular finding is disclosed on a case by case basis and derived from the analysis in Parts $B$ and $C$

\subsection{Summary}

In this chapter, the research model and case selection have been discussed. I have operationalised the variables that are included in the research model as presented in Figure 13.1. Based on the model, I have used legal entity type, source of funding, level of revenues and task classifications as case selection variables. Given the population of ZBOs that will be subject to KZBO, I have decided to focus on 'income transfer' and 'monitoring' class ZBOs. Within these classes, 12 ZBOs were selected of which 11 were willing to participate in the case study research. Because of the differences in services provided by income transfer and monitoring ZBOs, it is not possible to use a single model to test the alignment between legal and economic ZBO autonomy. Actual testing will therefore be based on tailor made autonomy indicators for each group of ZBOs.

In the next chapter, I will start by introducing the eleven ZBOs selected and then focus on their relative autonomy with respect to Parliament and minister. 


\section{Selected ZBOs and their institutional context}

In the previous chapter, I discussed the case selection for this study. I originally had selected 7 'income transfer' type ZBOs and 4 'monitoring' type ZBOs. Each of them has a specific task assigned by law. In this chapter a description of the history and tasks of the organisations studied will be given. These descriptions provide some background information on the institutions for those readers who are not familiar with one or more individual ZBOs. The description is given group-wise in alphabetical order.

\subsection{Income transfer ZBOs}

There are basically two types of income transfer ZBO. The main type redistributes income to citizens or institutions by disbursing money; the other type collects money for a specific purpose. All ZBOs selected here were originally created to disburse money rather than to collect money.

\subsubsection{CFV}

CFV's main task at present is monitoring rather than income transfer. Therefore, I will include CFV in the 'monitoring' group rather than in the 'income transfer' group (see section 15.2.2).

\subsubsection{CVZ}

CVZ - College voor Zorgverzekeringen (Health Insurance Board) - was created in 1999 as a result of the division of the former Ziekenfondsraad into a separate income transfer and advisory board entity and a monitoring entity. The monitoring entity has now evolved into the NZA (see section 15.2.5). Blaauwbroek, Van der Hoeven and Visser (1997) show that as early as 1900 efforts had been made to provide a standardised form of health insurance. These efforts ultimately resulted in the creation of the Ziekenfondsraad in 1949, governed by employers, employees and government. The Ziekenfondsraad had the character of an advisory board with some monitoring functions on health insurance funds. The creation of CVZ was the result of a shift in policy, resulting in more political influence on the health insurance program at the expense of employer and employee influence. Effectively this meant that the Ziekenfondsraad was hived in by creating new entities.

Formally, CVZ is a separate public legal entity, presently on the basis of the Zorgverzekeringswet [ZVW] of 2006. CVZ can be qualified as a subsidiary ZBO. The minister of Health, Welfare and Sports (minVWS) is responsible for CVZ. The minister relies on his staff, in this case a Director General and a monitoring team for both issues of policy and ownership. Policy issues are brought up from more than one directorate within minVWS, but the monitoring team coordinates actual commissioning. There is neither an interface unit in the ministry to deal with ZBO ownership issues nor a separate oversight unit to cover diagonal accountability for the activities of CVZ. 
CVZ has functions both in the domain of policy advice (mainly on the contents of the basic health insurance policy) as well as in executing insurance based activities for some dedicated groups, for example Dutch expatriates who are insured under the Dutch system and managing health program funds. ${ }^{173}$ Up until 2006, the insurance based activities were only a very small part of the organisation's activities. After ZVW came into effect, it appeared that partly unforeseen effects of that law required new insurance based tasks to be organised. These tasks were assigned to CVZ partly for practical reasons but partly also because other ZBOs with similar tasks were - according to respondents - not willing to provide these requested services. CVZ does not operate for ministries other than minVWS. The policy advice activities of CVZ have an effect on the income transfer activities as well because this advice determines the contents of the basic health insurance policy. Therefore, there is no need to reconsider the primary classification of CVZ.

As of 2008, CVZ has an executive board and a board of advisors. The executive board is appointed by the minister; the board of advisors is appointed by the executive board. There is no legislation under which a board of advisors is required. CVZ would have preferred to use a non-executive board, but that was not permitted by minVWS. Before 2008, CVZ had a board and an executive director to manage operations. Client panels or other types of horizontal accountability institutions do not exist. With respect to CVZ's policy advice functions expert committees are used. The CVZ website (www.cvz.nl) contains some information on operations such as budget documents and annual reports but no intermediate reports.

The CVZ annual reports are audited by a public auditor, who is appointed by CVZ's executive board. CVZ operates from one office and had operating expenses in 2008 of some $€ 45$ million (2006: $€ 52$ million) and staff of some 350 FTE. Program costs in 2008 amounted to $€ 40$ billion (2006: $€ 40$ billion). ${ }^{174}$

\subsubsection{RvR}

RvR - Raden voor Rechtsbijstand (Legal aid funding boards) - refer to 5 separate legal entities that all carry out the same function of covering the costs of legal aid to people on low incomes that need a form of legal aid. In this study RvR is regarded as a group of ZBOs. In practice, there is strong co-operation between the 5 separate entities and they are currently in the process of being merged; this was effectively finalised in early 2009. Formally, the reorganisation was finalised by July 1st 2010 when a new law on legal aid came into effect. RvR was originally part of the Ministry of Justice but was hived off in 1994.

173 Managing health program funds includes redistribution of funds over insurance companies which is based on differences in risk profiles - insurance companies are not allowed to refuse an application for basic insurance - and the distribution of resources of the health care fund AWBZ.

174 Only the care budgets are considered to be part of the ZBO domain; cure insurance is not included in $Z B O$ references. The care budget is just over half of the total program costs. The cure budget is relevant for non ZBO LEWSTs. 
Formally RvR has the status of a separate legal entity, based on the 'Wet op de Rechtsbijstand' (Law on legal aid) of 1993. RvR can be qualified as a subsidiary ZBO, with a legal basis as of the implementation of the Wet op de Rechtsbijstand (Parliament, 1995a, p. 70). The Minister of Justice, in actual fact the Secretary of State of Justice ${ }^{175}$, is responsible for RvR. Within the Ministry of Justice there is no separate unit for ownership of ZBOs. There is no separate oversight unit monitoring the performance and outcome of RvR's operations.

The main function of RvR is to provide legal aid funds to those who (financially) qualify for an application. The individual selects a lawyer and RvR pays the lawyer's fee directly. This system is driven by the practical consideration that the funds are earmarked for legal aid and it is more reassuring for lawyers to know that they will be paid directly rather than having to send an invoice to the client and rely on the client's willingness to pay the bill. Some special activities for other ministries are also carried out by RvR, but these are in fact all related to the main task of providing funds for legal aid.

Internally, each RvR has a non-executive board appointed by the minister. ${ }^{176}$ Daily management is the responsibility of an executive director and her staff. RvR is a member of the 'BenchmarkGroep' which provides a form of horizontal accountability. The website of RvR (www.rvr.org) provides information on operations, annual reports and budget documents but no intermediate financial statements. RvR had operating costs (including affiliated foundations) of $€ 53$ million in 2008 (2006: $€ 56$ million) and program costs of some €396 million (2006: €390 million).

\subsubsection{SVB}

SVB - Sociale Verzekeringsbank (Social Security Board) is one of the oldest ZBOs in existence. It was created in 1901 as Rijksverzekeringsbank, providing benefits on the basis of a 1901 labour accident law. SVB is a ZBO that was first hived off from government (1950s). During the decades that followed, several changes were made, with important landmarks being the transfer of labour disability insurance to what is now UWV in 1968 and the creation of a separate law on SVB in which it was stipulated that the minister appointed the president of the board. Members of the board were proposed to the minister by employer and employee organisations and formally appointed by the minister. In 1988 a merger with another income transfer (child benefits) organisation was performed, resulting in SVB having regional offices. A next step in hiving in was carried out in 2002 with the introduction of a new law on the organisation of social security. As of 2002 the minister appoints the full board of SVB without formal influence from employer and employee organisations.

175 A Secretary of State is more or less an under minister, a political function operating formally under the responsibility of a minister but having his own political authority. In this study, a Secretary of State is practically equivalent to a minister.

176 The organisational structure as of 2010 includes a single executive board and an Advisory Board which both advises the executive board as well as the Minister of Justice (Parliament, 2009d, p. 12). 
Formally, SVB is a separate public legal entity, in 2007 based on the SUWI law of 2002. SVB can be qualified as a subsidiary ZBO. The minister of Social Affairs and Employment (minSZW) is responsible for SVB. The minister relies on his staff, which in 2007 consisted of separate policy and ownership units. Furthermore, there is a separate oversight unit - IWI (in their own words: inspection service work and income; www.iwiweb.nl) - which independently assesses the compliance and effectiveness of SVB's and others activities ${ }^{177}$, which is a form of diagonal accountability relationship. IWI does not certify SVB's annual reports; that is a task assigned to a public auditor who is appointed by SVB's executive board.

SVB's main task is to implement the nationwide government pension plan ${ }^{178}$ AOW, Child Benefits as well as a Widow(er) and Orphan Benefit plan. These benefit plans are tax or premium funded and the responsibility of the Minister of SZW. In addition to this main function, SVB also administers some benefit plans for other government ministries and more recently has started to administer a specific AOW related benefit program for some local governments.

Internally, SVB has an executive board and a board of advisors, appointed by the SZW Minister. Horizontal accountability of SVB is formally organised by the use of a Client panel as well as participation in the 'Benchmarkgroep', which is a co-operative venture by several executive units of government, evaluating each other's performance. The SVB website (www.svb.nl) contains information on operations such as annual and quarterly reports as well as performance information.

SVB has a head office and several regional offices throughout the country. Some of these regional offices perform dedicated tasks for reasons of efficiency of scale. All regional offices can be regarded as SVB 'divisions' and have no separate legal status. Managers of regional offices are accountable to SVB's executive board. SVB's operating expenses in 2008 were some $€ 270$ million (2006: $€ 250$ million) and staff numbers total 3,350 employees (2006: 3,250). Program expenses in 2008 were some $€ 31.7$ billion (2006: €29.2 billion).

\subsubsection{UWV}

UWV - Uitvoeringsorganisatie Werknemersverzekeringen [employee benefit board] started in 2002 as the result of a merger of five private law institutions and a coordination board. All these UWV predecessors were regarded as ZBOs. The history of UWV goes back to the 1950s when social security benefit programs on, for example, unemployment emerged. This was on the initiative of employers and employees. Until 1995, employers and employees were almost fully in control of administering these programs and managing the relevant funds. In 1995, as a result of a Parliamentary inquiry into the efficiency and effectiveness of the programs themselves, it was concluded that employer and employee influence had to be minimised. Ultimately that led

\footnotetext{
177 IWI also operates as an oversight unit for UWV and social security benefits paid by local governments.

${ }^{178} \mathrm{AOW}$ is the main part of the first pillar in the pension plans structure, based on a pay as you go funding system (see e.g. Boot, 2008).
} 
to the 2002 SUWI law under which UWV was created. The SUWI law ended employee and employer representation on the board of the new organisation and can be regarded as a substantial step in the process of hiving in.

The governance structures of UWV and SVB are similar; I refer to the SVB text for details. Like SVB, UWV can be qualified as a subsidiary ZBO. As of January 2009, it was intended for UWV to merge with another entity in the social security arena to implement a more effective system for re-integrating unemployed and partially disabled people into the labour market. This development is not included in this study, but will essentially make no difference to the governance and control structures. ${ }^{179}$ Information on the website (www.uwv.nl) provides data on both operations (annual and intermediate reports) and performance and programs.

UWV is classified as an organisation providing income transfers. That core business can however be split up into four sub-domains: income provision, re-integration, medical assessments and database management, all requiring separate areas of expertise. The two main categories of benefits provided by UWV are disability benefits and unemployment benefits. The four sub-domains of operations all contribute to the core income transfer function. Some small tasks on behalf of third parties are still performed for historical reasons, but these tasks are being transferred to other organisations.

UWV is at present the largest ZBO in the Netherlands. It has a head office and regional offices at two levels (front office/back office) throughout the country. All regional offices provide all UWV services. Apart from the separation between front and back office, there is no specialisation. Managers of regional offices are accountable to UWV's executive board. UWV's operating expenses in 2008 were $€ 1.6$ billion (2006: $€ 1.8$ billion) and staff numbers in 2008 were some 13,300 FTE (2006: 15,800 FTE). Program expenses in 2008 were $€ 19$ billion (2006: €20 billion).

\subsubsection{FBKVB}

FBKVB - Fonds voor Beeldende Kunst, Vormgeving en Bouwkunst (Foundation for Visual Arts, Design and Architecture) - is one of the 10 funds in $2007^{180}$ that operate in the area of government funding of the Arts. FBKVB is structured as a private law ZBO - a foundation ZBO - under the responsibility of the minister of Education, Culture and Science, during 2007/2008 actually the Secretary of State at minOCW. The Fund was created in 1987. It is presently governed by the Wet op het Specifiek Cultuurbeleid 1993 [WSC1993]. Before the creation of the fund, minOCW was directly responsible for processing income transfer applications from artists. Therefore these funds are a classic example of hiving off.

Within minOCW, a separate policy unit is responsible for both ownership as well as commissioning activities with respect to the fund. There are no separate diagonal oversight units or ownership interface units within minOCW.

\footnotetext{
179 The other merged entity - CWI - was also governed by the SUWI law.
}

180 In 2008, two funds merged, but FBKVB was not involved. 
Within the Fund, the process of evaluating and granting funding is supported by dedicated expert committees. The internal organisation of the Fund consists of an executive board and a managing director, who is responsible for daily operations. The website of the Fund (www.fondsbkvb.nl) only provides information on the programs to be carried out, not on operations. The Fund has a staff of 19 FTE and operating expenses in 2008 totalled $€ 2.2$ million (2006: $€ 1.7$ million). Program expenses in 2008 were some $€ 22$ million (2006 €15 million). The budgets of the funds are distributed by minOCW in a 4 year cycle, based on the 'Cultuurnota' which is a politically reviewed document on distributing all income transfers to the arts sector. The fund uses a one year budget cycle for their programs given the budget made available by minOCW. FBKVB annual reports are audited by a public auditor, who is appointed by FBKVB's executive board.

\subsubsection{Vf/Pf}

$\mathrm{Vf} / \mathrm{Pf}$ is shorthand for two formally separate legal entities operating in the area of replacement, disability and unemployment in the primary education industry. Historically, Stichting Vervangingsfonds (replacement and disability), was created by primary and secondary education employers and employees in 1992, with the support of minOCW. Stichting Participatiefonds was created by the same partners in 1995 and focuses on unemployed teaching staff. At present both foundations - classified as 'Foundation-ZBOs' - are governed by separate boards, but the members of the board are by Statute also required to be a member of the board of the other foundation. As of 2007 secondary education is no longer subject to participation in the programs managed by Vf/Pf.

$\mathrm{Vf} / \mathrm{Pf}$ is formally governed by the statutes of the individual entities and two minOCW decrees on the functions of the entities. In the governance relationship between minister and boards, the minister is supported by the staff of the policy unit responsible for primary education, which covers both the commissioning as well as the 'ownership' role on behalf of the minister. The board of Vf/Pf is a one tier board, divided into an executive and a non-executive part and supported by a managing director. The 'executive board' has no separate policy authority, which is the domain of the 'non-executive board'. Members of the boards are appointed by employer and employee organisations in the education sector. The minister has no role in these appointments. There is no separate form of horizontal accountability. The website (www.vfpf.nl) provides essentially program information and no financial information or annual reports.

The main task of Vf/Pf is funding of replacement of (temporarily) disabled or unemployed educational staff in primary education. Funding is supported by premiums paid by the School Boards that are required to fund Vf/Pf. Funding of the School Boards however is performed by minOCW, so minOCW indirectly funds Vf/Pf.

$\mathrm{Vf} / \mathrm{Pf}$ operates from one office with some 70 FTE and has outsourced some of its activities. The organisation had operating costs in 2006 of approximately $€ 13 \mathrm{M}$. Program costs in 2006 amounted to some $€ 520 \mathrm{M}$. 


\section{$15.2 \quad$ Monitoring/Regulating ZBOs}

There is more variation in Monitoring and Regulating ZBOs than in income transfer ZBOs. One group performs general oversight on behaviour of citizens or institutions and/or regulates behaviour. Another group focuses on quality assurance. A third group focuses on monitoring policy effectiveness and a final group focuses on compliance monitoring. In the case selection, three general oversight and one quality assurance ZBO are included.

\subsubsection{AFM}

AFM - Stichting Autoriteit Financiële Markten [Netherlands Authority for the financial markets] - is responsible for supervising the conduct of institutions operating in the financial markets such as banks, pension funds and insurance companies. Another part of its function is licensing of financial market intermediaries as well as licensing public auditors. Overall supervision of financial markets in the Netherlands is divided between the AFM and DNB - the central bank - who are responsible for prudential supervision. AFM was established in 2002 as a Foundation ZBO. Its predecessor STE (Stichting Toezicht Effecten verkeer) ${ }^{181}$ was created in 1989 under the influence of European financial market regulations. STE had only been responsible for supervising securities trading and also had private law status. Before 1989, regulating and monitoring of the financial markets was essentially left to the industry. Although AFM still has private law status, history indicates that there has been a trend of hiving in financial market regulating and monitoring activities.

AFM's governance structure consists of an executive board as well as a non-executive board for its daily operations. AFM's executive board is appointed by the Minister of Finance, based on a proposal from the non-executive board. The non-executive board is also appointed by the Minister of Finance, based on a proposal made by the members of the old non-executive board. Within minFin, a policy unit is responsible for both policy as well as ownership issues. The governance structure is completed by an advisory panel, consisting of representatives of the supervised institutions, which comments on proposed legislation and the AFM's direct as well as indirect monitoring expenses (Parliament, 2003d, p. 19). This advisory panel may be regarded as a form of horizontal accountability. The motivation for this choice is that the financial industry monitoring body should as far as possible copy the institutional and accountability measures that are usual within the industry (source: interviews). Information on the website www.afm.nl provides both information on policy as well on governance structure, budgets and annual reports. Financial statements are audited by a public auditor appointed by AFM's nonexecutive board.

181 In the 1995 NCA-report on ZBOs (Parliament, 1995a), Effectenvernieuwingsbureau (securities renewal office) is mentioned. This entity was discontinued and its tasks were left to the market under BW2:86d (see Parliament, 1998b). 
AFM is an organisation that is in the process of developing its activities. Operating expenses in 2008 were $€ 78 \mathrm{M}(2006: € 72 \mathrm{M})$ and staff levels were approximately 430 FTE (both 2008 and 2006).

\subsubsection{CFV}

CFV - Centraal Fonds voor de Volkshuisvesting (Social Housing Associations Fund) was originally created in 1988 as the result of a change in financing of Social Housing Associations. The creation of the fund was supported by the social housing sector. CFV has always had a public law based status. CFV can be qualified as a subsidiary ZBO. There was no transfer of staff from a government unit.

Formally, CFV was created on the basis of the 'Woningwet' (Law on [Social] Housing). The Minister of Housing, Communities and Integration [WWI] is responsible for CFV. The organisation of WWI is embedded in the Ministry of Housing, Spatial Planning and the Environment (minVROM) and was created in 2007 when the Balkenende IV-cabinet took office. The minister relies on both a policy staff as well as a special interface unit responsible for the ownership role within the department for all ZBOs and executive agencies of minVROM. CFV has no separate non-executive board or other horizontal accountability structures. There is no form of diagonal accountability structure either. CFV's website (www.cfv.nl) provides both policy as well as operational documents. Intermediate (quarterly) financial reports do exist but are not published on the website.

The original task of CFV is income transfer from within the social housing sector. Before 1988, the Dutch State and local government lent money to social housing associations [SHAs]. CFV's original role was to support SHAs that faced problems in financing their building programs on the market, mostly due to solvency issues, by financially supporting restructuring of the debts of such a SHA. Resources were retrieved from within the sector by compulsory levies (Van der Schaar, Faber, Koffijberg \& Priemus, 1996, p. 144). Government still subsidised the sector based on previous funding programs. By the mid 1990s, financial ties between central government and SHAs were ended, resulting in financial liberalisation (Brandsen, 2004, p. 66). Gradually, CFV's task has evolved into a form of a financial oversight in which CFV monitors the social housing sector on behalf of the minister. At present (end 2008), the core function is the monitoring activities, but due to policy emphasis on reallocation of funds available within the social housing sector (e.g. Parliament, 2008g) there is a high probability that the income transfer role of CFV will grow in the near future. The key of the reallocation program is that wealthy SHAs should contribute to the restructuring of areas with a relatively weak housing environment. The reallocation of the funds that are needed for this program will be executed by CFV.

CFV has no regional offices or branches. Operating expenses in 2008 were some $€ 6.0$ M (2006: €5.1 M) and staff numbers were 36 FTE. CFV's annual report is audited by a public auditor who is appointed by the CFV board. 
Given the fact that the core function of CFV in 2007/2008 actually consists of monitoring activities I will compare CFV with the other monitoring ZBOs rather than with income transfer ZBOs.

\subsubsection{NMa}

Fair competition is essentially governed by EU regulations. Until 1998 competition oversight in the Netherlands was organised within the Ministry of Economic Affairs and spread over several units (Parliament, 1996b, p. 42). As of 1998, new legislation on competition and market concentration (Mededingingswet; Law on competition) was implemented, based on EU standards. Within the framework of the new law, the organisational structure of market oversight was changed as well. A new unit named NMa was created within minEZ, managed by a Director General. Formally, NMa was still subject to the hierarchical chain of command within minEZ, but the Director General had a mandate which allowed him to operate independently from case based instructions by the minister. In the debates on the proposed competition law in Parliament, a discussion on independence and impartiality of the new authority was held, partially influenced by comments from interest groups (Parliament, 1996c, p. 8). A result of this debate was that a resolution was debated in Parliament that required evaluation of the organisational structure after 3 years and which changed the status of the new authority into that of a ZBO. The cabinet adopted the resolution. As of July 1, 2005, the executive board of NMa was attributed ZBO status ${ }^{182}$; its staff is still part of the ministry's structure. Cabinet argued that it would take too much time to create a separate legal entity for the whole of the organisation and that attributing ZBO status to the Director General (executive board) was relatively easy (Parliament, 2001e, p. 21).

As a result, NMa's governance structure consists of an executive board. There is no advisory panel or non-executive board. Regarding the decisions to be made by the NMa, a distinction is made between the general competition and market regulation tasks on the one hand and specialised units for the Energy and Transport Industries. NMa and NZA (see 15.2.5) co-operate in cases of mergers in the medical sector.

$\mathrm{NMa}$ is the only ZBO in this study that has no separate legal status. Financial management is based on the requirements of CW2001 and cash based. Annual reports are audited by minEZ's audit unit and implicitly reviewed by the NCA. The website of the organisation (www.nma.nl) provides information on policy, governance structure, budgets and annual reports. Operational expenditure of NMa was €44 M in 2008 (2006: €36 M). Total staff numbers were 405 in 2008 (2006: 380).

\subsubsection{NAK}

NAK - Nederlandse Algemene Keuringsdienst voor zaaizaad en pootgoed [General inspection service for agricultural seeds and seed potatoes] - is one of 7 quality certifying

182 In the original proposal, the Director General would have ZBO status. However, having only a single executive as decision making authority was regarded as too vulnerable by Parliament and Cabinet, therefore, the proposed law was changed by creating an Executive Board (Parliament, 2001f). 
institutions related to minLNV. The history of this foundation goes back to 1932, when farmers organised their own quality assurance system. The Minister of Agriculture was not involved in the original creation of the foundation. At present, regulation in this domain is mainly based on EU directives, with relatively few possibilities to create national regulations. Due to these European regulations, NAK has been forced to hive off its commercial activities to a completely different legal entity, possibly with the result of losing some efficiency of scale. This change in operations has been discussed in Parliament, but the only thing the minister could do was to promise Parliament that the expected negative impact of this change would be put onto the European agenda (Parliament, 2008h).

NAK's governance structure is based on a board and a managing director for daily operations. The board mainly consists of specialists in the sector and is supported by two specialised committees, responsible for the contents of the inspection programs. There is no separate non-executive board. The president of the board is appointed by the full board after approval by minLNV. The other members of the board are appointed by relevant interest groups after consulting the president of the board. In the relationship between NAK and minLNV, the ministry has separated the policy program role from the ownership monitoring role. Information on fees and annual reports is available on the website www.nak.nl. NAK is one of these organisations that would qualify under Bohley's (1980) decentralisation argument for hiving off ${ }^{183}$, due to the fact that the activities of the organisation are only directly relevant for a very small group, the farmers who grow the relevant crops. However, history tells a different story. NAK is actually hived in into the government domain although it is still formally a separate private legal entity.

NAK is an organisation operating from one office with a staff of approximately 220 FTE in 2008 (2006: 220). Operating expenses were €27 M in 2008 and €21 M in 2006.

\subsubsection{NZA}

In section 15.1.1, I have already referred to Ziekenfondsraad, which was split up in 1999 into a monitoring ZBO and an income distribution and policy advice ZBO. NZA is the legal successor to the monitoring ZBO 'College Toezicht Zorgverzekeringen' [CTZ] (Health insurance monitoring Board) that was created after splitting up Ziekenfondsraad. In the Dutch healthcare system, many of the fees and prices to be charged by service providers are regulated. Although the present law allows for liberalisation of prices, a substantial part of the system is still controlled by price regulation. Until 2006, there was a separate ZBO (College Tarieven Gezondheidszorg [CTG]; Board on healthcare fees). On October 1, 2006, CTG and CTZ merged into the new NZA. NZA's tasks essentially cover the former monitoring functions as well as market regulation function - for example by assessing licences to merge hospitals - and a standard setting institution for prices in the regulated segment of the market. NZA's legal status is a public law legal entity. Given its history, NZA can be regarded as an entity that was hived in.

183 See section on privatisation of demand. 
NZA operates under the responsibility of minVWS. The ministry has organised its policy commissioning role as well as its ownership role within one unit of the Directorate General Cure. NZA governance structure consists of an (executive) board which is appointed by the Minister of VWS. NZA has no non-executive board; however the executive board is allowed to appoint an Advisory Board of experts. Such an Advisory Board currently exists. The task description of the Advisory Board covers executive board operational issues, which implies that the Advisory Board has a function similar to that of a non-executive Board rather than being a horizontal accountability instrument. Information on the website (www.nza.nl) discloses information on policy documents, governance structure and annual reports.

NZA's short history makes it difficult to provide adequate comparative data on operations. In 2005, the predecessors CTG and CTZ had operating expenses of $€ 27 \mathrm{M}$ and 200 FTE. 2008 data on NZA disclose operating expenses of $€ 30 \mathrm{M}$ and 240 staff members.

\subsection{Concluding remarks}

The 11 ZBOs described above are split up over two main categories of ZBO functionality. They vary in size, organisational structure and legal status. This choice was considered in depth when selecting the cases. However, a review of the history of the organisations reveals that the majority of the organisations were not hived off but hived in to the domain of government. Only FBKVB is an explicit case of hiving off; one may argue that NMa has characteristics of hiving off but as its staff is still part of minEZ, that is not a very strong case. 


\section{Formal and actual autonomy of income transfer ZBOs}

In this chapter and the next chapter, I will address the results of assessing formal and actual autonomy of the selected ZBOs, starting with income transfer ZBOs and then followed by the monitoring ZBOs. These evaluations form the basis for answering the research question for the empirical part of the study which is:

\section{Do Parliament's control tools match the control tools that fit the legal and economic characteristics of ZBO services?}

The research model used was presented in section 13.1. Because there are two different groups of ZBOs included in this study, I will discuss the relevant items for each group separately. In this chapter, the income transfer ZBOs will be discussed. In chapter 17, I will focus on the monitoring type ZBOs. The main themes for evaluation in both chapters are Authority, Service specifications, Market dimensions covering both supply and demand as well as Planning \& Control including the political debates regarding individual ZBOs between 2006 and 2008. These themes were operationalised in section 14.1 and led to a reference point of issues for the different types of ZBO functions identified.

The case selection is based on two groups of ZBOs with different functions. The legal dimension of autonomy will be discussed on a case by case basis by elaborating on ownership as well as formal and/or actual deviations from the four groups of authority issues that were discussed in Part B. The general rule is that if a provision has been made in the law or in decrees, this restricts the legal autonomy of the ZBO under scrutiny. ${ }^{184}$ As kZBO defines the general restrictions for all ZBOs, the assessment will focus on those restrictions or degrees of freedom in authority attributed in the case law that deviate from the KZBO standard. Furthermore, actual practice with respect to these regulations will be discussed. The economic indicators will also be discussed for each ZBO separately based on the product and market characteristics and actual control applied. I will start by discussing the legal dimension of autonomy in section 16.1, followed by an elaboration on the economic dimension of autonomy in section 16.2. The chapter will be concluded by an elaboration on observed mismatches between legal and economic dimension of autonomy and an assessment of the relative autonomy of the income transfer ZBOs studied in relation to each other.

\subsection{The legal dimension of autonomy}

For each of the cases the legal dimension of autonomy is discussed along the lines of (quasi) ownership and the four groups of authority issues than can be derived from kZBO. I will only discuss those areas in which a deviation between KZBO and ZBO case law or between kZBO and actual practice is observed, because kZBO is supposed to be the standard for controlling new and existing ZBOs which are explicitly listed as subject to

184 Of course, if the arrangement attributes power to the executive board of the ZBO that creates more degrees of freedom, autonomy will be increased. 
kZBO. Differences between ZBO case law and actual practice emerge indirectly from these observations: if a deviation between kZBO and case law exists, it is either continued, or mitigated in actual practice.

All assessments are based on data for fiscal 2007/2008. In each case, a short comment on developments regarding implementation of $\mathrm{kZBO}$ is also given. In the discussion on the individual cases, all mismatches are disclosed. In the overview of all assessments as well as in the general conclusion at the end of each case, I will focus on information, governance and cyclical arrangements because the normative measures are in general set when the ZBO is created. Furthermore, I will not consider measures of last resort: instruments only needed in very special cases as a tool for intervention. They will not affect autonomy during actual operations and several interviewees have indicated that tools such as intervening in cases of negligence are not used and are not likely to be used since they would fundamentally change the relationship between ZBO and minister. In the tables at the end of the discussion on each ZBO, an indication of the relevance of the measures is given based on the arguments mentioned above.

Table 16.1: Key data on income transfer ZBOs

\begin{tabular}{|c|c|c|c|c|c|c|}
\hline & $\stackrel{N}{3}$ & 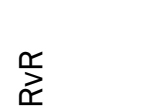 & œ & $\gtreqless$ & 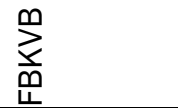 & $\frac{4}{\frac{4}{2}}$ \\
\hline Legal entity & $\begin{array}{l}\text { PLA, } \\
\text { subsidiary }\end{array}$ & $\begin{array}{l}\text { PLA, } \\
\text { subsidiary }\end{array}$ & $\begin{array}{l}\text { PLA, } \\
\text { subsidiary }\end{array}$ & $\begin{array}{l}\text { PLA, } \\
\text { subsidiary }\end{array}$ & $\begin{array}{l}\text { PLB, } \\
\text { foundation }\end{array}$ & $\begin{array}{l}\text { PLB, } \\
\text { foundation }\end{array}$ \\
\hline Funding & public & public & public & public & public & private \\
\hline $\begin{array}{l}\text { Operating revenues in } € M \\
2008\end{array}$ & 52 & 53 & 270 & 1,811 & 2 & 13 \\
\hline
\end{tabular}

In chapter 14, I discussed the case selection for this study. Key data on the six selected income transfer ZBOs is given in Table 16.1. 


\subsubsection{CVZ}

The assessment of CVZ's autonomy is based on the arrangements that were effective in 2007/2008. In his letter on adapting legislation to kZBO (Parliament, 2008f), minVWS announced that CVZ would be fully subject to kZBO. The proposed legislation has been submitted in 2009 but as of January 2010 is still being debated in Parliament (Parliament, 2009e).

\subsubsection{Normative measures}

CVZ has PLA status which has been defined in a separate section of the program law ZVW. PLA status implies that KZBO is fully applicable unless other measures are included in the case law. In the letter from minVWS (Parliament, 2008i) on implementation of kZBO, no exceptions are proposed.

PLA status classifies CVZ as a Subsidiary ZBO which implies that ownership is held by minister and the parent ministry. Interviewees in the CVZ case confirm that minVWS actually controls operating equity and can be regarded as the (quasi) owner of CVZ.

On one normative issue a deviation from kZBO is observed. In kZBO:9 the only restriction mentioned is on appointment of civil servants in the executive board.185 In ZVW, another restriction is introduced: members of the board also have to be recruited based on gender and ethnic/cultural background. Although this has no immediate effect on autonomy, it is a restriction in the degrees of freedom minVWS enjoys in its selection of members of the executive board. In practice, the CVZ executive board consists of one woman and two men, the ethnic/cultural dimension has not been covered.

\subsubsection{Information measures}

With respect to the information measures, deviations exist on two issues: the general right of inquiry is not included in ZVW and no arrangement has been made on submitting annual reports to Parliament. The right of inquiry in ZWV is restricted to performance information with respect to health insurance companies and relevant differences between budgeted and actual operational expenses and does not cover other issues with respect to operations. This seems to provide additional degrees of freedom, but some interviewees have indicated that the time to process decisions within minVWS depends on formal processing by the CVZ board rather than on informal information exchange. Furthermore, it was indicated that actual frequency of reporting to minVWS is once a month, also an indication of frequent information exchange. Effectively it seems that the general right of inquiry exists in practice. CVZ case law requires that the budget (plan) and annual reports including financial statements are made available to the general public. This is a broader regulation than kZBO in terms of contents. However, in terms of publication, it is a passive form rather than an active form as required by $k Z B O$. In practice, Parliament receives annual reports including financial statements from minVWS,

185 In practice, members of ZBO boards are very often former civil servants or politicians. 
based on the requirement in ZVW:76.2 that minVWS has to comment on the operations of CVZ to Parliament. This means that Parliament receives the information including a political annotation. This (at least theoretically) affects the autonomy of CVZ in a negative way given the possibility to comment on the minister's assessment of CVZ. Respondents indicate that this practice will cease to exist after fiscal 2007 as kZBO only requires submission of annual reports to Parliament and there is no longer a requirement for a minVWS assessment (Parliament, 2007j; 2008j). Indeed no separate assessment document on minVWS' Subsidiary ZBOs has been published as of fiscal 2008, although ZVW:76.2 still included this requirement at the end of fiscal 2009.

\subsubsection{Governance provisions}

The third group of legal issues regards governance structure. kZBO theoretically includes the power to create an executive and a non-executive board. Interviewees indicate that the CVZ executive board preferred to include a non-executive board in its governance structure as an institution that reflects on the operations of CVZ. MinVWS disagreed, in line with the Gerritsen Committee advice (2008), but did allow an advisory board to be created (minVWS, 2006a). As there is no formal two tier governance structure, a legal arrangement as meant in kZBO:7 seems to be obsolete. One can argue that as there is in fact a second - although non authoritative - body, an arrangement on the relationship between the two bodies should exist. In the governance code of the CVZ (executive) board, which has been approved by minVWS, the advisory board is mentioned and the executive board is entitled to decide on advisory board appointments and tasks. In practice, an arrangement as intended in kZBO actually exists. Another point to be mentioned is that no intervention measures in the event of negligence exist. Interviewees indicated that it is unlikely that such an arrangement will ever be used.

More important are four other governance issues. First, there are no measures for ex ante approval of mandates for assigned tasks. As a result the description of tasks assigned to CVZ in ZVW:64-ZVW:70 has a restrictive and limitative character. Interviewees have indicated that in particular CVZ functions that are related to some groups of individuals (uninsured and expatriates) created problems within CVZ and might be performed more efficiently in other ZBOs or government organisations. This has not been followed through due to the fact that other organisations were also facing important organisational and process changes. Second, ZVW does not include a general arrangement on secondary jobs for members of the executive board. Only a limited list of incompatibilities exists, which suggests some additional autonomy for CVZ's executive board, but this is mitigated by lower regulation in 'Regeling bezoldiging en beheerskosten bestuursorganen volksgezondheid [RBBBV] (Decree on remuneration and operating costs ZBOs minVWS), article 7. Furthermore, at the level of decrees based on ZVW, the requirement to report and publish secondary jobs is included. Therefore, there is no impact on autonomy compared to kZBO regulations. A third point to be discussed here is the issue of remuneration. $k Z B O: 14$ only stipulates that the minister determines remuneration of the board. In this case, RBBBV:1-4, the remuneration arrangement is 
fully described. It does not affect autonomy from a legal perspective as the regulation addresses minVWS rather than CVZ's executive board. However, the actual rules are more restrictive than the arrangement in kZBO. The legal requirements of WOPT on publication of remuneration are met because no member of the board receives compensation that exceeds the WOPT standards. In practice, the 2007 annual report disclosed remuneration; the generally available 2008 annual report did not. Finally, the optional arrangement in kZBO on asset related transactions is not included in ZVW. This is particularly relevant when creating legal entities, in the case of real estate transactions and providing collateral. Interviewees indicate that the issue of bankruptcy, which is also not covered in legislation, is merely theoretical. If CVZ's financial position became insolvent, respondents indicated that the minister would intervene anyway. On the issue of lending and borrowing, CVZ's position is covered in a separate law on funding and financing social security programs and its operating costs (WFSV). This law is older than the arrangement that exists for other ZBOs based on CW2001:45, but has the same impact. Therefore there is no impact on autonomy as a result of lending and borrowing transactions. Although not formally the case, controls on reserves other than an equalisation reserve (kZBO:32f) do exist. Interviewees indicated that at the civil servant level minVWS is the least critical about the subject of dedicated reserves in CVZ's balance sheet.

\subsubsection{Cyclical measures}

The last group of legal measures covers cyclical authority. Four issues are covered which all restrict CVZ's autonomy. First, CVZ's budget is not approved by minVWS but determined by minVWS. Determining a budget is a stronger authority tool than approval because the minister can change the budget. CVZ does not receive a letter of instruction to prepare the budget. Respondents indicate that such a letter would conflict with the independent character of the ZBO and is not necessary as the tasks assigned to CVZ are, according to the respondents, relatively stable in the course of time. This is a typical remark because determining the budget by minVWS mitigates the independent character of CVZ. Furthermore, the stability of tasks assigned can be contested, given the fact that the role attributed to CVZ on health insurance for expatriates was, according to the same respondents, a new task that was underestimated. To some extent this also holds for the new tasks on health services for illegal immigrants and people that do not pay compulsory insurance premiums. The respondents also indicate that after the initial budget proposal is submitted to minVWS a negotiation process emerges that effectively resembles an ex ante letter of instruction. The legal measures on submitting a budget by CVZ and determining the budget by minVWS (ZVW:71-72) provides only 2 months to complete this negotiation process, which is a relatively short timeframe given the internal processes at minVWS which include, according to respondents, a two stage review of the proposed draft and final budget.

Second, RBBBV requires that CVZ submits a multiyear budget plan. This is an arrangement that is not included in KZBO. From a ZBO perspective, it reduces autonomy 
as the board has to inform the Minister-Principal beforehand on future perspectives rather than during the budgeting process for the next fiscal year. ${ }^{186}$

Third, although an equalisation reserve is allowed, a ministerial decree (RBBBV:18) requires the equalisation reserve not to exceed $5 \%$ of the budget. This seems a plausible arrangement, but the general arrangement for executive agencies on the same subject states that the equalisation reserve must not exceed $5 \%$ of the average sales/revenues over the last three fiscal years (Regeling Baten-lastendiensten 2007, article 17.4b; Decree executive agencies 2007). The latter arrangement is a more flexible way of managing the equalisation reserve. Therefore, in my opinion the CVZ arrangement restricts autonomy. Respondents note that the issue of the level of reserves allowed is in practice still being discussed.

The last issue is a separate and explicit audit protocol described in RBBBV. This is not a requirement demanded by kZBO and restricts the professional judgement of the CVZ auditors, particularly because it prescribes in detail the level of control on each of the respective articles of ZVW. This also has a negative impact on autonomy.

\subsubsection{Impact of changes in legislation due to alignment to kZBO}

The proposed changes in legislation as a result of the implementation of kZBO did not pass through Parliament by January 1, 2010. The proposal includes several changes (Parliament, 2009e) which are discussed here. The 2007 legislation on CVZ included requirements on women as board members (ZVW:59.5) as well as listed incompatibilities. These restrictions are deleted which brings legislation in line with kZBO.

In the budgeting and reporting procedures, the wording of the legislation is changed to maintain requirements on working programs and multiyear budgets in the minVWS decision making process. This is in line with the 2007 legislation and thus does not alter the autonomy observed in the analysis above. The proposed ZVW:73 clarifies the scope of kZBO:26, 34 and 35 by stating that these kZBO articles refer to costs of CVZ's operations. As far as content is concerned, the legislation has the same (negative) impact on autonomy as the 2007 version of ZVW.

An inconsistency seems to exist with respect to approval of the budget documents in ZVW:75. The old and new ZVW:72 requires that minVWS sets the total budget for operations of CVZ. A separate budget document approval as referred to in ZVW:75.1 (new) seems to be obsolete; at least the old legislation did not cover a separate approval of working programs and budget documents. Other measures in ZVW:75.3 (new) address structure of budgets and annual reports as well as (the level of) the equalisation reserve. These measures are specified in the present RBBBV and remain unchanged. Effectively, the (negative) impact on autonomy compared to kZBO standards will continue to exist as well.

186 I recall that under AW1996:124I.4, consent to the multiyear budget was included in the regulation. Furthermore, it is common practice for departmental units under CW2001:5. 
Table 16.2: Legal measures on CVZ, formally or actually deviating from kZBO

\begin{tabular}{|c|c|c|c|c|c|c|}
\hline Authority issue & $\begin{array}{l}\text { Authority } \\
\text { Group }\end{array}$ & $\begin{array}{l}\text { Reference } \\
\text { kZBO }\end{array}$ & $\begin{array}{l}\text { Reference } \\
\text { case law }\end{array}$ & Actual practice & $\begin{array}{l}\text { Formal } \\
\text { mismatch } \\
\text { and impact }\end{array}$ & $\begin{array}{l}\text { Actual } \\
\text { mismatch } \\
\text { and } \\
\text { impact }\end{array}$ \\
\hline $\begin{array}{l}\text { Not appointing } \\
\text { civil servant to } \\
\text { board }\end{array}$ & Normative & 9 & ZVW:59 & in line & 0 & 0 \\
\hline $\begin{array}{l}\text { Appointment } \\
\text { based on gender } \\
\text { and or cultural } \\
\text { background }\end{array}$ & Normative & $\begin{array}{l}\text { not } \\
\text { included }\end{array}$ & ZVW:59.5 & applied & $\downarrow$ & 0 \\
\hline $\begin{array}{l}\text { Submit annual } \\
\text { report to } \\
\text { Parliament }\end{array}$ & Information & 18 & ZVW:76 & $\begin{array}{l}\text { minister submitted } \\
\text { annual report, till } \\
2007\end{array}$ & $\downarrow$ & $\uparrow$ \\
\hline $\begin{array}{l}\text { General right of } \\
\text { inquiry }\end{array}$ & Information & 20 & $\begin{array}{l}\text { ZVW:65-66, } \\
71\end{array}$ & in line & 0 & 0 \\
\hline Multiple bodies & Governance & 7 & $\begin{array}{l}\text { covered in } \\
\text { internal } \\
\text { governance } \\
\text { statute }\end{array}$ & $\begin{array}{l}\text { advisory board is } \\
\text { appointed }\end{array}$ & 0 & 0 \\
\hline $\begin{array}{l}\text { Ex ante approval } \\
\text { of mandates }\end{array}$ & Governance & 8 & $\begin{array}{l}\text { limitative } \\
\text { list of tasks } \\
\text { ZVW:64-70 }\end{array}$ & $\begin{array}{l}\text { no external } \\
\text { mandates }\end{array}$ & $\downarrow$ & 0 \\
\hline $\begin{array}{l}\text { Measure on } \\
\text { secondary jobs }\end{array}$ & Governance & 13 & $\begin{array}{l}\text { ZVW:59.6 + } \\
\text { RBBBV:7 }\end{array}$ & $\begin{array}{l}\text { disclosure on } \\
\text { website; } 2007 \text { in } \\
\text { annual report }\end{array}$ & 0 & 0 \\
\hline $\begin{array}{l}\text { Decision on and } \\
\text { disclosure of } \\
\text { remuneration }\end{array}$ & Governance & $\begin{array}{l}\text { kZBO:14 } \\
\text { WOPT:6 }\end{array}$ & $\begin{array}{l}\text { RBBV: } \\
\text { chapter } 1\end{array}$ & $\begin{array}{l}\text { 2007: disclosed; } \\
\text { 2008: not disclosed }\end{array}$ & 0 & 0 \\
\hline $\begin{array}{l}\text { Intervention in } \\
\text { case of } \\
\text { negligence }\end{array}$ & Governance & 23 & $\begin{array}{l}\text { not } \\
\text { included }\end{array}$ & not used & $\uparrow$ & 0 \\
\hline $\begin{array}{l}\text { Asset related } \\
\text { transactions: } \\
\text { borrowing and } \\
\text { lending }\end{array}$ & Governance & $32 d$ & WFSV:120 & in line & 0 & 0 \\
\hline $\begin{array}{l}\text { Asset related } \\
\text { transactions: } \\
\text { control on } \\
\text { reserves }\end{array}$ & Governance & $32 f$ & $\begin{array}{l}\text { not } \\
\text { included }\end{array}$ & $\begin{array}{l}\text { minVWS' attitude is } \\
\text { critical }\end{array}$ & 0 & 0 \\
\hline $\begin{array}{l}\text { Asset related } \\
\text { transactions: } \\
\text { bankruptcy }\end{array}$ & Governance & $32 g$ & $\begin{array}{l}\text { not } \\
\text { included }\end{array}$ & $\begin{array}{l}\text { intervention } \\
\text { beforehand expected }\end{array}$ & 0 & 0 \\
\hline $\begin{array}{l}\text { Asset related } \\
\text { transactions: } \\
\text { others }\end{array}$ & Governance & $\begin{array}{l}32 a-c ; \\
32 e\end{array}$ & $\begin{array}{l}\text { not } \\
\text { included }\end{array}$ & no actions observed & 0 & 0 \\
\hline $\begin{array}{l}\text { Approval of } \\
\text { budget }\end{array}$ & Cyclical & 29 & ZVW:72.1 & minister decides & $\downarrow$ & $\downarrow$ \\
\hline $\begin{array}{l}\text { Creating } \\
\text { equalisation } \\
\text { reserve }\end{array}$ & Cyclical & 33 & RBBBV:18 & in discussion & $\downarrow$ & $\downarrow$ \\
\hline $\begin{array}{l}\text { Submit multiyear } \\
\text { plan }\end{array}$ & Cyclical & none & RBBBV:12 & submitted & $\downarrow$ & $\downarrow$ \\
\hline Audit protocol & Cyclical & $\begin{array}{l}\text { not } \\
\text { included }\end{array}$ & RBBBV:15 & basis for auditing & $\downarrow$ & $\downarrow$ \\
\hline \multicolumn{7}{|l|}{ Explanation: } \\
\hline \multicolumn{4}{|c|}{ Included in determining autonomy } & \multicolumn{3}{|c|}{ Not included in determining autonomy } \\
\hline
\end{tabular}


Finally, minVWS will no longer assess CVZ's annual report as was the case under ZVW:76.2 (old). The general impression of the changed legislation is that it does not change the autonomy of CVZ as observed under the ZVW that was in effect in 2007.

\subsubsection{Conclusion}

The table above summarises the impact of the legal measures that deviate from the standard arrangement as laid down in kZBO. Two levels of deviations can be observed. First mismatches between formal and actual measures and the kZBO standard are discussed, which I shall label type 1 mismatches. Type 1 mismatches are found in annual report submission arrangements including comments by minVWS to Parliament; equalisation reserve controls which are stronger than those for executive agencies and actually discussed; decision making rather than approving budgets; strict function description which do not even allow for a discussion on providing services to other ministries; as well as the strict audit protocol used. All have a negative impact on autonomy.

The second level of mismatches is between formal and current actual measures. These are Type 2 mismatches. In practice asset controls are imposed, particularly on reserves other than the equalisation reserve, although no arrangement formally exists.

Finally, an inconsistency in information provision is found in providing annual reports to Parliament: ZVW still requires a comment by minVWS which as of 2008 has announced that due to kZBO there is no need for such a comment. The overall conclusion of this section is that CVZ's autonomy is formally reduced and practices tend to be even stricter, particularly with respect to asset controls. 


\subsubsection{RvR}

RvR is discussed as a (cluster of) 5 separate legal entities, working together with respect to efficient organisation of operations. RvR was formally merged on July 1, 2010 and by then legislation was aligned with kZBO. In her letter on implementation of kZBO, minJus announced she would only make an exception to kZBO:15 on the civil servant status of staff (Parliament, 2008i).

\subsubsection{Normative measures}

RvR has PLA status which is defined in article 2 of the program law on legal support (Wet op de Rechtsbijstand; [WRB]). Due to its PLA status, RvR is fully subject to kZBO, unless other measures are included in the case law.

The PLA status classifies RVR as a Subsidiary ZBO which implies that ownership is held by minJus. Interviewees confirm this position, although some of them indicated that no fundamental discussion on the ownership position was held. In practice, the ownership and commissioning role are attributed to the relevant program directorate rather than separated. From a political perspective, the State Secretary for Justice ${ }^{187}$, is formally responsible for RvR.

The compulsory normative requirements as stated in kZBO apply to RvR, except for kZBO:9. The July 2007 version of WRB has no restrictions on appointment of civil servants. It does have a restriction with respect to the number of lawyers that generally represent clients (in Dutch: Rechtsbijstandsverleners) on the Board (WRB:3.3). ${ }^{188}$ This deviation does not affect autonomy: interviewees indicated that no interventions with respect to Board members have been made. Furthermore, the Boards are consulted in appointment procedures, which gives them some influence on the actual appointments.

In the optional measures, two deviations from kZBO exist. First, the Minister of Justice announced that she would allow an exception on kZBO:15, the regulation on the legal position of staff. In her letter on the application of kZBO (Parliament, 2008i) minJus proposed to continue the present private law status of RvR's staff as defined in WRB:11. In theory, this means that RvR has autonomy on staff remuneration. The arrangement on the position of RvR staff is made in the program law rather than based on a ministerial decree as required by kZBO. This means that it is relatively hard to change the existing measures. In a separate decree (Subsidiebesluit raden voor rechtsbijstand [SRvR), an arrangement is included on the compensation procedure for wage increases. RvR is given compensation based on a fixed rule, which means that the Board has limited power to

187 State Secretary is a political official who represents a minister for a part of his political portfolio (GW:46.2) under ministerial responsibility. In practice, a State Secretary's political responsibility is similar to that of a minister.

188 Lawyers representing clients have a commercial interest in positive decisions on income transfers by RvR. Therefore some restrictions on board membership were made. In the revised version of WRB after the merger into one single board, kZBO:9 applies automatically and the only other restriction is incompatibility of membership in both Board and advisory board (WRB2010:3.2). 
increase wages (SRvR:4.1). The arrangement is compulsory and transparent. The only way minJUS can reduce compensation for wages is by defining the basis for compensation (SRvR:4.2).

Second, the data protection arrangement (kZBO:41) is not included in WRB. In SRvR a data protection arrangement is mentioned as one of the conditions for providing subsidies (actually program- and operating costs; SRvR:8.2) to RvR.

\subsubsection{Information measures}

RvR submits its annual report informally to MPs, without intervention by minJUS. This means that compared to a kZBO context, RvR has a higher level of autonomy because there is no minJUS role in this process. Interviewees indicate that policy related information is submitted by minJUS to Parliament. As no information on operations is provided, this has no effect on RvR's operational autonomy. Some interviewees also indicated that the RvR annual report is approved by minJUS. Formally an arrangement as meant in kZBO:34 does not apply to RvR. The procedure with respect to approval of resources spent by RvR is based on the subsidy provided to RvR. At the end of the fiscal year minJUS determines the subsidy to be provided to RvR based on the audited statement of accounts. This results in a formal letter from minJUS to the Board indicating that the subsidy has been approved. As a result, the formal position of RvR is less autonomous than in a case where a minister only approves the annual report as meant by kZBO:34.

Other information measures are formally and actually in line with kZBO or not applicable at all. Therefore, there is no additional impact on autonomy.

\subsubsection{Governance provisions}

In WRB no arrangement has been made for 'incoming mandates' (Parliament, 2000d, p. 23) for the ZBO as defined by kZBO:8. This means that RvR is restricted to delivering only those services that are described in the law which has a negative impact on autonomy.

RvR is managed by a board and directors for each of its jurisdictions. During 20072008 , debate on the future governance structure was ongoing. Key to the new structure would be one single organisation and, according to the respondents, preferably a two tier board. The members of the executive board were only part time; therefore an arrangement on secondary jobs would be odd. However, except for the limitation on lawyers representing clients on the board, no list of incompatibilities exists in the RvR legislation before the merger into a single organisation. ${ }^{189}$ The single organisation concept has been implemented; the main governance structure is based on a one tier executive board and an advisory board. Arrangements on two tier boards are therefore not found in the relevant case laws.

Given the provision (WRB:6.2) on remuneration in accordance with the measures for civil servants, no excess remuneration or bonuses are expected. The annual reports do

${ }^{189}$ After the merger, only incompatibility between executive board and advisory board is mentioned. 
not disclose information, but RvR is not mentioned on the minBZK blacklist of organisations that did not report based on WOPT (minBZK, 2009a, 2009b).

Intervention measures in the event of negligence and provisions on annulling decisions are not used in practice; only the intervention measure in kZBO:23 is included in the case law. The character of these measures is one of last resort and they do not have an impact on autonomy.

Three issues should be noted on asset related transactions as meant by kZBO:32. First, the case law describes explicitly control of a separate legal entity by RvR in WRB1823. This legal entity has been created and is operational. Second, the formal case law does not include an arrangement on creating other legal entities. In the SRvR decree (SRVR:14.1) the control tools regarding assets are mentioned indirectly by referring to $\mathrm{AWb}: 4: 71$. The setup of this part of the governance structure is rather complex, given the fact that three separate legal documents have to be studied. In practice, the impact on actual autonomy is minimal: they have not yet been used in practice. Secondly, only one issue mentioned in kZBO:32 is not covered. This regards bankruptcy arrangement which are, given the PLA status of RvR, practically irrelevant. There is therefore no impact due to this deviation. The third issue on asset related transactions is not mentioned in kZBO. It concerns ministerial consent on subsidising relationships with other entities than the legal entity mentioned in WRB:18; consent on changing IT systems and consent to transfer program resources from the dedicated equalisation reserve. In practice however the measures were not used; in the case of transfer of resources the actual position in fiscal 2007 and fiscal 2008 of the equalisation reserve is negative which means that a transfer of resources would result in an even more negative position. All these measures are included in SRVR rather than in WRB and have a negative effect on autonomy. Thematically, except for the subsidising issue, all these restrictions concern asset related issues and are assessed as one item.

\subsubsection{Cyclical measures}

Two items in the cyclical measures deviate from kZBO and have a negative impact on autonomy. First, kZBO requires approval of the annual budget. The formal arrangement is that minJUS gives its consent to the annual working program of RvR, which includes the budget. This arrangement seems to provide more autonomy to RvR than is given under kZBO:29. The autonomy is effectively reduced by lower level regulations. SRvR:6 states that the minister provides a budgetary framework and SRvR:7 indicates that minJUS decides on the application for subsidy to RvR. Effectively, this means that the consent to the working program and budget is formally overruled by the decision on the resources to be provided. Actual practice is in line with SRvR arrangements and confirm a negative impact on autonomy. 
Table 16.3: Legal measures on RvR, formally or actually deviating from kZBO

\begin{tabular}{|c|c|c|c|c|c|c|}
\hline Authority issue & $\begin{array}{l}\text { Authority } \\
\text { Group }\end{array}$ & $\begin{array}{l}\text { reference } \\
\text { kZBO }\end{array}$ & $\begin{array}{l}\text { reference } \\
\text { case law }\end{array}$ & Actual practice & $\begin{array}{l}\text { formal } \\
\text { mismatch } \\
\text { and } \\
\text { impact }\end{array}$ & $\begin{array}{l}\text { actual } \\
\text { mismatch } \\
\text { and } \\
\text { impact }\end{array}$ \\
\hline $\begin{array}{l}\text { Not appointing civil } \\
\text { servants to board }\end{array}$ & Normative & 9 & WRB:3 & in line with WRB:3 & 0 & 0 \\
\hline $\begin{array}{l}\text { Measure on legal } \\
\text { position of staff }\end{array}$ & Normative & 15 & WRB:11.1 & private law based & $\uparrow$ & $\uparrow$ \\
\hline $\begin{array}{l}\text { Requirement for data } \\
\text { protection }\end{array}$ & Normative & 41 & $\begin{array}{l}\text { Subsidy } \\
\text { Decree, } \\
\text { article } 8\end{array}$ & in line & 0 & 0 \\
\hline $\begin{array}{l}\text { Submitting annual } \\
\text { report to Parliament }\end{array}$ & Information & 18 & not included & $\begin{array}{l}\text { Informally } \\
\text { submitted to MPs }\end{array}$ & $\widehat{\uparrow}$ & $\uparrow$ \\
\hline $\begin{array}{l}\text { Frequency of } \\
\text { intermediate reports } \\
\text { to minister } \\
\text { determined by law }\end{array}$ & Information & $\begin{array}{l}\text { not } \\
\text { included }\end{array}$ & SRvR:9 & in line with SRvR & $\downarrow$ & $\downarrow$ \\
\hline $\begin{array}{l}\text { Approval of statement } \\
\text { of accounts }\end{array}$ & Information & 34 & $\begin{array}{l}\text { SRvR:7 } \\
\text { minJUS } \\
\text { determines } \\
\text { subsidy } \\
\text { rather than } \\
\text { approves } \\
\text { statement of } \\
\text { accounts }\end{array}$ & in line with SRvR & $\downarrow$ & $\downarrow$ \\
\hline $\begin{array}{l}\text { Ex ante approval of } \\
\text { mandates to the ZBO }\end{array}$ & Governance & 8 & not included & $\begin{array}{l}\text { no external } \\
\text { mandates }\end{array}$ & $\downarrow$ & $\downarrow$ \\
\hline $\begin{array}{l}\text { Measure on secondary } \\
\text { jobs of Board } \\
\text { members }\end{array}$ & Governance & 13 & not included & $\begin{array}{l}\text { Board is not full } \\
\text { time role }\end{array}$ & 0 & 0 \\
\hline $\begin{array}{l}\text { Decision on and } \\
\text { disclosure of } \\
\text { remuneration }\end{array}$ & Governance & $\begin{array}{l}\text { kZBO:14 } \\
\text { WOPT:6 }\end{array}$ & WRB:6.2 & $\begin{array}{l}\text { 2007/2008: not } \\
\text { disclosed }\end{array}$ & 0 & 0 \\
\hline $\begin{array}{l}\text { Annulling of ZBO } \\
\text { decisions }\end{array}$ & Governance & 22 & not included & $\begin{array}{l}\text { not used in } \\
\text { practice }\end{array}$ & $\uparrow$ & 0 \\
\hline $\begin{array}{l}\text { Intervention in event } \\
\text { of negligence }\end{array}$ & Governance & 23 & WRB:9.4 & $\begin{array}{l}\text { not used in } \\
\text { practice }\end{array}$ & 0 & 0 \\
\hline $\begin{array}{l}\text { Ministerial consent } \\
\text { when } \\
\text { creating/participating } \\
\text { in legal entity }\end{array}$ & Governance & $32 a$ & $\begin{array}{l}\text { WRB:18-23 } \\
\text { SRvR:14.1 }\end{array}$ & $\begin{array}{l}\text { only WRB-based } \\
\text { entities created }\end{array}$ & $\downarrow$ & 0 \\
\hline $\begin{array}{l}\text { Asset related } \\
\text { transactions: } \\
\text { borrowing and lending }\end{array}$ & Governance & $32 d$ & SRvR:14.1 & $\begin{array}{l}\text { Not used in } \\
\text { practice }\end{array}$ & $\downarrow$ & 0 \\
\hline $\begin{array}{l}\text { Asset related } \\
\text { transactions }\end{array}$ & Governance & $\begin{array}{l}\text { 32a-c, e-f } \\
+ \text { some } \\
\text { not } \\
\text { included }\end{array}$ & SRvR:14 & $\begin{array}{l}\text { not used in } \\
\text { practice }+ \\
\text { equalisation } \\
\text { reserves are } \\
\text { negative }\end{array}$ & $\downarrow$ & 0 \\
\hline Approval of budget & Cyclical & 29 & $\begin{array}{l}\text { WRB:42: } \\
\text { consent } \\
\text { SRvR:6/7: } \\
\text { determining }\end{array}$ & $\begin{array}{l}\text { Determining } \\
\text { rather than } \\
\text { approval }\end{array}$ & $\downarrow$ & $\downarrow$ \\
\hline $\begin{array}{l}\text { Creating equalisation } \\
\text { reserve }\end{array}$ & Cyclical & 33 & SRvR:10 & $\begin{array}{l}\text { equalisation } \\
\text { reserve negative }\end{array}$ & 0 & $\downarrow$ \\
\hline Audit protocol & Cyclical & $\begin{array}{l}\text { not } \\
\text { included }\end{array}$ & $\begin{array}{l}\text { Separate } \\
\text { document }\end{array}$ & basis for auditing & $\downarrow$ & $\downarrow$ \\
\hline \multicolumn{7}{|l|}{ Explanation: } \\
\hline \multicolumn{4}{|c|}{ Included in determining autonomy } & \multicolumn{3}{|c|}{ Not included in determining autonomy } \\
\hline
\end{tabular}


Secondly, as is the case with CVZ, a separate audit protocol exists, which states the audit requirements with respect to RvR. Again this affects autonomy negatively as it binds RvR's executive boards to a certain auditing program set by the minister rather than allowing the board to determine the scope of the auditing program itself. Interviewees indicated that the formal position of the RvR board is that of an executive board, but in practice its role tends to be similar to a non-executive board. Issuing a separate audit protocol by minJUS means that minJUS has taken over the role of the non-executive board in the auditing process, which supports the case for reduced autonomy of RvR.

\subsubsection{Impact of changes in legislation due to alignment with kZBO}

Two major changes can be observed in the new legislation: first the creation of the executive board and second, the creation of an advisory board, which did not formally exist before. In practice, the old boards operated as a form of non-executive board rather than an executive board. By creating an advisory board, an arrangement was created as defined by kZBO:7 on the relationship between two bodies. Effectively the impact on autonomy is nil.

The other changes observed in legislation are minor. MinJus does not state that kZBO is applicable. Because the new RvR is a new legal entity, kZBO applies directly for all compulsory measures within kZBO (Parliament, 2009d). WRB (new) only refers to kZBO with respect to the advisory board, the legal position of the staff and the funding procedures that are performed under the AWb subsidy framework. Legislation on this issue is in line with the legislation effective in 2007 . The only relevant change is found on 'level and supplementing' equalisation reserves, which can be regulated by ministerial decree. The 2007 version of WRB included an arrangement based on AWb:4.71 and $A W b: 4.72$ which is very similar to including measures from kZBO:32 and kZBO:33. In the new version of WRB only the equalisation reserve arrangement is continued. The SRVR decree has changed due to the new legislation which includes kZBO:32 as a ministerial control tool. The explanatory memorandum of WRB (new) on this issue states that the arrangement is aligned with kZBO:33. No explanation is given on the wording of the new arrangement, particularly on the issue of supplementing reserves.

The conclusion on the overall impact of the changes in WRB is that they do not affect autonomy as assessed on the 2007-2008 arrangements.

\subsubsection{Conclusion}

Table 16.3 discloses all deviations from kZBO that have an impact on autonomy. Type 1 mismatches that have a negative effect on autonomy are observed in minJUS determining subsidy rather than approving the statement of accounts, as well as budgetary control and the audit protocol. The annual report of RvR is not formally submitted to Parliament, which is a positive type 1 mismatch. Type 2 mismatches are observed for asset controls that are formalised but not actually used and would affect autonomy negatively. It should be noted that these asset controls are more restrictive than what is optionally described in kZBO. The overall assessment of RvR's legal position 
is that due to the subsidising relationship between RvR and minJUS governance and cyclical measures exist that both formally and actually reduce the autonomy of RvR compared to the standard kZBO framework. 


\subsubsection{SVB}

MinSZW announced in his letter on the implementation of kZBO that he would only adapt existing SUWI legislation on the issues of KZBO:15 and 33 on the status of ZBO staff and the equalisation reserve. Due to the fact that the SUWI law is relatively new, minSZW had been able to include kZBO-measures in the original SUWI law (Parliament, 2008k, p. 3). New legislation is effective as of January 1, 2009.

\subsubsection{Normative measures}

SVB has PLA status which has been defined in the SUWI organisation law. PLA status classifies SVB as a Subsidiary ZBO which implies that ownership is held by minister and parent ministry. Interviewees confirm the ownership role of the minister, at least by stating that legislation has reduced control by the board to such an extent that from a material perspective, minSZW controls SVB. One interviewee indicated that the role of owner of the organisation is mixed up with the policy objectives to be realised, reducing the relevance of the main question of ownership continuity of the organisation.

Deviations from kZBO are observed on two issues. First, the kZBO:9 measures on appointments of civil servants to the board are not included in the SUWI legislation. In practice, board members do not have civil servant status although some of them do have a history in the civil service. In practice, this deviation has no impact on autonomy. Formally, minSZW has the option to appoint a civil servant which theoretically reduces SVB's autonomy. Second, the position of the staff deviates from the kZBO:15 standard. The organisation law stipulates that staff are appointed on the basis of civil law. In the SVB case, a hybrid situation exists because the basic arrangement is based on civil law, but the pension plan is organised within the framework that is used for civil servants. The basic civil law arrangement on the position of staff increases autonomy from departmental measures. In the SUWI Regulations [RSUWI], Article 5.9c requires an explanation for wage increases but there is no fixed rule for increases in staff remuneration. The degrees of freedom for the SVB board are somewhat reduced by the pension plan arrangement because this part of staff costs are beyond the board's control.

kZBO:21 defines measures for a minister to give general instructions to a ZBO and assign it tasks. This measure is not included in the SUWI law, due to the separation of ZBO case law and program law. In the relevant program laws, the possibility to give instructions on policy rules are described, including measures to ensure rulings are made by impartial courts rather than minSZW if policy rule interpretations differ. For example, minSZW can set additional rules on program execution of the national old age pension plan AOW (AOW:7.4) and appeal is left to an impartial court (AOW:53). Therefore, effectively there is no impact on autonomy compared to the kZBO arrangement. 


\subsubsection{Information measures}

Information measures cover issues such as providing annual reports to minister and Parliament, minSZW approval of the statement of accounts and rules on structure and auditing of the statement of accounts. All these issues are covered in SUWI and or RSUWI. The audit regulations describe the auditing process in general, including accepted errors and an auditing plan. The auditing plan is not defined in detail as for an audit protocol and therefore allows for professional judgement. In general these measures do not affect autonomy.

A minister is expected to have a general right of inquiry, based on kZBO:20. The general provision is included in SUWI:72, but it has been elaborated upon in RSUWI, section 5.2. Information provision includes for example minutes of board meetings, plans regarding outsourcing, quality and frequency of information. Other provisions in RSUWI section 5.2 cover distribution of policy related information. The level of detail of information to be provided is an indicator of minSZW's control of SVB. I would argue that it does not essentially influence autonomy because a general right of inquiry means that a minister can ask whatever questions he likes. Regulation of information provision makes the relationship between minister and ZBO more transparent compared to a situation where no information requirements are specified.

Due to the restructuring in the way social security was organised in 2002, Parliament and minSZW agreed upon a special project status during the restructuring process. One of the elements in the special project status was frequent (quarterly) information provision towards Parliament on the progress made by SVB, including an assessment by minSZW. By the end of 2007 it was decided to discontinue the special project status but information provision to Parliament would continue to be on a similar level (Parliament, 2007k). Compared to kZBO, SUWI legislation extends requirements to the statement of accounts on an annual and a quarterly basis. Based on the special project status, in practice information provision is extended further to Parliament including a minszW assessment on the reports provided. This practice reduces autonomy compared to the general kZBO-arrangement.

\subsubsection{Governance provisions}

In kZBO:7, measures are included for situations where two tier boards are used within a ZBO. Formally, SVB does not have a two tier board but the executive board is supported by an advisory board appointed by minSZW (SUWI:3). After the SUWI evaluation and the subsequent change in SUWI law as of 2009 , the formal position of the advisory board has been discontinued. This was contrary to the advice of the consultant who had been commissioned to do the evaluation (PriceWaterhouseCoopers, 2006, p. 96). In practice the executive board still uses an advisory board, but the position of the advisory board is different due to a lack of a legislative position.

Article kZBO:8 on mandates is meant to cover the attribution of tasks to a ZBO by organisations other than the principal-ministry. The explanatory notes to the original kZBO 
proposal refer to a situation where a third party mandate threatens the primary operations of the ZBO as a possible reason for disapproval by a minister (Parliament, 2000d, p. 23). The requirement is not literally found in the SVB case. However, effectively in the SVB case law, an article (SUWI:13) is included that is materially equivalent to what is meant by kZBO:8. With some exceptions this arrangement is continued in the SUWI legislation as of January 1, 2009 (SUWI2009:5; Parliament, 2008I, p. 18). Interviewees indicated that SVB provides services to local governments in relation to old age benefits, AOW and for a pension support program for a group of unemployed people, which have been approved by minSzW. The mixture of activities led to differing interviewee opinions. Some claim that it results in less control by SZW, others claim that the mixture of activities is one of the reasons for a restrictive equity policy to prevent cross-subsidising activities.

MinSZW approves governance statutes and appoints the executive board of SVB. This is in line with kZBO. In SUWI:4, an explicit arrangement is made on secondary jobs of board members which is in line with kZBO.

Based on KZBO:14, the minister determines remuneration of a PLA. In SUWI:5.1 this arrangement has been made explicit for SVB. The level of remuneration is not mentioned in SUWI:5.1. In practice, for some board members remuneration is above the WOPT reporting level. The information is disclosed in SVB's annual reports and has led a motion in Parliament (Parliament, 2009f). Given the fact that the minister decides upon the remuneration there is no impact on autonomy compared to the kZBO-framework.

Interviewees indicate that tools such as those covered in KZBO:22-23 on annulment and intervention in case of negligence are tools of last resort and are not used in practice. Interviewees indicated that the tools are needed, but using them might be counterproductive and does not fit in with the relationship between board and minSZW. Impact on autonomy is therefore nil.

The SVB (and UWV) case are the only cases studied here in which measures on asset related transactions including bankruptcy measure are directly covered in the ZBO case law. The kZBO:32 measures are optional, which means that including them in the ZBO case law formally reduces autonomy compared to the basic kZBO provisions. In practice, only lending and borrowing, creating reserves other than equalisation reserves as well as participation in legal entities is relevant for SVB. SVB has been allowed to participate in a foundation that services the national pensions register to be operational as of 2011.190 This was initiated by an amendment to the pension law by MPs (Parliament, 2006g). Interviewees indicate that in the mid 1990s SVB was also involved in creating a separate information exchange organisation (RINIS) intended to improve information exchange between some public organisations. Assessment of asset related transactions other than borrowing and lending is regarded as one control instrument.

190 This register aims to provide an overview of all future pension income to be received by an individual based on accumulated rights to date from first and second pension plan pillars. 
On the subject of lending and borrowing, SVB's position is technically similar to the measures in CW2001. The arrangement is covered in an older law on funding social security benefits (Wet Financiering Sociale Verzekeringen [WFSV]. SVB is allowed to create reserves other than equalisation reserves after approval by minSZW. Case law is therefore stricter than KZBO. In practice such reserves are created. However, some interviewees indicated that once approval is given, SVB is not sure that the reserve will be maintained in times of budgetary problems. This is illustrated by the provisions made on the reorganisation program 'SVB Tien'. In SVB's 2007 annual report and statements of accounts, it is argued that part of the surplus gained in fiscal 2007 can be used to compensate for delays in cost reductions in the 'SVB Tien' program (SVB Annual report, 2007 , p. 72 ), to be decided upon by minSZW. It should also be noted that the reserve created in relation to 'SVB Tien' in fiscal 2006 was increased in 2007 (SVB Annual report 2007 , p. 79). The key point is that minSZW still has influence on the use of reserves after they have been created, which reduces SVB's autonomy.

\subsubsection{Cyclical measures}

The last group of measures regards cyclical authority. Most measures are in line with kZBO. MinSZW approves SVB's budget and SVB has to report on substantial differences between budget and actual expenditures. I have already referred to the special project status of the SUWI reform which leads to frequent intermediate reporting to Parliament. SVB's board decides upon the budget and the structure of the budget is given by minSZW under RSUWI. All these issues are applied in practice as well. The budgeting process in SUWI also covers a multiyear plan (SUWI:46.2), a requirement that is not mentioned in kZBO. This additional requirement affects autonomy negatively because developments in the near future are more difficult to discern compared to the case in which there is no requirement to submit multiyear plans.

Budget preparation by SVB is supported by a negotiated letter of instruction sent out in May t-1 in which the level of the budget and the assumptions are disclosed. Ultimately, the budget level is determined by minSZW and is used as a starting point for the internal budget processes within SVB, resulting in a final budget proposal to be submitted to minSZW by October $\mathrm{t}-1$. According to the interviewees the budgeting process for SVB ends with approval of the budget by minSZW including submitting the budgeting documents to Parliament. This is contrary to SUWI:46.2 which stipulates that minSZW should submit the multiyear plan to Parliament as well. Documents submitted to Parliament reveal that the SVB multiyear plan for fiscal 2007 and 2008 was submitted to Parliament, the document for fiscal 2009 was not (Parliament, 2006h; 2007l; 2008m).

Two other deviations from kZBO exist. First, the issue of approval of fees is discussed. SVB's main activities on behalf of minSZW are funded by authority biased fees based on WFSV. Funding covers both the resources needed for the respective programs as well as the resources needed for operations with respect to the programs. The fees are set by minSZW following a proposal from SVB. With respect to other SVB activities, no explicit measures exist. Interviewees indicate that budgets are negotiated and that an ex post re- 
calculation is performed based on volume and price levels. This means that fees are implicitly used for costs of operations for other services than those commissioned by minSZW. The solution provides some additional autonomy for SVB compared to the kZBO framework. However, increased autonomy is mitigated by another deviating arrangement, which is that minSZW does not allow SVB to use equalisation reserves (kZBO:33).

Interviewees noted that the decision not to allow SVB to use an equalisation reserve was driven by a political decision by minSZW, not by minFin or others. According to interviewees, the motivation was to have full control over resources spent by SVB. In the explanatory memorandum to the revised SUWI law, it is argued that an equalisation reserve does not fit the financial relationship between ZBO and minister, which differs from fully fee funded ZBOs (although not explicitly stated, ZBOs like RDW and Kadaster are meant here, jdk). MinSZW claims that the use of dedicated reserves provides a more transparent solution for use of resources (Parliament, 2008I, p. 18). Not allowing equalisation reserves was included in the original SUWI law and this practice has been continued. With respect to SVB in particular, some interviewees indicated that it makes it more difficult to agree upon fees charged for non-SZW services. In effect, SVB's autonomy is reduced as a result of this deviation from kZBO. 
Table 16.4: Legal measures on SVB, formally or actually deviating from kZBO

\begin{tabular}{|c|c|c|c|c|c|c|}
\hline Authority issue & $\begin{array}{l}\text { Authority } \\
\text { Group }\end{array}$ & $\begin{array}{l}\text { reference } \\
\text { kZBO }\end{array}$ & reference case law & Actual practice & $\begin{array}{l}\text { formal mismatch } \\
\text { and impact }\end{array}$ & $\begin{array}{l}\text { actual mismatch } \\
\text { and impact }\end{array}$ \\
\hline $\begin{array}{l}\text { Not appointing civil servants to } \\
\text { board }\end{array}$ & Normative & 9 & not included & none appointed & $\downarrow$ & 0 \\
\hline Measure on legal position of staff & Normative & 15 & SUWI:2.3 & $\begin{array}{l}\text { private law based, pension under civil } \\
\text { servants arrangement }\end{array}$ & $\uparrow$ & $\uparrow$ \\
\hline $\begin{array}{l}\text { Minister decides on general } \\
\text { instructions }\end{array}$ & Normative & 21 & in program laws & according to program laws & 0 & 0 \\
\hline $\begin{array}{l}\text { ZBO submits annual report to } \\
\text { minister }\end{array}$ & Information & 18 & $\begin{array}{l}\text { SUWI:49 } \\
\text { RSUWI: appendix } \\
\text { VIII }\end{array}$ & $\begin{array}{l}\text { Not only to minister but sent to Parliament } \\
\text { by minister including assessment by } \\
\text { minister. }\end{array}$ & $\downarrow$ & $\downarrow$ \\
\hline $\begin{array}{l}\text { Frequency of intermediate reports } \\
\text { to minister determined by law }\end{array}$ & Information & not included & SUWI:49.10 & $\begin{array}{l}\text { Due to project status also submitted to } \\
\text { Parliament, continued after end of project } \\
\text { status }\end{array}$ & $\downarrow$ & $\downarrow$ \\
\hline General right of inquiry & Information & 20 & $\begin{array}{l}\text { SUWI:72 } \\
\text { RSUWI, section } 5.2\end{array}$ & in line with legislation & 0 & 0 \\
\hline Multiple bodies & Governance & 7 & SUWI:3 & $\begin{array}{l}\text { existed but ended, new advisory board } \\
\text { appointed by executive board in } 2009\end{array}$ & 0 & $\downarrow$ \\
\hline Ex ante approval of mandates & Governance & 8 & SUWI:13; SUWI:34 & some activities realised based on SUWI13 & $\uparrow$ & $\uparrow$ \\
\hline $\begin{array}{l}\text { Decision on and disclosure of } \\
\text { remuneration }\end{array}$ & Governance & $\begin{array}{l}\text { kZBO:14 } \\
\text { WOPT: } 6\end{array}$ & SUWI:5.1 & $\begin{array}{l}\text { disclosed in annual reports } 2007 \text { and } \\
2008\end{array}$ & 0 & 0 \\
\hline Annulling of ZBO decisions & Governance & 22 & SUWI:80 & not used in practice & 0 & 0 \\
\hline Intervention in case of negligence & Governance & 23 & SUWI:80 & not used in practice & 0 & 0 \\
\hline $\begin{array}{l}\text { Asset related transactions: } \\
\text { borrowing and lending }\end{array}$ & Governance & $32 d$ & WFSV & applied & 0 & 0 \\
\hline Asset related transactions: others & Governance & 32a-c; e-f & SUWI:6 & $\begin{array}{l}\text { participation in pension register; } \\
\text { arrangement on reserves used, but } \\
\text { regularly under debate }\end{array}$ & $\downarrow$ & $\downarrow$ \\
\hline $\begin{array}{l}\text { Asset related transactions: } \\
\text { bankruptcy (optional) }\end{array}$ & Governance & $32 g$ & SUWI:6 & not used in practice & $\downarrow$ & 0 \\
\hline Approval of fees by minister & Cyclical & 17 & SUWI:45.3 & $\begin{array}{l}\text { Only holds for commissioning by minSZW } \\
\text { not for other services delivered }\end{array}$ & $\uparrow$ & $\uparrow$ \\
\hline Approval of budget by minister & Cyclical & 29 & SUWI:46.1 & Approval + submit to Parliament & $\downarrow$ & $\downarrow$ \\
\hline Submit multiyear plan & Cyclical & none & SUWI:46.2 & submitted & $\downarrow$ & $\downarrow$ \\
\hline Creating equalisation reserve & Cyclical & 33 & not included & not allowed & $\downarrow$ & $\downarrow$ \\
\hline \multicolumn{7}{|l|}{ Explanation: } \\
\hline \multicolumn{4}{|l|}{ Included in determining autonomy } & \multicolumn{3}{|l|}{ Not included in determining autonomy } \\
\hline
\end{tabular}




\subsubsection{Impact of changes in legislation due to alignment with kZBO}

New legislation including implementation of kZBO came into effect by January 2009. Three issues have been changed. The new provisions on staff and equalisation reserves do not change formal measures and the observed autonomy under the SUWI law effective in 2007. Along with these measures, minSzW has decided to formally discontinue the advisory board of SVB. As SVB has continued to use an advisory board, effectively there have been no changes in the autonomy of SVB's executive board. Direction of impact is in most cases similar. In the cases of mismatches between formal and actual measures, autonomy is decreased with respect to the status of the advisory board. In the other three cases (not appointing civil servants, measures on secondary jobs and bankruptcy) actual autonomy is tan more restricted than at the kZBO level.

\subsubsection{Conclusion}

Table 16.4 summarises the impact on autonomy based on the formal and actual deviations from kZBO. Type 1 mismatches with a negative impact are found on submission of annual as well as quarterly reports to Parliament by minSZW, formal and implemented asset controls as meant by kZBO:32, budgetary controls and the lack of an equalisation reserve. In the SVB case, some positive Type 1 mismatches can be observed as well: additional degrees of freedom exist in the mandates to deliver services to other public entities as well as additional degrees of freedom in determining fees for such services. In the case of formal abolishment of the advisory board, a negative Type 2 mismatch is observed due to no longer having a formal legal position for the advisory board. The general impression is that SVB faces reduced autonomy on the cyclical measures and on governance issues, particularly in the budgeting process as well as with respect to the role of the advisory board. An increase of autonomy can be observed in SVB's relations towards commissioners outside minSZW. 


\subsubsection{UWV}

UWV and SVB operate under the same SUWI framework. This means that in essence, formal measures are the same. I will emphasise differences with SVB and refer to SVB for other deviations. UWV also has PLA legal status. Nobody doubts the ownership role of minSZW. According to the interviewees this is performed in practice by a separate directorate within minSZW. Some interviewees indicated that materially the position of UWV is comparable to that of 'Belastingdienst' (Revenue services) which is from a formal perspective a unit subject to ministerial hierarchy. It was also indicated that UWV's activities are subject to regular changes and have a high political profile.

Like SVB, changes in legislation due to kZBO implementation are effective as of January 2009 and concern position of staff, equalisation reserve and advisory board.

\subsubsection{Normative measures}

As in the SVB case, there are two deviations from kZBO. The prohibition on appointing civil servants to the board is not included in the SUWI law, but is carried out in practice. This means formally reduced autonomy due to the risk of appointing civil servants. In practice, no civil servants are appointed which is in line with kZBO. On the issue of staff arrangements, an exception to KZBO:15 is allowed. UWV has its own private labour agreement including a separate pension scheme. This means that UWV has full control on labour costs, whereas in the SVB case there is some external influence on labour costs which is beyond ministerial control. ${ }^{191}$ The RSUWI:5.9 arrangement on explaining increases in wages holds for UWV as well. No fixed rules for wage increases exist. The main general reason for maintaining the exception to kZBO:15 is the complexity of changing the present system (Gerritsen Committee, 2008, p. 33).

Data protection measures as defined by kZBO:41 have been made explicit in the SUWI law and are also applied. Finally, minSZW's authority to decide upon policy rules is, like the SVB case, covered in the respective program laws applicable to UWV.

\subsubsection{Information measures}

Provision of information to minSZW is covered on the same basis as for SVB. This means frequent reporting in a described format and an assessment of the reported documents by minSZW is sent to Parliament. Some interviewees indicate that the special project status of SUWI was mainly meant for UWV given the complexity of restructuring and the high level of political attention for the programs executed by UWV.

Along with the formal information provision procedures, interviewees noted the high frequency (every two weeks) of meetings between minSZW and UWV's executive board, which is more frequent than meetings with SVB's board. One of the interviewees noted that there has been a discussion on allowing UWV's CEO to attend the regular meetings of minSZW and his staff, to at least have some influence on decisions made. The

191 The civil servants pension fund is governed by employers and employees in the public sector and can determine premiums independently of ministerial decisions. 
interviewee noted that control of UWV seems to be similar to that of executive agencies but without UWV involvement in operational decision making. Another interviewee noted that not only are formal structures relevant to the decision making process, but informal lines between different levels of staff are also very important and perhaps not used sufficiently which results in less influence in the decision making process.

\subsubsection{Governance provisions}

Formally, UWV has a one tier board supported by an advisory board (SUWI:3). Both boards are appointed by minSZW. The law also specifies distribution of responsibilities, in line with KZBO:7 measures. As of 2009, the formal position of the advisory board was discontinued. Interviewees indicated that UWV intends to create an advisory board appointed by the executive board. In UWV's 2009 Annual Report reference is made to the issue, including the idea of implementing a new advisory board in 2010 (UWV, 2009, p. 40). Some interviewees indicated that they would prefer to use a non-executive board because the civil service is not able to organise know how on UWV's operations given the political impact of any operational problem that is disclosed publicly.

Legislation allows other services to be provided than those directly assigned by law. In practice only very minor third party functions - historically driven - are still performed by UWV. The relevance of third party activities is declining over time.

Governance statutes (kZBO:4) and annulment and intervention authority (kZBO:2223) attributed to minSZW are included in SUWI law. Practices are similar to those for SVB and have no further impact on autonomy. One respondent indicated that using interventions would fundamentally undermine relations between minister and executive board. During the time framework of this research (2007-2008) no formal interventions were performed. In 2004, in an exceptional case in which the executive board of UWV had misinformed minSzW on issues regarding costs of offices, minSzW actually intervened and dismissed UWV's CEO (Parliament, 2004g). Again, according to the interviewees this is an exceptional case.

The issue of remuneration is covered in a similar way to SVB. Remuneration of the board is decided upon by minSZW and is disclosed in UWV's annual report. 
Table 16.5: Legal measures on UWV, formally or actually deviating from kZBO

\begin{tabular}{|c|c|c|c|c|c|c|}
\hline Authority issue & Authority Group & $\begin{array}{l}\text { reference } \\
\text { kZBO }\end{array}$ & reference case law & Actual practice & $\begin{array}{l}\text { formal } \\
\text { mismatch and } \\
\text { impact }\end{array}$ & $\begin{array}{l}\text { actual } \\
\text { mismatch } \\
\text { and impact }\end{array}$ \\
\hline $\begin{array}{l}\text { Not appointing civil servants } \\
\text { to board }\end{array}$ & Normative & 9 & not included & none appointed & $\downarrow$ & 0 \\
\hline $\begin{array}{l}\text { Measure on legal position of } \\
\text { staff }\end{array}$ & Normative & 15 & SUWI:2.3 & $\begin{array}{l}\text { private law based, pension under separate } \\
\text { arrangement }\end{array}$ & $\uparrow$ & $\uparrow$ \\
\hline $\begin{array}{l}\text { Minister decides on general } \\
\text { instructions }\end{array}$ & Normative & 21 & in program laws & according to program laws & 0 & 0 \\
\hline $\begin{array}{l}\text { ZBO submits annual report to } \\
\text { minister }\end{array}$ & Information & 18 & $\begin{array}{l}\text { SUWI:49 } \\
\text { RSUWI: appendix } \\
\text { VI }\end{array}$ & $\begin{array}{l}\text { Not only to minister but sent to Parliament } \\
\text { by minister including assessment by } \\
\text { minister. }\end{array}$ & $\downarrow$ & $\downarrow$ \\
\hline $\begin{array}{l}\text { Frequency of intermediate } \\
\text { reporting set in legislation }\end{array}$ & Information & $\begin{array}{l}\text { not } \\
\text { included }\end{array}$ & SUWI:49.10 & $\begin{array}{l}\text { Due to project status also submitted to } \\
\text { Parliament, continued after end of project } \\
\text { status }\end{array}$ & $\downarrow$ & $\downarrow$ \\
\hline General right of inquiry & Information & 20 & $\begin{array}{l}\text { SUWI:72 } \\
\text { RSUWI, section } 5.2\end{array}$ & $\begin{array}{l}\text { in line with legislation but very high level of } \\
\text { meetings between CEO and minSZW. }\end{array}$ & 0 & 0 \\
\hline Multiple bodies & Governance & 7 & SUWI:3 & $\begin{array}{l}\text { existed but ended; intention to continue } \\
\text { informally }\end{array}$ & 0 & $\downarrow$ \\
\hline Ex ante approval of mandates & Governance & 8 & SUWI:13; SUWI:34 & in practice not substantial $(<1 \%)$ & $\uparrow$ & 0 \\
\hline $\begin{array}{l}\text { Decision on and disclosure of } \\
\text { remuneration }\end{array}$ & Governance & $\begin{array}{l}\text { kZBO:14 } \\
\text { WOPT:6 }\end{array}$ & SUWI:5.1 & disclosed in annual reports 2007 and 2008 & 0 & 0 \\
\hline Annulling of ZBO decisions & Governance & 22 & SUWI:80 & not used in practice & 0 & 0 \\
\hline $\begin{array}{l}\text { Intervention in case of } \\
\text { negligence }\end{array}$ & Governance & 23 & SUWI:80 & not used in practice & 0 & 0 \\
\hline $\begin{array}{l}\text { Asset related transactions: } \\
\text { borrowing and lending }\end{array}$ & Governance & $32 d$ & WFSV & applied & 0 & 0 \\
\hline $\begin{array}{l}\text { Asset related transactions: } \\
\text { others }\end{array}$ & Governance & 32a-c; e-f & SUWI:6 & $\begin{array}{l}\text { participation in pension register; } \\
\text { arrangement on reserves used, but regularly } \\
\text { under debate; } \\
\text { real estate under political scrutiny }\end{array}$ & $\downarrow$ & $\downarrow$ \\
\hline $\begin{array}{l}\text { Asset related transactions: } \\
\text { creating/participating legal } \\
\text { entity (optional) }\end{array}$ & Governance & $32 a$ & SUWI:6 & participation in pension register & $\downarrow$ & $\downarrow$ \\
\hline $\begin{array}{l}\text { Asset related transactions: } \\
\text { bankruptcy (optional) }\end{array}$ & Governance & $32 g$ & SUWI:6 & not used in practice & $\downarrow$ & 0 \\
\hline
\end{tabular}




\begin{tabular}{|c|c|c|c|c|c|c|}
\hline Authority issue & Authority Group & $\begin{array}{l}\text { reference } \\
\text { kZBO }\end{array}$ & reference case law & Actual practice & $\begin{array}{l}\text { formal } \\
\text { mismatch and } \\
\text { impact }\end{array}$ & $\begin{array}{l}\text { actual } \\
\text { mismatch } \\
\text { and impact }\end{array}$ \\
\hline $\begin{array}{l}\text { Frequency of meetings board } \\
\text { and minister }\end{array}$ & Cyclical & none & none & 2 weekly frequency & 0 & $\downarrow$ \\
\hline Approval of fees by minister & Cyclical & 17 & SUWI:45.3 & $\begin{array}{l}\text { Program fees set by minSZW, including } \\
\text { costs of operations }\end{array}$ & $\uparrow$ & 0 \\
\hline Approval of budget by minister & Cyclical & 29 & SUWI:46.1 & Approval + submit to Parliament & $\downarrow$ & $\downarrow$ \\
\hline Submit multiyear plan & Cyclical & none & SUWI:46.2 & submitted & $\downarrow$ & $\downarrow$ \\
\hline Approval of budget by minister & Cyclical & 29 & SUWI:45.1-2 & $\begin{array}{l}\text { Approval + multiyear plan + submit to } \\
\text { Parliament }\end{array}$ & $\downarrow$ & $\downarrow$ \\
\hline Creating equalisation reserve & Cyclical & 33 & not included & not allowed & $\downarrow$ & $\downarrow$ \\
\hline \multicolumn{7}{|l|}{ Explanation: } \\
\hline \multicolumn{4}{|c|}{ Included in determining autonomy } & \multicolumn{3}{|l|}{ Not included in determining autonomy } \\
\hline
\end{tabular}


The optional measures on asset related transactions (kZBO:32) are included in SUWI case law, which means a reduction of autonomy compared to the standard kZBO arrangement. The lending and borrowing provisions are based on WFSV rather than on CW2001, but the impact is the same. UWV also participates in RINIS, a decision made by predecessors of UWV. Under SUWI law no participations in third parties were discussed or implemented. The issue of real estate management (kZBO:32b-c) is formally included in the SUWI law. This fact implies a reduction in autonomy compared to the kZBO framework as the wording of KZBO:32 is optional. In practice, UWV does not own real estate but leases its offices. The UWV re-organisation process has led to a reduction in staff. In the debate on the preparation of minSZW's 2008 budget, MPs explicitly addressed the impact of staff reduction on unused offices in UWV branches and requested information on standards of office space used by UWV compared to central government's standards. Furthermore they urged minSZW to initiate activities to reduce the area of unoccupied office space (Parliament, 2007m, p. 11). MinSZW responded by asking UWV in the letter of instruction to the 2009 budget (May 2008; minSZW, 2008, p. 4 ) to revise their office use plans. This means that UWV's autonomy on leasing office space is reduced as well.

The issue of creating reserves is a difficult matter, given the explicit position of minSZW on this. In practice, reserves can be created after consent from minSZW, but this also means according to some interviewees that administrative procedures are more complex than if UWV had more autonomy on the subject. On the other hand, interviewees are aware of the fact that UWV is currently funded by authority biased fees and has a high political profile, unlike some other ZBOs, which explains minSZW's position on the issue of creating reserves.

\subsubsection{Cyclical measures}

UWV budgets are approved by minSZW, in line with both KZBO and the SUWI law. I recall the special project status of SUWI which leads to frequent reporting to Parliament, effectively reducing UWV's autonomy compared to kZBO standards. The process of budgeting is based on a negotiated letter of instruction, resulting in submission of a formal budget document to minSZW by October t-1. In the UWV-case, the multiyear plans are submitted to Parliament separately from the budget for a particular fiscal year. Unlike the SVB case, a multiyear plan for fiscal 2010-2014 has been submitted to Parliament (Parliament, 2007n, 2008n, 2009g).

UWV is funded by authority biased fees, which are set by minSZW. Fees are set based on the expected program cost including cost of operations, which practically means that the budget needed for operations is negotiated and then included in the calculation of the overall fee. As UWV has no significant other commissioners, the kZBO measures on fees has no real meaning from an operations perspective and therefore does not affect autonomy. 
Like SVB, UWV is not allowed to create an equalisation reserve. The motivation for this divergence from kZBO is exactly the same as in the SVB case. Effectively it reduces UWV's autonomy compared to the KZBO-framework.

\subsubsection{Impact of changes in legislation due to alignment with kZBO}

New legislation including implementation of kZBO came into effect by January 2009. Three issues have been changed. The new measures on staff and an equalisation reserve do not change formal measures and the observed autonomy under the SUWI law effective in 2007. Along with these measures, minSzW has decided to formally discontinue the UWV advisory board. UWV has not been able to create a new advisory board during 2009.

\subsubsection{Conclusion}

UWV's autonomy is in general reduced compared to the kZBO-framework. UWV is faced with the same negative type 1 mismatches as observed for SVB regarding reporting, budgets, asset controls and equalisation reserves. With respect to real estate transactions the asset control issue was also subject to debate in Parliament. Type 2 mismatches are found in the abolishment of the advisory board and on the high frequency of meetings between the UWV executive board and minister. The main explanation for reduced autonomy is the high political profile of the organisation, including regular changes in the programs that ultimately determine the services and thus operations. 


\subsubsection{FBKVB}

FBKVB is a private law foundation, operating in the arena of stimulating the arts. Under kZBO, the measures for PLBs are slightly different from those for PLAs. Basically, only kZBO:1-9 on creating ZBOs, kZBO:17-23 on information provision and control and kZBO:26-35 on budgeting and reporting measures will apply. The main legal measures for FBKVB are its statutes as well as WSC1993 on culture policy.

MinOCW announced in his letter on implementation of kZBO (Parliament, 2008d) that he would change legislation on the art funds only with respect to kZBO:22 on annulling individual decisions. New legislation would be prepared, but by January 2010, no changes in WSC had been implemented or proposed.

\subsubsection{Normative measures}

No provisions for appointing civil servants are included in the statutes or in WSC1993. In practice, no civil servants are appointed which means that although the formal position is not in line with kZBO, the actual position of FBKVB is. Autonomy is therefore in line with kZBO measures.

The legal status of FBKVB staff (kZBO:15-16) is in line with the funds PLB status. There is no need to create separate measures to protect against minOCW influence.

On two normative issues, deviations from kZBO can be observed. First, no data protection measures exist. The FBKVB annual report discloses the names of artists who received a contribution from FBKVB. No further practical indications on data protection were found. Second, minOCW must approve general rules set by the fund's board and is even allowed to require a change in regulations set by the fund's board. The bottom line is that this wording formally seems to provide autonomy to FBKVB, but this autonomy is mitigated by the WSC1993:10.4 arrangement in which minOCW can instruct the board to change rules. Effectively this means that final power is in the hands of minOCW.

\subsubsection{Information measures}

In the relationship between minOCW and FBKVB, the main information measures are settled. This means that minOCW receives annual reports, has a general right of inquiry and rules are laid down on the structure of the statements of accounts. In a decree, an audit protocol is included which specifies what should be audited at a detailed level.

MinOCW does not approve the FBKVB annual report but ultimately decides upon the subsidies to be provided. Given the funding structure of FBKVB (four year periods of funding), in general this will mean that FBKVB has some increased autonomy compared to the kZBO-framework.

FBKVB annual reports are not formally sent to Parliament. Interviewees indicated that the document is sent to MPs. 


\subsubsection{Governance provisions}

From a governance perspective, FBKVB is supported by an advisory board mentioned in the statutes. Its role is described. However, the advisory board is not a body as defined by kZBO:7. The use of the advisory board has no impact on the board's autonomy in relation to minOCW. Art funds are dedicated organisations that are not likely to provide services for other ministries. The objective of FBKVB is laid down in the statutes and thus prevents it from delivering other services. Interviewees referred to the possibility of art funds being merged to operate more efficiently. Such a merger decision is taken by minOCW and will result in a new organisation. Interviewees indicated that discussions on a merger between FBKVB and other funds may be relevant in the future. In the present setting, the autonomy impact of not including kZBO:8 is neutral.

The issue of intervention in the event of negligence is not included in the statutes or WSC1993 but is left to the standard arrangement in BW2:298 which allows a court to dismiss board members. This is a standard procedure for all foundations and thus does not affect autonomy.

Control of asset related transactions varies. Treasury management is governed by the CW2001 provisions on borrowing and lending via minFin. It reduces autonomy of a foundation but is in fact a standard for ZBOs that is not covered in kZBO. Therefore there is no impact on autonomy from a ZBO perspective. This is different for the issue of using reserves: funding for the arts funds is based on a 4 year time frame. Within this time frame it is up to the board to use resources and create a reserve. In practice this means that reserves for unused program resources can be found, after costs of operations have been deduced. Bankruptcy measures are not included in statutes or law and are subject to standard BW2 procedures thus not affecting autonomy of FBKVB due to the optional character of kZBO:32. In the event of a decision to dissolve the fund, statutes include a provision that minOCW has to approve this decision, or decide directly on dissolving the fund in line with WSC1993:10.3. This measure might be relevant in case of a possible merger as referred to by the interviewees and formally reduces autonomy.

\subsubsection{Cyclical measures}

Budget procedure measures are generally in line with kZBO. FBKVB does not use fees for services, hence rules on this issue are obsolete. Given the subsidy relationship between fund and minister, minOCW formally determines the budget of the fund. According to interviewees this effectively means that minOCW, after hearing advice from the Council on Culture, sets a four year period budget on behalf of the FBKVB programs, including costs of operations. Separate measures on equalisation reserves are used. After the four year period, the subsidy is determined at the level of total expenses and then a new subsidy period will start. 
Table 16.6: Legal measures on FBKVB, formally or actually deviating from kZBO

\begin{tabular}{|c|c|c|c|c|c|c|}
\hline Authority issue & $\begin{array}{l}\text { Authority } \\
\text { Group }\end{array}$ & $\begin{array}{l}\text { reference } \\
\text { kZBO }\end{array}$ & $\begin{array}{l}\text { reference } \\
\text { case law }\end{array}$ & Actual practice & $\begin{array}{l}\text { formal } \\
\text { mismatch } \\
\text { and impact }\end{array}$ & $\begin{array}{l}\text { actual } \\
\text { mismatch } \\
\text { and impact }\end{array}$ \\
\hline $\begin{array}{l}\text { Not appointing } \\
\text { civil servants to } \\
\text { the board }\end{array}$ & Normative & 9 & none & $\begin{array}{l}\text { no civil servants } \\
\text { appointed }\end{array}$ & $\downarrow$ & 0 \\
\hline $\begin{array}{l}\text { Appointment of } \\
\text { staff }\end{array}$ & Normative & $\begin{array}{l}\text { kZBO:15 } \\
\text { (PLA) }\end{array}$ & none & $\begin{array}{l}\text { civil law } \\
\text { appointments }\end{array}$ & 0 & 0 \\
\hline $\begin{array}{l}\text { Minister decides } \\
\text { upon general } \\
\text { instructions }\end{array}$ & Normative & 21 & $\begin{array}{l}\text { WSC1993: } \\
10.4\end{array}$ & $\begin{array}{l}\text { approval by minOCW } \\
\text { with right to instruct } \\
\text { the board }\end{array}$ & 0 & 0 \\
\hline $\begin{array}{l}\text { Requirement for } \\
\text { data protection }\end{array}$ & Normative & 41 & none & no specific attention & $\uparrow$ & 0 \\
\hline $\begin{array}{l}\text { Submit annual } \\
\text { report to } \\
\text { Parliament }\end{array}$ & Information & 18 & none & $\begin{array}{l}\text { informally sent to } \\
\text { MPs }\end{array}$ & $\uparrow$ & $\uparrow$ \\
\hline $\begin{array}{l}\text { Approval of } \\
\text { statement of } \\
\text { accounts by } \\
\text { minister }\end{array}$ & Information & 34 & none & decision by board & $\uparrow$ & $\uparrow$ \\
\hline Multiple bodies & Governance & 7 & none & $\begin{array}{l}\text { advisory body based } \\
\text { on statutes }\end{array}$ & 0 & 0 \\
\hline $\begin{array}{l}\text { Ex ante approval } \\
\text { of mandates }\end{array}$ & Governance & 8 & $\begin{array}{l}\text { in } \\
\text { objectives } \\
\text { laid down } \\
\text { in statutes }\end{array}$ & not needed & 0 & 0 \\
\hline $\begin{array}{l}\text { Decision on and } \\
\text { disclosure of } \\
\text { remuneration }\end{array}$ & Governance & $\begin{array}{l}\text { kZBO:14 } \\
\text { WOPT:6 }\end{array}$ & none & $\begin{array}{l}\text { not reported in } \\
\text { annual reports, also } \\
\text { not on minBZK } \\
\text { blacklist }\end{array}$ & 0 & 0 \\
\hline $\begin{array}{l}\text { Intervention in } \\
\text { case of } \\
\text { negligence }\end{array}$ & Governance & 23 & none & $\begin{array}{l}\text { not used, covered in } \\
\text { BW2:298 }\end{array}$ & 0 & 0 \\
\hline $\begin{array}{l}\text { Asset related } \\
\text { transactions: } \\
\text { borrowing and } \\
\text { lending }\end{array}$ & Governance & $32 d$ & $\begin{array}{l}\text { CW2001:4 } \\
5\end{array}$ & in line with CW2001 & 0 & 0 \\
\hline $\begin{array}{l}\text { Asset related } \\
\text { transactions: } \\
\text { control on } \\
\text { reserves }\end{array}$ & Governance & $32 f$ & none & $\begin{array}{l}4 \text { year funding period } \\
\text { is relevant }\end{array}$ & 0 & $\uparrow$ \\
\hline $\begin{array}{l}\text { Asset related } \\
\text { transactions: } \\
\text { bankruptcy }\end{array}$ & Governance & $32 g$ & none & $\begin{array}{l}\text { not applicable, in line } \\
\text { with BW2 }\end{array}$ & 0 & 0 \\
\hline $\begin{array}{l}\text { Asset related } \\
\text { transactions: } \\
\text { dissolving entity }\end{array}$ & Governance & none & WSC:10.3 & $\begin{array}{l}\text { not used, but relevant } \\
\text { in possible cases of } \\
\text { mergers with other } \\
\text { funds }\end{array}$ & $\downarrow$ & 0 \\
\hline $\begin{array}{l}\text { Approval of } \\
\text { budget }\end{array}$ & Cyclical & 29 & BCU:33 & $\begin{array}{l}\text { determined once } \\
\text { every four years }\end{array}$ & $\uparrow$ & $\uparrow$ \\
\hline $\begin{array}{l}\text { Creating } \\
\text { equalisation } \\
\text { reserve } \\
\end{array}$ & Cyclical & 33 & none & $\begin{array}{l}\text { program reserves } \\
\text { during four years }\end{array}$ & 0 & 0 \\
\hline Audit protocol & Cyclical & $\begin{array}{l}\text { not } \\
\text { included }\end{array}$ & RCU:9 & in line with legislation & $\downarrow$ & $\downarrow$ \\
\hline \multicolumn{7}{|l|}{ Explanation: } \\
\hline \multicolumn{4}{|c|}{ Included in determining autonomy } & \multicolumn{3}{|c|}{ Not included in determining autonomy } \\
\hline
\end{tabular}


A final remark concerns auditing instructions which are not included in kZBO but in this case are included as a condition for providing subsidies to FBKVB. It reduces autonomy in the auditing process but within this framework, interviewees indicated that FBKVB's board is still responsible for appointing its auditor.

\subsubsection{Conclusion}

In the case of FBVKB, three positive Type 1 mismatches can be observed. These regard the relatively restricted role of minOCW in approving statements of accounts and budgets as well as providing annual reports to Parliament. This is partly mitigated by the relatively strict audit protocol which has been laid down. Given the four year budget cycle, control on reserves during this period is relatively low as well, resulting in a positive Type 2 mismatch because during this period there will be no discussion on the subject with minOCW and its staff. 


\subsubsection{Vf/Pf}

Like FBKVB, Vf/Pf is a PLB-type ZBO; actually two separate legal entities controlled by a boards that consist of the same people. Legal arrangements are basically the same for the two foundations. All income transfer ZBOs discussed above are regarded as owned by the relevant minister. This is different for Vf/Pf. Respondents indicate that although historically Vf/Pf was created on the initiative of minOCW, in practice the ownership role of minOCW is reduced although in case of dissolving Vf/Pf, assets would flow to minOCW.

MinOCW announced that he would postpone implementation of kZBO with respect to Vf/Pf until a new vision on particularly Vf has been developed. Effectively, till January 2010, no new legislation was prepared.

\subsubsection{Normative measures}

As Vf/Pf are PLBs, the main document which governs the organisations are the statutes. The board is responsible for staff, special arrangements are from a kZBO perspective not needed and not applied in practice as well. Members of the board can only be appointed from representatives of employers and employees in primary and secondary education. The independent president of the board cannot be a member of the groups mentioned before, but is no civil servant. Given the restrictions on appointing board members as well as the practice in appointing the president of the board, effectively the arrangement of kZBO:9 is met.

In the Vf/Pf case, no specific measures on systematic data protection exist. The basic legislation on education specifies that information on individuals may only be provided in specific cases. Effectively that reduces the possibilities of Vf/Pf to use the data, but the arrangement does not cover unauthorised access to data which is the key of kZBO:41. MinOCW announced that it would revise legislation on Vf/Pf based on a full reassessment of the position of the organisations (Parliament, 2008d). As a result, at least for the time being $\mathrm{Vf} / \mathrm{Pf}$ has additional autonomy on the issue of data protection.

\subsubsection{Information measures}

Most information measures are in line with kZBO requirements. MinOCW has a right of inquiry and specifies several issues of program information to be submitted to him. Annual reports are sent to minOCW and by minOCW to Parliament. The latter issue is formalised in program laws rather than in statutes or decrees. Formally, WPO:187.3 requires an annual report sent to Parliament. In practice, annual reports and statements of accounts are submitted, including a comment by minOCW. Annual reports and statements of accounts are submitted after the dates required by law. According to respondents this is due to the need to receive third party data before the Vf/Pf documents can be created. The time lag is covered by an intermediate letter of minOCW in which she discusses the financial position of Vf/Pf (e.g. Parliament, 2009h), but these letters are late as well. Effectively, the procedure has some negative impact on autonomy due to the requirement that minOCW is commenting on the annual report. This is a more 
active form of reporting compared to the mere kZBO-requirement of submitting a report to Parliament by the ZBO.

Autonomy is positively affected by the lack of a requirement to approve statements of accounts by minOCW. Statutes of Vf/Pf only cover that minOCW is informed on the statements of accounts.

Finally, the separate accounts requirement of kZBO:38 is not relevant as Vf/Pf only provide public services.

\subsubsection{Governance provisions}

Statutes of Vf/Pf describe a one tier board based on a split between managerial board and general board. Responsibilities of both parts of the board are described in the statutes which have to be approved by minOCW. Formally, BVf:2/BPf:2 do not include a precise requirement on the operations of the board, which means that this element in organising the board is part of the boards authority. It thus provides more autonomy than the requirement meant in kZBO:7 on multiple bodies. In practice, kZBO:7 does not apply as Pf/Vf only has a one tier board.

Articles k:ZB011-13 are not applicable given the PLB status. In practice no measures exist. This holds for kZBO:14 on remuneration as well, but Vf/Pf are subject to WOPT. Vf/Pf's statutes do not include arrangements on remuneration, neither do annual reports available. Based on the WOPT report 2008 and the non response document (blacklist) on WOPT 2008 (MinBZK, 2009a; 2009b), it can be concluded that remuneration is within the legal framework.

On the issue of asset related transactions, only the issue of lending and borrowing is included based on CW2001. This does reduce autonomy from a kZBO-perspective, but on the other hand, no full time-ZBO is excluded from the CW2001 measures. Therefore from a comparative perspective autonomy is not reduced. MinOCW has no control on creating reserves as meant in kZBO:32. Given the optional character of kZBO measures this has no effect on autonomy. In the statutes, an arrangement on dissolving the entity is included which requires approval of minOCW (statutes:15-16). This affects autonomy negatively as it is an arrangement that is not included in kZBO. Actually, the arrangement has not been used. Furthermore minOCW has to be involved in reallocation of remaining equity in case of dissolving Vf/Pf. This condition is in line with previous AW1996:12403.

Intervention in case of negligence is not covered in measures. Interviewees indicate that minOCW sometime uses informal pressure to achieve particular policy objectives. With respect to intervention in case of negligence this has not been the case. Because statutes do not include an arrangement on dismissal of a board member by the board in other than in specifically listed cases - not including negligence - influence of minOCW on this issue can only be informal and thus generates increased autonomy for Vf/Pf. Although not likely to be used, the lack of an intervention measure including the relatively weak position of minOCW in appointing the board of Vf/Pf generates additional degrees of freedom for the ZBO. 
Table 16.7: Legal measures on Vf/Pf, formally or actually deviating from kZBO

\begin{tabular}{|c|c|c|c|c|c|c|}
\hline Authority issue & $\begin{array}{l}\text { Authority } \\
\text { Group }\end{array}$ & $\begin{array}{l}\text { reference } \\
\text { kZBO }\end{array}$ & $\begin{array}{l}\text { reference } \\
\text { case law }\end{array}$ & Actual practice & $\begin{array}{l}\text { formal } \\
\text { mismatch } \\
\text { and impact }\end{array}$ & $\begin{array}{l}\text { actual } \\
\text { mismatch } \\
\text { and impact }\end{array}$ \\
\hline $\begin{array}{l}\text { Not appointing } \\
\text { civil servants to } \\
\text { the board }\end{array}$ & Normative & 9 & Statutes: 5 & in line with statutes & 0 & 0 \\
\hline $\begin{array}{l}\text { Appointment of } \\
\text { staff }\end{array}$ & Normative & $\begin{array}{l}\text { kZBO:15 } \\
\text { (PLA) }\end{array}$ & none & $\begin{array}{l}\text { civil law } \\
\text { appointments }\end{array}$ & 0 & 0 \\
\hline $\begin{array}{l}\text { Requirement for } \\
\text { data protection }\end{array}$ & Normative & 41 & none & $\begin{array}{l}\text { limitation of use of } \\
\text { individual data in } \\
\text { WPO:184 }\end{array}$ & $\uparrow$ & $\uparrow$ \\
\hline $\begin{array}{l}\text { Submit annual } \\
\text { report to } \\
\text { Parliament }\end{array}$ & Information & 18 & $\begin{array}{l}\text { submitted } \\
\text { by } \\
\text { minocW: } \\
\text { WPO:187. } \\
3\end{array}$ & $\begin{array}{l}\text { submitted by } \\
\text { minOCW: WPO:187.3 }\end{array}$ & $\downarrow$ & $\downarrow$ \\
\hline $\begin{array}{l}\text { Approval of } \\
\text { statement of } \\
\text { accounts by } \\
\text { minister }\end{array}$ & Information & 34 & $\begin{array}{l}\text { Statutes:1 } \\
3.3 \text { for } \\
\text { informatio } \\
n\end{array}$ & in line with statutes & $\uparrow$ & $\uparrow$ \\
\hline Multiple bodies & Governance & 7 & $\begin{array}{l}\text { Statutes, } \\
\text { BVf:2; } \\
\text { BPf:2 }\end{array}$ & $\begin{array}{l}\text { in line with statutes: } \\
\text { theoretically multiple } \\
\text { body possible; in } \\
\text { practice single body }\end{array}$ & $\uparrow$ & $\uparrow$ \\
\hline $\begin{array}{l}\text { Decision on and } \\
\text { disclosure of } \\
\text { remuneration }\end{array}$ & Governance & $\begin{array}{l}\text { kZBO:14 } \\
\text { WOPT:6 }\end{array}$ & none & $\begin{array}{l}\text { not disclosed but also } \\
\text { not mentioned in } \\
\text { WOPT non-response } \\
\text { document }\end{array}$ & 0 & 0 \\
\hline $\begin{array}{l}\text { Intervention in } \\
\text { case of } \\
\text { negligence }\end{array}$ & Governance & 23 & none & $\begin{array}{l}\text { not used or likely to } \\
\text { be used }\end{array}$ & $\uparrow$ & $\uparrow$ \\
\hline $\begin{array}{l}\text { Asset related } \\
\text { transactions: } \\
\text { borrowing and } \\
\text { lending }\end{array}$ & Governance & $32 d$ & $\begin{array}{l}\text { CW2001:4 } \\
5\end{array}$ & in line with CW & 0 & 0 \\
\hline $\begin{array}{l}\text { Asset related } \\
\text { transactions: } \\
\text { dissolving entity }\end{array}$ & Governance & none & $\begin{array}{l}\text { BPf:4.2g } \\
\text { BVf:4.2g }\end{array}$ & not applied yet & $\downarrow$ & 0 \\
\hline $\begin{array}{l}\text { Approval of } \\
\text { budget }\end{array}$ & Cyclical & 29 & none & $\begin{array}{l}\text { realised based on } \\
\text { fees, no formal } \\
\text { approval }\end{array}$ & $\uparrow$ & 0 \\
\hline $\begin{array}{l}\text { Creating } \\
\text { equalisation } \\
\text { reserve }\end{array}$ & Cyclical & 33 & none & $\begin{array}{l}\text { in line with control } \\
\text { agreement and } \\
\text { actually used }\end{array}$ & $\uparrow$ & 0 \\
\hline \multicolumn{7}{|l|}{ Explanation: } \\
\hline \multicolumn{4}{|c|}{ Included in determining autonomy } & \multicolumn{3}{|c|}{ Not included in determining autonomy } \\
\hline
\end{tabular}

\subsubsection{Cyclical measures}

The last group of measures regards cyclical issues. MinOCW has a role in approving the general fees set by Vf/Pf, which include costs of operations. This is in line with kZBO:17. Other measures in line with KZBO regard the decision of the board to determine the budget and the requirement to report on substantial differences from planning based on a "control agreement" which is a bilateral document rather than a ministerial decree.

MinOCW does not approve budgets, she merely approves fees and assesses the level of fees on risks regarding continuity in operations of school boards subject to Vf/Pf's jurisdiction (BPf:5.2). As total costs of Vf/Pf have to be covered by fees, approval of 
budgets would not have any additional value. Interviewees indicate that they are aware of kZBO regulations on this issue, but no criteria for assessment of budgets were prepared at that time. Effectively, the impact on autonomy of not approving budgets is neutral.

Finally, the measure on equalisation reserves is mentioned. Again, no measure is found in the law. In the "control agreement" an arrangement is made, based on a range of solvency levels. If solvency is outside this range, minOCW and Vf/Pf discuss how the solvency level should be achieved again. Effectively, this has resulted into transfers of excess reserves at Pf to minOCW (Annual report Pf 2006). The control agreement uses solvency levels actually focusing on program costs rather than costs of operations and uses different ranges for reserves for each of the two funds. Negative results on operations are covered within the reserve level for programs as well. Effectively, the formal position suggests autonomy, whereas the actual position on equalisation reserves is in line with kZBO.

\subsubsection{Conclusion}

In the Vf/Pf case, positive Type 1 mismatches are observed in the lack of submitting annual reports to Parliament, the degrees of freedom given in the statement of accounts and the options to create a non-executive board. A negative Type 1 mismatch is found in the comments to the annual report to be submitted to Parliament by minOCW, including the annual report $\mathrm{s}$ of $\mathrm{Vf} / \mathrm{Pf}$. Type 2 mismatches are found in the regulations on the approval of budgets and equalisation reserve. From a formal perspective, autonomy seems above kZBO standard, but additional control agreements mitigate the degrees of freedom on equalisation reserve as well as the decision on the budget, which is ultimately determined by the fees set and approved by minOCW. 


\subsubsection{Relative autonomy of income transfer ZBOs from a legal perspective}

In the previous sections, the autonomy of the individual income transfer ZBOs was discussed from a legal perspective. The general conclusion is that on a number of issues, mismatches exist. In this section, I will not consider the normative measures and the measures of last resort as discussed in section 16.1. An overview of all indicators used for the assessment is disclosed in appendix 10.

The general conclusion is that most ZBOs studied here have a level of autonomy that is both formally (type 1 mismatch) as well as actually (type 2 mismatch) below the standards set in kZBO given their status of income transfer ZBOs. Only PLB ZBOs have higher levels of autonomy than the standards used. For the PLBs, actual autonomy is at a higher level than formal autonomy. In the FBKVB case, planning and control elements generate additional degrees of freedom due to the four year budget cycle which results in limited use of tools such as submitting annual reports and approval of statements of accounts. In the case of Vf/Pf, the increase in actual autonomy is explained by a lack of a direct relationships between board and minister.

The PLA type ZBOs all have reduced autonomy compared to the standard used. In the RvR case, formal and actual autonomy at a general level are in line, but at a more detailed level differences in formal and actual autonomy can be observed due to the negative equalisation reserve and low level relationship between minister and RvR boards. The upward shift in autonomy for CVZ is also explained by a low level of relationship between minister and CVZ board. SVB and UWV are subject to the same legislation resulting in similar levels of formal autonomy. Here, practices diverge strongly. SVB's autonomy is further reduced due to the ending of the formal role of the advisory board. This also holds for UWV, but in that case, intensity of the relationship between minister and board as well as fewer degrees of freedom on providing services for other commissioners explains the difference compared to SVB. Figure 16.1 discloses the formal and actual level of control on income transfer ZBOs compared to each other.

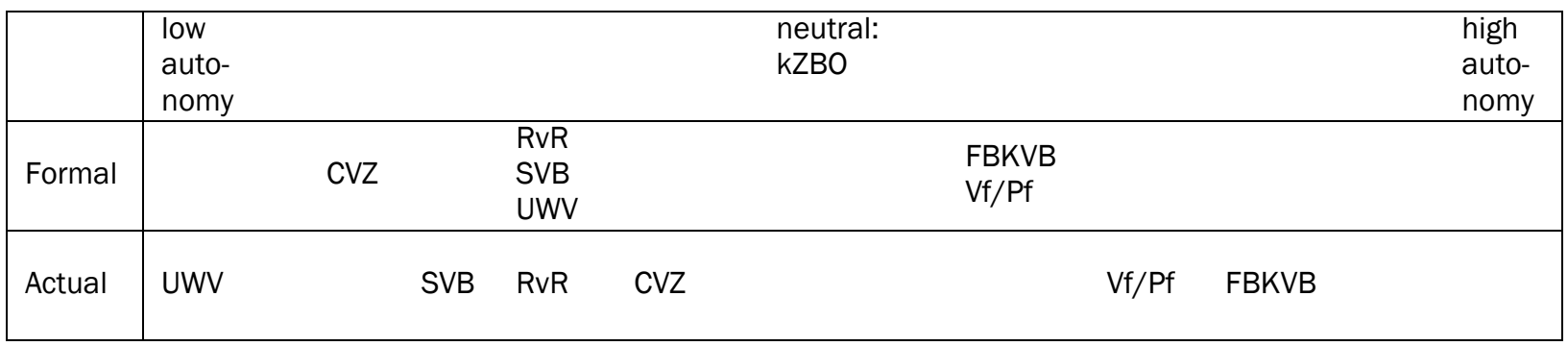

Figure 16.1: Formal and actual autonomy of income transfer ZBOs from a legal perspective

In the following section, I will address the economic dimensions related to autonomy, starting with the service specifications for the services provided by the ZBOs. 


\subsection{The economic dimension of autonomy}

In this subsection, I will discuss the impact of economic variables on income transfer ZBOs. I will discuss each ZBO separately and start the assessment with the issue of market dimensions and service specifications. Thereafter, responsibility accounting including planning and control issues will be discussed. Unlike the assessment from the legal perspective, mismatch can only be based on differences between the expected (see Table 14.8) economic characteristics and the actual characteristics found. This is due to the fact that income transfers imply commissioning based on citizen demand and mass production processes. ${ }^{192}$ Deviations from standards may have a positive or a negative impact which will also be indicated. This means that whereas in the legal setting differences between similar ZBOs could be found in a formal setting, in an economic setting the starting point for all ZBOs of a subtype is the same. With respect to documents submitted to Parliament on ZBO operations, I have chosen to conclude there is a negative impact on autonomy if more than 5 documents are submitted. Five documents would cover a budget document, a document regarding the annual reports as well as two intermediate reports related to VJN and NJN which are the regular intermediate reports submitted to Parliament.

After discussing the last case, a comparative assessment on the autonomy of income transfer ZBOs studied will be given, which shows the deviations from the standard as well as differences between ZBOs. In the summary tables below, the factors used in a comparative setting are highlighted. In general an indicator is only included once to avoid overemphasising particular indicators such as performance. The same assessment structure will be used for the monitoring/regulating type ZBOs in chapter 17.

192 Only in very specialised forms of income transfers, for example in relation to companies and investments, is unit production possible. This is not the case here. 


\subsubsection{CVZ}

\subsubsection{Demand and supply characteristics}

Unlike the other ZBOs CVZ is not a pure income transfer organisation. A substantial part of the activities performed within the organisation are to define standard health insurance policies as well as for research purposes. This is reflected in the share of income transfer activities to total cost of operations. CVZ's income transfers to health insurance companies resemble series production rather than mass production because it is based on an ex ante estimated transaction and a single ex post transaction. These income transfers are still strongly rule driven. Mass production does exist with respect to the income transfers to particular groups of individuals who have to comply with the general ZVW health insurance law.

The policy advice services delivered can be characterised as unit production close to research activities. The complexity of services delivered is reflected in the amount of funding based on income transfers. This reduces autonomy compared to a full income transfer institution because series and individual production requires additional control by commissioners.

Table 16.8: Classification and impact of market characteristics on CVZ's autonomy

\begin{tabular}{|c|c|c|c|}
\hline & Expected & Actual & Impact \\
\hline \multicolumn{4}{|l|}{ Product characteristics } \\
\hline Public good type & Impure good & Impure good & 0 \\
\hline \multicolumn{4}{|l|}{ Activities } \\
\hline $\begin{array}{l}\% \text { income transfer activities in operating costs (2007, annual } \\
\text { report) }\end{array}$ & 100 & 52 & $\uparrow$ \\
\hline Production type & Mass & $\begin{array}{l}\text { Mass, Series } \\
\& \text { Individual }\end{array}$ & $\downarrow$ \\
\hline \multicolumn{4}{|l|}{ Demand } \\
\hline \% Funding from central government (2007, annual report) & 100 & 100 & 0 \\
\hline \% Public funding (2007, annual report) & 100 & 100 & 0 \\
\hline \% Funding largest demand initiator (2007, annual report) & 100 & 100 & 0 \\
\hline Type of funding charges & $\begin{array}{l}\text { Not } \\
\text { applicable }\end{array}$ & $\begin{array}{l}\text { Not } \\
\text { applicable }\end{array}$ & 0 \\
\hline Budget funding & Activity based & Lump sum & $\downarrow$ \\
\hline Commissioning & Request & Request & 0 \\
\hline Demand dependency & 1 department & 1 department & 0 \\
\hline \multicolumn{4}{|l|}{ Supply } \\
\hline Competitors & No & No & 0 \\
\hline Budget Typology & Output & Input & $\downarrow$ \\
\hline Production form & $\begin{array}{l}\text { Contract } \\
\text { provision }\end{array}$ & $\begin{array}{l}\text { Contract } \\
\text { Provision }\end{array}$ & 0 \\
\hline Included in determining autonomy & \multicolumn{3}{|c|}{ Not included in determining autonomy } \\
\hline
\end{tabular}

CVZ is fully dependent on one ministry for its demand, like most of the other income transfer ZBOs selected. From a budget typology perspective, one might expect that a mass production income transfer organisation could be funded with an output based budget. In actual fact the budget has an input character at the level of a lump sum for total costs of operations, or at least a lump sum for both defining health insurance 
policies and income transfer on the one hand and for research on the other (source: interviews + Parliament, 2006i, p. 184). The additional controls affect both the policy advice as well as the income transfer activities. As a result, the autonomy of CVZ is reduced.

\subsubsection{Planning and control}

CVZ uses accruals accounting in line with the expected standards for ZBOs. The actual level of fixed assets are above the standard set here, but 2007 data disclose that some $75 \%$ of fixed assets concern furniture and installations in the leased office premises. The other assets are related to IT. One of the interviewees noted that CVZ was having a debate with minVWS on this issue because including computer software as assets on the balance sheet is not standard practice within the Dutch government. ${ }^{193}$ Asset specificity is thus not an issue and autonomy is not affected.

CVZ's budget has been in a transition phase during 2007 and 2008. Initially, the budget was not fully included in ministry budgets due to the funding history of its predecessor. This had changed in 2006, but some parts of the CVZ budget were still divided over a number of budget articles. During 2006 and 2007 budgets were transferred to one budget line item in which all budgets for all Health Sector ZBOs are included (Parliament, 2006i, p. 126; 2007o, p. 117-119). Transparency in terms of disclosing a separate budget for CVZ therefore does not exist, generating additional autonomy for CVZ. Parliament is informed on the approval of CVZ's annual reports, but not separately on the budgets. There are no instructions on how budgets are to be calculated. According to interviewees this is because such an instruction would conflict with the 'impartial status' of CVZ as a ZBO. The original CVZ 2007 budget was not approved by the minVWS, because in his opinion, the link between budget and activities was insufficiently transparent (minVWS, 2006b). In the letters of approval by minVWS to CVZ two issues can be mentioned: first the administratively separate research budget, which is a lump sum budget for research activities performed by CVZ. Management thus does not have full flexibility in the use of resources attributed to CVZ. Secondly, an explicit cash-flow forecast is given on a monthly basis (MinVWS, 2007a; MinVWS, 2008a). Interviewees indicate that one of the reasons for a separate research budget is that in the past not all research resources were used and unused resources should be at the disposal of minVWS. The disclosure of cash flows in the approval letter is unusual for ZBOs. According to interviewees this can be explained by the desire of minVWS to have adequate liquidity planning for the full minVWS budget. A final point to be made is that investment programs or projects can be applied for on a separate basis, which is an indication for separate investment control by minVWS. Such investment controls are basically in line with cost centre responsibilities, but they are based on ad hoc proposals if they cannot be financed from within CVZ's full authorised budget.

193 Except for executive agencies for which inclusion of software on the balance sheet is permitted. 
Table 16.9: Planning \& control of CVZ and impact on autonomy

\begin{tabular}{|c|c|c|c|c|}
\hline & Expected & fiscal 2007 & fiscal 2008 & Impact \\
\hline \multicolumn{5}{|l|}{ Accounting issues } \\
\hline Accounting System & Accruals & Accruals & Accruals & 0 \\
\hline$\%$ fixed assets & $<10 \%$ & $15 \%$ & $17 \%$ & 0 \\
\hline $\begin{array}{l}\text { Budget disclosure of operating costs in } \\
\text { ministry budgets }\end{array}$ & Line item & $\begin{array}{l}\text { Multiple } \\
\text { articles }\end{array}$ & $\begin{array}{l}\text { Included in } \\
\text { article }\end{array}$ & $\uparrow$ \\
\hline Responsibility centre type & $\begin{array}{l}\text { Standard cost } \\
\text { centre }\end{array}$ & $\begin{array}{l}\text { Discretionary } \\
\text { Cost Centre }\end{array}$ & $\begin{array}{l}\text { Discretionary } \\
\text { Cost Centre }\end{array}$ & $\downarrow$ \\
\hline \multicolumn{5}{|l|}{ Planning \& control } \\
\hline Budget instruction by Minister-Principal & Yes & No & No & $\uparrow$ \\
\hline $\begin{array}{l}\text { Approval of budget document mentioned to } \\
\text { Parliament by minister }\end{array}$ & Yes & No & No & $\uparrow$ \\
\hline $\begin{array}{l}\text { Approval of fees mentioned to Parliament by } \\
\text { minister }\end{array}$ & $\begin{array}{l}\text { Not } \\
\text { applicable }\end{array}$ & $\begin{array}{l}\text { Not } \\
\text { applicable }\end{array}$ & $\begin{array}{l}\text { Not } \\
\text { applicable }\end{array}$ & 0 \\
\hline $\begin{array}{l}\text { Approval of annual report mentioned to } \\
\text { Parliament by minister }\end{array}$ & Yes & $\begin{array}{l}\text { Separate } \\
\text { assessment }\end{array}$ & No & $\uparrow$ \\
\hline $\begin{array}{l}\text { Frequency of reporting by minister to } \\
\text { Parliament }\end{array}$ & Yearly & $\begin{array}{l}\text { Two } \\
\text { intermediate } \\
\text { reports }\end{array}$ & $\begin{array}{l}\text { Two } \\
\text { intermediate } \\
\text { reports }\end{array}$ & $\downarrow$ \\
\hline $\begin{array}{l}\text { Performance indicators reported to } \\
\text { Parliament in ministries' budget documents }\end{array}$ & Output & None & None & $\uparrow$ \\
\hline $\begin{array}{l}\text { Performance indicators reported to } \\
\text { Parliament in ministries' Annual reports }\end{array}$ & Output & None & None & $\uparrow$ \\
\hline $\begin{array}{l}\text { Performance indicators reported to } \\
\text { Parliament in ZBO Budget documents }\end{array}$ & Output & $\begin{array}{l}\text { Not } \\
\text { Submitted }\end{array}$ & $\begin{array}{l}\text { Not } \\
\text { Submitted }\end{array}$ & $\uparrow$ \\
\hline $\begin{array}{l}\text { Performance indicators reported to } \\
\text { Parliament in ZBO Annual reports }\end{array}$ & Output & $\begin{array}{l}\text { Not } \\
\text { Submitted }\end{array}$ & Various types & 0 \\
\hline Frequency of reporting to Minister & $\begin{array}{l}\text { Parliament's } \\
\text { frequency }\end{array}$ & Quarterly & Quarterly & $\downarrow$ \\
\hline \multicolumn{5}{|l|}{ Political Debate } \\
\hline $\begin{array}{l}\text { Number of documents submitted to } \\
\text { Parliament regarding operations of ZBO }\end{array}$ & 0 & 15 & 8 & $\downarrow$ \\
\hline $\begin{array}{l}\text { Number of discussion/questions on } \\
\text { operations of ZBO by MPs related to budget } \\
\text { and annual report }\end{array}$ & 0 & 5 & 2 & 0 \\
\hline $\begin{array}{l}\text { Number of discussion/questions on } \\
\text { operations of ZBO by MPs other than budget } \\
\text { and annual report }\end{array}$ & 0 & 8 & 1 & 0 \\
\hline Included in determining autonomy & \multicolumn{4}{|c|}{ Not included in determining autonomy } \\
\hline
\end{tabular}

Planning \& Control in the relationship between Parliament, minVWS and CVZ is based on the regular arrangements of Budget, First and Second supplementary budget and annual report. At the level of the arrangements between minVWS and CVZ, the governance agreement stipulates quarterly reporting by CVZ to minVWS. Interviewees indicated that as of 2009 planning and control will be aligned with the monthly procedures that apply to ministry units, which reduces the autonomy of CVZ. One other issue regarding planning and control should be mentioned. CVZ made a formal objection to a reduction in its staff levels under a government restructuring program. This is an exceptional step in a relationship between ZBO and ministry. Interviewees indicated that part of the problem was caused by misinterpretation and uncertainty on tasks to be delivered by CVZ and the fact that some temporary staff was not included in CVZ's structural staff levels. The problem was solved by a mutual agreement between CVZ and minVWS and the complaint 
was withdrawn. From a control perspective, this discussion is in my opinion another indicator that CVZ is input controlled rather than output controlled and thus more a discretionary cost centre than a standard cost centre.

Parliament does not have high awareness of the discussions described above. In 2007 and 2008, a total of 16 questions were raised on operations, mainly focusing on technicalities related to budget transfers. Four questions concern the level of budget, 3 concern impact of operations on quality of services. Direct questions on performance do not exist; there is no performance related information available to Parliament.

The general impression on CVZ is that CVZ faces some restrictions in autonomy compared to the expected standard for ZBOs. Particularly in the planning and control domain, it is remarkable to see that minVWS uses rather strict controls but that disclosure of information on CVZ to Parliament does not cover performance indicators or information on budget approval. Furthermore, an assessment of CVZ's performance by minVWS is no longer performed. From a Parliamentary perspective, one could claim that CVZ has substantial autonomy, but in the relationship between minVWS and CVZ the opposite seems to be the case. 


\subsubsection{RvR}

\subsubsection{Demand and supply characteristics}

RvR is in line with the expected market perspective characteristics. In this case, the budget seems to be activity based This is for example suggested by the performance indicators in the minJus budget documents which disclose price and volume, but in the end budget overruns due to changes in volume result in a future cash flow claim on minJus which is disclosed in the annual reports as (fixed) financial assets, rather than receivables. According to interviewees, these fixed financial assets can be regarded as a form of negative equalisation reserve. Given the context of growth in demand and proposed budget cuts, interviewees doubt whether a positive equalisation reserve is realistic. Formally, RvR is controlled on a standard cost centre basis but as the corresponding compensation is not provided by minJus, materially RvR is controlled as a discretionary cost centre.

A last note is that RvR provides services for minJus as well as minVROM. From a commissioning point of view, demand is driven by requests from citizens funded by minJus only. The financial relevance of tasks assigned by minVROM is according to the interviewees minimal and cannot be found in budget documents because the costs of operations for the minVROM activities are included in minJus' budget.

Table 16.10: Classification and impact of market characteristics on RvR's autonomy

\begin{tabular}{|c|c|c|c|}
\hline & Expected & Actual & Impact \\
\hline \multicolumn{4}{|l|}{ Product characteristics } \\
\hline Public good type & Impure good & Impure good & 0 \\
\hline \multicolumn{4}{|l|}{ Activities } \\
\hline $\begin{array}{l}\text { \% income transfer activities in operating costs (2007, annual } \\
\text { report) }\end{array}$ & 100 & 100 & 0 \\
\hline Production type & Mass & Mass & 0 \\
\hline \multicolumn{4}{|l|}{ Demand } \\
\hline \% Funding from central government (2007, annual report) & 100 & 100 & 0 \\
\hline \% Public funding (2007, annual report) & 100 & 100 & 0 \\
\hline \% Funding largest demand initiator (2007, annual report) & 100 & 100 & 0 \\
\hline Type of funding charges & $\begin{array}{l}\text { Not } \\
\text { applicable }\end{array}$ & $\begin{array}{l}\text { Not } \\
\text { applicable }\end{array}$ & 0 \\
\hline Budget funding & Activity based & Lump sum & $\downarrow$ \\
\hline Commissioning & Request & Request & 0 \\
\hline Demand dependency & 1 department & $\begin{array}{l}\text { multiple } \\
\text { departments }\end{array}$ & 0 \\
\hline \multicolumn{4}{|l|}{ Supply } \\
\hline Competitors & No & No & 0 \\
\hline Budget Typology & Output & Input & $\downarrow$ \\
\hline Production form & $\begin{array}{l}\text { Contract } \\
\text { provision }\end{array}$ & $\begin{array}{l}\text { Contract } \\
\text { Provision }\end{array}$ & 0 \\
\hline
\end{tabular}




\subsubsection{Planning and control}

In the RvR case, the program budget and operating budget are mixed up in one line item in the budget of minJUS. There are no explicit documents to assess or approve budget documents or annual reports submitted to Parliament ${ }^{194}$. Key data including output type performance information is given in the ministry's budget documents. Fixed assets are only a small figure in RvR's balance sheet. From a perspective of asset specificity, the assets listed are not relevant as they relate to leased offices.

Table 16.11: Planning \& control of RvR and impact on autonomy

\begin{tabular}{|c|c|c|c|c|}
\hline & Expected & fiscal 2007 & fiscal 2008 & Impact \\
\hline \multicolumn{5}{|l|}{ Accounting issues } \\
\hline Accounting System & Accruals & Accruals & Accruals & 0 \\
\hline \% fixed assets & $<10 \%$ & $1 \%$ & $1 \%$ & 0 \\
\hline $\begin{array}{l}\text { Budget disclosure of operating costs in } \\
\text { ministry's budgets }\end{array}$ & Line item & Line item & Line item & 0 \\
\hline Responsibility centre type & $\begin{array}{l}\text { Standard cost } \\
\text { centre }\end{array}$ & $\begin{array}{l}\text { Standard cost } \\
\text { centre }\end{array}$ & $\begin{array}{l}\text { Standard cost } \\
\text { centre }\end{array}$ & $\downarrow$ \\
\hline \multicolumn{5}{|l|}{ Planning \& control } \\
\hline Budget instruction by Minister-Principal & Yes & Yes & Yes & 0 \\
\hline $\begin{array}{l}\text { Approval of budget document mentioned to } \\
\text { Parliament by minister }\end{array}$ & Yes & No & No & $\uparrow$ \\
\hline $\begin{array}{l}\text { Approval of fees mentioned to Parliament by } \\
\text { minister }\end{array}$ & $\begin{array}{l}\text { Not } \\
\text { applicable }\end{array}$ & $\begin{array}{l}\text { Not } \\
\text { applicable }\end{array}$ & $\begin{array}{l}\text { Not } \\
\text { applicable }\end{array}$ & 0 \\
\hline $\begin{array}{l}\text { Approval of annual report mentioned to } \\
\text { Parliament by minister }\end{array}$ & Yes & No & No & $\uparrow$ \\
\hline $\begin{array}{l}\text { Frequency of reporting by minister to } \\
\text { Parliament }\end{array}$ & Yearly & $\begin{array}{l}\text { Two } \\
\text { intermediate } \\
\text { reports }\end{array}$ & $\begin{array}{l}\text { Two } \\
\text { intermediate } \\
\text { reports }\end{array}$ & $\downarrow$ \\
\hline $\begin{array}{l}\text { Performance indicators reported to } \\
\text { Parliament in ministries' budget documents }\end{array}$ & Output & Output & Output & 0 \\
\hline $\begin{array}{l}\text { Performance indicators reported to } \\
\text { Parliament in ministries' Annual reports }\end{array}$ & Output & Output & Output & 0 \\
\hline $\begin{array}{l}\text { Performance indicators reported to } \\
\text { Parliament in ZBO Budget documents }\end{array}$ & Output & $\begin{array}{l}\text { Not } \\
\text { Submitted }\end{array}$ & $\begin{array}{l}\text { Not } \\
\text { Submitted }\end{array}$ & $\uparrow$ \\
\hline $\begin{array}{l}\text { Performance indicators reported to } \\
\text { Parliament in ZBO Annual reports }\end{array}$ & Output & $\begin{array}{l}\text { Not } \\
\text { Submitted }\end{array}$ & $\begin{array}{l}\text { Not } \\
\text { Submitted }\end{array}$ & $\uparrow$ \\
\hline Frequency of reporting to Minister & $\begin{array}{l}\text { Parliamentary } \\
\text { frequency }\end{array}$ & $\begin{array}{l}\text { Two } \\
\text { intermediate } \\
\text { reports }\end{array}$ & $\begin{array}{l}\text { Two } \\
\text { intermediate } \\
\text { reports }\end{array}$ & 0 \\
\hline \multicolumn{5}{|l|}{ Political Debate } \\
\hline $\begin{array}{l}\text { Number of documents submitted to } \\
\text { Parliament regarding operations of ZBO }\end{array}$ & 0 & 12 & 17 & $\downarrow$ \\
\hline $\begin{array}{l}\text { Number of discussion/questions on } \\
\text { operations of ZBO by MPs related to budget } \\
\text { and annual report }\end{array}$ & 0 & 2 & 3 & 0 \\
\hline $\begin{array}{l}\text { Number of discussion/questions on } \\
\text { operations of ZBO by MPs other than budget } \\
\text { and annual report }\end{array}$ & 0 & 1 & 3 & 0 \\
\hline Included in determining autonomy & \multicolumn{4}{|c|}{ Not included in determining autonomy } \\
\hline
\end{tabular}

Within the planning \& control process, minJUS sends a letter of instruction to RvR, including an estimate of volume of services and price levels. This letter may be seen as a

194 These documents are submitted to RvR. 
form of commissioning instruction. The budget proposal which is submitted by RvR to minJUS based on the instruction is a proposal for a single fiscal year instead of a multiyear proposal. The relevant letters of instruction also only cover a single fiscal year. In the ministry's budget documents however, both a multiyear budget estimate is given as well as a multiyear estimate on income transfer volumes (Parliament, 2007p, p. 45). Frequency of reporting by RvR to minJUS is on a four monthly basis, which is in line with the reporting frequency of a minister to Parliament.

RvR's annual budget is then approved by a letter which has the status of a decision open to appeal. Respondents indicate that this is merely a matter of form of approving the budget proposal given the best estimate of production at a certain moment. According to respondents processes within RvR are relatively stable. As a result there is no need to discuss the level of budget and processes in detail.

At the point when the formal letter of approval is sent out, according to the interviewees it is internally known that the budget will be changed in the First supplement to the annual budget, basically due to changes in the volume of income transfers provided by RvR. The budget decision making process is a matter of debate at the civil servant level without intervention at the political level. At the political level, involvement is found when the First and Second supplement to the budget have to be authorised. In fact, the emphasis is on program costs rather than on costs of operations. The main political issue on budgets in fiscal 2007 and 2008 has been a proposed cut to the program budget. This is reflected in the questions submitted in Parliament: 7 out of 9 questions are related to this issue. One question focused on a technical explanation of a budget overrun on costs of operations and one addressed internal procedures for a particular group of legal aid cases.

The annual report discloses the actual volume and price of income transfers delivered and this is confirmed in the final supplement to the budget for a fiscal year, in which the actual financial result will be authorised by Parliament. Differences due to variations in average costs of income transfers are included in the equalisation reserve on the balance sheet and not included in the final supplement to the budget. Interviewees indicate that this method of accounting is difficult to understand for outsiders.

The overall impression on the economic characteristics of RvR is similar to that for CVZ. Strict control by minJUS even results in structurally negative equalisation reserves. Information provision to Parliament on operations is minimal because no explicit statement on approval of budgets or performance assessment is given. 


\subsubsection{SVB}

\subsubsection{Demand and supply characteristics}

SVB operates in a quasi competitive market. SVB's main function of providing old age pensions is supplemented by other activities for a number of ministries as well as local governments. There is no explicit specification as to the volume of services by ministries other than minSZW according to respondents. In the minSZW case, a budget letter in May specifies the requirements and budget level for the next fiscal year.

Table 16.12: Classification and impact of market characteristics on SVB's autonomy

\begin{tabular}{|c|c|c|c|}
\hline & Expected & Actual & Impact \\
\hline \multicolumn{4}{|l|}{ Product characteristics } \\
\hline Public good type & Impure good & Impure good & 0 \\
\hline \multicolumn{4}{|l|}{ Activities } \\
\hline $\begin{array}{l}\text { \% income transfer activities in operating costs (2007, annual } \\
\text { report) }\end{array}$ & 100 & 100 & 0 \\
\hline Production type & Mass & Mass & 0 \\
\hline \multicolumn{4}{|l|}{ Demand } \\
\hline \% Funding from central government (2007, annual report) & 100 & 26 & $\uparrow$ \\
\hline \% Public funding (2007, annual report) & 100 & 100 & 0 \\
\hline \% Funding largest demand initiator (2007, annual report) & 100 & 88 & 0 \\
\hline Type of funding charges & $\begin{array}{l}\text { Authority } \\
\text { biased }\end{array}$ & $\begin{array}{l}\text { Authority } \\
\text { biased }\end{array}$ & 0 \\
\hline Budget funding & Activity based & Lump sum & $\downarrow$ \\
\hline Commissioning & Request & Request & 0 \\
\hline Demand dependency & 1 department & mixture & $\uparrow$ \\
\hline \multicolumn{4}{|l|}{ Supply } \\
\hline Competitors & No & Yes & $\uparrow$ \\
\hline Budget Typology & Output & Input & $\downarrow$ \\
\hline Production form & $\begin{array}{l}\text { Contract } \\
\text { provision }\end{array}$ & $\begin{array}{l}\text { Contract } \\
\text { Provision }\end{array}$ & 0 \\
\hline Included in determining autonomy & \multicolumn{3}{|c|}{ Not included in determining autonomy } \\
\hline
\end{tabular}

The quasi competitive environment SVB operates in can be illustrated by the assignment of executing a program on schoolbooks to SVB rather than IBGroep in 2008 (Parliament, 20080). Although the budget of SVB is based on a cost calculation and allocation model, the budget effectively has the character of a lump sum budget. This is best illustrated by the authority of minSZW to authorise reallocation of unused resources at the end of a fiscal year (contrary to the regulations in kZBO:33). The character of the budget instruction letter sent out in May stipulates the maximum level of budget for most of SVB's activities (minSZW, 2006) as well as the political desire to control SVB's operations from within one ministry. The minister of Youth and Family (minJG) once stated in Parliament that he does not like the idea that political responsibility for SVB's operations is divided over different ministries (Parliament, 2007q, p. 27-2095). This is an implicit reference to Verhoest's (2002, p. 66-67) co-ordination issue seemingly aiming at the Minister-Principal responsibility of minSzW as the funding for minJG's child benefit program is still under minJG's own budget. Funding of SVB is partially based on 
contributions by ministries (some $26 \%$ ), on premiums levied directly from citizens ${ }^{195}$ and payments from local governments which have commissioned SVB to provide supplements in case of partial AOW benefits. From a control perspective, $88 \%$ of resources are generated from activities related to minSZW.

\subsubsection{Planning and control}

SVB uses accruals accounting for its financial control. In this case assets as a percentage of balance sheet totals are low but that is due to the substantial levels of program cost related items on the balance sheet. SVB owns rather than leases offices, which cover 95\% of fixed assets on the balance sheet. IT infrastructure is only a minor issue, which indicates that asset specificity does not seem to be relevant. Some respondents indicated that human capital is a relevant asset within SVB. This is also a form of asset specificity but not reflected in financial statements. Human capital asset specificity effectively has some positive effect on autonomy.

SVB is the organisation which has the widest variety of commissioners of the ZBOs selected for this study. There is no single SVB budget disclosed in ministry documents. The data provided in the appendix on ZBOs and RWTs in budgets and annual reports by minSZW (Parliament, 2006j, p. 171; Parliament, 2007r, p. 165) only discloses what is included in the minSZW budget instructions and therefore does not include some of the activities on behalf of minVWS as well as estimated revenues generated from local governments for services to supplement AOW pensions. The missing revenues cover some $10 \%$ of total operating costs in 2007 . From a formal perspective, the majority of operating costs are not included in the budget proposal as there is no formal budget article for costs of AOW operations. This is due to the premium based funding system for AOW, which is not a part of the formal government budget. Therefore, the formal conclusion is that only part of SVB's budget is included in the budget document. If one accepts a wider definition of government budget, the conclusion would be that SVB's budget is disclosed over multiple items within minSZW's budget. ${ }^{196}$ Related to the issue of funding disclosure is the approval of fees for SVB. SVB's costs of operations are included in the calculation of program fees, but not as separate fees for services delivered. Therefore, one can argue that approval of fees is not applicable from an operations perspective. ${ }^{197}$

SVB is one of the three ZBOs that are subject to the SUWI legislation. The restructuring process that is at the heart of this legislation has been declared as a special project in Parliament, which requires frequent information exchange between minister and Parliament. Some respondents commented that the arrangements between minister and Parliament were not necessary in the SVB case as SVB is an organisation without

195 In practice premiums are levied directly by the fiscal authorities (Belastingdienst) and then transferred to SVB.

196 The fees charged from local government for the AOW supplement are according to the respondents negotiated and not subject to ministerial approval.

197 The premiums set for relevant programs are however reported to Parliament and are even fixed by law in the case of the AOW pension plan. 
new tasks assigned and programs that are well developed and do not often change. Given the number of questions submitted with respect to SVB's operations (6 in 2007 and 18 in 2008) respondents have a point: questions with respect to UWV add up to over 100.

Table 16.13: Planning \& control of SVB and impact on autonomy

\begin{tabular}{|c|c|c|c|c|}
\hline & Expected & fiscal 2007 & fiscal 2008 & Impact \\
\hline \multicolumn{5}{|l|}{ Accounting issues } \\
\hline Accounting System & Accruals & Accruals & Accruals & 0 \\
\hline$\%$ fixed assets & $<10 \%$ & $1 \%$ & $1 \%$ & 0 \\
\hline $\begin{array}{l}\text { Budget disclosure operating costs in } \\
\text { ministry's budgets }\end{array}$ & Line item & $\begin{array}{l}\text { Partially } \\
\text { included }\end{array}$ & $\begin{array}{l}\text { Partially } \\
\text { included }\end{array}$ & $\uparrow$ \\
\hline Responsibility centre type & $\begin{array}{l}\text { Standard cost } \\
\text { centre }\end{array}$ & $\begin{array}{l}\text { Discretionary } \\
\text { cost centre }\end{array}$ & $\begin{array}{l}\text { Discretionary } \\
\text { cost centre }\end{array}$ & $\downarrow$ \\
\hline \multicolumn{5}{|l|}{ Planning \& control } \\
\hline Budget instruction by Minister-Principal & Yes & Yes & Yes & 0 \\
\hline $\begin{array}{l}\text { Approval of budget document mentioned to } \\
\text { Parliament by minister }\end{array}$ & Yes & $\begin{array}{l}\text { Separate } \\
\text { document }\end{array}$ & $\begin{array}{l}\text { Separate } \\
\text { document }\end{array}$ & 0 \\
\hline $\begin{array}{l}\text { Approval of fees mentioned to Parliament by } \\
\text { minister }\end{array}$ & $\begin{array}{l}\text { Not } \\
\text { applicable }\end{array}$ & $\begin{array}{l}\text { Not } \\
\text { applicable }\end{array}$ & $\begin{array}{l}\text { Not } \\
\text { applicable }\end{array}$ & 0 \\
\hline $\begin{array}{l}\text { Approval of annual report mentioned to } \\
\text { Parliament by minister }\end{array}$ & Yes & $\begin{array}{l}\text { Separate } \\
\text { document } \\
\text { including } \\
\text { assessment }\end{array}$ & $\begin{array}{l}\text { Separate } \\
\text { document } \\
\text { including } \\
\text { assessment }\end{array}$ & $\downarrow$ \\
\hline $\begin{array}{l}\text { Frequency of reporting by minister to } \\
\text { Parliament }\end{array}$ & Yearly & Quarterly & May/August & $\downarrow$ \\
\hline $\begin{array}{l}\text { Performance indicators reported to } \\
\text { Parliament in ministries' budget documents }\end{array}$ & Output & $\begin{array}{l}\text { Input to } \\
\text { outcome }\end{array}$ & $\begin{array}{l}\text { Input to } \\
\text { outcome }\end{array}$ & 0 \\
\hline $\begin{array}{l}\text { Performance indicators reported to } \\
\text { Parliament in ministries' Annual reports }\end{array}$ & Output & $\begin{array}{l}\text { Input to } \\
\text { outcome }\end{array}$ & $\begin{array}{l}\text { Input to } \\
\text { outcome }\end{array}$ & 0 \\
\hline $\begin{array}{l}\text { Performance indicators reported to } \\
\text { Parliament in ZBO Budget documents }\end{array}$ & Output & $\begin{array}{l}\text { Input to } \\
\text { outcome }\end{array}$ & $\begin{array}{l}\text { Input to } \\
\text { outcome }\end{array}$ & 0 \\
\hline $\begin{array}{l}\text { Performance indicators reported to } \\
\text { Parliament in ZBO Annual reports }\end{array}$ & Output & $\begin{array}{l}\text { Input to } \\
\text { outcome }\end{array}$ & $\begin{array}{l}\text { Input to } \\
\text { outcome }\end{array}$ & 0 \\
\hline Frequency of reporting to Minister & $\begin{array}{l}\text { Parliamentary } \\
\text { frequency }\end{array}$ & Quarterly & May/August & 0 \\
\hline \multicolumn{5}{|l|}{ Political Debate } \\
\hline $\begin{array}{l}\text { Number of documents submitted to } \\
\text { Parliament regarding operations of ZBO }\end{array}$ & 0 & 25 & 40 & $\downarrow$ \\
\hline $\begin{array}{l}\text { Number of discussion/questions on } \\
\text { operations of ZBO by MPs related to budget } \\
\text { and annual report }\end{array}$ & 0 & 1 & 8 & 0 \\
\hline $\begin{array}{l}\text { Number of discussion/questions on } \\
\text { operations of ZBO by MPs other than budget } \\
\text { and annual report }\end{array}$ & 0 & 5 & 10 & $\downarrow$ \\
\hline Included in determining autonomy & \multicolumn{4}{|c|}{ Not included in determining autonomy } \\
\hline
\end{tabular}

Due to the special project status, Parliament is informed quarterly on approval of budgets as well as receiving annual reports and receives performance information on programs and operations of SVB. These reports are submitted by minSZW and include an assessment of SVB's performance, implying restrictions on autonomy compared to the standards. In 2008 minSZW and the SUWI partners changed the frequency of intermediate reporting to two reports on a 4 monthly basis. The frequency implemented 
in 2008 is practically in line with intermediate reporting procedures to Parliament. This reporting practice was continued after the special project status ended by June 2008 (Parliament, 2008p). Although respondents indicated that performance is relevant when calculating budgets, the level of budget is in fact set by the letter of instruction sent out in May. This is sufficient to conclude that SVB classifies as a discretionary responsibility centre. The argument is even emphasised by direct remarks and questions by members of Parliament on the level of remuneration of top management (Parliament, 2009f; in fact a motion) and the promise by minSzW to report separately on costs of housing and ICT of the SUWI organisations as of 2009 (Parliament, 2008q).

In the SVB case, autonomy is reduced by the planning and control tools applied. Information to Parliament is submitted frequently, including an assessment by minSZW. This practice results in transparency but also reduces autonomy of operations given the fact that reporting is done several times a year. Although market characteristics allow for increased autonomy given the variety in commissioning, actual control resembles a discretionary cost centre level rather than a standard cost centre level, which also reduces autonomy. 


\subsubsection{UWV}

\subsubsection{Demand and supply characteristics}

UWV has market characteristics similar to SVB. However, there are differences as well. The main difference between UWV and SVB is that in 2007 and 2008 UWV only delivered services that were assigned by minSzW. One of the reasons for this difference might according to some of the interviewees be that there are differences in the degree in which the operations of both organisations can be classified as 'in control'. The documents sent to Parliament with respect to the SUWI operation are an indication of this difference: whereas the SVB re-organisation program is hardly mentioned in these documents, UWV operations are discussed in detail due to errors and failures (e.g. on ICT projects; most recently, see Parliament, 2008r198).

Table 16.14: Classification and impact of market characteristics on UWV's autonomy

\begin{tabular}{|c|c|c|c|}
\hline & Expected & Actual & Impact \\
\hline \multicolumn{4}{|l|}{ Product characteristics } \\
\hline Public good type & Impure good & Impure good & 0 \\
\hline \multicolumn{4}{|l|}{ Activities } \\
\hline $\begin{array}{l}\text { \% income transfer activities in operating costs (2007, annual } \\
\text { report) }\end{array}$ & 100 & 100 & 0 \\
\hline Production type & Mass & Mass & 0 \\
\hline \multicolumn{4}{|l|}{ Demand } \\
\hline \% Funding from central government (2007, annual report) & 100 & 100 & 0 \\
\hline \% Public funding (2007, annual report) & 100 & 100 & 0 \\
\hline \% Funding largest demand initiator (2007, annual report) & 100 & 100 & 0 \\
\hline Type of funding charges & $\begin{array}{l}\text { Authority } \\
\text { biased }\end{array}$ & $\begin{array}{l}\text { Authority } \\
\text { biased }\end{array}$ & 0 \\
\hline Budget funding & Activity based & Lump sum & $\downarrow$ \\
\hline Commissioning & Request & Request & 0 \\
\hline Demand dependency & 1 department & 1 department & 0 \\
\hline \multicolumn{4}{|l|}{ Supply } \\
\hline Competitors & No & No & 0 \\
\hline Budget Typology & Output & Input & $\downarrow$ \\
\hline Production form & $\begin{array}{l}\text { Contract } \\
\text { provision }\end{array}$ & $\begin{array}{l}\text { Contract } \\
\text { Provision }\end{array}$ & 0 \\
\hline Included in determining autonomy & \multicolumn{3}{|c|}{ Not included in determining autonomy } \\
\hline
\end{tabular}

\subsubsection{Planning and control}

This section on UWV is to be regarded as a selection by the researcher on the issues that were discussed during fiscal 2007 and 2008. A full discussion is far beyond the scope or the purpose of the study as a whole. The examples however do indicate that the environment in which UWV operates is turbulent and that this has an impact on political attention for the organisation and the level of detail of political control. UWV is not only the largest (in staff and operating costs) but also the most complex ZBO of the ZBOs discussed here.

198 In this document, 47 questions are raised by MPs on the failure of an important ICT project within UWV. 
Like SVB, the financial relevance of fixed assets compared to balance sheet totals is minimal due to large amounts of program cost related balance sheet items. Most of the fixed assets listed concern investments in the (leased) offices. Outside the balance sheet, asset specificity is found in human capital, particularly in the medical staff responsible for assessing disability. Human capital influences production levels of services but does not contribute to additional autonomy related to Parliamentary control.

From a control perspective, UWV and SVB are managed under the same rules. Economic context as well as planning and control have a similar structure. However, UWV is under far more political scrutiny than SVB. This is due to a few reasons which are reflected in the type of questions asked by MPs. First, UWV is a merged organisation that started in 2002 under a single management. Procedures had to be lined up, harmonised and modernised. In some cases this was not immediately successful such as with the sickness benefit ICT system that failed in the last quarter of 2006 (Parliament, 2006k). Secondly, Parliament had passed several new program laws that had to be implemented, amongst them one on a full restructuring of disability benefits. This led to discussions on re-assessing beneficiaries under the old program. With respect to the old program, debate on assessment fairness was part of the political discussions, implying that UWV management was imposing pressure on physicians to compromise their professional standards, resulting in a motion for an independent investigation (Parliament 2007s). It also resulted in the development of a new ICT system for the new program. Due to managerial problems, the ICT project for the new program failed (e.g. Parliament, 2008s). MPs asked nearly 50 questions regarding this problem. ${ }^{199}$ The third important project was a transfer in levying premiums (the main funding source) from UWV's predecessors to the tax authorities. This again resulted in ICT related problems which were regularly discussed in Parliament (e.g. Parliament, 2007t).

By mid fiscal 2008, a proposal for a revised SUWI law was submitted in Parliament. In this law a merger of UWV and CWI as of 2009 is the main issue. The idea of the merger was supported by the management of both organisations (Parliament, 2008t; Parliament, 2008u).

On a more practical level, the merger and the process of reducing staff levels from some 24,000 to a little over 16,000 employees in 6 years (UWV, 2009, p. 31) led to unoccupied office space and MPs explicitly addressed minSZW to co-ordinate better use of office space, at least within the SUWI domain but even across government if necessary (Parliament, 2007u). These examples indicate that UWV operates in a relatively unstable environment, unlike most other ZBOs studied here. At some stages, minSZW indicated that its responsibility for UWV operations was only limited: the minister is responsible for program outcomes; quality assurance is the responsibility of UWV management (Parliament, 2008v).

199 In the analysis of the number of questions, this example is regarded as a single question on one single issue. 
Table 16.15: Planning \& control of UWV and impact on autonomy

\begin{tabular}{|c|c|c|c|c|}
\hline & Expected & fiscal 2007 & fiscal 2008 & Impact \\
\hline \multicolumn{5}{|l|}{ Accounting issues } \\
\hline Accounting System & Accruals & Accruals & Accruals & 0 \\
\hline$\%$ fixed assets & $<10 \%$ & $1 \%$ & $1 \%$ & 0 \\
\hline $\begin{array}{l}\text { Budget disclosure of operating costs in } \\
\text { ministry budgets }\end{array}$ & Line item & $\begin{array}{l}\text { Partially } \\
\text { included }\end{array}$ & $\begin{array}{l}\text { Partially } \\
\text { included }\end{array}$ & $\uparrow$ \\
\hline Responsibility centre type & $\begin{array}{l}\text { Standard cost } \\
\text { centre }\end{array}$ & $\begin{array}{l}\text { Discretionary } \\
\text { cost centre }\end{array}$ & $\begin{array}{l}\text { Discretionary } \\
\text { cost centre }\end{array}$ & $\downarrow$ \\
\hline \multicolumn{5}{|l|}{ Planning \& control } \\
\hline Budget instruction by Minister-Principal & Yes & Yes & Yes & 0 \\
\hline $\begin{array}{l}\text { Approval of budget document mentioned to } \\
\text { Parliament by minister }\end{array}$ & Yes & $\begin{array}{l}\text { Separate } \\
\text { document }\end{array}$ & $\begin{array}{l}\text { Separate } \\
\text { document }\end{array}$ & 0 \\
\hline $\begin{array}{l}\text { Approval of fees mentioned to Parliament by } \\
\text { minister }\end{array}$ & $\begin{array}{l}\text { Not } \\
\text { applicable }\end{array}$ & $\begin{array}{l}\text { Not } \\
\text { applicable }\end{array}$ & $\begin{array}{l}\text { Not } \\
\text { applicable }\end{array}$ & 0 \\
\hline $\begin{array}{l}\text { Approval of annual report mentioned to } \\
\text { Parliament by minister }\end{array}$ & Yes & $\begin{array}{l}\text { Separate } \\
\text { document } \\
\text { including } \\
\text { assessment }\end{array}$ & $\begin{array}{l}\text { Separate } \\
\text { document } \\
\text { including } \\
\text { assessment }\end{array}$ & $\downarrow$ \\
\hline $\begin{array}{l}\text { Frequency of reporting by minister to } \\
\text { Parliament }\end{array}$ & Yearly & Quarterly & May/August & $\downarrow$ \\
\hline $\begin{array}{l}\text { Performance indicators reported to } \\
\text { Parliament in ministries' budget documents }\end{array}$ & Output & $\begin{array}{l}\text { Input to } \\
\text { outcome }\end{array}$ & $\begin{array}{l}\text { Input to } \\
\text { outcome }\end{array}$ & 0 \\
\hline $\begin{array}{l}\text { Performance indicators reported to } \\
\text { Parliament in ministries' Annual reports }\end{array}$ & Output & $\begin{array}{l}\text { Input to } \\
\text { outcome }\end{array}$ & $\begin{array}{l}\text { Input to } \\
\text { outcome }\end{array}$ & 0 \\
\hline $\begin{array}{l}\text { Performance indicators reported to } \\
\text { Parliament in ZBO Budget documents }\end{array}$ & Output & $\begin{array}{l}\text { Input to } \\
\text { outcome }\end{array}$ & $\begin{array}{l}\text { Input to } \\
\text { outcome }\end{array}$ & 0 \\
\hline $\begin{array}{l}\text { Performance indicators reported to } \\
\text { Parliament in ZBO Annual reports }\end{array}$ & Output & $\begin{array}{l}\text { Input to } \\
\text { outcome }\end{array}$ & $\begin{array}{l}\text { Input to } \\
\text { outcome }\end{array}$ & 0 \\
\hline Frequency of reporting to Minister & $\begin{array}{l}\text { Parliamentary } \\
\text { frequency }\end{array}$ & Quarterly & May/August & 0 \\
\hline \multicolumn{5}{|l|}{ Political Debate } \\
\hline $\begin{array}{l}\text { Number of documents submitted to } \\
\text { Parliament regarding operations of ZBO }\end{array}$ & 0 & 42 & 62 & $\downarrow$ \\
\hline $\begin{array}{l}\text { Number of discussion/questions on } \\
\text { operations of ZBO by MPs related to budget } \\
\text { and annual report }\end{array}$ & 0 & 9 & 15 & $\downarrow$ \\
\hline $\begin{array}{l}\text { Number of discussion/questions on } \\
\text { operations of ZBO by MPs other than budget } \\
\text { and annual report }\end{array}$ & 0 & 54 & 90 & $\downarrow$ \\
\hline Included in determining autonomy & \multicolumn{4}{|c|}{ Not included in determining autonomy } \\
\hline
\end{tabular}

Respondents indicated that some of the measures laid down on planning and control of UWV make it difficult to manage the organisation. They feel for example that monitoring of UWV's activities by IWI - the monitoring institution of minSZW - is pro-active rather than re-active as would be logical, given the role of IWI in relation to the tasks of the core staff in minSZW which also discuss control of UWV. Furthermore, requests for ex ante assessment on viability of new programs from a perspective of operations ('uitvoeringstoets') by UWV are not always sent to Parliament, which means that Parliament might not be fully aware of possible risks. Respondents also indicated that UWV is sometimes reluctant to be sufficiently critical in these ex ante program assessments. On the unoccupied office space problem, a respondent indicated that before ending lease of an office, UWV has to have minSZW's consent, which might have 
an impact on the power to act proactively. Respondents also indicate that they have problems with the level of detail of control by minSzW on the issue of staff reductions as well as on performing programs more efficiently. The latter problem is related to the strict separation of program budgets and operating budgets which does not enable additional operating resources to be used to stop benefits from having to be paid to individuals.

In the UWV case, both Parliament and minister use control tools that have a negative impact on autonomy. Indicators are found in cost control and frequency of reporting including the special project status of SUWI implementation. The underlying problem is the complexity of the organisation, high political attention, the instability of its programs and its size, which is particularly reflected in questions asked by MPs. 


\subsubsection{FBKVB}

\subsubsection{Demand and supply characteristics}

FBKVB is not really a mass production organisation like the other organisations selected. Based on the decision making process described by the interviewees, one can argue that selecting projects to be subsidised within fund sub-committees resembles series production including elements of professional judgement 200 rather than continuous mass production.

Table 16.16: Classification and impact of market characteristics on FBKVB's autonomy

\begin{tabular}{|c|c|c|c|}
\hline & Expected & Actual & Impact \\
\hline \multicolumn{4}{|l|}{ Product characteristics } \\
\hline Public good type & Impure good & Impure good & 0 \\
\hline \multicolumn{4}{|l|}{ Activities } \\
\hline $\begin{array}{l}\text { \% income transfer activities in operating costs (2007, annual } \\
\text { report) }\end{array}$ & 100 & 100 & 0 \\
\hline Production type & Mass & $\begin{array}{l}\text { Series } \\
\text { including } \\
\text { professional } \\
\text { judgement }\end{array}$ & $\uparrow$ \\
\hline \multicolumn{4}{|l|}{ Demand } \\
\hline \% Funding from central government (2007, annual report) & 100 & 100 & 0 \\
\hline \% Public funding (2007, annual report) & 100 & 100 & 0 \\
\hline \% Funding largest demand initiator (2007, annual report) & 100 & 100 & 0 \\
\hline Type of funding charges & $\begin{array}{l}\text { Not } \\
\text { applicable }\end{array}$ & $\begin{array}{l}\text { Not } \\
\text { applicable }\end{array}$ & 0 \\
\hline Budget funding & Lump sum & Lump sum & 0 \\
\hline Commissioning & Request & Request & 0 \\
\hline Demand dependency & 1 department & 1 department & 0 \\
\hline \multicolumn{4}{|l|}{ Supply } \\
\hline Competitors & No & No & 0 \\
\hline Budget Typology & Output & Input & $\downarrow$ \\
\hline Production form & $\begin{array}{l}\text { Contract } \\
\text { provision }\end{array}$ & $\begin{array}{l}\text { Grant } \\
\text { Provision }\end{array}$ & $\uparrow$ \\
\hline Included in determining autonomy & \multicolumn{3}{|c|}{ Not included in determining autonomy } \\
\hline
\end{tabular}

Furthermore, the budget structure of the art funds is different from all other income transfer organisations selected. A budget is allocated for a 4 years period and it is up to the fund to manage the distribution of resources over both operating costs and program costs. Only after the end of the 4 year period is a final (financial) conclusion drawn. According to the interviewees this form of budgeting was chosen to deliberately create an arm's length relationship between the State supporting Art and an impartial judgement on the allocation of the budget both to the various art funds as well as to artists applying for financial support. In fact, the services provided resemble a grant provision type of service rather than contract service provision. This can be derived from the present system of budget allocation but also from history. An interviewee indicated that one of the arguments for creating the art funds - particularly as a private law entity - was to avoid

200 Dedicated committees assess proposals from artists. 
procedures akin to Awb from individual applicants for grants. Although this idea did not hold from a legal perspective, it does have its impact on autonomy from an economic perspective through the funding systems.

Overall, production in the FBKVB environment does not allow for output budgeting controls. In practice the control level is close to an input budget with traditional cost control within the organisation and a budgeted level of costs of operations over a four year period.

FBKVB is one of 10 art funds; they compete amongst each other and with other interest groups for part of the 4 year budget to be distributed. Once the impartial allocation of budgets has been decided, the different funds operate in different areas of the arts and do not compete for delivering services. Interviewees indicated that FBKVB's activities are related to some other art funds' activities. According to one interviewee mergers are not on the agenda yet, particularly due to the expected increase in power of a merged fund within the arts sector as a whole. Therefore, my conclusion is that there is no market competition between the different funds.

\subsubsection{Planning and control}

FBKVB is one of a group of ZBOs distributing income transfers in the arts sector. Budgeting for these organisations is based on an independent decision on behalf of minOCW and basically applies for four years. Respondents indicated that the Minister of OCW as well as Parliament only intervene on the distributed level of budgets if there is a general need for fiscal interventions, otherwise the budget is allocated for four years. As a result, intermediate questions on budgeting as well as reporting to Parliament do not exist. Furthermore, FBKVB's budget is not disclosed separately in minOCW's budget but is part of the larger budget for all income transfers in the arts sector. There are no clear budget instructions for setting up a bottom up budget. A reporting structure document is provided by minOCW. Respondents indicated that during a fiscal year budget monitoring is performed at the civil servant level only. From the ministry's perspective, it was indicated that there is a desire to link objectives to resources. However, this has not yet been carried out. Costs of operations are included in the budget. There are no separate measures although an estimate for total costs of operations during the four year period is made.

Some questions have been raised in Parliament during fiscal 2007 and 2008. The main issue was the creation of a governance code for the individual funds. Respondents indicated that this is related to the actual position of the board of a fund with respect to management and the advisory boards that evaluate applications for an income transfer. Some questions were raised on the actual distribution of funds to individuals or classes of artists, but minOCW explicitly does not intervene in decisions by the fund unless legislation on freedom of speech and expression is violated (Parliament, 2007v).

Given the level of detail in the requirements for the annual reports to be provided, one can argue that actual control is at the level of separate cost classes such as wages of 
separate sub-units in the organisation, costs of offices, depreciation and the like (minOCW, 2005, p. 15). Therefore management responsibility tends to be at a discretionary cost centre level rather than a standard cost centre level as might be expected in an income transfer ZBO.

Table 16.17: Planning \& control of FBKVB and impact on autonomy

\begin{tabular}{|c|c|c|c|c|}
\hline & Expected & fiscal 2007 & fiscal 2008 & Impact \\
\hline \multicolumn{5}{|l|}{ Accounting issues } \\
\hline Accounting System & Accruals & Accruals & Accruals & 0 \\
\hline$\%$ fixed assets & $<10 \%$ & $2 \%$ & $3 \%$ & 0 \\
\hline $\begin{array}{l}\text { Budget disclosure of operating costs in } \\
\text { ministry budgets }\end{array}$ & Line item & $\begin{array}{l}\text { Included in } \\
\text { article }\end{array}$ & $\begin{array}{l}\text { Included in } \\
\text { article }\end{array}$ & $\uparrow$ \\
\hline Responsibility centre type & $\begin{array}{l}\text { Standard cost } \\
\text { centre }\end{array}$ & $\begin{array}{l}\text { Discretionary } \\
\text { cost centre }\end{array}$ & $\begin{array}{l}\text { Discretionary } \\
\text { cost centre }\end{array}$ & $\downarrow$ \\
\hline \multicolumn{5}{|l|}{ Planning \& control } \\
\hline Budget instruction by Minister-Principal & No & No & No & $\uparrow$ \\
\hline $\begin{array}{l}\text { Approval of budget document mentioned to } \\
\text { Parliament by minister }\end{array}$ & Yes & No & No & $\uparrow$ \\
\hline $\begin{array}{l}\text { Approval of fees mentioned to Parliament by } \\
\text { minister }\end{array}$ & $\begin{array}{l}\text { Not } \\
\text { applicable }\end{array}$ & $\begin{array}{l}\text { Not } \\
\text { applicable }\end{array}$ & $\begin{array}{l}\text { Not } \\
\text { applicable }\end{array}$ & 0 \\
\hline $\begin{array}{l}\text { Approval of annual report mentioned to } \\
\text { Parliament by minister }\end{array}$ & Yes & No & No & $\uparrow$ \\
\hline $\begin{array}{l}\text { Frequency of reporting by minister to } \\
\text { Parliament }\end{array}$ & Yearly & Yearly & Yearly & 0 \\
\hline $\begin{array}{l}\text { Performance indicators reported to } \\
\text { Parliament in ministries' budget documents }\end{array}$ & Output & None & None & $\uparrow$ \\
\hline $\begin{array}{l}\text { Performance indicators reported to } \\
\text { Parliament in ministries' Annual reports }\end{array}$ & Output & None & None & $\uparrow$ \\
\hline $\begin{array}{l}\text { Performance indicators reported to } \\
\text { Parliament in ZBO Budget documents }\end{array}$ & Output & $\begin{array}{l}\text { Not } \\
\text { Submitted }\end{array}$ & $\begin{array}{l}\text { Not } \\
\text { Submitted }\end{array}$ & $\uparrow$ \\
\hline $\begin{array}{l}\text { Performance indicators reported to } \\
\text { Parliament in ZBO Annual reports }\end{array}$ & Output & $\begin{array}{l}\text { Not } \\
\text { Submitted }\end{array}$ & $\begin{array}{l}\text { Not } \\
\text { Submitted }\end{array}$ & $\uparrow$ \\
\hline Frequency of reporting to Minister & Yearly & Yearly & Yearly & 0 \\
\hline \multicolumn{5}{|l|}{ Political Debate } \\
\hline $\begin{array}{l}\text { Number of documents submitted to } \\
\text { Parliament regarding operations of ZBO }\end{array}$ & 0 & 10 & 6 & $\downarrow$ \\
\hline $\begin{array}{l}\text { Number of discussion/questions on } \\
\text { operations of ZBO by MPs related to budget } \\
\text { and annual report }\end{array}$ & 0 & 0 & 0 & 0 \\
\hline $\begin{array}{l}\text { Number of discussion/questions on } \\
\text { operations of ZBO by MPs other than budget } \\
\text { and annual report }\end{array}$ & 0 & 6 & 3 & 0 \\
\hline Included in determining autonomy & \multicolumn{4}{|c|}{ Not included in determining autonomy } \\
\hline
\end{tabular}

In general, FBKVB has additional degrees of freedom compared to the expected standards, particularly because information to Parliament during and after a fiscal year is minimal. This is partially explained by the four year funding cycle. Actual control of operations at the ministerial and executive board level is at a discretionary cost centre rather than the expected standard cost centre level. 


\subsubsection{Vf/Pf}

\subsubsection{Demand and supply characteristics}

Finally, Vf/Pf is discussed. The activities of Vf/Pf focus on services for school boards and are indirectly funded by minOCW as part of minOCW's funding of the school boards. Therefore, formal funding from central government does not occur. Given the number of the (locally organised) school boards (see. e.g. Parliament, 2006a, p 76), there is no largest demand generating organisation to be identified, resulting in some additional autonomy. Theoretically, the Minister of OCW decides appointments to the organisation executing the programs now performed by Vf/Pf (WetPO:184). This suggests that competition would be possible between service providers. However, Vf/Pf was deliberately created to deliver these services and therefore, there is no competition on providing the services. As Vf/Pf is not allowed to provide other services than those on unemployment and disability benefits, it cannot compete with other ZBOs as is the case with SVB.

Table 16.18: Classification and impact of market characteristics on Vf/Pf's autonomy

\begin{tabular}{|c|c|c|c|}
\hline & Expected & Actual & Impact \\
\hline \multicolumn{4}{|l|}{ Product characteristics } \\
\hline Public good type & Impure good & Impure good & 0 \\
\hline \multicolumn{4}{|l|}{ Activities } \\
\hline $\begin{array}{l}\text { \% income transfer activities in operating costs (2007, annual } \\
\text { report) }\end{array}$ & 100 & 100 & 0 \\
\hline Production type & Mass & Mass & 0 \\
\hline \multicolumn{4}{|l|}{ Demand } \\
\hline \% Funding from central government (2007, annual report) & 0 & 0 & 0 \\
\hline \% Public funding (2007, annual report) & 100 & 100 & 0 \\
\hline \% Funding largest demand initiator (2007, annual report) & Iow & low & 0 \\
\hline Type of funding charges & $\begin{array}{l}\text { Authority } \\
\text { biased }\end{array}$ & $\begin{array}{l}\text { Authority } \\
\text { biased }\end{array}$ & 0 \\
\hline Budget funding & Activity based & Activity based & 0 \\
\hline Commissioning & Request & Request & 0 \\
\hline Demand dependency & $\begin{array}{l}\text { outside } \\
\text { departments }\end{array}$ & $\begin{array}{l}\text { outside } \\
\text { departments }\end{array}$ & 0 \\
\hline \multicolumn{4}{|l|}{ Supply } \\
\hline Competitors & Yes & No & $\downarrow$ \\
\hline Budget Typology & Output & Input & $\downarrow$ \\
\hline Production form & $\begin{array}{l}\text { Contract } \\
\text { provision }\end{array}$ & $\begin{array}{l}\text { Regulated } \\
\text { Provision }\end{array}$ & $\uparrow$ \\
\hline Included in determining autonomy & \multicolumn{3}{|c|}{ Not included in determining autonomy } \\
\hline
\end{tabular}

A remark should be made on the fees charged, which can be characterised as authority biased fees rather than market biased fees. Indications for this conclusion include the fact that school boards are obliged to participate in the Vf/Pf system plus the link between approval of fees by the Minister of OCW and the compensation given by minOCW in the funding of school boards for the costs charged by Vf/Pf (Besluit Particiaptiefonds:5). Furthermore, from a demand perspective, there is no immediate 
relationship between the services provided by Vf/Pf and the level of funding charged from an individual school board.

Compared to the other income transfer organisations for which an activity based budget was expected, Vf/Pf is the only one for which it can be argued that the actual operations budget is still activity based. Interviewees indicated that although part of the operations are subsidised by minOCW, no criteria exist to evaluate and control Vf/Pf's operating costs. As a result, volume of activities rather than a given budget determines total operating costs.

\subsubsection{Planning and control}

The budget of Vf/Pf is implicitly included in minOCW's budget. The main source of income Vf/Pf receives is meant to cover program costs. This budget is generated by levies from primary schools, whose budgets are included in minOCW's budget. A second source of income is a direct transfer of resources from minOCW to Vf/Pf to cover costs of operations. The annual reports of Vf/Pf show that not all costs of operations are covered by minOCW's contribution (Vf/Pf, 2007). Therefore, the conclusion is that Vf/Pf's budget is only partly included in minOCW's budget documents. Asset specificity is not an issue, nor are human resources as part of the activities are outsourced and nor are fixed assets. The Vf/Pf balance sheet does not show any fixed assets at all.

The budgeting process is based on a bottom up process from within Vf/Pf without instructions by minOCW. Respondents indicated that informally general trends in primary school funding and wage increases are mentioned by minOCW to Vf/Pf. These general indications cannot be regarded as instructions for service levels when preparing the budget.

$\mathrm{Vf} / \mathrm{Pf}$ does include some performance indicators in its annual report, mainly process and some output indicators with respect to the programs executed. Reporting is on a quarterly basis to minOCW at the civil servant level. Respondents indicate that there is no attention on Vf/Pf operations at a political level. When necessary, minOCW includes changes in Vf/Pf's budgets in the First and Second supplement to the budget. This only happens on rare occasions. In fiscal 2007 and 2008, excess equity from Pf was returned to minOCW. This is disclosed in the relevant budget documents and has lead to some questions in Parliament (Parliament, 2007w, p. 10). This intervention had no impact on Vf/Pf operations but concerns program continuity. If too much equity was withdrawn, it might result in higher premiums in the future.

Respondents indicated that there is no framework given for planning and control. Furthermore, no formal approval procedures and assessment criteria for costs of operations exist. On the other hand, respondents at minOCW indicated that they do have an interest in the estimates of the volume of users for Vf/Pf's programs because this has an impact on minOCW's budget levels. A last point to be mentioned with respect to planning and control is that respondents indicated that there is a standard for minimum and maximum levels of equity, which is different for the two funds. Respondents 
indicated that there is no rationale given for maximum levels. Minimum levels vary (1\% Pf; 3\% Vf; source: respondents) due to different levels of uncertainty in the two funds.

$\mathrm{Vf} / \mathrm{Pf}$ can be characterised as a profit centre rather than a cost centre. The role of the ZBO is to match revenues raised by premiums with expenses. The board of Vf/Pf has the power to determine the premium, which is different from for example UWV where a premium level is merely a suggestion they make to minSZW. Given the fact that Vf/Pf's budgets are not approved by minOCW and that there are hardly any planning and control measures between minOCW and Vf/Pf, the executive board's responsibility is broader than mere cost controls.

Table 16.19: Planning \& control of Vf/Pf and impact on autonomy

\begin{tabular}{|c|c|c|c|c|}
\hline & Expected & fiscal 2007 & fiscal 2008 & Impact \\
\hline \multicolumn{5}{|l|}{ Accounting issues } \\
\hline Accounting System & Accruals & Accruals & Accruals & 0 \\
\hline$\%$ fixed assets & $<10 \%$ & $0 \%$ & $0 \%$ & 0 \\
\hline $\begin{array}{l}\text { Budget disclosure of operating costs in ministry } \\
\text { budgets }\end{array}$ & Line item & $\begin{array}{l}\text { Partially } \\
\text { included }\end{array}$ & $\begin{array}{l}\text { Partially } \\
\text { included }\end{array}$ & $\uparrow$ \\
\hline Responsibility centre type & $\begin{array}{l}\text { Standard } \\
\text { cost centre }\end{array}$ & Profit centre & Profit centre & $\uparrow$ \\
\hline \multicolumn{5}{|l|}{ Planning \& control } \\
\hline Budget instruction by Minister-Principal & No & No & No & $\uparrow$ \\
\hline $\begin{array}{l}\text { Approval of budget document mentioned to } \\
\text { Parliament by minister }\end{array}$ & Yes & No & No & $\uparrow$ \\
\hline $\begin{array}{l}\text { Approval of fees mentioned to Parliament by } \\
\text { minister }\end{array}$ & Yes & No & No & $\uparrow$ \\
\hline $\begin{array}{l}\text { Approval of annual report mentioned to Parliament } \\
\text { by minister }\end{array}$ & Yes & $\begin{array}{l}\text { Yes } \\
\text { including } \\
\text { assessment }\end{array}$ & $\begin{array}{l}\text { Yes } \\
\text { including } \\
\text { assessment }\end{array}$ & $\downarrow$ \\
\hline Frequency of reporting by minister to Parliament & Yearly & $\begin{array}{l}\text { Intermediat } \\
\text { e report }\end{array}$ & $\begin{array}{l}\text { Intermediat } \\
\text { e report }\end{array}$ & 0 \\
\hline $\begin{array}{l}\text { Performance indicators reported to Parliament in } \\
\text { ministries' budget documents }\end{array}$ & Output & No & No & $\uparrow$ \\
\hline $\begin{array}{l}\text { Performance indicators reported to Parliament in } \\
\text { ministries' Annual reports }\end{array}$ & Output & No & No & $\uparrow$ \\
\hline $\begin{array}{l}\text { Performance indicators reported to Parliament in } \\
\text { ZBO Budget documents }\end{array}$ & Output & $\begin{array}{l}\text { Not } \\
\text { Submitted }\end{array}$ & $\begin{array}{l}\text { Not } \\
\text { Submitted }\end{array}$ & $\uparrow$ \\
\hline $\begin{array}{l}\text { Performance indicators reported to Parliament in } \\
\text { ZBO Annual reports }\end{array}$ & Output & Output & Output & 0 \\
\hline Frequency of reporting to Minister & Yearly & Quarterly & Quarterly & $\downarrow$ \\
\hline \multicolumn{5}{|l|}{ Political Debate } \\
\hline $\begin{array}{l}\text { Number of documents submitted to Parliament } \\
\text { regarding operations of ZBO }\end{array}$ & 0 & 9 & 11 & $\downarrow$ \\
\hline $\begin{array}{l}\text { Number of discussion/questions on operations of } \\
\text { ZBO by MPs related to budget and annual report }\end{array}$ & 0 & 0 & 0 & 0 \\
\hline $\begin{array}{l}\text { Number of discussion/questions on operations of } \\
\text { ZBO by MPs other than budget and annual report }\end{array}$ & 0 & 1 & 2 & 0 \\
\hline Included in determining autonomy & \multicolumn{4}{|c|}{ Not included in determining autonomy } \\
\hline
\end{tabular}

The Vf/Pf case shows very contrasting perspectives. On the one hand, the organisation seems to be managed as a profit centre rather than a cost centre but the controls applied by minOCW in terms of frequency of reporting as well as explicit assessment of the annual report by minOCW towards Parliament indicate stronger controls than expected in 
an income transfer ZBO setting. On all other control items, the autonomy experienced by $\mathrm{Vf} / \mathrm{Pf}$ is above expected levels. 


\subsubsection{Relative economic autonomy of income transfer ZBO's}

Income transfer ZBOs can ideally be controlled at a level of activity which implies standard cost centres. They are expected to be fully funded by government controlled resources due to the characteristics of income transfers. Production is expected to be at a contract based level as government is in control of the program and citizens can only apply for an income transfer rather than generate actual demand. These characteristics, together with demand driven by a single ministry, are classified as a neutral position on a scale of autonomy. FBKVB and Vf/Pf deviate somewhat from this general standard. FBKVB is expected to have a lower frequency of reporting to minOCW given the four year budget cycle that is used in this case. In the Vf/Pf case, regulations suggest competition allowing for more degrees of freedom and the reporting frequency can be low as there is only an indirect relationship between minOCW and Vf/Pf operations. Actual autonomy of an income transfer ZBO is assessed based on not only the market characteristics, but also the system of planning and control implemented in the relationship between ministry and ZBO. Figure 16.2 shows the expected and actual autonomy of the selected income transfer ZBOs.

\begin{tabular}{|c|c|c|c|c|c|c|c|c|c|}
\hline & $\begin{array}{l}\text { low } \\
\text { auto- } \\
\text { nomy }\end{array}$ & & & & $\begin{array}{l}\text { neu- } \\
\text { tral }\end{array}$ & & & & $\begin{array}{l}\text { high } \\
\text { auto- } \\
\text { nomy }\end{array}$ \\
\hline Expected & & & & & $\begin{array}{l}\text { CVZ } \\
\text { RvR } \\
\text { SVB } \\
\text { UWV }\end{array}$ & FBKVB & $\begin{array}{l}\text { Vf/ } \\
\text { Pf }\end{array}$ & & \\
\hline Actual & & UWV & SVB & $\begin{array}{l}\text { CVZ } \\
\text { RvR }\end{array}$ & & & & $\begin{array}{l}\text { Vf/ } \\
\text { Pf }\end{array}$ & FBKVB \\
\hline
\end{tabular}

Figure 16.2 Expected and actual autonomy of income transfer ZBOs from an economic perspective

The four public law income transfer ZBOs were expected to comply with a standard cost centre, contract based service provision model indicated in Figure 16.2 as the 'neutral' position on autonomy. The two private law entities are expected to have some additional autonomy due to differences in markets and funding.

The actual position on a scale of economic autonomy shows that autonomy is at a lower level for all PLAs and that autonomy increases for the two PLBs. Appendix 10 gives an overview of factors which have a positive or negative impact on a particular ZBO's autonomy.

The analysis shows a remarkable difference between control by Parliament and control by the Minister-Principal. In general, Ministers-Principals use more control tools than might be expected for a ZBO income transfer organisation. This is most clearly 
expressed in the responsibility centre type of ZBO which can in most cases only be classified as discretionary cost centres rather than the expected standard cost centre.

Parliamentary control varies. I have used mentioning of approval of budgets and annual reports as a standard for income transfer ZBOs. In these cases, a strong divergence is disclosed. In three cases, the annual report of the ZBO is explicitly assessed by the Minister-Principal in Parliamentary documents. MinSZW acts consistently and assesses the annual reports of its ZBOs on behalf of Parliament. ${ }^{201}$ MinOCW does not operate consistently; Vf/Pf's annual reports are explicitly assessed whereas the annual report of FBVKB is not assessed. The annual reports of CVZ and RVR are not assessed by their Minister-Principal on behalf of Parliament. In the case of CVZ it should be noted that the initial practice of assessing annual reports was discontinued after fiscal 2007. The effect is that Parliament has a less direct control tool than in cases where an explicit assessment is given.

Differences in control and autonomy are also found in ex ante and ex post performance indicators submitted to Parliament. Performance information is submitted both ex ante and ex post in only two cases. In the case of CVZ and Vf/Pf ex post information is given. For RvR only ex ante information is submitted to Parliament and no performance data on FBKVB is available to Parliament. Not submitting performance information increases ZBO autonomy ZBO because Parliament is not fully able to assess production and possible impact on budgets of a particular ZBO.

For UWV and SVB, a reduction in autonomy can be observed due to a high level of reporting to Parliament, partially driven by the special project status during the research period. The reporting frequency continued after the special project status had ended. The autonomy of the two PLB ZBOs is in general increased by the relatively low level of information provided to Parliament.

When the focus shifts from information to Parliament to information to the MinisterPrincipal, a different conclusion must be made. The standard used here is that a minister must be able to inform Parliament on a timely basis within the regular budgetary process in Parliament, implying two intermediate reports - VJN and NJN - a year. In practice, two ZBOs - CVZ and Vf/Pf report more frequently to their Ministers-Principal. For CVZ reporting tends to be on a monthly basis, which is in line with (hierarchical) departmental reporting rather than reporting by an arm's length entity. For Vf/Pf, reporting is on a quarterly basis; less frequent than CVZ but not aligned with the Parliamentary reporting procedures.

The general conclusion on economic autonomy of income transfer ZBOS is that PLAs experience stronger controls then expected whereas PLBs have more autonomy. The expected differences between the services provided by income transfer ZBOS are relatively low, which emphasises the contrast between actual and formal control levels even more.

201 In fact minSZW is only Minister-Principal for three full time ZBOs, all subject to the SUWI legislation. 


\subsection{Mismatches in income transfer ZBOs}

In this section, I will discuss the mismatches observed between legal and economic measures for the individual ZBOs, based on the research question for the empirical section of the study:

\section{Do Parliament's control tools match the control tools that fit the legal and economic characteristics of (income transfer) ZBO services?}

Appendix 10 gives a comparative overview of the legal and economic indicators used and their impact on autonomy. In this section, I will focus only on market and planning and control factors because these elements are based on the relationship between services delivered and required control levels. If a fully open market existed, ex ante control as in traditional government would not be needed, whereas for pure public goods without any opportunity to outsource production or obtain funding from sources other than general taxation, a traditional compliance based control system would be needed. The fact that ZBOs can be used suggests that at least the extreme of full compliance based control systems needs not to be used.

Controlling ZBOs has two levels. I have focused on the political level, not considering daily operations within the ZBO. At the political level, two sublevels exist: one in the relationship between Parliament and Minister-Principal and/or minister-commissioner, the other in the relationship between Minister-Principal and/or minister-commissioner and the board of the ZBO. The legal measures on ZBOs refer to authority attributed to the minister-principal and in most cases only indirectly affect Parliament's position on ZBOs. Only on the issue of submitting annual reports to Parliament is a direct relation between ZBO and Parliament created based on legislation. Furthermore, it can be observed that most information, governance and cyclical measures cover planning and control factors rather than market factors as identified in the economic sections of this study. Only the measures on approval of mandates for other services (kZBO:8) and approval of fees (KZBO:17) can be related to market factors; the latter only if other services are allowed. This means that in terms of mismatches, a strong emphasis on planning and control will be found.

In the PLA cases, except for CVZ, formal and actual levels of legal autonomy are below the expected standards. Economic autonomy is in practice below the expected level as well but compared to the economic standard set for income transfer ZBOs, expected levels of autonomy did not diverge. This means that a mismatch in terms of opposite developments in economic and legal autonomy does not occur: all PLA income transfer ZBOs studied here face reduced autonomy. That does not mean that there are no inconsistencies at all. In one case, expected and actual levels of legal autonomy are at the same level and only economic autonomy decreases further. In two cases, both legal and economic autonomy decrease compared to the standards set. In the last case, legal autonomy increases whereas economic autonomy decreases. I will discuss the individual 
cases below, emphasising issues of decreased autonomy and possible inconsistencies within economic or legal autonomy.

CVZ shows contrary developments in legal and economic autonomy. Legal autonomy would be at the same low level formally and in actual fact if the reporting and assessment requirement regarding the annual report had been continued in 2008 . Contrary to the legislation, as of 2008 minVWS no longer submits an assessed annual report to Parliament. In general, legal autonomy is low due to determination rather than approval of budgets, the requirement to submit multiyear plans to the Minister-Principal and restrictions on the discussion on equalisation reserves. Neither a contract nor an ex ante budgeting instruction is given to prepare the following year's budget proposal. The CVZ budget is determined by minVWS and laid down in a budget letter with a summary of discussions on priorities for the next fiscal year. Within the economic dimension, contrasts are stronger. The overall effect shown is neutral but consists of factors which increase autonomy such as lack of separate approval for and disclosure of budgets, mitigated by lack of instructions, frequency of reporting to both Parliament as well as to the Minister-Principal.

In the case of RvR, legal autonomy also shows a reduction between formal and actual autonomy. Not submitting the annual report to Parliament both formally and in actual fact has a positive impact on autonomy, mitigated by restrictions on services to be provided as well as determination of budgets and annual reports by minJUS due to the funding arrangement chosen. The additional impact is found in the measure for treatment of receivables: rather than including them as receivables on the balance sheet, an equalisation reserve is created implying a future claim on minJUS for services delivered. This makes the legal arrangement that allows reallocation of equalisation reserves to projects practically useless due to a lack of resources. RvR's budget is based on a letter of instruction and resembles a service level contract based on price and volume, but effectively the level of budget approved in the Parliamentary budgeting process overrules actual levels and costs of production. In the economic dimension, some factors create additional autonomy (reporting of budget and annual report to Parliament) and some (responsibility centre type, practically lump sum funding and frequency of reporting to Parliament) have a negative effect on autonomy. The overall result is negative, again with internal inconsistencies.

SVB and UWV share the same economic and legal framework, resulting in the same formal position compared to standards. This means that formal legal autonomy is below standard levels and expected economic autonomy is at the standard level defined. For SVB, no changes are observed in the legal position; the additional degrees of freedom on services for other commissioners are mitigated by strict controls on budgets, reporting, the equalisation reserve and multiyear plans. UWV and SVB have to deal with a budget instruction at a given budget level and expected volumes of production. Performance standards are included on general levels but only for SZW related services. Economic 
autonomy is reduced compared to standards; again the option to deliver services to other commissioners increases autonomy, whereas detailed reporting and assessment of performance towards Parliament reduces autonomy.

In the UWV case, both legal and economic autonomy show a negative tendency. UWV's legal autonomy is further decreased by practical restrictions on services to other commissioners. In the economic dimension, UWV's autonomy is strongly diminished. Except for disclosure of budgets in departmental budget documents, actual controls are based on a discrete cost centre with high frequency of intermediate reporting to both Parliament and minister.

The two PLB-type income transfer ZBOs studied here show higher levels of both economic and legal autonomy compared to expected standards. This means that strong mismatches between the economic and legal perspective are not observed. However, formal and actual legal autonomy remains at the same general level, whereas in the economic dimension, additional increases in actual autonomy can be observed.

In the FBKVB case, legal autonomy is at a high level due to the funding system for the art funds which covers a four year period. This has an impact on approval of statements of accounts, approval of budgets and submitting annual reports to Parliament. It should be noted that these increases in autonomy are partially mitigated by controls outside the direct planning and control factors. MinOCW uses a detailed audit protocol for all institutions in the arts sector which also has to be applied to FBKVB. Economic autonomy increases above expected levels. Expected economic autonomy was only increased based on lower levels of reporting to minOCW. However, actual responsibility centre type is below expected levels whereas budget approval and budget disclosure controls and a lack of performance information towards Parliament are indicators for increased autonomy.

Finally, in the Vf/Pf case, actual autonomy increases slightly compared to expected and formal levels. This is a result of a mixture of strong economic controls laid down by minOCW and assessment of annual reports which affect autonomy negatively and increased autonomy in terms of responsibility centres and lack of budget and performance information towards Parliament. Positive factors slightly outnumber negative impacts and most elements diverge from the expected levels of autonomy.

From a legal perspective, there is a distinction between PLA and PLB ZBOs. The latter have a higher level of formal as well as observed autonomy. Except for SVB and UWV, the focus is mainly on the budget set by Ministers-Principal. In the SVB and UWV cases, budgets are also major controls but approval letters on the budgets do include performance levels. Therefore, budget approval letters tend to resemble an SLA based agreement. From an economic perspective, most budgets are lump sum rather than activity based; particularly in the CVZ case, even tending towards segregated budgets rather than a single lump sum budget. Investment budgets are not a real issue due to low 
levels of asset specificity. Furthermore, restructuring programs within organisations are authorised by the Minister-Principal and disclosed as earmarked reserves on a balance sheet.

The overall conclusion of this section is that mismatches are not found in terms of divergent trends in legal versus economic autonomy. All PLA type income transfer ZBOs tend to have reduced autonomy and thus more controls than given in the standards, whereas the PLB type income transfer ZBOs tend to have an increased level of autonomy compared to the standards. Only SVB shows in the observed control tools a match between legal and economic control tools; in all other cases a mismatch was observed, although not a full divergence between legal and economic control tools. Within the individual dimensions, contradictions can be found. In most cases reduced autonomy in terms of the responsibility centre type is observed, whereas information on budgets in departmental documents tends to indicate more autonomy. 


\section{Formal and actual autonomy of monitoring ZBOs}

\subsection{The legal dimension of autonomy}

In this chapter, the five ZBOs that have been classified as 'monitoring' ZBOs will be discussed. I recall that CFV is included in this group of ZBOs since the activities performed by this ZBO have shifted from merely income transfer to an industry monitoring institution which is also responsible for income transfers when required. Three ZBOs discussed here classify as market regulators (AFM, NMa, NZA). CFV is characterised by policy monitoring and income transfers. Finally, NAK can be qualified as a quality assurance ZBO, testing and certifying samples. These differences have an impact on the expected standard degrees of freedom, particularly from an economic perspective.

The structure of the chapter is similar to that for income transfer ZBOs: I will start with legal issues which impact on autonomy and then focus on the economic dimensions of autonomy. The chapter is concluded with a comparative overview on mismatches between legal and economic autonomy and relative autonomy of the 5 monitoring ZBOs selected.

Table 17.1: key data on monitoring ZBOs

\begin{tabular}{|c|c|c|c|c|c|}
\hline & AFM & CFV & NAK & NMa & $\mathrm{NZA}$ \\
\hline Legal entity & $\begin{array}{l}\text { PLB, } \\
\text { foundation }\end{array}$ & $\begin{array}{l}\text { PLA, } \\
\text { subsidiary }\end{array}$ & $\begin{array}{l}\text { PLB, } \\
\text { foundation }\end{array}$ & $\begin{array}{l}\text { PLA, } \\
\text { Shelter }\end{array}$ & $\begin{array}{l}\text { PLA, } \\
\text { subsidiary }\end{array}$ \\
\hline Funding & private & private & private & public & public \\
\hline $\begin{array}{l}\text { Operating revenues } \\
\text { in } € M 2008\end{array}$ & 78 & 6 & 27 & 44 & 30 \\
\hline
\end{tabular}

Four out of the five ZBOs selected here have a separate legal status. The fifth, NMa, has no separate legal status but is part of the legal entity State. I refer to section 15.2.2 for more details on the creation of NMa. Here, it is sufficient to state that ownership is in the hands of minEZ. Key data on the five ZBOs are presented in Table 17.1. 


\subsubsection{AFM}

In its letter on implementing kZBO (Parliament, 2008w), minFin announced that he would submit a proposal to change relevant legislation in line with kZBO after evaluation of the relevant law on financial monitoring [Wet op het financieel toezicht; WFT] in early 2010. In the same letter, minFin announced he would exclude the measures for setting of policy rules by minFin, annulling measures and creating an equalisation reserve in the future legal framework with respect to AFM.

\subsubsection{Normative measures}

AFM is a PLB-type ZBO, which implies that normative measures to govern the relationship between minister and AFM staff are not required within the kZBO-framework.

Legislation or statutes do not include an explicit prohibition on appointing civil servants. One can argue that AFM's statutes implicitly address the prohibition by stating that board members operate fully independently and without any instructions from third parties. In practice, civil servants are not appointed although board members were former civil servants or even former ministers.

The data protection measure in kZBO are not explicitly included in WFT. Both statutes as well as WFT include explicit measures on confidential information which imply that AFM has to ensure confidentiality. These measures have no impact on operational autonomy.

\subsubsection{Information measures}

Deviations on information measures can be found in ministerial consent to the annual report rather than approval, not directly submitting the annual report to Parliament and the separate accounts requirement of kZBO:38. MinFin receives AFM's annual report including the statement of accounts. Furthermore, minFin has a general right of inquiry.

Ministerial consent rather than ministerial approval of annual reports is based on the division of authority between executive board, non-executive board and minister. I will discuss details of the governance provisions in the following sub-section. It is the nonexecutive board which has been the power to approve annual reports. Practice is in line with formal provisions and has a positive impact on autonomy.

AFM's annual report is submitted to minFin and minFin is required to submit the annual report to Parliament. The wording of WFT separates annual report (WFT:1:36) and statement of accounts (WFT:1:33). In practice, the full document is sent to Parliament, without comments from minFin (e.g. Parliament, 2009i). This procedure implies that no impact on autonomy compared to the kZBO-framework is observed.

The requirement of $k Z B O: 38$ on separate accounts focuses on PLBs that deliver public and private services simultaneously. This is not the case for AFM. However, AFM's funding is based on a separation of costs of activities for groups of monitored institutions. Each of these groups pays its own fees. Interviewees indicated that fees can only be charged if the group being monitored benefits from the monitoring system. Repressive 
monitoring is to be funded by government. The basis for this arrangement is found in a research document on allocation of monitoring costs. The main principles were officially published in 2000 (Staatscourant, 2000). In practice it means that some form of separation of costs is required, which is reflected in AFM's budget documents and annual reports. This practice means that a reduction of autonomy can be observed, AFM cannot simply reallocate costs to a particular group of monitored institutions.

\subsubsection{Governance provisions}

MinFin appoints AFM's executive board based on a proposal from AFM's non-executive board. MinFin can ignore the non-executive board proposal but interviewees indicated that minFin's role in relation to the executive and non-executive board is limited to last resort decision making. An interviewee indicated that appointments to the board are coordinated on the initiative of AFM before a formal proposal is submitted. This means that the formal arrangements for appointing the board reduce autonomy and in practice minFin does have power to influence a proposal for the AFM non-executive board. In a letter to Parliament on the governance structure, it was explicitly stated that AFM's nonexecutive board is primarily responsible for operations (Parliament, 2003d, p. 19-21) and according to the interviewees minFin is responsible for the institutional setting and monitoring framework. The institutional setting is completed by an advisory panel in which all stakeholders are represented. This panel focuses on costs, new policy rules and administrative burdens resulting from the monitoring process (Parliament, 2003d, p. 1921). MinFin has the right to dismiss members of the (non-) executive board; incompatible jobs are mentioned for both executive and non-executive board within the statutes. This is an additional restriction from a kZBO perspective: the kZBO:13 provision on secondary jobs is only aimed at PLA-type ZBOs and therefore there is a reduction in AFM's autonomy. Overall, the main governance structure of AFM implies that the authority of minFin with respect to governance is reduced from a kZBO perspective.

The law (WFT:1:26.4) stipulates that minFin only consents to remuneration rather than deciding upon remuneration. Again this is due to the differences in governance structure, and in line with kZBO:14 in which it is stipulated that a minister only determines remuneration for PLA type ZBOs. However, minFin has been actively involved in reducing remuneration of the board (minFin, 2007b) by discussing the subject with the non-executive board. Remuneration is disclosed in AFM's 2007 and 2008 annual reports.

Interviewees indicate that the role of the non-executive board is also relevant in cases of negligence. Formally, minFin has a role but respondents indicated that intervention by minfin would have a serious impact on markets and is therefore unlikely.

Financing and treasury management are the only asset related transactions which are specifically addressed. Like most ZBOs, AFM has to borrow and lend using minFin's facilities. Most asset related transactions are not explicitly covered in WFT, but in statutes. This means effectively that the non-executive board approves the decisions of the executive board. This is in line with kZBO measures which only stipulate asset related transactions as optional measures. Only in the event of bankruptcy and dissolution of 
AFM, does minFin have a role in deciding upon the remaining resources. A formal distinction is drawn between bankruptcy and dissolution. In the case of dissolution, explicit approval by minFin must be given, whereas in case of bankruptcy minFin has no formal role in the decision. The dissolution and bankruptcy provisions reduce autonomy on this issue from two perspectives: first, kZBO:32 is merely an optional measure. Including it in statutes therefore means that a restriction is created. Secondly, in a normal foundation, the (non-) executive board would have the power to decide on reallocation of remaining resources rather than minFin. Of course, bankruptcy and dissolution measures have not been used in practice.

In 2007-2008 minFin has the authority to annul AFM decisions. This authority is however restricted to the requirement that only general regulations set by AFM can be annulled on the condition that minFin issues a decree governing the issue at hand (WFT:1:29). A measure like this is in line with the idea of the kZBO measure (Parliament, $2000 d$, p. 27). One can argue that it restricts the autonomy of AFM due to the fact that minfin has to issue a decree; one can also argue that as it only concerns general regulations, AFM is immune to interventions on a case basis and thus has more autonomy than under the general kZBO:22 provisions. According to the interviewees in practice the measure is another ultimum remedium, which is very unlikely to be used. Impact on autonomy is thus minimal if any. In the proposal for changes as a result of the implementation of kZBO, the kZBO:22 measure is to be excluded given the international regulatory setting in which AFM operates (Parliament, 2008w) and because annulling a decision would not be in line with the impartial position AFM holds towards government. As a result, AFM's formal autonomy will increase, though materially nothing will change.

\subsubsection{Cyclical measures}

The governance structure of AFM also has an impact on cyclical measures. MinFin does not approve budgets and statements of accounts, it merely consents to them. Cyclical measures such as reporting on differences and decision making by the board on the budgets are in line with kZBO. An additional requirement in the budgeting process is that the advisory panel has to be consulted (WFT:1:39) but this does not affect the decision making position of the executive board and thus does not affect autonomy.

With respect to fees WFT states that minFin determines rather than approves fees. Calculating fees is based on separate decrees. The fee is based on relevant cost and includes an arrangement for compensation for financial penalties imposed by AFM on the financial industry. Some interviewees indicated that this is part of an arrangement to compensate the financial industry for activities they perform on behalf of government free of charge.202 The restrictions on calculating fees reduces AFM autonomy in determining fee levels.

Formal budget structure rules do not exist, although WFT allows for such rules. Respondents indicated that at minFin's request the budget is set up based on the

202 In particular reporting of irregular financial transactions was mentioned. 
principles of the VBTB model used in government. From a practical perspective, the budget is split up into sub-budgets for the different sub-groups of monitored institutions. MinFin only consents to the budget proposal from AFM's non-executive board. Some interviewees indicated that approval is given, but the publication of AFM's budget explicitly uses consent. If the budget as a whole was privately funded by fees, consent would be logical given the determination of fees by minFin. A substantial part of the budget consists of activities on behalf of the general public, covered by government funding. Therefore approval of the budget would be in line with kZBO measures. Present measures and practices thus suggest some additional autonomy for AFM.

A last point to be made is that formally AFM is allowed to create equity due to a net income result. This is in line with kZBO:33. In practice, interviewees indicated that net income is included in the calculation of fees to be determined for the next fiscal year. This means that in practice, autonomy of AFM on creating reserves is reduced.

\subsubsection{Conclusion}

Overall, AFM's autonomy is reduced both formally and in reality. Key explanations are the measures which relate to appointment and remuneration of the board and the restrictions on fees and equalisation reserves, which are partially the result of pressure from stakeholders. 
Table 17.2: Legal measures on AFM, formally or actually deviating from kZBO.

\begin{tabular}{|c|c|c|c|c|c|c|}
\hline Authority issue & $\begin{array}{l}\text { Authority } \\
\text { Group }\end{array}$ & $\begin{array}{l}\text { reference } \\
\text { kZBO }\end{array}$ & reference case law & Actual practice & $\begin{array}{l}\text { formal } \\
\text { mismatch } \\
\text { and impact }\end{array}$ & $\begin{array}{l}\text { actual } \\
\text { mismatch } \\
\text { and impact }\end{array}$ \\
\hline Not appointing civil servant in board & Normative & 9 & $\begin{array}{l}\text { Statutes 5.1.c } \\
\text { independency }\end{array}$ & No civil servants appointed & 0 & 0 \\
\hline Measure on appointment of staff & Normative & 15 & none & Civil law appointments & 0 & 0 \\
\hline Data protection measure & Normative & 41 & $\begin{array}{l}\text { Statutes:17 } \\
\text { WFT:1:89-1:93a }\end{array}$ & In line with legislation & 0 & 0 \\
\hline $\begin{array}{l}\text { Submit annual report to Minister and } \\
\text { Parliament. }\end{array}$ & Information & 18 & $\begin{array}{l}\text { submitted by minister; } \\
\text { WFT:1.36.2 }\end{array}$ & $\begin{array}{l}\text { Officially and electronically published; } \\
\text { WFT1:33 }\end{array}$ & 0 & 0 \\
\hline Approval of statement of accounts & Information & 34 & consent; WFT:1:30.4 & $\begin{array}{l}\text { Consent, Approval by non executive } \\
\text { board }\end{array}$ & 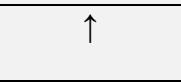 & $\uparrow$ \\
\hline Requirement for separate accounts & Information & 38 & $\begin{array}{l}\text { WFT:1:40; BBFT: } 6 \text { separate } \\
\text { accounts for public activities }\end{array}$ & in line with case law & $\downarrow$ & $\downarrow$ \\
\hline Multiple bodies & Governance & 7 & $\begin{array}{l}\text { Statutes:6 } \\
\text { WFT:1:26 }\end{array}$ & $\begin{array}{l}\text { Power attributed to non-executive } \\
\text { board and advisory panel }\end{array}$ & $\uparrow$ & $\uparrow$ \\
\hline Appointment of board & Governance & 12 & Statutes:4 & $\begin{array}{l}\text { Minister appoints on proposal non- } \\
\text { executive board and is heard informally }\end{array}$ & $\downarrow$ & $\downarrow$ \\
\hline $\begin{array}{l}\text { Measure on secondary jobs of Board } \\
\text { members }\end{array}$ & Governance & 13 & Statutes:5; 10 & In line with statutes & $\downarrow$ & $\downarrow$ \\
\hline $\begin{array}{l}\text { Decision on and disclosure of } \\
\text { remuneration }\end{array}$ & Governance & $\begin{array}{l}\text { kZBO:14 } \\
\text { WOPT:6 }\end{array}$ & $\begin{array}{l}\text { WFT:1:26.4; ministerial } \\
\text { consent }\end{array}$ & $\begin{array}{l}\text { Reported in annual reports, active } \\
\text { involvement of minFin in remuneration }\end{array}$ & 0 & $\downarrow$ \\
\hline Intervention in case of negligence & Governance & 23 & WFT:1:43 & $\begin{array}{l}\text { Ultimum remedium tool, unlikely to be } \\
\text { used. Primary role non-executive board }\end{array}$ & 0 & 0 \\
\hline $\begin{array}{l}\text { Asset related transactions: borrowing } \\
\text { and lending }\end{array}$ & Governance & $32 d$ & CW2001:45 & In line with CW2001 & 0 & 0 \\
\hline Asset related transactions & Governance & 32a-c; e-f & $\begin{array}{l}\text { Statutes: } 6.4 \text {, except for } \\
\text { creating reserves }\end{array}$ & $\begin{array}{l}\text { In line with authority non executive } \\
\text { board; including reserves. }\end{array}$ & 0 & 0 \\
\hline Asset related transactions: bankruptcy & Governance & $32 g$ & Statutes:19 & Not applied in practice & $\downarrow$ & 0 \\
\hline $\begin{array}{l}\text { Asset related transactions: } \\
\text { dissolving entity }\end{array}$ & Governance & none & $\begin{array}{l}\text { Statutes:19 Minister approves } \\
\text { and decides upon use of } \\
\text { remaining resources }\end{array}$ & Not applied in practice & $\downarrow$ & 0 \\
\hline Approval of fees & Cyclical & 17 & WFT:1:40 & Minister determines fees & $\downarrow$ & $\downarrow$ \\
\hline Approval of budget & Cyclical & 29 & Statutes:6 & Minister consents & $\uparrow$ & $\uparrow$ \\
\hline Creating equalisation reserve & Cyclical & 33 & WFT:1:35 net income & $\begin{array}{l}\text { Agreement with stakeholders to use net } \\
\text { income to decrees future fees; } \\
\text { WFT:1:35.2 }\end{array}$ & $\downarrow$ & $\downarrow$ \\
\hline
\end{tabular}




\subsubsection{CFV}

In her letter on implementation of KZBO, minWWI announced she would introduce a new governance code for CFV including a non-executive board (Parliament, 2008x). By January 2010, no proposals to change the relevant legislation had yet been submitted.

MinWWI is currently (2008) regarded as the Minister-Principal for CFV. Interviewees noted that the minister's position on 'ownership' responsibility is not as straightforward as in other cases. This is due to the history of CFV and according to respondents is reflected by stakeholder representation on the board. Furthermore, respondents indicated that (excess) equity in CFV will not automatically be transferred to minWWI.

\subsubsection{Normative measures}

CFV is a PLA type ZBO. Except for a data protection provision, the normative measures on the relationship between minister and staff and exclusion of appointing civil servants in the executive board are covered in the ZBO case law. MinWWI is allowed to issue general instructions on policy rules which has been implemented by a separate decree 'Besluit Centraal Fonds voor de Volkshuisvesting' [BCFV].

Absence of data protection measure was not explicitly discussed, but one of the interviewees mentioned that providing information is one of the core activities of CFV and is in line with cabinet policy. In the internal regulations on the board, an explicit confidentiality arrangement is included. The confidentiality arrangement covers use of information, not the technical aspects of data protection as meant by kZBO:41. Without formal measure on technical data protection, CFV's autonomy increases compared to the kZBO standard. The monitoring framework document on CFV (minVROM, 2006, p. 15) announced that kZBO:41 will be implemented for CFV. Materially this implies that CFV is expected to organise technical data protection and thus from a kZBO standard, there is no impact on autonomy.

\subsubsection{Information measures}

The CFV legislation includes measures for submitting annual reports to minWWI, a general right of inquiry and rules on the structure of the statement of accounts including auditing requirements. The relevant regulation on auditing is an open standard referring to BW2 and requires some explicit compliance testing. The Woningwet (law on housing) does not formally include measures on approving annual reports. In her letter on the 2006 annual report, minWWI approved the statement of accounts 'in anticipation of changes in the law' (minWWI, 2007a). In the monitoring framework on CFV, it is suggested that the measures then current already allowed for approval of annual reports (MinVROM, 2006, p. 18). However, I did not find such measures and the letter of minWWI also suggests that no approval rights had been formally institutionalised. Effectively, this means that compared to kZBO, no impact on autonomy can be observed. 


\subsubsection{Governance provisions}

CFV is managed by a one tier board and a managing director. The relationship between board and managing director resembles that of a two tier board given the statute of the board and the mandate to the managing director. A report on the future organisation of CFV (Schilder Committee, 2006, p. 41) suggested creating a non-executive board in line with the governance structure of AFM. Interviewees indicated that this might be implemented in the future. The letter from minWWI on implementation of kZBO (Parliament, 2008x) explicitly refers to a future two tier board. Effectively, no changes in governance structure had been implemented by the end of 2008 . The fact that this change in governance structure has not yet been implemented, given the discussion on two tier boards, has no formal impact on autonomy from a basic kZBO perspective. From the CFV perspective it does however mean that formalising an increase in autonomy has been delayed. In practice CFV operates as if a two tier board exists, which effectively means that autonomy is at a higher level than the kZBO standard.

MinWWI has included measures on secondary jobs in the law, generally referring to stakeholders in CFV including civil servants. The wording of Woningwet:71c. 4 consists of a limiting list of incompatibilities. This suggests additional autonomy because kZBO wording addresses incompatibilities in an open standard, which means that a case based assessment is needed (KZBO:13.1). Board members are selected on a particular preset profile (internal governance statute, articles 1 and 3). The latter can also be regarded as a safeguard against incompatibilities. Board member secondary jobs are disclosed in the annual reports. No provision is included for reporting secondary jobs once a board member has been appointed. The overall perspective is that degrees of freedom do exist compared to the basic kZBO arrangements.

According to kZBO:14 board remuneration is determined by minWWI. The internal governance statute (article 17) stipulates that the board decides on remuneration and minWWI approves the decision of the board. Furthermore, the board decides upon the remuneration of the managing director without further approval by minWWI (management statute, article 1). These arrangements generates some additional autonomy for CFV. MinWWI monitors remuneration critically and referred to remuneration standards based on the Dijkstal Committee reports (minWWI, 2007a). In the 2007 and 2008 annual reports remuneration of board and managing director are disclosed in line with WOPT requirements. In both cases, it was explicitly stated that no financial arrangements exist in the event of dismissal of management. Despite minWWl's warnings in 2007, the board was able to increase management remuneration above the remuneration standards. This, and the fact that the board rather than minWWI decides on remuneration are indications for increased autonomy compared to kZBO standards. 
Table 17.3: Legal measures on CFV, formally or actually diverging from kZBO.

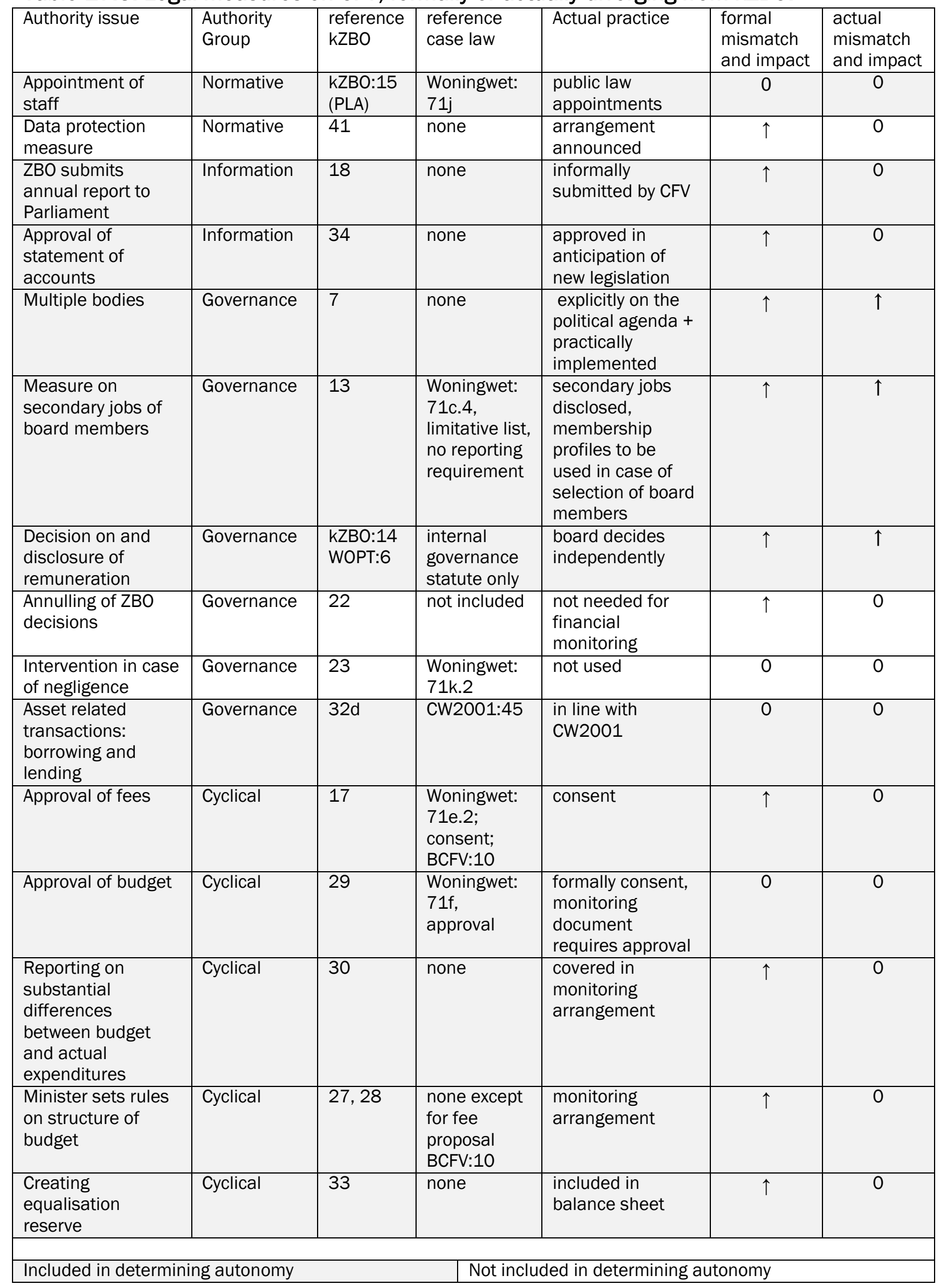


In the event of negligence, minWWI can suspend or dismiss the executive board. This is in line with kZBO measures. In addition to kZBO - which merely specifies that the minister has to act - an explicit measure on continuation of CFV activities is defined. In the CFV case, minWWI has to temporarily take over operations and the costs will be charged to CFV (Woningwet:71k.2). The CFV arrangement does not affect autonomy because compared to the basic kZBO case, how to act in particular cases is made explicit and thus contributes to transparency. Interviewees did not recall any interventions by minWWI with respect to negligence.

The issue of annulling ZBO decisions is not covered in the CFV case law. Interviewees indicated that CFV has no formal decision making role with respect to social housing associations, except for a decision on financial support. Financial support criteria are set in relevant case law. With respect to its monitoring activities, CFV generates the relevant data and assesses it, but it is up to minWWI to finally decide upon actions, including licensing of social housing associations. Furthermore, a debate continues on the monitoring role of CFV, particularly on whether the social housing sector should be monitored horizontally or vertically (as is practically the case). The issue of annulling is not excluded in the suggested changes due to kZBO. Effectively, the impact of the lack of a annulling arrangement on autonomy seems minimal.

Other governance arrangements are in line with kZBO practices. MinWWI has the power to approve internal governance statutes, appoints the board and can intervene in case of negligence. On asset related transactions, only the lending and borrowing provision under CW2001:45 is applicable. There are no other asset transaction related restrictions and given the optional character of such restrictions, there is no impact on autonomy. An interviewee commented that if asset related transactions were relevant, they would be included in the budget document and as a result be indirectly (dis)approved.

\subsubsection{Cyclical measures}

The last group of legal measures concerns cyclical measures. Decision making on the budget is in line with kZBO measures: the board decides and minWWI approves the budget. MinWWI does not approve the fees levied by CFV but only consents. In this case consent is sufficient because the decree CFV [BCFV] includes specific instructions as to how the fee is to be determined. This includes the requirement that the sum of the fees must cover the total budget. As the budget is approved by minWWI, approval of fees would thus imply a double approval of the budget (Woningwet:71e; BCFV:10). Interviewees note that the budget covers all CFV costs, including program costs due to income transfers. In practice the level of income transfers has been nil for several years, which means that CFV's annual budget actually covers costs of operations. Given the relationship between approval of the budget and the description of calculation methods for fees to be charged, ministerial consent rather than approval of fees does not have an impact on CFV's autonomy. In her letter on the 2008 budget, minWWI consents rather than approves the budget. It could not be clarified whether this was a deliberate choice or 
an error in wording as the letter also consents to the level of fees set at nil (minWWI, 2007b). Based on the wordings used in the internal minVROM monitoring document, approval for the budget should be given (minVROM, 2006, p. 11). I therefore conclude that practices are in line with formal measures.

There are no formal measures given on frequency of reporting, reporting on substantial differences and budget structure. Woningwet:71f.3 allows rules to be set for the budget structure, but this has not been carried out. In the minWWI monitoring document reporting and budget structure measures are given, which means that in practice an arrangement exists.

MinWWI did not claim exceptions to the kZBO framework for cyclical measures (Parliament, 2008x). Implicitly all cyclical measures should therefore be applied in the future. There is an equalisation reserve for operations on CFV's balance sheet, but this is not based on a formal arrangement. Furthermore, interviewees indicated that there are no limitations laid down on the equalisation reserve. From a legal perspective, this means that CFV has autonomy in line with kZBO.

\subsubsection{Conclusion}

The overall impression on the legal autonomy of CFV is that CFV has increased autonomy on issues relating to the board, information structure and on cyclical measures. In practice most of the degrees of freedom are mitigated, particularly concerning cyclical measures. Only on appointment of the board and related issues such as secondary jobs and remuneration is autonomy in practice at a higher level than prescribed by kZBO. 


\subsubsection{NAK}

MinLNV announced in her letter on implementation of kZBO that she would fully apply kZBO to monitoring institutions (Parliament, 2008y). As of January 1, 2010 ZPW has been changed by simply stating that kZBO applies to the monitoring institutions (ZPW2005:24).

\subsubsection{Normative measures}

NAK is a PLB type ZBO which means that arrangements on the position of its staff towards the minister are not applicable. NAK statutes and legislation do not cover these issues. The same holds for the provision that a member of the board cannot be a civil servant. Interviewees indicated that in the past, civil servants were members of the board, but this practice has ended. In the present law on the agricultural monitoring institutions there is an explicit measure to ensure technical data protection as meant by kZBO:41. In practice this means that there is no impact on autonomy compared to the kZBO-framework found in normative measures.

\subsubsection{Information measures}

NAK submits its annual reports to minLNV based on provisions of ZPW2005:9. This article also requires the annual report to be submitted directly to Parliament. Interviewees indicated that this is not actual practice: Parliament neither formally nor informally receives annual reports from NAK. MinLNV has to approve the annual reports. This arrangement is based on the statutes rather than formal legislation. In the former ZPW1966, several requirements were included on the contents of statutes but not on approval of statements of accounts. In the monitoring protocol based on ZPW1966 (June 2004) reference is made to approval of statements of accounts, 'in anticipation of the new ZPW (i.e. ZPW 2005, jdk) and kZBO'. Effectively minLNV approves statements of accounts with a focus on performance information rather than financial information ${ }^{203}$, which means that NAK autonomy increases.

Finally, legislation requires separate accounting for ZBO activities. This regulation was relevant until the formal separation of NAK and NAK-AGRO as of July 2008. Since July 2008, NAK has only been allowed to provide ZBO services which makes separate accounts obsolete. Of course separation of the two entities affects autonomy of the 'old' NAK-organisation, but the requirement to use separate accounts is in line with kZBO.

\subsubsection{Governance provisions}

NAK's governance structure is based on a one tier board with a managing director. In the statutes, it is stipulated that management is responsible for daily operations, "under supervision' of the board. The board has authoritative powers such as determining fees and regulations, which result in a hybrid structure of monitoring and decision making within one and the same body of the organisation. Interviewees indicated that an advisory board is used which operates as NAK's interface to the agricultural industry. No special

203 Only staff budget is explicitly mentioned. 
arrangements on this advisory board exist, except that the statutes include creation of an advisory board by the NAK board, increasing autonomy.

Ex ante approval of mandates is not explicitly covered in legislation or in practice. The wording of ZPW2005:19 allows only a limited list of activities, which also means that no other mandates can be given. This is emphasised by the debate on separation of public and private services and thus results in a restriction of autonomy.

The only other formalised governance provisions are intervention in the event of negligence and annulling of ZBO decisions (kZBO:22). These minLNV powers have not been used on NAK, but interviewees indicated that in the 1990ies, in exceptional cases minLNV has exerted substantial pressure using the civil servants on the boards of the agricultural monitoring institutions to change some of their procedures.

Measures for approving internal governance structures, (re) appointment and dismissal of the board, measures on secondary jobs and remuneration of the board in kZBO only address PLA type ZBOs. NAK's statutes include an arrangement on approval of the appointment and dismissal of the president of the board by minLNV. After consulting the president other members are selected from representatives of NAK's stakeholders. The ex ante approval arrangement thus has a negative impact on autonomy from the kZBO framework. On the issue of remuneration, autonomy seems to increase. NAK is not subject to ministerial decisions on remuneration of the board given its PLB status. Based on WOPT, NAK has to disclose remuneration. In practice, information on remuneration was not filed for fiscal 2008 (minBZK 2009b). It is thus not possible to assess remuneration which is an indication for increased autonomy.

Ministerial consent on lending and borrowing is not included in the legal framework, but NAK is subject to CW2001:45.2 in which restrictions on lending and borrowing from the market are included. Compared to the standard rule of CW2001:45.1 which covers most ZBOs, NAK experiences increased autonomy. The other asset related measures except for use of reserves are not included in legislation or statutes. Practically, reserves are treated as equalisation reserves and will be discussed in the section on cyclical measures. According to interviewees the lack of a provision on creating legal entities resulted in NAK being able to create a company without prior knowledge or consent by minLNV. Because kZBO:32 is an optional measure, no impact on autonomy can be observed. Statutes do include a liquidation measure - not covered in kZBO - which requires ministerial consent. This provision theoretically has a negative impact on autonomy given the kZBO measures, but has of course not been used yet. 
Table 17.4: Legal measures on NAK, formally or actually diverging from kZBO.

\begin{tabular}{|c|c|c|c|c|c|c|}
\hline Authority issue & $\begin{array}{l}\text { Authority } \\
\text { Group }\end{array}$ & $\begin{array}{l}\text { reference } \\
\text { kZBO }\end{array}$ & $\begin{array}{l}\text { reference } \\
\text { case law }\end{array}$ & Actual practice & $\begin{array}{l}\text { formal } \\
\text { mismatch } \\
\text { and impact }\end{array}$ & $\begin{array}{l}\text { actual } \\
\text { mismatch } \\
\text { and impact }\end{array}$ \\
\hline $\begin{array}{l}\text { Not appointing civil } \\
\text { servants to board }\end{array}$ & Normative & 9 & none & $\begin{array}{l}\text { no civil } \\
\text { servants } \\
\text { appointed }\end{array}$ & 0 & 0 \\
\hline $\begin{array}{l}\text { Submit annual report } \\
\text { to Parliament }\end{array}$ & Information & 18 & $\begin{array}{l}\text { ZPW2005: } \\
9.2\end{array}$ & not performed & 0 & $\uparrow$ \\
\hline $\begin{array}{l}\text { Approval of statement } \\
\text { of accounts }\end{array}$ & Information & 34 & $\begin{array}{l}\text { Statutes:1 } \\
7.5\end{array}$ & $\begin{array}{l}\text { approved by } \\
\text { minLNV, focus } \\
\text { on } \\
\text { performance }\end{array}$ & 0 & $\uparrow$ \\
\hline $\begin{array}{l}\text { Requirement to } \\
\text { separate accounts for } \\
\text { ZBO activities and non- } \\
\text { ZBO-activities }\end{array}$ & Information & 38 & $\begin{array}{l}\text { ZPW2005: } \\
23\end{array}$ & $\begin{array}{l}\text { used, but } \\
\text { obsolete as of } \\
\text { July } 2008\end{array}$ & 0 & 0 \\
\hline Multiple bodies & Governance & 7 & none & $\begin{array}{l}\text { statutes allow } \\
\text { advisory } \\
\text { committees }\end{array}$ & $\uparrow$ & $\uparrow$ \\
\hline $\begin{array}{l}\text { Ex ante approval by } \\
\text { minister for mandates } \\
\text { to the ZBO }\end{array}$ & Governance & 8 & $\begin{array}{l}\text { ZPW2005: } \\
19 \text { limited } \\
\text { services }\end{array}$ & $\begin{array}{l}\text { none; but only } \\
\text { public services } \\
\text { allowed }\end{array}$ & $\downarrow$ & $\downarrow$ \\
\hline $\begin{array}{l}\text { (re)appointment and } \\
\text { dismissal of board }\end{array}$ & Governance & 12 & $\begin{array}{l}\text { Statutes:5. } \\
2\end{array}$ & $\begin{array}{l}\text { ex ante } \\
\text { approval only } \\
\text { for president } \\
\text { of board }\end{array}$ & $\downarrow$ & $\downarrow$ \\
\hline $\begin{array}{l}\text { Decision on and } \\
\text { disclosure of } \\
\text { remuneration }\end{array}$ & Governance & $\begin{array}{l}\text { kZBO:14 } \\
\text { WOPT:6 }\end{array}$ & none & $\begin{array}{l}\text { not disclosed; } \\
\text { mentioned in } \\
\text { WOPT non- } \\
\text { response } \\
\text { document }\end{array}$ & 0 & $\uparrow$ \\
\hline $\begin{array}{l}\text { Intervention in case of } \\
\text { negligence }\end{array}$ & Governance & 23 & none & $\begin{array}{l}\text { not used or } \\
\text { likely to be } \\
\text { used }\end{array}$ & $\uparrow$ & 0 \\
\hline $\begin{array}{l}\text { Asset related } \\
\text { transactions: } \\
\text { borrowing and lending }\end{array}$ & Governance & $32 d$ & $\begin{array}{l}\text { CW2001: } \\
45.2\end{array}$ & $\begin{array}{l}\text { in line with } \\
\text { CW2001:45.2 }\end{array}$ & $\uparrow$ & $\uparrow$ \\
\hline $\begin{array}{l}\text { Asset related } \\
\text { transactions: others }\end{array}$ & Governance & $\begin{array}{l}32 \mathrm{a}-\mathrm{c} ; \\
32 \mathrm{e}-\mathrm{g}\end{array}$ & none & $\begin{array}{l}\text { creating legal } \\
\text { entity was } \\
\text { realised }\end{array}$ & 0 & 0 \\
\hline $\begin{array}{l}\text { Asset related } \\
\text { transactions: } \\
\text { dissolving entity }\end{array}$ & Governance & none & $\begin{array}{l}\text { Statutes: } \\
19.3\end{array}$ & $\begin{array}{l}\text { not likely to be } \\
\text { applied }\end{array}$ & $\downarrow$ & 0 \\
\hline $\begin{array}{l}\text { Minister sets rules on } \\
\text { structure of budget }\end{array}$ & Cyclical & 27,28 & none & $\begin{array}{l}\text { no } \\
\text { arrangements } \\
\text { with minLNV }\end{array}$ & $\uparrow$ & $\uparrow$ \\
\hline Approval of budget & Cyclical & 29 & none & $\begin{array}{l}\text { realised based } \\
\text { on fees, } \\
\text { submitted for } \\
\text { information }\end{array}$ & $\uparrow$ & 0 \\
\hline Approval of fees & Cyclical & 17 & $\begin{array}{l}\text { ZPW2005: } \\
21\end{array}$ & $\begin{array}{l}\text { approved by } \\
\text { minLNV }\end{array}$ & 0 & 0 \\
\hline $\begin{array}{l}\text { Creating equalisation } \\
\text { reserve }\end{array}$ & Cyclical & 33 & $\begin{array}{l}\text { statutes17 } \\
.2 \text { and } \\
\text { control } \\
\text { agreement }\end{array}$ & $\begin{array}{l}\text { in line with } \\
\text { control } \\
\text { agreement } \\
\text { and actually } \\
\text { used }\end{array}$ & 0 & 0 \\
\hline \multicolumn{3}{|c|}{ Included in determining autonomy } & \multicolumn{4}{|c|}{ Not included in determining autonomy } \\
\hline
\end{tabular}




\subsubsection{Cyclical measures}

The key cyclical provision for NAK is the approval of fees by minLNV. The budget is not approved and not mentioned in ZPW2005.204 NAK's statutes include a rule that the budget as approved by the board has to be brought to the attention of minLNV. The information agreement mentioned before requires a budget to be submitted, but again no approval requirements are found. A separate letter sent in June 2007 by minLNV discloses assessment criteria for the level of fees proposed by NAK (minLNV, 2007). Interviewees indicated that these criteria restrict autonomy compared to the previously used procedures, but they only address systematic calculation of fees. Other financial technical instructions with respect to preparation of the budget such as the level of interest or inflation are not given according to the interviewees. As NAK is fully funded by fees, the impact on autonomy of the absence of budget approval is minimal. Furthermore, no standards for the structure of the budget (kZBO:27-28) are given. Interviewees indicated that investment decisions (kZBO:27a) are left to the board and not covered in separate agreements with minLNV. This means that NAK has increased autonomy on preparation of the budget compared to kZBO-standards.

Measures on equalisation reserves are included in the statutes rather than the formal law. Other reserves may be used, but in practice reserves are regarded as one line item in the balance sheet in discussions with minLNV. The letter on assessment of the calculation of fees includes a maximum level of $50 \%$ of annual sales for reserves. From a kZBO:33 perspective, the arrangement is in line, although the level of reserves is high and according to interviewees required due to uncertainty in agricultural production.

\subsubsection{Conclusion}

In general, the conclusion on the legal setting of NAK is that formal autonomy is reduced on other activities and appointment of the (president) of the board. Increases in formal autonomy exist in borrowing and lending procedures as well on budget measures. Actual autonomy is above the expected level of autonomy. The main reasons are to do with controls on the annual report and statements of accounts as well as on remuneration.

204 ZPW2005 includes a budget arrangement for other entities but that article is explicitly excluded for the quality assurance ZBOs. 


\subsubsection{NMa}

NMa is a PLA type ZBO, but has no separate legal status. Hence it qualifies as a 'Shelter ZBO'. In her letter on implementation of kZBO, minEZ announced she will apply kZBO to $\mathrm{NMa}$, except for the accruals accounting (KZBO:27) measures and the annulment provision (kZBO:22). On January 1, 2010, legislation to change relevant legislation (MW) was underway in Parliament (Parliament, 2009j) and will be effective as of January 1, 2011.

\subsubsection{Normative measures}

In MW, no explicit measure prohibiting the appointment of civil servants to the board are included. In practice, civil servants are not appointed. Normative measures on subordination of staff to the board, legal position of staff and setting policy rules are all included in legislation. I recall that the provision on subordination of staff is particularly relevant in this case since the staff formally consists of civil servants made available to the NMa board (MW:5a). The conclusion is that normative measures have no impact on autonomy compared to the kZBO framework.

\subsubsection{Information measures}

Most of the information measures are explicitly included in MW. The requirement to use separate accounts (KZBO:38) is not relevant given the PLA status of NMa. Because NMa is a Shelter ZBO, kZBO:34 on approval of statements of accounts is not applicable. Effectively this means that minEZ determines NMa's financial statements. Some respondents indicated that this does not affect the autonomy of NMa. At the final stage of determining or approving statements of accounts autonomy may not be affected, but during operations actual practice is different. This will be discussed in section 17.2.4.2.

NMa does not submit its annual report to Parliament. In MW:5g, it is stipulated that the annual report is submitted to minEZ and that minEZ is required to submit the annual report including assessment to Parliament. This arrangement is stronger than the basic arrangement in kZBO:18. It does not affect autonomy immediately, because it has an impact on the Minister-Parliament relationship. However, an effect may be observed indirectly because Parliament has a direct opportunity to discuss the assessment with minEZ.

Interviewees indicated that discussions in Parliament on annual reports focus on policy rather than the financial position of NMa. Interviewees also indicated that informal discussions between MPs and the executive board of NMa are sometimes organised. In these cases, minEZ has prior knowledge of such meetings. 205 The fact that such meetings are allowed is an indication of the increased autonomy of the NMa board.

205 Formal meetings between Parliament and Executive Boards of ZBOs regarding accountability are not usual in the Dutch political system (Scheltema Committee, 1993, p. 23). 


\subsubsection{Governance provisions}

The ZBO status of NMa is formally attributed to the board only. This means that no measures on the relationships between different bodies are required. NMa not only provides competition services on behalf of minEZ. Present legislation covers arrangements for minEZ to grant approval for services to be delivered on behalf of other ministries. The competition law explicitly mentions activities of NMa with respect to power supply, but it also concerns competition in (public) transport (source: website NMa) as well as in the health and care sector (e.g. Parliament, 2007x, p. 4). The provision of $\mathrm{MW}: 5 a$ is therefore in line with kZBO:8 and does not affect autonomy.

The provisions on appointments to the board, secondary jobs and on the internal governance statutes all apply to NMa. On the issue of remuneration, minEZ determines remuneration of the board. The annual reports of NMa disclose remuneration of the president of NMa based on WOPT:6. This implies that the other members of the board receive remuneration below the maximum levels mentioned in WOPT. No indications on performance related remuneration are given. These measures have no impact on NMA's board compared to kZBO-arrangements.

Arrangements on intervention in case of negligence (kZBO:23) exist. Annulling ZBO decisions is not included, given the impartial judgement role of NMa (Parliament, 2008z, p. 5). This arrangement generates additional autonomy compared to the kZBOframework.

Asset related transactions are not included in MW. This is related to the legal status of NMa as a Shelter ZBO rather than a Subsidiary ZBO. In effect this only restricts NMa on the issue of borrowing and lending, which has to be performed within the budgetary framework of minEZ's budget rather than by submitting a financing request to the State Treasury. All other asset related arrangements are optional, which means that from a kZBO perspective no additional restrictions exist.

\subsubsection{Cyclical measures}

The Shelter ZBO status of NMa also has an impact on the cyclical measures. Formally kZBO:33 does not apply. Furthermore, kZBO:29 requires budgets to be approved by a minister. In the NMa case, minEZ determines the budget which formally restricts autonomy. Interviewees indicated that proposed increases are treated similarly to proposals from regular units within minEZ. According to interviewees within the financial framework the Nma board has more degrees of freedom to determine a working program than regular units within minEZ. This means that NMa operations are managed in a more or less similar way to kZBO:29. Reporting on substantial differences (kZBO:30) is covered in $\mathrm{MW}: 5 \mathrm{i} .2$. Interviewees also indicated that $\mathrm{NMa}$ has to submit multiyear plans in line with standard arrangements for departmental units.

Finally, NMa is not funded by fees, but can in some cases (for example a merger) charge a fee as compensation for the costs related to the licence issued. These fees are published in a ministerial decree which has not been changed since publication in 2006 . 
There is no role for NMa's executive board in determining the fees. As these fees do not affect operations, no impact on autonomy can be observed.

Table 17.5: Legal measures on NMa, formally or actually diverging from kZBO.

\begin{tabular}{|c|c|c|c|c|c|c|}
\hline Authority issue & $\begin{array}{l}\text { Authority } \\
\text { Group }\end{array}$ & $\begin{array}{l}\text { reference } \\
\text { kZBO }\end{array}$ & $\begin{array}{l}\text { reference } \\
\text { case law }\end{array}$ & Actual practice & $\begin{array}{l}\text { formal } \\
\text { mismatch } \\
\text { and } \\
\text { impact }\end{array}$ & $\begin{array}{l}\text { actual } \\
\text { mismatch } \\
\text { and } \\
\text { impact }\end{array}$ \\
\hline $\begin{array}{l}\text { Not appointing } \\
\text { civil servants to } \\
\text { board }\end{array}$ & Normative & 9 & none & $\begin{array}{l}\text { no civil } \\
\text { servants } \\
\text { appointed }\end{array}$ & 0 & 0 \\
\hline $\begin{array}{l}\text { Appointment of } \\
\text { staff }\end{array}$ & Normative & $\begin{array}{l}\text { kZBO:15 } \\
\text { (PLA) }\end{array}$ & MW:5a & $\begin{array}{l}\text { civil servants } \\
\text { made available }\end{array}$ & 0 & 0 \\
\hline $\begin{array}{l}\text { Submit annual } \\
\text { report to } \\
\text { Parliament }\end{array}$ & Information & 18 & $\begin{array}{l}\text { MW:5g.3 } \\
\text { submitted } \\
\text { and } \\
\text { commented } \\
\text { by minEZ }\end{array}$ & $\begin{array}{l}\text { in line with } \\
\text { case law }\end{array}$ & $\downarrow$ & $\downarrow$ \\
\hline $\begin{array}{l}\text { Discussing } \\
\text { activities of NMa } \\
\text { in Parliament by } \\
\text { NMa-board }\end{array}$ & Information & none & none & $\begin{array}{l}\text { Occasional } \\
\text { Informal } \\
\text { meetings }\end{array}$ & 0 & $\widehat{\uparrow}$ \\
\hline $\begin{array}{l}\text { Approval of } \\
\text { statement of } \\
\text { accounts }\end{array}$ & Information & 34 & $\begin{array}{l}\text { none, } \\
\text { because not } \\
\text { applicable }\end{array}$ & $\begin{array}{l}\text { determining } \\
\text { given Shelter } \\
\text { ZBO-status }\end{array}$ & $\downarrow$ & $\downarrow$ \\
\hline Multiple bodies & Governance & 7 & $\begin{array}{l}\text { none, not } \\
\text { applicable }\end{array}$ & not applicable & 0 & 0 \\
\hline $\begin{array}{l}\text { Decision on and } \\
\text { disclosure of } \\
\text { remuneration }\end{array}$ & Governance & $\begin{array}{l}\text { kZBO:14 } \\
\text { WOPT: } 6\end{array}$ & $M W: 4 a$ & $\begin{array}{l}\text { remuneration } \\
\text { president NMa } \\
\text { disclosed in } \\
\text { annual reports } \\
2007 / 2008 \\
\text { based on WOPT }\end{array}$ & 0 & 0 \\
\hline $\begin{array}{l}\text { Annulling of ZBO } \\
\text { decisions }\end{array}$ & Governance & 22 & none & $\begin{array}{l}\text { impartial } \\
\text { judgement } \\
\text { does not allow } \\
\text { intervention }\end{array}$ & $\uparrow$ & $\uparrow$ \\
\hline $\begin{array}{l}\text { Asset related } \\
\text { transactions: } \\
\text { borrowing and } \\
\text { lending }\end{array}$ & Governance & $32 d$ & $\begin{array}{l}\text { not } \\
\text { applicable, } \\
\text { subject to } \\
\text { department } \\
\text { al rules }\end{array}$ & $\begin{array}{l}\text { subject to } \\
\text { departmental } \\
\text { rules }\end{array}$ & $\downarrow$ & $\downarrow$ \\
\hline $\begin{array}{l}\text { Asset related } \\
\text { transactions: } \\
\text { others }\end{array}$ & Governance & 32a-c; e-g & $\begin{array}{l}\text { not } \\
\text { applicable }\end{array}$ & not used & 0 & 0 \\
\hline Approval of budget & Cyclical & 29 & $\begin{array}{l}\text { MW5i.1: } \\
\text { submit draft } \\
\text { budget }\end{array}$ & $\begin{array}{l}\text { minister } \\
\text { determines } \\
\text { financial } \\
\text { framework, } \\
\text { working } \\
\text { program } \\
\text { decided upon } \\
\text { by Board }\end{array}$ & $\downarrow$ & 0 \\
\hline $\begin{array}{l}\text { Submit multiyear } \\
\text { plan }\end{array}$ & Cyclical & none & CW:5 & in line with CW & $\downarrow$ & $\downarrow$ \\
\hline $\begin{array}{l}\text { Creating } \\
\text { equalisation } \\
\text { reserve }\end{array}$ & Cyclical & 33 & none & $\begin{array}{l}\text { not applicable } \\
\text { for Shelter ZBO }\end{array}$ & 0 & 0 \\
\hline \multicolumn{3}{|c|}{ Included in determining autonomy } & \multicolumn{4}{|c|}{ Not included in determining autonomy } \\
\hline
\end{tabular}




\subsubsection{Impact of changes in legislation due to alignment with kZBO}

The proposal to change legislation states that kZBO is applicable except for kZBO:22. Furthermore new measures are included in the modified legislation which require minEZ to hold discussions with other relevant ministries before intervening if $\mathrm{NMa}$ is found negligent. NMa's annual reports also have to be assessed by minEZ before being submitted to Parliament. These minEZ assessments must include the opinions and evaluations from other ministers who have commissioned services from NMa. The optional measures in kZBO:21 on policy rules to be set by minEZ was divided in two parts: general policy rules are laid down by minEZ and NMa is allowed to implement these rules. In the new proposal, NMa has to submit draft operational rules to minEZ before they are determined by NMa. This new arrangement is a restriction on autonomy compared to the current situation.

\subsubsection{Conclusion}

The general impression of the legal measures with respect to $\mathrm{NMa}$ is that due to its Shelter ZBO status, formal autonomy is reduced on financial management issues. Actual autonomy is also reduced, but less so than indicated by the formal rules. Due to the impartial judgement role of NMa, some increased autonomy can be observed in decision making arrangements. A very special case is that sometimes the executive board of NMa have direct discussions with MPs which is an indication of the autonomy of NMa has in performing its program. 


\subsubsection{NZA}

NZA is a separate legal entity PLA type ZBO. In its letter on application of kZBO, minVWS announced that NZA would be subject to kZBO except for kZBO:17 on approval of fees and kZBO:22 on annulling NZA decisions (Parliament, 2008f). On January 1, 2010, a proposal for changes in WMG had been submitted to Parliament. The proposal is still being discussed in Parliament.

\subsubsection{Normative measures}

The NZA board controls staff based on WMG:6. This article also covers measures stipulating that staff have a position similar to that of civil servants within ministries. These rules are in line with kZBO arrangements.

There is explicit measure prohibiting the appointment of civil servants to the board. This means that theoretically a civil servant might be appointed, reducing autonomy. Practically, civil servants are not appointed, which means that NZA practices are in line with kZBO. In 2007 and 2008, a former minister was a member of the board. This appointment shows that recruitment of ZBO boards from within the public services is permitted. Only hierarchical subordination to a minister, once appointed as a board member is not allowed under kZBO.

An explicit technical data protection arrangement as meant by kZBO:41 is not included in legislation. WMG:67 however requires that all information submitted to NZA must be treated as confidential and explicit measures on availability of different types of information are also included in WMG. This requirement effectively implies that NZA has to implement systems to ensure assure data confidentiality. Therefore, there is no impact on autonomy.

MinVWS is allowed to issue general instructions to NZA on tasks assigned under WMG but also on operations of NZA (WMG:7.1a). The level of detail used by minVWS in his instruction letter on the budget is an indication of minVWS' role in planning and prioritising NZA's operations. The measure reduces autonomy given the kZBO:21 provision which focuses on policy instructions.

\subsubsection{Information measures}

All information issues are included in WMG except for submitting the annual report to Parliament. The rules on submitting the annual report diverge to enable minVWS to write an assessment on NZA's annual report. Interviewees indicated that the practice of writing an assessment was continued until fiscal 2007 and then ended. From a formal perspective, this means that the arrangement restricts autonomy due to the explicit assessment by minVWS. Practically, at least as of 2008, autonomy is increased because the annual report is no longer submitted to Parliament.

Given the PLA status of NZA, no requirements on using separate accounts are required by $k Z B O$. In practice, the activities of NZA only focus on public tasks which 
means that there is no need for such a requirement. Overall, the information measures do not affect NZA's autonomy

\subsubsection{Governance provisions}

An explicit arrangement on relations between different bodies within NZA is not required because formally, there is no non-executive board or advisory board. Interviewees indicated that in practice an informal advisory board is used by the NZA Board, which is accepted by minVWS. Effectively this arrangement has no impact on NZA's autonomy.

The rules on board appointments, internal governance statutes and secondary jobs are all included in WMG. Board members are not allowed to be members of other regulatory authorities. Furthermore they are not allowed to have a (financial) interest in institutions which might lead to discussions on impartiality. Finally, minVWS can issue a decree on other incompatibilities. As a result the WMG:4.6 provision is more restrictive than KZBO:13, which only requires a Board member not to accept a secondary job with a possible conflict of interest.

With respect to remuneration, RBBBV:2 explicitly describes remuneration to a maximum level below top civil servants. This measure reduces minnows' degree of freedom rather than that of the NZA-board due to the increased transparency if minVWS wants to increase remuneration. A minister's flexibility is greater under the general kZBO:14 rules. Due to the RBBBV:2 provision, WOPT-reporting is not applicable.

A measure in the event of negligence is included in WMG. This is in line with kZBO. The annulling measure in WMG:9 is more restrictive than the kZBO wording. Essentially the difference is that under kZBO:22 any decision can be annulled, whereas in WMG:9 only general decisions can be annulled. In practice, these measures have not been used. The current WMG:9 annulling measure will be continued which means that kZBO:22 will be excluded after legislation is adapted to kZBO (Parliament, 2008f). Effectively this means an increase in autonomy compared to the kZBO measures.

WMG does not include any measure on asset related transactions. As is the case for most ZBOs, NZA is subject to CW2001:45.1. as of 2008. Before 2008, NZA had some additional degrees of freedom since it was listed as subject to CW2001:45.2 which only sets restrictions on treasury management rather than requiring it to operate via State Treasury. The 2008 practice is in line with the practice of many other PLAs, including all PLAs discussed in this study. In practice, NZA's annual report discloses borrowing from minVWS. Interviewees indicated that the procedure for borrowing from minVWS was a shortcut which could be facilitated given the budgetary position of minVWS.

In terms of autonomy no impact can be observed because borrowing is still performed within the framework of the Dutch State's financial position rather than externally. Because kZBO:32 covers optional arrangements, the impact of WMG measures on autonomy is nil. 


\subsubsection{Cyclical measures}

Finally, cyclical measures are discussed. WMG:12 requires minVWS to determine rather than approve the budget. This also implies that the executive board of NZA only submits a budget proposal. This measure reduces autonomy compared to the kZBO framework. The measure seems to conflict with WMG:14 in which reference is made to approval of the budget plan submitted by NZA. If however under WMG:12, minVWS determines the budget for NZA operations, such an approval can only cover the allocation within the budget as defined by minVWS. Additionally, WMG:11 requires a multiyear budget for the four fiscal years following the budget year. This rule is not included in kZBO either and brings the budgeting process of NZA more in line with traditional ministerial budgeting. An interviewee noted that the multiyear budget must include announced budget reductions if relevant in a particular fiscal year.

As mentioned previously the RBBBV includes a regulation on the level of the equalisation reserve (RBBBV:18) as part of the measures which allow minVWS to set rules on the structure of the budget in WMG:14.3. Except for the level of the equalisation reserve, these arrangements are in line with kZBO. Compared to the regulations on equalisation reserves in executive agencies, which allow for an equalisation reserve based on a 3 year average budget level (Decree executive agencies 2007:17.4c), the arrangement in RBBBV:18 is more restrictive as it only allows reference to the budget for the relevant fiscal year.

A last remark concerns kZBO:17. NZA is allowed to determine the fees for several medical services (WMG:1k) and operations are fully funded by minVWS. The kZBO arrangement is meant to (partially) cover costs of operations (Parliament, 2000d, p. 26). The exception claimed on kZBO:17 by minVWS in its letter on the implementation is therefore incorrect (Parliament, 2008f, p. 7) and is ignored as not applicable.

\subsubsection{Impact of changes in legislation due to alignment with kZBO}

Along with the announced exceptions as stated in the letter on implementation of kZBO (Parliament, 2008f), some additional changes were made which will influence the autonomy of NZA. Under current legislation some secondary jobs are explicitly excluded. This will be changed to the general kZBO arrangement. Furthermore, minVWS is no longer entitled to issue instructions on NZA's operations. These two changes have a positive impact on autonomy. Changes without an impact are a maintaining of the requirement to provide a multiyear budget, the requirements regarding intermediate changes in the budget and the proposals on auditing, which include not only effectiveness but also compliance and auditability. MinVWS will be able to set rules on the level of the equalisation reserve, which is a restrictive regulation compared to kZBO but is now implemented in RBBBV:18. Finally, in the relationship to Parliament, minVWS will no longer submit its assessment on NZA's annual report to Parliament. In general, this 
means that the additional restrictions in current legislation are incorporated into the new legal framework.

Table 17.6: Legal measures on NZA, formally or actually diverging from kZBO.

\begin{tabular}{|c|c|c|c|c|c|c|}
\hline Authority issue & $\begin{array}{l}\text { Authority } \\
\text { Group }\end{array}$ & $\begin{array}{l}\text { reference } \\
\text { kZBO }\end{array}$ & $\begin{array}{l}\text { reference } \\
\text { case law }\end{array}$ & Actual practice & $\begin{array}{l}\text { formal } \\
\text { mismatch } \\
\text { and } \\
\text { impact }\end{array}$ & $\begin{array}{l}\text { actual } \\
\text { mismatch } \\
\text { and } \\
\text { impact }\end{array}$ \\
\hline $\begin{array}{l}\text { Not appointing civil } \\
\text { servants to board }\end{array}$ & Normative & 9 & none & $\begin{array}{l}\text { no civil servants } \\
\text { appointed }\end{array}$ & $\downarrow$ & 0 \\
\hline $\begin{array}{l}\text { Data protection } \\
\text { measure }\end{array}$ & Normative & 41 & $\begin{array}{l}\text { WMG: } 67 \\
\text { confidential } \\
\text { treatment of } \\
\text { data }\end{array}$ & $\begin{array}{l}\text { implies } \\
\text { systematic data } \\
\text { protection }\end{array}$ & 0 & 0 \\
\hline $\begin{array}{l}\text { Minister decides } \\
\text { upon general } \\
\text { instructions on } \\
\text { tasks }\end{array}$ & Normative & 21 & $\begin{array}{l}\text { WMG7.1 } \\
\text { includes } \\
\text { operations }\end{array}$ & $\begin{array}{l}\text { includes } \\
\text { operations }\end{array}$ & $\downarrow$ & $\downarrow$ \\
\hline $\begin{array}{l}\text { Submit annual } \\
\text { report to } \\
\text { Parliament }\end{array}$ & Information & 18 & WMG:15.2 & $\begin{array}{l}\text { till fiscal } 2007 \text { in } \\
\text { line with WMG, } \\
\text { afterwards } \\
\text { discontinued }\end{array}$ & $\downarrow$ & $\widehat{\uparrow}$ \\
\hline Multiple bodies & Governance & 7 & none & $\begin{array}{l}\text { informal } \\
\text { advisory board } \\
\text { accepted by } \\
\text { minVWS }\end{array}$ & 0 & 0 \\
\hline $\begin{array}{l}\text { Measure on } \\
\text { secondary jobs of } \\
\text { Board members }\end{array}$ & Governance & 13 & WMG4.6 & in line with WMG & $\downarrow$ & $\downarrow$ \\
\hline $\begin{array}{l}\text { Decision on and } \\
\text { disclosure of } \\
\text { remuneration }\end{array}$ & Governance & $\begin{array}{l}\text { kZBO:14 } \\
\text { WOPT:6 }\end{array}$ & RBBBV:2.3 & $\begin{array}{l}\text { in line with } \\
\text { RBBBV }\end{array}$ & 0 & 0 \\
\hline $\begin{array}{l}\text { Annulling of ZBO } \\
\text { decisions }\end{array}$ & Governance & 22 & WMG:9 & $\begin{array}{l}\text { in line with } \\
\text { WMG:9 but not } \\
\text { used }\end{array}$ & $\uparrow$ & $\uparrow$ \\
\hline $\begin{array}{l}\text { Asset related } \\
\text { transactions: } \\
\text { borrowing and } \\
\text { lending }\end{array}$ & Governance & $32 d$ & $\begin{array}{l}\text { as of 2008: } \\
\text { CW2001:45 }\end{array}$ & $\begin{array}{l}\text { Incidental } \\
\text { borrowing from } \\
\text { minVWS rather } \\
\text { than from State } \\
\text { Treasury }\end{array}$ & 0 & 0 \\
\hline $\begin{array}{l}\text { Asset related } \\
\text { transactions: } \\
\text { others }\end{array}$ & Governance & $\begin{array}{l}\text { 32a-c; e- } \\
\text { g }\end{array}$ & none & not applicable & 0 & 0 \\
\hline Approval of budget & Cyclical & 29 & $\begin{array}{l}\text { WMG:12: } \\
\text { minister } \\
\text { determines } \\
\text { budget }\end{array}$ & $\begin{array}{l}\text { in line with } \\
\text { WMG:12 }\end{array}$ & $\downarrow$ & $\downarrow$ \\
\hline $\begin{array}{l}\text { Submit multiyear } \\
\text { budget }\end{array}$ & Cyclical & none & WMG:11.2c & $\begin{array}{l}\text { in line with } \\
\text { WMG:11 }\end{array}$ & $\downarrow$ & $\downarrow$ \\
\hline $\begin{array}{l}\text { Creating } \\
\text { equalisation } \\
\text { reserve }\end{array}$ & Cyclical & 33 & $\begin{array}{l}\text { RBBBV:18 } \\
\text { limitation on } \\
1 \text { year basis }\end{array}$ & $\begin{array}{l}\text { in line with } \\
\text { RBBBV }\end{array}$ & $\downarrow$ & $\downarrow$ \\
\hline Audit protocol & Cyclical & none & & & 0 & $\downarrow$ \\
\hline \multicolumn{3}{|c|}{ Included in determining autonomy } & \multicolumn{4}{|c|}{ Not included in determining autonomy } \\
\hline
\end{tabular}




\subsubsection{Conclusion}

Except for the increased autonomy on annulling ZBO decisions which is related to the impartial judgement role of NZA, several arrangements exist which negatively affect the autonomy of NZA. On budgetary measures and NZA operations in particular, the legislation prescribes measures that go beyond the general kZBO measures. Examples are multiyear budgets and the determination of the budget by minVWS. Actual autonomy is somewhat less restricted because of the change in submitting annual reports to Parliament. 


\subsubsection{Relative autonomy of monitoring ZBOs from a legal perspective}

In most cases, substantial differences can be observed between the formal and actual autonomy of monitoring ZBOs. Figure 17.1 discloses the position of monitoring ZBOs between each other. The scores are based on the findings described above as summarised in Appendix 10 for all legal indicators that do not have the character of a control tool of last resort.

First, the group of market regulators is discussed. In all three cases, formal autonomy is lower than might be expected from the kZBO framework. Actual autonomy is at a higher level for NZA and AFM but not beyond expected standard levels. In the case of NMa, an important element in its low formal and actual autonomy is its legal status as a unit within minEZ rather than a separate legal entity. A remarkable point in the NMa case is that, with prior knowledge of minEZ, the NMa board sometimes discusses its services directly with Parliament, which is very unusual in the Dutch context. Furthermore, interviewees indicated that frequent meetings between minister and board are organised.

NZA has nearly as many formal restrictions as NMa, despite its status as a separate legal entity. Budgetary control in NZA is at the level of its budget being determined by minVWS rather than approving the budget. Restrictions on reserves also have an effect on formal autonomy. The only reason for an increase in autonomy here is the fact that as of 2008 the annual report is no longer assessed by minVWS or submitted to Parliament.

AFM's autonomy is determined by a number of factors which reduce autonomy as well as factors which increase autonomy. I only mention the role of minFin in the appointment of the board, which is included in AFM's statutes. In kZBO, measures only exist for appointments made to PLA type ZBOs, whereas AFM is a PLB type ZBO. Factors negatively affecting AFM's autonomy include restrictions on budget and fees as well as on creating reserves, based on preventing cross subsidising activities for different target groups. The other two market regulating ZBOs are faced with issues that reduce autonomy only. AFM's actual autonomy increases due to the low number of restrictions on structuring budgets and low numbers of meetings between board and minister. On the other hand, autonomy is restricted due to an intervention by minFin on remuneration of the board.

In Woningwet, very few arrangements on controlling CFV are made. This results in a high level of formal autonomy compared to the kZBO standard. In practice autonomy is at a lower level, but still above kZBO standards. The main cyclical issues of CFV are in fact in line with kZBO; what remains are governance arrangements on the appointment of board and remuneration issues. Finally, NAK's autonomy is above standards and in practice is even higher compared to the formal measures. Like the AFM case, both formal and actual autonomy of NAK are determined by measures some of which have a negative effect and some a positive effect on autonomy. I mention the appointment of the president of the board is left to the Minister-Principal, which is beyond standards for PLBs 
and affects autonomy negatively. Issues that increase autonomy are degrees of freedom in submitting annual reports and financial statements structures. Another issue worth mentioning but not immediately affecting autonomy is the level of the equalisation reserve which is very high given the uncertainty in production levels over the years.

\begin{tabular}{|c|c|c|c|c|c|c|c|}
\hline & $\begin{array}{l}\text { low } \\
\text { auto- } \\
\text { nomy }\end{array}$ & & & $\begin{array}{l}\text { neutral: } \\
\text { kZBO }\end{array}$ & & & $\begin{array}{l}\text { high } \\
\text { auto- } \\
\text { nomy }\end{array}$ \\
\hline Formal & $\begin{array}{l}\text { NMa } \\
\text { NZA }\end{array}$ & & AFM & & NAK & & CFV \\
\hline Actual & $\mathrm{NMa}$ & $\mathrm{NZA}$ & & AFM & CFV & NAK & \\
\hline
\end{tabular}

Figure 17.1 Formal and actual autonomy of monitoring ZBOs from a legal perspective

The following section will address the economic dimension of autonomy of the monitoring ZBOs. After that assessment, conclusions can be drawn on mismatches between legal and economic autonomy of the monitoring ZBOs studied. 


\subsection{The economic dimension of autonomy}

In this subsection, I will discuss impact of economic variables on the selected monitoring ZBOs. Each of the monitoring ZBOs will be assessed on the same market characteristics and planning and control indicators as was carried out for the income transfer ZBOs.

In general monitoring activities are expected to be relatively independent from government intervention to ensure impartiality. Since monitoring is performed on behalf of society as a whole, government funding based on lump sum budgets and State commissioning are to be expected, particularly for market regulators. In market regulatory services it is not likely that detailed instructions on budgets and activities can be given by the Minister-Commissioner because that might result in a conflict on the issue of impartiality. Management has responsibility for operations throughout a fiscal year and intermediate reporting to Minister and Parliament are exceptions given the use of lump sum budgets and non-intervention policy by the political system. Supply will be based on contract services, although production specifications will be abstract rather than detailed. This is caused by the fact that monitoring implies individual production rather than mass production.

NAK is a quality assurance ZBO which essentially has two different characteristics. NAK services allow for mass production and demand from citizens rather than state commissioning as is the case with market regulators. The expected position of NAK is adapted to be in line with these characteristics. CFV's services have some similarities to the services of the market regulators, but it delivers impure public services for a particular group rather than services for society as a whole. 


\subsubsection{AFM}

\subsubsection{Demand and supply characteristics}

The services of AFM are intended to ensure a fair market position for all participants in the financial markets. To some extent, this market regulation task may be compared to a policing task. AFM's website regularly publishes warnings on unfair trading by individuals, which is a reflection of this policing activity. Therefore, I have classified AFM's function as one of a pure public good rather than an impure public good.

All of AFM's activities can be classified as monitoring activities. Respondents indicated that some consulting activities are performed on behalf of minFin, which are funded by the government. In minFin's 2007 budget document, reference is made to the activities funded directly by government such as compliance and criminal investigations as well as monitoring of some special groups (Parliament, 2006I, p. 27). All other activities are funded by the entities monitored. This results in a rather special combination of task classification as public good and substantial funding by some groups (banks, insurance companies, pension funds, financial consultants) in society. Although funding is based on fees rather than on payments by government, this does not affect autonomy given the authority biased character of the funding, which does not allow costs of operations to exceed the total fees charged.

Table 17.7: Classification and impact of market characteristics on AFM's autonomy

\begin{tabular}{|c|c|c|c|}
\hline & Expected & Actual & Impact \\
\hline \multicolumn{4}{|l|}{ PRODUCT CHARACTERISTICS } \\
\hline Public good type & Pure good & Pure good & 0 \\
\hline \multicolumn{4}{|l|}{ ACTIVITIES } \\
\hline $\begin{array}{l}\text { \% monitoring activities in operating costs (2007, annual } \\
\text { report) }\end{array}$ & 100 & 100 & 0 \\
\hline Production type & individual & mixture & $\uparrow$ \\
\hline \multicolumn{4}{|l|}{ DEMAND } \\
\hline \% Funding from central government (2007, annual report) & 100 & 30 & $\uparrow$ \\
\hline \% Public funding (2007, annual report) & 100 & 30 & $\uparrow$ \\
\hline \% Funding largest demand initiator (2007, annual report) & 100 & 30 & 0 \\
\hline Type of funding charges & not applicable & $\begin{array}{l}\text { Authority } \\
\text { biased }\end{array}$ & 0 \\
\hline Budget funding & Lump sum & Lump sum & 0 \\
\hline Commissioning & State & $\begin{array}{l}\text { State }+ \\
\text { Request }\end{array}$ & 0 \\
\hline Demand dependency & $\begin{array}{l}\text { Single } \\
\text { ministry }\end{array}$ & mixture & $\uparrow$ \\
\hline \multicolumn{4}{|l|}{ SUPPLY } \\
\hline Competitors & No & No & 0 \\
\hline Budget Typology & Task & Task & 0 \\
\hline Production form & $\begin{array}{l}\text { Contract } \\
\text { Provision }\end{array}$ & $\begin{array}{l}\text { Regulated } \\
\text { Provision }+ \\
\text { Contract } \\
\text { provision } \\
\end{array}$ & 0 \\
\hline Included in determining autonomy & \multicolumn{3}{|c|}{ Not included in determining autonomy } \\
\hline
\end{tabular}


AFM is not fully dependent on demand from one commissioner; minFin is the largest single organisation funding AFM. However the majority of AFM's activities are initiated by or the result of applying for and obtaining a licence to provide a financial service by individual companies. Therefore, commissioning resembles a citizen's request for something rather than full state commissioning and a mixture of demand dependency rather than single demand only. This does not have an impact on autonomy because these requests are still part of the market regulation services to be executed by AFM.

Production is expected to be of a contract provision type given the pure public good character. In practice, production is a mixture between contract provision for tasks assigned by minfin and regulated provision for all other activities. This mixture of provision of services does not affect AFM's autonomy because the emphasis in production at AFM is on general monitoring rather than on decisions on individual cases except for the licensing processes. Only the funding character of production differs.

Legislation requires a certain specification to allocate costs to monitored entities. This specification is aligned along certain types of tasks assigned such as monitoring suppliers or inspections with respect to integrity (Parliament, 2008aa, p. 111). The classification is also used as a basis to charge fees from the monitored institutions (Decree funding financial monitoring, December 2003). Although input control elements do exist for AFM - MP's refer to the level of staff (Parliament, 2008ab, p.4 and p. 8) and respondents indicate that $A F M$ is subject to staff reduction programs imposed by government - the budget is better described as a lump sum based task budget. Due to the increased functions assigned to AFM, operating costs have increased from some $€ 51$ million (2005 Annual Report) to some $€ 78$ million in 2008. In both cases, the budget was substantially higher than actual operating costs. Respondents indicated that the influence of government on the budget levels is relatively low, because AFM's nonexecutive board and advisory boards have a role in the approval of the budgets. According to respondents the 2007 coalition agreement has led to an agreement on a maximum level of budget for AFM rather than a budget cut which has been proposed for many other ZBOs.

\subsubsection{Planning and control}

As indicated before, AFM's budget is by and large funded by the financial institutions being monitored rather than by the State. Therefore, the budget is only partially found in minFin's budget documents. MinFin does not submit a letter of instruction on services to be delivered or on budgets in the preparatory stage of AFM's budget. Furthermore, no separate budget or fee approval announcement is sent to Parliament. Approval of budgets is in this case explicitly published by AFM in the official journal of the State 'Staatscourant'. Approval of annual reports is mentioned separately. In the 2007 case, this has led to 24 separate questions on the annual report; no questions were submitted on the 2008 report.

AFM's balance sheet only shows intangible fixed assets. These assets concern the development costs of monitoring programs to be included in future fees. 
The ministry's budget document does not include performance indicators with respect to AFM. In AFM's budget document as submitted to minFin, performance indicators are included. Respondents indicate that minFin and AFM have agreed to present budget documents as well as annual reports based on the VBTB format which is also the standard for ministries. The annual report does disclose a variety of performance indicators. In minFin's annual report, some process indicators and an overview of expenses is included. The annual report is submitted to Parliament but without assessment or explicit statement of consent by minFin, which increases autonomy. The increase in autonomy is mitigated due to the fact that the summary in minFin's annual report also includes relevant financial information on AFM.

Table 17.8: Planning and control of AFM and impact on autonomy

\begin{tabular}{|c|c|c|c|c|}
\hline & Expected & fiscal 2007 & fiscal 2008 & Impact \\
\hline \multicolumn{5}{|l|}{ ACCOUNTING ISSUES } \\
\hline Accounting System & Accruals & Accruals & Accruals & 0 \\
\hline$\%$ fixed assets & $<10 \%$ & 0 & 0 & 0 \\
\hline $\begin{array}{l}\text { Budget disclosure of operating costs in ministry } \\
\text { budget }\end{array}$ & Line item & $\begin{array}{l}\text { Partially } \\
\text { included }\end{array}$ & $\begin{array}{l}\text { Partially } \\
\text { included }\end{array}$ & $\uparrow$ \\
\hline Responsibility centre type & $\begin{array}{l}\text { Complete } \\
\text { cost centre }\end{array}$ & $\begin{array}{l}\text { Complete } \\
\text { cost centre }\end{array}$ & $\begin{array}{l}\text { Complete } \\
\text { cost centre }\end{array}$ & 0 \\
\hline \multicolumn{5}{|l|}{ PLANNING \& CONTROL } \\
\hline Budget instruction by Minister-Principal & No & No & No & 0 \\
\hline $\begin{array}{l}\text { Approval of budget document mentioned to } \\
\text { Parliament by minister }\end{array}$ & Yes & No & No & $\uparrow$ \\
\hline $\begin{array}{l}\text { Approval of fees mentioned to Parliament by } \\
\text { minister }\end{array}$ & Yes & No & No & $\uparrow$ \\
\hline $\begin{array}{l}\text { Approval of annual report mentioned to } \\
\text { Parliament by minister }\end{array}$ & Yes & $\begin{array}{l}\text { No; key data } \\
\text { in annual } \\
\text { report minFin }\end{array}$ & $\begin{array}{l}\text { No; key data } \\
\text { in annual } \\
\text { report minFin }\end{array}$ & 0 \\
\hline Frequency of reporting to Parliament & Yearly & Departmental & Departmental & $\downarrow$ \\
\hline $\begin{array}{l}\text { Performance indicators reported to Parliament } \\
\text { in ministries' budget documents }\end{array}$ & Throughput & None & None & $\uparrow$ \\
\hline $\begin{array}{l}\text { Performance indicators reported to Parliament } \\
\text { in ministries' Annual reports }\end{array}$ & Throughput & Throughput & Throughput & 0 \\
\hline $\begin{array}{l}\text { Performance indicators reported to Parliament } \\
\text { in ZBO Budget documents }\end{array}$ & Throughput & $\begin{array}{l}\text { Not } \\
\text { Submitted }\end{array}$ & $\begin{array}{l}\text { Not } \\
\text { Submitted }\end{array}$ & $\uparrow$ \\
\hline $\begin{array}{l}\text { Performance indicators reported to Parliament } \\
\text { in ZBO Annual reports }\end{array}$ & Throughput & $\begin{array}{l}\text { Throughput } \\
\text { and output }\end{array}$ & $\begin{array}{l}\text { Throughput } \\
\text { and output }\end{array}$ & 0 \\
\hline Frequency of reporting to Minister & Yearly & $\begin{array}{l}\text { Two } \\
\text { intermediate } \\
\text { reports }\end{array}$ & $\begin{array}{l}\text { Two } \\
\text { intermediate } \\
\text { reports }\end{array}$ & $\downarrow$ \\
\hline \multicolumn{5}{|l|}{ POLITICAL DEBATE } \\
\hline $\begin{array}{l}\text { Number of documents submitted to Parliament } \\
\text { regarding operations of ZBO }\end{array}$ & 2 & 22 & 27 & $\downarrow$ \\
\hline $\begin{array}{l}\text { Number of discussion/questions on operations } \\
\text { of ZBO by MPs related to budget and annual } \\
\text { report }\end{array}$ & 0 & 31 & 2 & 0 \\
\hline $\begin{array}{l}\text { Number of discussion/questions on operations } \\
\text { of ZBO by MPs other than budget and annual } \\
\text { report }\end{array}$ & 0 & 10 & 16 & 0 \\
\hline Included in determining autonomy & \multicolumn{4}{|c|}{ Not included in determining autonomy } \\
\hline
\end{tabular}

Respondents indicated that substantial differences in the budget should be reported to minFin. In practice this has led to reporting to Parliament in the normal planning and 
control process within ministries with changes in the budget in the second supplement 2007 as well as in the first and second supplement to the 2008 budget. This means that reporting frequencies to both Parliament as well as to minFin are at a higher level than might be expected for an impartial market regulator. It should be noted that in the years studied here, AFM was still in a development stage. Respondents did not explicitly refer to this development stage as a reason for additional control.

The system of funding for AFM requires all excess fees paid during a fiscal year to be returned to contributors in the following fiscal year. This is an indication that cost control leads for AFM. AFM is responsible for full costs with relatively low influence from minFin. This leads to the conclusion that AFM can be classified as a complete cost centre, in line with expectations for monitoring ZBOs.

A final remark is made on documents submitted to Parliament. Both in 2007 and 2008 large numbers of documents were submitted. In fiscal 2007 the emphasis was directly on AFM operations including substantial numbers of questions on AFM's annual report. In fiscal 2008, issues varied. Not only did they discuss operations directly but also the impact of new regulations on AFM's operations.

The overall perspective is that the mixture of functions result in more autonomy from a production perspective, reinforced by the measures for funding AFM. Under planning and control, information on approval of budgets and fees is not given, increasing autonomy. The frequency of intermediate reporting mitigates this increase in autonomy to some extent. In general AFM's economic autonomy is at a higher level than might be expected for a market regulator. 


\subsubsection{CFV}

\subsubsection{Demand and supply characteristics}

CFV's monitoring functions concern the financial position of Social Housing Associations (SHAs) and are supplemented with income transfers if necessary. A classification as a pure public good is not realistic as it exclusively aims at SHAs and not on the real estate market as a whole. Therefore, the classification is at best an impure public good. Although historically different, respondents indicated that for a number of years, CFV's actual activities have focused on monitoring the financial resilience of SHAs. No applications for income transfers were submitted in fiscal 2007 and 2008. Some old applications were however still being processed. Most of the operating costs can therefore be allocated to CFV's monitoring activities.

Monitoring activities are generally based on individual production rather than on mass production. In this case, monitoring has the characteristics of series production, for example when general assessment of the financial position of SHAs is performed. Income transfer activities are in general case based, although in the announced temporary program forms of series production can be observed. This at least applies for generating the incoming income transfers by levies. The observed complexity of activities results in some additional autonomy.

Table 17.9: Classification and impact of market characteristics on CFV's autonomy

\begin{tabular}{|c|c|c|c|}
\hline & Expected & Actual & Impact \\
\hline \multicolumn{4}{|l|}{ PRODUCT CHARACTERISTICS } \\
\hline Public good type & Impure good & Impure good & 0 \\
\hline \multicolumn{4}{|l|}{ ACTIVITIES } \\
\hline $\begin{array}{l}\text { \% monitoring activities in operating costs (2007, annual } \\
\text { report) }\end{array}$ & 100 & 100 & 0 \\
\hline Production type & Individual & mixture & $\uparrow$ \\
\hline \multicolumn{4}{|l|}{ DEMAND } \\
\hline \% Funding from central government (2007, annual report) & 100 & 0 & 0 \\
\hline \% Public funding (2007, annual report) & 100 & 0 (no funding) & 0 \\
\hline \% Funding largest demand initiator (2007, annual report) & 100 & $\begin{array}{l}\text { Not } \\
\text { applicable }\end{array}$ & 0 \\
\hline Type of funding charges & $\begin{array}{l}\text { Not } \\
\text { applicable }\end{array}$ & $\begin{array}{l}\text { Authority } \\
\text { biased }\end{array}$ & 0 \\
\hline Budget funding & Lump sum & Lump sum & 0 \\
\hline Commissioning & State & State & 0 \\
\hline Demand dependency & $\begin{array}{l}\text { Single } \\
\text { ministry }\end{array}$ & mixture & 0 \\
\hline \multicolumn{4}{|l|}{ SUPPLY } \\
\hline Competitors & No & No & 0 \\
\hline Budget Typology & Task & Task & 0 \\
\hline Production form & $\begin{array}{l}\text { Contract } \\
\text { Provision }\end{array}$ & $\begin{array}{l}\text { Regulated } \\
\text { Provision }\end{array}$ & 0 \\
\hline Included in determining autonomy & \multicolumn{3}{|c|}{ Not included in determining autonomy } \\
\hline
\end{tabular}

Funding is generated by authoritative levies from within the sector, although the levy has been set at zero for a number of years. Costs of operations are covered by interest 
received on program equity. Low interest rates paid by minFin - due to interest rates on the capital and money markets - have an impact on net income from operations. The CFV arrangement on treasury management is in line with the rules for PLAs. Interviewees indicated that in the past, CFV had more treasury management autonomy than it has now. Compared to the past, autonomy is reduced; compared to present standards, autonomy is in line with arrangements. The authoritative levies, if applied, have to be based on total costs of income transfers including costs of operations. This is not essentially different from an authorised budget funded by government from a funding perspective, which means that no additional autonomy is generated.

The State commissions monitoring activities. Only if a SHA is in financial distress, demand would be generated on a citizen's request basis. A temporary program on restructuring urban areas (see e.g. Parliament, 2008g) is likely to result in applications for support by SHAs. This means that CFV's actual tasks will again be a mixture of monitoring and income transfer functions implying that delivery of services is not fully dependent on one single source of demand.

The variety in demand for services does not affect autonomy because the characteristics of demand for income transfers is based on citizen requests rather than (autonomous) citizen demand in a market setting. The production form of services that results has no effect on autonomy because the shift from government provision of monitoring services to regulated provision of services is only due to the lack of government funding but essentially the same compared to when government funded CFV.

\subsubsection{Planning and control}

CFV uses accruals accounting. Only a very small level of fixed assets are disclosed on the balance sheet; staff is the key asset. In terms of asset specificity this means that production depends on knowledge rather than on transferable technology.

CFV's budget is not disclosed in minVROM/minWWl's budget documents due to the fee based funding system. Respondents indicated very little influence by the minister on the budgeting process. There are no budget instructions given, although this might have been expected given the policy related issues in CFV's monitoring functions. In approval letters on budgets and annual reports, some general questions are mentioned by minWWI which have to be addressed during the following fiscal year but these questions do not have the character of instructions on services to be delivered. Levies charged have been zero for a number of years. If additional functions are to be performed on behalf of minVROM and minWWI, these are discussed at civil servant level and do not reach political decision levels. The system of funding including the lack of budgeting instructions generates additional autonomy for CFV.

CFV's funding system is based on recovery of costs incurred by fees. Practically speaking CFV's operations are funded from interest earned on the program costs. At the civil service level respondents indicated that it is known that continued funding of operating activities from interest is not sustainable due to low interest rates. Whether this issue is known at the political level is uncertain. In 2008, interest income was sufficient 
due to a higher level of financial assets resulting from a new program fee for restructuring urban areas rather than higher levels of interest rates. As a result, CFV is controlled on total costs without strict boundaries as is the case in a discretionary cost centre, in line with the expected responsibility centre type for a monitoring ZBO.

Table 17.10: Planning and control of CFV and impact on autonomy

\begin{tabular}{|c|c|c|c|c|}
\hline & Expected & fiscal 2007 & fiscal 2008 & Impact \\
\hline \multicolumn{5}{|l|}{ ACCOUNTING ISSUES } \\
\hline Accounting System & Accruals & Accruals & Accruals & 0 \\
\hline \% fixed assets & $<10 \%$ & $3 \%$ & $3 \%$ & 0 \\
\hline $\begin{array}{l}\text { Budget disclosure of operating costs in ministry } \\
\text { budgets }\end{array}$ & Line item & none & none & $\uparrow$ \\
\hline Responsibility centre type & $\begin{array}{l}\text { Complete } \\
\text { cost centre }\end{array}$ & $\begin{array}{l}\text { Complete } \\
\text { cost centre }\end{array}$ & $\begin{array}{l}\text { Complete } \\
\text { cost centre }\end{array}$ & 0 \\
\hline \multicolumn{5}{|l|}{ PLANNING \& CONTROL } \\
\hline Budget instruction by Minister-Principal & Yes & No & No & $\uparrow$ \\
\hline $\begin{array}{l}\text { Approval of budget document mentioned to } \\
\text { Parliament by minister }\end{array}$ & Yes & No & $\begin{array}{l}\text { In } \\
\text { minVROM's } \\
\text { annual } \\
\text { report } 2007\end{array}$ & $\uparrow$ \\
\hline $\begin{array}{l}\text { Approval of fees mentioned to Parliament by } \\
\text { minister }\end{array}$ & Yes & No & No & $\uparrow$ \\
\hline $\begin{array}{l}\text { Approval of annual report mentioned to Parliament } \\
\text { by minister }\end{array}$ & Yes & No & No & $\uparrow$ \\
\hline Frequency of reporting to Parliament & Yearly & No & No & $\uparrow$ \\
\hline $\begin{array}{l}\text { Performance indicators reported to Parliament in } \\
\text { ministries' budget documents }\end{array}$ & Throughput & None & None & $\uparrow$ \\
\hline $\begin{array}{l}\text { Performance indicators reported to Parliament in } \\
\text { ministries' Annual reports }\end{array}$ & Throughput & None & None & $\uparrow$ \\
\hline $\begin{array}{l}\text { Performance indicators reported to Parliament in } \\
\text { ZBO Budget documents }\end{array}$ & Throughput & $\begin{array}{l}\text { Not } \\
\text { Submitted }\end{array}$ & $\begin{array}{l}\text { Not } \\
\text { Submitted }\end{array}$ & $\uparrow$ \\
\hline $\begin{array}{l}\text { Performance indicators reported to Parliament in } \\
\text { ZBO Annual reports }\end{array}$ & Throughput & $\begin{array}{l}\text { informally } \\
\text { submitted: } \\
\text { Throughput }\end{array}$ & $\begin{array}{l}\text { informally } \\
\text { submitted: } \\
\text { Throughput }\end{array}$ & $\uparrow$ \\
\hline Frequency of reporting to Minister & Yearly & Quarterly & Quarterly & $\downarrow$ \\
\hline \multicolumn{5}{|l|}{ POLITICAL DEBATE } \\
\hline $\begin{array}{l}\text { Number of documents submitted to Parliament } \\
\text { regarding operations of ZBO }\end{array}$ & 0 & 2 & 11 & 0 \\
\hline $\begin{array}{l}\text { Number of discussion/questions on operations of } \\
\text { ZBO by MPs related to budget and annual report }\end{array}$ & 0 & 0 & 0 & 0 \\
\hline $\begin{array}{l}\text { Number of discussion/questions on operations of } \\
\text { ZBO by MPs other than budget and annual report }\end{array}$ & 0 & 0 & 12 & 0 \\
\hline
\end{tabular}

Information to Parliament on CFV operations is minimal. Basically, the ZBO appendix in the Minister-Principal's budget document describes the activities of CFV without any financial data either on budgets or on the levels of fees. Respondents indicated that MPs receive CFV's annual report informally. Theoretically this allows them to submit questions to the minister. No questions were raised on the funding of CFV in Parliament's documents for FY 2007 and 2008. In the ministry's 2007 and 2008 annual reports, the appendix on ZBOs and RWTs discloses an assessment of CFVs activities. However, this is performed inconsistently. With respect to fiscal 2007, approval of CFV's 2006 annual report and 2008 budget is mentioned; in fiscal 2008 no reference to this subject was 
found (Parliament, 2008ac, p. 232; Parliament, 2009k, p. 82-83). The relatively low interest in operations is also reflected in the lack of performance information on CFV.

Monitoring of CFV is based on a monitoring protocol (minVROM, 2006), which has later been changed to a more general monitoring protocol for all ZBOs and RWTs affiliated to minVROM (minVROM, 2008). In the approval letter of minWWI on the 2008 budget, CFV is asked to think about controlling the level of operating costs, rather than given an instruction to cap or reduce budgets (MinWWI, 2007b). In the letter of approval to the 2006 annual report, a discussion on information provision is addressed as an issue. The only other point mentioned in this letter refers to remuneration of the executive and non-executive board (minVROM, 2007). Apparently no other issues were of relevance to be discussed with CFV. The monitoring protocol requires quarterly reports to be submitted to the Minister-Principal. This is carried out and reduces autonomy compared to the expected frequency of annual reporting only for monitoring ZBOs.

The data shows a variation in documents submitted. In 2008 the number of documents and resulting questions is higher than in 2007. All questions raised that have some relation to operations concerned either political debates on the restructuring levy to be charged or problems of individual housing associations on governance issues. Although questions do concern CFV's operations, they actually focus on functions to be assigned to CFV and have no immediate impact on autonomy in (daily) operations.

Although CFV is formally not just a pure monitoring institution, planning and control is basically carried out in hindsight; in fact it is almost invisible to MPs. Therefore the actual autonomy experienced by CFV is greater than might be expected from a theoretical perspective. 


\subsubsection{NAK}

\subsubsection{Demand and supply characteristics}

NAK is a monitoring institution performing quality assurance functions. This kind of service is a sub-type of the monitoring group of services with a different expected market profile. Demand and supply are based on a market model; government only regulates provision of services. The public service character of quality assurance does not allow for more than recovery of structural costs rather than profit based production. As a result, expected autonomy is substantially higher than in case of the market regulators that are discussed here as well.

NAK provides quality assurance in the agricultural industry. Anyone who is planning to grow and trade agricultural products needs a quality assurance approval. In terms of qualification of services, this allows for exclusion and thus cannot qualify as a pure public good. Quality assurance is based on world-wide international standards and EU regulations and must be controlled by government. Therefore, NAK services qualify as impure public goods. In 2007-2008, this led to some debate in Parliament as NAK had to separate its private activities from its monitoring activities to comply with international standards (Parliament, 2007y). This is also the only topic on which questions were raised in Parliament with respect to NAK.

Table 17.11: Classification and impact of market characteristics on NAK's autonomy

\begin{tabular}{|c|c|c|c|}
\hline & Expected & Actual & Impact \\
\hline \multicolumn{4}{|l|}{ PRODUCT CHARACTERISTICS } \\
\hline Public good type & Pure good & Impure good & 0 \\
\hline \multicolumn{4}{|l|}{ ACTIVITIES } \\
\hline $\begin{array}{l}\text { \% monitoring activities in operating costs (2007, annual } \\
\text { report) }\end{array}$ & 100 & 100 & 0 \\
\hline Production type & Mass & Mass & 0 \\
\hline \multicolumn{4}{|l|}{ DEMAND } \\
\hline \% Funding from central government (2007, annual report) & 0 & 0 & 0 \\
\hline \% Public funding (2007, annual report) & 0 & 0 & 0 \\
\hline \% Funding largest demand initiator (2007, annual report) & $\begin{array}{l}\text { Not } \\
\text { applicable }\end{array}$ & $\begin{array}{l}\text { Not } \\
\text { applicable }\end{array}$ & 0 \\
\hline Type of funding charges & $\begin{array}{l}\text { Authority } \\
\text { biased }\end{array}$ & $\begin{array}{l}\text { Authority } \\
\text { biased }\end{array}$ & 0 \\
\hline Budget funding & Activity based & Activity based & 0 \\
\hline Commissioning & Demand & Demand & 0 \\
\hline Demand dependency & Others & Others & 0 \\
\hline \multicolumn{4}{|l|}{ SUPPLY } \\
\hline Competitors & Yes & No & $\downarrow$ \\
\hline Budget Typology & Output & Output & 0 \\
\hline Production form & $\begin{array}{l}\text { Regulated } \\
\text { Provision }\end{array}$ & $\begin{array}{l}\text { Regulated } \\
\text { Provision }\end{array}$ & 0 \\
\hline Included in determining autonomy & \multicolumn{3}{|c|}{ Not included in determining autonomy } \\
\hline
\end{tabular}

From a market perspective, only one divergence from expected standards can be observed. NAK's position is one of a group of organisations providing quality assurance in the agricultural sector. This might suggest competition and legislation suggests that 
minLNV assigns the quality assurance role to institutions by decree. In practice there is no competition. Each of the quality assurance entities monitors a separate branch of agriculture. The lack of competition reduces NAK's autonomy to some extent.

\subsubsection{Planning and control}

The atypical position of NAK is also found in the planning and control process. In planning and control, the expected levels of control deviates for budget disclosure in the MinisterPrincipal's budget document. This would theoretically result in only disclosing the budget in the appendix given the market characteristic of citizen demand. Production allows for output related rather than throughput related performance information and reporting to the Minster-Principal can be provided on a yearly basis given the regulated service provision character of NAK services. The market nature of the services and the legislation on services do not require a detailed budget instruction from minLNV and such a document does not exist.

Table 17.12: Planning and control of NAK and impact on autonomy

\begin{tabular}{|c|c|c|c|c|}
\hline & Expected & fiscal 2007 & fiscal 2008 & Impact \\
\hline \multicolumn{5}{|l|}{ ACCOUNTING ISSUES } \\
\hline Accounting System & Accruals & Accruals & Accruals & 0 \\
\hline$\%$ fixed assets & $<10 \%$ & $55 \%$ & $56 \%$ & $\uparrow$ \\
\hline $\begin{array}{l}\text { Budget disclosure of operating costs in ministry } \\
\text { budgets }\end{array}$ & $\begin{array}{l}\text { Only in } \\
\text { appendix }\end{array}$ & None & None & $\uparrow$ \\
\hline Responsibility centre type & $\begin{array}{l}\text { Complete } \\
\text { cost centre }\end{array}$ & $\begin{array}{l}\text { Investment } \\
\text { centre }\end{array}$ & $\begin{array}{l}\text { Investment } \\
\text { centre }\end{array}$ & $\uparrow$ \\
\hline \multicolumn{5}{|l|}{ PLANNING \& CONTROL } \\
\hline Budget instruction by Minister-Principal & No & No & No & 0 \\
\hline $\begin{array}{l}\text { Approval of budget document mentioned to } \\
\text { Parliament by minister }\end{array}$ & Yes & No & No & $\uparrow$ \\
\hline $\begin{array}{l}\text { Approval of fees mentioned to Parliament by } \\
\text { minister }\end{array}$ & Yes & No & No & $\uparrow$ \\
\hline $\begin{array}{l}\text { Approval of annual report mentioned to Parliament } \\
\text { by minister }\end{array}$ & Yes & No & No & $\uparrow$ \\
\hline Frequency of reporting to Parliament & Yearly & None & None & $\uparrow$ \\
\hline $\begin{array}{l}\text { Performance indicators reported to Parliament in } \\
\text { ministries' budget documents }\end{array}$ & Output & None & None & $\uparrow$ \\
\hline $\begin{array}{l}\text { Performance indicators reported to Parliament in } \\
\text { ministries' Annual reports }\end{array}$ & Output & None & None & $\uparrow$ \\
\hline $\begin{array}{l}\text { Performance indicators reported to Parliament in } \\
\text { ZBO Budget documents }\end{array}$ & Output & $\begin{array}{l}\text { Not } \\
\text { Submitted }\end{array}$ & $\begin{array}{l}\text { Not } \\
\text { Submitted }\end{array}$ & $\uparrow$ \\
\hline $\begin{array}{l}\text { Performance indicators reported to Parliament in } \\
\text { ZBO Annual reports }\end{array}$ & Output & $\begin{array}{l}\text { Not } \\
\text { Submitted }\end{array}$ & $\begin{array}{l}\text { Not } \\
\text { Submitted }\end{array}$ & $\uparrow$ \\
\hline Frequency of reporting to Minister & Yearly & Yearly & Yearly & 0 \\
\hline \multicolumn{5}{|l|}{ POLITICAL DEBATE } \\
\hline $\begin{array}{l}\text { Number of documents submitted to Parliament } \\
\text { regarding operations of ZBO }\end{array}$ & 0 & 12 & 5 & $\downarrow$ \\
\hline $\begin{array}{l}\text { Number of discussion/questions on operations of } \\
\text { ZBO by MPs related to budget and annual report }\end{array}$ & 0 & 1 & 0 & 0 \\
\hline $\begin{array}{l}\text { Number of discussion/questions on operations of } \\
\text { ZBO by MPs other than budget and annual report }\end{array}$ & 0 & 3 & 2 & 0 \\
\hline Included in determining autonomy & \multicolumn{4}{|c|}{ Not included in determining autonomy } \\
\hline
\end{tabular}


NAK uses equipment to provide their service, which is reflected in the level of fixed assets on the balance sheet. This also results in another level of asset specificity compared to other organisations and to more autonomy. NAK receives no formal budget instructions from minLNV; the budgeting process is bottom up and left to the managing director and the executive board. Although NAK's statute prohibits the generation of profits, full responsibility for all financial operations including investments remains within the organisation, which can therefore be classified as an investment centre.

Parliament is not informed on the approval of its budget, fees or annual reports by minLNV. Since the NAK annual report is not submitted to Parliament, performance information is not available. All these indicators demonstrate an increase in autonomy compared to what might be expected.

Respondents indicated that due to the transition of activities under new legislation as of 2005, the monitoring role of minLNV has been increasing. This is reflected in a letter from minLNV in which criteria for assessing proposed fees are discussed. Essentially, the requirements state a balanced budget, transparent calculation of the fees and a limitation on the equalisation reserve to a specified (in this case 50\%) level (minLNV, 2007). The civil servants in minLNV handle almost all issues that have to do with NAK based on an information protocol (minLNV, 2004). Intermediate financial reporting to minLNV is not necessary. The minister is only involved when questions are raised in Parliament. Although monitoring is made more explicit by these arrangements, essentially they do not affect NAK's operational autonomy.

Finally, a comment must be made about debate in Parliament. In 2007 in particular a substantial number of documents were submitted to Parliament. Most of these documents concerned tasks assigned to NAK including the separation of public and private tasks based on EU regulations. One document is highlighted here: in minBZK's letter on the civil service (Parliament, 2007f), NAK is included in the list of entities to be monitored with respect to staff number developments within the organisation, which is an indication for some reduced autonomy for the organisation.

NAK's position as a monitoring ZBO with respect to planning and control implies more degrees of freedom than expected. This is mainly due to the very light monitoring procedures within minLNV, which are caused by type of monitoring service provided. 


\subsubsection{NMa}

\subsubsection{Demand and supply characteristics}

$\mathrm{NMa}$ is the key market regulating institution. Its role is based on European competition regulations, implemented in Dutch competition law. The key function can be classified as a pure public service: non-excludable and non-rival. NMa production is individual case based, be it on mergers or on reporting of unfair competition. All market indicators are in line with this type of service: nearly fully government funded, lump sum budget based on tasks assigned and contract provision of services.

Unlike what might be expected, three ministries are involved in commissioning $\mathrm{NMa}$ services. The separate Energy Office and Transport Office are commissioned by minEZ and minVW respectively. MinEZ also commissions general competition monitoring and minfin has a role in commissioning the monitoring of financial services.

NMa charges fees for some licences. Respondents indicated that merger fees are only based on average costs and are not intended to be funding fees. Fees charged to the Energy Industry (some $€ 2.6 \mathrm{M}$ in 2007) are according to respondents supposed to cover all costs of the Energy Office; whereas the Transport Office is funded by government. Respondents were not aware of the logic behind this differentiation. NMa can impose fines on organisations; according to respondents these fines are not relevant for budgetary control. Overall, these fees do not have an impact on NMa's autonomy.

Table 17.13: Classification and impact of market characteristics on NMa's autonomy

\begin{tabular}{|c|c|c|c|}
\hline & Expected & Actual & Impact \\
\hline \multicolumn{4}{|l|}{ PRODUCT CHARACTERISTICS } \\
\hline Public good type & Pure good & Pure good & 0 \\
\hline \multicolumn{4}{|l|}{ ACTIVITIES } \\
\hline $\begin{array}{l}\% \text { monitoring activities in operating costs (2007, annual } \\
\text { report) }\end{array}$ & 100 & 100 & 0 \\
\hline Production type & Individual & Individual & 0 \\
\hline \multicolumn{4}{|l|}{ DEMAND } \\
\hline \% Funding from central government (2007, annual report) & 100 & 94 & 0 \\
\hline \% Public funding (2007, annual report) & 100 & 94 & 0 \\
\hline \% Funding largest demand initiator (2007, annual report) & 100 & 94 & 0 \\
\hline Type of funding charges & $\begin{array}{l}\text { Not } \\
\text { applicable }\end{array}$ & $\begin{array}{l}\text { Authority } \\
\text { biased }\end{array}$ & 0 \\
\hline Budget funding & Lump sum & Lump sum & 0 \\
\hline Commissioning & State & State & 0 \\
\hline Demand dependency & $\begin{array}{l}\text { Single } \\
\text { ministry }\end{array}$ & $\begin{array}{l}\text { Multiple } \\
\text { ministries }\end{array}$ & $\uparrow$ \\
\hline \multicolumn{4}{|l|}{ SUPPLY } \\
\hline Competitors & No & No & 0 \\
\hline Budget Typology & Task & Task & 0 \\
\hline Production form & $\begin{array}{l}\text { Contract } \\
\text { provision }\end{array}$ & $\begin{array}{l}\text { Contract } \\
\text { provision }\end{array}$ & 0 \\
\hline Included in determining autonomy & \multicolumn{3}{|c|}{ Not included in determining autonomy } \\
\hline
\end{tabular}


Although there are some deviations from the expected classification of demand and supply, these have a minor impact on the actual autonomy of $\mathrm{NMa}$, compared to what is the expected level of autonomy for market regulator.

\subsubsection{Planning and control}

The NMa governance structure is based on ZBO status for the executive board and civil servant status for the staff, who are seconded to the executive board. As a result, the full budget of $\mathrm{NMa}$ is included in the standard framework for ministries and is based on cash accounting rather than accruals accounting. The budget is found in a separate line item in minEZ's budget documents. Real budgetary instructions other than within the standard departmental framework are not issued to NMa. The NMa budget is disclosed on a gross basis: total expenses and total income is presented separately in minEZ's budget document.

Table 17.14: Planning and control of NMa and impact on autonomy

\begin{tabular}{|c|c|c|c|c|}
\hline & Expected & fiscal 2007 & fiscal 2008 & Impact \\
\hline \multicolumn{5}{|l|}{ ACCOUNTING ISSUES } \\
\hline Accounting System & Accruals & Cash & Cash & $\downarrow$ \\
\hline$\%$ fixed assets & $<10 \%$ & not applicable & not applicable & 0 \\
\hline $\begin{array}{l}\text { Budget disclosure of operating costs in ministry } \\
\text { budgets }\end{array}$ & Line item & Line item & Line item & 0 \\
\hline Responsibility centre type & $\begin{array}{l}\text { Complete } \\
\text { cost centre }\end{array}$ & $\begin{array}{l}\text { Discretionary } \\
\text { cost centre }\end{array}$ & $\begin{array}{l}\text { Discretionary } \\
\text { cost centre }\end{array}$ & $\downarrow$ \\
\hline \multicolumn{5}{|l|}{ PLANNING \& CONTROL } \\
\hline Budget instruction by Minister-Principal & No & No & No & 0 \\
\hline $\begin{array}{l}\text { Approval of budget document mentioned to } \\
\text { Parliament by minister }\end{array}$ & $\begin{array}{l}\text { Not } \\
\text { applicable }\end{array}$ & $\begin{array}{l}\text { Not } \\
\text { applicable }\end{array}$ & $\begin{array}{l}\text { Not } \\
\text { applicable }\end{array}$ & 0 \\
\hline $\begin{array}{l}\text { Approval of fees mentioned to Parliament by } \\
\text { minister }\end{array}$ & $\begin{array}{l}\text { Not } \\
\text { applicable }\end{array}$ & $\begin{array}{l}\text { Not } \\
\text { applicable }\end{array}$ & $\begin{array}{l}\text { Not } \\
\text { applicable }\end{array}$ & 0 \\
\hline $\begin{array}{l}\text { Approval of annual report mentioned to } \\
\text { Parliament by minister }\end{array}$ & Yes & $\begin{array}{l}\text { Includes } \\
\text { assessment }\end{array}$ & $\begin{array}{l}\text { Includes } \\
\text { assessment }\end{array}$ & $\downarrow$ \\
\hline Frequency of reporting to Parliament & Yearly & Departmental & Departmental & $\downarrow$ \\
\hline $\begin{array}{l}\text { Performance indicators reported to Parliament } \\
\text { in ministries' budget documents }\end{array}$ & Throughput & None & None & $\uparrow$ \\
\hline $\begin{array}{l}\text { Performance indicators reported to Parliament } \\
\text { in ministries' Annual reports }\end{array}$ & Throughput & None & None & $\uparrow$ \\
\hline $\begin{array}{l}\text { Performance indicators reported to Parliament } \\
\text { in ZBO Budget documents }\end{array}$ & Throughput & $\begin{array}{l}\text { Not } \\
\text { Submitted }\end{array}$ & $\begin{array}{l}\text { Not } \\
\text { Submitted }\end{array}$ & $\uparrow$ \\
\hline $\begin{array}{l}\text { Performance indicators reported to Parliament } \\
\text { in ZBO Annual reports }\end{array}$ & Throughput & Outcome & Outcome & 0 \\
\hline Frequency of reporting to Minister & Yearly & Monthly & Monthly & $\downarrow$ \\
\hline \multicolumn{5}{|l|}{ POLITICAL DEBATE } \\
\hline $\begin{array}{l}\text { Number of documents submitted to Parliament } \\
\text { regarding operations of ZBO }\end{array}$ & 0 & 28 & 34 & $\downarrow$ \\
\hline $\begin{array}{l}\text { Number of discussion/questions on operations } \\
\text { of ZBO by MPs related to budget and annual } \\
\text { report }\end{array}$ & 0 & 7 & 5 & 0 \\
\hline $\begin{array}{l}\text { Number of discussion/questions on operations } \\
\text { of ZBO by MPs other than budget and annual } \\
\text { report }\end{array}$ & 0 & 28 & 25 & $\downarrow$ \\
\hline Included in determining autonomy & Not include & determining & tonomy & \\
\hline
\end{tabular}


The cash based accounting system suggests that only cost centre based responsibility can exist. In practice, respondents indicated that NMa is fully subject to budgeting regulations for ministries including those on possible staff reductions (Parliament, 2007f, p. 47). There is one exception indicated by respondents: the use of consultants is not as strictly regulated as is usual for other government units. In some cases, Parliament has discussed the level of staff available for $\mathrm{NMa}$, often in relation to new tasks to be assigned (Parliament, 2007x, p. 4-5). In fact, the strong budgetary control means that the actual responsibility of management is reduced to that of a discretionary cost centre.

Due to the governance structure, planning and control is aligned with minEZ's structure. Respondents indicated that no performance indicators are included in the $\mathrm{NMa}$ budget documents submitted to minEZ. As a result, no performance indicators are given in minEZ's budget documents submitted to Parliament. The argument is that this emphasises the impartial role NMa has in relation to its funding ministries. In hindsight, the NMa annual report is submitted to Parliament and includes various types of performance indicators, including outcome indicators. Furthermore, minEZ explicitly assesses NMa's annual report which reduces autonomy compared to the expected practice of merely submitting an annual report to Parliament.

MPs have asked some questions on the internal standards set by $\mathrm{NMa}$, based on a report by the NCA on competition policy. The same document reveals that MPs - and their support staff - apparently have missed the essential separation of executive board and staff (Parliament, 2007z, question 8) which was extensively discussed in Parliament in 1997 and in 2000 (Parliament, 1997d; Parliament 2001h, p. 13).

Other questions raised in Parliament often refer to monitoring the postal sector, the health sector and the energy sector. These questions are mainly related to the program but may also have an impact on the work NMa has to carry out for adequate monitoring (see for example Parliament, 2007aa, questions 48, 79 and 81). A last issue that regularly leads to discussions in Parliament concerns fines imposed by NMa. Respondents indicated that the revenues were included in minEZ's budget document due to financial relevance although it was known that the revenues were being legally contested in court. In practice this has led to frequent questions by MPs. According to the respondents, the practice used by minEZ was new and court rulings on the initial fines sometimes led to reduced and or delayed revenues. These had to be reported in supplements to the budgets and attracted attention from MPs.

The organisational set up of NMa reduces autonomy within planning and control. NMa has a high level of political attention, including attention on operations, which also reduces autonomy. The general conclusion is that NMa's autonomy is from a planning and control perspective reduced compared to standards for market regulators. 


\subsubsection{NZA}

\subsubsection{Demand and supply characteristics}

NZA is the market regulator for the health sector. Part of its mission statement is as follows: 'The NZA creates and monitors properly functioning health and care markets. The interests of consumers are central in the performance of these tasks...' (NZA, 2009, p. 7). This suggests that NZA provides pure public services in the interest of all participants. However, one of its main objectives is 'proper execution of regulated fees, budgeting and insurance laws'. Part of this task is not based on impartiality, but driven by direct budgetary control directives given by minVWS (e.g. Parliament, 2006m). In the search for documents on NZA budgets, I found 6 instructions for fiscal 2007 and 2008 aimed at budgetary control. In my opinion these instructions mitigate the impartial role of NZA, because it acts as if it is an executive office of minVWS. Therefore, NZA services are impure public services rather than pure public services. It also means that NZA not only provides market regulating services but rather a mixture of services. The data does not reveal that NZA is fully funded on a lump sum basis by minVWS and that minVWS is the only initiator and commissioner for NZA's services.

Table 17.15: Classification and impact of market characteristics on NZA's autonomy

\begin{tabular}{|c|c|c|c|}
\hline & Expected & Actual & Impact \\
\hline \multicolumn{4}{|l|}{ PRODUCT CHARACTERISTICS } \\
\hline Public good type & Pure good & Impure good & $\uparrow$ \\
\hline \multicolumn{4}{|l|}{ ACTIVITIES } \\
\hline $\begin{array}{l}\% \text { monitoring activities in operating costs (2007, annual } \\
\text { report) }\end{array}$ & 100 & $<100$ & 0 \\
\hline Production type & Mass & Mass & 0 \\
\hline \multicolumn{4}{|l|}{ DEMAND } \\
\hline \% Funding from central government (2007, annual report) & 100 & 100 & 0 \\
\hline \% Public funding (2007, annual report) & 100 & 100 & 0 \\
\hline \% Funding largest demand initiator (2007, annual report) & 100 & 100 & 0 \\
\hline Type of funding charges & $\begin{array}{l}\text { Not } \\
\text { applicable }\end{array}$ & $\begin{array}{l}\text { Not } \\
\text { applicable }\end{array}$ & 0 \\
\hline Budget funding & Lump sum & Lump sum & 0 \\
\hline Commissioning & State & State & 0 \\
\hline Demand dependency & $\begin{array}{l}\text { Single } \\
\text { ministry }\end{array}$ & $\begin{array}{l}\text { Single } \\
\text { ministry }\end{array}$ & 0 \\
\hline \multicolumn{4}{|l|}{ SUPPLY } \\
\hline Competitors & No & No & 0 \\
\hline Budget Typology & Task & Task & 0 \\
\hline Production form & $\begin{array}{l}\text { Contract } \\
\text { provision }\end{array}$ & $\begin{array}{l}\text { Contract } \\
\text { Provision }\end{array}$ & 0 \\
\hline Included in determining autonomy & \multicolumn{3}{|c|}{ Not included in determining autonomy } \\
\hline
\end{tabular}

The supply side of the market for NZA is as to be expected: no competitors and "contract provision' based on a task budget. In this case the latter factor is very visible in the annual reports. For each separate sub-project, an indication of effort spent in number of days is given. Respondents indicated that this is driven by minVWS' desire to present information along the lines of the VBTB model used in central government. 
My conclusion is that due to the mixture and characteristics of its services, NZA is not fully a market regulator. From a market perspective, NZA characteristics are in line with expected characteristics of a market regulator. An exception is the public service type observed, which is due to the mixture of services and not a pure but an impure public service.

\subsubsection{Planning and control}

NZA's budget is included in the budget article that covers all health sector ZBOs under minVWS; only the appendix on ZBOs discloses the budget to be appropriated to NZA.

NZA uses accruals accounting. The level of fixed assets on the balance sheet is high, but details reveal that these assets are related to leased office space. Therefore, no impact on autonomy from asset specificity is observed.

With respect to commissioning, the letter of instruction sent out by minVWS does not only provide a financial framework, but explicitly lists a number of policy related services that should be delivered in the relevant fiscal year (minVWS, 2007b). Minister and NZA do discuss progress in NZA's activities twice a year and high level civil servants discuss progress 5 to 6 times a year or when needed. According to the respondents, these discussions are mainly focused on policy issues. Respondents indicated that the letter has a top down character and is not a negotiated document between NZA and minVWS. Furthermore, instructions are at a detailed level and the budget includes the announcement of budget cuts in future years (minVWS, 2007b). The proposed 2008 budget as submitted to minVWS is line item based and includes a separate investment budget. In the letter of approval on the 2008 budget, no reference is made to the separate investment budget as proposed by NZA. However, the letter includes an estimate of the monthly payments by minVWS to NZA. Furthermore, a detailed specification of some temporary expenses is required. Respondents indicated that the budgeting process is difficult due to changing political priorities on costs of operations. Until 2006, staff control was primarily aimed at hiring consultants. As of 2007 attention shifted to the core staff. In the NZA case, respondents indicated that this has led to a forced reduction in NZA's core staff. Formally, the letter of approval by minVWS is to be regarded as a decision to which objections can be made (minVWS, 2008b). From a responsibility centre perspective, this level of financial management tends to be a discretionary cost centre rather than a complete cost centre.

Respondents indicated that the basic planning and control cycle in the relationship between NZA and minVWS is based on a mid-term review only. Some respondents indicated that there is a mismatch in the expected role of minVWS in NZA's planning and control cycle. MinVWS apparently focuses more on controlling rather than on monitoring and strategic debates on planning and control at NZA. The information protocol that has been defined between minVWS and NZA covers the specification on the information NZA has to provide to minVWS as a result of its monitoring activities. In the notes to the information protocol, it is admitted that demand is generated by minVWS and in the event of unforeseen issues arising, NZA has to arrange extra capacity to cover this. If capacity is 
not available, it is up to NZA to put forward a proposal to deal with this. Although not stated explicitly, this means that either an increase in budget should follow, or - more likely - that prioritising means that other activities are delayed.

Table 17.16: Planning and control of NZA and impact on autonomy

\begin{tabular}{|c|c|c|c|c|}
\hline & Expected & fiscal 2007 & fiscal 2008 & Impact \\
\hline \multicolumn{5}{|l|}{ ACCOUNTING ISSUES } \\
\hline Accounting System & Accruals & Accruals & Accruals & 0 \\
\hline \% fixed assets & $<10 \%$ & $36 \%$ & $32 \%$ & 0 \\
\hline $\begin{array}{l}\text { Budget disclosure of operating costs in ministry } \\
\text { budgets }\end{array}$ & Line item & $\begin{array}{l}\text { Included in } \\
\text { article }\end{array}$ & $\begin{array}{l}\text { Included in } \\
\text { article }\end{array}$ & $\uparrow$ \\
\hline Responsibility centre type & $\begin{array}{l}\text { Complete } \\
\text { cost centre }\end{array}$ & $\begin{array}{l}\text { Discretionary } \\
\text { cost centre }\end{array}$ & $\begin{array}{l}\text { Discretionary } \\
\text { cost centre }\end{array}$ & $\downarrow$ \\
\hline \multicolumn{5}{|l|}{ PLANNING \& CONTROL } \\
\hline Budget instruction by Minister-Principal & No & Yes & Yes & $\downarrow$ \\
\hline $\begin{array}{l}\text { Approval of budget document mentioned to } \\
\text { Parliament by minister }\end{array}$ & Yes & No & No & $\uparrow$ \\
\hline $\begin{array}{l}\text { Approval of fees mentioned to Parliament by } \\
\text { minister }\end{array}$ & $\begin{array}{l}\text { Not } \\
\text { applicable }\end{array}$ & $\begin{array}{l}\text { Not } \\
\text { applicable }\end{array}$ & $\begin{array}{l}\text { Not } \\
\text { applicable }\end{array}$ & 0 \\
\hline $\begin{array}{l}\text { Approval of annual report mentioned to } \\
\text { Parliament by minister }\end{array}$ & Yes & $\begin{array}{l}\text { Yes; separate } \\
\text { document } \\
\text { includes } \\
\text { assessment }\end{array}$ & No & $\uparrow$ \\
\hline Frequency of reporting to Parliament & Yearly & $\begin{array}{l}\text { In regular } \\
\text { budgeting } \\
\text { process }\end{array}$ & $\begin{array}{l}\text { In regular } \\
\text { budgeting } \\
\text { process }\end{array}$ & $\downarrow$ \\
\hline $\begin{array}{l}\text { Performance indicators reported to Parliament } \\
\text { in ministries' budget documents }\end{array}$ & Throughput & None & None & $\uparrow$ \\
\hline $\begin{array}{l}\text { Performance indicators reported to Parliament } \\
\text { in ministries' Annual reports }\end{array}$ & Throughput & None & None & $\uparrow$ \\
\hline $\begin{array}{l}\text { Performance indicators reported to Parliament } \\
\text { in ZBO Budget documents }\end{array}$ & Throughput & $\begin{array}{l}\text { Not } \\
\text { Submitted }\end{array}$ & $\begin{array}{l}\text { Not } \\
\text { Submitted }\end{array}$ & $\uparrow$ \\
\hline $\begin{array}{l}\text { Performance indicators reported to Parliament } \\
\text { in ZBO Annual reports }\end{array}$ & Throughput & $\begin{array}{l}\text { Input \& } \\
\text { Throughput \& } \\
\text { detailed } \\
\text { qualitative }\end{array}$ & $\begin{array}{l}\text { Input \& } \\
\text { Throughput \& } \\
\text { detailed } \\
\text { qualitative }\end{array}$ & $\downarrow$ \\
\hline Frequency of reporting to Minister & Yearly & $\begin{array}{l}\text { Mid term } \\
\text { review }\end{array}$ & $\begin{array}{l}\text { Mid term } \\
\text { review }\end{array}$ & $\downarrow$ \\
\hline \multicolumn{5}{|l|}{ POLITICAL DEBATE } \\
\hline $\begin{array}{l}\text { Number of documents submitted to Parliament } \\
\text { regarding operations of ZBO }\end{array}$ & 0 & 14 & 21 & $\downarrow$ \\
\hline $\begin{array}{l}\text { Number of discussion/questions on operations } \\
\text { of ZBO by MPs related to budget and annual } \\
\text { report }\end{array}$ & 0 & 3 & 4 & 0 \\
\hline $\begin{array}{l}\text { Number of discussion/questions on operations } \\
\text { of ZBO by MPs other than budget and annual } \\
\text { report }\end{array}$ & 0 & 7 & 14 & $\downarrow$ \\
\hline Included in determining autonomy & Not include & determining & onomy & \\
\hline
\end{tabular}

Having a mid-term review implies that no intermediate reporting to Parliament is expected. Only in event of the assignment of new tasks, may Parliament be informed during a fiscal year as part of the regular reporting cycle (Parliament, 2007ab, p. 6). Performance information is only found in the NZA annual report, not in the minVWS documents. Most of the information is of an input or process type. NZA provides operational information on each of its main objectives in annual reports, but this 
information does not allow the costs of each of these objectives to be assessed. The financial statements do not disclose segmented information which makes it impossible to determine a fair indication of monitoring and other activities (NZA, 2009, p. 177). Again, the level of detail is an indication for reduced autonomy on NZA's operations.

MinVWS used to provide separate documents in which approval and assessment of annual reports of the relevant ZBOs were discussed (Parliament, 2008j). In this letter the minister announced that this practice will not be continued. This change in policy results in some additional autonomy, at least because MPs no longer have an incentive to put questions to minVWS.

Finally, some remarks on questions submitted by MPs. The fact that instructions are issued and sent to Parliament results in questions from MPs. Furthermore, questions are submitted on individual cases with respect to mergers and governance issues and the position of NZA in these cases. This affects operations because the implicit question is 'shouldn't NZA have acted?' Other issues regard new tasks to be assigned (structurally and temporary) either based on documents from minVWS or on the initiative of MPs. For example, MPs submitted a motion to let NZA develop criteria for financial support for pharmacists as well as a fee structure for pharmacists (Parliament, 2008ad and 2008ae). Such interventions indicate that MPs play a role in the services provided by NZA, but as there are no references made to prioritisation or additional financial resources, it seems that such questions are regarded as the well known free lunch.

The general impression on the planning and control aspects of NZA is that the organisation has fewer degrees of freedom than might be expected for a market regulator. Although at first glance, budgetary control with only a mid-term review seems moderate, the requirements for information provision on a line item basis and strict staff control measures reduce autonomy substantially. 


\subsubsection{Relative autonomy of monitoring ZBOs from an economic perspective}

Monitoring-type ZBOs are a less homogeneous group of ZBOs than income transfer ZBOs. In the examples selected, three ZBOs qualify as market regulators, one as a policy monitoring institution (CFV) and one as a quality assurance institution (NAK). These differences have some impact on the expected standard levels of autonomy; particularly for quality assurance. The comparative description is based on the findings in the individual cases as they are summarised in Appendix 10 excluding arrangements of last resort as was also performed from the legal perspective.

I have used complete cost centres, commissioned by government under contract provision of services and demand generated from a single ministry as the standard market characteristics for monitoring ZBOs. For quality assurance, regulated provision and citizen demand are important deviations from a market perspective.

On planning and control issues, I have taken as the standard approval of budgets and annual reports including yearly reporting to both Parliament and Minister-Principal. Again, degrees of freedom for quality assurance are at a higher level because output indicators can be used. Due to private funding, disclosure of budgets should be performed in the ZBO appendix in the Minister-Principal's budget because no contribution from government is expected.

\begin{tabular}{|l|llll|}
\hline & $\begin{array}{l}\text { low } \\
\text { auto- } \\
\text { nomy }\end{array}$ & neutral & & $\begin{array}{l}\text { high } \\
\text { auto- } \\
\text { nomy }\end{array}$ \\
\hline Expected & & & & NAK \\
& & CFV $\begin{array}{l}\text { AFM } \\
\text { NZA } \\
\text { NMa }\end{array}$ & & CFV \\
Actual & & & AFM & NAK \\
& & NMa & & NZA
\end{tabular}

Figure 17.2 Expected and actual autonomy of monitoring ZBOs from an economic perspective

Figure 17.2 shows the expected and actual autonomy from an economic perspective for the ZBOs studied here. On the level of expected autonomy, NMa is set at a lower level than the other market regulators due to the lack of legal entity status which means that it has to comply with departmental procedures and accounting rules.

Actual autonomy for the five monitoring ZBOs varies widely. At one extreme is CFV which has substantially more degrees of freedom than might be expected. In general, information on CFV's operations is minimal, with the exception of a high level of reporting to the Minister-Principal. At the other end of the spectrum is NMa. In this case frequency of reporting to Parliament, cost control emphasis in terms of a discretionary responsibility centre and explicit assessment of annual reports by the Minister-Principal reduce autonomy compared to standards. NZA's position on autonomy is above neutral, based on reporting frequencies to Parliament and the fact that as of 2008 an annual report is 
no longer submitted to Parliament. NZA's position is negatively affected by its discretionary cost centre responsibilities. In the AFM case, an increase in autonomy can be observed, which is mainly based on lack of information to Parliament and the mixture of services provided, partially mitigated by additional controls for minFin. Finally, NAK's position is in line with expectations, very low frequency and content of information both to Parliament and Minster-Principal.

On a comparative level, Figure 17.2 discloses the differences between the various ZBOs. Three observations can be made. First, on the market dimension, hardly any differences from standards are found. Second, deviations from standards with respect to information to Parliament generally have a positive effect on autonomy; information to Parliament is often not explicitly available. The exception is NMa in which case due to the Shelter-ZBO characteristics, budgets and financial ex post information are included in the MinisterPrincipal's documents. Third, overall ministerial control reduces autonomy. This is most explicitly visible for NMa, given its legal status, but also for NZA where very detailed levels of reporting and cost controls are applied.

The general conclusion on autonomy of the monitoring ZBOs is that ministerial controls are in most cases stronger than the expected standard, reducing autonomy, whereas from a Parliamentary perspective, autonomy generally diverges positively from the standards. In this case the variation in autonomy is relatively wide. There is no overall trend observed in autonomy, even if NAK as a very different type of monitoring institution is not considered.

\subsection{Mismatches in monitoring ZBOs}

In this section, I will assess the mismatches observed between legal and economic arrangements of the individual monitoring ZBOs, based on the research question for the empirical section of the study:

\section{Do Parliament's control tools match the control tools that fit the legal and economic characteristics of (monitoring) ZBO services?}

In Appendix 10, a comparative overview of legal and economic indicators used and their impact on autonomy is given. In this section, I will focus only on market and planning and control elements because these issues are based on the relationship between services delivered and required control levels. The discussion on mismatches is based on the same principles as was used for the income transfer ZBOs.

If the direction of the legal and economic indicators is negative overall or positive overall, a mismatch in terms of full divergence of control tools cannot be observed. Inconsistencies within groups of indicators may still exist. With respect to the monitoring ZBOs studied here, only the actual position of NZA shows whether a mismatch between economic (positive) and legal (negative) autonomy is observed. The overall result on market and planning and control indicators of autonomy for the monitoring ZBOs is that 
legal autonomy tends to increase compared to the standards used, except for CFV, and that except for NMa, economic autonomy increases as well.

In the AFM case, only small changes can be observed. From a legal perspective as well as from an economic perspective, some indicators generate increased autonomy whereas others generate decreased autonomy. What can be noted is that only planning and control issues determine the economic position and that this is also found in the legal measures on autonomy. Issues to be highlighted are restrictions on reserves, submitting multiyear plans and frequency of reporting to both Parliament and minister.

In the CFV case, formal autonomy is at a high level, but practices reveal that many of the legal issues are covered by monitoring arrangements at the level of civil servants. From an economic perspective, autonomy increases, mainly because there is hardly any flow of information from CFV and minister on operations to Parliament. Although not a pure mismatch, the change in position of CFV has elements of a mismatch based on the opposite directions of movement from formal to actual autonomy. In general terms, the minister imposes more (legal) controls whereas Parliamentary (economically characterised) controls are loosened compared to standard levels.

In the NAK case, both economic and legal autonomy increase compared to the standards used. The economic characteristics of NAK allowed for a higher standard level of autonomy. In practice, factors such as low political attention by minister and not submitting annual reports to Parliament explain part of the increased legal autonomy which is mitigated by the role minLNV has in approving NAK's budget. From an economic perspective, the observed increase in autonomy is stronger, mainly due to planning and control factors. NAK is - along with Vf/Pf - one of the few ZBOs for which an increase in the responsibility centre classification is observed. The increase in autonomy is partially mitigated by NAK's position on competition, which cannot be achieved.

NMa's position is from the perspective of operational control strongly determined by the legal status of the entity. Compared to expected levels of autonomy, no changes are observed in the legal domain; the only positive factor on autonomy is direct informal meetings with Parliament. The economic position of $\mathrm{NMa}$ is analytically similar to that of AFM and NZA and the standard used here for monitoring ZBOs. Actual autonomy is strongly reduced by determining rather than approving budgets and statements of accounts, the multiyear plans to be submitted as well as the lack of an equalisation reserve. Practically this means that NMa's economic and legal position match.

Finally, NZA's position can be classified as a real mismatch between actual legal and economic indicators. Formally, NZA's legal autonomy is reduced by determining the budget for operations, multiyear plans and restrictions on equalisation reserves. Furthermore, legislation requires that an assessed annual report is submitted to Parliament. Actual autonomy increases, but remains below standards due to the fact that submission of an assessed annual report has been discontinued. Economic autonomy increases as well, which results in more autonomy than under the standards. As was also 
observed in other cases, information to Parliament generates additional autonomy, partially mitigated due to a downgrade in responsibility centre type and strict reporting frequencies to minVWS, which is in line with the strict legal arrangements. The overall result on economic indicators remains positive.

Legal status does indicate different levels of control as with the income transfer cases. SLAs are not really expected for monitoring ZBOs, particularly not for the market regulators. The budgetary instructions to NZA show that in this case minVWS has substantial influence on a ZBO that is supposed to operate impartially. An explanation for this level of control is found in the mixture of tasks assigned: market regulation does not match with budgetary control on cure and care service providers. From an economic perspective, budgets can be classified as lump sum budgets as might be expected, except for NAK where an activity based budget is possible and practically applied. Like the income transfer cases, controls on investments are not found due to low levels of asset specificity. Again NAK is the exception. Treasury controls are based on CW and are equal for all monitoring ZBOs except for NAK which is allowed to operate at a higher level of autonomy. Evidence in the NZA case showed that rules can be ignored, when minVWS rather than the State Treasury financed investments in offices to be leased.

The overall impression on mismatches in autonomy for monitoring ZBOs is not as straightforward as in the income transfer case. One can observe increases in autonomy on both dimensions for PLBs, but the observed differences between AFM as a market regulator and NAK as a quality assurance institution are substantial. In the AFM case, a match between legal and economic controls is found both formally and in practice; in the NMa case, an actual match - at a low level - is observed. In all other cases, mismatches although not fundamentally diverging were found.

Within the PLA group, one can claim that the legal status of NMa as a Shelter ZBO explains the difference with the other two market regulators. Furthermore, the real mismatch in economic and legal indicators of NZA needs attention; a strong focus on the relationship between organisation and minister-principal affects autonomy negatively whereas the relationship with Parliament is neglected. Finally, the degrees of freedom in legislation for CFV are mitigated in practice, but economically little attention is given to the organisation, which generates other degrees of freedom. 


\section{Legal and economic control of assessed ZBOs}

In the previous two chapters, legal and economic variables determining formal and actual autonomy of selected income transfer and monitoring ZBOS have been evaluated. At the end of each chapter a short evaluation of the mismatches observed was given which allows the research question of this study to be answered:

\section{Do Parliamentary control tools match the legal and economic operational autonomy attributed to ZBOs?}

In principle, three answers can be given to the research question. First, a match between legal and economic control tools can be observed. Secondly, a mismatch can be based on strong legal control tools and relatively weak economic control tools. Third, a mismatch can be based on relatively weak legal control tools and strong economic control tools. Mismatches may be observed both in the formal legal and expected economic control tools on a ZBO, which covers a theoretical assessment. Mismatches can also be observed in the practical application of the control tools as they were set. The theoretical assessment of control tools has to be based on a standard which allows divergences to be observed. I have developed a standard level of use of legal and economic control tools to determine autonomy for both the income transfer ZBOs and monitoring ZBOs studied.

The standard for the legal control tools is derived from kZBO. The choice of kZBO rather than AW1996 is driven by the fact that kZBO intends to set a standard for new ZBOs and is also meant as a standard for existing ZBOs, although that requires changes in the existing (July 2007) ZBO case laws. The only differentiation made in kZBO is based on the legal status of a ZBO and this is included in the relevant standards for the individual ZBOs studied. Furthermore, the arrangement in kZBO on annulling ministerial decisions is not used as part of the standard for market regulator ZBOs because these types of ZBOs need to operate on an impartial basis. In general, kZBO covers normative, information, governance and cyclical issues. This covers a wide range of control tools which are not always relevant from an economic perspective. If mismatches between legal and economic control tools have to be assessed, only those legal control tools that aim at services provided and planning and control should be included in the assessment. Other control tools may affect autonomy as well but do not affect the economic position of a ZBO. For example, appointment of a board is not relevant from an economic perspective.

From an economic perspective, market dimensions determine how production can be organised. The planning and control tools that are needed are determined by product characteristics as well as the market environment in which the individual ZBO delivers its services. Unlike the legal setting, this means that no uniform standard for all ZBOs can be laid down from an economic perspective. Although not perfect, the classification into five 
groups of services (Smullen \& Van Thiel, 2002) including relevant subgroups does allow standards to be set for (sub)groups of ZBOs.

With respect to income transfer ZBOs, activity based budgeting, and standard cost centre responsibility types are expected to be the standard. Demand is generated on a citizen's request basis as funding is provided by government. As a logical result, planning and control will be performed on a frequent basis, at least to ministers, and not just at the budgeting and annual reporting stage. Parliament is to be informed on a yearly basis on issues regarding operations, which reflects the arm's length position of ZBOs. Performance information is likely to be available on an ex ante as well as ex post basis because income transfer decisions are at least measurable on an output or production level. The market and planning and control standards set for market regulation ZBOS are different. In a market regulation context, lump sum budgeting and complete cost centre responsibility centres related to State commissioning are the standards used. Impartiality is an important issue for monitoring institutions, which means that planning and control should allow for freedom in operations. As a result, less frequent reporting levels, public funding given the pure public good characteristics and process based rather than output based performance indicators can be expected. The market regulator task also implies a bias towards ex post information given the degrees of freedom required to operate impartially.

\subsection{General conclusions}

The general conclusion on mismatches in economic and legal control is that most ZBOs tend to have less legal autonomy than economic autonomy, or in other words, legal controls are stronger than economic controls resulting in mismatches between the two sets of control tools. In only three cases is matching control actually observed (AFM, SVB, $\mathrm{NMa}$ ) and in one case (AFM) design of control tools is balanced. Balanced control does not mean that control is in line with expected economic and legal standards; it merely means that increases and decreases in autonomy from a legal and economic perspective are balanced as a whole.

The full answer to the research question therefore is that 3 cases show matching economic and legal control tools affecting autonomy to a similar extent and that in 8 cases a mismatch is observed.

Table 18.1 shows control bias as observed for the individual ZBOs, both on the level of design of control tools as well as on the level of practical application of the control tools. The table discloses only direction of control bias based on the relevant standards used. It does not disclose the relative position of autonomy of the individual ZBOs. In two of the three cases in which matching actual control is observed, control levels are higher than standards expected by design, thus reducing autonomy of that particular ZBO. In the third case - AFM - control levels are below standard levels, leading to an increase in autonomy. 
Table 18.1: Control bias and level of control of ZBOs studied

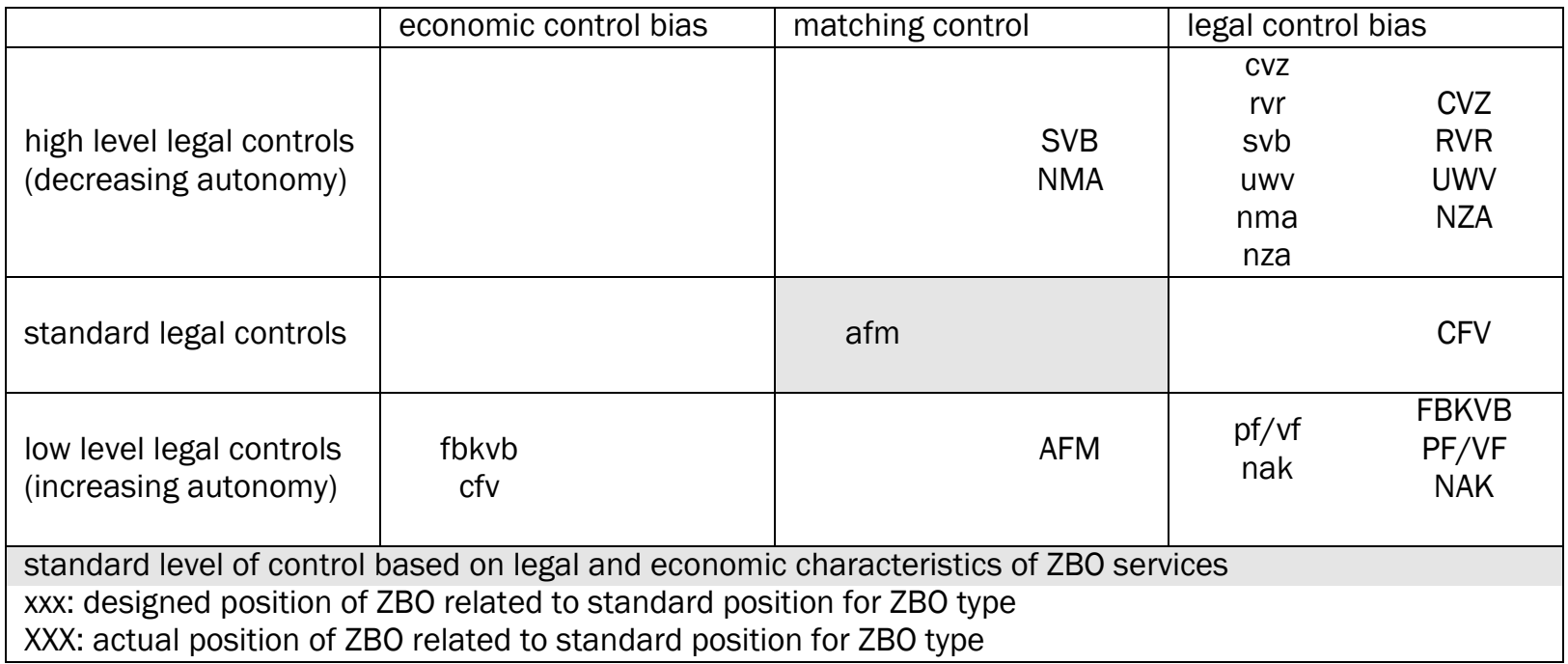

In Figure 18.1 the position of the individual ZBOs on a scale of legal and economic autonomy is shown. Two things draw immediate attention. First, the PLB type ZBOs tend to have increased levels of autonomy from both a legal as well as from an economic perspective, above the standard design given the legal status and product characteristics of the services provided and in fact even beyond the levels of control as designed for the individual cases. These PLBs therefore have more autonomy compared to the standards by design and in practice even more autonomy.

The assessment of PLA type ZBOs shows the reverse picture. All PLA-type ZBOs except CFV - face restricted legal and economic autonomy with an actual legal control bias. In the CFV case a shift from an economic control bias to a legal control bias is observed due to the fact that the lack of formal regulation in the law is mitigated by practical arrangements. However low levels of disclosure of information, particularly towards Parliament result in increased autonomy on planning and control issues.

The difference between PLA type and PLB type ZBOs is clearly observed with the income transfer type ZBOs (CVZ, RVR, SVB, UWV, FBKVB and Vf/Pf) as well as within the group of market regulators (AFM, NMa, NZA). The observations generally hold for the designed control levels as well as for the actually applied control levels for the individual ZBOs. It means that generally the design of control measure for income transfer ZBOs is based on a legally biased, more restrictive control for the PLA-type income transfer ZBOs and a legally biased, more permissive level of control for the PLB type income transfer ZBOs. 


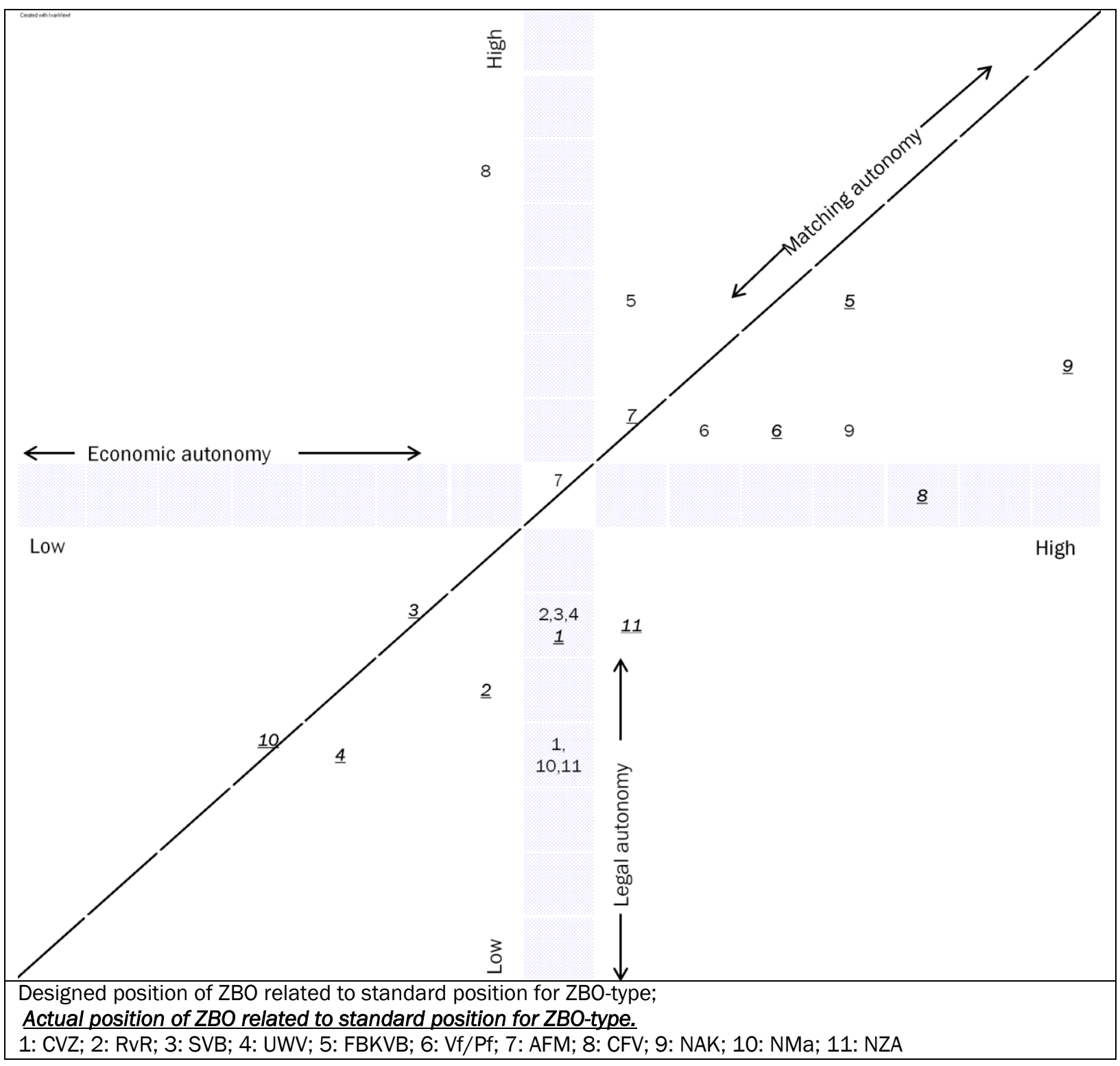

Figure 18.1: Designed and actual autonomy of ZBOs studied based on market and planning and control autonomy factors.

In the market regulator group, AFM shows an increased but balanced level of autonomy compared to standard levels of control whereas NMa also shows a matching but substantially more restrictive level of autonomy due to its Shelter rather than Subsidiary ZBO status. In the NZA case, a mismatch is observed with a legal control bias although control is less tight in practice than it is by design. This is mainly due to limited disclosure of information towards Parliament.

In the last monitoring case - NAK - a legal control bias can be observed, but both economic as well as legal control tools are above standards for monitoring ZBOs. The main reason for this is that NAK's services are based on citizen demand rather than being commissioned by the state and/or on citizen request. 


\subsection{Autonomy of income transfer ZBOs}

The general observations stated above are based on an aggregated assessment of the individual ZBOs. On a more detailed level, legal control tools on market and planning and control for income transfer ZBOs tend to have a negative impact on the ZBOs studied. Most prominent control tools deviating from the kZBO standard used are found on three issues. First, additional control on equalisation reserves, ranging from not allowing them at all (UWV, SVB) to purely theoretical arrangements given the use of reserves (RvR). Second, approval of budgets is in some cases changed into determination of budgets as if the particular ZBO is subject to a hierarchy (RvR, CVZ) or is explicitly mentioned to Parliament, allowing for direct debates between Parliament and minister. Third, in some cases (CVZ, SVB, UWV) multiyear plans have to be submitted to the Minister-Principal which is also not required by kZBO. These observations hold for the designed as well as the actual dispositions.

Three additional economic controls for income transfer ZBOs are found as well. First, although income transfers generally allow for measurable production and thus for activity based budgeting, actual practice shows that budgets tend to have a lump sum character. This is most visible in the RvR case where budget overruns have to be transferred to fixed financial assets on the balance sheet rather than as receivables. It also holds for SVB, UWV and CVZ; all three experience a strong focus on the defined level of the budget and in the CVZ case even on some separate parts of the budget. Second, and related to this funding method is the fact that responsibility centre types do not qualify as standard cost centres but as discretionary cost centres with an emphasis on compliance rather than on efficient production. A last issue to be mentioned is that in all income transfer cases, including the PLB type ZBOs, substantial numbers of documents were submitted to Parliament. UWV is clearly at the top of the list, both in number of documents as well as in number of questions submitted on operations. Relatively low numbers of questions were submitted on the PLB type ZBOs.

Economic control tools that are less used than might be expected are budget instructions including expected service levels. Such instructions are possible given the measurable character of the services provided, but in only three cases are they used (RVR, SVB, UWV). The other three ZBOs are free to prepare a budget without substantial involvement by the minister-commissioner. In the CVZ case, interviewees even indicated that a budget instruction would conflict with CVZ's arm's length position. For Parliament, control on an ex ante basis is made difficult because only partial - if any - budgets are disclosed on the income transfer ZBOs. Parliament is generally not informed on approval of the ZBO budget by the Minister-Principal. Only in the case of SVB and UWV is the lack of availability of this control tool mitigated by setting up reporting alongside the formal budget documents. Budgets on operations by income transfer ZBOs are not always transparent. In an income transfer ZBO, two types of budgets exist: those for providing the services and those for the actual income transfers. In annual reports, the different 
budgets are separately accounted for, but when allocating the budget, particularly in the PLBs, the separation between costs of operations and costs of programs is not available.

The economic control tools used can be attributed to ministerial control tools and Parliamentary control tools, when information is supposed to be available to Parliament. The data shows that in general, economic control tools relevant for a minister are applied more restrictively than expected, except for budget instructions. Control tools towards Parliament generate more autonomy; disclosure of information towards Parliament is overall lower than expected, except for the issue of frequency of reporting which tends to be in line with the basic planning \& control cycle towards Parliament.

Finally, I recall a few remarkable issues on individual ZBOs. First, RvR is funded on the basis of a subsidy arrangement. This is from an operations perspective unusual as the character of the services delivered is based on a contracting out basis rather than a grant to reduce costs for citizens. Furthermore, a subsidy arrangement allows for appeals in the event of differing opinions which might be undesirable from a governance perspective. Although not formally set up as a subsidy relationship, the determination of budgets in the case of CVZ resulted in the start of an appeal procedure which shows that this is not purely a theoretical situation. Second, intervention in the event of negligence is a control tool of last resort, which has not been used within the timeframe of this study. However, costs of office leases did lead in the case of UWV to the dismissal of UWV's CEO in 2004 (Parliament, 2004g). Third, in three cases (CVZ, RvR, FBKVB) detailed audit protocols were given which specify control levels for auditing the financial statements of ZBOs, including required levels of attention when auditing particular items. Even more remarkable perhaps is that minOCW behaves inconsistently: it prescribes a detailed audit protocol for FBKVB, but similar arrangements are not applied to Vf/Pf which is ultimately also funded by minOCW's contributions. Fourth, the differences between SVB and UWV, both operating under the same basic legislation, are due to the wider variety of services allowed for SVB and the high level of political attention given to UWV. Fifth, control tools within Vf/Pf show a wide variety. I already mentioned lack of budget instructions generating more autonomy, but neither budgets nor fees are reported to Parliament. On the other hand, minOCW submits an assessed annual report to Parliament and requires a high level of reporting frequency although once (program) fees have been set there is no longer any immediate budgetary impact on minOCW. It seems that the same holds for legal arrangements; sometimes additional controls are applied, on other issues, control is less strict. Compared to the other five income transfer ZBOs which show a clear positive or negative impact on autonomy, Vf/Pf's position is more ambiguous.

Autonomy of PLA income transfer ZBOs is thus generally below expected levels given the product commercial characteristics of the services. Only in one case -SVB - is a balance between legal and economic control found, although at reduced levels of autonomy. 


\subsection{Autonomy of monitoring ZBOs}

As in the cases of income transfer ZBOs, autonomy of PLBs in the monitoring ZBO group is at a higher level than PLA autonomy. The key divergence of NAK can be explained by its role as a quality assurance institution rather than a market regulator or policy monitoring institution.

Application of control tools within the monitoring ZBOs is more ambiguous than in the income transfer case. For NMa, both legal and economic control tools reduce autonomy; tools that affect autonomy positively are not found. The other two market regulators show an ambiguous set of applied control tools. For AFM, economic control tools show high levels of reporting to both Parliament as well as minister, but approval and disclosure of budgets and fees towards Parliament is not covered. From a legal perspective, audit protocols and strict regulation on statements of accounts and budgets are given. In the NZA case, legal control tens to be restrictive but economic controls are ambiguous. In this case, the ambiguity is found in strict control towards minVWS whereas control tools relevant for Parliament such as information on approval of budgets, fees and annual reports are not used.

In the NAK and CFV case the general trend on both legal as well as on economic controls is positive; the only exception is the lack of competition in the NAK case which is legally implied.

Control tools on monitoring ZBOs relevant for Parliament generally generate additional autonomy for the ZBOs selected; only frequency of reporting to Parliament shows a variety in applied controls. Reporting on AFM and NMa is frequent whereas for the other three ZBOs separate reporting is nothing more than what is found in the appendices on ZBOs in the budget and annual report documents of the Principal-Ministers. Information on approval of budgets or fees is generally not provided. Frequency of reporting to the minister is applied more frequently than expected standard levels, often on a quarterly basis or otherwise not aligned to the reporting frequency needed to fit in with the budgeting processes in Parliament. Another difference is found in responsibility centre types, which express less autonomy in two (NMa, NZA) of the three market regulator ZBOs.

Finally, I will note some particular issues on individual ZBOs. First, in the case of CFV, legal autonomy seems to be high given the legislation, but practical arrangements as laid down in a departmental monitoring document mitigate these degrees of freedom. From an economic perspective, service characteristics do not require additional degrees of freedom, but in fact a high degree of freedom is provided given the funding system and the historical role of stakeholders other than minVROM within CFV. Second, it is remarkable that in a market regulation setting a detailed letter of instruction is submitted. This applies to NZA and is to some extent due to the two conflicting services to be provided. On the one hand NZA provides market regulation services, on the other 
policy monitoring up to imposing fees on the medical sector. Third and also related to NZA, rules can apparently be ignored if needed. The procedure of providing financing by minVWS with respect to the new NZA offices is not in line with the basic rule that financing is provided by the State Treasury. Fourth, inconsistent policies on the use of staff set by political authorities have an impact on operations of a ZBO. This was brought to the fore by NZA which was confronted with a focus on reducing the hiring of consultants and maintaining relevant knowledge within the core organisation until fiscal 2006. After that, the emphasis was on reducing core staff rather than consultants without a corresponding debate on tasks assigned which made hiring of staff more complex. Fifth, although annulment decisions are an instrument of last resort, some respondents indicated that a minister can use his powers to change arrangements prior to a possible formal annulling of a decision. Sixth, in the case of NAK, equalisation reserves are allowed up to a high level compared to other ZBOs or to the executive agency arrangement. This is due to uncertainties in demand on a yearly basis related to the agricultural sector in which production also depends on the weather during the growing season.

From a perspective of the services provided, variation in the group of monitoring ZBOs is broader than in the income transfer group. CFV and NAK are part of different sub-groups within the monitoring group as a whole. In the market regulation group, variation should be low given service characteristics. In this case, the legal status of ZBOs is an indicator for the level of autonomy. In the NZA case, control is influenced by a mixture of regulatory and policy monitoring tasks in which, according to respondents, balance still has to be found given the fact that NZA is a relatively young organisation.

\subsection{Control by ministers}

The eleven ZBOs studied are controlled by seven Ministers-Principal; three MinistersPrincipal are responsible for two ZBOs. Only in the case of minSZW can it be argued that control of the respective ZBOs SVB and UWV is aligned. Two comments on this can be made. At the en of 2008 minSZW is Minister-Principal of only three full time ZBOs, which are all subject to the same legislation. Differences based on legislation are not found. The differences that were observed are due to the different market and political positions of SVB and UWV. The second remark regards control as Minister-Principal on SVB. MinSZW used a separate unit to control SVB from a principal perspective and left the commissioning role to the respective commissioning units inside or outside minSZW. In practice, the emphasis of the controlling unit is on the services provided by SVB on behalf of minSZW. Others are neglected once approval to provide the service has been given. This results in a risk of not having a full overview of all services provided by SVB. In a statement in Parliament, minJG however implied that he relied on the monitoring and controlling role of minSZW for the services provided by SVB. The question is whether Ministers-Commissioners can actually rely on minSZW's SVB monitoring function. 
The other two Ministers-Principal, minOCW and minVWS are responsible for more ZBOs, with diverging legal frameworks as well as diverging service characteristics. Although differences in service characteristics may justify different control tools, it may also be that there is no reason for differences in control tools. At least five inconsistencies were observed. First, an inconsistency was observed in issuing budget instructions by minVWS. In the case of CVZ no budget instruction is provided. According to interviewees this is to ensure the arm's length position of CVZ. In the NZA case, a budget instruction is given, not only on the level of budgets and general instructions on programs but at a rather detailed level of the services to be provided in the new fiscal year. NZA's role as a market regulator suggests that the organisation is able to set its monitoring program impartially and independently but in actual fact this is overruled by the instructions from minVWS. The differences in arrangements are even more striking as they are set by the same Directorate General within minVWS acting as both principal and commissioner for the two ZBOs discussed.

Second, minOCW sets a detailed audit protocol for the art funds including FBKVB. Although Vf/Pf has substantially more costs processed, such an audit protocol is not defined.

Third, a more general inconsistency on separation of program budgets and operating budgets can be observed. Within the minOCW domain, both Vf/Pf as well as FBKVB have budgets which include costs of operations. The former IBGroep used a separation between program and operations budget. On a more general level, the same observation can be made. SVB, UWV and CVZ are separately controlled on operating budgets as was the case for IBGroep. In the case of CVZ this is most visible as CVZ's budget is funded by minVWS separately from the program budgets. SVB and UWV's budgets are funded by fees which makes the separation less visible. In the intermediate reports on SVB and UWV the focus is on costs of operations and results rather than the key program costs. For RvR, again budgets include costs of operations although in the details of minJus' budget proposal unit costs of operations can be found. The conclusion is that transparency on differences between costs of operations and costs of programs is not always available for income transfer ZBOs. This is even more remarkable as in the case of income transfer executive agencies, program costs are explicitly excluded.

Fourth, ministers do not act consistently over time. In the appendix on ZBOs by minVROM in the 2007 annual report, approval of the 2008 budget and annual report are explicitly mentioned, a practice which was discontinued in the 2008 annual report of minVROM as well as in minWWl's report after the transfer of responsibility for CFV to minWWI. Similarly, minVWS discontinued its practice to assess the annual reports of its ZBOs with the argument that KZBO made this obsolete but ignoring the still extant legal requirement to do so.

Fifth, another inconsistency when comparing ZBOs and executive agencies is the level of the equalisation reserves. I have indicated that minVWS restricts the level of equalisation reserves by decree to a maximum of $5 \%$ of the budget for a fiscal year. The 
general rule on executive agencies, including those under minVWS is however $5 \%$ on the average budget over three years. An explicit motivation for this difference was not given. An interviewee suggested that this might have be based on historical reasons.

The discussion on the autonomy of ZBOs is concluded with a best practices comment. The debate on ZBOs is a debate on ministerial control, authority and services provided, but also a debate on the opportunities for Parliament to use its right to authorise budgets and the information required to do so. The arrangement in kZBO to submit ZBO annual reports directly to Parliament is a formal expression of the request for information by Parliament. However, MPs who were consulted in the context of this study also mentioned information overload. The appendices in departmental budget documents and annual reports are a form of finding a balance between information overload and relevant information. It seems that the solution used by minFin to provide summarised performance and financial information within the appendix is a form that provides that balance, although information, particularly on the balance sheet, is still missing. This is an issue explicitly referred to by the NCA (Parliament, 2006a). Irrespective of the reasons for the variation in autonomy as observed in this study, the practice used by minFin can contribute to more transparency and improved political understanding of what might be labelled an arm's length black box delivering public services. After all, one of the main reasons for introducing kZBO was political primacy on public services. The new law does not achieve these expectations given the divergences from the standards shown here but perhaps the more pragmatic information solutions might contribute more substantially. 


\section{Summary and Conclusions}

In this study I have assessed the operational autonomy of a Dutch type of arm's length organisations, Zelfstandige Bestuursorganen (ZBOs) from a legal and economic perspective. The research question in this study is:

\section{Do Parliamentary control tools match the legal and economic operational autonomy attributed to ZBOs?}

In the following sections, I will address the relevance of ZBOs and the background to the research question. Then I will discuss the methodology used to carry out the research project. The actual research project is discussed in sections 19.4 till 19.6. The chapter is concluded with an assessment of results and an outlook for future research.

\subsection{Role of ZBOs in Dutch National Government.}

Dutch central government has, like many other governments in the last three decades, discussed and implemented a variety of options of privatisation and autonomisation of activities that were previously managed within the hierarchical structure of ministries.

ZBOs are organisations that operate on behalf of central government and deliver unilaterally binding decisions given a task and program description set by Parliament and ministers, in an organisational setting outside the hierarchical structure of central government. This theoretically means that they have more degrees of operational management freedom than purely hierarchical units within a ministry which provide similar services. Most ZBOs have a public law structure (Public Law Administrations; PLA; OECD, 2002, p. 19). Private law based ZBOs do also exist, mostly for historical reasons. They are labelled as Private Law Bodies (PLB).

In many western countries (except Scandinavia; Statskontoret, 2001), creating at arm's length entities really started in the 1980s under fiscal pressure and new emerging theories on public (financial) management. In the Netherlands, this period was also used to re-assess the organisation of service delivery by central government resulting in new organisational structures. In the Dutch political context in which corporatist elements and organisation of activities within separate religious groups has been an important factor, the use of arm's length organisations - including what is now labelled a ZBO, was practiced even before World War II. After the war, the development of the welfare state led to an increase in government services including an increase in the use of ZBOs (Van Thiel, 2000).

The relevance of ZBOs for government can be illustrated based on a variety of indicators. First, although the definition of a ZBO seems unambiguous, different publications provide different numbers of ZBOs in existence, ranging from over 100 (e.g. Parliament, 2008b) to over 600 (Van Thiel, 2009). These differences arise from differences over time, but 
more importantly from different interpretations as to what is to be counted. Some publications count every single organisation which is classified as a ZBO; others group together organisations that provide the same type of activities and then start counting. In my case, I have used a reference list provided by minBZK on the Internet on July 12007. This list does not treat all cases equally. Some ZBOs are grouped; others - which might be grouped - are listed separately. After modifying the list to produce a more consistent grouping of organisations, I ended up with a list of 128 ZBOs, which are associated with all central government ministries.

Another relevant issue is the impact of ZBOs on government budgets. Again estimates vary, depending on what is included. A wide definition of financial relevance includes both program costs to be processed by ZBOs (particularly in case of income transfers) as well as operating costs of the organisations (to put it simply: cost of staff). In the wide definition, and based on the 2006 annual reports, estimated total ZBO costs are some $€ 80$ billion, which is approximately $15 \%$ of Dutch GDP and some $40 \%$ of total national government spending. Using a restricted definition which only focuses on operating costs, these same annual reports result in an estimate of some $€ 7$ billion, just below the estimated operating costs of executive agencies ( $n=38$ in 2006). Unambiguous estimates of numbers of staff at ZBOs are not available, but an estimate of 56,000 (Parliament, $2007 a$, p. 4) seems plausible given estimates on numbers of staff in executive agencies (Kraan, 2006, p. 226).

ZBOs cannot be ignored, either in number or in financial relevance within the structure of central government. To put it differently, it is sufficiently relevant to discuss controlling ZBOs in Parliament.

\subsection{The background to the research problem.}

The label ZBO was first used by Scheltema in 1974, when he drew attention to a lack of organisational legal framework for these organisations. This remained the case until 1995 when ZBOs became a serious issue on the political agenda: the key theme was insufficient political accountability. A Netherlands Court of Audit [NCA] report in 1995 (Parliament, 1995a) led to reconsidering the general institutional arrangements. By 2009, the NCA concluded that ministries had managed to organise improved control tools, but accountability issues at the political level have still not been solved (Parliament, 2009b).

The issue of accountability is however difficult to manage if service delivery standards are not made explicit. For Parliament ministry budget documents are the main source of information on ZBOs. These documents are also the basis on which to set budgets when a ZBO is fully funded by government. In particular, ZBOs that are not fully funded by government are beyond ex ante financial control by Parliament. This is what initially triggered this study: how does Parliament control ZBOs when budgets are not even disclosed in the budget authorisation process? In the early preparation stage of the study, 
it appeared that the variety in services provided by ZBOs as well as types of ZBOs required an assessment of the control tools available to Parliament that are in line with the characteristics of the different types of ZBOs.

The emphasis on control by Parliament implies that using an organisation and management or a public administration perspective on the reasons for creating a ZBO cannot provide an answer to the research problem. ZBO operations are determined by the legal restrictions that are set when the organisation is created as well as the tasks assigned and the economic dimensions that are related to executing these tasks. The two legal and economic frameworks can be used to develop an expected standard set of control tools given the characteristics of the services delivered by a ZBO. These standards can be compared to both the formal standards set for an individual ZBO as well as to the actual use of the controls in practice. This is expected to hold for the legal control tools as well as the economic control tools. However, if legal standards and economic standards set do not correlate with each other, this might result in conflicts in actual ZBO operations and ambiguity in the use of controls by Parliament and minister. An assessment of matching control arrangements should be based on similarities in legal and economic measures. It is not useful to try and find a mismatch between a legal control such as appointment of the board of a ZBO with economic control tools because there is no economic equivalent of a rule on appointments. Therefore, the focus is on those control tools that are relevant for the services to be provided (market characteristics) and for planning and control. That does not mean that normative legal control tools do not affect autonomy. Ministerial influence and thus impact on ZBO autonomy changes if a minister has the power to appoint and dismiss ZBO board members. By testing whether or not economic and legal standards match in individual cases these problems can be revealed. Figure 19.1 visualises the idea of matching autonomy. On the central point, a full match between economic and legal autonomy exists based on the standard level of autonomy derived for a particular type of ZBO. If formal and actual autonomy move along the diagonal line, there is still a match, only at a higher or lower level of autonomy than was expected from the standard. If however formal and actual autonomy are not on the diagonal line, then a mismatch is observed. Two options exist: first, above the diagonal line, legal autonomy is at a higher level than economic autonomy, which means that management has more degrees of freedom than the economic characteristics of $a$ particular ZBO allow for. If a ZBO is positioned below the diagonal line, then the legal framework restricts management more than is required given the economic characteristics of the services provided by that ZBO. To put it into political terms: if a ZBO is positioned above the diagonal, politicians have either deliberately set legal autonomy at a higher level than expected based on the standards or are not aware of a mismatch between economic and legal autonomy. Below the diagonal line, legal control tools restrict the autonomy more than might be expected given the characteristics of services, again either deliberately or accidentally. On the diagonal line, matching control exists but at higher or lower levels than expected. 


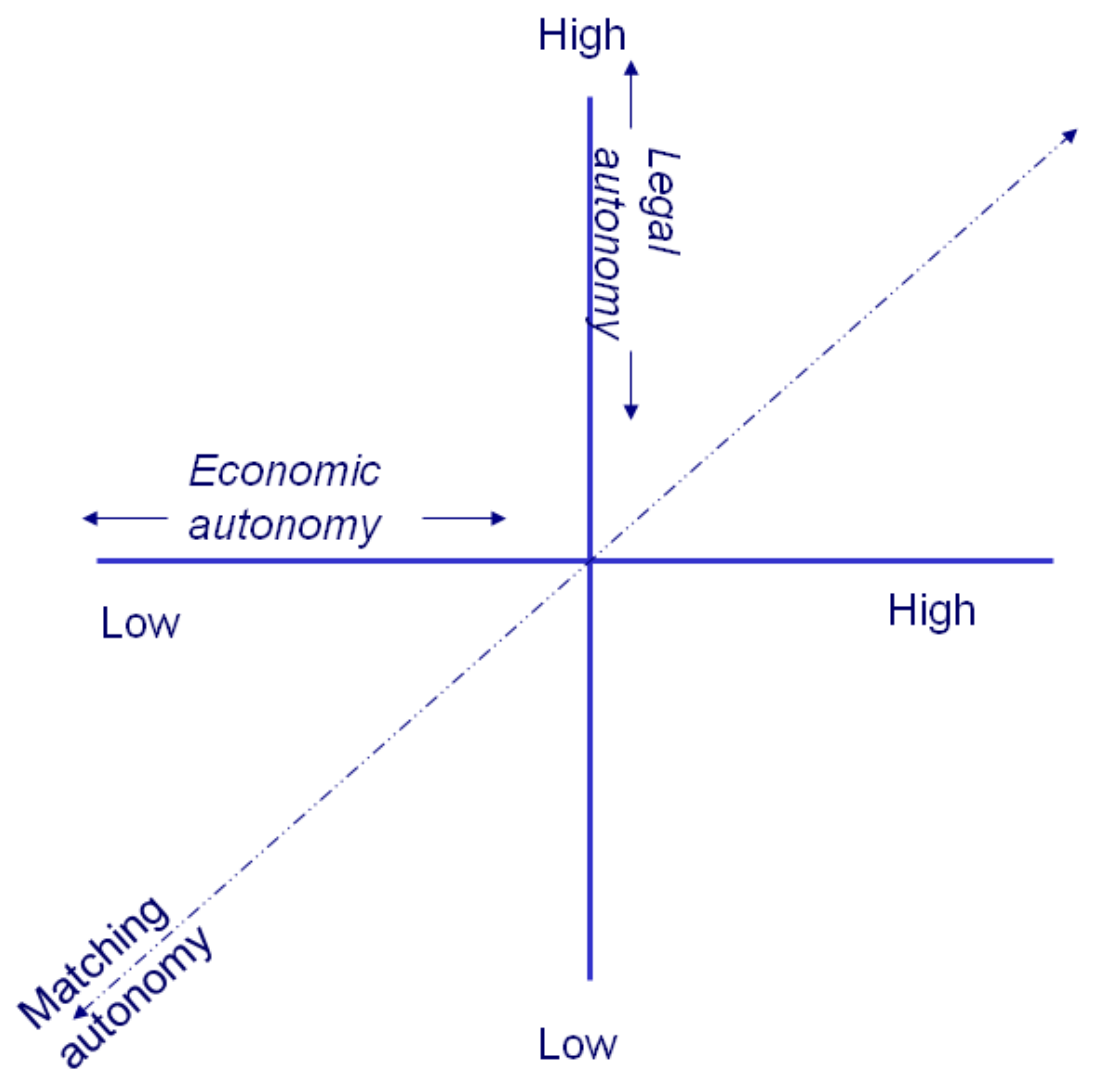

Figure 19.1: Match in legal and economic autonomy of ZBOs

Studies on the legal dimensions of the use of ZBOs and particularly on the neoinstitutional economic dimensions of ZBOs have previously been performed (e.g. Zijlstra, 1997; Kummeling et al, 1999; Van Leerdam, 1999). On a more general level such studies also exist for similar organisations in other (western) jurisdictions (e.g. Barker, 1982; OECD, 2002). This study contributes to knowledge on ZBOs as it explicitly uses a combination of two different sets of knowledge and as a result generates a multidisciplinary approach to the use of (a specific form of) organising and providing government services at arm's length of the traditional hierarchical structures.

\subsection{Methodology}

The study focuses on operations of ZBOs. A literature study from both a legal and economic perspective is used to find relevant indicators for autonomy of ZBOs. Other lines of literature provide references for classification and structuring the group of ZBOs into similar groups of entities. This grouping enables standards to be developed from a legal and economic perspective to assess formal and actual autonomy of the individual ZBOs that were selected in the empirical part of the study.

Based on the knowledge retrieved from the literature, a multiple case study design based on a stratified sample was used. This choice was driven by the fact that given the size and variety within the population a random sample would not allow general conclusions to be drawn. A single case study might have resulted in a more detailed description of that individual case but does not allow cases to be compared. By 
controlling the cases on the main variable 'type of services delivered', I was able to assess whether or not ZBOs providing similar tasks are faced with similar controls from the political system. Another reason for a case study design is found in the fact that although several studies on ZBOs have been published, these studies generally focus on a mono-disciplinary approach, for example purely from a legal or an economic perspective. Finally, preparing and executing a survey on the population as a whole would probably give an indication of perceived - not observed - autonomy by respondents and does not provide the level of detail that can be achieved with case study research.

Ultimately, I have selected 11 cases within 2 groups of ZBOs (Income Transfers and Monitoring). The selection is based on the relevance of the individual groups of ZBOs in numbers, financial relevance and a variety in legal status. The individual cases were not selected randomly but based on creating sufficient variety within the groups.

The research design is based on data triangulation using different research techniques. I started with a description of the field of ZBOs based on a list provided by the Minister of the Interior (minBZK) on the Internet as of 1st July 2007. Based on that list, I have searched the Internet for annual reports for the ZBOs listed. The list of 1st July 2007 serves two purposes: (1) mapping the field of ZBOs and (2) defining a starting position for actual research by using the relevant regulations and measures in place on that date as $a$ framework for assessing ZBO autonomy.

Actual research is based on a literature study identifying of legal and economic variables that affect ZBO control and autonomy. Based on the variables identified, a semi-structured questionnaire was developed which is the basis for interviews with respondents from within ZBOs as well as from the ministries which have political responsibility for ZBO operations. At the ZBO level, respondents were interviewed involved in the interaction between ministry and management of the ZBO. At ministry level, generally staff from the key financial unit and staff from the relevant policy area were interviewed. Interview protocols were produced and then approved by the respondents. To obtain an idea on Parliamentary opinions regarding the issue of controlling ZBOs, I arranged interviews with Members of Parliament. Their opinions can be used to explain some findings, but do not determine the actual assessment of the formal and actual autonomy observed from the other data.

Along with the interviews, a set of (internal) documents regarding planning \& control on the ZBO were studied. These documents included instructions by ministries and proposed ZBO budgets. They provide additional information on formal and actual levels of control. A last set of documents regards the documents submitted to Parliament on the ZBOs selected. These documents reveal what is regarded as relevant for control by Parliament or, when documents are submitted to Parliament by (in)direct request of Parliament, on the political emphasis made on operational control of the selected ZBOs.

All data found was scored on the legal and economic variables derived from the literature study. The research was based on data from fiscal 2007 and 2008. The ZBO 
population changes regularly and some of the ZBOs mentioned in the study no longer exist. The ZBOs that are covered in the case studies still exist as of mid-2010 and in only one case (UWV) has there been a substantial change in tasks assigned However this does not affect Parliamentary control on this ZBO.

Internal validity was ensured as far as possible by guaranteeing anonymity for the respondents, although it cannot be excluded that in some cases politically driven answers were given. External validity was realised by creating a short time frame in which all interviews were held and to focus on the last fiscal year that had been concluded in Parliament. As there has been no change in political views on ZBOs in the last few years, the observed results can be regarded as valid up to mid-2010.

\subsection{The legal dimension of ZBO control}

Control of ZBOs from a legal perspective means that formal regulations and distribution of powers (authority) is discussed. The research question in Part B of the study was:

\section{Which indicators for autonomy can be derived from legal theory and how do they match control of ZBO operations?}

The Dutch legal framework does not include the concept of 'autonomy'. Therefore indicators have to be derived from legislation in general. In the Dutch constitutional setting, ministerial responsibility is a key issue. A minister holds office until he loses a vote of confidence. The minister is held accountable for all acts with respect to the ministry he is hierarchically leading. In case of arm's length organisations outside the hierarchical structure there is no full responsibility. The minister is then accountable for: a) acts with respect to the responsibilities attributed, b) system responsibility implying monitoring and intervention when necessary and c) individual actions towards the entity.

With respect to the issue of ministerial responsibility and autonomy of ZBOs, in fact four sources of indicators exist. First, budgeting legislation is the reflection of one of the key powers of Parliament: allocation, authorisation and appropriation of budgets. Second, ZBOs operate in a public sector environment; therefore a discussion on general public law measures must be included. The cluster of legislation also includes civil law given the fact that some ZBOs have private entity legal status. Furthermore, civil law covers elements of contracting arrangements which might also be relevant for ZBOs. Finally, the ZBO-case law is relevant. ZBO-case law is not a separate dimension but the reflection of the will of Parliament on distribution of authority and the tasks assigned to the ZBO. Although ZBO case law finalises the formal arrangements on ZBOs, I have made a distinction in the discussion on general legal measures and the legal framework in individual cases. The individual legal frameworks of ZBOs are only discussed in the empirical Part D of this study.

In budgeting law (Comptabiliteitswet 2001; CW2001) a major rule is that a budget passed by Parliament only has effect within the hierarchy of the State. A minister cannot 
claim that he is out of budget when an individual or institution applies for a service. This doctrine also holds in the relationship between minister and ZBO. Thus authorisation of a ZBO budget by Parliament does not ensure that the budget is a maximum spending level. Furthermore, developments in budgeting methods, particularly to forms of outcome based budgeting as expressed in the Dutch VBTB system have resulted in a less detailed level of budgets being submitted to Parliament. A ZBO budget might be disclosed separately, but it is also possible that it is hidden in a larger budget or that no budget is authorised at all. The latter case occurs when a ZBO is fully funded by fees from citizens and fees are not authorised by Parliament. As a result, the budgetary control tool is relatively blunt.

Budgeting law includes measures to create private law legal entities. Parliament is notified of a proposal to create an entity and can either require that a law is passed or accepts the proposal from the minister. Creating a public law entity always requires a law to be passed in Parliament. Except for some financing and treasury measures no other rules are provided in CW2001. To some extent this is remarkable because no ex ante assessment is performed on an organisation before it is given autonomous status as a ZBO to look at its readiness to adopt the relevant (accruals) accounting techniques and control tools.

In general, one can claim that autonomy from a budgeting law perspective can be derived from three issues: a) the level of detail of disclosure and authorisation of the ZBO's budget, b) particularly when budgets are based on measurable production: control on cost prices, investments and production volume; and finally $\mathrm{c}$ ), the restrictions imposed upon the ZBO on treasury issues which also negatively affect a ZBO's autonomy.

The second line of legislation is general public law. ZBOs were not mentioned in the Constitution or as separate legal entities in formal law until end 2006. In that year a framework law on ZBOs finally passed through Parliament after more than ten years of debate. One can split the assessment of general public law into three stages. The first stage started with Scheltema's inaugural speech in 1974 when he first explicitly addressed the issue. At this point all ZBO regulations were actually ZBO case laws. After the NCA's critical report in 1995, ZBOs became firmly embedded in the political agenda. In 1996 this was reflected in a separate section on instructions for writing legislation (AW1996). New ZBO-case law had to be based on these instructions which included measures on normative, cyclical and governance issues as well as information provision (Kummeling et al., 1999, p. 39). In particular the cyclical and governance measures include options that may or may not be included in ZBO-case laws. These measures are the basic tools for distributing authority between a minister and the management of $a$ ZBO. If few options are included in the ZBO-case law, ZBO management autonomy will increase. In 2006, a formal framework law (Kaderwet ZBO; kZBO) was passed. The law applies to newly created ZBOs. Existing ZBOs may be subject to the new law if Parliament and minister decide to do so. Ministers had a one year time span to decide on the 
position of existing ZBOs, which in practice meant that they had to comply or explain why not on individual cases. This process was monitored by a committee of civil servants (Gerritsen Committee, 2008). Basically, all PLAs are subject to kZBO, unless a change in the positioning or tasks assigned to a PLA is expected in the near future. PLB-type ZBOs are also supposed to be subject to KZBO; the main exception being companies that provide ZBO services as only a very small part of their core business. Within the population of 128 ZBOs as used in this study, 56 are subject to kZBO, the others are not. The ZBOs not subject to kZBO are mainly reconsideration and discontinuation cases (34 ZBOs) or ZBOs that are no longer listed by the Ministry of the Interior ( 21 ZBOs). In all cases where kZBO is not immediately applied, old legislation is still applicable. The kZBO legislation has fewer options for distributing authority than the former AW1996, which means that in general ZBO autonomy has been reduced. However, as adoption of ZBOcase law is based on a 'comply or explain' rule, it is still possible that exceptions will be made for particular measures as described in kZBO. Actual distribution of authority as laid down in the ZBO-case law therefore determines the level of autonomy of an individual ZBO.

The third line of legislation of relevance for ZBO autonomy is Civil Law. The basic rule is that a ZBO has PLA status. PLA status can be obtained in two ways: first, a separate unit as part of the legal entity State is created. Such a unit is attributed operational autonomy but for its budgeting procedures is fully subject to the standards used for ministries. This form of PLA is labelled a 'Shelter' ZBO and is generally used for relatively small units where it would be inefficient to set up a full organisational structure. The second group of PLAs have separate legal entity status and are labelled 'Subsidiary' ZBOs because their position vis a vis a principal-ministry is similar to that of a company operating under a holding structure. A public legal entity is created by law, which means that Parliament has to give consent to a proposal by a minister in which the governance structure of the new public law legal entity is described. This means that in theory Parliament has full control on the issues to be included in the governance structure of the new entity and can thus influence the distribution of authority and in effect the level of autonomy of the PLA type ZBO.

In addition to PLA's there is another group of ZBOs which are created based on private law. The role of Parliament in creating a PLB is less prominent than in case of a PLA. If a minister proposes creating a private law legal entity, Parliament is given the opportunity to comment or require legislation. If not, the implicit assumption is that the minister is allowed to create the private law legal entity. The governance structure for Enterprise ZBOs (private companies) is given in civil law and is basically shareholder driven. In the case of Foundation ZBOs (no shareholders, no distribution of profit) the governance structure as laid down in the statutes is fully at the discretion of those who create the entity. Depending on the involvement of a minister when creating a Foundation ZBO, one can argue that the autonomy of a Foundation ZBO fully created by a minister is 
lower than that of a Foundation ZBO which was created by individuals with some kind of ministerial backing.

Creating a new entity and attributing a ZBO status to it is not the only way in which an entity is included within the ZBO framework. It is possible that an already existing private law entity provides public services. If the governance structure of such a private entity changes into a governance structure with substantial control tools for a minister-principal, this is referred to as 'hiving in' of an entity. Hiving in is a concept that is relevant for entities whose governance structure is changed towards more political control. If the services provided have a ZBO character of unilateral decision making, this means that they might also be subject to the ZBO framework. Several ZBOs have been hived in in the past, including some which are discussed in this study.

Another issue related to the legal structure is whether or not a minister allows a nonexecutive board and advisory board to be used in the governance structure of the ZBO. Non-vertical governance structures may contribute to accountability of arm's length organisations. These measures do not live up to the expectations of replacing vertical governance structures (Schillemans, 2005, 2007). In the past, several ZBOs used nonvertical governance structures and kZBO includes the power to use such structures. In practice, the trend following implementation of kZBO is that ministers have tried to abolish formal multi-layer governance structures because they might negatively affect ministerial influence (Gerritsen Committee, 2008).

A last point to be made refers to contracting relations. ZBOs provide services on a legal basis to several users. Depending on issues of measurability one can compare the provision of ZBO services with contract relations. If such a contract relationship is essentially a contract between ZBO and ministry as commissioner, funder and user, then the ZBO is faced with lower autonomy compared to the case where a ZBO provides a service to a citizen who is also paying for the service and using it. In the first case budgetary control is driven by the resources available to the ministry, whereas in the second case a flexible budget exists, which is based on actual citizen demand.

To summarise the legal perspective on autonomy, four main points are relevant: what is the legal status of a ZBO, which control tools are defined in CW2001, what kind of quasi contracts on service delivery exist and how is the distribution of authority between minister and management settled.

\subsection{The economic dimension of ZBO control}

Whereas distribution of authority affecting autonomy is an issue that is formalised in legislation and lower regulations, autonomy is also influenced by characteristics of services and the economic environment in which these services are delivered. After all, providing ZBO services is not an issue of a free private market, but part of decisions 
made in the political sphere on the production and delivery of these services. The research question in Part $\mathrm{C}$ of the study was:

\section{Which indicators for autonomy can be derived from economic theory and how do they match control of ZBO operations?}

Three main issues are covered in the economic dimension of control. First, Neo Institutional Economics [NIE] is discussed, followed by comments on the product characteristics of services delivered by ZBOs. The third issue concerns market characteristics of the services provided. Product and market characteristics result in a particular planning and control system appropriate to these characteristics. That planning and control system may formally and/or actually exist, perhaps with deviations from expected control tools. An assessment on setting up and using planning and control systems in the relationship between Parliament, Minster-Principal and ZBO is the last step in evaluating economic control tools.

I will start with some comments on the theoretical framework on the economic perspective of service provision by ZBOs as based on Neo Institutional Economics [NIE] theories. The general object of study in this theory is that institutional arrangements provide for efficient production if the different interests of owners and managers of organisations are aligned as far as possible.

In NIE, the concepts principal and agent are often used. These concepts are also used in a public administration context and have a slightly different meaning in this field of literature. In brief, the original principal - agent debate is on the unaligned interests of shareholder(s) and managers due to information differences. In public administration theories the principal is often actually the commissioner or consumer of services who has less information than the provider of the service. This is illustrated in the relationship between a doctor and a patient, where the patient is the principal and the doctor the agent. In a public sector context the politically responsible person often has two roles: one as 'quasi' owner of the organisation (Minister-Principal) and one as commissioner and sometimes even consumer of a service. This creates confusion and therefore I have used the original interpretation and use 'owner' or Minister-Principal when referring to the institution/person that bears the risk for services to be produced by the organisation and is not responsible for demand for services. The latter institution/person is labelled 'commissioner'.

Neo Institutional Economics consists of three main lines of theory, all of which can contribute to an assessment of ZBO autonomy. First, 'property rights theory' claims that efficient production will be stimulated when management of an organisation has as much control as possible on the productive assets of the organisation. Having full property rights ('abusus') by management indicates a higher level of autonomy than a mere 'usus' right which allows assets to be used but not to benefit from the returns they provide. An abusus right has risks from a general interest control perspective for two reasons: 1 ) without regulations there is no control on residual income and 2) financing of assets by a non-government institution is generally more expensive than financing government. 
Therefore, if a ZBO is allowed to finance its assets on the capital market, this will result in additional use of public resources due to higher interest rates. Without restrictions on abusus rights a ZBO by Parliament, the power of re-allocating resources is handed over to management of the ZBO.

The second line of theory is 'transaction cost theory'. This theory focuses on the perspective of optimal production structures between organisations, or in other words should an organisation produce particular services within the organisation or should it outsource production. Three issues are relevant when making this choice. First, "asset specificity' is an indication for mutual dependency between organisations. If techniques or knowledge are not freely available on the market a mutual dependency between organisations exists and theory suggests that it might be better to integrate production. In terms of ZBO autonomy, high levels of asset specificity give negotiating power to ZBO's management and thus a higher level of autonomy can be observed. The second issue is uncertainty. If uncertainty is high, it is very costly to monitor production outside your own organisation; production processes can be adjusted more efficiently within the organisation. The last point is frequency of transactions. If you rarely produce a particular type of service, maintaining the knowledge within your organisation is costly and probably a specialised firm can provide the service at lower cost. High uncertainty and high frequency of transactions are indications for a need to integrate production. However, a ZBO is deliberately set at arm's length of government but sometimes produces a substantial volume of standardised services which would suggest service provision should not be outsourced. To manage uncertainty and frequency risks, more control instruments in the relationship between minister and ZBO can be expected.

The third line of theory is 'agency theory'. The key concept here is the possible abuse of information asymmetry that exists between owner and manager of an organisation, be it only due to time lag. Again several control tools can be used to reduce the risks. If regulations -legal controls - are used, this directly affects the discretionary powers of management and may negatively affect efficient production. Therefore, control tools like persuasion and incentives are proposed, which do not have a negative effect on managerial autonomy but result in improved alignment between the interests of owner and managers. Applied to ZBOs, this means that a ZBO in which control tools other than directives are used has relatively greater autonomy than a ZBO where directives are the main control tool.

Neo institutional theory concerns relationships between organisations. A second important issue affecting operational autonomy are production characteristics. Two issues are relevant from a production characteristics perspective. First, production processes are relevant. Control tools used for mass production processes tend to be impersonal and based on regulation. If production processes result in (professional) unit production, control tools governing staff are more important than regulations. Second, measurability of production is relevant. If production can be measured, this allows for 
relatively unsophisticated control tools and low transaction costs. If production cannot be measured other, more complex control tools have to be used which have a negative effect the level of transaction costs.

Third, demand and supply for services was discussed. I will start with demand. Public finance literature distinguishes between public goods, impure public goods and market goods. A pure public good is non-excludable and non-rival. No person can be excluded from using the service and an additional user does not harm the use by all other users. Impure public goods and market goods may allow for forms of funding other than general taxes, particularly when the service is attributable to individual users. The question on generating demand was discussed in the legal section of this study from a contracting perspective, ranging from full state demand to free market demand. From a funding perspective, if a citizen is at least requesting a service, forms of citizen funding are possible. The general idea behind user funding is that only those who actually benefit from a service pay for it. The economic literature uses a wide variety of labels for different forms of funding by citizens. The bottom line of the variety addressed is based on the distinction between 'authority biased' funding in cases where a fee is charged for a nonreciprocal service without a direct relation between payment and service and 'market biased' funding - generally where output budgets are used - in which case there is a direct relationship between service delivered and payment. An example of authority biased funding is found in monitoring fees paid by financial institutions to the Dutch central bank (DNB); an example of a market biased funding is found in the registration fee to be paid for motor vehicle registration to RDW. A ZBO that is able to generate market biased funding will in general have a higher level of autonomy than a ZBO that is generating authority biased funding or fully depends on a ministry budget for its funding.

From a supply side perspective, the dichotomy between integrated government production and fully private production no longer holds. Government can use the market for several parts of the production process. Boorsma and Mol (1983) identified three intermediate stages of production. First, contract provision in which government funds and plans production but production itself is performed outside government, for example in a ZBO. Second, grant provision where government only funds production and third, regulated provision in which government only plans production. ZBO autonomy is influenced by these different production arrangements. In contract provision government control is relatively high and thus autonomy is low, whereas in cases of regulated provision and particularly what is labelled 'start-up' grant provision, government control is relatively low and thus autonomy of a ZBO is relatively high. Not all forms of production as described here are applicable to all ZBOs or to all forms of demand. For example a start up grant given to a PLA is highly unlikely given the legal status of the ZBO. The impact on autonomy holds for all ZBOs.

In terms of autonomy, non government funded ZBOs are expected to have the highest level of autonomy. Within non government funded ZBOs, those which are funded with a 
market biased fee are expected to have a higher level of autonomy than those which are funded by an authority biased fee. Traditional government funding is expected to result in a low level of autonomy.

The last issue discussed from an economic perspective are the control tools available to minister and Parliament. I will highlight some issues here. First, Verhoest (2002) addressed the issue of co-ordination between commissioners of an organisation in the case of multiple commissioners. This is an issue that is relevant in the case of ZBOs because in most cases a minister has two roles: both owner and commissioner of the organisation. In a number of cases, it is possible that the commissioner role in particular is performed by more than one minister, which requires co-ordination and prioritising. Lack of co-ordination generates degrees of freedom and thus management autonomy.

A second point to be addressed from a control perspective is the concept of responsibility accounting as used in private sector companies with separate divisions. There are similarities between divisionally organised companies and the relationship between minister and ZBO. This allows using a modified form of the responsibility accounting model for assessing relative autonomy of a ZBO. If a ZBO is only allowed to manage a fixed cost budget, this means strict control and thus low levels of autonomy. If a ZBO is allowed to manage costs and revenues and has nearly full control over available assets, the level of autonomy is high.

A third and last point to be made from a control perspective is the mismatch between accounting systems used, which might have an impact on the level of production delivered by a ZBO or on a ZBO's balance sheet. This issue is relevant in the case of government funding and strict application of a fixed budget for the ZBO. In that case, demand that exceeds planned demand cannot be met by supply due to a lack of financial resources. This might result in waiting lists or if that is not possible, debt financing needed for the additional resources in combination with high levels of receivables on the balance sheet. It is obvious that a ZBO faced with restrictions as described here faces a lower level of autonomy than a ZBO which is at least allowed to be funded directly with a flexible budget.

When summarising the economic perspective of autonomy, four points are relevant. First NIE provides a general theoretical framework for managing relations between Parliament and Minister on the one hand and ZBO on the other. Second, from a production perspective, production characteristics and the resulting variety for (budgetary) control are relevant. Third, the market perspective provides indicators for autonomy based on the origin of demand and corresponding funding of services. The organisation of supply can also be used as an indicator. Finally, from a control perspective the idea of responsibility accounting and possible mismatches in accounting systems have an impact on ZBO autonomy. 


\subsection{Formal and actual autonomy of ZBOs studied}

The last part of the research is the assessment of the legal and economic autonomy of 11 ZBOs selected from within the 'income transfer' and 'monitoring' groups of ZBOs. The research question for this part of the study was:

\section{Do Parliament's control tools match the control tools that fit to the legal and economic characteristics of ZBO services?}

Because income transfer ZBOs and monitoring ZBOs have different characteristics, I first developed a standard for assessing the autonomy of these two groups of ZBOs. This standard is based on the kZBO framework for the legal perspective, with some variation in ministerial power to intervene. The legal framework allows formal and actual autonomy to be discussed, based on KZBO and the actual findings and behaviour based on ZBO case law.

The economic framework enables a standard to be derived given the economic characteristics of the services provided, but this can only be derived by evaluating specific economic characteristics. Therefore, my standard for an economic assessment of autonomy is labelled 'expected' rather than formal autonomy and is then compared to the actual behaviour of owners, commissioners and agents in relation to ZBO operations. As stated before, only controls that affect market position and planning and control result in possible mismatches in legal and economic autonomy. From a legal perspective, normative and governance controls particularly have an effect on autonomy but it is hard to qualify such control tools in terms of mismatches between legal and economic control tools. In Table 19.1 I have summarised the standards on markets and planning and control used to assess autonomy of income transfer and monitoring ZBOs. 
Table 19.1: Expected standard measures determining autonomy of ZBOs

\begin{tabular}{|c|c|c|}
\hline Variable & $\begin{array}{l}\text { Income transfer } \\
\text { ZBOs }\end{array}$ & Monitoring ZBOs \\
\hline \multicolumn{3}{|l|}{ Governance issues } \\
\hline Ex ante approval mandates (kZBO:8) & Yes & Yes \\
\hline Approval kZBO:32 transactions & No & No \\
\hline Intervention in case of negligence (kZBO:11) & Yes & Yes \\
\hline Nullification of decisions (kZBO:22) & Yes & No \\
\hline Approval of governance statute (kZBO:11) & Yes & Yes \\
\hline Appointment of executive board (kZBO:12) & Yes & Yes \\
\hline $\begin{array}{l}\text { Measure secondary jobs of executive board members } \\
\text { (kZBO:13) }\end{array}$ & Yes & Yes \\
\hline \multicolumn{3}{|l|}{ Cyclical issues } \\
\hline Approval of budgets/fees (kZBO:17; 24) & Yes & Yes \\
\hline $\begin{array}{l}\text { Reporting on substantial differences between budget and } \\
\text { results (kZBO:30) }\end{array}$ & Yes & Yes \\
\hline Creation of equalisation reserve (kZBO:33) & Yes & Yes \\
\hline Rules on structure budget given (kZBO:27-28) & Yes & Yes \\
\hline \multicolumn{3}{|l|}{ Market dimension } \\
\hline Source of funding & 100\% government & 100\% government \\
\hline Production type & Mass & Individual \\
\hline Budget funding & Activity based & Lump sum \\
\hline Budget typology & Output & Task \\
\hline Production form & Contract & Contract \\
\hline Commissioning & Request & Government \\
\hline Demand dependency & 1 ministry & 1 ministry \\
\hline Competition & No & No \\
\hline \multicolumn{3}{|l|}{ Planning \& control } \\
\hline Responsibility centre type & Standard cost centre & $\begin{array}{l}\text { Complete cost } \\
\text { centre }\end{array}$ \\
\hline \% fixed assets & $<10 \%$ & $<10 \%$ \\
\hline Budget disclosure & Line item & Line item \\
\hline Budget instruction by Minister-Principal & Yes & No \\
\hline Approval budget documents mentioned to Parliament & Yes & Yes \\
\hline Approval fees mentioned to Parliament & Not applicable & Not applicable \\
\hline Approval annual report mentioned to Parliament & Yes & Yes \\
\hline Frequency of reporting to minister & $\begin{array}{l}\text { Parliament's } \\
\text { frequency }\end{array}$ & Annually \\
\hline Ex ante performance indicators & Output indicators & Not available \\
\hline Ex post performance indicators & Output indicators & Process indicators \\
\hline
\end{tabular}

Assessing the individual ZBOs based on these standards results in formal or expected and actual deviations from the standard set. It also allows positioning the individual ZBOs towards each other; not being subject to a measure means ceteris paribus that the particular ZBO has a higher level of autonomy than similar ZBOs that do have to comply with that measure. Figure 19.2 shows the result of the evaluation. 


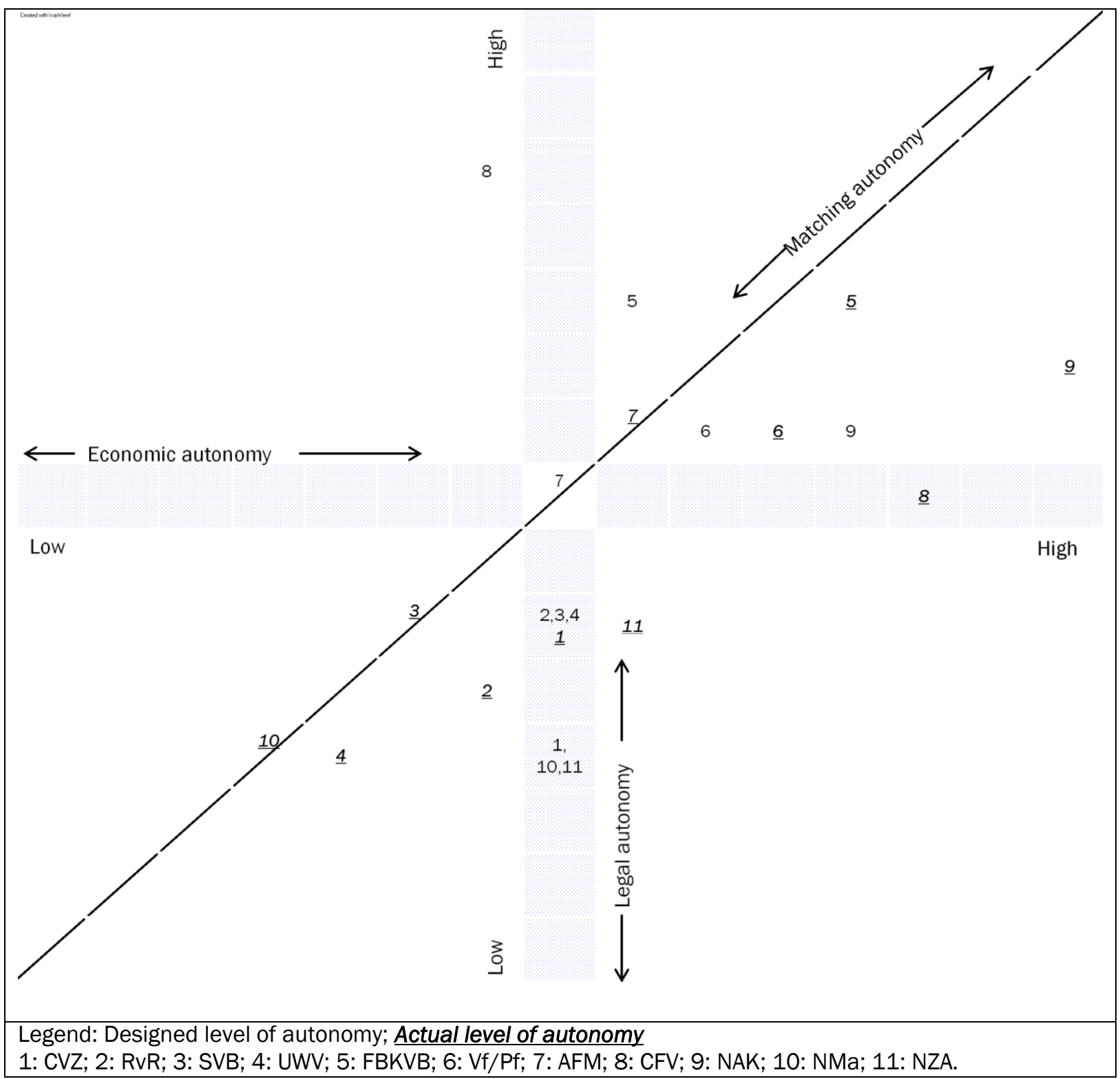

Figure 19.2: Designed and actual autonomy of ZBOs studies based on market and planning and control autonomy factors.

The summary of conclusions and observations in this study is:

1. After testing designed and actual control tools in eleven cases, in only three cases a match of actual legal and economic control tools is found.

2. In eight cases, emphasis is on legal controls rather than on economic controls.

3. Public law ZBOs are controlled on a more restrictive basis than was expected.

4. Income transfer ZBOs are faced with more restrictive controls than monitoring ZBOs.

5. Ownership and commissioning role are not clearly separated and in some cases ministries act inconsistently.

6. Budgetary control, often based on lump sum budgets prevails over activity based budgetary controls.

7. Performance information is not provided on a consistent basis. 
I recall the research problem which was:

\section{Do Parliamentary control tools match the legal and economic operational autonomy attributed to ZBOs?}

Based on the results found in the study, the answer to the research problem is that in only one case a full match between legal and economic operational autonomy is found. In two other cases a match is found in the actual application of legal and economic control tools. In all other cases a mismatch either by design or in application of control tools was found. On a more detailed level the answer to the research problem can be summarised as follows:

1. Only AFM shows matched controls although the observed controls indicate higher levels of autonomy than formal controls.

2. SVB and NMa show matching observed controls; in both cases formal controls have a legal control bias. Control levels in these cases are higher than the standards set.

3. In one case - NZA - observed controls show divergence between legal and economic controls although overall control has a legal control bias both in observed as well as in formal controls.

4. Three of four PLA income transfer ZBOs (except SVB) have a strong legal control bias and both economic as well as legal controls are more restrictive than expected control levels. A key explanation for this is a lack of using real activity based funding for these organisations which is theoretically possible given the production characteristics of the organisations.

5. The PLB income transfer ZBOs also face observed legal control bias, but controls are less restrictive than for the PLA income transfer ZBOs. FBKVB's formal autonomy was expected to have an economic control bias but the funding system based on a four year period results in a shift from an economic to a legal control bias.

6. Differences between the three market regulation ZBOs are substantial, which can mainly be explained by differences in legal status.

7. With respect to NAK, both by design as well as in practice, relatively few restrictions were found. Those that were found were based on legal control tools. Overall, NAK has a high level of autonomy compared to the framework used.

8. CFV's position shifts from a formal economic control bias to a low level of legal control bias based on operational legal non-formalised control measures and a relatively low level of applied economic control tools.

9. Several inconsistencies were observed even in those cases where ZBOs were controlled by one Minister-principal.

Differences in legal status tend to be reflected in autonomy. PLB type ZBOs are faced with fewer controls than PLAs although this is not needed given the standards based on 
service characteristics and markets. Secondly, with the exception of SVB and UWV, real performance related quasi contracts were not observed. Third, from an economic perspective, budgetary controls are generally more restrictive than might be expected; particularly in the income transfer ZBOs where activity based budgets were expected. Fourth, asset specificity and investment controls were not really an issue in the cases studied. Financing is based on the same rules for most ZBOs, irrespective of services provided and legal status. A final point is that if normative and governance controls that do not directly affect market or planning and control are included in the assessment, the general trend is that PLAs tend to be controlled more strictly and PLBs generally have even more degrees of freedom.

From a comparative perspective, RVR and UWV face low levels of autonomy. In the UWV case, an important explanation is the restrictions on services to be provided that result in lower levels of autonomy than were observed in the SVB case controlled by the same Minister-Principal. RvR's autonomy is reduced because budgets are explicitly determined unilaterally as subsidies rather than as compensation for services provided and excess services are not compensated for. CVZ's autonomy is from a legal perspective equivalent to SVB's autonomy but CVZ has some additional degrees of freedom due to relatively low levels of transparency towards Parliament. Finally, a comparison between the three market regulators shows substantial differences due to legal status. NZA's autonomy is reduced because NZA suffers from a mixture of assigned tasks including imposing budget restrictions upon hospitals which cannot be classified as part of its impartial monitoring task. Furthermore, NZA faces strong budgetary controls partially due to the fact that it is a relatively new organisation and its relationship with the commissioning ministry is still developing.

Several inconsistencies were observed in the case studies. I mention minVWS' relation to NZA and CVZ. First, in the NZA case, focus on staff control shifted from temporary staff to core staff which made it hard to build the new organisation. Second, CVZ does not receive a letter of instruction on the budget whereas NZA does. From a perspective of policy independence one might expect that NZA would have more autonomy on this issue. Third, in the CVZ case an advisory board is allowed and in the NZA case it is not. In both cases it would be possible to argue that the specific knowledge needed to execute tasks assigned allows for an advisory board. Not only minVWS operates inconsistently. In the CFV case, a letter of approval on the annual report 2007 was sent to CFV, but this was not done for fiscal 2008. In the minOCW case, it can be observed that FBKVB faces a detailed audit protocol and Vf/Pf does not. This is odd if one considers that both PLBs provide income transfers, which means that their core business is similar.

I have now summarised actual findings in a nutshell. The last section of this chapter will discuss the implications of these findings for ex ante Parliamentary and ministerial 
control of ZBOs within a context of opinions from MPs and the comments made by NCA on ex post control.

\subsection{Assessment of results}

In this subsection, I will provide a general assessment of results and finalise the actual study. In the next chapter, some proposals for improvements based on the study findings as well as future research issues will be presented.

\subsubsection{Generalisation}

A multiple case study research design enables individual cases to be assessed and the different cases to be compared. It does however not enable full generalisations on the population. Two remarks can be made in this respect. First, in two of the cases selected, I have actually picked one ZBO out of a number of ZBOs that have been assigned similar tasks within a particular policy domain. The art fund and agricultural quality assurance organisation can be regarded as representative cases for the other organisations in these areas. This means that the assessment results can be generalised to the other relevant organisations. Secondly, some conclusions might be indications for general problems. I refer to the fact that in only one case - AFM - a full match was found on both formal and observed autonomy and that all but one (CFV) PLA type ZBO face lower levels of economic autonomy than might be expected given their task description. In 8 of the 11 selected cases, observed autonomy on market characteristics and planning and control show mismatches between legal and economic controls with a bias towards legal controls. Economic autonomy does not change fundamentally when the organisational environment of an arm's length organisation changes because the services do not change. The study also shows that typical issues that are relevant from a NeoInstitutional perspective such as control on assets and remuneration are not perceived as relevant. The focus seems to be on budgetary control by minister and indirectly Parliament rather than on production of services delivered. From an economic perspective, this means that using a ZBO format, an executive agency format or even a private contract provision format is essentially irrelevant. The essential issue from an economic perspective will be whether strict budgetary controls prevail over demand volumes that require flexible budgets. In the cases studied here, cash based budgetary controls from within central government have a stronger impact on political control of ZBOs than demand driven issues. A common denominator on these observations seems to be that the organisations with low levels of economic autonomy are all primarily funded by central government, which might explain the bias towards cash based budgetary controls.

The standards used here are derived from the kZBO framework and economic characteristics of services. I have not commented on legal controls before, but at least two issues need additional attention. First, planning and control in government is based on the preparation and approval of an annual budget, which is deliberately 
complemented by a multiyear perspective on budget levels for the next four fiscal years. In only four of the eleven cases does the budget preparation process for the ZBOs studied here require inclusion of a multiyear plan and in five cases such a plan is actually prepared. This is particularly odd for directly government funded ZBOs since government contributions to those ZBOs are to be included in the budget plans of the respective ministries. In my opinion, this should have been reflected in kZBO, but it is not.

Another issue from kZBO is the interpretation of the concept fee. Both minSZW as well as minVWS use arguments to decide on economic controls which are not adequate. In the minVWS case, a decision can be made on fees to be charged by cure and care providers. The fee will be set by NZA on a general instruction by minVWS. This type of fee has no relation to the fee for NZA services, which is what is meant by kZBO:17. In the NZA-case, fees for operations could not be based on production as is the case with activity based services for income transfer ZBOs, but might be applied in a similar context as in the AFM-case: covering the costs of NZA's market regulation role by those who are under NZA supervision. In the minSZW case, the argument is more or less the opposite. MinSZW uses the argument that equalisation reserves (KZBO:33) are only relevant in cases of fee funded ZBOs rather than for government funded ZBOs. In his argument minSZW does not consider that activity based funding which is possible for an income transfer ZBO is similar to the case of a fee funded organisation. Actually minSZW implies that budgetary compliance control overrules production based controls (see Parliament, 2008I, p. 18).

I did not study the other three main types of ZBOs (stewardship, research and licensing). Other research (e.g. Mol \& de Kruijf, 2004; Deelen \& Eertink, 2004) includes references to some of these groups. Given the findings here, it would also be worthwhile to carry out research on these types of ZBOs, preferably starting from the dichotomy between substantially government funded and mainly privately funded ZBOs. In stewardship and licensing ZBOs in particular, the expected levels of economic autonomy may be higher than for income transfer ZBOs, given the possibilities for services based on citizen demand and private funding. The research group of ZBOs is expected to have a similar level of autonomy to the monitoring ZBOs studied here.

\subsubsection{The role of Parliament}

A second issue that needs some attention here is the political debate on ZBOs in Parliament. In three interviews with (former) MPs, the position of ZBOs in government operations was discussed. Some general remarks can be derived from these interviews. The use of ZBOs is regarded by MPs as problematic, except for those cases where impartial judgement is a key argument for creating a ZBO. In other cases, full ministerial responsibility should prevail, or the activities should be organised under a private law regime. All respondents comment that historical context determines the present organisational structure and that it will not be possible to fundamentally change the 
present situation. Particularly, as one respondent indicated, the debate on kZBO has only been completed recently and a fundamental revision of organisational structures is politically not feasible. This remark is typical for political practices in the Netherlands: once a consensus decision has been made, it is hard to change that decision again.

If a ZBO structure is used, a deliberate reduction of ministerial responsibility is organised. This implies that the organisation can generally be assessed on an ex post rather than an ex ante basis. It would not be constitutionally appropriate according to respondents for MPs to intervene in the operating budgets of ZBOs by for example proposing amendments to the budget. An ex post assessment of ZBOs is however problematic, for at least two reasons. First, the present (2008) ex post information provision on ZBOs is rather minimal and does not disclose budgets or performance information adequately. An increase of ex post information would, for reasons of symmetry with the budgeting process, according to respondents imply that similar information is also provided on an ex ante basis. Secondly, MPs cannot process the information provided to them on a structural basis given the vast amount of information submitted. Some respondents suggested that expert Parliamentary staff might assess the information for MPs, which might also be a solution for the present fragmented approach on policy execution assessment in Parliament. MPs operate on the basis of policy domains rather than on a general view of government organisation. Respondents were not negative on the use of standard formats for presenting ZBO operations information on a similar basis to the information provided on executive agencies or the practices used with respect to affiliated entities in local government.

Comments by MPs again stress the relevance of the difference between impartial judgement type ZBOs versus other types of ZBOs. In actual fact, it can be seen that two of the major impartial judgement type ZBOs have lower levels of operational autonomy than the standard used in this study. This is due to a mixture of tasks in one case and the governance structure in another. A critical re-assessment of ZBOs providing impartial judgement might therefore be considered. Secondly, although not made that explicit, the distinction between government funded and privately funded ZBOs is an issue. Respondents addressed this implicitly by referring to either full ministerial responsibility for real government tasks or further privatisation of other tasks. The problem is most explicitly found in this study in the Vf/Pf case, where private funding in fact is a form of indirect government funding and control of the ZBO. This is problematic given both freedom in operations as well as on a more fundamental political debate how the key service provided by Vf/Pf should be organised. In other cases, particularly in the licensing and stewardship ZBOs not studied here, tasks might be regarded as key government tasks but due to private funding are not under similar levels of control as fully government funded entities. I am not sure whether politicians realise that such differences exist, except when case-based questions arise in Parliament. At least, the respondents did not address this issue explicitly. More transparency on the relationship 
between funding and services provided might result in a better understanding of required differences in control of ZBOs.

Despite the relative arm's length position of ZBOs, in most cases substantial numbers of questions were raised in Parliament. This is particularly the case for UWV (and SVB to a lesser extent) due to the frequency of explicit reporting to Parliament. In most other cases, questions are based on either changes in programs affecting the operations of a ZBO or on events that draw attention from MPs. In the case of the three market regulation ZBOs (AFM, NMa, NZA) in particular, questions seem to be event driven, which is contrary to the impartial role of these ZBOs.

\subsubsection{Information provision}

A third issue regards information provision in general. On this subject, the NCA has produced a series of documents as a result of its original 1995 findings on controlling ZBOs. 206 I will only summarise the findings of the NCA, based on their 2009 retrospective report (Parliament, 2009b). The NCA has focused on monitoring ZBOs by ministers and emphasises ex post assessment of ZBOs. On three issues, improvements are observed by the NCA based on observations from 2005 and 2008. These issues are monitoring by the individual ministries, based on monitoring visions and arrangements; compliance levels have improved and finally, ex post public accountability by ZBOs has strongly improved.

What has not been implemented sufficiently by ministries is a risk based monitoring system for ZBO operations. In my opinion, this issue should be part of the monitoring visions and arrangements. Furthermore, the opinions of minFin as representative of Cabinet and NCA diverge on this issue: minFin argues that sufficient attention is given to this issue (Parliament, 2009b, p. 22). Although the issue of risk management was not explicitly included in my research, the number of event driven questions in Parliament with respect to ZBOs as well as the focus on budgetary control in Parliament might be indications that the NCA is right. The last issue not being carried out sufficiently is information provision to Parliament. Although again NCA and minFin have different opinions, this remains a political issue which was also addressed in the interviews held within the framework of this study. NCA admits that the majority of fee funded budgets actually program and operating budgets added up (jdk) - are disclosed, especially in the minVWS and minSZW budgets (Parliament, 2009b, p. 24). However, examples of substantial undisclosed ZBO (operating) budgets are also given. This is an omission that needs to be resolved in order to allow for ex ante and ex post assessment of the financial position of ZBOs. The issue does not only concern operating budgets, but also the financial position, including balance sheet information in general (Parliament, 2009b, p. 25). The need for such information is stressed again by the debate on the financial

206 The NCA report covers ZBOs as meant in this study but also covers RWTs, not being ZBOs. The appendix to the NCA report (Parliament, 2009b, p. 92-93) discloses that only three PLB ZBOs do not yet publicly submit their annual reports (fiscal 2007). This means that focusing on ZBOs based on the NCA report does not result in bias. 
position of Kadaster in 2008/2009 (Parliament, 2009I), when fees had to be increased due to a substantial decline in the level of activities and a very low level of equity within the organisation. In this study, the equity issue was also illustrated by the risky funding position of CFV, which has to rely on the interest received from program equity to cover operating costs.

Fourth, the results disclosed in this study are based on an assessment of controls formalised and applied during fiscal 2007 and 2008, before formal implementation of kZBO. At the start of fiscal 2010, some ZBOs were subject to new legislation arising from kZBO, adapting their existing controls to the kZBO framework. However, in four cases, new legislation had not even been submitted to Parliament although the intention to do so had been announced (Parliament, 2008b). In three other cases, the legislative process was not yet complete. Based on what is known on the changes in legislation, the conclusions on the autonomy of the ZBOs studied here do not change.

\subsubsection{Public management reform}

Finally, a comment on public management reform in general is made. Ter Bogt (1999, p. 15) developed a number of hypotheses on the impact of autonomisation. Most of the hypotheses regarding the economic dimension of autonomisation seem to have low impact. Van Thiel (2006) indicates that although indicators exist on the managerial style for creating ZBOs - as a proxy for the economic dimension of autonomisation (jdk) - it is not a dominant style for creating ZBOs. Ter Bogt (2003) showed that issues like political rationality may also have an impact on autonomisation decisions. Indicators like uncertainty as expressed in the UWV case or a mixture of tasks that do not fit very well together (NZA) and strict budgetary controls (CVZ) all confirm that the ideas of public management reform are not always understood or applied consistently. It is also illustrative that one of my political respondents wondered why there was a need to change the governance structure of IBGroep from ZBO to executive agency status as there were no indications that IBGroep was doing a bad job. ${ }^{207}$ These findings show that the basic line of reforms based on new public management and neo institutional theories such as disaggregation and decentralisation (Pollitt, 2004, p. 329; Pollitt \& Bouckaert, 2004, p.88) do not hold and that other elements, for example complexity theory as addressed by Teisman and Van Buuren (2007, p. 183), political rationality (Ter Bogt, 2003) or cultural aspects such as styles of reform (Van Thiel, 2006) have an impact as well.

On a more general level, Rainey (2009, p. 74-80) noted that control of organisations is not only based on ownership and funding issues but also on political authority and modes of social controls related to stakeholders of the organisation. This results in a continuum of autonomy rather than a dichotomy on which organisations can be

207 I refer to Ter Bogt (2003, p. 174) who noted that the original decision on autonomisation of IBGroep was driven by political arguments. 
classified. The variation in ZBO autonomy found in this study is another illustration of this continuum. Perhaps the most explicit example is found in the UWV case. UWV is under high levels of political scrutiny. Several examples of operational problems leading to political attention were mentioned in this study. In a recent paper, Westerveld (2010) noted that performance of UWV is not always as it should be, she also noted that one of the problems that negatively affects UWV's position is excess control in combination with new services to be provided in relatively unstable environments. I think that in at least three other cases discussed here, similar problems can be observed. I recall CVZ's problems in finding a solution for (real) mass production based income transfers, NZA's mixture of tasks which conflicts with its role as market regulator and AFM's new tasks which will at the very least result in discussions on the level of costs to be allocated to those being monitored.

Historical contexts have resulted in the organisational environments for ZBOs as they stand in 2010. Changing only the organisational setting in which arm's length government institutions operate does not solve problems on controlling these organisations. One respondent even claimed that although perhaps strongly controlled by central government, the arm's length position of a ZBO can be useful if negotiations with other public sector entities have to be performed in order to achieve some of central government's goals. The arm's length organisation is in that case relatively more flexible than a pure hierarchical unit can ever be.

Politicians should be aware of the differences in service characteristics provided by ZBOs as well as of the relative stability of the underlying programs. In all cases, program responsibility is a political issue which will (in)directly affect the political system and its legitimacy. Taking responsibility for the program is at the heart of transparent service provision by any government institution, irrespective of its governance structure. Studying legal and economic autonomy of arm's length organisations can contribute to identifying mismatches in control measures. The examples discussed in this study can at least be used as a benchmark for future institutional changes. 


\section{Recommendations and future research}

\subsection{Develop standard format for information provision on ZBOs}

This study has shown that the information on ZBOs provided to Parliament varies widely, depending on funding and budget disclosure methods in ministry budget documents. The only standard that exists is the reference list to ZBOs and RWTs as included in the appendices to the ministries' budget documents. Even given this standard, ministries disclose information on ZBOs differently, ranging from a mere listing including budgetary funding (minVWS, annual report 2008) to a detailed level of assessment and financial position of selected ZBOs as is the case in the minFin 2008 annual report.

Balance sheet information is provided in one of these cases, as was suggested by the NCA (Parliament, 2009b, p. 35) and originally suggested in the legislative procedures to CW2001 (Parliament, 2002e, p. 4-5). Furthermore, the NCA suggests including information on non budget funded RWTs, including those of ZBOs (Parliament, 2009b, p. 25) and refers to discussions in Parliament on this issue. Information provision to Parliament is thus still a weak point in ZBO accountability to Parliament.

Basically, three solutions can be used to overcome the problems observed. First, a suggestion might be to include all operating budgets of ZBOs in ministry budgets. This solution suggests however that ministerial control on the variety of budgets and fees is similar, which is not in line with the responsibility attributed to the minister in several cases. A second model could be that ZBO budgets and annual reports are disclosed similarly to the procedures used for executive agencies. It means that operating budgets as well as investment budgets are disclosed in the ministry's budget document/annual report and would result in an overview of the full financial position of individual ZBOs. Although this solution allows differentiating between regular budgets of ministries and other budgets to be authorised, in some cases there might still be a problem in authorising fees, particularly if a minister only approves or consents to the level of fees for a particular ZBO. A third and last option could be to use the model that has been developed for local governments with respect to reporting on associated entities. In this model, it is not direct authorisation of budgets that is the main issue, but the objectives to be achieved by a particular entity. In more sophisticated examples of reporting, risks including a summary of the financial position of individual associated entities is given. Disclosing ZBOs along the lines of the associated entity model used by local governments reflects the difference between executive agencies and ZBOs from a governance perspective and allows for summarised reporting both in the budgeting stage as well as in the accountability stage. Full details of a ZBO's financial position are not necessary given the measures in KZBO on submitting individual ZBO annual reports to Parliament.

I would not suggest following the line of consolidation as is suggested by IPSAS. Although most ZBOs will qualify as controlled entities, consolidation would not contribute to transparency for two reasons. First, because ZBOs are financed by the state, their 
debts are included in State debt. Furthermore, from an asset perspective, at least the ZBOs studied here do not show substantial assets which would be disclosed in a consolidated financial statement. More important is that consolidation without segmentation would not provide relevant decision making information on ZBOs. Relevant segmentation would mean that disaggregation at least at the level of ministries of government is needed and that is precisely as is suggested in disclosing information along the associated entity model used by local governments.

\section{$20.2 \quad$ Use one Ministry-principal for all ZBOs.}

The results of this study show that a great variety in controlling ZBOs exists despite the fact that they deliver similar tasks. This variety seems to be due to different opinions within respective ministries on the ownership role with respect to ZBOs. Within the present system, emphasis on ZBOs is strongly focused on programs, which is basically logical as a ZBO is only an organisational structure in which programs are to be realised. The efficiency of operations is not often discussed. Furthermore, it seems that a countervailing power that assesses the impact of changes in demand or in programs is not strong given the fact that a minister aims at realising his policy objects and simultaneously controls the budget of the ZBO. This is reflected for example in the debates on using temporary or structural staff in the NZA case, problems in the use of resources for restructuring programs such as SVB-Tien, the claim on minJus of RvR and the pressure on UWV with regular changes in programs. A last point to be made is that expertise on the ownership role towards ZBOs is scattered over nearly all ministries and most likely not used efficiently.

If ownership responsibility is separated from program responsibility, checks and balances between the two different types of interest can be realised. A proposal like this is certainly not new (Van Thiel, Canté \& Meerkerk, 2009) and is even applied for state participations in the Netherlands as of 2001 (e.g. Parliament, 2006c, p. 36), in which case minFin is responsible for managing the shareholder role of the state. This management program can in my opinion be extended to ZBOs given the fact that ZBOs are not hierarchically subordinated to ministries. Given the political relevance of ZBOs I would suggest that management will be organised within minFin and not in a separate foundation as is proposed for shares held by government (Parliament, 2010) in financials due to the financial crisis of 2007-2009. Of course separating ownership and program responsibility does not solve all problems given the fact that minFin also has influence on changes in programs of different ministries.

\subsection{Use control structures aligned to services provided}

Not only do the legal status and motives for creating a ZBO vary, but more importantly, the type of services and economic characteristics of these services vary greatly between ZBOs. The study shows that there is no co-ordinated structure in the budgeting processes between ZBO and 'parent' ministry. Even within groups of ZBOs that deliver similar services there is no standard control structure observed. Some ministries seem to regard 
ZBOs as subsidised units when they allocate resources to a ZBO on the basis of a decision that can be appealed; others manage their relationship with ZBOs with some form of commissioning by issuing letters of instruction on budgets which aim to define the level of services to be expected. Based upon the expected standard arrangements as discussed in section 14.3, ministries can develop a control standard for ZBOs that reflects relevant differences but also allows disclosing to Parliament the similarities that exist amongst ZBOs that deliver services on behalf of different ministries.

\section{$20.4 \quad$ Changes in kZBO}

Based on the findings, some comments and improvements on kZBO can be given. First, in my opinion, kZBO:32d on approval on borrowing and lending is obsolete given the fact that based on CW2001:45.1 most ZBOs are already subject to treasury management within the State's framework and those who are not are at least subject to liquidity management under rules set by minFin. Another solution would be to split kZBO:32 in two new articles, one for all ZBOs, covering kZBO:32a, b, c, e and $f$ (creating legal entity, property rights on assets as well as lease, guarantees and equalisation reserves) and one for PLBs covering kZBO:32d and kZBO:32g on bankruptcy and a new sub article covering dissolution of PLBs. The issue on dissolution of PLBs is by now not covered. A PLA can only be dissolved by law which means that political control is guaranteed. In a PLB case, dissolution is, without specific arrangements, the responsibility of the Board. This means that the Board also can decide upon residual value after dissolution and use it for other than public purposes. Including an arrangement in the statutes of a PLB that the ministerprincipal has a final word in dissolution can prevent this. Including such a requirement in kZBO:32 would be the logical supplement to a final word of a minister-principal in case of bankruptcy.

Second, kZBO:12-14 on appointment and remuneration of ZBO boards only cover measures for PLAs. In practice, it is not unusual that for PLBs similar arrangements are included in statutes. Giving a minister responsibility for appointing a PLB board shows the relevance of the PLB for public services. It does not block involvement of third parties as it is still possible to make arrangements for influence on appointing of the board by third parties (see e.g. AFM and Vf/Pf). Furthermore, a measure on remuneration of the Board of a PLB which is approved or decided upon by a minister prevents from non-transparent responsibilities in case remuneration is set at levels above those which are politically acceptable (see Dijkstal Committee, 2004, 2007). The arguments used in the explanatory notes to kZBO (Parliament, 2000d) do not hold in my opinion. First, the explanatory notes themselves are inconsistent because they state that those PLBs that only provide public services are very similar to PLAs (Parliament, 2000d, p. 33). Second, the general argument used is that PLB governance arrangements in civil law are sufficient and if public law governance measures would be imposed, this might result in inconsistencies with the civil law framework, particularly for those PLBs that provide private services as well (Parliament, 2000d, p. 7). We now (as of 2008) know that kZBO 
generally only is applied to part of the ZBO population, in fact those PLAs and PLBs that only provide public services. Given the similarities in service characteristics, there is no need for different measures on appointment and remuneration of ZBO boards anymore. It would be inappropriate to include measures of this kind within the subsidy requirements as meant in Awb. Therefore I would suggest applying kZBO:12-14 to PLBs only providing public services as well.

Third, based on a request by Parliament (Parliament, 2002h), annual reports of ZBOs have to be submitted to Parliament directly (kZBO:18). The wording of kZBO does not cover the intentions of MPs to have both annual reports and financial statements and should be changed for that reason only. I would suggest that not only annual report and financial statements should be submitted, but that the minister-principal is required to give an assessment on these documents. Providing an assessment by the minister principal is part of his system accountability role when using other organisational structures that traditional departmental structures. Furthermore, it highlights the political issues with respect to ZBOs and can contribute to the information overload problem as observed by MPs. From a practical point of view such an arrangement would prevent that ZBOs only provide program information (see NZA) or that ministers simply stop providing information because the law does not require doing so (minVWS).

Fourth, I have observed that it is not common to provide multiyear budgets of ZBOs, even in those cases where a ZBO is fully government funded. This is odd, as CW2001 requires that a multiyear budget is prepared for a department. This can only be done if relevant underlying information is available. In case of ZBO-services the underlying information must come from the ZBO and if not, the ZBO budget is merely imposed by the commissioning minister without taking into account the services to be delivered in the future. Including a requirement in KZBO to submit multiyear budgets provides the relevant estimate for the future and can be used as an early warning indicator for future developments. Given the legal status of multiyear budgets of departments, it would not be a binding level of budget beyond political control.

Fifth, ZBOs can more or less be created out of the blue, without critical assessment whether a government unit or other entity is really able to provide services and manage operations adequately. This is in strong contrast with creating executive agencies where an ex ante assessment of the new organisation, including issues of financial management has to be realised before a government unit is granted the executive agency status. I would suggest that a similar procedure is explicitly used in case of creating new ZBOs. Having a procedure has two advantages: it clarifies whether the organisation is fit for the job but it also restricts debates on what is needed to realise a ZBO status. The history on executive agencies has shown that there has been a time in which the process of creating a new executive agency was overregulated (Mookhoek, 2008) and clear cut rules helps to focus an assessment for a new organisation. 


\subsection{Authorisation of investments}

In traditional cash accounting system, all cash flows, whether relevant for daily operations or for investments in assets are included in a budget. If Parliament is to authorise case based budgets, Parliament has the power to decide on production capacity of an organisation. In the cases studied here, production capacity strongly depends on human capital but also on ICT projects. The impact of project decisions on ICT can be substantial as it may affect the level of future expenditures of an organisation. In the SVB and UWV case, debates on investment decision were made within the framework of a wider reorganisation project and an effort was made to show expected effects of investments, at least in the SVB-Tien Program. In the NZA case, investments in the new NZA office were financed in a less explicit form: the only indication I found was disclosure in NZA's annual report 2007. Parliament was thus only indirectly informed. Although it would not be efficient to discuss all individual investments of ZBOs, transparency would at least require that on the level of total and major investments Parliament is informed. Such a practice is common in the case of executive agencies, even when they are not funded through the government budget.

\subsection{Define a standard for the level of equalisation reserves}

Unspent resources in a cash accounting system are basically available for reallocation by Parliament. In an accruals accounting system, unspent resources may be an indication of efficient production and are disclosed on the balance sheet as reserves. The framework law on ZBOs allows equalisation reserves on operations as a tool to mitigate different results over time. Political opinions on the issue diverge as was expressed by minSzW who only allows dedicated reserves with reference to the allocation right of Parliament. In the study a variety of levels and control methods on equalisation reserves were found. Except for the NAK case, there were no explicit economic reasons used for the differences in levels of equalisation reserves. If kZBO allows equalisation reserves, it would be useful to define the level of acceptable equalisation reserves, preferably based on risk profiles related to production within ZBOs. As ZBOs are not meant to generate profits and are in many cases government funded, a basic level of equalisation reserves might be similar to what is practice in executive agencies (Regeling Baten Lasten diensten 2007; Decree executive agencies 2007). If other arrangements are needed, an explicit debate on the level of equalisation reserves can be included in a debate on the ZBO case law. A standard arrangement should also include a restriction on negative equalisation reserves to prevent from cases as RvR where a huge claim on minJus has been accumulated which is unlikely to be realised in the future.

\subsection{A draft decision model on autonomisation}

In this study several issues on controlling ZBOs were discussed. A main conclusion is that in the cases studied, an emphasis on legal rather than economic control seems to exist. Overemphasising legal controls may result in undesired inefficiencies in service delivery 
of ZBOs. Although it was not a specific issue in this study, it seems to be reasonable to claim that those services delivered by Dutch central government that could have been (internally or externally) autonomised actually have been autonomised or were not autonomised deliberately. An indication for this is the fact that political focus as of 2010 seems to be on mergers and efficiencies of scale rather than on creating new autonomised entities for tasks that were not autonomised before.

If restructuring is one of the key issues in the near future, it might be worthwhile to use some of the experiences found in this study that allows for an assessment of a possible new governance structure for autonomised entities. From an economic perspective, two issues may contribute to such a model. First, in my opinion, it looks like as if the origins of demand for services have been neglected in the control tools of ZBOs. If demand is generated on a citizen's demand basis, higher levels of autonomy can be used in combination with substantial influence from those in demand for services. This means that external autonomisation is a possible solution with relatively low levels of control, perhaps essentially only on fees to be determined (see Wattel, 1995) and maximum levels of reserves.

If however demand originates from the State or is based on citizen's requests, there is a need for more restrictive controls as services are paid for by taxes or at best authority biased fees. Within the group of State demand or citizen's request services, a group of services based on impartial judgement are included (see the main monitoring institutions in this study). In these cases a governance structure with involvement from outside the political system seems necessary to assure impartiality, but budgetary control is required given the fact that funding is realised from compulsory resources.

The second issue regards uncertainty as defined under TCT. If uncertainty exists, regular political interventions are likely to occur which means that closer monitoring and possibly more intensified control and instructions are required. Uncertainty and external autonomisation seem to be conflicting issues as was shown in the cases of UWV, CVZ (on new programs) and NZA (on a new organisation). Uncertainty related to the execution of programs would suggest that at best internal autonomisation might be a solution. Particularly for cases in which measurable production exists, budgeting can essentially be based on a flexible basis. If uncertainty is low, external autonomisation is possible, particularly if uncertainty on the volume of demand is not likely to exist. If however politicians wish to use more restricitve fixed budgets related to measurable services, that is possible but at the expense of service levels towards citizens. In an internal autonomisation setting, it is immediately clear that political choices made have an effect on services towards citizens. That is also a weak point, the question is whether politicians are really willing to accept that they have to choose if programs and as a result costs of operations result in budget overruns. In those cases where services cannot be measured the only solution is that a fixed budget is appropritated. Again, a difference can be observed between cases with or without uncertainty. If uncertainty exists, the only logical 
solution would be not to autonomise the services. Although the argument is essentially incorrect, perceived uncertainty of politicians on their control of 'Belastingdienst' was the reason not to create an executive agency 'Belastingdienst'. If no uncertainty exists and services cannot be measured, the additional control tools needed next to a fixed budget suggest that a closer monitoring would result in internal autonomisation rather than external autonomisation.

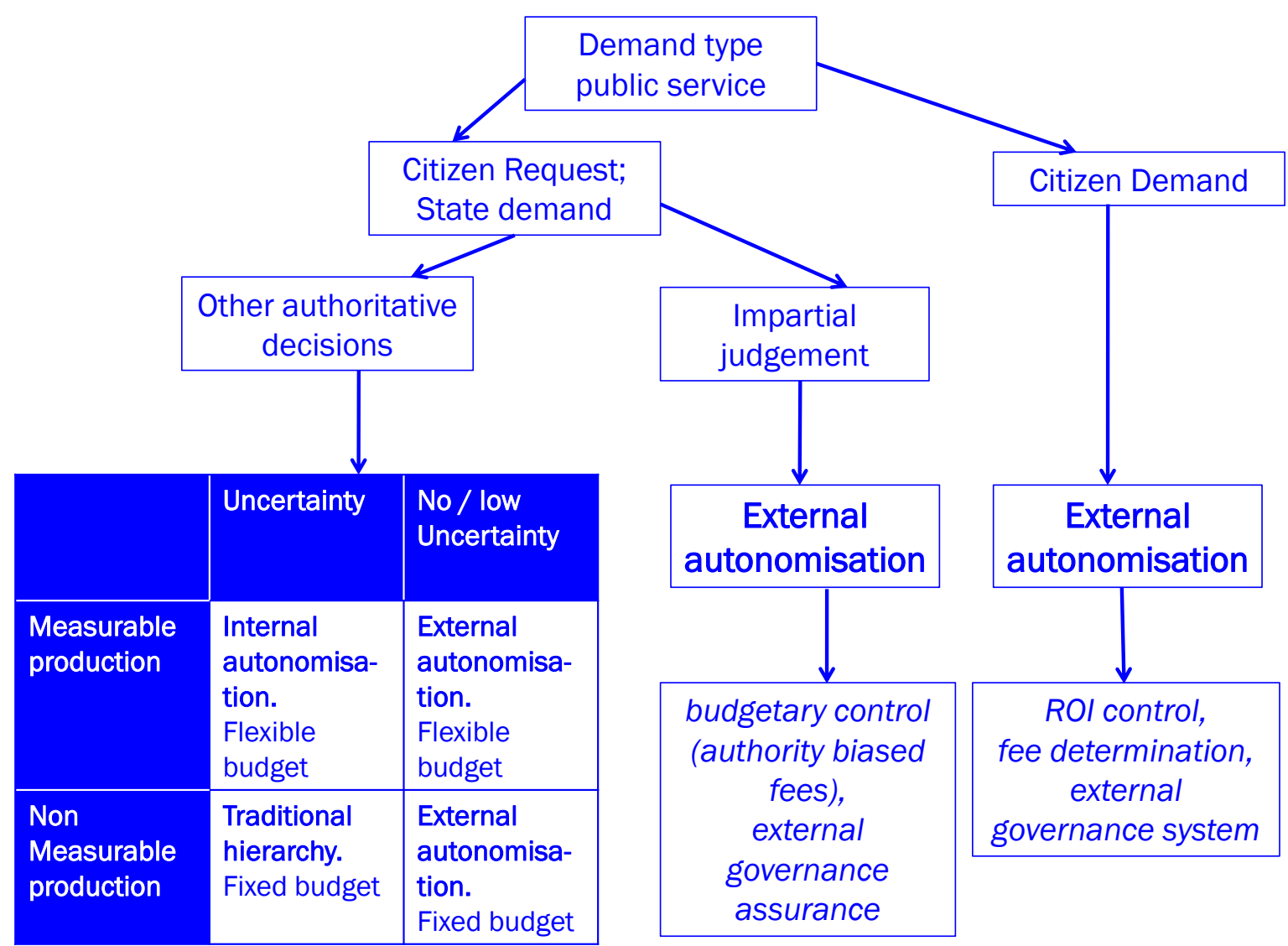

Figure 20.1: A draft model for deciding on autonomisation.

The draft model that is presented here might need further testing, but can at least contribute to the debates on organisation of Dutch national government in the near future.

\section{$20.8 \quad$ Future research.}

This study has focused on two main categories of ZBOs: income transfer ZBOs and monitoring ZBOs. Three other groups exist and within the group of monitoring ZBOs, some subgroups can be identified that may have different economic characteristics (e.g. quasi judicial entities versus training entities). Future research might focus on the groups not included in this study.

A second issue that might be useful is to focus on political stability of services to be provided by all types of arm's length organisations. The issue of political stability is not 
new; it was addressed by the Sint Committee in 1994. In some debates it was indirectly addressed, for example on the internal autonomisation of Belastingdienst which was not allowed for reasons that politicians feared to lose control (Parliament, 2003e). In the NCA reports is has not been a separate topic because the NCA mainly focuses on ex post information and not on creating (internally) autonomised organisations. Some of the problems discussed in the CVZ, UWV and NZA case have to do with instability and would be worthwhile to do research on drivers of instability and the necessary control tools if instability of programs is to be expected. Knowledge based on instability may be used in cases when restructuring of autonomised organisations is to be considered or when new organisations have to be created.

Third, similar arguments can be used for a research project on political relevance of services provided by arm's length organisations. The debates in the last decades on forms of autonomisation have shown trends towards creating ZBOs at one stage and then towards executive agencies in another stage. A structural assessment of the required political influence and thus on possible relative autonomy from traditional hierarchical structures has not been realised. In some cases, it seems that executive agencies have more degrees of freedom (for example due to economic characteristics of services) than some ZBOs. In other cases, ZBOs were dissolved and integrated into executive agencies apparently without rational arguments other than supposed efficiency gains and increased ministerial control (Parliament, 2009m). Research focusing on structural drivers of political relevance of public services might be helpful to identify preferred forms of autonomisation, both for new cases as well as for existing cases if reorganisations are to be discussed. Although it is likely to be late, such research could contribute to the assessment of the position of those ZBOs which are for other reasons than discontinuation not included under the kZBO-framework. 


\section{Bestuurlijke samenvatting}

\section{Inleiding}

Verzelfstandiging en decentralisatie van publieke dienstverlening is in de afgelopen drie decennia een belangrijke thema geweest. Er werden (nieuwe) organisaties op afstand van de overheid geplaatst, veelal met als argument efficiëntieverbetering. In mijn onderzoek heb ik mij gericht op de bestuurlijke aansturing van een bepaalde vorm van verzelfstandiging te weten Zelfstandige Bestuursorganen (ZBOs). De centrale probleemstelling voor het onderzoek luidt als volgt:

Passen de sturingsinstrumenten van het Parlement bij de juridische en economische zelfstandigheid zoals die op het gebied van bedrijfsvoering aan ZBOs is toebedeeld?

Verzelfstandiging impliceert dat het management van een organisatie meer vrijheidsgraden krijgt om de bedrijfsvoering van de organisatie in te richten en aan te sturen. Om dit te kunnen realiseren is het nodig dat een op elkaar aansluitend juridisch en economisch beheersingsinstrumentarium voor de organisatie bestaat en wordt toegepast. Indien dat niet het geval is ontstaat interpretatieruimte en mogelijk ook een conflict over de uitvoering van taken van in dit geval ZBOs. Er kan sprake zijn van een gebrek in het formele beheersingsinstrumentarium, maar ook omdat in de praktijk wordt afgeweken van wat formeel is voorgeschreven.

In deze bestuurlijke samenvatting ga ik kort in op de resultaten uit het onderzoek. Een meer uitgebreide Nederlandstalige samenvatting is afzonderlijk beschikbaar.

ZBOs zijn organisaties die diensten verlenen namens de centrale overheid. Het centrale kenmerk van ZBO diensten ten opzichte door andere verzelfstandigde organisaties geleverde diensten is dat het gaat om eenzijdig bindende beslissingen van een bestuursorgaan dat opereert buiten de hierarchische structuur van de rijksoverheid. Een voorbeeld van een ZBO is het Kadaster. Het Kadaster draagt onder andere zorg voor de registratie van vastgoed. Een organisatie als de NV Nederlandse Spoorwegen valt niet onder het begrip ZBO; vervoersdiensten zijn niet als eenzijdig bindende beslissingen aan te merken. Alhoewel de hierboven gegeven omschrijving lijkt te duiden op een eenduidige definitie is dat niet het geval. Bovendien zijn er in de loop van de tijd verschillende telmethoden voor het vaststellen van het aantal ZBOs gebruikt. Deze twee factoren hebben er toe geleid dat in de literatuur over ZBOs aantallen worden genoemd tussen ruim 100 en ruim 600 .

Voor dit onderzoek heb ik gebruik gemaakt van de op 1 juli 2007 door het ministerie van Binnenlandse Zaken (minBZK) op internet gepubliceerde lijst van ZBOs. Die lijst is zodanig bewerkt dat ZBOs die soortgelijke taken vervullen als één organisatie zijn geteld. Ter illustratie: er waren destijds circa 20 regionale Kamers van Koophandel die in dit 
onderzoek als één organisatie zijn beschouwd omdat de aansturing vanuit het ministerie van Economische Zaken niet fundamentaal zal verschillen. Na bewerking van de lijst van minBZK kwam ik uit op 128 verschillende ZBOs die in 2006 samen circa $€ 7$ miljard kosten voor hun bedrijfsvoering kenden. Daarnaast gaven ze samen circa $€ 80$ miljard programma kosten (uitkeringen) uit. De totale kosten van de ZBOs besloegen ongeveer $40 \%$ van het totaal van de uitgaven op de Rijksbegroting.

\section{Theoretische achtergronden}

Verzelfstandiging roept bestuurlijke vraagstukken op. Aan de ene kant wordt doelbewust verzelfstandigd, aan de andere kant geven politici regelmatig aan dat ze willen ingrijpen op (onderdelen) van de bedrijfsvoering van die organisaties. Verder geldt dat voor het Parlement niet altijd helder is vast te stellen welke uitgaven door ZBOs worden gedaan. In de Rijksbegroting worden uitgaven van sommige ZBOs niet meegenomen omdat de diensten van het ZBO door middel van bijdragen van burgers worden betaald. Ook komt het voor dat de informatie over de prestaties van ZBOs summier is.

$\mathrm{Na}$ een jarenlange discussie naar aanleiding van een kritisch rapport van de Algemene Rekenkamer in 1995 is in 2007 de kaderwet Zelfstandige Bestuursorganen van kracht geworden. Die wet beoogt een standaard pakket beheersmaatregelen voor ZBOs vast te leggen. In hoofdlijnen kiest de kaderwet voor uniformering van regelgeving, ongeacht de onderliggende karakteristieken van diensten die de ZBOs leveren. Uniformering wordt verder beperkt omdat uitzonderingen op de in de kaderwet vastgelegde normen mogelijk blijven. Van de 128 ZBOs uit mijn onderzoek staat slechts voor iets minder dan de helft vast dat de kaderwet (gedeeltelijk) daadwerkelijk van toepassing zal zijn. De beoogde uniformering van bestuurlijke aansturing wordt dus niet gerealiseerd.

Bij het ontwikkelen van het theoretisch kader zijn drie verschillende juridische invalshoeken gehanteerd: relevante begrotingswetgeving zoals opgenomen in de Comptabiliteitswet, het bestuursrecht en in het bijzonder de relevante regelgeving rondom ZBOs en het privaatrecht. Privaatrecht is relevant omdat een aantal ZBOs een privaatrechtelijke in plaats van een publiekrechtelijke status heeft. Bovendien kan het privaatrecht behulpzaam zijn om de contractuele relaties te beschrijven tussen twee organisaties die formeel juridisch onafhankelijk van elkaar zijn. De drie hierboven genoemde juridische invalshoeken vormen het algemene kader en ijkpunt voor de beoordeling van de positionering van individuele ZBOs. De feitelijke invulling van de juridische positionering van een ZBO blijkt uit de specifieke wet voor het desbetreffende ZBO.

Vanuit economisch perspectief is gebruik gemaakt van de in neo-institutionele theorie benoemde beheersingsinstrumenten die passen bij organisaties waar sprake is van een scheiding tussen management en eigendom van de organisatie. Daarnaast is gebruik gemaakt van theorie die betrekking heeft op produktie en product-karakteristieken zoals 
massa- en stuksproduktie en meetbaarheid van produktie. In de derde plaats is de 'markt' voor ZBO-diensten beoordeeld. Alhoewel er gelet op de positionering van ZBOs niet echt sprake is van een markt, kunnen marktkenmerken waaronder de organisatie van aanbod, bekostiging van diensten en de opdrachtgever-functie een bijdrage leveren in de beschrijving van de door ZBOs geleverde diensten. De economische kenmerken die uit de theorie kunnen worden afgeleid bepalen uiteindelijk de mogelijkheden voor het beheersingsinstrumentarium dat aansluit bij de door het ZBO geleverde diensten. Vanuit theoretisch economisch perspectief betekent dit dat differentiatie van het bestuurlijk beheersingsinstrumentarium noodzakelijk is.

Mijn onderzoek startte in de tijd dat de discussie over de inhoud van de kaderwet nog niet was afgerond. Ik heb ervoor gekozen om onderzoek te doen naar de regelgeving in relatie tot de economische kenmerken van ZBOs. De aanleiding daarvoor was dat uit eerder onderzoek bekend was dat er een grote variëteit aan ZBOs bestaat, deels veroorzaakt door verschillende juridische positionering, deels veroorzaakt door verschillen in bekostiging van ZBOs. Door onderzoek te doen naar samenhang tussen juridische en economische beheersingsmaatregelen beoog ik meer inzicht te krijgen in het spanningsveld tussen verzelfstandiging en bestuurlijke controle op de bedrijfsvoering van ZBOs. De veronderstelling is dat wanneer juridische en economische beheersingsmaatregelen onvoldoende op elkaar aansluiten, de feitelijke bestuurlijke sturing en beheersing van een ZBO problematisch is en leidt tot ongewenste toe- of afname van de autonomie van de organisatie.

\section{Bevindingen}

Het is niet mogelijk om in een onderzoek tot in detail alle ZBOs door te lichten. Ik heb me daarom beperkt tot 11 gevallen uit twee hoofdgroepen ZBOs. Ik heb gekozen voor ZBOs die inkomensoverdrachten verstrekken of een toezichtsfunctie vervullen. Bij de selectie van de betrokken ZBOs heb ik mij gebaseerd op de beschrijvingen van de kerntaken van die ZBOs zoals opgenomen in de jaarstukken.

In het geval dat de door ZBOs geleverde diensten vergelijkbaar zijn zou mogen worden verwacht dat de geformuleerde en toegepaste beheersingsinstrumenten ook vergelijkbaar zijn. Dit betekent dat op basis van de gevonden juridische en economische kenmerken een toetsingskader kan worden ontwikkeld voor vergelijkbare ZBOs. Ik heb dat toetsingskader toegepast op zes ZBOs die inkomensoverdrachten verzorgen en vijf ZBOs die een toezichtsfunctie vervullen.

Er zijn twee onderzoeksmethoden toegepast om tot een beoordeling van de aansluiting tussen het juridische en economische beheersingsinstrumentarium te komen. In de eerste plaats is gekeken naar de regelgeving en de documenten uit de planning \& control cyclus van een ZBO. In de tweede plaats zijn interviews met functionarissen van ZBOs en de betrokken 'eigenaar'-ministeries gehouden. Aanvullend is ook met enkele (voormalige) Kamerleden gesproken. Door gebruik te maken van twee verschillende 
onderzoeksmethoden wordt inzicht verschaft in zowel de formele als de feitelijke toepassing van het beheersingsinstrumentarium voor ZBOs vanuit het bestuurlijk perspectief.

De navolgende algemene conclusie en observaties zijn uit het onderzoek af te leiden:

1. In slechts drie gevallen is feitelijk sprake van aansluiting tussen juridisch en economisch beheersinstrumentarium.

2. In acht gevallen ligt het accent op het juridische beheersingsinstrumentarium.

3. Publiekrechtelijke ZBOs kennen een meer restrictief beheersingsinstrumentarium dan vooraf mocht worden verwacht.

4. ZBOs die inkomensoverdrachten verzorgen kennen een stringenter beheersingsinstrumentarium dan ZBOs met een toezichtsrol

5. De rollen opdrachtgever en eigenaar worden onvoldoende helder gescheiden en in sommige gevallen is sprake van inconsistent gedrag binnen ministeries.

6. Budgetbeheersing op basis van lump sum gaat ook in gevallen waar activiteiten gestuurde budgetten mogeljk zijn toch voor.

7. Prestatie-informatie wordt maar gedeeltelijk en niet consistent ter beschikking gesteld.

Op basis van deze bevindingen is de conclusie uit het onderzoek dat in de meeste gevallen geen sprake is van aansluiting tussen het juridische en economische beheersingsinstrumentarium voor ZBOs. In de kern ligt het accent op het juridische beheersingsinstrumentarium en wordt geen recht gedaan aan de economische karakteristieken van de dienstverlening door ZBOs.

\section{Kanttekeningen}

De bevindingen uit het onderzoek gelden specifiek voor de elf onderzochte organisaties. Toch zijn op basis van het onderzoek ook enkele bredere kanttekeningen te maken. In de eerste plaats kunnen de bevindingen niet zondermeer worden gegeneraliseerd. Wel geldt dat de bevindingen voor NAK en FBKVB redelijkerwijs ook van toepassing zijn voor de overige ZBOs die behoren tot de cultuurfondsen respectievelijk certificeerders van landbouwprodukten.

In de tweede plaats geldt dat op basis van interviews met Kamerleden blijkt dat sprake is van moeizame informatievoorziening naar het Parlement. Tegelijkertijd stellen de geïnterviewden vast dat ook snel een risico van informatie-overvloed bestaat. Een meer gestructureerde benadering van de informatievoorziening naar Kamerleden over alle ZBOs en niet alleen die ZBOs die uit de Rijksbegroting worden bekostigd kan toegevoegde waarde hebben. Uit de gesprekken met Kamerleden bleek ook dat zij denken dat voor ZBOs die een quasi juridische functie uitvoeren (denk aan marktmeesters of instellingen als de commissie gelijke behandeling) er andere en minder beperkende sturingsinstrumenten nodig zijn dan voor de andere ZBOs. 
Een laatste kanttekening heeft betrekking op de onderliggende ideëen rondom hervormingen in publiek management (Public Management Reform/New Public Management). Uit het onderzoek blijkt dat er een grote verscheidenheid aan besturingsinstrumenten voor ZBOs is ontstaan. Dat bevestigt eerdere onderzoeksbevindingen over beperkte consistentie in het Nederlandse verzelfstandigingsbeleid, in ieder geval voor ZBOs. Er zijn in het onderzoek ook binnen individuele ministeries procedures en handelwijzen aangetroffen ten opzichte van verschillende ZBOs die op zijn minst als onderling niet consistent kunnen worden beschouwd. Andere factoren zoals historische achtergronden, verschillen in cultuur bij betrokken organisaties en complexiteit van dienstverlening lijken ook een rol te spelen bij de inrichting van het beheersingsinstrumentarium in individuele gevallen.

\section{Aanbevelingen}

Naar aanleiding van de bevindingen uit het onderzoek zijn de volgende aanbevelingen het overwegen waard.

1. Ontwikkel een eenduidige standaard voor informatievoorziening over ZBOs.

2. Benoem één eigenaar voor alle ZBOs.

3. Stem planning en control af op de karakteristieken van de geleverde diensten.

4. Pas de kaderwet Zelfstandige Bestuursorganen op punten aan.

5. Laat de Tweede Kamer investeringen goedkeuren.

6. Bepaal een norm voor de omvang van egalisatiereserves.

Vanuit onderzoeksperspectief is het te overwegen om nader onderzoek te doen naar bestuurlijke relevantie en stabiliteit van door ZBOs te leveren diensten als criterium voor besluitvorming over verzelfstandiging van publieke dienstverlening. 


\section{Part E: References and indices}




\section{Bibliography}

\section{Academic}

Abma, T. \& Noordegraaf, M. (2003). Public Managers Amidst Ambiguity: Towards a Typology of Evaluative Practices in Public Management. Evaluation 9 (3), 285-306. Allers, M.A. \& Elhorst, J.P. (2005). Tax Mimicking and Yardstick Competition among Local Governments in the Netherlands. International tax and public finance. 12 (4), 493513.

Anderson, G.M.(1991) The fiscal significance of user charges and earmarked taxes. A survey. in Wagner, R.E. (ed.) Charging for government. 13-33. London: Routledge. Andeweg, R.B. \& Irwin, G.A. (2002). Governance and politics of the Netherlands. Basingstoke: Palgrave/Macmillan.

Anthony, R.N. \& Govindarajan, V. (1998). Management control systems, 9th ed., Boston etc.: Irwin/McGraw-Hill.

Anthony, R. N. \&Young, D.W. (1999), Management control in non profit organizations $6^{\text {th }}$ ed. Boston etc: Irwin/McGrawHill.

Anthony, R. N. \& Young, D.W. (2003), Management control in non profit organisations. 7th ed. Boston MA: Irwin/McGrawHill.

Antheunissen, W. (1948). De comptabiliteitswet 1927. Den Haag: Staatsdrukkerij en Uitgeverijbedrijf.

Atrill, P. \& McLaney, E. (2009). Management accounting for decision makers. 6th ed. Harlow: Pearson Education.

Arrow, K.J. (1985). The economics of agency. in: J.W. Pratt \& R.J. Zeckhauser (eds). Principals and agents: the structure of business. (37-54) Boston MA: Harvard business school press.

Arrowsmith, S. (2003). Government Procurement in the WTO, The Hague/London/New York.: Kluwer law international.

Ashworth, A. (2002). Pre contract studies. Development economics, tendering and estimating, $2^{\text {nd }}$ ed. Oxford etc: Blackwell Publishing.

Baarsma, B. \& Theeuwes, J. (2008). De verwarde onderneming. Economisch Statistische Berichten. 93 (458) 68-71.

Babbie, E. (2008). The basics of social research. Belmont (CA): Thompson Higher Education.

Bannink, D.B.D. (2004). The reform of Dutch disability insurance. Enschede: University of Twente

Barker, A. (1982). Quangos in Britain. Basingstoke: Macmillan.

Bij, J. van der. (1993). Doelmatigheid en de rijksbegroting. Een staatsrechtelijke en economische visie op de rijksbegroting. Groningen: Wolters Noordhoff

Behn, R.D. (2001). Rethinking democratic accountability. Washington DC: Brookings institution press. 
Behn, R.D. (2002). The Psychological Barriers to Performance Management: Or Why Isn't Everyone Jumping on the Performance-Management Bandwagon? Public Performance \& Management Review., 26 (1) pp. 5-25.

Bekke, H. \& van Gestel, N. (2004). Publiek verzekerd. Voorgeschiedenis en start van het Uitvoeringsinstituut Werknemersverzekeringen (UWV) 1993-2003. Antwerpen/Apeldoorn: Garant-Uitgevers

Bennet, J.T., \& DiLorenzo, T.J. (1983). Underground government. The off-budget public sector. Washington: Cato Institute.

Bent, J. van den. (1989). Financieel Management bij de Rijksoverheid. 's Gravenhage, SDU uitgevers.

Berens, W., Bücker, H. \& Finken, T. (1998). Einführung der Kosten- und Leistungsrechnung in Landesbildungseinrichtungen Nordrhein-Westfalens. Kostenrechnungspraxis: Zeitschrift für Betriebsrechnung, Kostenrechnung und Planung, 42 (6) 373-380.

Berg, J.Th.J. (1981). De regering. In: Andeweg, R.B., Hoogerwerf, A. \& Thomassen, J.J.A. (red), Politiek in Nederland (220-245). Alphen aan den Rijn: Samsom.

Berge, J.B.J.M. ten \& Zijlstra, S.E. (2000). De publiekrechtelijke rechtspersoon in ontwikkeling. in Berge, J.B.J.M. ten, Zijlstra, S.E., Timmerman, L. \& Buijn, F.K. De ontwikkeling van de rechtspersoon in het publiekrecht en het privaatrecht. Handelingen van de Nederlandse Juristen-Vereniging 130 (1), pp. 5-101. Deventer: W.E.J. Tjeenk Willink.

Berle, A.A. \& Means, G.C. (1932/2009). The modern corporation and private property. New York: Commerce Clearing House. Reprinted 2009 by Transaction Publishers, New York and London.

Bhimani, A., Horngren, C.T., Datar, S.M. \& Foster, G. (2008). Management and cost accounting. 4th ed. Harlow: FT-Prentice Hall.

Bij, J. van der (1993). Doelmatigheid en rijksbegroting. Een staatsrechtelijke en economische visie op de rijksbegroting. Groningen: Wolters-Noordhoff

Birchall, J. (2002). Mutual, Non-profit or public interest company? An evaluation of options for the ownership and control of water utilities. Annals of Public and Cooperative Economics 73 (2) 181-213.

Blaauwbroek, H., Hoeven, E. van der \& Visser, E. (1997). In het belang van de verzekerde. Zeist: Stichting Historie Ziekenfondswezen.

Blankart, C.B. (1986). Limits to privatization. European Economic Review. 31 346-351.

Blomgren Bingham, L., Nabatchi, T. \& O'Leary, R. (2005). The new governance: practices and processes for stakeholder and citizen participation in the work of government. Public Administration Review. 65 (5) 547-558.

Bodie, Z, Kane, A. \& Marcus, A.J. (1996). Investments. 3rd edition. Chicago etc: Irwin.

Bogt, H.J. ter. (1998). Neo-institutionele economie, management control en verzelfstandiging van overheidsorganiaties. Capelle aan den IJssel: Labyrint Publication. 
Bogt, H.J. ter (1999). Verzelfstandiging van overheidsorganisaties. Theorie en praktijk. Bestuurskunde 1999 (1). 2-17.

Bogt, H.J. ter. (2003). A transaction cost approach to the autonomization of government organizations. A political transaction cost framework confronted with six cases of autonomization in the Netherlands. European Journal of law and economics 16 (2). 149-186.

Bohley, P. (1980) Gebühren und Beiträge. in : F. Neumark, N. Andel \& H. Haller. Handbuch der Finanzwissenschaft Band II. (917-948). Tübbingen: J.C.B. Mohr (Paul Siebeck).

Bokkes, W.Th.M. (1989) Privatisering belicht vanuit de transactiekostenbenadering Enschede: Universiteit Twente.

Bolkestein, N. \& Wel, D. van der (1959). Het goedkeuringsrecht. Haarlem: H.D. Tjeenk Willink.

Boorsma, P.B. (1982) Rationalisatie van het uitgavenbeleid van de Rijksoverheid. In A. Hoogerwerf (red). Overheidsbeleid, $2^{e}$ gewijzigde druk. pp. (320-347). Alphen aan den Rijn: Samsom.

Boorsma, P.B \& Mol, N.P. (1983) Privatisering, 's Gravenhage: Stichting Maatschappij en Onderneming.

Boorsma, P.B., Maessen, F.C.M.M. \& Schild J.A. (1999). 'Van beleidsbegroting tot beleidsverantwoording' in relatie tot beleidsanalyse en prestatiebegroting: een historische vergelijking vanuit een beleidsanalytisch perspectief, Beleidsanalyse, 28, (1/2), 15-28, Den Haag: SDU uitgevers.

Boot, A. (2008). Nederlands pensioenstelsel verre van af. Economisch Statistische berichten, 93 (4531), 164-167.

Borman, C. (1993). Aanwijzingen voor de regelgeving en andere voor de regelgeving relevante aanwijzingen. Zwolle: W.E.J. Tjeenk Willink.

Bouckaert, G. (1998). Public Sector Performance Management in a Principal Agent Context. in P.B. Boorsma \& A. Halachmi.(eds) Inter and Intra Government Arrangements for Productivity: an Agency Approach. (137-146) Boston, Dordrecht, London: Kluwer academic Publishers.

Bouckaert, G. \& Dooren, W. van. (2003). Performance measurement and management in public sector organisations. In T. Boviard \& E. Löffler (eds). Public management and governance. (127-136). London: Routledge.

Bouckaert, G. \& Peters, G.B. (2004). What is available and what is missing in the study of quangos? In C. Pollitt \& C. Talbot (eds). Unbundled government. A critical analysis of the global trend to agencies, quangos and contractualisation. (22-49). London: Routledge.

Bouma, J.L.. (1982). Leerboek der bedrijfseconomie. Deel 1. Inleiding tot de bedrijfseconomie. 's Gravenhage: Delwel.

Bouma, J.L. \& Helden, G.J. van. (1994). Management accounting en economische organisatietheorie. Schoonhoven: Academic service. 
Bovens, M. (2000). De vierde macht revisited. Over ambtelijke macht en publieke verantwoording. Utrecht: Universiteit Utrecht.

Bovens, M. (2005) Publieke verantwoording: een analysekader. in W. Bakker \& K. Yesilkagit, Publieke verantwoording. (p. 25-55). Amsterdam: Boom

Boxum, J.L., Ridder, J. de \& Scheltema, M. (1989). Zelfstandige bestuursorganen in soorten Deventer: Kluwer.

Boxum, J.L. (1997). Algemene wetgeving voor zelfstandige bestuurslichamen. Deventer: Kluwer.

Braband, W.J. van (1986). Tweede Kamer worstelt met haar toezichtsfunctie. Economisch Statistische berichten, 71, (3584), 1201-1202.

Brandsen, T. (2004). Quasi-market governance. An anatomy of innovation. Utrecht: Lemma.

Brealy, R.A. \& Myers, S.C. (1991). Principles of corporate finance. $4^{\text {th }}$ ed.. New York etc: McGrawHill.

Buchanan, J.M. (1991). The constitutional economics of earmarking. in R.E. Wagner(ed.). Charging for government. (152-162). London: Routledge.

Burg, V.A.M. van der. (1986). De norm voor het bestuur van een overheidsstichting is het belang van de stichting. TVVS: maandblad voor ondernemingsrecht en rechtspersonen. 29 (1) 11-13.

Burkens, M.C., Kummeling, H.R.B.M., Vermeulen, B.P. \& Widdershoven, R.J.G.M. (2001). Beginselen van de democratische rechtsstaat. Inleiding tot de grondslagen van het Nederlandse staats- en bestuursrecht. Deventer: W.E.J. Tjeenk Willink.

Carnegie, G.D. \& West, B.P. (2003) How well does accrual accounting fit the public sector?, Australian journal of public administration. 62 (2) 83-86.

Chan, J.L.. (2003). Government Accounting: An assessment of theory, purposes and standards. Public Money and Management. 23 (1) pp. 13-20.

Chow, D.S.L., Humphrey, C \& Moll, J.. (2007). Developing Whole of Government Accounting in the UK: Grand claims, practical complexities and a suggested future research agenda. Financial Accountability and Management 23 (1) 27-54.

Christiaens, J. , Reyniers, B. \& Rollé, C. (2010). Impact of IPSAS on reforming governmental financial information systems: a comparative study. International Review of Administrative Sciences 76 (3) 537-554.

Coase, R.H. (1937) The nature of the firm. Economica 4 (16). pp 386-405.

Cornforth, C. (ed.). (2003). The governance of public and non-profit organisations, Routledge: London/New York.

Cullis, J. \& Jones, Ph. (1998). Public Finance and Public choice. $2^{\text {nd }}$ ed.. Oxford: Oxford University Press.

Dalhuisen, A. (2004) Op afstand en toch dichtbij. De overheidsstichting binnen handbereik. Master thesis. Enschede: University of Twente. 
Deelen, M. \& Eertink, D. (2004). Het Kadaster tien jaar ZBO: op zoek naar evenwicht., in S. van Thiel (ed.). Governance van uitvoeringsorganisaties. Nieuwe vraagstukken voor sturing in het publieke domein. (p. 115-126), Apeldoorn: Kadaster.

Dees, M. \& Neelissen, P. \& Steenhoek, K.J. (2004). Uitstel of afstel? De Accountant. 110(5) 42-45.

Dekkers, H. (2007). Driekwart van de burgers is er op vooruit gegaan. Gemeentereiniging en Afvalmanagement. 98 (9) 22-23.

Dijk, P.L., \& Ploeg, T.J. van der (1997). Van vereniging en stichting, coorporatie en onderlinge waarborgmaatschappij. Deventer: Gouda Quint.

DiMaggio, P.J. \& Anheier, H.K. (1990). The sociology of non profit organisations and sectors. Annual review of Sociology, 16 137-159.

Dolman, D. (1987) Begrotingsfuncties en Parlement. Openbare Uitgaven. 19 (4) pp. 147152.

Domberger, S. (1998). The contracting organization. A strategic guide to outsourcing. Oxford: Oxford university press.

Douma, S. \& Schreuder, H. (1998). Economic approaches to organisations. $2^{\text {nd }}$ ed. London etc: Prentice Hall.

Drury, C. (2008). Management and Cost Accounting. $7^{\text {th }}$ ed. London etc: South-Western Cengage learning.

Dunleavy, P. (1991) Democracy, Bureaucracy and Public Choice. New York: Harvester.

Dussen, J.W. van der. (2002). De vernieuwde comptabiliteitswet. Overheidsmanagement, 15 (9), pp. 239-241

Eggertsson, T. (1990). Economic behavior and institutions. Cambridge: Cambridge University Press

Eijgelshoven, P.J., Nentjes, A. \& Velthoven, B.C.J. van. (1996). Markt en overheid. Groningen: Wolters-Noordhoff.

Eijlander, Ph., Voermans, W.J.M. (2000). Wetgevingsleer. Den Haag: Boom Juridische Uitgevers.

Eisenhardt, K.M. (1989). Agency Theory: An Assessment and Review. The Academy of Management Review. 14 (1) 57-74.

Epstein, D. \& O'Halloran, S. (1999). Delegating Powers. A Transaction cost politics approach to policy making under separate powers. Cambridge: Cambridge University Press.

Esping-Andersen, G. (1990). The three worlds of welfare capitalism, Oxford: Blackwell Publishers

Esping-Andersen, G. (1999). Social foundations of post-industrial economies, Oxford: Oxford University Press.

Fama, E.F. \& Jensen, M.C. (1983a). Agency Problems and Residual Claims. Journal of Law and Economics. 26 (2) 327-349

Fama, E.F. \& Jensen, M.C. (1983b). Separation of Ownership and Control. Journal of Law and Economics. 26 (2) 301-325 
Flinders, M.V. (1999a). Setting the scene. in M.V. Flinders \& M.J. Smith (eds.) Quangos, accountability and reform. The politics of quasi government. (3-16) Basingstoke/London: Macmillan Press

Flinders, M. (1999b) Why do governments love quangos? in Flinders, M. \& Smith, M.J. (eds). Quangos, accountability and reform. The politics of quasi government. (2639) Basingstoke: Macmillan Press.

Flinders, M.V. \& M.J. Smith (eds.) (1999). Quangos, accountability and reform. The politics of quasi government. Basingstoke/London: Macmillan Press

Flynn, N. (1993) Public sector Management. 2nd ed., New York etc.: Harvester/Wheatsheaf.

Flynn, N. (2007) Public sector Management. $5^{\text {th }}$ ed., Los Angeles etc.: Sage Publications.

Forward, R. (1976). The quango as a communal instrument. Australian journal of public administration, 35 (3), 244-250.

Fountain, J.E. (2001). Paradoxes of public sector customer service. Governance 14 (1), 55-73.

Freeman, R.J. \& Shoulders, C.D. (2000). Governmental and non profit accounting. Theory and practice, $6^{\text {th }}$ ed.. Upper Saddle River, NJ: Prentice Hall.

Furubotn, E.G. \& Pejovich, S. (1972). Property rights and economic theory: a survey of recent literature. Journal of Economic Literature, 10 (4) 1137-1162.

Garner, M.R. (1996) The theory of public enterprise reconsidered. Annals of public and cooperative economics. 67 (1) 85-115.

Genugten, M. van. (2008). The art of alignment. Transaction cost economics and the provision of public services at the local level. Retrieved May 29, 2010 from: http://doc.utwente.nl/58769/1/thesis van_Genugten.pdf

Geurts, P. (1999). Van probleem naar onderzoek. Baarn: Coutinho.

Glendon, M.A., Gordon, M.W. \& Osakwe, C. (1985). Comparative legal traditions. St. Paul (Minn): West Publishing Co.

Goddard, M. \& Mannion, R. (2004) The role of horizontal and vertical approaches to performance measurement and improvement in the UK public sector. Public Performance and Management Review. 28 (1) 75-95.

Goedhart, C. (1958). Capital selecta der economie XX: Hoofdlijnen van de leer der openbare financiën. Leiden: H.E. Stenfert Kroese.

Goedhart, C. (1975). Hoofdlijnen van de leer der openbare financiën, $3^{e}$ druk. Leiden: H.E. Stenfert Kroese.

Goorden, C.P.J. (1997). Verzelfstandiging: naar een doorzichtig en geregeld bestuur. in C.P.J. Goorden, , M.M. den Boer \& F.K. Buijn. ZBO's, Verzelfstandiging en privatisering. (7-124). Alphen aan den Rijn: Samsom H.D. Tjeenk Willink.

Grapperhaus, F.H.M. (1989) Belasting, vrijheid en eigendom, Zutphen: De Walburg Pers/Kluwer. 
Gray, A., Jenkins, B. \& Segsworth, B. (1993). Budgeting, Auditing and evaluation. Functions and integration in seven governments. New Brunswick, London: Transaction Publishers.

Greer, A. \& Hoggett, P. \& Maile, S. (2003). Are quasi-governmental organisations effective and accountable?. In C. Cornforth (ed.) The governance of public and non-profit organisations. (p. 40-56). London: Routledge.

Gregory, M.R. (2004). Make or buy. Using cost analysis to decide whether or not outsource public services. Government Finance Review. 20 (4), p. 15-21

Greve, C. \& Flinders, M. \& Thiel, S. van (1999) Quangos - What's in a name. Defining quangos from a comparative perspective. Governance: an international journal of policy and administration 12 (2) 129-146.

Greve, C. (2008). Contracting for public services. London: Routledge.

Groenendijk, N.S. (1998). Overheidsinkomsten. Enschede: Twente University Press.

Groot, T.L.C.M. \& Helden, G.J. van (2003). Financieel management van non-profit organisaties 4e druk. Groningen: Stenfert Kroese

Grossekettler, H. (2000). Steuerstaat versus Gebührenstaat. Vor- und Nachteile. in: U. Sacksofsky \& J. Wieland (Hrsg).Vom Steuerstaat zum Gebührenstaat. 24-45. Baden-Baden: Nomos Verlagsgesellschaft.

Groves, H.M. \& Bish, R.L. (1973). Financing Government, $7^{\text {th }}$ ed., New York etc.: Holt, Rinehart and Winston Inc.

Günther, T. \& Schill, O. (2000). Der Haushaltsplan als Ergebnis der Kostenplanung. Intergration von kommunaler Haushaltsplanung und Planung in der Kosten- und Erlösrechnung. Kostenrechnungspraxis: Zeitschrift für Betriebsrechnung, Kostenrechnung und Planung. 44 (3) 185-195.

Guthrie, J. (1998) Application of accrual accounting in the Australian public sector rhetoric or reality? Financial Accountability and Management. 14 (1) 1-18.

Guthrie, J., Humphrey, C., Jones, L.R. \& Olson, O. eds. (2005). International public financial management reform. Progress, contradictions and challenges. Greenwich (Ct): Information age publishing

Guttman, D. (2003). Contracting United States Government work: Organizational and constitutional models. Public Organization Review 2003 (3) 281-299.

Hammond, T.H. \& Knott J.H. (1996) Who controls bureaucracy?: Presidential power, congressional dominance, legal constraints, and bureaucratic autonomy in a model of multi institutional policy-making. Journal of Law, Economics and Organization. 12 (1) 119-166.

Hart, O. \& Moore, J. (1990). Property rights and the nature of the firm. . Journal of Political Economy. 98 (6) 1119-1158.

Hazeu, C.A. (2000). Institutionele economie. Een optiek op organisatie- en sturingsvraagstukken. Bussum: Coutinho

Hazeu, C.A. (2004) Woningcorporaties, arm leven, rijk sterven? Tijdschrift voor Openbare Financiën. 36 (4) p 188-197. Den Haag: SDU. 
Helden, G. J. van (1997). Verzelfstandiging bezien vanuit de transactiekostentheorie. in: N.P. Mol \& H.A.A. Verbon. Neo-institutionele economie en openbaar bestuur. $2^{\mathrm{e}}$ herziene druk. (37-59) 's Gravenhage: Vuga.

Hepworth, N. (2003), Preconditions for Successful implementation of accrual accounting in central government, Public Money and Management, 23 (1) 37-43.

Heun, W. (1989) Staatshaushalt und Staatsleitung. Das Haushaltsrecht im parlementarischen Regierungssystem des Grundgesetzes. Baden-Baden: Nomos Verlag.

Heuvelhof, E.F. ten, Ringeling, A.B., Sluis, A. van \& Thiel, S. van, (2001). ZelfReinigend Vermogen. Bestuurlijke rapportage over het stelsel van 'niet-reinigbaar' verklaringen en de daarbij betrokken actoren. Rotterdam: Erasmus Universiteit.

Hillman, A.L. (2003). Public finance and public policy. Cambridge: Cambridge University Press.

Hofstede, G. (1981). Management control of public and non profit activities. Accounting, Organizations and Society. 6 (3) 193-211,

Hogwood, B.W. (1995). The 'growth of quangos: evidence and explanations. in F.F. Ridley \& D. Wilson (eds), 1995, The quango debate (29-47) Oxford: Oxford University Press.

Holterman, Th. (2000). artikel 134, in: Koekoek, A.K. (red), de Grondwet. Een systematisch en artikelsgewijs commentaar. $3^{\mathrm{e}}$ druk. pp 498-501. Deventer: W.E.J. Tjeenk Willink.

Hood, C. (2004). Controlling public services and government: towards a cross-national perspective. in: C. Hood, O. James, B. Guy Peters \& C. Scott (ed.), Controlling modern government. Variety, commonality and change. p. 3-24. Cheltenham/Northampton MA: Edward Elgar.

Hood, C., James, O., Peters, B. \& Scott, C (eds). (2004). Controlling modern government. Variety, commonality and change. Cheltenham/Northampton MA: Edward Elgar.

Hoogerwerf, A. (1982). Het beleidsproces, in A.Hoogerwerf (red.), Overheidsbeleid, 2e gewijzigde druk, (49-69). Alphen aan den Rijn: Samsom.

Horngren, C.T., Sundem, G.L., Stratton, W.O., Burgstahler, D \& Schatzberg. (2011). Introduction to management accounting. 15th edition. Upper Saddle River NJ.: Pearson.

Huijgen, W.G. (1995). Economische eigendom. Zwolle: H.J. Tjeenk Willink.

Hunt, D. (1995) Worthwhile bodies. In Ridley, F.F. \& Wilson, D. (eds) The Quango Debate. (14-28) Oxford etc: Oxford University Press

Hyndman, J. \& Eden, R. (2001). Rational management, performance targets and executive agencies: views from agency chief executives in Northern Ireland. Public Administration 79 (3) 579-598.

Jander, M. (1999). OTHER FEATURES - SLA Monitoring - SLA MONITORING TOOLS: HEAVYWEIGHT HELP - New SLA monitoring packages that report on a range of 
WAN services could help hold carriers to the pledges they make. Data Communications 28 (2) 107-116.

Janse de Jonge, E.J. (1993). Het Budgetrecht. Rechtsvergelijkende studie naar de begrotingsbehandeling door het Parlement in de Verenigde Staten, Engeland en Nederland. Zwolle.: W.E.J. Tjeenk Willink.

Janse de Jonge, E.J. (2000) artikel 104, in: A.K. Koekoek (red), de Grondwet. Een systematisch en artikelsgewijs commentaar, 3e druk. pp 498-501 Deventer: W.E.J. Tjeenk Willink.

Jensen, M.C. \& Meckling, W.H. (1976). Theory of the firm: managerial behaviour, agency costs and ownership structure. Journal of Financial Economics 1976 (3) 305-360.

Jensen, M.C. (1983). Organization theory and Methodology. The accounting review, 58 (2) 319-339

Jones, L.R. \& McCaffery, J.L. (2005) Contemporary Public Financial Management and Budget Reform in the US Federal Government, in: Guthrie, J., Humphrey, C., Jones, L.R. \& Olson, O. (eds. International Public management reform, pp 323-359, Greenwich CT: Information Age Publishers.

Jongsma, O. (2008). Monster zonder waarde: de maatschappelijke onderneming. Nederlandsch Juristenblad 83 (4) 217-220.

Joyce, P.G. \& Meyers, R.T. (2001). Budgeting during the Clinton presidency, Public Budgeting and Finance 21, (1) pp 1-21.

Kalders, P., \& Erp, J. van \& Peters,K. (2004). Overheid in spagaat. Over spanningen tussen verticale en horizontale sturing. Bestuurskunde, 13 (8) 338-346.

Kaplan, R.S. \& Norton, D.P. (1996). The balanced scorecard: translating strategy into action. Boston, MA: Harvard Business School Press.

Kee, R.C. \& Robbins, W.A. (2003). Public sector outsourcing: a modified decision model. Journal of government financial management. 52 (2), p. 46-52.

Kettl, D. F. (1993). Sharing Power. Public Governance of private markets. Washington DC: Brookings.

Kettl, D. F. (2002). The transformation of governance Public administration for TwentyFirst Century America. Baltimore and London: The Johns Hopkins University Press.

Kettl, D.F. (2008). Public Bureaucracies. in: R.A.W. Rhodes, S.A. Binder \& B.A. Stockman. The Oxford handbook of political institutions. (366-384). Oxford: Oxford University Press.

Kickert, W. (1998). Aansturing van verzelfstandigde overheidsdiensten. Over publiek management van hybride organisaties. Alphen aan den Rijn: Samsom.

Kickert, W. (2008). The study of public management in the Netherlands. Managing complex networks and public governance. in W. Kickert (ed.): The study of public management in Europe and the US. A comparative analysis of national distinctiveness (122-143). London/New York: Routledge

Kloosterman, D.R., Winter, H.B., Noordam, F.M., \& Ridder, J. de (2002) In zelfstandigheid geregeld. Groningen: Rijksuniversiteit Groningen. 
Kluiver, H.J. de. (1998). Overheidsstichting en overheidsaansprakelijkheid, in: S.C.J.J., Kortman, F.J. Oranje, A.A. van Rossum \& J.W.H. van Wijk. Overheid en Onderneming. Tussen publiek en privat ondernemen. (79-102). Deventer: W.E.J. Tjeenk Willink.

Kok, L. (2003). Outsourcing van ICT door overheidsinstellingen. Amsterdam: SEO.

Koppell, J.G.S. (2003). The politics of quasi-government. Hybrid organizations and the dynamics of bureaucratic control. Cambridge: Cambridge University Press.

Kortmann, C.A.J.M. \& Bovend'Eert, P.P.T. (2006). Inleiding consititutioneel recht. vijfde druk. Deventer: Kluwer

Kraan, D.J. (2006) De organisatie van de publieke sector. in C.A. de Kam \& Ros A.P. (red). Jaarboek Overheidsfinanciën 2006. (225-246). Den Haag: SDU uitgevers.

Kruijf, J.A.M. de. (2009). Inzicht in de Nederlandse publieke sector door consolidatie? MAB 83 (7/8), 255-262.

Kruijf, J.A.M. de \& Mol, N.P. (2007a). Réfome de la comptabilité et mesure de la performance des agences du gouvernement des Pays-Bas. Revue française d'administration publique. 30 (123), 301-321.

Kruijf, J.A.M. de \& Mol, N.P. (2007b) Resultaatverantwoordelijkheid bij agentschappen en zelfstandige bestuursorganen. MAB 81 (11) 564-573.

Kuiper, G.M. (1999). Financiële controle op zelfstandige bestuursorganen, dissertation. Groningen: Rijksuniversiteit Groningen.

Kummeling, H.R.B.M. \& Duijkersloot A.P.W. (2003). Agencies and the Netherlands. in: T. Zwart. \& L. Verhey (eds). (2003). pp. 79-112. Agencies in European and Comparative law. Antwerp: Intersentia.

Kummeling, H.R.B.M. \& Duijkersloot A.P.W. \& Minderman G.D. \& Schagen, J.A. van \& Zijlstra S.E. (1999). Verkenningen van verantwoordelijkheid : ministeriële verantwoordelijkheid voor het toezicht op de financiën van zelfstandige instellingen op het terrein van onderwijs en onderzoek. Deventer: W.E.J. Tjeenk Willink.

Künneke, R.W. (1991). Op armlengte van de overheid. Enschede: Universiteit Twente.

Künneke, R.W. (1997). Verzelfstandiging bezien vanuit de property rights theorie, in: N.P. Mol, \& H.A.A. Verbon (red). Neo-institutionele economie en openbaar bestuur. Perspectieven op de verzelfstandiging van overheidsdiensten. $2^{\mathrm{e}}$ herziene druk, 17-36. Den Haag: Vuga.

Künneke, R.W. \& Manders, A.M.P. (1997). Verzelfstandiging van electriciteitsbedrijven, in: N.P. Mol, \& H.A.A. Verbon (red). Neo-institutionele economie en openbaar bestuur. Perspectieven op de verzelfstandiging van overheidsdiensten. $2^{\mathrm{e}}$ herziene druk, 101-116. Den Haag: Vuga.

Lane, J.E. (2000). The public sector. Concepts, models and approaches. $3^{\text {rd }}$ ed. London etc : Sage.

Lapsley, I. (1994). 'Responsibility accounting revived? Market reforms and budgetary control in health care', Management accounting research, 5 (3-4) 337-352. 
Larsson, T. (2002). Sweden. in: OECD. Distributed public governance. (181-208). Paris: OECD

Lauth, T.P. (2002). The separation of powers principle and budget decision making. in A. Khan \& W. Bartley Hildreth (eds). Budget theory in the public sector. (42-76) Westport, CT/London: Quorum books.

Lee, R.D. \& Burns, R.C. (2000) Performance measurement in state budgeting: advancement and backsliding from 1990 to 1995. Public Budgeting and Finance. 20 (1) pp. 38-54

Leerdam, J. van. (1999). Verzelfstandiging en politieke economie. Over de betekenis van het nieuw institutionalisme voor de instelling en aansturing van zelfstandige bestuursorganen. Delft: Eburon.

Lijphart, A. (1975) The politics of accommodation: pluralism and democracy in the Netherlands, Berkley CA.: University of California Press.

Likierman, A. (2003) Planning and controlling UK public expenditure on a resource bases, Public Money and Management, 23 (1), pp 45-50.

Linker, P.J. (2006). Sturing in de Rijksdienst. Nieuwe inzichten verenigd in hèt sturingsmodel. Assen, Van Gorcum.

Locke, M., Begum, N. \& Robson, P.. (2003). Service users and charity governance, in Cornforth, C. (ed.), The governance of public and non-profit organisation. 57-73, Routledge: London/New York

Lohtia, R. Brooks, C.M. \& Krapfel, R.E. (1994) What constitutes a transaction specific asset? An examination of the dimensions and types. Journal of Business Research 30 (3) 261-270

Lonsdale, J. (2007). Walking a thightrope?. The changing role of State Audit in accountability regimes in Europe. in: M.L. Bemelmans-Videc, J. Lonsdale and B. Perrin (eds) Making accountability work. Dilemmas for evaluation and audit., 85104. New Brunswick/London: Transaction Publishers

Lüder, K.G. (1992). A contingency model of governmental accounting innovations in the political-administrative environment. Research in governmental and nonprofit accounting. 7(-) 99-127

Lüder, K. \& Jones, R. (2003). Reforming governmental accounting and budgeting in Europe. Frankfurt am Main: Fachverlag Moderne Wirtschaft.

Lyden F.J. \& Miller E.G. (eds) (1982). Public budgeting: program planning and implementation $4^{\text {th }}$ ed. Englewood Cliffs etc: Prentice-Hall.

Maeijer, J.M.M. (1997). Privatisering. Nadere verkenning van een al te gemakkelijk ingeslagen weg. Zwolle: W.E.J. Tjeenk Willink.

Maltby, P. (2003). Public Interest Companies. Fad or permanent fixture?. New Economy, 10 (1) 21-27.

Mann, C.L. (1999). Is the US trade deficit sustainable? Washington DC: Institute for international Economics.

Masson, K. (2005). Community Ltd?. Solicitors Journal. 31 (Spring). 23-25 
McCaffery, J.L. \& Jones, L.R. (2001). Budgeting and financial management in the federal government. Greenwich (Ct): Information Age Publishing.

McGuire, L. (2003). Transferring marketing to professional public services. Local governance, 29 (1) 55-77.

Meerkerk, I. van (2008). Zakelijk sturen op afstand? Een onderzoek naar de financieeleconomische sturingsrelaties tussen ministeries en ZBOs. Master thesis. Rotterdam: Erasmus Universiteit.

Meier, K.J. \& O'Toole, L.J. (2006). Bureaucracy in a democratic state. A governance perspective. Baltimore: The John Hopkins University Press.

Meijerink, M.H. (2005). Het einde van de hybriditeit? in M.H. Meijerink \& G.D. Minderman (red). Naar een andere publieke sector. Hybriditeit en een andere wijze van publieke taakvervulling. Den Haag: SDU uitgevers.

Merchant K.A. (1998) Modern management control systems., Upper Saddle River, NJ: Prentice Hall.

Mills, E.S. (1987). User fee. in: J. Eatwell, M. Milgate \& P. Newman (ed.). The new Palgrave. A dictionary of economics. Vol. 4. 776-768 London: MacMillan Reference Books.

Minderman, G.D. (2000). Tweede Kamer en rijksfinanciën. Een studie naar parlementaire sturing van rijksfinanciën in Nederland. Den Haag: Boom Juridische uitgevers.

Minderman, G.D. (2002). Nieuwe comptabiliteitswet zet Staten-Generaal op het verkeerde been. Nederlandsch Juristenblad, 77 (32), pp 1604-1608.

Minderman, G.D. (2003). Hoofdlijnen van het nieuwe recht der rijksfinanciën. Den Haag: SDU uitgevers.

Mintzberg, H. (1979). The structure of organizations. Englewood Cliffs: Prentice Hall.

Moe, R.C. (2002). United States. in: OECD Distributed Public Governance. (243-266) Paris: OECD.

Moe, T.M. (1984). The new economics of organisation. American Journal of Political Science 28 (4), 739-777.

Moe, T.M. (2006). Political control and the power of the agent. Journal of Law, Economics and Organisation 22 (1), 1-29

Mol, N.P. (1988) De allocatiefunctie van de overheidsbegroting. Enschede: Universiteit Twente.

Mol, N. (1989) Contract-Based Management Control in Government Organizations. International Review of Administrative Sciences. 55 (3): 365-379.

Mol, N.P. (1997). Operationele budgettering. Efficiency en effectiviteit in activiteitenbudgetten. Alphen aan den Rijn: Samsom/H.D. Tjeenk Willink.

Mol, N.P. (1998). Bedrijfseconomie voor de collectieve sector, $4^{\mathrm{e}}$ druk. Alphen aan den Rijn: Samsom/Vuga.

Mol, N.P. (2006) Operationele budgettering in de publieke sector. Den Haag: SDU uitgevers 
Mol, N.P. (2008). Bedrijfseconomie voor de collectieve sector, 5e druk. Bussum: Uitgeverij Coutinho.

Mol, N.P. \& Kruijf, J.A.M. de. (2002). Resultaatgerichte bekostigingsstructuren bij de overheid. Enschede: Universiteit Twente.

Mol, N.P. \& Kruijf, J.A.M. de. (2003) Accounting for hybridity: Accrual budgeting in the Dutch central government, Journal of Public Budgeting, Accounting and Financial Management, 15 (4), 542-564.

Mol, N.P. \& Kruijf, J.A.M. de. (2004). Performance management in Dutch central government, International review of administrative sciences, 70 (1), 33-50.

Mol, N.P., Verbon, H.A.A. \& Vries, P. de (1997). Verzelfstandiging van overheidsdiensten: interpretatiekaders uit de neo-institutionele economie. in N.P. Mol \& H.A.A. Verbon. Neo-institutionele economie en openbaar bestuur. 2e herziene druk. (1-15). 's Gravenhage: Vuga.

Monsen, N. (2001). Cameral accounting and cash flow reporting: some implications for use of the direct or indirect method. The European Accounting review. 10 (4) 705724.

Mookhoek, M. (2008). Groen licht voor agentschappen. Van overnormering naar de kern van de zaak. Tijdschrift voor public governance, audit \& control 6 (6), 41-44.

Moran, M. (2008). Economic institutions. in: R.A.W. Rhodes, S.A. Binder \& B.A. Rockman (eds). The Oxford handbook of political institutions. (144-162) Oxford: Oxford University Press.

Mulder, J. (1995). Comptabiliteitsrecht van het rijk. Zwolle: W.E.J. Tjeenk Willink.

Musgrave, R.A. (1959) The theory of Public Finance, International Student edition. New York/Toronto/London/Tokyo: McGraw-Hill.

Musgrave, R.A. \& Musgrave, P.B. (1973). Public Finance in theory and practice. Tokyo etc: McGraw-Hill Kogakusha.

Musgrave, R.A. \& Musgrave, P.B. (1989). Public finance in theory and practice. New York etc: McGraw-Hill.

Neelen, G.H.J.M. (1993). Principal-agent relations in non-profit organizations: a comparative analysis of housing associations and municipal housing companies in The Netherlands. Enschede: Universiteit Twente.

Neelen, G.H.J.M. (1997). Verzelfstandiging bezien vanuit de agency theorie. in: N.P. Mol \& H.A.A. Verbon. Neo-institutionele economie en openbaar bestuur. $2^{\mathrm{e}}$ herziene druk. (61-82). 's Gravenhage: Vuga.

Nelson, P. (1970). Information and consumer behaviour. Journal of Political Economy. 78 (2) 311-329

Neumark, F. (1961). Wirtschafts- und Finanzprobleme des Interventionsstaates. Tübbingen: J.C.B. Mohr (Paul Siebeck).

Newman, J. (2003). Changing equalities. Politics, policies and practice, in: T. Boviard, \& E. Löffler, Public management and governance. (203-212). London: Routledge. 
Nicolaï, P. (1997) Rechtstoepassing door het bestuur. in: P. Nicolaï, B.K. Olivier, I.C. van der Vlies, L.J.A. Damen \& B.J. Schueler (red.) Bestuursrecht (305-344). Amsterdam: Factotum

Nijkamp, P \& Ubbels, B. (1998). Waarom wegen altijd duurder worden. Economische en Statistische Berichten. 83 (4166) 668-671.

Niskanen, W.A. (1968). The peculiar economics of bureaucracy. The American Economic Review. 58 (2), p 293-305.

Nobes, C. \& Parker R. (2004). Comparative international accounting. Harlow: Pearson education limited.

Nolan, B.C. (eds). (2001). Public sector reform. An international perspective, Houndmills/New York: Palgrave MacMillan.

Offeren, D.H. (2002). Geografische omzetsegmentatie in de jaarrekening. Een attitudeonderzoek. Haarlem: D.H. van Offeren.

Olson, O., Humphrey, C. \& Guthrie, J. (2001) Caught in an evaluatory trap: a dilemma for public services under NPFM. The European Accounting review. 10 (3) pp. 505-522

Oosteroom, R. van (2002) 'Netherlands', in OECD, Distributed Public Governance. Agencies, Authorities and other government bodies, (113-132). Paris: OECD.

Oosteroom, R. van \& Soons, A. (2002) Op weg nar een koperen jubileum: Reconstructie van de totstandkoming en ontwikkeling van het agentschapsmodel in Nederland. in: A.D. Kraak, \& R. van Oosteroom, (red). Agentschappen: innovatie in bedrijfsvoering, (19-35). Den Haag: SDU.

Osborne, D.E. \& Gaebler, T.A. (1992) Reinventing government: how the entrepreneurial spirit is transforming the public sector. Reading (MA) etc: Addison-Wesley.

Ott, D.J \& Ott, A.F. (1982). The budget process, in Lyden F.J. \& Miller E.G. (eds) (1982). Public budgeting: program planning and implementation $4^{\text {th }}$ ed. pp 69-93. Englewood Cliffs etc: Prentice-Hall.

Ouchi, W.G. \& Maguire, M.A. (1975). Organisational control: two functions. Administrative Science Quarterly. 20 (4) pp 559-569

Ouchi, W.G. (1977). The relationship between organizational structure and organizational control. Administrative Science Quarterly. 22 (1) pp 96-113

Ouchi, W.G. (1979). A Conceptual Framework for the Design of Organizational Control Mechanisms. Management Science. 25 (9) 833-848

Perrin, J. (1998). Resource accounting and budgeting. From cash to accruals in 25 years, Public Money and Management, 18 (2) pp. 7-10.

Peters, J.A.F. (1992). Piercing the private veil. Weekblad voor privaatrecht, notariaat en registratie. 123 (6074), pp. 978-984.

Peters, J.A.F. (1997). ZBO's, verzelfstandiging en privatisering. Een korte beschouwing over de VAR-preadviezen 1997. Nederlands tijdschrift voor bestuursrecht. 1997 (4) 139-146

Petersen, T. (1993). The economics of organisation: the principal-agent relationship. Acta Sociologica 36(3) 277-293. 
Pierson, N.G. (1913). Leerboek der Staatshuishoudkunde, Band II, $3^{e}$ druk, Haarlem: De Erven F. Bohn.

Pijls, A. (2006). Modernisering van het rechtspersonenrecht: de maatschappelijke onderneming. Masterscriptie Financieel Recht. Rotterdam: Erasmus Universiteit.

Pike, R. \& Neale, B. (2006). Corporate finance and investment. Decisions and strategies. 5th edition. Harlow:: FT/Prentice Hall.

Plas, F. van der, Hart, I. van der \&Mayland, R. (2003). Bevriezing posttarieven is vlees noch vis, Economische en Statistische Berichten 88, (4401) 196-198.

Plug, P., Timmerman, R. \&Dekker, A. (2004). Aansturen van verzelfstandigde organisaties. Het creëren van effective verbindingen tussen beleid en uitvoering, Utrecht: Berenschot Fundatie.

Pollitt, C. (1990) Managerialism and the public services: the Anglo-American experience. Oxford: Blackwell.

Pollitt, C. (2004). Theoretical overview. in C. Pollitt \& C. Talbot (eds). (2004). Unbundled Government. A critical analysis of the global trend to agencies, quangos and contractualisation. pp 319-341. London/New York: Routledge.

Pollitt, C.; Bathgate, K.; Caulfield, J.; Smullen, A.; Talbot, C. (2001). Agency Fever? Analysis of an International Policy Fashion. Journal of Comparative Policy Analysis 3(3), pp. 271-290

Pollitt. C. \& Bouckaert, G. (2004). Public management reform. A comparative analysis. $2^{\text {nd }}$ ed. Oxford: Oxford University Press.

Pollitt, C., Talbot, C., Caulfield, J. \& Smullen, A. (2004). Agencies. How do governments do things through semi-autonomous organisations. Basingstoke: Palgrave-Macmillan.

Pollitt, C. \& Talbot, C. (eds). (2004). Unbundled Government. A critical analysis of the global trend to agencies, quangos and contractualisation. London/New York: Routledge.

Pollitt, C. (2007). Convergence or divergence: what has been happening in Europe? in: C. Pollitt, S. van Thiel \& V. Homburg, New Public Management in Europe. Adaption and alternatives. (10-25). Basingstoke/New York: Palgrave Macmillan.

Pot, C.W. van der, Elzinga, D.J., Lange, R. de \& Hoogers, H.G. (2006). Handboek van het Nederlandse Staatsrecht. 15e druk. Deventer: Kluwer.

Potter, B. (2001) Financial accounting reforms in the Australian public sector. An episode in institutional thinking. Accounting, Auditing and Accountability Journal 15 (1) 6993.

Rainey, H.G. (2009). Understanding and managing public organisations. 4th ed. San Francisco: Josey Bass.

Reed, B.J. \& Swan, J.W. (1990). Public Finance Administration. Englewood Cliffs NJ: Prentice Hall.

Ridley, F.F. \& Wilson, D. (eds.). (1995). The quango debate. Oxford: Oxford University Press. 
Robinson, M. (1998) Accrual accounting and the efficiency of the core public sector. Financial Accountability and Management. 14 (1) 21- 37.

Robinson, M. (2002) Output-purchase funding and budgeting systems in the public sector, Public Budgeting \& Finance 22. (4), pp. 17-33.

Robinson, M. (2003). Performance budgeting: lessons from a comparative overview. Paper presented at the $9^{\text {th }}$ Cigar conference at Bodø.

Rochet, C., Cabane, M. \& Formery, S. France. in : OECD Distributed Public Governance. (71-96) Paris: OECD.

Rosen, H.S. (2005). Public Finance. $7^{\text {th }}$ ed. Boston etc: McGraw-Hill.

Ru, H.J. de, Burggraaf, J. L. \& Spaans, L.A.J. (2005). De maatschappelijke onderneming. Den Haag: Boom Juridische uitgevers.

Schaar, J. van der, Faber, A.W., Koffijberg, J.J., Priemus, H. (1996). Volkshuisvesting in Goud. Verandering en continuiteit in beleid en organisatie van het DirectoraatGeneraal van de Volkshuisvesting. Den Haag: Ministerie VROM.

Schaik, F. van (2007). Overheidsvermogen getrouw in beeld. Schuiven wij de rekening door naar toekomstige generaties? Inaugural speech. Amsterdam: University of Amsterdam.

Schaik, F. van (2008). De consolidatiekring van overheden in Nederland. MAB 82 (11) 467-476.

Scheltema, M. (1974). Zelfstandige bestuursorganen. Groningen: Rijksuniversiteit Groningen.

Schillemans, T. (2005). Horizontale verantwoording bij ZBOs en agentschappen. Een inventarisatie en analyse bij 74 monopolisten. Den Haag: Raad voor de Maatscahppelijke Ontwikkeling.

Schillemans, T. (2007). Verantwoording in de schaduw van de macht. Horizontale verantwoording bij zelfstandige uitvoeringsorganisaties. Den Haag: Lemma.

Schillemans, T. \& Bovens, M. (2004). Horizontale verantwoording bij zelfstandige bestuursorganen in: S. van Thiel, (red). Governance van de uitvoeringsorganisaties. Nieuwe vraagstukken voor sturing in het publieke domein. (27-37). Apeldoorn: Kadaster.

Schreuder, C.A. (1994). Publiekrechtelijke taken, private rechtspersonen. Deventer: Kluwer.

Schroten, K. (2000). De overheidsstichting op het niveau van de centrale overheid. Deventer: W.E.J. Tjeenk Willink.

Schick, A. (1966), The road to PPB. The stages of budget reform. Public administration review 26, 243-258, Washington: American society for public administration.

Schick, A. (2000) The federal budget. Politics, Policy and Progress, revised edition. Washington D.C.: Brookings institution press.

Schick, A. (2002) Can national legislatures regain an effective voice in budget policy? OECD journal on budgeting. 1 (3) pp.15-41. 
Schueler, B.J. (1997). Het algemeen bestuursrprocesrecht voor de behandeling van bezwaar en beroep. in: P. Nicolaï, B.K. Olivier, I.C. van der Vlies, L.J.A. Damen \& B.J. Schueler (red.) Bestuursrecht (649-720). Amsterdam: Factotum

Sclar, E.D. (2000) You don't always get what you pay for: the economics of privatization. Ithaca: Cornell University Press.

Seerden, R. \& Stroink, F. (eds.), (2002a). Administrative law of the European Union, its member States and the United States. Antwerp: Intersentia.

Seerden, R. \& Stroink, F., (2002b). Administrative law in the Netherlands. in: Administrative law of the European Union, its member States and the United States. (p. 145-198) Antwerp: Intersentia.

Shadish, W.R., Cook, T.D. \& Campbell, D.T. (2002). Experimental and quasi-experimental designs for generalized causal inference. Boston, New York: Houghton Mifflin Company.

Simon, H. (1978) Rationality as process and as product of thought. American Economic Review, 68 (2), 1-16.

Simon, M. (1989). De strategische functietypologie. Functioneel denkraam voor management. Deventer: Kluwer Bedrijfswetenschappen.

Simon, M. (2005). De strategische functie van een organisatie-eenheid en hybriditeit. in M.H. Meijerink \& G.D. Minderman (red). Naar een andere publieke sector. Hybriditeit en een andere wijze van publieke taakvervulling. Den Haag: SDU uitgevers.

Smith, L. (2004). Time to end the quango culture. Public Finance (30-07-2004), p. 21.

Smullen, A. \& Thiel, S. van (2002). Agentschappen: eenheid in verscheidenheid in: Kraak, A.D. \& Oosteroom, R. van (red). Agentschappen: innovatie in bedrijfsvoering, (3644). Den Haag: SDU.

Smullen, A. (2007). Translating Agency Reform. PhD Thesis. Rotterdam: Erasmus University

Sołtysiński, S. (2005). The Rise and Fall of the Golden Share Concept in Privatised Companies in: P. Demaret, (ed.). 30 years of European legal studies at the College of Europe. (313-331). Brussels: P.I.E.-Lang.

Songer, D.R., Segal, J.T. \& Cameron, C.M. (1994). The hierarchy of justice. Testing a principal-agent model of Supreme Court -Circuit Court interactions. American Journal of Political Science. 38 (3) 673-696.

Stiglitz, J.E. (2000) Economics of the Public Sector, 3 ${ }^{\text {rd }}$ ed. New York/London: W.W. Norton.

Stone, B. (1995) Administrative accountability in the 'Westminster' democracies: Towards a New conceptual framework. Governance: an international journal of policy and administration 8 (4) 505-526.

Stuurman, S. (1983). Verzuiling, kapitalisme en patriarchaat. Nijmegen: SUN Socialitiese Uitgeverij Nijmegen 
Sutton, T. (2004). Corporate financial accounting and reporting. 2nd edition. Harlow: Prentice Hall.

Swanborn, P.G. (2003). Case-study's. Wat, wanneer en hoe? Amsterdam/Meppel: Boom.

Talbot, C. (2004). The agency idea. in: C. Pollitt \& C. Talbot (eds). (2004). Unbundled Government. A critical analysis of the global trend to agencies, quangos and contractualisation. pp 3-21. London/New York: Routledge.

Taylor, P.E. (1961). The economics of public finance, $3^{\text {rd }}$ ed.. New York: The Macmillan company.

Teisman, G. \& Buuren, A. van (2007). Implementing NPM: a complexity perspective on Public Management Reform Trajectories. in C. Pollitt, S. van Thiel \& V. Homburg. New Public Management in Europe. Adaption and alternatives. pp 181-195. Basingstoke/New York: PalgraveMacMillan.

Thiel, S. van. (2000). Quangocratization: Trends, causes and consequences. Utrecht: University of Utrecht. Also published in 2001 by Ashgate publishers, Aldershot.

Thiel, S. van (2006). Styles of reform. Differences in quango creation between policy sectors in the Netherlands. Journal of Public Policy., 26(2) 115-140

Thiel, S. van (2007). Bestuurskundig onderzoek. Een methodologische inleiding. Baarn: uitgeverij Coutinho.

Thiel, S. van. (2009). De aansturing van ZBOs. Openbaar Bestuur. 19 (2) 22-24.

Thiel, S. van \& Buuren, A. van. (2001). Ontwikkeling van het aantal zelfstandige bestuursorganen tussen 1993 en 2000: zijn zbo's 'uit' de mode? Bestuurswetenschappen 55(5) 386-404

Thiel, S. van, Leeuw, F.L., Siegers, J.J. \& Flap, H.D. (1999) Oorzaken van verzelfstandiging. Empirische verklaring voor de toename in verzelfstandiging. Bestuurskunde. 1999 (1) 28-43.

Thiel, S. van \& Leeuw, F.L. (2002). The performance paradox in the public sector. Public performance \& management review. 25 (3) 267-281

Thiel, S. van \& Pollitt, C. (2007). The management and control of executive agencies: an Anglo-Dutch comparison. in: C. Pollitt, S. van Thiel \& V. Homburg, New Public Management in Europe. Adaption and alternatives. ( 52-70). Basingstoke/New York: Palgrave Macmillan.

Thiel, S. van \& CRIPO team (2009). The rise of executive agencies: comparing the agencification of 25 tasks in 21 countries. (Draft paper). Leiden: NIG annual work conference.

Thiel, S. van, Canté, L \& Meerkerk, I. van (2009). Eigenaar van een zelfstandig bestuursorgaan (deel 2). Openbaar Bestuur 19 (3) 12-14.

Thomassen, J. (2010)., De permanente crisis van de democratie. Enschede: Universiteit Twente.

Thompson, F.J. ed. (1993) Revitalizing state and local public service : strengthening performance, accountability, and citizen confidence. San Francisco, Jossey-Bass Publishers 
Tijdink, J.L.J.L. (1998). Issues of personal problematic debt. Enschede, University of Twente.

Trappenburg, M., Schillemans, T. \& Bovenkamp, H. van de. (2009). Clientenraden en klantenfora. in: M. Bovens \& T. Schillemans (eds). Handboek publieke verantwoording. (181-204). Den Haag. Lemma.

Tubbing, H. (2007) Kasspekkende scholen? Op weg naar risicomanagement in het voortgezet onderwijs. Tijdschift voor public controlling 5(3) p. 26-29. Den Haag: SDU uitgevers

Veld, R.J. in 't. (1995). Spelen met vuur. Over hybride organisaties. Amsterdam: Vuga.

Velde, H. te. (2007). Gerrit Zalm als politicus. In J. Sprenger, J. Smits, P. van Veller, P. Daalmans, K. Heineken, E. van Koesveld \& M. Roscam Abbing. (red.) Per Saldo. Overheidsfinanciën en fiscaliteit na twaalf jaar minister Zalm. (pp. 13-22). Den Haag: SDU Uitgevers

Verbaan, W.C. (1983) Zelfbeheer I. Heroverwegingsrapport verbetering bedrijfsvoering overheid. Den Haag: Ministerie van Financiën.

Verhoest, K. (2002). Resultaatgericht verzelfstandigen. Een analyse vanuit een verruimd principaal-agent perspectief. Leuven: Katholieke Universiteit Leuven.

Vining, A.R. \& Weimer, D.R. (1990). Government supply and government production failures. A framework based on contestability. Journal of Public Policy . 10 (1), 122.

Vis, J.J. (1986) De betekenis van een regeerakkoord. In Vis, J.J.; Kok, F.X.M. \& Friese, P.C. Regeerakkoord 1986 tekst \& uitleg. (7-13) 's Gravenhage: Vuga.

Visser, B.L.W. (1986). Toezicht in bestuurlijke rechtsverhoudingen. Deventer: Kluwer.

Wagner, R.E. (ed.) (1991). Charging for government, London: Routledge

Wall, R. and West, P. (2002). United Kingdom, in OECD, 2002, Distributed Public Governance, pp 113-132, OECD, Paris.

Warmelink, H.G. (1993). Parlement en Begroting. Groningen: Wolters-Noordhoff.

Waterman, R.W. \& Meier, K.J. (1998). Principal-agent models. An expansion? Journal of Public Administration Research and Theory 8 (2) 173-202.

Wattel, P.J. (1995). De reikwijdte van fundamentele rechten in belastingzaken. Handelingen der Nederlandsche Juristen-Vereeniging. 125 (1) 175-222

Weber, M. (1947). The theory of social and economic organization. New York: The free press of Glencoe.

West, W.F. (1997). Searching for a theory of bureaucratic structure. Journal of Public Administration Research and Theory. 7 (4), 591-613

Westerveld, M. (2010). Het UWV in verandering. Openbaar Bestuur 20 (11), 11-15.

Weetman, P. (2006). Management accounting. Harlow: FT/Prentice Hall.

Weizsäcker, E.U., O.R. Young \& Finger, M. (2005) Limits to privatization. in: Weizsäcker, E.U., O.R. Young \& Finger, M. Limits to privatization. (3-15) London: Earthscan.

Wijk, H.D. van., Konijnenbelt, W. \& Made, R. van de (1999). Hoofdstukken van bestuursrecht, $11^{\mathrm{e}}$ druk. Den Haag: Elsevier Bedrijfsinformatie. 
Wijk, J.W.H. van. (1998). Beleid inzake staatsdeelnemingen, in S.C.J.J., Kortman, F.J. Oranje, A.A. van Rossum \& J.W.H. van Wijk. Overheid en Onderneming (3-42). Deventer: W.E.J. Tjeenk Willink.

Wildavsky, A. (1992). Political implications of budget reform: a retrospective. Public Administration Review. 52 (6) 594-599.

Wildavsky. (2001). Budgetary reform in an age of big government. In: Wildavsky, A. Budgeting and governing. (133-162). New Brunswick, London: Transaction Publishers.

Wildavsky, A. \& Caiden, N. (2001). The new politics of the budgetary process $4^{\text {th }}$ ed. New York etc: Addison Wesley Longman.

Williamson, O.E. (1973). Markets and Hierarchies: Some Elementary Considerations The American Economic Review, 63 (2) 316-325

Williamson, O.E. (1990). The firm as a nexus of treaties: an introduction. in M. Aoki, B. Gustafsson \& O.E. Williamson (eds). The firm as a nexus of treaties. (1-25). London etc. Sage publications.

Williamson, O.E. (1993). The logic of economic organisation. in O.E. Williamson \& S.G. Winter (eds). The nature of the firm. New York/Oxford: Oxford University Press.

Wilson, J. Q. (1989). Bureaucracy. What government agencies do and why they do it. New York: Basic books

Wilson. (1995) Quangos in the skeletal state. In Ridley, F.F. \& Wilson, D. (eds) The Quango Debate. (3-13) Oxford etc: Oxford Universisty Press

Wolfson, D. (2008). De vorm van de maatschappelijke onderneming. Economisch Statistische Berichten 93 (4528) 72-75.

Woodward, J. (1965). Industrial organisation: theory and practice. London: Oxford University Press.

Wouters, M., Anderson, J.C. \& Wynstra, F. (2005). The adoption of total cost of ownership for sourcing decisions - a structural equation analysis. Accounting, Organisation and Society 30 (2), p. 167-191.

Yin, R.K. (2009). Case study research. Design and methods. 4th ed.. Los Angeles etc: Sage Publications.

Zijlstra, S.E. (1997) Zelfstandige bestuursorganen in een democratische rechtsstaat. 's Gravenhage: Vuga.

Zijlstra, S.E. (2009) Bestuurlijk organisatierecht. Deventer: Kluwer.

Zwart, T. (2003). Independent regulatory agencies in the US. in T. Zwart \& L. Verhey, (eds). Agencies in European and Comparative law (3-18). Antwerp: Intersentia.

Zwart, T. \& Verhey, L. (eds). (2003). Agencies in European and Comparative law. Antwerp: Intersentia. 


\section{Non academic documents and website documents}

Berenschot (2002). De evaluatie van het baten-lasten dienst model. Een bijdrage aan doelmatiger werken. Utrecht: Berenschot.

Blair Consulting Group (1999). User Fees. Where does the Buck stop?. Aylmer, Quebec: The Blair Consulting Group. Retrieved August 18, 2003 from www.Cmemec.ca/shared/upload/buck_stop.pdf.

CBS

Statline.

http://statline.cbs.nl/StatWeb/start.asp?LA=nI\&DM=SLNL\&lp=Search\%2FSearch, most recent visit, February 20, 2008

CTSV. (2000). Vierde vervolgrapportage ontvlechting. Onderzoek naar de financiële scheiding van publiek en privaat bij de uitvoering van de werknemersverzekeringen. Zoetermeer: CTSV.

Dijkstal committee (2004) Over dienen en verdienen. Retrieved October 18, 2004 from http://www.minbzk.nl/contents/pages/8601/commissiedijkstal-3-luik.pdf .

Dijkstal Committee. (2007). Normeren en waarderen. Retrieved September 21, 2007 from http://www.minbzk.nl/onderwerpen/openbaarbestuur/topinkomens/commissie-dijkstal/publicaties?Actltmldt=108279

Gemeente Arnhem (2008). Geactualiseerd overzicht verbonden partijen 2007. Retrieved, November 14 , 2008 from

http://www.arnhem.nl/dsresource?objectid=48713\&type=org .

Gerritsen Committee (2008). ZBOs binnen kaders. Rapportage op hoofdlijnen van het Begeleidingsteam Kaderwet zbo's. Den Haag: Ministerie van Financiën. Retrieved, September 21, 2007 from http://www.rijksoverheid.nl/bestanden/documentenen-publicaties/rapporten/2002/05/14/zbo-s-binnen-

kaders/zbosbinnenkaders.pdf

Handvestgroep publiek verantwoorden (2005). Code goed bestuur uitvoeringsorganisaties. Retrieved on January26, 2009 from http://www.publiekverantwoorden.nl/profiel/code goed_bestuur.pdf

GPOC (2002), Annual report of the Government Prices Oversight Commission. Retrieved, August 19, 2003 from www.gpoc.tas.gov.au .

IBGroep (2006). IB Groep. Benchmark uitvoeringsorganisatie 2005/2006. RBB-IV. Retrieved September 20, 2007 from http://www.ibgroep.nl/Images/ibgroep\%20rapport tcm7-5807.pdf .

IPSASB (2007). 2007 IFAC Handbook of International Public Sector Accounting Standards Board Pronouncements. New York: IFAC.

Kadaster. (2007). Jaarverslag 2006. Apeldoorn: Dienst voor het Kadaster en Openbare Registers.

Kiesraad (2006). Organisatie. Retrieved November 9, 2006 from http://www.kiesraad.nl/organisatie kiesraad/virtuele map/samenstelling,. 
Kohnstamm Committee (2004) Een herkenbare staat: investeren in de overheid. Den Haag: Ministerie van Binnenlandse Zaken en Koninkrijksrelaties.

Nederlandse Zorgautoriteit. (2009). Jaarverslag 2008. Utrecht, NZA.

Ministerie van Binnenlandse Zaken en Koninkrijksrelaties (2007a). ZBO-register. $\begin{array}{llll}\text { Retrieved } \quad \text { February } 2007 & \text { from: }\end{array}$ http://almanak.zboregister.overheid.nl/sites/min_bzk2/index.php.

Ministerie van Binnenlandse Zaken en Koninkrijksrelaties (2007b). ZBO-register Retrieved July 1, 2007 from: http://almanak.zboregister.overheid.nl/sites/min_bzk2/index.php .

Ministerie van Binnenlandse Zaken en Koninkrijksrelaties (2009a). Topinkomens: 1a: overschrijdingen zonder ontslagvergoeding. Retrieved October 3, 2010 from: http://www.rijksoverheid.nl/bestanden/documenten-enpublicaties/rapporten/2009/12/17/rapportage-publiek-gefinancierdetopinkomens-conform-wopt/overschrijdingzonderontslag-hersteld24-03-2010.pdf . Ministerie van Binnenlandse Zaken en Koninkrijksrelaties (2009b). Topinkomens: 3: Non response WOPT verantwoordingen 2008, Retrieved October 3, 2010 from: http://www.rijksoverheid.nl/bestanden/documenten-enpublicaties/rapporten/2009/12/17/rapportage-publiek-gefinancierdetopinkomens-conform-wopt/3nonresponswoptverantwoording2008.pdf

Ministerie van Financiën (1991) Verder bouwen aan beheer. Den Haag: SDU.

Ministerie van Financiën (2000a) Government Governance. Corporate governance in the public sector. Why and how? Retrieved February 25, 2008 from http://www.minfin.nl/binaries/minfin/assets/pdf/old/fee_paper_van_nov_2000. pdf .

Ministerie van Financiën (2000b) Handleiding government governance. Een instrument ter toetsing van de governance bij de rijksoverheid. Retrieved February 25, 2008 from

http://www.minfin.nl/binaries/minfin/assets/pdf/old/handleiding_government_g overnance $6 e$ dr.pdf.

Ministerie van Financiën (2002) Referentielijst RWTs en ZBOs. Rechtspersonen met een wettelijke taak en zelfstandige bestuursorganen. Den Haag. Ministerie van Financiën.

Ministerie van Financiën (2003) Comptabiliteitswet 2001, zoals deze luidt na de eerste wijziging van die wet dd 4-9-2003. versie november 2003. Retrieved November 22 , 2006 from:

http://www.treasury.nl/upload/legal/2454/comptabiliteitswet\%202001.pdf.

Ministerie van Financiën. (2007a). Regeling Baten-lasten diensten. Retrieved, November 14, 2008 from http://www.minfin.nl/dsresource?objectid=3895\&type=pdf Ministerie van Financiën. (2007b). Beloningsbeleid AFM. Retrieved, October 5, 2010 from: http://www.minfin.nl/dsresource?objectid=36785\&type=pdf 
Ministerie van Justitie. (2007). Wijziging van Boek 2 van het Burgerlijk Wetboek in verband met de introductie van een rechtsvorm voor de maatschappelijke onderneming. Retrieved, April 14, 2009 from http://www.justitie.nl/onderwerpen/wetgeving/maatschappelijkeonderneming/in dex.aspx

Ministerie van Landbouw, Natuurbeheer en Voedselkwaliteit (2004). Aansturings- en informatieprotocol Nederlandse Algemene Keuringsdienst voor zaaizaad en pootgoed van Landbouwgewassen.

Ministerie van Landbouw, Natuurbeheer en Voedselkwaliteit (2007). Algemene criteria beoordeling fytosanitaire tarieven, kenmerk TRCDL/2007/1529.

Ministerie van Onderwijs, Cultuur en Wetenschappen (2005). Handboek verantwoording cultuursubsidies fondsen.

Ministerie van Sociale Zaken en Werkgelegenheid (2004). Deskundigenoordeel huisvesting UWV. Retrieved on October 1, 2010 from: http://home.szw.nl/index.cfm?menu item id=14126\&hoofdmenu item id=1382 6\&rubriek id=391818\&link id=37675

Ministerie van Sociale Zaken en Werkgelegenheid (2006). Kaders voor (concept)jaarplan 2007; de meibrief.

Ministerie van Sociale Zaken en Werkgelegenheid (2008). Meibrief 2009., kenmerk UB/A/2008/11415

Ministerie van Volksgezondheid, Welzijn en Sport (2006a). Brief Bestuursmodel CVZ m.i.v. 2007, kenmerk Z/VU-2677612.

Ministerie van Volksgezondheid, Welzijn en Sport (2006b). Brief Jaarplan 2007 CVZ, kenmerk ORG/26084984.

Ministerie van Volksgezondheid, Welzijn en Sport (2007a). Brief Jaarplan en begroting 2007 CVZ, kenmerk MC-U-2750381.

Ministerie van Volksgezondheid, Welzijn en Sport (2007b). Brief Jaarplan en begroting 2008 NZA, kenmerk MC-U-2784765.

Ministerie van Volksgezondheid, Welzijn en Sport (2008a). Goedkeuring Jaarplan/Begroting 2008, kenmerk MC-U-2839442.

Ministerie van Volksgezondheid, Welzijn en Sport (2008b). Goedkeuring werkprogramma en begroting (NZA), kenmerk MC-U-2875463.

Ministerie van Volkshuisvesting, Ruimtelijke ordening en Milieubeheer (2006). Toezichtsarrangement Centraal Fonds voor de Volkshuisvesting.

Ministerie van Volkshuisvesting, Ruimtelijke ordening en Milieubeheer (2008). Toezicht op basis van vertrouwen. Uitvoeringstoezicht op zelfstandige organisaties 2008

Ministerie van Wonen, Wijken en integratie (2007a). Goedkeuring jaarstukken CFV 2006, kenmerk CSG/FEZ/2007053681.

Ministerie van Wonen, Wijken en Integratie (2007b). Begroting 2008 inclusief voorgestelde heffingsbijdrage. Kenmerk CSG/FEZ2007120677. 
NRC (2008, October 27). Plasterk onder druk over subsidie podiumkunsten. NRC Handelsblad, p. 1.

NZA (2009). Jaarverslag 2008. Utrecht: NZA

OECD. (1998). User charging for government services. Best practices guidelines and case studies. Occasional papers nr 22. Paris: OECD.

OECD. (2002). Distributed Public Governance. Agencies, Authorities and other government bodies. Paris: OECD.

OECD. (2005). Modernising Government. The way forward. Paris: OECD.

Participatiefonds en Vervangingsfonds (2007). Jaarverslag Participatiefonds 2006; Jaarverslag Vervangingsfonds 2006.

PriceWaterhouseCoopers. (2006). SUWI-Evaluatie 2006. Een evaluatie van de wet Structuur Uitvoeringsorganisatie Werk en Inkomen (Wet SUWI). Den Haag: PriceWaterhouseCoopers Advisory N.V.

Rob. (2004). Commentaar op het rapport 'Een herkenbare staat', van de werkgroep Verzelfstandigde organisaties op Rijksniveau ('werkgroep Kohnstamm'.) Den Haag: Rob.

Scheltema Committee (1993). Steekhoudend Ministerschap, betekenis en toepassing van de ministeriële verantwoordelijkheid. published as Parliament (1993) (Kamerstukken II, vergaderjaar 1992-1993, 21427 nr 40-41). Den Haag: SDU.

Schilder Committee (2006). Advies toezicht op woningcorporaties. Amsterdam: DNB.

Simons Committee. (1960) Rapport van de commissie tot voorbereiding van een herziening van de comptabiliteitswet. Den Haag: Staatsdrukkerij en uitgeverijbedrijf.

Sint Committee. (1994). Verantwoord verzelfstandigen. Den Haag: Ministerie van Binnenlandse Zaken.

Staatscourant. (1995). Aanwijzingen voor de regelgeving. Staatscourant 1995 (251), p. 6.

Staatscourant (2000). Maat houden. Bekendmaking van het kader voor de doorberekening van toelatings- en handhavingskosten., Staatscourant, 2000 (90), p. 9.

Statskontoret. (2001). What lessons can we learn from the UK's next steps agencies model?, $\quad$ Retrieved $\quad$ October 18,2004 from http://www.statskontoret.se/upload/Publikationer/2001/200123.pdf.

Thiel, S. van \& Yesilkagit, K. (2006). Respondentenrapport Cobra enquete. Retrieved July 6, 2007 from http://www.publicmanagementcobra.org/pub/paper/20061027 COBRA Nederland.pdf

Tokmetzis, D. (2006). We willen ons eigen geluid laten horen. PM 2 (12), 3-5, Retrieved September 21, $2007 \quad$ from http://www.pm.nl/files/pdf/jaargang2/PMS Handvestgroep 23_11.pdf

UWV (2009). Jaarverslag 2008. Retrieved July 1, 2008 from http://www.uwv.nl/Images/jaarverslag\%202008 tcm26-205169.pdf 
UWV (2010). Jaarverslag 2009. Retrieved April 15, 2010 from http://www.uwvjaarverslag.nl/Downloads/UWV_Jaarverslag_2009.pdf

VROM Raad (2003). Omgaan met overmaat. De vermogens van de woningcorporaties als sturingsopgave. Den Haag: Vrom Raad.

WFZ (2009). Korte historie van het WFZ. Retrieved on November 27, 2009 from http://www.wfz.nl/index2.php?content=wat;

Wijffels Committee. (2006). Rapport van de projectgroep Rechtsvorm maatschappelijke onderneming. Den Haag: Ministerie van Justitie. 


\section{Websites}

Relevant websites of government institutions related to the ZBOs studied. All most recently visited June 19, 2010.

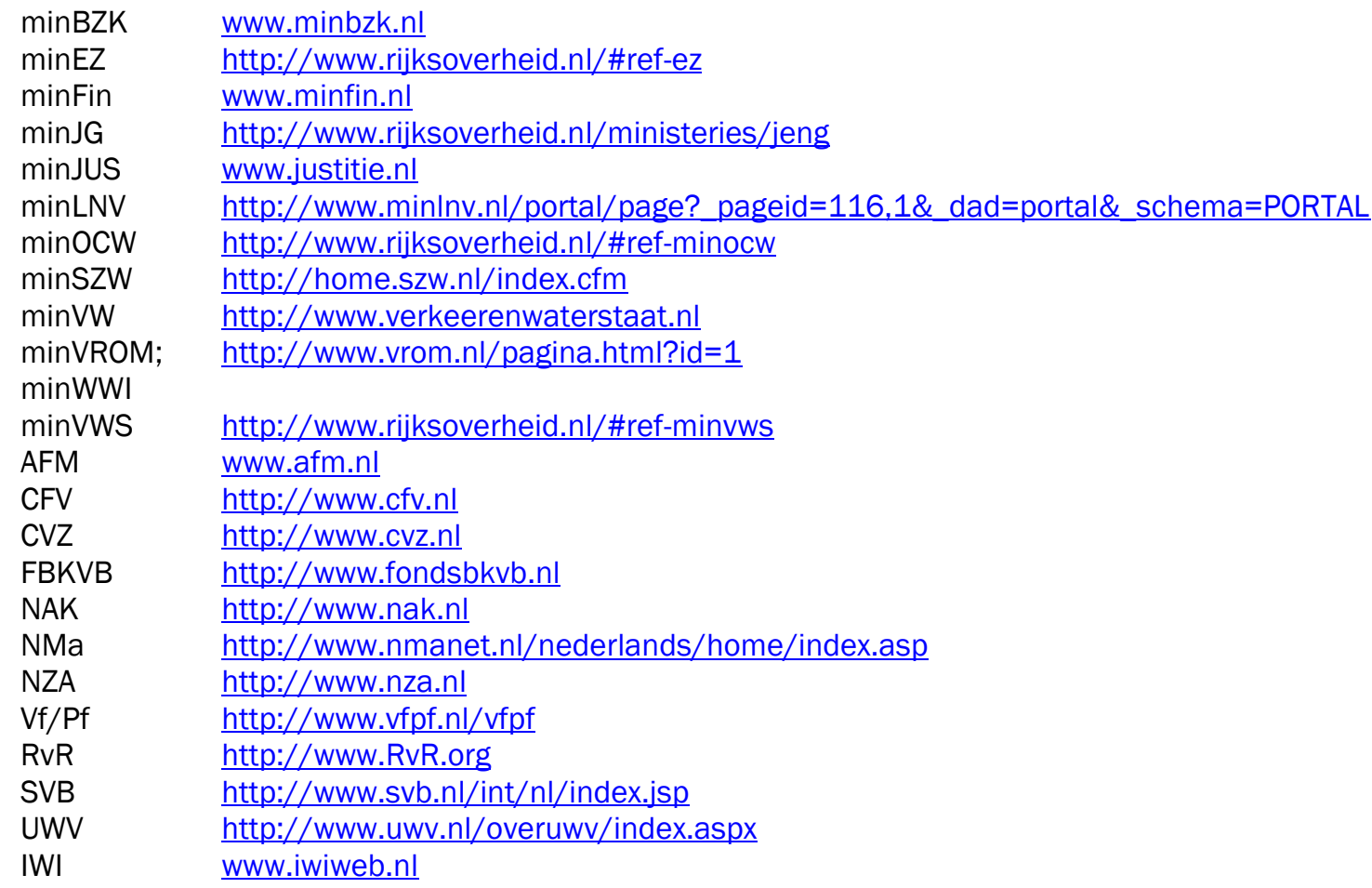




\section{Parliamentary documents}

Note on Parliamentary documents:

All documents published as of January 1, 1995 are available on:

http://parlando.sdu.nl/cgi/login/anonymous and on http://www.overheid.nl/op/

The search key is the five-digit number.

Parliament. (1963) Comptabiliteitswet. Memorie van Toelichting. (Kamerstukken II, Vergaderjaar 1963-1964, 7760 nr 3). Den Haag: SDU uitgevers.

Parliament. (1982) Heroverwegingen. Tweede ronde profijtbeginsel en privatisering (Kamerstukken II, Vergaderjaar 1981-1982, 16625 nr 40). Den Haag: SDU uitgevers.

Parliament. (1984). Heroverweging collectieve uitgaven. Brief van de minister van Financiën. (Kamerstukken II, Vergaderjaar 1983-1984, 16625 nr 66). Den Haag: SDU uitgevers.

Parliament. (1989). Notitie Functionele Decentralisatie. (Kamerstukken II, Vergaderjaar 1988-1989, 21042 nr 2). Den Haag: SDU uitgevers.

Parliament. (1993a). Verzelfstandiging van de Rijksdienst van hetKadaster en de Openbare Registers (Organisatiewet Kadaster) Memorie van Toelichting. (Kamerstukken II, Vergaderjaar 1992-1993, 23007 nr 3). Den Haag: SDU uitgevers.

Parliament. (1993b). Steekhoudend ministerschap. Betekenis en toepassing van de ministeriële verantwoordelijkheid (Scheltema Committee). (Kamerstukken II, Vergaderjaar 1992-1993, 21427 nrs 40-41). Den Haag: SDU uitgevers.

Parliament (1994a). Verslag Zesde Wijziging Comptabiliteitswet. (Kamerstukken II, Vergaderjaar 1994-1995, 23796 nr 7). Den Haag: SDU uitgevers. note:

Parliament (1994b). Memorie van toelichting Zesde Wijziging Comptabiliteitswet. (Kamerstukken II, Vergaderjaar 1994-1995, 23796 nr 3). Den Haag: SDU uitgevers.

Parliament. (1994c) Nota naar aanleiding van het verslag Zesde Wijziging Comptabiliteitswet. (Kamerstukken II, Vergaderjaar 1994-1995, 23796 nr 8). Den Haag: SDU uitgevers.

Parliament. (1994d) Aanvulling van de algemene wet bestuursrecht (Derde tranche algemene wet bestuursrecht). Memorie van toelichting (Kamerstukken II, Vergaderjaar 1993-1994, 23700 nr 3). Den Haag: SDU uitgevers.

Parliament. (1995a). Verslag van de Algemene Rekenkamer over 1994. Deel 3, Zelfstandige Bestuursorganen en ministeriële verantwoordelijkheid. (Kamerstukken II, Vergaderjaar 1994-1995, 24130 nr 3). Den Haag: SDU uitgevers. 
Parliament. (1995b). Brief van de minister van Binnenlandse Zaken. (Kamerstukken II, Vergaderjaar 1994-1995, 24130 nr 5). Den Haag: SDU uitgevers.

Parliament. (1995c). Motie van het lid Scheltema-de Nie. (Kamerstukken II, Vergaderjaar 1994-1995, 24130 nr 11). Den Haag: SDU uitgevers.

Parliament. (1995d) Amendement van het lid Liemburg. (Kamerstukken II, Vergaderjaar 1994-1995, 23796 nr 17). Den Haag: SDU uitgevers.

Parliament. (1996a). Begroting 1997 Volksgezondheid, Welzijn en Sport. (Kamerstukken II, Vergaderjaar 1996-1997, 25000 XVI nr 2). Den Haag: SDU uitgevers.

Parliament. (1996b). Begroting 1997 Economische Zaken. (Kamerstukken II, Vergaderjaar 1996-1997, 25000 XIII nr 2). Den Haag: SDU uitgevers.

Parliament. (1996c). Nieuwe regels omtrent de economische mededinging (Mededingingswet) (Kamerstukken II, Vergaderjaar 1996-1997, 25000 XIII nr 2). Den Haag: SDU uitgevers.

Parliament. (1997a). Marktwerking, deregulering en wetgevingskwaliteit. Brief van de ministers van Economische Zaken en van Justitie. (Kamerstukken II, Vergaderjaar 1997-1998, 24036 nr 69). Den Haag: SDU uitgevers.

Parliament. (1997b). Zelfstandige Bestuursorganen. Brief van de minister van Binnenlandse Zaken. (Kamerstukken II, Vergaderjaar 1996-1997, 25268 nr 1). Den Haag: SDU uitgevers.

Parliament. (1997c). Vragen van de leden Van der Hoeven (CDA) en Bakker (D66) over de situatie bij het USZO te Groningen. (Aanhangsels bij Kamerstukken II, Vergaderjaar 1996-1997, nr 842). Den Haag: SDU uitgevers.

Parliament. (1997d). Nieuwe regels omtrent de economische mededinging (Mededingingswet). Motie van de leden Van der Ploeg en Koning. (Kamerstukken II, Vergaderjaar 1996-1997, 24707 nr 39). Den Haag: SDU uitgevers.

Parliament. (1998a). Begroting 1999 Binnenlandse Zaken en Koninkrijksrelaties. Motie van het lid Van der Hoeven. (Kamerstukken II, Vergaderjaar 1998-1999, 26200 VII nr 13). Den Haag: SDU uitgevers.

Parliament. (1998b). Wijziging van boek 2 van het Burgerlijk Wetboek in verband met de invoering van een regeling voor de vervanging van verloren gegane aandeelbewijzen alsmede intrekking van de Effectenvernieuwingswet. (Kamerstukken II, Vergaderjaar 1997-1998, 26133 nr 3). Den Haag: SDU uitgevers.

Parliament. (2000a) Verantwoording en toezicht bij Rechtspersonen met een wettelijke taak., (Kamerstukken II, Vergaderjaar 1999-2000, 26982 nr 1). Den Haag: SDU uitgevers.

Parliament. (2000b). Miljoenennota 2001. (Kamerstukken II, Vergaderjaar 2000-2001, $27400 \mathrm{nr}$ 1). Den Haag: SDU uitgevers.

Parliament. (2000c). Tegoeden Tweede Wereldoorlog. (Kamerstukken II, Vergaderjaar 1999-2000, 25839 nr 17). Den Haag: SDU uitgevers. 
Parliament (2000d) Regels betreffende Zelfstandige bestuursorganen (Kaderwet Zelfstandige Bestuursorganen). Memorie van Toelichting. (Kamerstukken II, Vergaderjaar 2000-2001, 27426 nr 3). Den Haag: SDU uitgevers.

Parliament. (2000e). Vermogensvorming bij instellingen op afstand van het rijk. (Kamerstukken II, Vergaderjaar 2000-2001, 27066 nr 2). Den Haag: SDU uitgevers.

Parliament. (2000f). Regels betreffende Zelfstandige bestuursorganen (Kaderwet Zelfstandige Bestuursorganen). Voorstel van wet. (Kamerstukken II, Vergaderjaar 2000-2001, 27426 nr 1-2). Den Haag: SDU uitgevers.

Parliament. (2000g). Toekomstige structuur van de uitvoering werk en inkomen (SUWI). Verslag van een algemeen overleg. (Kamerstukken II, Vergaderjaar 1999-2000, 26448 nr 10). Den Haag: SDU uitgevers.

Parliament (2001a), Begroting 2002 Sociale Zaken en Werkgelegenheid. (Kamerstukken II, Vergaderjaar 2001-2002, 28000 XV nr 1-2). Den Haag: SDU uitgevers.

Parliament (2001b), Sociale Nota. (Kamerstukken II, Vergaderjaar 2001-2002, 28001 XV $\mathrm{nr}$ 2). Den Haag: SDU uitgevers.

Parliament. (2001c) Verantwoording en toezicht bij Rechtspersonen met een wettelijke taak deel 2., (Kamerstukken II, Vergaderjaar 2000-2001, 27656 nr 2). Den Haag: SDU uitgevers.

Parliament. (2001d). Wijziging van de Comptabiliteitswet houdende bepalingen inzake het beheer van liquide middelen van rechtspersonen die collectieve middelen beheren, inzake de financiering van die rechtspersonen en inzake de beheersing van het EMU-saldo voor zover dit saldo door het financieel beheer van deze rechtspersonen wordt beïnvloed (Eerste wijziging van de Comptabiliteitswet 2001). Memorie van Toelichting. (Kamerstukken II, Vergaderjaar 2001-2002, $28035 \mathrm{nr} 3)$. Den Haag: SDU uitgevers.

Parliament. (2001e). Wijziging van de Mededingingswet in verband met het omvormen van de Nederlandse mededingingsautoriteit tot zelfstandig bestuursorgaan. Nota naar aanleiding van het verslag. (Kamerstukken II, Vergaderjaar 2000-2001, 27639 nr 5). Den Haag: SDU uitgevers.

Parliament. (2001f). Wijziging van de Mededingingswet in verband met het omvormen van de Nederlandse mededingingsautoriteit tot zelfstandig bestuursorgaan. Nota van wijziging. (Kamerstukken II, Vergaderjaar 2000-2001, 27639 nr 7). Den Haag: SDU uitgevers.

Parliament. (2001g). Regels tot vaststelling van een structuur voor de uitvoering van taken met betrekking tot de arbeidsvoorziening en socialeverzekeringswetten (Wet structuur uitvoeringsorganisatie werk en inkomen) (Kamerstukken II, Vergaderjaar 2000-2001, 27588 nr 3). Den Haag: SDU uitgevers.

Parliament. (2001h). Wijziging van de Mededingingswet in verband met het omvormen van de Nederlandse mededingingsautoriteit tot zelfstandig bestuursorgaan. 
Memorie van Toelichting. (Kamerstukken II, Vergaderjaar 2000-2001, 27639 nr 3). Den Haag: SDU uitgevers.

Parliament. (2002a) Verantwoording en toezicht bij Rechtspersonen met een wettelijke taak deel 3., (Kamerstukken II, Vergaderjaar 2003-2004, 28655 nrs 1-2). Den Haag: SDU uitgevers.

Parliament (2002b). Kaderwet Zelfstandige Bestuursorganen. Voorstel van wet zoals het luidt na de daarin t/m 19 maart 2002 aangebrachte wijzigingen. (Kamerstukken II, Vergaderjaar 2001-2002, 27426 nr 63) Den Haag: SDU uitgevers.

Parliament (2002c). Vaststelling van de Wet inzake het beheer van de financiën van het Rijk (Comptabiliteitswet 2001). Derde nota van wijziging. (Kamerstukken II, Vergaderjaar 2001-2002, 27849 nr 11). Den Haag: SDU uitgevers.

Parliament. (2002d). Kaderwet Zelfstandige Bestuursorganen. Amendement van het lid Belinfante. (Kamerstukken II, Vergaderjaar 2001-2002, 27426 nr 26). Den Haag: SDU uitgevers.

Parliament. (2002e). Vaststelling van de Wet inzake het beheer van de financiën van het Rijk (Comptabiliteitswet 2001). Tweede nota van wijziging (Kamerstukken II, Vergaderjaar 2001-2002, 27849 nr 9). Den Haag: SDU uitgevers.

Parliament. (2002f). Kaderwet Zelfstandige Bestuursorganen. Amendement van het lid Van den Berg. (Kamerstukken II, Vergaderjaar 2001-2002, 27426 nr 15). Den Haag: SDU uitgevers.

Parliament. (2002g). Kaderwet Zelfstandige Bestuursorganen. Amendement van het lid Van Middelkoop. (Kamerstukken II, Vergaderjaar 2001-2002, 27426 nr 19). Den Haag: SDU uitgevers.

Parliament (2002h). Amendement van de leden Scheltema-de Nie en Te Veldhuis. (Kamerstukken II, Vergaderjaar 2001-2002, 27426 nr 38). Den Haag: SDU uitgevers.

Parliament (2002i). Handelingen Tweede Kamer Vergaderjaar 2001-2002, 50e Vergadering. pp 50-3529 t/m 50-3549. Den Haag: SDU uitgevers.

Parliament (2002j). Amendement van de leden Scheltema-de Nie C.S.. (Kamerstukken II, Vergaderjaar 2001-2002, 27426 nr 21). Den Haag: SDU uitgevers.

Parliament. (2003a) Begroting en verantwoording in balans. Het baten-lastenstelsel voor de Rijksoverheid. (Kamerstukken II, Vergaderjaar 2002-2003, 28860 nr 1-2). Den Haag: SDU uitgevers.

Parliament. (2003b) Miljoenennota 2004. (Kamerstukken II, Vergaderjaar 2003-2004, 29200 nr 1). Den Haag: SDU uitgevers.

Parliament. (2003c) Structuur uitvoering werk en inkomen (SUWI). Brief van de minister van Financiën. (Kamerstukken II, Vergaderjaar 2002-2003, 26448 nr 81). Den Haag: SDU uitgevers.

Parliament. (2003d). Hervorming van het toezicht op de financiële marktsector. (Kamerstukken II, Vergaderjaar 2002-2003, 28122 nr 16). Den Haag: SDU uitgevers. 
Parliament. (2003e). Amendement van het lid De Nerée tot Babberich c.s. (Kamerstukken II, Vergaderjaar 2003-2003, 29200IXB nr 7). Den Haag: SDU uitgevers.

Parliament. (2004a). Begroting XV Sociale Zaken en Werkgelegenheid. (Kamerstukken II, Vergaderjaar 2004-2005, 29800 XV nr 1-2). Den Haag: SDU uitgevers.

Parliament. (2004b). Verantwoording en toezicht bij Rechtspersonen met een wettelijke taak deel 4.Verslag van een algemeen overleg. (Kamerstukken II, Vergaderjaar 2003-2004, 29450 nr 5). Den Haag: SDU uitgevers.

Parliament. (2004c). Verantwoording en toezicht bij Rechtspersonen met een wettelijke taak deel 4. (Kamerstukken II, Vergaderjaar 2003-2004, 29450 nr 1-2). Den Haag: SDU uitgevers.

Parliament. (2004d). Regeling voor een sociale verzekering voor geneeskundige verzorging ten behoeve van de gehele bevolking (Zorgverzekeringswet.) Memorie van Toelichting. (Kamerstukken II, Vergaderjaar 2003-2004, 29763 nr 3)., Den Haag: SDU uitgevers.

Parliament. (2004e). Verantwoording en toezicht bij Rechtspersonen met een wettelijke taak deel 4. Verslag van een algemeen overleg. (Kamerstukken II, Vergaderjaar 2003-2004, 29450 nr 5). Den Haag: SDU uitgevers.

Parliament. (2004f). Staat van de beleidsinformatie 2004. (Kamerstukken II, Vergaderjaar 2004-2005, 29550 nrs 1-2). Den Haag: SDU uitgevers.

Parliament (2004g). Structuur van de uitvoering werk en inkomen (SUWI). Brief van de minister en de staatssecretaris van Sociale Zaken en Werkgelegenheid. (Kamerstukken II, Vergaderjaar 2007-2008, 26448 nr 109). Den Haag: SDU uitgevers.

Parliament. (2005a). Zelfstandige Bestuursorganen. Brief van de minister voor bestuurlijke vernieuwing en koninkrijksrelaties. (Kamerstukken II, Vergaderjaar 2004-2005, 25268 nr 20). Den Haag: SDU uitgevers.

Parliament. (2005b). Kaderwet Zelfstandige Bestuursorganen. Brief van de Minister van Financiën (Kamerstukken II, Vergaderjaar 2004-2005, 25268 nr 21). Den Haag: SDU uitgevers.

Parliament. (2005c). Kaderwet Zelfstandige Bestuursorganen. Brief van de Minister van Binnenlandse Zaken en Koninkrijksrelaties (Kamerstukken I, Vergaderjaar 20042005, 27426 A). Den Haag: SDU uitgevers.

Parliament (2005d) Evaluatie VBTB. (Kamerstukken II, Vergaderjaar 2004-2005, 29.949 $n$ r 1). Den Haag: SDU uitgevers.

Parliament. (2005e). Handelingen 58ste vergadering. (Kamerstukken II, Vergaderjaar 2004-2005), pp [58-3737]-[58-3752]. Den Haag: SDU uitgevers.

Parliament (2006a), Verantwoording en toezicht bj rechtspersonen met een wettelijke taak, deel 5. (Kamerstukken II, Vergaderjaar 2006-2007, 30850 nr 1-2). Den Haag: SDU uitgevers. 
Parliament (2006b), Brief van de minister van Sociale Zaken en Werkgelegenheid. (Kamerstukken II, Vergaderjaar 2005-2006, 26448 nr 238). Den Haag: SDU uitgevers.

Parliament. (2006c). Deelnemingenbeleid Rijksoverheid (Kamerstukken II, Vergaderjaar 2005-2006, 28165 nr 46). Den Haag: SDU uitgevers.

Parliament (2006d). Miljoenennota 2007. (Kamerstukken II, Vergaderjaar 2006-2006, $30800 \mathrm{nr}$ 1). Den Haag: SDU uitgevers.

Parliament (2006e), Verantwoording en toezicht bj rechtspersonen met een wettelijke taak, deel 5. Ministerie van OCW. (Kamerstukken II, Vergaderjaar 2006-2007, $30850 \mathrm{nr}$ 6). Den Haag: SDU uitgevers.

Parliament (2006f), Herplaatsing aandelen TNT Post Groep (TPG); Deelnemingenbeleid Rijksoverheid, (Kamerstukken II, Vergaderjaar 2006-2007, 27638 nr 6). Den Haag: SDU uitgevers.

Parliament (2006g), Regels betreffende pensioenen (Pensioenwet). Amendement van het lid Verbeek C.S., (Kamerstukken II, Vergaderjaar 2005-2006, 30413 nr 58). Den Haag: SDU uitgevers.

Parliament (2006h). Structuur van de uitvoering werk en inkomen (SUWI). Brief van de minister van Sociale Zaken en Werkgelegenheid. (Kamerstukken II, Vergaderjaar 2006-2007, 26448 nr 309). Den Haag: SDU uitgevers.

Parliament (2006i). Vaststelling van de begrotingsstaten van het ministerie van Volksgezondheid, Welzijn en Sport (XVI) voor het jaar 2007. Memorie van Toelichting (Kamerstukken II, Vergaderjaar 2006-2007, 30800 XVI nr 2). Den Haag: SDU uitgevers.

Parliament (2006j). Vaststelling van de begrotingsstaten van het ministerie van Sociale Zaken en Werkgelegenheid (XV) voor het jaar 2007. Memorie van Toelichting (Kamerstukken II, Vergaderjaar 2006-2007, 30800 XV nr 2). Den Haag: SDU uitgevers.

Parliament (2006k). Structuur van de uitvoering werk en inkomen (SUWI). Brief van de minister van Sociale Zaken en Werkgelegenheid. (Kamerstukken II, Vergaderjaar 2006-2007, 26448 nr 312). Den Haag: SDU uitgevers.

Parliament (2006I). Vaststelling van de begrotingsstaten van het ministerie van Financiën (IXB) voor het jaar 2007. Memorie van Toelichting (Kamerstukken II, Vergaderjaar 2006-2007, 30800 IXB nr 2). Den Haag: SDU uitgevers.

Parliament (2006m). Vaststelling van de begrotingsstaten van het ministerie van Volksgezondheid, Welzijn en Sport (XVI) voor het jaar 2007. Brief van de minister van Volksgezondheid, Welzijn en Sport (Kamerstukken II, Vergaderjaar 20062007, 30800 XVI nr 18). Den Haag: SDU uitgevers.

Parliament (2007a), Lof der eenvoud. (Kamerstukken II, Vergaderjaar 2006-2007, 30942 nr 2). Den Haag: SDU uitgevers.

Parliament. (2007b). Verantwoording en toezicht bij Rechtspersonen met een wettelijke taak deel 5. Rapport van de Algemene Rekenkamer over het ministerie van 
Economische Zaken. (Kamerstukken II, Vergaderjaar 2006-2007, 30850 nr 11). Den Haag: SDU uitgevers.

Parliament. (2007c). Zelfstandige bestuursorganen. Modernisering van de overheid. Brief van de minster Binnenlandse Zaken en Koninkrijksrelaties. (Kamerstukken II, Vergaderjaar 2007-2008, 25268 nr 46). Den Haag: SDU uitgevers.

Parliament. (2007d). Trendnota Arbeidszaken Overheid 2008. Brief van de minster van Onderwijs, Cultuur en Wetenschappen. (Kamerstukken II, Vergaderjaar 20072008, $31201 \mathrm{nr}$ 4).Den Haag: SDU uitgevers.

Parliament. (2007e). Miljoenennota 2008. (Kamerstukken II, Vergaderjaar 2007-2008, 31200 nr 1). Den Haag: SDU uitgevers.

Parliament. (2007f). Trendnota Arbeidszaken Overheidspersoneel 2008. Brief van de minster Binnenlandse Zaken en Koninkrijksrelaties. (Kamerstukken II, Vergaderjaar 2007-2008, 31201 nr 3). Den Haag: SDU uitgevers.

Parliament (2007g). Brief van de minister van Financiën. (Kamerstukken II, Vergaderjaar 2007-2008, 28.165 nr. 69). , SDU, Den Haag

Parliament. (2007h). Huurbeleid. Evaluatie integrale herziening huurwetgeving. Brief van de minster voor wonen, wijken en integratie. (Kamerstukken II, Vergaderjaar 2007-2008, 27926 nr 123). Den Haag: SDU uitgevers.

Parliament. (2007i). Financieel Jaarverslag van het Rijk (Kamerstukken II, Vergaderjaar 2007-2008, 31031 nr 1). Den Haag: SDU uitgevers.

Parliament. (2007j). Zelfstandige bestuursorganen. Brief van de minister van Volksgezondheid, Welzijn en Sport. (Kamerstukken II, Vergaderjaar 2007-2008, $25268 \mathrm{nr} 45)$. Den Haag: SDU uitgevers.

Parliament (2007k). Structuur van de uitvoering werk en inkomen (SUWI). Brief van de minister en de staatssecretaris van Sociale Zaken en Werkgelegenheid. (Kamerstukken II, Vergaderjaar 2007-2008, 26448 nr 342). Den Haag: SDU uitgevers.

Parliament (2007I). Structuur van de uitvoering werk en inkomen (SUWI). Brief van de minister van Sociale Zaken en Werkgelegenheid. (Kamerstukken II, Vergaderjaar 2007-2008, 26448 nr 350). Den Haag: SDU uitgevers.

Parliament. $(2007 \mathrm{~m})$. Begroting van het ministerie van Sociale Zaken en Werkgelegenheid (XV) voor het jaar 2008. Verslag van een wetgevingsoverleg. (Kamerstukken II, Vergaderjaar 2007-2008, 31200XV nr 62). Den Haag: SDU uitgevers.

Parliament (2007n). Structuur van de uitvoering werk en inkomen (SUWI). Brief van de minister van Sociale Zaken en Werkgelegenheid. (Kamerstukken II, Vergaderjaar 2007-2008, 26448 nr 331). Den Haag: SDU uitgevers.

Parliament. (2007o). Jaarverslag van het ministerie van Volksgezondheid, Welzijn en Sport (XVI), (Kamerstukken II, Vergaderjaar 2007-2008, 31031XVI nr 1). Den Haag: SDU uitgevers. 
Parliament. (2007p). Begroting van het ministerie van Justitie (VI). Memorie van Toelichting. (Kamerstukken II, Vergaderjaar 2007-2008, 31200VI nr 2). Den Haag: SDU uitgevers.

Parliament (2007q). Handelingen Tweede Kamer Vergaderjaar 2007-2008, 27e Vergadering. pp 27-2073 t/m 27-2095. Den Haag: SDU uitgevers.

Parliament. (2007r). Begroting van het ministerie van Sociale Zaken en Werkgelegenheid (XV). Memorie van Toelichting. (Kamerstukken II, Vergaderjaar 2007-2008, 31200XV nr 2). Den Haag: SDU uitgevers.

Parliament (2007s). Structuur van de uitvoering werk en inkomen (SUWI). Motie van het lid Ulenbelt. (Kamerstukken II, Vergaderjaar 2007-2008, 26448 nr 322). Den Haag: SDU uitgevers.

Parliament. (2007t). Belastingdienst. Structuur van de uitvoering werk en inkomen (SUWI) Verslag van een schriftelijk overleg. (Kamerstukken II, Vergaderjaar 20062007, 31066 nr 8). Den Haag: SDU uitgevers.

Parliament. (2007u). Structuur van de uitvoering werk en inkomen (SUWI) Motie van het lid Heerts c.s.. (Kamerstukken II, Vergaderjaar 2007-2008, 26448 nr 321). Den Haag: SDU uitgevers.

Parliament. (2007v). Aanhangels van de handelingen. (Kamerstukken II, Vergaderjaar 2007-2008, Aanhangel van de handelingen nr 1405). Den Haag: SDU uitgevers.

Parliament. (2007w). Wijziging van de begrotingsstaten van het Ministerie van Onderwijs, Cultuur en Wetenschap (VIII) voor het jaar 2007 (wijziging samenhangende met de Voorjaarsnota). Lijst van vragen en antwoorden. (Kamerstukken II, Vergaderjaar 2007-2008, 31061VIII nr 3). Den Haag: SDU uitgevers.

Parliament. (2007x). Wijziging van de begrotingsstaten van het Ministerie van Economische Zaken (XIII) voor het jaar 2007 (wijziging samenhangende met de Voorjaarsnota). Verslag houdende een lijst van vragen en antwoorden. (Kamerstukken II, Vergaderjaar 2007-2008, 31061XII nr 3). Den Haag: SDU uitgevers.

Parliament. (2007y). Begroting van het ministerie van Landbouw, Natuurbeheer en Voedselkwaliteit (XIV) voor het jaar 2007. Brief van de minister van Landbouw, Natuurbeheer en Voedselkwaliteit. (Kamerstukken II, Vergaderjaar 2007-2008, 31200XIV nr 103). Den Haag: SDU uitgevers.

Parliament. (2007z). Toezicht op mededinging door de NMa. Lijst van vragen en antwoorden. (Kamerstukken II, Vergaderjaar 2007-2008, 31055 nr 4). Den Haag: SDU uitgevers.

Parliament. (2007aa). Begroting van het ministerie van Economische Zaken (XIII) voor het jaar 2008. Verslag houdende een lijst van vragen en antwoorden. (Kamerstukken II, Vergaderjaar 2007-2008, 31200XIII nr 4). Den Haag: SDU uitgevers.

Parliament. (2007ab). Wijziging van de begrotingsstaten van het Ministerie van Volksgezondheid, Welzijn en Sport (XVI) voor het jaar 2007 (wijziging 
samenhangende met de Voorjaarsnota). Memorie van toelichting (Kamerstukken

II, Vergaderjaar 2007-2008, 31061XVI nr 2). Den Haag: SDU uitgevers.

Parliament. (2008a). Begroting XV Sociale Zaken en Werkgelegenheid. (Kamerstukken II,

Vergaderjaar 2008-2009, 31700 XV nr 2). Den Haag: SDU uitgevers.

Parliament. (2008b). Zelfstandige bestuursorganen. Brief van de minister van

Binnenlandse Zaken en Koninkrijksrelaties. (Kamerstukken II, Vergaderjaar 20072008, 25268 nr 63). Den Haag: SDU uitgevers.

Parliament. (2008c). Evaluatie van het baten lasten model. (Kamerstukken II, Vergaderjaar 2008-2009, 28737 nr 17). Den Haag: SDU uitgevers.

Parliament. (2008d). Zelfstandige bestuursorganen. Brief van de minister van Onderwijs, Cultuur en Wetenschappen. (Kamerstukken II, Vergaderjaar 2007-2008, 25268 nr 50). Den Haag: SDU uitgevers.

Parliament. (2008e). Cultuursubsidies 2009-2012. Verslag van een Algemeen Overleg (Kamerstukken II, Vergaderjaar 2007-2008, 31482 nr 15).Den Haag: SDU uitgevers.

Parliament. (2008f). Zelfstandige bestuursorganen. Brief van de minister van Welzijn, Volksgezondheid en Sport. (Kamerstukken II, Vergaderjaar 2007-2008, $25268 \mathrm{nr}$ 57). Den Haag: SDU uitgevers.

Parliament. (2008g). Aanpak wijken. Verslag van een schriftelijk overleg. (Kamerstukken II, Vergaderjaar 2008-2009, 30995 nr 59). Den Haag: SDU uitgevers.

Parliament. (2008h). Vaststelling van de begrotingsstaten van het ministerie van Landbouw, Natuurbeheer en Voedselkwaliteit (XIV) voor het jaar 2008. Verslag van een algemeen overleg. (Kamerstukken II, Vergaderjaar 2007-2008, 31200 XIV nr 206). Den Haag: SDU uitgevers.

Parliament. (2008i). Zelfstandige bestuursorganen. Brief van de minister van Justitie. (Kamerstukken II, Vergaderjaar 2008-2009, 25268 nr 60). Den Haag: SDU uitgevers.

Parliament. (2008j). Zelfstandige bestuursorganen. Brief van de minister van Volksgezondheid, Welzijn en Sport. (Kamerstukken II, Vergaderjaar 2008-2009, 25268 nr 70). Den Haag: SDU uitgevers.

Parliament. (2008k). Zelfstandige bestuursorganen. Brief van de minister van Sociale Zaken en Werkgelegenheid. (Kamerstukken II, Vergaderjaar 2008-2009, 25268 nr 55). Den Haag: SDU uitgevers.

Parliament. (2008I). Wijziging van de Wet structuur uitvoeringsorganisatie werk en inkomen en enkele andere wetten in verband met de evaluatie van deze wet, de Kaderwet zelfstandige bestuursorganen en deregulering. (Kamerstukken II, Vergaderjaar 2007-2008, 31514 nr 3). Den Haag: SDU uitgevers.

Parliament (2008m). Structuur van de uitvoering werk en inkomen (SUWI). Brief van de minister van Sociale Zaken en Werkgelegenheid. (Kamerstukken II, Vergaderjaar 2008-2009, 26448 nr 390). Den Haag: SDU uitgevers. 
Parliament (2008n). Structuur van de uitvoering werk en inkomen (SUWI). Brief van de minister van Sociale Zaken en Werkgelegenheid. (Kamerstukken II, Vergaderjaar 2008-2009, 26448 nr 365). Den Haag: SDU uitgevers.

Parliament. (20080). Wijziging van diverse onderwijswetten in verband met het door de scholen om niet ter beschikking stellen van lesmateriaal aan de leerlingen in het voortgezet onderwijs Brief van de Staatssecretaris van Onderwijs, Cultuur en Wetenschappen. (Kamerstukken II, Vergaderjaar 2007-2008, 31325 nr 10). Den Haag: SDU uitgevers.

Parliament. (2008p). Structuur van de uitvoering werk en inkomen (SUWI). Brief van het presidium. (Kamerstukken II, Vergaderjaar 2007-2008, 26448 nr 370). Den Haag: SDU uitgevers.

Parliament. (2008q). Structuur van de uitvoering werk en inkomen (SUWI) Brief van de minister van Sociale Zaken en Werkgelegenheid. (Kamerstukken II, Vergaderjaar 2007-2008, 26448 nr 363). Den Haag: SDU uitgevers.

Parliament. (2008r). Structuur van de uitvoering werk en inkomen (SUWI) Verslag van een schriftelijk overleg. (Kamerstukken II, Vergaderjaar 2008-2009, $26448 \mathrm{nr}$ 386). Den Haag: SDU uitgevers.

Parliament. (2008s). Structuur van de uitvoering werk en inkomen (SUWI) Verslag van een schriftelijk overleg. (Kamerstukken II, Vergaderjaar 2008-2009, $26448 \mathrm{nr}$ 386). Den Haag: SDU uitgevers.

Parliament. (2008t). Structuur van de uitvoering werk en inkomen (SUWI) Brief van de minister en staatssecretaris van Sociale Zaken en werkgelegenheid. (Kamerstukken II, Vergaderjaar 2007-2008, 26448 nr 362). Den Haag: SDU uitgevers.

Parliament. (2008u). Wijziging van de Wet structuur uitvoeringsorganisatie werk en inkomen en enkele andere wetten in verband met de evaluatie van deze wet, de Kaderwet zelfstandige bestuursorganen en deregulering (Kamerstukken II, Vergaderjaar 2007-2008, 31514 nr 2). Den Haag: SDU uitgevers.

Parliament. (2008v). Reïntegratiebeleid. Brief van de minister van Sociale Zaken en Werkgelegenheid. (Kamerstukken II, Vergaderjaar 2007-2008, 28719 nr 56). Den Haag: SDU uitgevers.

Parliament. (2008w). Zelfstandige bestuursorganen. Brief van de minister van Financiën. (Kamerstukken II, Vergaderjaar 2008-2009, 25268 nr 56). Den Haag: SDU uitgevers.

Parliament. (2008x). Zelfstandige bestuursorganen. Brief van de minister van Wonen, Wijken en integratie. (Kamerstukken II, Vergaderjaar 2008-2009, 25268 nr 54). Den Haag: SDU uitgevers.

Parliament. (2008y). Zelfstandige bestuursorganen. Brief van de minister van Landbouw, Natuur en Voedselkwaliteit. (Kamerstukken II, Vergaderjaar 2008-2009, $25268 \mathrm{nr}$ 48). Den Haag: SDU uitgevers. 
Parliament. (2008z). Zelfstandige bestuursorganen. Brief van de minister van Economische Zaken. (Kamerstukken II, Vergaderjaar 2008-2009, 25268 nr 53). Den Haag: SDU uitgevers.

Parliament. (2008aa). Jaarverslag en slotwet ministerie van Financiën 2007. (Kamerstukken II, Vergaderjaar 2007-2008, 31444 IX B nr 1). Den Haag: SDU uitgevers.

Parliament. (2008ab). Vaststelling van de begrotingsstaten van het Ministerie van Financiën (IXB) voor het jaar 2008. Lijst van vragen en antwoorden. (Kamerstukken II, Vergaderjaar 2007-2008, 31200 IX B nr 34). Den Haag: SDU uitgevers.

Parliament. (2008ac). Jaarverslag en slotwet ministerie van Volkshuisvesting, Ruimtelijke ordening en Milieubeheer 2007. (Kamerstukken II, Vergaderjaar 2007-2008, 31444 XI nr 1). Den Haag: SDU uitgevers.

Parliament. (2008ad). Geneesmiddelenbeleid. Motie van het lid Van Gerwen (Kamerstukken II, Vergaderjaar 2007-2008, 29477 nr 59). Den Haag: SDU uitgevers.

Parliament. (2008ae). Geneesmiddelenbeleid. Motie van het lid Van Gerwen (Kamerstukken II, Vergaderjaar 2007-2008, 29477 nr 60). Den Haag: SDU uitgevers.

Parliament. (2009a). Wijziging van Boek 2 van het Burgerlijk Wetboek houdende regels voor de vereniging of stichting tot instandhouding van een maatschappelijke onderneming; Memorie van toelichting. (Kamerstukken II, Vergaderjaar 20082009, 32003, nr 1-3). Den Haag: SDU uitgevers.

Parliament. (2009b). Verantwoording en toezicht bij Rechtspersonen met een wettelijke taak deel 5. (Kamerstukken II, Vergaderjaar 2009-2010, 30850 nr 31-32). Den Haag: SDU uitgevers.

Parliament. (2009c). Wijziging van de Uitvoeringswet huurprijzen woonruimte (instelling van een landelijke huurcommissie); Memorie van toelichting. (Kamerstukken II, Vergaderjaar 2008-2009, 31903 nr 3). Den Haag: SDU uitgevers.

Parliament. (2009d). Aanpassing van de Wet op de Rechtsbijstand in verband met de bestuurlijke centralisatie van de raden voor rechtsbijstand. Memorie van Toelichting. (Kamerstukken II, Vergaderjaar 2009-2010, 31835 nr 3). Den Haag: SDU uitgevers.

Parliament. (2009e). Aanpassing van enige wetten teneinde een aantal zelfstandige bestuursorganen onder de werking van de Kaderwet zelfstandige bestuursorganen te brengen. (Kamerstukken II, Vergaderjaar 2009-2010, 31950 nr 2). Den Haag: SDU uitgevers.

Parliament. (2009f). Jaarverslag en Slotwet Ministerie van Sociale Zaken en Werkgelegenheid 2008. Motie van het lid Karabulut (Kamerstukken II, Vergaderjaar 2008-2009, 31924XV nr 13). Den Haag: SDU uitgevers. 
Parliament. (2009g). Structuur van de uitvoering werk en inkomen Brief van de minister en staatssecretaris van sociale zaken en werkgelegenheid (Kamerstukken II, Vergaderjaar 2008-2009, 26448 nr 397). Den Haag: SDU uitgevers.

Parliament. (2009h). Vaststelling van de begrotingsstaten van het ministerie van Onderwijs, Cultuur en Wetenschap (VIII) voor het jaar 2009. Brief van de staatssecretaris van onderwijs, cultuur en wetenschap. (Kamerstukken II, Vergaderjaar 2008-2009, 31700VIII nr 199). Den Haag: SDU uitgevers.

Parliament. (2009i). Vaststelling van de begrotingsstaten van het ministerie van Financiën (IXB) voor het jaar 2009. Brief van de ministers van Financiën, en van Sociale Zaken en Werkgelegenheid. (Kamerstukken II, Vergaderjaar 2008-2009, 31700 IXB nr 24). Den Haag: SDU uitgevers.

Parliament. (2009j). Aanpassing van de EZ-instellingswetten aan de Kaderwet Zelfstandige Bestuursorganen. (Kamerstukken II, Vergaderjaar 2009-2010, $32151 \mathrm{nr}$ 2). Den Haag: SDU uitgevers.

Parliament. (2009k). Jaarverslag en Slotwet Ministerie van Wonen, Wijken en Integratie 2008. (Kamerstukken II, Vergaderjaar 2008-2009, 31924XVIII nr 1). Den Haag: SDU uitgevers.

Parliament. (2009I). Jaarverslag en Slotwet Ministerie van Volkshuisvesting, Ruimtelijke ordening en Milieubeheer en van de begrotingsstaat van het Waddenfonds 2008. Brief van de minister van Volkshuisvesting, Ruimtelijke ordening en Milieubeheer (Kamerstukken II, Vergaderjaar 2008-2009, 31924XI nr 10). Den Haag: SDU uitgevers.

Parliament. (2009m). Instellen dienst Uitvoering Onderwijs als baten-lasten dienst. Brief van de minister van onderwijs, cultuur en wetenschap. (Kamerstukken II, Vergaderjaar 2008-2009, 31982 nr 1). Den Haag: SDU uitgevers.

Parliament. (2010). Beheer Staatsparticipaties in financiële instellingen. Brief van de minister van Financiën. (Kamerstukken II, Vergaderjaar 2009-2010, 32000 nr 4). Den Haag: SDU uitgevers. 


\section{List of figures}

FIGURE 1.1: MATCHING OF LEGAL AND ECONOMIC AUTONOMY OF ZBOS. 30

FIGURE 2.1 TIME LINE OF THE BUDGET PROCESS IN DUTCH CENTRAL GOVERNMENT.

FIGURE 2.2: DIFFERENT TYPES OF ORGANISATIONS FOR DELIVERING GOVERNMENT SERVICES. ADAPTED

FROM VAN THIEL (2000, P. 8) 50

FIGURE 2.3: DIFFERENT TYPES OF ZBOS WITHIN THE QUANGO SPECTRUM ADAPTED FROM VAN THIEL

(2000, P. 8). $\quad 54$

FIGURE 2.4: NATIONAL LEVEL QUANGOS IN THE NETHERLANDS. ADAPTED FROM KUMMELING ET AL. (1999, P. 26)

FIGURE 2.5: AUTONOMY FROM A BW2-SHAREHOLDER PERSPECTIVE 66

FIGURE 3.1: MOST IMPORTANT LEGISLATION INFLUENCING AUTONOMY OF ZBOS

FIGURE 4.1: EFFECT OF AUTHORISATION OF DIFFERENT TYPES OF BUDGETS ON CONTROLLABILITY OF THE ZBO BUDGET $\quad 105$

FIGURE 6.1: ORGANISATION OF THE DUTCH STATE $\quad 132$

FIGURE 6.2: CONTRACTING MODELS AND DISTRIBUTION OF PRIME RESPONSIBILITY. 148

FIGURE 6.3: LEGAL FORMS OF ZBOS, CONTRACT RELATIONS AND EXPECTED AUTONOMY 157

FIGURE 8.1: ECONOMIC ISSUES WITH AN IMPACT ON AUTONOMY OF ZBO OPERATIONS 169

FIGURE 10.1: TYPE OF ORGANISATION BY CHARACTERISTICS OF TASKS (SOURCE: WILSON, 1989, P. 158-

FIGURE 11.1: BUDGET TYPOLOGY (MOL, 1989) 222

FIGURE 13.1: MATCHING OF LEGAL AND ECONOMIC AUTONOMY OF ZBOS. 242

FIGURE 14.1: PERCENTAGE OF ZBOS FOR WHICH (ESTIMATED) OPERATING REVENUES IN FISCAL 2006

ARE AVAILABLE 253

FIGURE 14.2: CUMULATIVE DISCLOSED 2006 ZBO OPERATING REVENUES BY TASK GROUP ( $N=60) \quad 256$

FIGURE 14.3: EX ANTE KNOWLEDGE ON SOURCES OF FUNDING (N=128) 257

FIGURE 14.4: SOURCES OF FUNDING OF ZBOS (N=60) 257

FIGURE 14.5: (ESTIMATED) REVENUES, LEGAL ENTITY TYPE AND SOURCE OF FUNDING ( $N=128)$

FIGURE 14.6: FINANCIAL RELEVANCE AND PROPOSALS REGARDING ZBOS NOT SUBJECT TO KZBO ( $\mathrm{N}=72$, ADAPTED FROM PARLIAMENT, 2008B) 260

FIGURE 14.7: LEGAL STATUS AND SOURCES OF FUNDING OF ZBOS UNDER THE KZBO-FRAMEWORK ( $N=49$ )

FIGURE 14.8: DISTRIBUTION OF KZBO UNITS BASED ON EX ANTE CLASSIFICATIONS (N=49) $\quad 261$

FIGURE 14.9: ZBOS PARTICIPATING IN THE CASE STUDIES 262

FIGURE 16.1: FORMAL AND ACTUAL AUTONOMY OF INCOME TRANSFER ZBOS FROM A LEGAL PERSPECTIVE

FIGURE 16.2 EXPECTED AND ACTUAL AUTONOMY OF INCOME TRANSFER ZBOS FROM AN ECONOMIC PERSPECTIVE

FIGURE 17.1 FORMAL AND ACTUAL AUTONOMY OF MONITORING ZBOS FROM A LEGAL PERSPECTIVE 372

FIGURE 17.2 EXPECTED AND ACTUAL AUTONOMY OF MONITORING ZBOS FROM AN ECONOMIC PERSPECTIVE

FIGURE 18.1: DESIGNED AND ACTUAL AUTONOMY OF ZBOS STUDIED BASED ON MARKET AND PLANNING AND CONTROL AUTONOMY FACTORS.

FIGURE 19.1: MATCH IN LEGAL AND ECONOMIC AUTONOMY OF ZBOS 410

FIGURE 19.2: DESIGNED AND ACTUAL AUTONOMY OF ZBOS STUDIES BASED ON MARKET AND PLANNING AND CONTROL AUTONOMY FACTORS.

FIGURE 20.1: A DRAFT MODEL FOR DECIDING ON AUTONOMISATION. 


\section{List of tables}

TABLE 1.1 PARLIAMENTARY CONTROL TOOLS AT THE DIFFERENT CONTROL LEVELS 17

TABLE 2.1: CLASSIFICATION OF ACTIVITIES OF AUTONOMOUS ENTITIES 68

TABLE 2.2: ZBOS SUBJECT TO KZBO BASED ON DATA MINBZK 69

TABLE 2.3: NUMBER OF ZBOS BY LEGAL ENTITY AND SUBJECT TO KZBO

TABLE 2.4: RELEVANCE OF TYPES OF QUANGOS 2007

TABLE 4.1: REQUIREMENTS ON CREATING PRIVATE ENTITIES AND ZBOS IN CW. 83

TABLE 4.2: INFORMATION ON ALL ZBOS TO BE INCLUDED IN BUDGETS OF MINISTRIES AND ANNUAL REPORTS (SOURCE: PARLIAMENT, 2002E, P. 4-5) 88

TABLE 4.3: CW2001 AND EFFECT ON AUTONOMY OF OPERATIONS OF ZBOS 89

TABLE 4.4: SUMMARY OF CONTROL INDICATORS UNDER IPSAS $6 \quad 100$

TABLE 4.5: LINE ITEMS IN THE BUDGET LAW OF MINVROM IN NOMINAL AMOUNTS (OWN CALCULATIONS)

TABLE 4.6: INFLUENCE OF PARLIAMENT ON ZBO BUDGETS AS STATED BY LAW.

TABLE 5.1: ZBOS BY LEGAL STATUS LISTED IN THIS STUDY TO BE INCLUDED UNDER KZBO (SOURCE: PARLIAMENT, 2008B) 114

TABLE 5.2: AUTHORITY ISSUES HAVING IMPACT ON AUTONOMY AS MENTIONED IN 'AANWIJZINGEN' AS OF

$1996 \quad 117$

TABLE 5.3: AUTHORITY ISSUES IMPACTING AUTONOMY AS MENTIONED IN KZBO 121

TABLE 6.1: EXPECTED GOVERNMENT INFLUENCE AND IMPACT OF FINANCIAL RISK FOR DIFFERENT TYPES OF LEGAL ENTITIES

TABLE 7.1: INDICATORS AFFECTING RELATIVE AUTONOMY OF ZBOS FROM A LEGAL PERSPECTIVE. 163

TABLE 9.1: LEVELS OF POLICY AND OPERATIONAL CONTROL OF AN EXECUTIVE CENTRAL GOVERNMENT

ORGANISATION (SOURCE: VERHOEST, 2002, P. 37) 180

TABLE 10.1: FORMS OF PROVISION OF PUBLIC SERVICES (SOURCE: BOORSMA \& MOL, 1983) 190

TABLE 10.2: DIFFERENT SUPPLY MODELS PER ZBO TYPE 196

TABLE 10.3: PURE AND IMPURE PUBLIC SERVICES

TABLE 10.4: CONCEPTS AND CLASSIFICATION OF FORMS OF FUNDING IN THE PUBLIC SECTOR 208

TABLE 10.5: PRODUCTION CHARACTERISTICS OF ZBO SERVICES 212

TABLE 10.6: RELATION BETWEEN DEMAND AND PROVISION OF SERVICES

TABLE 11.1: ELEMENTS OF RESPONSIBILITY ATTRIBUTED TO MANAGEMENT 218

TABLE 11.2: ELEMENTS OF RESPONSIBILITY ATTRIBUTED TO PUBLIC SECTOR MANAGEMENT 220

TABLE 12.1: RELATION BETWEEN DEMAND AND PROVISION OF SERVICES 236

TABLE 12.2: INDICATORS AFFECTING RELATIVE AUTONOMY OF ZBOS FROM AN ECONOMIC PERSPECTIVE

TABLE 14.1: LEGAL VARIABLES, VALUES AND THEIR IMPACT ON AUTONOMY.

TABLE 14.2: ECONOMIC VARIABLES, VALUES AND IMPACT ON AUTONOMY

TABLE 14.3: ECONOMIC VARIABLES, VALUES AND IMPACT ON AUTONOMY (CONTINUED) 248

TABLE 14.4: UNIQUE ZBOS AND ZBOS AGGREGATED TO GROUP LEVEL BY LEGAL STATUS

TABLE 14.5: (ESTIMATED) OPERATING EXPENSES/CASH PAYMENTS OF ZBOS IN FISCAL 2006

TABLE 14.6: STAFF NUMBERS AND OPERATING EXPENSES PER ZBO 2006

TABLE 14.7: CLASSIFICATION OF ZBOS BY MAIN TASKS OF THE ENTITY 256

TABLE 14.8: EXPECTED STANDARD MEASURES DETERMINING ZBO AUTONOMY 266

TABLE 16.1: KEY DATA ON INCOME TRANSFER ZBOS

TABLE 16.2: LEGAL MEASURES ON CVZ, FORMALLY OR ACTUALLY DEVIATING FROM KZBO 287

TABLE 16.3: LEGAL MEASURES ON RVR, FORMALLY OR ACTUALLY DEVIATING FROM KZBO 292

TABLE 16.4: LEGAL MEASURES ON SVB, FORMALLY OR ACTUALLY DEVIATING FROM KZBO 300 
TABLE 16.5: LEGAL MEASURES ON UWV, FORMALLY OR ACTUALLY DEVIATING FROM KZBO

304

TABLE 16.6: LEGAL MEASURES ON FBKVB, FORMALLY OR ACTUALLY DEVIATING FROM KZBO

TABLE 16.7: LEGAL MEASURES ON VF/PF, FORMALLY OR ACTUALLY DEVIATING FROM KZBO

310

314

TABLE 16.8: CLASSIFICATION AND IMPACT OF MARKET CHARACTERISTICS ON CVZ'S AUTONOMY

318

TABLE 16.9: PLANNING \& CONTROL OF CVZ AND IMPACT ON AUTONOMY

TABLE 16.10: CLASSIFICATION AND IMPACT OF MARKET CHARACTERISTICS ON RVR'S AUTONOMY

TABLE 16.11: PLANNING \& CONTROL OF RVR AND IMPACT ON AUTONOMY

TABLE 16.12: CLASSIFICATION AND IMPACT OF MARKET CHARACTERISTICS ON SVB'S AUTONOMY

TABLE 16.13: PLANNING \& CONTROL OF SVB AND IMPACT ON AUTONOMY

TABLE 16.14: CLASSIFICATION AND IMPACT OF MARKET CHARACTERISTICS ON UWV'S AUTONOMY

TABLE 16.15: PLANNING \& CONTROL OF UWV AND IMPACT ON AUTONOMY

TABLE 16.16: CLASSIFICATION AND IMPACT OF MARKET CHARACTERISTICS ON FBKVB'S AUTONOMY

TABLE 16.17: PLANNING \& CONTROL OF FBKVB AND IMPACT ON AUTONOMY

TABLE 16.18: CLASSIFICATION AND IMPACT OF MARKET CHARACTERISTICS ON VF/PF'S AUTONOMY

TABLE 16.19: PLANNING \& CONTROL OF VF/PF AND IMPACT ON AUTONOMY

TABLE 17.1: KEY DATA ON MONITORING ZBOS

TABLE 17.2: LEGAL MEASURES ON AFM, FORMALLY OR ACTUALLY DEVIATING FROM KZBO.

TABLE 17.3: LEGAL MEASURES ON CFV, FORMALLY OR ACTUALLY DIVERGING FROM KZBO.

TABLE 17.4: LEGAL MEASURES ON NAK, FORMALLY OR ACTUALLY DIVERGING FROM KZBO.

TABLE 17.5: LEGAL MEASURES ON NMA, FORMALLY OR ACTUALLY DIVERGING FROM KZBO.

TABLE 17.6: LEGAL MEASURES ON NZA, FORMALLY OR ACTUALLY DIVERGING FROM KZBO.

TABLE 17.7: CLASSIFICATION AND IMPACT OF MARKET CHARACTERISTICS ON AFM'S AUTONOMY

TABLE 17.8: PLANNING AND CONTROL OF AFM AND IMPACT ON AUTONOMY

TABLE 17.9: CLASSIFICATION AND IMPACT OF MARKET CHARACTERISTICS ON CFV'S AUTONOMY

TABLE 17.10: PLANNING AND CONTROL OF CFV AND IMPACT ON AUTONOMY

TABLE 17.11: CLASSIFICATION AND IMPACT OF MARKET CHARACTERISTICS ON NAK'S AUTONOMY

TABLE 17.12: PLANNING AND CONTROL OF NAK AND IMPACT ON AUTONOMY

TABLE 17.13: CLASSIFICATION AND IMPACT OF MARKET CHARACTERISTICS ON NMA'S AUTONOMY TABLE 17.14: PLANNING AND CONTROL OF NMA AND IMPACT ON AUTONOMY

TABLE 17.15: CLASSIFICATION AND IMPACT OF MARKET CHARACTERISTICS ON NZA'S AUTONOMY

TABLE 17.16: PLANNING AND CONTROL OF NZA AND IMPACT ON AUTONOMY

TABLE 18.1: CONTROL BIAS AND LEVEL OF CONTROL OF ZBOS STUDIED

TABLE 19.1: EXPECTED STANDARD MEASURES DETERMINING AUTONOMY OF ZBOS

TABLE 20.1: INSTRUCTIONS AFFECTING AUTONOMY OF ZBOS IN ‘AANWIJZINGEN’ AND ‘KZBO’
320

322

323

325

327

329

331

333

335

336

338

347

352

355

360

364

369

374

376

378

380

382

383

385

386

388

390

399

421

71 


\section{Index}

internal -

\section{A}

Aanwijzingen voor de regelgeving

1996 version48, 52, 113, 116, 117, 118, 119, 120, 122, $125,151,153,159,161,183,194,413,2,71$

2008 version $.52,53,118,154,159,161,2,71$ Accountability

diagonal $154,184,269,272,276$

horizontal -27, 154, 155, 156, 163, 270, 271, 274, 275, 276,279

vertical $27,155,156,163,184$

Accounting

- systems... 47, 92, 94, 95, 98, 104, 225, 226, 241, 253, 419

accruals -... 48, 49, 54, 92, 94, 95, 97, 98, 99, 100, 101, $104,105,161,223,224,253,386$

cash - ...............47, 54, 55, 94, 226, 227, 253, 386, 62 responsibility - ........................ 25, 215, 216, 218, 419

Agency Theory...20, 23, 24, 171, 172, 178, 180, 185, 234, 451,2

Agent .449

appropriation ...... 9, 10, 12, 13, 19, 28, 32, 34, 66, 79, 86 $101,109,133,136,152,160,162,412$

Arbeidsvoorziening. Kliq.

at arm's length $4,5,6,7,8,11,12,20,26,27,34,38,44$, $49,50,52,61,63,64,65,67,69,71,79,104,111$, $133,139,209,241,417,5,36,38$

Authorisation... 3, 4, 6, 7, 9, 10, 11, 12, 19, 23, 24, 25, 27, $28,29,31,32,34,40,43,66,69,70,75,76,77,78$, $79,80,82,84,86,90,92,93,95,96,102,103,104$, $105,106,107,108,109,130,131,132,133,136,144$ $150,155,156,157,160,162,168,177,185,187,195$, $202,216,219,225,227,228,236,241,247,248,255$, $257,258,408,412,413$

Authority

approval.... 7, 82, 84, 97, 100, 108, 109, 115, 119, 120

$121,129,140,151,156,266,278,319,323,324$,

$326,327,336,337,375,380,389,391,421,5,19$, $21,22,23,24,30,31,32,33,61,62,72$

consent.... 4, 7, 38, 57, 79, 82, 83, 108, 114, 115, 117, $121,131,132,135,136,142,150,331,414,32,73$ determining......11, 12, 24, 45, 64, 75, 77, 79, 98, 105, $140,145,150,168,172,198,207,227,233,241$, $248,263,338,391,411,35$

ministerial $4,18,51,57,124,125,135$ Autonomisation

external 43,54

\section{B}

BBV 98,2

Board

advisory.. 116, 123, 154, 180, 182, 269, 334, 375, 415, 25

executive $33,43,44,77,118,119,121,123,125,140$, $141,142,154,182,219,266,270,271,272,273$, $274,275,276,277,278,279,338,375,381,384$, $386,387,415,421$

non executive..................118, 123, 138, 141, 142, 154

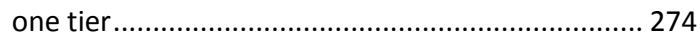

Budget law 19, 46, 47, 77, 80, 84, 86, 106, 107, 109, 160, $241,249,5$

Budget Law

Budgeting...7, 8, 18, 19, 24, 26, 27, 29, 33, 36, 38, 46, 48, $49,54,55,67,79,80,81,85,86,91,92,93,94,96$, $97,98,103,105,106,107,109,125,127,159,160$, $162,167,168,180,207,208,216,224,236,333,334$, $379,384,387,388,389,398,412,413,414,427,457$, $459,460,462,61,62$

Burgerlijk Wetboek 43, 44, 81, 141, 157, 469, 474, 483, 2

\section{C}

CBG-MEB 61,2

CBP $61,108,133,210,2,8$

CBR $112,189,2,15$

CBS $61,107,137,467,7$

CGB $24,61,108,2$

Civil law..20, 36, 43, 44, 45, 51, 52, 54, 56, 57, 60, 76, 81, $82,84,86,94,111,112,113,116,117,118,119,121$ $122,123,125,126,127,128,129,130,132,133,134$, $135,136,137,143,144,145,146,147,148,149,150$, $151,152,156,157,159,160,161,162,163,167,177$, $178,241,251,252,253,258,261,272,273,275,413$ $414,426,5,19,73$

Client $.21,22,23,118,271$ COA. $.71,254,7$

Commissariaat voor de Media ...................................... 224 Commissioning.....9, 24, 33, 51, 53, 62, 63, 64, 67, 96, 97, $114,128,145,146,147,149,155,156,157,162,163$, $184,191,192,204,229,241,246,247,248,269,273$, $274,279,322,324,373,375,385,389,398,29,40$ Commissioner 23, 64, 65, 66, 145, 146, 147, 149, 168, $171,174,180,184,213,226,247,263,375,388$, $415,416,419,27,39$ 
Comptabiliteitswet....4, 20, 43, 44, 45, 48, 55, 80, 81, 82, $83,84,85,88,91,97,109,113,133,159,412,468$, $473,475,476,2,34,36,61,62$ 1927 version $20,82,2$ 1976 version $20,82,83,85,86,2$ 2001 version. $12,19,46,47,56,66,83,85,86,87,88$, $89,91,94,95,98,133,160,178,225,255,277$, $412,413,2$

Consolidation $49,99,103,104,6$

Contract

quasi ..........67, 128, 146, 147, 148, 156, 162, 180, 415

Council of Economic Advisers. CTG. $278,279,2$ CTSV $134,178,467$ $\mathrm{CTZ}$ $278,279,2$

CWI $71,273,330,7,16$

\section{D}

Devolution 17

Dienst Wegverkeer...45, 91, 108, 201, 210, 254, 418, 3, 9 DNB $.55,56,275,418,470,2,9$

\section{E}

Economic independence $25,36,167,175,207$ Equity $6,28,48,51,88,97,100,138,144,160,163,175$, $199,337,379,429,6,19,31,37,38,61,62$

Executive agency.17, 42, 50, 52, 54, 58, 61, 98, 106, 107, $111,133,134,142,173,425,429,460,463,468,5,10$ Expenditures ... 46, 79, 92, 94, 95, 96, 104, 105, 106, 121, $124,160,219,226,227,254,277,457,30,32,73$

Expenses.... 5, 91, 94, 95, 96, 97, 101, 104, 177, 181, 184, $185,198,203,207,216,217,226,227,246,253,254$, $255,260,265,270,272,273,274,275,276,278,279$, $338,386,389,32,62$

\section{$\mathbf{F}$}

Fees

authority biased 208

fee ...... 7, 89, 90, 91, 92, 155, 200, 201, 213, 257, 271, $391,418,428,458,468,30$

Financing $197,227,453$

Funding.7, 9, 10, 11, 12, 13, 20, 24, 25, 27, 54, 62, 63, 79, $81,84,89,90,95,97,98,111,117,119,124,142$, $145,146,147,153,156,160,162,163,180,190,191$, $193,194,195,196,197,200,202,203,204,206,207$ $208,212,213,219,224,226,230,235,236,237,241$, $246,247,257,258,259,260,261,262,264,265,266$, $267,270,272,273,274,276,318,319,322,325,326$
$329,330,333,336,373,374,377,378,379,382,385$ $387,388,398,418,419,421,423,427,429,462,20$, $22,24,29,31,33,51,61,62,65,69,71,73$ funder $23,149,415,27$

\section{G}

Gemeentewet $38,90,2$

Governance. 129, 246, 266, 421, 447, 451, 452, 453, 455, $458,460,462,463,465,468,470,21,23$

diagonal. 153

vertical 153

Grondwet.42, 43, 44, 45, 57, 81, 82, 88, 89, 90, 113, 131, $132,413,454,455,2,5$

\section{H}

Hiving in $41,62,271,273,275$ Hiving off $41,191,273,278,279$ Horizontalisation 18 Hybrid

hybridity........ 28, 51, 57, 121, 131, 136, 193, 207, 459 organisations $27,28,51$

\section{I}

IBGroep $25,107,111,189,256,429,467,3,10$ IFRS $48,99,2,3$ Income transfer7, 10, 11, 22, 38, 63, 67, 72, 96, 111, 143, $189,200,211,218,222,236,245,254,261,262,263$, $267,269,270,271,273,274,275,276,277,282,317$, $318,322,324,325,329,333,334,336,337,340,347$, $374,378,379,397,408,411,420,7,31$

Income transfers. $68,142,61$ Information asymmetry 181 Input.. 24, 34, 94, 156, 180, 181, 183, 189, 221, 222, 230, $236,247,248,318,321,375,390$

IPSAS 7, 49, 55, 93, 95, 97, 99, 100, 101, 135, 199, 219, 2 , 3, 6

- Board... $93,135,467$

\section{J}

Jewish Humanitarian Fund .83

\section{K}

Kadaster 10, 28, 50, 53, 63, 136, 148, 219, 429, 451, 462, $467,473,2,9$

Kiesraad ............... 57, 60, 61, 112, 116, 133, 189, 467, 11 KvK ...................................62, 69, 251, 252, 257, 2, 10 


\section{$\mathbf{L}$}

Licencing

$68,212,236,256,261,266$

Licensing

Line item budget .....18, 95, 106, 107, 168, 216, 323, 386, 389, 391

Lump sum budget $104,105,189,212,246,247,318,319$, $325,373,375,385,388,398$

\section{M}

Maatschappelijke onderneming. 138, 455, 461, 462, 466, $469,471,483$

$\mathrm{CIC}$ 123

Market good $12,247,418$

Miljoenennota $46,474,476,478,479,5,43$

Monitoring ....68, 212, 223, 256, 261, 263, 266, 275, 347, $381,421,454,20,21,22,24,26,28,56,57,59,62$

\section{$\mathbf{N}$}

Neo Institutional economics $20,168,171,233,416$ Neo Institutional Economics168, 171, 173, 174, 185, 233 234, 241, 416, 419

Netherlands Court of Audit ... 3, 5, 6, 8, 11, 17, 18, 20, 23, $28,34,47,49,51,59,61,65,68,69,76,81,83,85$, $88,89,91,99,103,104,112,114,119,155,223,224$, $275,277,387,408,413,425,428,3,27,38,74$ NIVRA 57

Non-excludable $24,200,201,418$ Non-rival $12,24,200,201,385,418$ NPM. $27,53,61,461,464$ NV SCG 142

\section{0}

Openbare Lichamen 43

Operating costs ..... 5, 10, 11, 24, 32, 58, 65, 98, 108, 111 $144,160,218,227,252,254,271,318,320,322,323$, $324,325,326,327,329,331,333,335,336,337,338$, $374,375,376,378,380,381,382,383,385,386,388$, $389,390,408,429,21,23,65,69$

Outcome...... 23, 41, 44, 49, 63, 65, 77, 79, 83, 93, 97, 98, $104,129,159,177,180,182,184,210,211,221,271$, 330,413

Output ... 7, 21, 64, 79, 93, 94, 97, 98, 104, 105, 129, 159, $183,210,211,212,216,217,219,220,221,222,226$, $236,248,265,318,321,323,418$

Outsourcing 456 contracting out 191 tendering 57
Owner ..... 20, 21, 23, 64, 65, 66, 128, 131, 136, 139, 142, $149,150,151,156,167,168,171,175,178,179,181$, $182,183,184,199,202,234,263,416,417,419,27$, 32

ownership .....18, 21, 23, 24, 48, 55, 62, 64, 65, 66, 67, $127,129,131,142,146,150,168,171,174,176$, $178,179,184,185,269,271,272,273,274,275$, $276,278,279,281,325,347,448,455,466,35$ principal . 20, 21, 22, 23, 146, 148, 149, 154, 168, 171, $178,179,180,181,182,416,460,463$

\section{P}

Performance . 18, 221, 224, 248, 320, 323, 327, 331, 335, $338,376,380,383,386,390,398,449,452,457,459$, $462,30,66,70$

Private Law Body6, 54, 57, 81, 84, 94, 102, 116, 118, 120, $121,127,161,194,196,226,246,258,263,265,282$, $347,407,414,428,3,4,7,8,9,10,13,14,15,16,17$, 19,73

Privatisation $.53,187,188,189,202,235$ demand $22,187,203,207,235$ supply...... $187,189,196,203$

Production

mass - . 8, 209, 210, 211, 222, 228, 229, 235, 236, 248, $255,318,333,373$

serial $210,318,333$

unit - ...... $209,211,212,222,237,255$

Property Rights $149,174,175,176,452,453$

Property Rights Theory PRT $23,24,25,171,174,177,185,233,3$ abusus 177,178

Public good

impure. $8,24,230,374,378,382,418$ pure.... 8, 12, 13, 24, 25, 202, 230, 235, 247, 263, 374, $378,382,418$

Public law.8, 20, 36, 43, 44, 45, 50, 52, 54, 55, 57, 60, 62, $63,76,78,81,82,91,112,116,118,119,125,127$ $129,131,133,134,135,136,137,140,143,146,148$ $150,152,156,157,159,162,167,189,205,241,251$, $252,258,276,278,340,407,412,413$

Public Law Administration .... 6, 54, 57, 94, 102, 116, 117, $118,121,128,131,161,162,163,194,196,226,246$ $258,263,282,347,407,414,418,425,3,4,7,8,9$, $10,11,12,13,14,15,16,17,71,72,73,74$

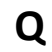

Quango $50,51,57,67,453,454,466,3,5$ 


\section{$\mathbf{R}$}

Research.... 1, 29, 30, 68, 69, 75, 167, 212, 216, 256, 261, $266,457,465,3,28$

Reserve

equalisation -....98, 102, 121, 124, 266, 322, 324, 384, $421,61,62,73$

Reserves $97,109,19,28,31,32$

Residual value. $24,100,175,185$

\section{Responsibility}

ministerial. $8,18,20,28,40,41,42,43,44,51,53,54$, $62,71,78,79,80,85,86,87,109,113,118,131$, $159,221,225,412,426,427,37$ system . $19,44,118,155,159,182,412$

Responsibility Centre...266, 320, 323, 327, 331, 335, 338, 376, 380, 383, 386, 390, 421, 61, 65, 69 Expense centre 216,217 Investment Centre. $218,220,248,266,62$ Profit Centre $218,220,266,61$ Revenue Centre. 218,220 RWT. $18,54,59,61,70,71,103,155,3,24$

\section{S}

Scheltema Committee.....18, 40, 42, 51, 62, 65, 153, 192, 470,473

Service delivery

consolidated provision $190,196,213,236$

contract provision...190, 192, 194, 196, 212, 213, 235, 236

grant provision $189,190,193,213,236$

private provision $190,196,213,236$

regulated provision .189, 190, 194, 195, 196, 213, 236 Simons Committee $20,82,470$

Sint committee 5, 8, 9, 20, 25, 26, 51, 52, 62, 65, 119, 470 SLA. $64,66,86,87,107,145,146,223,454,3,29$

Social housing associations $276,379,3$

Stakeholder ... 153

State owned enterprise. $55,56,61,71$

State participations

Stewardship

Subsidising

$68,212,256,261,265,266,28$ 197,200

\section{$\mathbf{T}$}

Taxes 4, 7, 38, 48, 68, 79, 89, 90, 91, 92, 93, 94, 101, 105, $160,187,188,190,197,200,202,203,204,205,206$, $218,219,227,235,257,258,272,330,418,447$

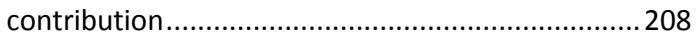

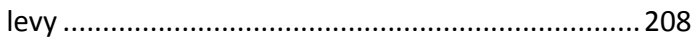

tax prices 207 TCT

Asset specificity. $172,174,233$

TenneT $142,143,16$

Transaction Cost Theory .. 3 asset specificity $172,173,174,184,212,229,233,417$ Transaction costs 172,174 Treasury $46,88,89,163,3,31,34,61,62$

\section{Z}

ZвO .... 3, 4, 5, 6, 7, 8, 9, 10, 11, 12, 13, 17, 18, 19, 23, 24, $25,28,29,30,31,32,33,34,35,37,38,40,41,45$, $46,48,51,52,53,57,58,60,61,62,63,64,65,66$, $67,68,69,70,71,72,75,76,77,78,79,80,83,84$, $86,87,88,89,90,91,92,94,95,96,97,98,99,102$, $103,104,105,106,107,108,109,111,112,113,114$, $116,117,118,119,120,121,122,123,124,125,127$, $128,129,133,134,135,136,137,138,139,140,141$, $142,143,144,145,146,147,148,149,151,152,153$, $154,155,156,157,159,160,161,162,163,167,168$, $169,171,173,174,177,178,179,183,184,185,188$, $190,191,192,193,195,196,198,201,207,208,210$, $211,212,213,216,222,223,225,227,228,229,233$, $234,235,236,237,241,242,245,246,247,248,249$, $250,251,252,253,254,255,256,257,258,259,260$, $261,263,265,267,269,271,272,273,275,276,277$, $278,296,319,320,323,327,329,331,335,338,340$, $347,376,380,383,384,386,390,400,407,408,409$, 411, 412, 413, 414, 415, 416, 417, 418, 419, 420, 421, $425,426,427,428,429,451,452,468,473,474,475$, $476,477,2,3,4,5,7,10,14,18,19,24,27,28,29$, $30,31,32,33,34,35,37,38,40,41,44,66,70,71$, $72,73,74$

Association $144,148,156,5$ Enterprise -................142, 143, 144, 148, 156, 414, 5 Foundation -... 102, 140, 144, 145, 148, 156, 157, 275, 414,17

framework law on -.... 6, 20,31, 34, 35, 43, 52, 53, 57, $67,69,70,76,87,91,94,98,102,103,104,113$, $114,115,116,118,119,120,121,122,123,124$, $125,129,135,136,140,151,153,154,159,161$, $163,178,182,183,194,225,241,245,250,251$, $252,253,254,256,258,259,260,261,262,263$, $266,267,281,316,325,340,372,392,413,415$, $420,421,427,2,7,27,35,36,37,38,42,43,46$, $47,49,51,53,54,55,57,59,60,61,62,71,73,74$ Shelter -.. 133, 134, 135, 137, 144, 145, 148, 156, 190, 226, 17

Subsidiary -............. 135, 136, 137, 144, 148, 156, 157

Ziekenfondsraad .............................................. 269, 278 
Part F: Appendices 


\section{List of abbreviations}

\begin{tabular}{|c|c|}
\hline Aanwijzingen & General instructions on legislation; Aanwijzingen voor de regelgeving; \\
\hline AW1996: $x$ & Article $x$ of ‘Aanwijzingen' 1996-2007 version \\
\hline AW2008:x & Article $x$ of 'Aanwijzingen' October 2008 version \\
\hline ACBG & Agency CBG. Operational part of CBG-MEB, has Government Agency status \\
\hline AFM & $\begin{array}{l}\text { Netherlands Authority for the financial Markets. Autoriteit Financiële Markten. } \\
\text { (ZBO) }\end{array}$ \\
\hline $\mathrm{AOB}$ & Accrual Output Budgeting (used in Australia) \\
\hline AOW & National old age pension plan, first pillar. Algemene Ouderdomswet \\
\hline AT & Agency Theory \\
\hline Awb & Dutch General Administrative law, Algemene wet bestuursrecht \\
\hline AWBZ & Medical Care insurance program. Algemene wet bijzondere ziektekosten \\
\hline BBV & Local Government Accounting Regulations, Besluit Begroting en Verantwoording \\
\hline BCFV & $\begin{array}{l}\text { Decree Centraal Fonds Volkshuisvesting. Besluit Centraal Fonds } \\
\text { Volkshuisvesting. }\end{array}$ \\
\hline $\mathrm{BCU}$ & Decree on funding of cultural activities. Bekostigingsbesluit cultuuruitingen \\
\hline BV & Besloten Vennootschap (similar to Ltd) \\
\hline BW & Dutch Civil Code, Burgerlijk wetboek \\
\hline BWX:y.z & Reference to Book X, article y, section z of Dutch Civil Code. \\
\hline CBG-MEB & Medicines Evaluation Board. College ter beoordeling van geneesmiddelen (ZBO) \\
\hline CBP & Dutch Data Protection Authority; College Bescherming Persoonsgegevens (ZBO) \\
\hline CBR & $\begin{array}{l}\text { Driving licence examination office; Centraal Bureau Rijvaardigheidsbewijzen } \\
\text { (ZBO). }\end{array}$ \\
\hline CFV & Centraal Fonds Volkshuisvesting (ZBO) \\
\hline CGB & Dutch Equal Treatment Commission; Commissie Gelijke Behandeling \\
\hline CTG & Board on health/care fees; College Tarieven Gezondheidszorg (ZBO) \\
\hline CTZ & Health insurance monitoring board; College Toezicht Zorgverzekeringen (ZBO) \\
\hline CVZ & Health Care insurance board. College voor Zorgverzekeringen (ZBO) \\
\hline CW & Government Budgeting and Accounting Act; Comptabiliteitswet \\
\hline CW1927 & Government Budgeting and Accounting Act 1927; Comptabiliteitswet 1927 \\
\hline CW1976 & Government Budgeting and Accounting Act 1976; Comptabiliteitswet 1976 \\
\hline CW1976-I & $\begin{array}{l}\text { Government Budgeting and Accounting Act } 1976 \text { before 6th revision; } \\
\text { Comptabiliteitswet 1976, voor 6e wijziging }\end{array}$ \\
\hline CW1976-II & $\begin{array}{l}\text { Government Budgeting and Accounting Act 1976, as of 6th revision; } \\
\text { Comptabiliteitswet } 1976 \text { vanaf } 6 \text { e wijziging }\end{array}$ \\
\hline CW2001 & Government Budgeting and Accounting Act 2001; Comptabiliteitswet 2001 \\
\hline CWX:y.z & Government Budgeting and Accounting Act year X, paragraph y, subparagraph z \\
\hline DNB & Dutch Central Bank De Nederlandsche Bank (hybrid ZBO) \\
\hline ESA95 & European System of Accounts 1995 \\
\hline EU & European Union \\
\hline FBKVB & $\begin{array}{l}\text { Foundation for Visual arts, design and architecture. Fonds Beeldende Kunsten, } \\
\text { Vormgeving en Bouwkunst. (ZBO) }\end{array}$ \\
\hline GA & Government Agency \\
\hline GemW & Local Government Act; Gemeentewet \\
\hline GW & Constitution; Grondwet \\
\hline IFRS & International financial reporting standards (private sector) \\
\hline IOOV & Inspection on public safety; Inspectie Openbare Orde en Veiligheid. \\
\hline IPSAS & International Public Sector Accounting Standard \\
\hline IPSASX:y.z & IPSAS nr X, paragraph y, subparagraph z \\
\hline IWI & Inspection service for work and income; Inspectie Werk en Inkomen. \\
\hline HR & Supreme Court; Hoge Raad der Nederlanden \\
\hline Kadaster & Land Registry Office. Dienst Kadaster (ZBO) \\
\hline KvK & Chamber of Commerce, Kamer van Koophandel \\
\hline kZBO & Framework Law on ZBOs; Kaderwet zelfstandige bestuursorganen \\
\hline kZBO:X & Reference to article $\mathrm{x}$ of Framework law on ZBOs \\
\hline MinBuZa & Ministry of Foreign Affairs. Ministerie van Buitenlandse Zaken \\
\hline
\end{tabular}




\begin{tabular}{|c|c|}
\hline MinBZK & $\begin{array}{l}\text { Ministry of the Interior/Home office. Ministerie van Binnenlandse Zaken en } \\
\text { Koninkrijksrelaties }\end{array}$ \\
\hline MinDEF & Ministry of Defense. Ministerie van Defensie. \\
\hline MinEZ & $\begin{array}{l}\text { Ministry of Economic Affairs/Ministry of Trade and Industry. Ministerie van } \\
\text { Economische Zaken }\end{array}$ \\
\hline MinFin & Ministry of Finance/Treasury. Ministerie van Financiën \\
\hline MinJus & Ministry of Justice. Ministerie van Justitie \\
\hline MinJG & Ministry of Youth and Family. Ministerie van Jeugd en Gezin \\
\hline MinLNV & $\begin{array}{l}\text { Ministry of Agriculture, Nature and Food quality. Ministerie van Landbouw, } \\
\text { Natuurbeheer and Voedselkwaliteit }\end{array}$ \\
\hline MinOCW & $\begin{array}{l}\text { Ministry of Education, Culture and Science. Ministerie van Onderwijs, Cultuur en } \\
\text { Wetenschappen }\end{array}$ \\
\hline MinSZW & $\begin{array}{l}\text { Ministry of Social Affairs and Employment. Ministerie van Sociale Zaken en } \\
\text { Werkgelegenheid }\end{array}$ \\
\hline MinVROM & $\begin{array}{l}\text { Ministry of Housing, Spatial Planning, and Environment. Ministerie van } \\
\text { Volkshuisvesting, Ruimtelijke Ordening en Milieubeheer }\end{array}$ \\
\hline MinVW & $\begin{array}{l}\text { Ministry of Transport, Public Works and Watermanagement. Ministerie van } \\
\text { Verkeer en Waterstaat. }\end{array}$ \\
\hline MinVWS & $\begin{array}{l}\text { Ministry of Health, Welfare and Sport. Ministerie van Volksgezondheid, Welzijn } \\
\text { en Sport }\end{array}$ \\
\hline MinWWI & $\begin{array}{l}\text { Ministry of Housing, Communities and Integration. Ministerie van Wonen, Wijken } \\
\text { en Integratie. }\end{array}$ \\
\hline MP & Member of Parliament \\
\hline NAK & $\begin{array}{l}\text { Dutch general inspection service for agricultural seeds and seed potatoes. } \\
\text { Nederlandse Algemene Keuringsdienst voor zaai en pootgoed van } \\
\text { landbouwgewassen (ZBO) }\end{array}$ \\
\hline NCA & Netherlands Court of Audit; Algemene Rekenkamer \\
\hline $\mathrm{NMa}$ & Netherlands Competition Authority. Nederlandse Mededingingsautoriteit (ZBO) \\
\hline MW & Law on competition; Mededingingswet \\
\hline NV & Naamloze Vennootschap (similar to PLC) \\
\hline NJN & Najaarsnota (2nd supplement to budget, november) \\
\hline NZA & Dutch Healthcare Authority. Nederlandse Zorgautoriteit (ZBO) \\
\hline$P \& C$ & Planning \& Control \\
\hline Vf/Pf & Participatiefonds/Vervangingsfonds. Formally 2 ZBOs but operating together. \\
\hline PLA & Public Law Agency \\
\hline PLB & Private Law Body \\
\hline PRT & Property Rights Theory \\
\hline Quango & Quasi non governmental organisation \\
\hline RAB & Resource Accounting and Budgeting (UK) \\
\hline RBBBV & $\begin{array}{l}\text { Decree on remuneration and operating costs ZBOs minVWS. Regeling } \\
\text { bezoldiging en beheerskosten bestuursorganen volksgezondheid. }\end{array}$ \\
\hline RDW & Department of Road Transport, Dienst Wegverkeer. \\
\hline RINIS & $\begin{array}{l}\text { (inter)National Information exchange institute. Routeringsinstituut } \\
\text { (inter)Nationale Informatiestromen }\end{array}$ \\
\hline RSUWI & Regulations SUWI. Regeling SUWI. \\
\hline RvR & Council for legal support. Raad voor Rechtsbijstand (ZBO) \\
\hline RWT & Legal Entity with Statutory Task; Rechtspersoon met wettelijke taak \\
\hline$R \& D$ & Research and development \\
\hline SHA & Social Housing Association; Woningcorporatie \\
\hline SLA & Service Level Agreement; Service Niveau Overeenkomst \\
\hline SRvR & $\begin{array}{l}\text { Decree on subsidising Council for legal support; Subsidiebesluit raden voor } \\
\text { Rechtsbijstand }\end{array}$ \\
\hline STE & Securities trade monitoring foundation; Stichting Toezicht Effectenverkeer. \\
\hline SUWI & $\begin{array}{l}\text { Case law on structure of social security organisation; Wet structuur } \\
\text { uitvoeringsorganisatie werk en inkomen. }\end{array}$ \\
\hline SVB & Sociale Verzekeringsbank (ZBO) \\
\hline TCT & Transaction Cost Theory \\
\hline UWV & Uitvoeringsinstituut Werknemersverzekeringen (ZBO) \\
\hline IPSAS & International Public Sector Accounting Standards \\
\hline IFRS & International Financial Reporting Standards \\
\hline IBGroep & Informatie Beheer Groep (former ZBO) \\
\hline
\end{tabular}


Decree on subsidising cultural activities. Regeling subsidies en uitkeringen cultuuruitingen

RINIS

RvS

VJN

WFT

WGA

WMG

WOPT

WRB

WSC1993

WTE

ZBO

ZPW2005

ZVW

Data exchange institute. Routeringsinstituut (inter)nationale informatiestromen Council of State, Raad van State. High Authority of State, to be consulted on every proposal for a law.

Voorjaarsnota (1st supplement to budget; June)

Law on financial monitoring. Wet op het financieel toezicht

Whole of Government Accounts

Law on market structure in the health/care sector, Wet marktordening gezondheidszorg

Law on publication of high level remuneration for publicly funded activities, Wet Openbaarheid uit publieke middelen gefinancierde topinkomens

Law on legal support; Wet op de rechtsbijstand

Law on Culture policy; Wet op het specifiek cultuurbeleid

Law on stock trading; Wet Toezicht effecten verkeer

Public body; literally: Autonomous Authoritative Body; Zelfstandig

Bestuursorgaan, see PLA and PLB

Law on agricultural seeds and plants 2005 (Zaaizaad- en Plantgoedwet 2005)

Zorgverzekeringswet; law on health care insurance 


\section{List of frequently used concepts}

Association ZBO Cabinet

Eerste Kamer

Enterprise ZBO

Foundation APB

Government

government

Minister

Parliament

Dutch Senate

Slotwet

Subsidiary APB

Tweede Kamer

Shelter APB

Regeerakkoord

Miljoenennota

Hiving off

Hiving in

Unit

Entity

Openbaar Lichaam

Slotwet

Quango

Agentschap
A ZBO that has the civil law status of an association (or similar entities) Joint assembly of Ministers under presidency of the Prime Minister

Dutch Senate/House of Lords

A ZBO that has the civil law legal status of either NV (PLC) or BV (Ltd)

A ZBO that has the civil law legal status of a foundation

Formal definition of the authority Government: King and Ministers according to section 42 of the Constitution

Description of the general public authority on the national level

The minister who is responsible and may be held accountable for the policy domain in which an APB operates. When a specific minister is meant this is made explicit, e.g. the Minister of Finance

General description of the elected bodies at the national level, consists of two Houses: House of Representatives and Senate

Eerste Kamer

Final budget act, brings authorised budget in line with realisation of spending. An Autonomous Public Body which has the status as a separate public legal entity

Dutch House of Representatives/House of commons

A ZBO without separate legal status, but part of the legal entity State.

Coalition agreement. Document stating plans of cabinet in office

Budget memorandum. Annual document presented by the Minister of Finance stating the fiscal position of the Dutch State and the general policy program for a fiscal year

Transferring activities from within government to an entity at arm's length of government

Bringing a former fully private entity under arm's length control of government Part of organisation that is specifically addressed. In ZBO context it refers to either all ZBOs or to those ZBOs that are part of the legal entity State but operate at arm's length.

Refers only to organisations that have a separate legal status. In a ZBO context using entity excludes those ZBOs that are part of the legal entity State.

Public Body as defined in constitution, article 134, not having a ZBO status.

Finalising budget law. Submitted at the end of the fiscal year to approve last changes and discharge minister for his responsibility during the fiscal year.

Quasi autonomous no governmental organisation. Refers to all forms of arm's length organisations

Similar to executive agency. Also known as 'Baten-lastendienst' 


\section{Financial definitions (Source: IPSAS, 2008)}

Cash receipts

Cash payments

Cash flow

Contributions from owners

\section{Expenses}

Revenue

Consolidation

Consolidated financial

statements

Economic entity

Segment

\author{
Cash inflows \\ Cash outflows \\ Inflows and outflows of cash
}

means future economic benefits or service potential that has been contributed to the entity by parties external to the entity, other than those that result in liabilities of the entity, that establish a financial interest in the net assets/equity of the entity, which:

(a) Conveys entitlement both to distributions of future economic benefits or service potential by the entity during its life, such distributions being at the discretion of the owners or their representatives, and to distributions of any excess of assets over liabilities in the event of the entity being wound up; and/or (b) Can be sold, exchanged, transferred or redeemed.

Decreases in economic benefits or service potential during the reporting period in the form of outflows or consumption of assets or incurrences of liabilities that result in decreases in net assets/equity, other than those relating to distributions to owners. The gross inflow of economic benefits or service potential during the reporting period when those inflows result in an increase in net assets/equity, other than increases relating to contributions from owners.

The process of preparing consolidated financial statements.

The financial statements of an economic entity presented as those of a single entity.

A group of entities comprising a controlling entity and one or more controlled entities.

A distinguishable activity or group of activities of an entity for which it is appropriate to separately report financial information for the purpose of evaluating the entity's past performance in achieving its objectives and for making decisions about the future allocation of resources. 


\section{Appendix 1A: Full list of ZBOs as of July 1, 2007}

The list presented below is adapted from MinBZK, (2007a). The modification regards grouping of entities that actually perform the same task but regionally or functionally split over a number of separate legal entities. An example is 'Kunstenfondsen' which regards of 10 separate legal entities providing income transfers in the Arts-sector. Column 2 of Table A - 1 gives the list of entities included in the cluster when in the original list of minBZK, the entities are presented separately. Column 3 indicates the status of these ZBOs under kZBO based on a letter of minBZK (Parliament, 2008b) and Column 4 indicates (an estimate of) operating turnover as presented in the annual reports 2006 of the entities. Column 5 indicates the main type of activities realised by this ZBO. The bold printed entities were involved in the case studies.

Table A - 1: ZBOs and clusters of ZBOs

\begin{tabular}{|c|c|c|c|c|c|c|c|}
\hline (Group)Name & Elements of groups & kZBO status & $\begin{array}{l}\text { (Estimated) } \\
\text { operating } \\
\text { turnover } \\
2006 \text { in } € \\
\mathrm{mln}\end{array}$ & Legal Status & $\begin{array}{l}\text { Minister } \\
\text { Principal }\end{array}$ & Activity & Remarks \\
\hline Autoriteit Financiële Markten (AFM) & - & Yes & 73 & $\operatorname{PLB}(f)^{*}$ & minFin & $\mathrm{M}$ & \\
\hline Bevoegde autoriteiten Rijnvaart & unknown & No & & & minVW & & BZK2008-list only \\
\hline Bureau beheer Landbouwgronden & - & No & 1 & $\operatorname{PLA}(\mathrm{s}) * *$ & $\min L N V$ & S & \\
\hline Bureau Financieel Toezicht & - & Yes & 5 & PLA & minJUS & $\mathrm{M}$ & \\
\hline $\begin{array}{l}\text { Centraal administratiekantoor } \\
\text { bijzondere ziektekosten }\end{array}$ & - & No & & PLB & minVWS & & BZK2008-list only \\
\hline $\begin{array}{l}\text { Centraal Bureau voor de Statistiek } \\
\text { (CBS) }\end{array}$ & - & Yes & 182 & PLA & $\min E Z$ & $\mathrm{~S}$ & \\
\hline $\begin{array}{l}\text { Centraal Fonds voor de } \\
\text { Volkshuisvesting (CFV) }\end{array}$ & - & Yes & 5 & PLA & minVROM & $\mathrm{T}$ & \\
\hline $\begin{array}{l}\text { Centraal Orgaan opvang } \\
\text { Asielzoekers (COA) }\end{array}$ & - & Yes & 501 & PLA & minJUS & $\mathrm{S}$ & \\
\hline $\begin{array}{l}\text { Centrale commissie voor } \\
\text { mensgebondenonderzoek }\end{array}$ & - & Yes & 1 & PLA (s) & minVWS & $\mathrm{R}$ & \\
\hline Centrale Landinrichtingscommissie & - & Not listed\# & 1 & PLA (s) & minLNV & $\mathrm{S}$ & \\
\hline $\begin{array}{l}\text { Centrale organisatie Werk en } \\
\text { inkomen (CWI) }\end{array}$ & - & Yes & 383 & PLA & minSZW & $\mathrm{L}$ & $\begin{array}{l}\text { merged wiht UWV in } \\
2009\end{array}$ \\
\hline
\end{tabular}




\begin{tabular}{|c|c|c|c|c|c|c|c|}
\hline (Group)Name & Elements of groups & kZBO status & $\begin{array}{l}\text { (Estimated) } \\
\text { operating } \\
\text { turnover } \\
2006 \text { in } € \\
\text { mln }\end{array}$ & Legal Status & $\begin{array}{l}\text { Minister } \\
\text { Principal }\end{array}$ & Activity & Remarks \\
\hline Centrum indicatiestellingen zorg & - & No & & & minVWS & & BZK2008-list only \\
\hline $\begin{array}{l}\text { Certificerende en } \\
\text { keuringsinstanties } \\
\text { arbeidsomstandigheden }\end{array}$ & $\begin{array}{l}\text { 23, names not disclosed, part } \\
\text { time ZBOs }\end{array}$ & Not listed & 0 & PLB & $\operatorname{minSZW}$ & $\mathrm{M}$ & \\
\hline $\begin{array}{l}\text { College Bescherming } \\
\text { Persoonsgegevens (CBP) }\end{array}$ & - & Yes & 5 & PLA (s) & minJUS & $\mathrm{R}$ & \\
\hline College Bouw Zorginstellingen & - & No & 12 & PLA & $\operatorname{minVWS}$ & $\mathrm{L}$ & \\
\hline College Sanering Zorginstellingen & - & No & 3 & PLA & minVWS & $\mathrm{T}$ & \\
\hline $\begin{array}{l}\text { College ter beoordeling van } \\
\text { geneesmiddelen }\end{array}$ & - & Yes & 1 & PLA (s) & $\operatorname{minVWS}$ & $\mathrm{L}$ & \\
\hline $\begin{array}{l}\text { College van Toezicht } \\
\text { auteursrechten en naburige } \\
\text { rechten }\end{array}$ & - & Yes & 1 & PLA (s) & minJUS & $\mathrm{M}$ & \\
\hline $\begin{array}{l}\text { College van Toezicht op de } \\
\text { Kansspelen }\end{array}$ & - & No & 1 & PLA (s) & minJus & $\mathrm{L}$ & \\
\hline $\begin{array}{l}\text { College voor de toelating van } \\
\text { bestrijdingsmiddelen }\end{array}$ & - & Yes & 7 & PLA & $\min L N V$ & $\mathrm{~L}$ & \\
\hline College voor Zorgverzekeringen & - & Yes & 52 & PLA & $\operatorname{minVWS}$ & $T$ & \\
\hline Commissariaat voor de media & - & Yes & 5 & PLA & $\operatorname{minOCW}$ & $\mathrm{M}$ & \\
\hline $\begin{array}{l}\text { Commissie Advies gevaarlijke } \\
\text { stoffen door de lucht }\end{array}$ & - & No & & & $\operatorname{minVW}$ & & BZK2008-list only \\
\hline $\begin{array}{l}\text { Commissie Algemene } \\
\text { Oorlogsongevallenregeling } \\
\text { Indonesië }\end{array}$ & - & No & 1 & PLA (s) & minVWS & $\mathrm{T}$ & \\
\hline $\begin{array}{l}\text { Commissie Eindtermen } \\
\text { Accountantsopleiding }\end{array}$ & - & Yes & & & minFin & $\mathrm{R}$ & BZK2008-list only \\
\hline $\begin{array}{l}\text { Commissie examens } \\
\text { scheepswerktuigkundigen }\end{array}$ & - & No & 1 & PLA (s) & $\operatorname{minVW}$ & $\mathrm{R}$ & \\
\hline Commissie gelijke behandeling & - & Yes & 4 & PLA (s) & minJUS & $\mathrm{R}$ & \\
\hline $\begin{array}{l}\text { Commissie Schadefonds } \\
\text { geweldsmisdrijven }\end{array}$ & - & Yes & 1 & PLA (s) & minJUS & $\mathrm{R}$ & \\
\hline Commissie Stuurliedenexamens & - & No & 1 & PLA (s) & minVW & $\mathrm{R}$ & \\
\hline $\begin{array}{l}\text { Commissie van beheer } \\
\text { Geneeskundige verzorging Politie }\end{array}$ & - & Not listed & 1 & PLA (s) & $\operatorname{minBZK}$ & $T$ & \\
\hline
\end{tabular}




\begin{tabular}{|c|c|c|c|c|c|c|c|}
\hline (Group)Name & Elements of groups & kZBO status & $\begin{array}{l}\text { (Estimated) } \\
\text { operating } \\
\text { turnover } \\
2006 \text { in } € \\
\mathrm{mln}\end{array}$ & Legal Status & $\begin{array}{l}\text { Minister } \\
\text { Principal }\end{array}$ & Activity & Remarks \\
\hline $\begin{array}{l}\text { Commissie van beroep art } 3 \text { Wet } \\
\text { rijonderricht }\end{array}$ & - & No & 1 & PLA (s) & $\operatorname{minVW}$ & $\mathrm{R}$ & \\
\hline $\begin{array}{l}\text { Commissie van beroep } \\
\text { Loodsenexamens }\end{array}$ & - & No & & & $\operatorname{minVW}$ & & BZK2008-list only \\
\hline $\begin{array}{l}\text { Commissie voor de } \\
\text { Zeevisvaartexamens }\end{array}$ & - & No & 1 & PLA (s) & $\operatorname{minVW}$ & $\mathrm{R}$ & \\
\hline $\begin{array}{l}\text { Commissies voor de } \\
\text { gebiedsaanwijzing }\end{array}$ & $\begin{array}{l}12 \text { regionally organised } \\
\text { committees }\end{array}$ & Not listed & 1 & PLA (s) & minVWS & $\mathrm{L}$ & \\
\hline $\begin{array}{l}\text { Commissies voor de samenstelling } \\
\text { van de rassenlijsten }\end{array}$ & $\begin{array}{l}5 \text { for separate groups of } \\
\text { agricultural products }\end{array}$ & Not listed & 1 & PLA (s) & $\min L N V$ & $\mathrm{~L}$ & \\
\hline De Nederlandsche Bank (DNB) & - & Yes & 90 & PLB & $\operatorname{minFIN}$ & $\mathrm{M}$ & \\
\hline $\begin{array}{l}\text { Dienst voor het kadaster en } \\
\text { openbare registers (Kadaster) }\end{array}$ & - & Yes & 225 & PLA & minVROM & $\mathrm{L}$ & \\
\hline Dienst Wegverkeer (RDW) & - & Yes & 181 & PLA & $\operatorname{minVW}$ & $\mathrm{L}$ & \\
\hline $\begin{array}{l}\text { Erkende particuliere } \\
\text { onderzoeksbureaus } \\
\text { Schepenbesluit }\end{array}$ & 7 & Not listed & 0 & PLB & $\operatorname{minVW}$ & $\mathrm{M}$ & \\
\hline Erkenninghouders APK & numerous, unknown & No & 0 & PLB & minVW & $\mathrm{M}$ & \\
\hline $\begin{array}{l}\text { Examencommissie amateur } \\
\text { radiozendexamens }\end{array}$ & - & No listed & 1 & PLA (s) & minEZ & $\mathrm{R}$ & \\
\hline $\begin{array}{l}\text { Examencommissie } \\
\text { Certificaatloodsen }\end{array}$ & - & No & 1 & PLA (s) & $\operatorname{minVW}$ & $\mathrm{R}$ & \\
\hline $\begin{array}{l}\text { Examencommissie voor maritieme } \\
\text { radiocommunicatie }\end{array}$ & - & Not listed & 1 & PLA (s) & minEZ & $\mathrm{R}$ & \\
\hline Examencommissies Luchtvaart & - & No & & & minVW & & BZK2008-list only \\
\hline Faunafonds & - & Yes & 2 & PLA & minLNV & $\mathrm{T}$ & \\
\hline Fonds MKZ-Al & - & No & & & minLNV & & BZK2008-list only \\
\hline Gerechtsdeurwaarders & numerous, unknown & Not listed & 0 & PLB & minJUS & $\mathrm{R}$ & \\
\hline Grondkamers & 6 , regionally organised & Yes & 1 & PLA (s) & minLNV & $\mathrm{R}$ & \\
\hline $\begin{array}{l}\text { Herinrichtingscommissie Oost- } \\
\text { Groningen en de Gronings-Drentse } \\
\text { Veenkoloniën }\end{array}$ & - & No & 1 & PLA (s) & $\operatorname{minLNV}$ & $\mathrm{R}$ & \\
\hline Hiswa Vereniging & - & No & 0 & PLB & minVW & $\mathrm{L}$ & \\
\hline
\end{tabular}




\begin{tabular}{|c|c|c|c|c|c|c|c|}
\hline (Group)Name & Elements of groups & kZBO status & $\begin{array}{l}\text { (Estimated) } \\
\text { operating } \\
\text { turnover } \\
2006 \text { in } € \\
\mathrm{mln}\end{array}$ & Legal Status & $\begin{array}{l}\text { Minister } \\
\text { Principal }\end{array}$ & Activity & Remarks \\
\hline Huurcommissies & 59 & Yes & 1 & PLA (s) & minVROM & $\mathrm{R}$ & $\begin{array}{l}\text { in } 2010 \text { merged into } \\
\text { one ZBO }\end{array}$ \\
\hline IJkbevoegden & unknown & Not listed & 0 & PLB & $\min E Z$ & $\mathrm{M}$ & \\
\hline Informatie Beheer Groep (IBGroep) & - & No & 148 & PLA & minOCW & $T$ & $\begin{array}{l}\text { in } 2010 \text { merged with } \\
\text { executive agency } \\
\text { and lost ZBO status }\end{array}$ \\
\hline Kamer voor de binnenvisserij & - & No & 1 & PLA (s) & minLNV & $\mathrm{R}$ & \\
\hline Kamers van Koophandel & 20 , regional jurisdictions & Yes & 200 & PLA & $\min E Z$ & $\mathrm{~L}$ & \\
\hline $\begin{array}{l}\text { Kenniscentra beroepsonderwijs } \\
\text { bedrijfsleven }\end{array}$ & unknown & No & & & minOCW & & BZK2008-list only \\
\hline $\begin{array}{l}\text { Keuringsinstanties art } 10.3 \\
\text { Telecommunicatiewet }\end{array}$ & 6 & Not listed & 0 & PLB & $\min E Z$ & $\mathrm{M}$ & \\
\hline Keuringsinstanties bouwproducten & unknown & No & 0 & PLB & minVROM & $\mathrm{M}$ & \\
\hline Keuringsinstanties geluidshinder & unknown & No & 0 & PLB & minVROM & $\mathrm{M}$ & \\
\hline $\begin{array}{l}\text { Keuringsinstanties } \\
\text { pleziervaartuigen }\end{array}$ & 3 & No & 0 & PLB & $\operatorname{minVW}$ & $\mathrm{M}$ & \\
\hline $\begin{array}{l}\text { Keuringsinstanties uitrusting } \\
\text { Zeeschepen }\end{array}$ & 5 & No & 0 & PLB & $\operatorname{minVW}$ & $\mathrm{M}$ & \\
\hline Keuringsinstanties V\&W overig & 4 & No & 0 & PLB & minVW & $\mathrm{M}$ & \\
\hline Keuringsinstanties VWS & 7 & No & 0 & PLB & minVWS & $\mathrm{M}$ & \\
\hline
\end{tabular}




\begin{tabular}{|c|c|c|c|c|c|c|c|}
\hline (Group)Name & Elements of groups & kZBO status & $\begin{array}{l}\text { (Estimated) } \\
\text { operating } \\
\text { turnover } \\
2006 \text { in } € \\
\text { mln }\end{array}$ & Legal Status & $\begin{array}{l}\text { Minister } \\
\text { Principal }\end{array}$ & Activity & Remarks \\
\hline $\begin{array}{l}\text { Keuringsinstellingen } \\
\text { Landbouwproducten }\end{array}$ & $\begin{array}{l}\text { Stichting Nederlandse } \\
\text { Algemene Kwaliteitsdienst } \\
\text { voor de Tuinbouw (NAK-T) } \\
\text { Stichting } \\
\text { Bloembollenkeuringsdienst } \\
\text { Stichting Nederlandse } \\
\text { Algemene Keuringsdienst voor } \\
\text { Zaaizaad en Pootgoed } \\
\text { Landbouwgewassen (NAK) } \\
\text { Stichting Centraal Orgaan voor } \\
\text { Kwaliteitsaangelegenheden in } \\
\text { de Zuivel } \\
\text { Stichting Controlebureau voor } \\
\text { Pluimvee, Eieren en } \\
\text { Eiproducten Stichting } \\
\text { Kwaliteitscontrolebureau voor } \\
\text { Groenten en Fruit } \\
\text { Stichting SKAL }\end{array}$ & Yes & $70-75$ & & $\min L N V$ & $\mathrm{M}$ & $\begin{array}{l}\text { Listed separately by } \\
\text { minBZK }\end{array}$ \\
\hline Kiesraad & - & No & 1 & PLA (s) & $\min B Z K$ & $\mathrm{R}$ & \\
\hline Koninklijke Bibliotheek & - & No & 41 & PLA & $\operatorname{minOCW}$ & $\mathrm{S}$ & \\
\hline $\begin{array}{l}\text { Koninklijke Nederlandse Academie } \\
\text { van Wetenschappen (KNAW) }\end{array}$ & - & No & 134 & PLA & $\operatorname{minOCW}$ & $\mathrm{R}$ & \\
\hline
\end{tabular}




\begin{tabular}{|c|c|c|c|c|c|c|c|}
\hline (Group)Name & Elements of groups & kZBO status & $\begin{array}{l}\text { (Estimated) } \\
\text { operating } \\
\text { turnover } \\
2006 \text { in } € \\
\text { mln }\end{array}$ & Legal Status & $\begin{array}{l}\text { Minister } \\
\text { Principal }\end{array}$ & Activity & Remarks \\
\hline Kunstenfondsen & $\begin{array}{l}\text { Mondriaan Stichting } \\
\text { Stichting Fonds Beeldende } \\
\text { Kunsten, Vormgeving en } \\
\text { Bouwkunst (FBKVB) } \\
\text { Stichting Fonds voor } \\
\text { Amateurkunst en } \\
\text { Podiumkunsten (2008: } \\
\text { Cultuurparticipatie) } \\
\text { Stichting Fonds voor de } \\
\text { Scheppende Toonkunst } \\
\text { (2008: Podiumkunsten+) } \\
\text { Stichting Fonds voor } \\
\text { Podiumprogrammering en } \\
\text { marketing (2008: } \\
\text { Podiumkunsten +) } \\
\text { Stichting Nederlands Fonds } \\
\text { voor de Film } \\
\text { Stichting Stimuleringsfonds } \\
\text { voor Architectuur } \\
\text { Stichting Fonds voor de } \\
\text { Letteren } \\
\text { Stichting Nederlands Literair } \\
\text { Productie- en Vertalingenfonds } \\
\text { Stimuleringsfonds } \\
\text { Nederlandse Culturele } \\
\text { Omroepproducties }\end{array}$ & Yes & 10 & & $\min O C W$ & $T$ & $\begin{array}{l}\text { Listed separately by } \\
\text { minBZK }\end{array}$ \\
\hline $\begin{array}{l}\text { Landelijk Bureau Inning } \\
\text { Onderhoudsbijdragen (LBIO) }\end{array}$ & - & Yes & 9 & PLA & minJUS & $\bar{T}$ & \\
\hline $\begin{array}{l}\text { Landelijk Selectie- en } \\
\text { Opleidingsinstituut Politie } \\
\text { (Politieacademie) }\end{array}$ & - & Yes & 174 & PLA & $\min B Z K$ & $\mathrm{R}$ & \\
\hline $\begin{array}{l}\text { Landelijke commissie Toezicht } \\
\text { indicatiestelling }\end{array}$ & - & Not listed & 1 & PLA (s) & $\operatorname{minOCW}$ & $\mathrm{R}$ & \\
\hline
\end{tabular}




\begin{tabular}{|c|c|c|c|c|c|c|c|}
\hline (Group)Name & Elements of groups & kZBO status & $\begin{array}{l}\text { (Estimated) } \\
\text { operating } \\
\text { turnover } \\
2006 \text { in } € \\
\mathrm{mln}\end{array}$ & Legal Status & $\begin{array}{l}\text { Minister } \\
\text { Principal }\end{array}$ & Activity & Remarks \\
\hline $\begin{array}{l}\text { Landelijke en regionale } \\
\text { examencommissies } \\
\text { verkeersinformatie en } \\
\text { verkeersaanwijzingen }\end{array}$ & unknown & No & 0 & PLB & minVW & $\mathrm{R}$ & \\
\hline $\begin{array}{l}\text { Landelijke geschillencommissie } \\
\text { weer samen naar school }\end{array}$ & - & No & 1 & PLA (s) & $\operatorname{minOCW}$ & $\mathrm{R}$ & \\
\hline $\begin{array}{l}\text { Luchtverkeersleiding Nederland } \\
\text { (LVNL) }\end{array}$ & - & Yes & 163 & PLA & $\operatorname{minVW}$ & $\mathrm{S}$ & \\
\hline $\begin{array}{l}\text { Medisch-etische } \\
\text { toetsingscommissies }\end{array}$ & $\begin{array}{l}33 \text { regionally organised } \\
\text { committees }\end{array}$ & No & 1 & PLA (s) & $\operatorname{minVWS}$ & $\mathrm{R}$ & \\
\hline $\begin{array}{l}\text { Nationale Commissie voor } \\
\text { Internationale Samenwerking en } \\
\text { Duurzame ontwikkeling (NCDO) }\end{array}$ & - & No & $3-5$ & PLA & $\operatorname{minBuZa}$ & $\mathrm{R}$ & \\
\hline $\begin{array}{l}\text { Nederlands Bureau } \\
\text { Brandweerexamens }\end{array}$ & - & Yes & 3 & PLA & $\operatorname{minBZK}$ & $\mathrm{R}$ & \\
\hline $\begin{array}{l}\text { Nederlands instituut voor } \\
\text { Brandweer en Rampenbestrijding } \\
\text { (Nibra) }\end{array}$ & - & Yes & 24 & PLA & $\operatorname{minBZK}$ & $\mathrm{R}$ & $\begin{array}{l}\text { In } 2010 \text { known as } \\
\text { Nederlands instituut } \\
\text { voor Fysieke } \\
\text { Veiligheid }\end{array}$ \\
\hline Nederlands Meetinstituut BV & - & Yes & 33 & PLB & minEZ & $\mathrm{M}$ & \\
\hline Nederlandse loodsencorporatie & - & No & & & minVW & & BZK2008-list only \\
\hline Nederlandse Medediningsautoriteit & - & Yes & 36 & & $\min E Z$ & $\mathrm{M}$ & \\
\hline $\begin{array}{l}\text { Nederlandse Omroep Stichting } \\
\text { (NOS) }\end{array}$ & - & No & 105 & PLB (f) & $\operatorname{minOCW}$ & $T$ & \\
\hline $\begin{array}{l}\text { Nederlandse Organisatie voor } \\
\text { Toegepast Natuurwetenschappelijk } \\
\text { onderzoek (TNO) }\end{array}$ & - & No & 583 & PLA & $\operatorname{minOCW}$ & $\mathrm{R}$ & \\
\hline $\begin{array}{l}\text { Nederlandse organisatie voor } \\
\text { Wetenschappelijk onderzoek } \\
\text { (NWO) }\end{array}$ & - & Yes & 35 & PLA & $\operatorname{minOCW}$ & $T$ & \\
\hline $\begin{array}{l}\text { Nederlandse Transplantatie } \\
\text { Stichting }\end{array}$ & - & Yes & 21 & PLB (f) & $\operatorname{minVWS}$ & S & \\
\hline Nederlandse Zorgautoriteit & - & Yes & 25 & PLA & minVWS & $\mathrm{M}$ & \\
\hline
\end{tabular}




\begin{tabular}{|c|c|c|c|c|c|c|c|}
\hline (Group)Name & Elements of groups & kZBO status & $\begin{array}{l}\text { (Estimated) } \\
\text { operating } \\
\text { turnover } \\
2006 \text { in } € \\
\text { mln }\end{array}$ & Legal Status & $\begin{array}{l}\text { Minister } \\
\text { Principal }\end{array}$ & Activity & Remarks \\
\hline $\begin{array}{l}\text { Nederlands-Vlaamse Accreditatie } \\
\text { organisatie voor het hoger } \\
\text { onderwijs }\end{array}$ & - & Yes & 6 & PLA & $\operatorname{minOCW}$ & $\mathrm{M}$ & \\
\hline Notarissen & unknown & Not listed & 0 & PLB & minJUS & $\mathrm{R}$ & \\
\hline $\begin{array}{l}\text { Onafhankelijke Post- en } \\
\text { Telecommunicatie Autoriteit (OPTA) }\end{array}$ & - & Yes & 17 & PLA & $\min E Z$ & $\mathrm{M}$ & \\
\hline Onderzoeksraad voor Veiligheid & - & Yes & 8 & PLA & $\operatorname{minBZK}$ & $\mathrm{R}$ & \\
\hline $\begin{array}{l}\text { Openbare Academische } \\
\text { Ziekenhuizen }\end{array}$ & 6 & Not listed & 512 & PLA & minOCW & $\mathrm{R}$ & $\begin{array}{l}\text { Excluding regular } \\
\text { medical services } \\
\text { and } 2 \text { similar private } \\
\text { hospitals also not } \\
\text { included. }\end{array}$ \\
\hline $\begin{array}{l}\text { Organisatie ter verbetering van de } \\
\text { binnenvisserij }\end{array}$ & - & Not listed & 1 & PLA (s) & $\min L N V$ & $\mathrm{R}$ & \\
\hline Pensioen- en Uitkeringsraad & - & No & 27 & PLA & minVWS & $\mathrm{T}$ & \\
\hline Pensioenuitvoerders & 87 & No & & PLB & $\operatorname{minSZW}$ & & BZK2008-list only \\
\hline Raad voor de plantenrassen & - & Yes & 2 & PLA (S) & minLNV & $\mathrm{L}$ & \\
\hline $\begin{array}{l}\text { Raad voor het korps landelijke } \\
\text { politiediensten }\end{array}$ & - & Not listed & 1 & PLA (s) & $\min B Z K$ & Other & \\
\hline Raden voor Rechtsbijstand & $\begin{array}{l}\text { RvR Amsterdam } \\
\text { RvR Arnhem } \\
\text { RvR ‘s Gravenhage } \\
\text { RvR ‘s Hertogenbosch } \\
\text { RvR Leeuwarden }\end{array}$ & Yes & 74 & PLA & minJUS & $T$ & $\begin{array}{l}\text { In } 2009 \text { merged into } \\
\text { one ZBO. }\end{array}$ \\
\hline $\begin{array}{l}\text { Reconstructiecommissie Midden- } \\
\text { Delfland }\end{array}$ & - & No & 1 & PLA (s) & $\min L N V$ & $\mathrm{~S}$ & \\
\hline Regionale loodsencorporaties & unknown & No & & & $\operatorname{minVW}$ & & BZK2008-list only \\
\hline $\begin{array}{l}\text { Regionale verwijzingscommissies } \\
\text { voortgezet onderwijs }\end{array}$ & unknown & No & 1 & PLB & $\operatorname{minOCW}$ & $\mathrm{R}$ & \\
\hline $\begin{array}{l}\text { Registratiecommissies en } \\
\text { opleidingscolleges KNMG, KNMP } \\
\text { en NMT }\end{array}$ & 10 & No & 0 & PLB & $\operatorname{minVWS}$ & L & \\
\hline Rijkshavenbeheerders & unknown & No & 1 & PLA (s) & minVW & $\mathrm{S}$ & \\
\hline Rijkshavenmeesters & unknown & No & 1 & PLA (s) & minVW & & \\
\hline
\end{tabular}




\begin{tabular}{|c|c|c|c|c|c|c|c|}
\hline (Group)Name & Elements of groups & kZBO status & $\begin{array}{l}\text { (Estimated) } \\
\text { operating } \\
\text { turnover } \\
2006 \text { in } € \\
\text { mln }\end{array}$ & Legal Status & $\begin{array}{l}\text { Minister } \\
\text { Principal }\end{array}$ & Activity & Remarks \\
\hline Sociale Verzekeringsbank & - & Yes & 270 & & $\operatorname{minSZW}$ & $\mathrm{T}$ & \\
\hline Staatsbosbeheer & - & No & 136 & PLA & $\min L N V$ & $\mathrm{~S}$ & \\
\hline Staatsexamencommissie & - & No & 1 & PLA (s) & $\operatorname{minOCW}$ & $\mathrm{R}$ & \\
\hline Staatsexamencommissie NT-2 & & No & & & minOCW & & BZK2008-list only \\
\hline $\begin{array}{l}\text { Stichting Administratie } \\
\text { Indonesische Pensioenen }\end{array}$ & - & No & 1 & PLB (f) & $\operatorname{minBZK}$ & $T$ & \\
\hline $\begin{array}{l}\text { Stichting Airport coordination } \\
\text { Netherlands }\end{array}$ & - & Yes & 1 & PLB (f) & $\operatorname{minVW}$ & S & \\
\hline Stichting Argonaut & - & No & & PLB (f) & minVWS & & BZK2008-list only \\
\hline $\begin{array}{l}\text { Stichting Borgstellingsfonds voor } \\
\text { de Landbouw }\end{array}$ & - & Yes & 1 & PLB (f) & $\min L N V$ & $T$ & \\
\hline $\begin{array}{l}\text { Stichting Bureau } \\
\text { Architectenregister }\end{array}$ & - & Yes & 1 & PLB (f) & minVROM & $\mathrm{L}$ & \\
\hline $\begin{array}{l}\text { Stichting Centraal Bureau } \\
\text { Rijvaardigheidsbewijzen (CBR) }\end{array}$ & - & Yes & 89 & PLB (f) & minVW & $\mathrm{L}$ & \\
\hline $\begin{array}{l}\text { Stichting Donorgegevens } \\
\text { Kunstmatige Bevruchting }\end{array}$ & - & Yes & 1 & PLB (f) & minJUS & $S$ & \\
\hline $\begin{array}{l}\text { Stichting Erkenningregeling } \\
\text { koeltechniek }\end{array}$ & - & Not listed & 0 & PLB (f) & minVROM & $\mathrm{L}$ & \\
\hline $\begin{array}{l}\text { Stichting Examenbureau } \\
\text { Beroepsvervoer }\end{array}$ & - & No & 0 & $\operatorname{PLB}(\mathrm{f})$ & $\operatorname{minVW}$ & $\mathrm{R}$ & \\
\hline $\begin{array}{l}\text { Stichting Examens } \\
\text { Vakbekwaamheid honden- en } \\
\text { kattenbesluit }\end{array}$ & - & Not listed & 0 & PLB (f) & $\min L N V$ & $\mathrm{R}$ & \\
\hline $\begin{array}{l}\text { Stichting Fonds Patiënten } \\
\text { Gehandicapten en Ouderen (Fonds } \\
\text { PGO) }\end{array}$ & - & No & 2 & PLB (f) & minVWS & $T$ & \\
\hline $\begin{array}{l}\text { Stichting Fonds Vrijwillig vervroegd } \\
\text { uittreden overheidspersoneel } \\
\text { (VutFonds) }\end{array}$ & - & No & 0 & $\operatorname{PLB}(\mathrm{f})$ & $\min B Z K$ & $T$ & \\
\hline Stichting Het Gebaar & - & No & 1 & PLB (f) & minVWS & $T$ & \\
\hline $\begin{array}{l}\text { Stichting inschrijving Eigen Vervoer } \\
\text { (SIEV) }\end{array}$ & - & No & 0 & PLB (f) & minVW & $\mathrm{L}$ & \\
\hline Stichting Joods Humanitair Fonds & - & No & 0 & PLB (f) & $\operatorname{minFIN}$ & $T$ & \\
\hline
\end{tabular}




\begin{tabular}{|c|c|c|c|c|c|c|c|}
\hline (Group)Name & Elements of groups & kZBO status & $\begin{array}{l}\text { (Estimated) } \\
\text { operating } \\
\text { turnover } \\
2006 \text { in } € \\
\text { mln }\end{array}$ & Legal Status & $\begin{array}{l}\text { Minister } \\
\text { Principal }\end{array}$ & Activity & Remarks \\
\hline Stichting Koppeling & - & No & & PLB (f) & minVWS & & BZK2008-list only \\
\hline Stichting Maror-gelden Overheid & - & No & 0 & PLB (f) & $\operatorname{minFIN}$ & $\mathrm{T}$ & \\
\hline $\begin{array}{l}\text { Stichting Nationale en } \\
\text { Internationale Wegvervoer } \\
\text { organisatie }\end{array}$ & - & Yes & 4 & PLB (f) & $\operatorname{minVW}$ & $\mathrm{L}$ & \\
\hline Stichting Nidos & - & No & 0 & PLB (f) & minJUS & Other & \\
\hline $\begin{array}{l}\text { Stichting Ontwikkelings- en } \\
\text { saneringsfonds voor de Landbouw }\end{array}$ & - & Yes & 1 & PLB (f) & minLNV & $T$ & \\
\hline $\begin{array}{l}\text { Stichting Ontwikkelings- en } \\
\text { saneringsfonds voor de Visserij }\end{array}$ & - & Yes & 1 & PLB (f) & $\min L N V$ & $T$ & \\
\hline $\begin{array}{l}\text { Stichting opleiding maatschappij en } \\
\text { gezondheid }\end{array}$ & - & No & & PLB (f) & minVWS & & BZK2008-list only \\
\hline $\begin{array}{l}\text { Stichting Rechtsherstel Sinti en } \\
\text { Roma }\end{array}$ & - & No & 0 & PLB (f) & minVWS & $\mathrm{T}$ & \\
\hline $\begin{array}{l}\text { Stichting scheepsafvalstoffen en } \\
\text { vaardocumenten }\end{array}$ & - & No & & PLB(f) & minVW & & BZK2008-list only \\
\hline $\begin{array}{l}\text { Stichting Stimuleringsfonds } \\
\text { openbare gezondheidszorg }\end{array}$ & - & Not listed & 0 & PLB (f) & minVWS & $T$ & \\
\hline $\begin{array}{l}\text { Stichting Uitvoering } \\
\text { omslagregelingen WTZ }\end{array}$ & - & No & 3 & PLB (f) & $\operatorname{minVWS}$ & $T$ & \\
\hline Stichting VAM & - & Yes & 0 & PLB (f) & minVW & $\mathrm{R}$ & \\
\hline Stichting VAMEX & - & Yes & & PLB (f) & minVW & $\mathrm{R}$ & BZK2008-list only \\
\hline Stichting Vf/Pf & $\begin{array}{l}\text { Stichting Vervangingsfonds } \\
\text { Stichting Participatiefonds }\end{array}$ & Yes & 13 & PLB (f) & $\operatorname{minOCW}$ & $T$ & \\
\hline $\begin{array}{l}\text { Stichting Waarborgfonds Eigen } \\
\text { Woningen }\end{array}$ & - & No & 4 & PLB (f) & minVROM & $T$ & \\
\hline $\begin{array}{l}\text { Stichting Ziektekostenverzekering } \\
\text { Krijgsmacht }\end{array}$ & - & No & 1 & PLB (f) & $\min D E F$ & $T$ & \\
\hline Stimuleringsfonds voor de pers & - & Yes & 1 & PLA & minOCW & $T$ & \\
\hline TenneT (EnerQ + Certiq) & - & No & 7 & PLB & $\min E Z$ & $\mathrm{~S}$ & \\
\hline $\begin{array}{l}\text { Uitvoeringsinstituut } \\
\text { Werknemersverzeke-ringen (UWV) }\end{array}$ & - & Yes & 1,811 & PLA & $\operatorname{minSZW}$ & $T$ & $\begin{array}{l}\text { In } 2009 \text { merged with } \\
\text { CWI. }\end{array}$ \\
\hline Uitvoeringsorganen AWBZ & $\begin{array}{l}65 \text { private health insurance } \\
\text { companies }\end{array}$ & No & 163 & PLB & $\operatorname{minVWS}$ & $T$ & \\
\hline
\end{tabular}




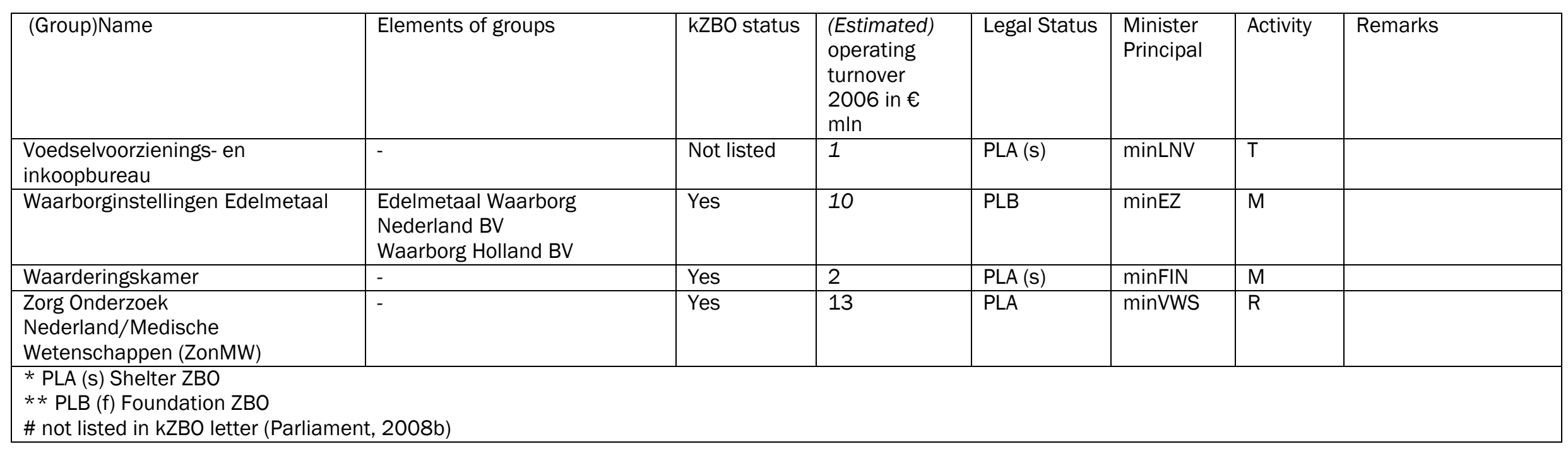




\section{Appendix 1B: Legal basis of selected ZBOs}

Table A - 2: Legal basis of selected ZBOs

\begin{tabular}{|c|c|c|c|c|}
\hline Name & Legal basis & Character legal basis & $\begin{array}{l}\text { Original version present } \\
\text { legislation* }\end{array}$ & Last change \\
\hline AFM & $\begin{array}{l}\text { Wet Toezicht Effectenverkeer 1995, art 40; } \\
\text { Overdrachtsbesluit Wet toezicht effectenverkeer } \\
1995 .\end{array}$ & Decree based on Program Law & 1995 & $\begin{array}{l}2002 \text { change legal } \\
\text { entity name }\end{array}$ \\
\hline CFV & Woningwet, art. 71 & Program Law & Decree, 1992 & 2001 \\
\hline CVZ & Zorgverzekeringswet, art. 58 & Program Law & 2006 & 2006 \\
\hline FBKVB & Wet op het specifiek cultuurbeleid, art. 9 & Mandate based on program law & 1993 & 1998 \\
\hline NAK & $\begin{array}{l}\text { Zaaizaad- en Plantgoedwet 2005, art. } 19 \text { and 89; } \\
\text { Besluit aanwijzing toezichthouders Zaaizaad- en } \\
\text { plantgoedwet } 2005\end{array}$ & Decree based on Program law & 2005 & none \\
\hline NMa & Mededingingswet, art. 2 & Program Law & 1998 & 2005, ZBO-status \\
\hline NZA & Wet Marktordening Gezondheidszorg, art. 3 & Program Law & 2006 & none \\
\hline Vf/Pf & $\begin{array}{l}\text { Wet Primair Onderwijs, art. } 183 \text { and 184; } \\
\text { Besluit Participatiefonds } \\
\text { Besluit Vervangingsfonds }\end{array}$ & Decree based on Program Law & 1996 & 2004 \\
\hline RvR & Wet op de Rechtsbijstand, art. 2 & Program Law & 1995 & 2003 \\
\hline SVB & $\begin{array}{l}\text { Wet Structuur uitvoeringsorganisatie werk en } \\
\text { inkomen, art } 2\end{array}$ & Organisation Law & 2002 & none \\
\hline UWV & $\begin{array}{l}\text { Wet Structuur uitvoeringsorganisatie werk en } \\
\text { inkomen, art } 2\end{array}$ & Organisation Law & 2002 & none \\
\hline
\end{tabular}




\section{Appendix 2: Documents requested for preparation of interviews}

1. Most recent version of statutes in case of a private law ZBO (PLB)

2. Management (performance) contracts and decrees on mandates

3. General instructions on planning and control

4. Letter of approval of the annual report 2006 as well as separate documents regarding approval of allocation of (excess) equity/reserves.

5. Budget instructions or other documents from the parent ministry that are used to prepare the budget for fiscal year 2008.

6. Approval document budget or fees fiscal 2008

7. Most recent interim report to the minister on fiscal 2007. 


\section{Appendix 3: Documents used in interviews}

This appendix provides an overview of documents received and studied in relation to the interviews. Legislation is available at http://wetten.overheid.nl/zoeken. Parliamentary documents can be found at https://zoek.officielebekendmakingen.nl/zoeken/parlementaire documenten;. If other documents are publicly available, the website is referred to.

\section{AFM}

\section{a. Legislation}

Law on securitiestrading 1995

Decree monitoring securities trading, withdrawn, October 2007

Revised Statutes Stichting AFM, May 31, 2006

Transformation decree Law on securities trading

Regulation monitoring costs law on securities trading, fiscal 2000

Decree determining percentages of monitoring costs law on securities trading, fiscal 2003

Law on financial monitoring (as of October2006)

Regulation on funding Financial Monitoring ((December 19, 2003)

Decree funding Financial monitoring (October 12, 2006)

Executive regulations Financial monitoring

b. Other documents

Policy and priorities document 2007-2009, No date

Annual report 2007 AFM, most recently retrieved on June 20, 2010 from

http://www.afm.nl/layouts/afm/default.aspx /medi a/files/jaarverslag/afm-2007.ashx

Budget 2008 AFM, dated November 30, 2007, most recently retrieved on June 20,2010 from

http://www.afm.nl/layouts/afm/default.aspx /medi a/files/begroting/begroting-2008.ashx

Report 'Maat houden' referring to proportional calculation of monitoring fees. Staatscourant, May 10, 2000.

\section{CFV}

\section{a. Legislation}

Law on Housing

Decree of October 17, 1988. Regards subsidising, monitoring and policy decrees to be issued by CFV

\section{b. Other documents}

Annual report 2006

Letter minVROM: Approval annual report 2006. dated June 20, 2007, CST/FEZ/2007053681 4th Quarterly report 2007. Dated February 2008

Annual report 2007
Wet Toezicht Effectenverkeer 1995

Besluit Toezicht Effectenverkeer 1995, ingetrokken, Oktober 2007.

Gewijzigde Statuten Stichting AFM, 31 mei 2006 Overdrachtsbesluit Wet Toezicht Effectenverkeer 1995

Regeling Toezichtskosten Wet Toezicht Effectenverkeer 1995, jaar 2000.

Vaststellingsregeling percentages toezichtskosten Wet Toezicht Effectenverkeer 1995 voor het jaar 2003.

Wet Financieel Toezicht

Regeling bekostiging Financieel Toezicht, 19 december 2003

Besluit bekostiging Financieel Toezicht 12 oktober 2006

Uitvoeringsregeling WFT

Beleid en prioriteiten AFM. Periode 2007-2009.

Geen datum

Jaarverslag 2007 AFM

Begroting 2008 AFM

Maat houden. Bekendmaking van het kader voor de doorberekening van toelatings- en handhavingskosten, Staatscourant, 10 mei 2000

\section{Woningwet}

Besluit van 17 oktober 1988, tot vaststelling van een algemene maatregel van bestuur krachtens artikel 59 , vijfde lid van de Woningwet.

CFV Jaarverslag 2006

Goedkeuring jaarstukken CFV 2006, 20 Juni 2007, CST/FEZ/2007053681

Centraal Fonds Volkshuisvesting. Vierde kwartaalrapportage 2007. Februari 2008 CFV Jaarverslag 2007 


\section{CFV}

Budget and multiyear budget 2008-2012. Dated October 2007

Letter minVROM: Approval budget 2008. Dated December 14, 2007. CST/FEZ2007/120677

Advice: monitoring SHAs. (Schilder Committee), dated June 20, 2006

Monitoring document minVROM, version 2008

Monitoring arrangement CFV, May 15, 2006

Document on main operations CFV 2008.

\section{CVZ}

\section{a. Legislation}

Health insurance law

Regulation on remuneration and operating costs authoritative bodies in the public health sector.

\section{b. Other documents}

Annual report 2006,

http://www.cvz.nl/resources/CVZ_jaarverslag2006 tcm28-23044.pdf visited Oct 28, 2008

Annual report CVZ program funds 2006,

http://www.cvz.nl/resources/rpt0704\%20financieel -jaarverslag 2006 tcm28-23012.pdf visited Oct 28, 2008

Letter minVWS: Approval annual report 2006, dated Aug 23, 2007, MC-U-2786671

Budget 2007 CVZ

Letter minVWS: Budget 2007 CVZ, dated Oct. 16, 2006, Z/VU-2723653

Letter minVWS: Budget 2007, dated March 15, 2007, MC-U-2750381

Annual report 2007, http://www.cvz.nl/resources/Jaarverslag2007 tcm 28-26706.pdf visited Oct 28, 2008

Annual report CVZ program funds 2007, http://www.cvz.nl/resources/financieeljaarverslag2 007 tcm28-26303.pdf visited Oct 28, 2008

Letter minVWS: approval annual report 2007, dated July 28, 2008, MC-U-2861077

Budget $2008 \mathrm{CVZ}$,

http://www.cvz.nl/resources/CVZ\%20Jaarplan\%202 008 tcm28-25517.pdf, visited Oct 28, 2008

Letter minVWS: Approval budget 2008, dated March 31, 2008, MC-U2839442

Letter minVWS: Governance structure CVZ as of 2007, dated April 28, 2006, Z/VU-2677612 Information provision document VWS-CVZ, dated Dec 21, 2007

Governance arrangement between CVZ and minVWS, dated Dec 21, 2007, including appendix

http://www.publiekverantwoorden.nl/rapporten/visi tatierapport CVZ.pdf , visited Oct 28, 2008 Handvestgroep publiek verantwoorden: Report on assessment of CVZ. Dated March 2007.
Begroting 2008 en meerjarenprognose 2008 tot en met 2012 Centraal Fonds Volkshuisvesting, oktober 2007

Begroting 2008 inclusief voorgestelde heffingsbijdrage. 14 december 2007. CST/FEZ2007/120677

Advies toezicht op woningcorporaties (Commissie Schilder), dated 20 Juni, 2006

Toezicht op basis van vertrouwen.

Uitvoeringstoezicht op zelfstandige organisaties 2008

Toezichtsarrangement Centraal Fonds voor de Volkshuisvesting. 15 mei 2006

Overzicht primaire processen CFV 2008

\author{
Zorgverzekeringswet \\ Regeling bezoldiging en beheerskosten \\ bestuursorganen volksgezondheid
}

Jaarverslag 2006 CVZ

Financieel Jaarverslag Fondsen CVZ 2006

Goedkeuring Jaarrekening 2006, 23 augustus 2007, MC-U-2786671

Jaarplan 2007 CVZ.

Jaarplan 2007 CVZ, 16 Oktober 2006, Z/VU-

2723653

Jaarplan en begroting 2007, 15 maart 2007, MC-U2750381

Jaarverslag 2007 CVZ

Financieel Jaarverslag Fondsen CVZ 2007

Goedkeuring Jaarverantwoording 2007, 28 juli 2008, MC-U-2861077

Jaarplan 2008 CVZ

Goedkeuring Jaarplan/Begroting 2008, 31 maart 2008, MC-U2839442

Bestuursmodel CVZ m.i.v. 2007, 28 April 2006, Z/VU-2677612

Informatiestatuut VWS-CVZ, 21 december 2007.

Governance arrangement tussen het College voor Zorgverzekeringen en het ministerie van VWS, 21 december 2007, inclusief bijlagen

Verslag van de visitatie van het College voor Zorgverzekeringen. Maart, 2007.

Handvestgroep Publiek Verantwoorden. Verslag van de visitatie van het College voor Zorgverzekeringen, maart 2007 


\section{FBKVB}

\section{a. Legislation}

Law on culture policy 1993

Statutes, dated April 29, 1997

Decree on funding cultural activities

Decree on subsidising and payment of cultural activities

\section{b. Other documents}

Annual report 2006 most recently retrieved on June 20, 2010 from

http://www.fondsbkvb.nl/downloads/jaarverslagen/ jaarverslag 2006.pdf

Letter minOCW on assessment annual report 2006, dated November 23, 2007

Letter minOCW on funding procedures fiscal 2009-

2012, dated November 19, 2007

Accountibility document, dated April 2005

Mandate to director, dated April 17, 2007

Mandate to deputy director, dated April 17, 2007

Mandate to controller/CFO, dated April 17, 2007

Funding decision by minOCW fiscal 2005-2008,

dated November 28, 2003

\section{NAK}

\section{a. Legislation}

Law on agricultural seeds and plants 2005

Announcement NAK-statutes, dated December 11, 2007.

Mandate to director Plantenziektenkundige Dienst, dated August 27, 2007

Mandate to Plantenziektenkundige Dienst and monitoring institutions, dated August 31, 2007

Regulation fees Plantenziektenkundige Dienst and monitoring institutions, dated August 21, 2007

Decree on trading agricultural seeds, dated

December 8, 2005

Decree on appointment of civil servants monitoring Law on plant diseases, dated August 31, 2007

\section{b. Other documents}

Letter minLNV: Approval statement of accounts 2006. Dated September 10, 2007 ,

TRCJZ/2007/2854

Annual report 2007 NAK. last retrieved on June 20, 2010 from

http://www.nak.nl/documents/NAK\%20Jaarverslag2007\%20definitief.pdf

Letter minLNV: approval fees 2008. Dated April 11, 2008. TRCJZ/2008/1015

Letter minLNV: General criteria on assessment of fees. Dated June 6, 2007. TRCDL/2007/1529

Letter minLNV: instruction on treasury management. Dated August 26, 2004. TRCFEZ/2004/2521

Monitoring and information protocol NAK, dated June 4, 2004. Based on old legislation.

Letter minLNV: draft mandate. Dated June 8, 2007,
Wet specifiek cultuurbeleid

Statuten,

Bekostigingsbesluit cultuuruitingen

Regeling subsidies en uitkeringen cultuuruitingen.

Jaarverslag 2006

Beoordeling jaarverantwoording 2006

Subsidieprocedure 2009-2012 cultuurfondsen.

Handboek verantwoording cultuursubsidies

Fondsen,

Mandaatbesluit directie

Mandaatbesluit adjunct directeur

Mandaatbesluit hoofd financiële zaken

Subsidiebeschikking periode 2005-2008

Zaaizaad en Plantgoedwet 2005

Bekendmaking Statuten Nak, 11 december 2007.

Mandaatbesluit LNV Directeur

Plantenziektenkundige Dienst, 27 augustus 2007

Mandaatbesluit LNV Plantenziektenkundige Dienst en de keuringsdiensten, 31 augustus 2007

Regeling tarieven Plantenziektenkundige Dienst en de keuringsdiensten, 21 augustus 2007

Besluit verhandeling teeltmateriaal, 8 december 2005

Besluit Aanwijzing ambtenaren en personen belast met toezicht Plantenziektenwet, 31 augustus 2007.

Goedkeuring financieel jaarverslag 2006. 10

september 2007, TRCJZ/2007/2854

Jaarverslag 2007 NAK.

Goedkeuring tarieven 2008. 11 april 2008.

TRCJZ/2008/1015

Algemene criteria beoordeling fytosanitaire tarieven.

6 juni 2007. TRCDL/2007/1529

Aanwijzing rechtspersonen met een beperkte kasbeheerfunctie. 26 augustus 2004.

TRCFEZ/2004/2521

Aansturings- en informatieprotocol Nederlandse

Algemene Keuringsdienst voor zaaizaad en

pootgoed van Landbouw gewassen. 4 juni 2004

(oude regelgeving)

Letter minLNV: aanbieding concept mandaatbesluit 
TRCJZ/2007/1887

Multiyear agreement minLNV and NAK on tasks assigned. Dated June 15, 2007, TRCJZ/2007/1974 Management Statute, dated November 13, 2007. Company profile 2007. 75 years Nak.

\section{$\mathrm{NMa}$}

\section{a. Legislation}

Law on competition

Decree on NMa fees

Governance arrangement minEZ-NMa.

Staatscourant, 20 december 2005 nr 247, p. 14 Information exchange arrangement minEZ-NMa, dated December 8, 2005. WJZ 5719432

\section{b. Other documents}

Annual report 2007, last retrieved on June 20 , 2010 from

http://www.nmanet.nl/Images/Jaarverslag\%20NMa

\%202007\%20integraal_tcm16-113025.pdf

\section{NZA}

\section{a. Legislation}

Law on market structure health sector

Decree on governance structure NZA 2007, dated

December 17, 2007

Appendix 1 to Decree of December 17, 2007

Appendix 2 to Decree of December 17, 2007.

Provisional Governance regulations NZA. Dated September 29, 2006. MC/MO-2716649

Governance regulations NZA. Dated March 7, 2007, MC-U-2753768

Regulation on remuneration and operating costs authoritative bodies in the public health sector.

\section{b. Other documents}

Annual report 2007 part 1. last retrieved on June 20, 2010 from

http://www.nza.nl/104107/141620/NZa-

jaarverslag-2007.pdf

Annual report 2007 part 2. last retrieved on June 20, 2010 from

http://www.nza.nl/104107/141620/NZa-

jaarverslag-2007.pdf

Statement of accounts 2007. Dated March 7, 2008.

Letter minVWS: approval annual report 2007. dated July 28, 2008, MC-U-2866567

Letter minVWS: instructions budget 2008 , dated July 12, 2007, MC-U-2784765

Information arrangement VWS-NZA, October 2, 2006.

Budget and activities 2008 NZA, December 17, 2007
Plantkeur. 8 Juni 2007, TRCJZ/2007/1887

Meerjarige overeenkomst Plantkeur tussen minLNV en NAK, 15 Juni 2007, TRCJZ/2007/1974

Directiestatuut, 13 november 2007

Bedrijfsinformatie 2007. 75 Jaar Nak

Mededingingswet.

Besluit kostenverhaal NMa

Relatiestatuut EZ-NMA. Staatscourant, 20 december 2005 nr 247, p. 14

Regeling gegevensuitwisseling NMA-EZ, 8 december 2005. WJZ 5719432

NMa Jaarverslag 2007

Wet marktordening gezondheidszorg

Besluit organisatie, mandaat, volmacht en machtiging NZa 2007, 17 december 2007.

Bijlage 1 bij Besluit organisatie etc: Werkwijze NZA: Sturing en verantwoording. Juli 2007. OV/8608240 Bijlage 2 bij Besluit organisatie etc: Rechtspositie personeel. OV/8608238

Voorlopig Bestuursreglement van de Nederlandse Zorgautoriteit, zoals vastgesteld op grond van artikel 124 , derde lid, van de Wet marktordening gezondheidszorg door de Minister van Volksgezondheid, Welzijn en Sport bij brief van 29 september 2006, nr MC/MO-2716649

Bestuursreglement Nederlandse Zorgautoriteit. 7 maart 2007, MC-U-2753768

Regeling bezoldiging en beheerskosten bestuursorganen volksgezondheid

NZA in beeld. Jaarverslag 2007.

Jaarverslag 2007. Verantwoordingsdocument. last retrieved on June 20, 2010 from http://www.nza.nl/104107/141620/NZajaarverslag-2007.pdf

Nederlandse Zorgautoriteit. Jaarrekening 2007. 7 maart 2008.

Letter minVWS: goedkeuring jaarverantwoording 2007. 28 juli 2008, MC-U-2866567

Letter minVWS: aandachtspunten voor de begroting en werkprogramma 2008, 12 juli, 2007, MC-U2784765

Informatiestatuut VWS-NZA, 2 oktober 2006

Werkprogramma 2008 en begroting 2008 NZA, 17 december 2007 


\section{NZA}

Letter minVWS: approval budget 2008. Dated September 16, 2008. MC-U-2875463

Document on activities NZA 2008, no date.

\section{RvR}

\section{a. Legislation \\ Law on legal support}

b. Other documents

Letter minJUS: Framework 2006. Dated July 13, 2005. 5360843/05/DTR

Budget 2006 RvR The Hague

Letter minJUS: Funding 2006. Approval of budget.

Dated February 6, 2006. 5401576/06/DTR

Letter minJUS: supplement on funding 2006. Dated

November 28, 2006. 5455481/06/DIRR

Statement of accounts RvR 2006 The Hague.

Letter minJUS: finalising funding 2006/approval

annual report 2006. Dated February 15, 2008.

5530374/08

Report external auditor RvR The Hague 2006.

February 28, 2007.

Management letter 2006 external auditor RvR The Hague. February 28, 2007.

Letter minJUS: Framework 2007. Dated July 19, 2006. 5432104/06/DRB

Draft Annual report 2007 The Hague Branch, version March 21, 2008

Budget 2007, Estimate 2006, Dated October 11, 2006. Management document

Budget 2007. Draft for approval to Board. Dated October 11, 2006.

Letter minJUS: Funding 2007. Approval of budget. Dated February 28, 2007. 5469527/07/DIRR Letter minJUS: supplement on funding 2007. Dated November 28, 2007. 5517170/07

Management letter external auditor RvR The Hague 2007. February 7, 2008. (powerpoint presentation) Report external auditor RvR The Hague 2007. February 7, 2008. (powerpoint presentation) Reassessment of funding system 2001. No date Letter minJUS: management summary reporting. Dated March 26, 2008. 5536985/08. Including appendix full report.

Letter minJUS: Financial reporting. Dated April 25, 2003. 5222491/803

Benchmark Group. Benchmark RvR 2006/2007. March 2007. including appendices.

Memo dated September 15, 2006 on internal benchmark 2005.

Memo dated May 9, 2007 on internal benchmark 2005/2006

Memo dated August 21, 2007. Budget 2008

Budget 2008. No date

Monitoring document minJUS, dated January 2, 2007.
Letter minVWS: goedkeuring werkprogramma en begroting (2008). 16 september 2008. MC-U2875463

Consultatiedoucment NZA agenda 2008, geen datum.

Wet op de rechtsbijstand.

Kaderbrief 2006. 13 juli 2005. 5360843/05/DTR

Jaarplan en begroting 2006. RvR Den Haag.

Subsidiebrief 2006. 6 februari 2006.

5401576/06/DTR

Aanvullende subsidiebrief 2006. 28 november 2006. 5455481/06/DIRR

Jaarrekening 2006 RvR Den Haag.

Subsidievaststelling 2006. Goedkeuring jaarverslag. 15 februari 2008. 5530374/08

Rapport van bevindingen accountant RvR Den Haag 2006. 28 februari 2007

Management letter accountant RvR Den Haag 2006. 28 februari 2007

Kaderbrief 2007. 19 juli 2006. 5432104/06/DRB

Concept jaarverslag RvR Den Haag. 21 maart 2008.

Begroting 2007/Raming 2006. 11 oktober 2006.

Concept jaarplan 2007. Ter goedkeuring voor de Raad. 11 Oktober 2006.

Subsidiebrief 2007. 28 februari 2007.

5469527/07/DIRR

Aanvullende subsidiebrief 2007. 28 november 2007. 5517170/07

Management letter accountant RvR Den Haag 2007. 7 februari 2008 (powerpoint)

Rapport van bevindingen accountant RvR Den Haag 2007. 7 februari 2008 (powerpoint)

Herijking bekostigingsysteem 2001.

aangepaste management samenvatting verantwoord gerapporteerd. 26 maart 2008. 5536985/08.

Integraal rapport ook beschikbaar.

Financiële verantwoording. 25 april 2003.

5222491/803

Rijksbrede benchmark. Benchmark RvR 2006/2007. met bijlagen.

Memo 15 september 2006. Concept Benchmark Raden 2005.

Memo 9 mei 2007. interne benchmark 2005-2006.

Memo 21 augustus 2007. Jaarplan 2008. Jaarplan/Begroting 2008. Raad voor Rechtsbijstand. Financieel-economisch toezichtsstatuut ZBO's, RWT's en overige instellingen. DFEZ, 2 januari 2007. 


\section{SVB}

\section{a. Legislation}

Law on structure work and income (SUWI)

Decree on experimenting SUWI.

Decree SUWI

Regulations SUWI

\section{b. Other documents}

Letter minSZW. Approval annual report 2006. Dated May 16, 2007. UB/A/2007/9895

Letter minSZW. Framework for budget 2007. Dated

April, 26, 2006. UB/A/2006/32722

3rd Quarter report SVB 2007, Dated November

2007

3rd Quarter policy report 2007. Dated November

2007

Annual report 2007.

Budget and multiyear plan 2008-2012. Dated

September 2007.

Letter minSzW. Approval budget 2008. Dated

November 30, 2007. UB/A/2007/32307

Handvestgroep publiek verantwoorden: Report on

assessment of SVB. Dated December 2005

\section{UWV}

\section{a. Legislation}

Law on structure work and income (SUWI)

Decree on experimenting SUWI.

Decree SUWI

Regulations SUWI

b. Other documents

Letter minSZW. Framework budget 2007 and

multiyear budget 2008-2011. no date.

UB/A/2006/32704

UWV 3rd Quarter report 2007. Dated November

2007. Most recently retrieved on June 20, 2010

from

http://www.uwv.nl/Images/UWV\%20drie\%20kwarta

lenverslag\%202007_tcm26-149944.pdf

Annual report 2007. Most recently retrieved on June

20,2010 from

http://www.uwv.nl/Images/UWV\%20jaarverslag\%20

2007 tcm26-161481.pdf

Letter UWV advisory board on annual report 2007.

Dated March 18, 2008.

Draft letter minSZW on macro economic variables to be used in budget 2008 .

Letter minSZW. Approval budget 2008. Dated

November 28, 2007. UB/A/2007/32634.

Letter minSZW. Framework budget 2009. no date.

UB/A/2008/11415

Letter minSZW. Change in Regulations SUWI. Dated

February 26, 2008. UB/A/2008/5815
Wet SUWI

Besluit experimenten SUWI

Besluit SUWI

Regeling SUWI

Jaarverslag 2006. Goedkeuringsbrief. 16 mei 2007 UB/A/2007/9895

Kaders voor (concept) jaarplan 2007; de meibrief.

26 april 2006. UB/A/2006/32722

De SVB in de eerste drie kwartalen van 2007.

November 2007.

Kwartaalbericht SVB. Beleidsverantwoording.

November 2007

SVB Jaarverslag 2007

Meerjarenplanning 2008 tm 2012. September 2007

Definitief jaarplan 2008. 30 november 2007. UB/A/2007/32307

Handvestgroep publiek verantwoorden. Verslag van de visitatie van de Sociale verzekeringsbank.

Wet SUWI

Besluit experimenten SUWI

Besluit SUWI

Regeling SUWI

Kader van (concept) jaarplan 2007 en (concept) meerjarenbeleidsplan 2008-2011: de meibrief. UB/A/2006/32704

UWV drie kwartalenverslag 2007. November 2007.

Jaarverslag 2007.

Brief Raad van advies over jaarverslag 2007. 18 Maart 2008.

Concept brief macro-economische variabelen en concept meerjarenkader.

Jaarplan UWV 2008. 28 november 2007.

UB/A/2007/32634

Meibrief 2009. UB/A/2008/11415

Wijziging regeling SUWI. 26 februari 2008.

UB/A/2008/5815 


\section{$\mathrm{Vf} / \mathrm{Pf}$}

\section{a. Legislation}

Law on primary education

Statutes Vf, dated June 21, 1999

Statutes Pf, dated June 23, 1999

Decree Vf, dated November 7, 1994

Decree Pf, dated June 14, 1996.

\section{b. Other documents}

Annual report $2006 \mathrm{Vf}$

Annual report $2006 \mathrm{Pf}$

4th Quarterly report 2007 Vf

4th Quarterly report 2007 Pf

Monitoring and management agreement minoCW-Pf

Monitoring and management agreement minOCW-Vf
Wet Primair onderwijs

Statuten Stichting Vervaningsfonds, 21 juni 1999

Statuten Stichting Participatiefonds, 23 juni 1999

Besluit Vervangingsfonds, 7 november 1994

Besluit Participatiefonds, 14 juni 1996

Jaarverslag 2006 Vervangingsfonds

Jaarverslag 2006 Participatiefonds

Vervangingsfonds, Financiële rapportage, Oct 2007dec 2007

Participatiefonds, Financiële rapportage, Oct 2007dec 2007

Beheersovereenkomst Participatiefonds voor het onderwijs

Beheersovereenkomst Vervangingsfonds en

bedrijfsgezondheidszorg voor het onderwijs 2008 


\section{Appendix 4: Questionnaire ZBOs and parent ministries}

The questions below were the basis for semi structured interviews and have a set of preset answers to make classification of the answers given in the interviews for reasons of comparison possible. Most questions were post both to ministries and ZBOs. When otherwise, an indication is given with respect to whom the question was posed.

Table A - 3: Questionnaire ZBOs and answer classes.

\begin{tabular}{|c|c|}
\hline \multirow{2}{*}{\multicolumn{2}{|c|}{$\begin{array}{l}\text { General Questions } \\
\text { Name of ZBO }\end{array}$}} \\
\hline & \\
\hline Is ZBO subject to kZBO & Yes/No \\
\hline Interviewee + function & Open end question \\
\hline How was the ZBO created? & $\begin{array}{l}\text { By law } \\
\text { Based on law } \\
\text { By statute through minister } \\
\text { By statute, minster \& third party } \\
\text { By statute through third party supported by minister } \\
\text { By statute through third party only }\end{array}$ \\
\hline What was the motive for creating this ZBO & $\begin{array}{l}\text { Mass production } \\
\text { Independent/Impartial judgement } \\
\text { Cooperation with third parties }\end{array}$ \\
\hline Is the formally given motive also the actual motive & Yes/No/don't know \\
\hline \multicolumn{2}{|l|}{ Ownership } \\
\hline $\begin{array}{l}\text { Who is to be regarded as the owner of the ZBO and } \\
\text { why }\end{array}$ & $\begin{array}{l}\text { Minister } \\
\text { Secretary General } \\
\text { Director General } \\
\text { Citizens/companies } \\
\text { Board }\end{array}$ \\
\hline $\begin{array}{l}\text { Who is to be regarded as the commissioner and } \\
\text { funder of the ZBO }\end{array}$ & $\begin{array}{l}\text { State, directly } \\
\text { State, but citizens generates demand } \\
\text { Other public sector entity } \\
\text { Citizen/company, within framework given by state } \\
\text { Don't know }\end{array}$ \\
\hline $\begin{array}{l}\text { Who is to be regarded as the final user of the ZBO's } \\
\text { services }\end{array}$ & $\begin{array}{l}\text { State, directly } \\
\text { Society as a whole } \\
\text { Individual citizen } \\
\text { Companies/organisations } \\
\text { Don't know }\end{array}$ \\
\hline \multicolumn{2}{|l|}{ Authority and governance structure } \\
\hline $\begin{array}{l}\text { What role did Parliament have on the attribution } \\
\text { and distribution of authority in relation to this ZBO } \\
\text { (ministry only) }\end{array}$ & $\begin{array}{l}\text { Accepted proposed law } \\
\text { Amended proposed law } \\
\text { Changed proposed law by asking questions } \\
\text { Don't know } \\
\text { Not applicable }\end{array}$ \\
\hline $\begin{array}{l}\text { Did Parliament discuss the distribution of authority } \\
\text { at another stage than when it discussed creation of } \\
\text { the ZBO (ministry only) }\end{array}$ & $\begin{array}{l}\text { Yes, based on NCA reports } \\
\text { Yes, based on incidents } \\
\text { Yes, based on evaluations } \\
\text { Yes, otherwise } \\
\text { No } \\
\text { Don't know }\end{array}$ \\
\hline $\begin{array}{l}\text { In the case of FAPK and NAK, separate mandate } \\
\text { decrees exist. Other ZBOs that are governed by the } \\
\text { same laws have no separate decrees. Can you } \\
\text { elaborate on the background of these decrees? } \\
\text { (ministry only) }\end{array}$ & Open end question \\
\hline
\end{tabular}




\begin{tabular}{|c|c|}
\hline $\begin{array}{l}\text { What document describes the authority for the } \\
\text { management of the ZBO }\end{array}$ & $\begin{array}{l}\text { Law } \\
\text { Statute } \\
\text { Separate management contract } \\
\text { Otherwise } \\
\text { Don't know }\end{array}$ \\
\hline $\begin{array}{l}\text { When did the minister uses his authority on the } \\
\text { following issues most recently: } \\
\text { a. Approve policy rules } \\
\text { b. Suspend or dismiss a decision of the ZBO } \\
\text { c. Approve asset transactions } \\
\text { d. Approve the creation of reserves } \\
\text { e. Use his powers in case of negligence }\end{array}$ & $\begin{array}{l}\text { Fiscal } 2007 \\
\text { Fiscal } 2006 \\
\text { Before fiscal } 2006 \\
\text { Not at all } \\
\text { Don't know }\end{array}$ \\
\hline $\begin{array}{l}\text { Did the minister directly or indirectly use other tools } \\
\text { than the authority attributed to him in order to } \\
\text { achieve his goals }\end{array}$ & Open end question \\
\hline $\begin{array}{l}\text { What is the frequency of using authoritative power } \\
\text { by the minister }\end{array}$ & $\begin{array}{l}\text { More frequent than monthly } \\
\text { Monthly } \\
\text { Quarterly } \\
\text { Semi annually } \\
\text { Annually } \\
\text { Incidentally } \\
\text { Don't know }\end{array}$ \\
\hline What powers are used & Open end question \\
\hline $\begin{array}{l}\text { Does the governance structure include other forms } \\
\text { of monitoring than those attributed to the minister }\end{array}$ & $\begin{array}{l}\text { Yes, internal monitoring structure } \\
\text { Yes, separate external monitoring institution } \\
\text { No } \\
\text { Don't know }\end{array}$ \\
\hline $\begin{array}{l}\text { If so, is there a representative on behalf of the } \\
\text { minister included in these other governance } \\
\text { structures? }\end{array}$ & $\begin{array}{l}\text { Yes, civil servant parent ministry } \\
\text { Yes, civil servant minFin } \\
\text { Yes, civil servant minBZK } \\
\text { Yes, civil servants from several ministries } \\
\text { No }\end{array}$ \\
\hline $\begin{array}{l}\text { Can you describe the role of these other governance } \\
\text { structures within the whole governance structure of } \\
\text { the ZBO }\end{array}$ & Open end question \\
\hline \multicolumn{2}{|l|}{ Tasks assigned } \\
\hline What is according to you the main task of the ZBO & $\begin{array}{l}\text { Stewardship, } \\
\text { Income transfer } \\
\text { Monitoring } \\
\text { Research/Examination } \\
\text { Licensing } \\
\text { Otherwise }\end{array}$ \\
\hline Can you qualify secondary tasks of the ZBO & $\begin{array}{l}\text { Stewardship, } \\
\text { Income transfer } \\
\text { Monitoring } \\
\text { Research/Examination } \\
\text { Licensing } \\
\text { Otherwise } \\
\text { No secondary task }\end{array}$ \\
\hline $\begin{array}{l}\text { Do the different tasks of the ZBO result in conflicts } \\
\text { of interest }\end{array}$ & $\begin{array}{l}\text { Not at all } \\
\text { Sometimes } \\
\text { Regularly } \\
\text { Frequently } \\
\text { No secondary task }\end{array}$ \\
\hline $\begin{array}{l}\text { Are arrangements made to cope with prioritising the } \\
\text { different activities of the ZBO }\end{array}$ & $\begin{array}{l}\text { Yes, namely.... } \\
\text { No arrangements } \\
\text { Not applicable }\end{array}$ \\
\hline $\begin{array}{l}\text { How important is specific knowledge available in } \\
\text { your staff relevant for executing your tasks (ZBO } \\
\text { only) }\end{array}$ & \\
\hline
\end{tabular}




\begin{tabular}{|c|c|}
\hline $\begin{array}{l}\text { To what extent is flexibility in hiring and assigning } \\
\text { staff to tasks an important issue in your } \\
\text { organisation (ZBO only) }\end{array}$ & \\
\hline $\begin{array}{l}\text { Would it be possible to transfer tasks your } \\
\text { organisation is executing presently to another } \\
\text { organisation and if so, under what conditions (ZBO } \\
\text { only) }\end{array}$ & \\
\hline Commissioning & \\
\hline $\begin{array}{l}\text { How would you qualify commissioning a task to this } \\
\text { ZBO in terms of performance and funding }\end{array}$ & $\begin{array}{l}\text { Rule driven, quantity and price leading } \\
\text { Rule driven, available budget leading } \\
\text { SLA leading, budget follows } \\
\text { Resources leading } \\
\text { Don't know }\end{array}$ \\
\hline $\begin{array}{l}\text { Where (in what kind of document) are the } \\
\text { arrangements made on performance to be realised } \\
\text { laid down }\end{array}$ & $\begin{array}{l}\text { Unilateral budget letter from ministry } \\
\text { SLA } \\
\text { Budget proposal bottom up } \\
\text { No explicit arrangements } \\
\text { Don't know }\end{array}$ \\
\hline $\begin{array}{l}\text { What is the role of the minister in the process of } \\
\text { commissioning }\end{array}$ & $\begin{array}{l}\text { Funder \& specifying SLA } \\
\text { Partially funding \& specifying SLA } \\
\text { Partially funding, no SLA } \\
\text { SLA only }\end{array}$ \\
\hline $\begin{array}{l}\text { What is the frequency of institutionalised meetings } \\
\text { between the minister and the Board of the ZBO }\end{array}$ & $\begin{array}{l}\text { Monthly } \\
\text { Quarterly } \\
\text { Semi-annually } \\
\text { Annually } \\
\text { Incidentally } \\
\text { Don't know }\end{array}$ \\
\hline $\begin{array}{l}\text { What is the frequency of meetings between civil } \\
\text { servants and ZBO on matters such as } \\
\text { commissioning }\end{array}$ & $\begin{array}{l}\text { More frequent than monthly } \\
\text { Monthly } \\
\text { Quarterly } \\
\text { Semi annually } \\
\text { Annually } \\
\text { Incidentally } \\
\text { Don't know }\end{array}$ \\
\hline $\begin{array}{l}\text { What is the frequency of meetings between civil } \\
\text { servants and ZBO on operational issues }\end{array}$ & $\begin{array}{l}\text { More frequent than monthly } \\
\text { Monthly } \\
\text { Quarterly } \\
\text { Semi annually } \\
\text { Annually } \\
\text { Incidentally } \\
\text { Don't know }\end{array}$ \\
\hline $\begin{array}{l}\text { Which control tools does the minister use in case no } \\
\text { commissioning document exists }\end{array}$ & Open end question \\
\hline $\begin{array}{l}\text { What will happen when the ZBO indicates that its } \\
\text { operational budget is insufficient to realised the } \\
\text { performance specified in the commissioning } \\
\text { document }\end{array}$ & $\begin{array}{l}\text { Report to minister } \\
\text { Shift activities to next year, no additional resources } \\
\text { Shift activities to next year, including additional } \\
\text { resources } \\
\text { Neither shift nor additional resources } \\
\text { Renegotiate budget } \\
\text { Report in annual report } \\
\text { Civil law based effects } \\
\text { Don't know }\end{array}$ \\
\hline $\begin{array}{l}\text { Do measures exist for coping with adapting } \\
\text { performance specifications or tasks during a fiscal } \\
\text { year. }\end{array}$ & $\begin{array}{l}\text { Budget=Budget } \\
\text { Report in intermediate reports } \\
\text { Report in annual report } \\
\text { Adapt SLA } \\
\text { No measures taken } \\
\text { Don't know }\end{array}$ \\
\hline
\end{tabular}




\begin{tabular}{|c|c|}
\hline $\begin{array}{l}\text { Are tasks assigned in the form of an additional } \\
\text { commission document? }\end{array}$ & Yes/no \\
\hline $\begin{array}{l}\text { Are arrangements made how to cope with } \\
\text { additionally commissioned tasks }\end{array}$ & Open end question \\
\hline $\begin{array}{l}\text { Is the ZBO asked in advance to assess the } \\
\text { operational impact of a change in the contents of } \\
\text { tasks (uitvoeringstoets) }\end{array}$ & $\begin{array}{l}\text { Yes } \\
\text { No, change is joint project of ZBO and ministry } \\
\text { No, } \\
\text { Don't know }\end{array}$ \\
\hline $\begin{array}{l}\text { Is the assessment by the ZBO on the operational } \\
\text { impact of changes in tasks presented to and } \\
\text { discussed in Tweede Kamer }\end{array}$ & $\begin{array}{l}\text { Yes, TK is informed } \\
\text { Yes, document is debated in TK } \\
\text { No } \\
\text { Not applicable } \\
\text { Don't know }\end{array}$ \\
\hline $\begin{array}{l}\text { Is the impact on operational resources from } \\
\text { changes in the program discussed in Tweede Kamer }\end{array}$ & $\begin{array}{l}\text { Yes } \\
\text { No, not part of assessment } \\
\text { No } \\
\text { Not applicable } \\
\text { Don't know }\end{array}$ \\
\hline $\begin{array}{l}\text { Does the ZBO perform activities that are not derived } \\
\text { from laws (non-legal tasks) }\end{array}$ & Yes/no \\
\hline $\begin{array}{l}\text { Which arrangements have been made on pricing } \\
\text { and monitoring with respect to non-legal tasks. }\end{array}$ & $\begin{array}{l}\text { Operate separate accounts } \\
\text { Arrangements on fees and cost recoverage } \\
\text { No arrangements, market determines fees } \\
\text { Not applicable } \\
\text { Don't know }\end{array}$ \\
\hline $\begin{array}{l}\text { Which arrangements have been made to provide } \\
\text { tasks by the ZBO to other ministries of central } \\
\text { government }\end{array}$ & $\begin{array}{l}\text { Always approval in advance } \\
\text { Approval afterwards } \\
\text { Not allowed } \\
\text { No arrangements made } \\
\text { Not applicable } \\
\text { Don't know }\end{array}$ \\
\hline $\begin{array}{l}\text { Which arrangements have been made to provide } \\
\text { tasks by the ZBO to other organisations, not being } \\
\text { part of central government }\end{array}$ & $\begin{array}{l}\text { Always approval in advance } \\
\text { Approval afterwards } \\
\text { Not allowed } \\
\text { No arrangements made } \\
\text { Not applicable } \\
\text { Don't know }\end{array}$ \\
\hline $\begin{array}{l}\text { Who determines the degrees of freedom a ZBO has } \\
\text { in developing new services }\end{array}$ & $\begin{array}{l}\text { Minister as a result of demand in TK } \\
\text { Minister given the ministry's programs } \\
\text { Initiative bottom up } \\
\text { Not applicable } \\
\text { Don't know }\end{array}$ \\
\hline \multicolumn{2}{|l|}{ Preparing budget for next fiscal year } \\
\hline $\begin{array}{l}\text { Who decides on the assumptions required to } \\
\text { prepare the budget for the next fiscal year }\end{array}$ & $\begin{array}{l}\text { Minister of parent ministry } \\
\text { Multiple commissioners } \\
\text { Bottom up from ZBO } \\
\text { Don't know }\end{array}$ \\
\hline What is included under these assumptions & $\begin{array}{l}\text { Wage/price index, Net result, Performance standard } \\
\text { (quantity of services), Cost standard (prices), other } \\
\text { assumptions (each of these items may be } \\
\text { mentioned) }\end{array}$ \\
\hline $\begin{array}{l}\text { What is the ultimate decisive factor for approval or } \\
\text { determining of the budget by the minister }\end{array}$ & $\begin{array}{l}\text { Full cost recovering fee } \\
\text { Production level and quality } \\
\text { Total expenditures } \\
\text { Don't know }\end{array}$ \\
\hline How would you characterise the budget of this ZBO & $\begin{array}{l}\text { Split up in compartments } \\
\text { Operational budget not necessarily balanced } \\
\text { Lump sum } \\
\text { Performance budget } \\
\text { Don't know }\end{array}$ \\
\hline
\end{tabular}




\begin{tabular}{|c|c|}
\hline How would you characterise production of this ZBO & $\begin{array}{l}\text { Individually funded services } \\
\text { Group funding, pay as you go } \\
\text { Group based, funded by parliament } \\
\text { Pure collective good } \\
\text { Don't know }\end{array}$ \\
\hline \multicolumn{2}{|l|}{ Budget and reporting } \\
\hline $\begin{array}{l}\text { Which considerations exist to make a separation } \\
\text { between operational costs and program costs of a } \\
\text { ZBO in the budget of the 'parent' ministry } \\
\text { (ministries monitoring income transfer ZBOs only) }\end{array}$ & Open end question \\
\hline $\begin{array}{l}\text { Is the approval or determining of the budget } \\
\text { separately reported to Tweede Kamer }\end{array}$ & $\begin{array}{l}\text { Yes, in separate letter } \\
\text { Yes, in annual report ministry } \\
\text { Yes, otherwise } \\
\text { No } \\
\text { Don't know }\end{array}$ \\
\hline $\begin{array}{l}\text { Is the approval or determining of fees of the ZBO } \\
\text { separately reported to Tweede Kamer }\end{array}$ & $\begin{array}{l}\text { Yes, in separate letter } \\
\text { Yes, in annual report ministry } \\
\text { Yes, otherwise } \\
\text { No } \\
\text { Don't know }\end{array}$ \\
\hline $\begin{array}{l}\text { Did Tweede Kamer in the most recent debate on the } \\
\text { 'parent' ministry's budget or on the occasion of } \\
\text { receiving a letter on approval of the ZBOs budget } \\
\text { discuss the ZBO's budget }\end{array}$ & $\begin{array}{l}\text { Yes, on operational costs } \\
\text { Yes, on program costs } \\
\text { Yes, on evaluation } \\
\text { Yes, other cause for debate } \\
\text { No } \\
\text { Not applicable } \\
\text { Don't know }\end{array}$ \\
\hline $\begin{array}{l}\text { If so, did Tweede Kamer include performance } \\
\text { indicators/data in that discussion }\end{array}$ & $\begin{array}{l}\text { Yes, } \\
\text { No, } \\
\text { Not applicable } \\
\text { Don't know }\end{array}$ \\
\hline $\begin{array}{l}\text { Did the debate in Tweede Kamer result in a change } \\
\text { of operational budgets of the ZBO }\end{array}$ & $\begin{array}{l}\text { Yes, in budget as a whole } \\
\text { Yes, including separately earmarked budget } \\
\text { No } \\
\text { Not applicable } \\
\text { Don't know }\end{array}$ \\
\hline $\begin{array}{l}\text { Does the ZBO prepare a budget including an } \\
\text { overview over more than one fiscal year }\end{array}$ & Yes/no/don't know \\
\hline What is the basis for preparing a multiyear budget & $\begin{array}{l}\text { Contract agreement on production volume } \\
\text { Contract agreement on a licence basis } \\
\text { Financial framework nominally } \\
\text { Financial framework, real terms } \\
\text { Not applicable } \\
\text { Don't know }\end{array}$ \\
\hline $\begin{array}{l}\text { Which requirements are given to prepare a } \\
\text { multiyear budget }\end{array}$ & $\begin{array}{l}\text { Structural cost recovery } \\
\text { Multiyear budget, unchanged policies } \\
\text { Multiyear budget, based on estimated production } \\
\text { No arrangements } \\
\text { Not applicable } \\
\text { Don't know }\end{array}$ \\
\hline $\begin{array}{l}\text { What arrangements have been made for financing } \\
\text { the assets of the ZBO }\end{array}$ & $\begin{array}{l}\text { Equity and capital markets } \\
\text { Egalisation reserve and capital markets } \\
\text { Regulated reserves and capital markets } \\
\text { Guaranteed equity } \\
\text { Borrowing from Treasury } \\
\text { Is included in the budget } \\
\text { Not applicable } \\
\text { Don't know }\end{array}$ \\
\hline
\end{tabular}




\begin{tabular}{|c|c|}
\hline $\begin{array}{l}\text { Does the budget of the ZBO include a separate } \\
\text { section on investments }\end{array}$ & $\begin{array}{l}\text { Yes, with separate decisions } \\
\text { No, full part of budget } \\
\text { No, included in the fees to be charged } \\
\text { Not applicable } \\
\text { Don't know }\end{array}$ \\
\hline $\begin{array}{l}\text { Which resources are used to fund irregular non- } \\
\text { investment expenditures }\end{array}$ & $\begin{array}{l}\text { Separate resources allocated in advance } \\
\text { Earmarking reserves after consent by minister } \\
\text { Earmarking reserves reported in annual report } \\
\text { Only on request of minster possible } \\
\text { No arrangements made } \\
\text { Not applicable } \\
\text { Don't know }\end{array}$ \\
\hline $\begin{array}{l}\text { Does Tweede Kamer receive documents regarding } \\
\text { this ZBO other than budget information or letters on } \\
\text { approval of budgets }\end{array}$ & Yes/no/don't know \\
\hline How would you characterise these documents & Includes elaboration in case of answer ' other' \\
\hline $\begin{array}{l}\text { How often does Tweede Kamer receive such } \\
\text { documents }\end{array}$ & $\begin{array}{l}\text { More frequent than monthly } \\
\text { Monthly } \\
\text { Quarterly } \\
\text { Semi annually } \\
\text { Annually } \\
\text { Regularly } \\
\text { Incidentally } \\
\text { Don't know }\end{array}$ \\
\hline Did Tweede Kamer discuss these documents & $\begin{array}{l}\text { Yes, operational costs } \\
\text { Yes, program costs } \\
\text { Yes, policy } \\
\text { Yes, evaluation } \\
\text { Yes, other cause for debate } \\
\text { No, } \\
\text { Not applicable } \\
\text { Don't know }\end{array}$ \\
\hline $\begin{array}{l}\text { Would you as owner of this ZBO, even without } \\
\text { requirements of minFin include data on this ZBO in } \\
\text { the ministry's budget/annual report (ministry only) }\end{array}$ & Open end question \\
\hline \multicolumn{2}{|l|}{ Planning \& Control } \\
\hline $\begin{array}{l}\text { How will politicians be informed on changes in the } \\
\text { budget of the ZBO during the fiscal year }\end{array}$ & $\begin{array}{l}\text { Minister is informed only } \\
\text { Reported in ministry's intermediate reports to TK } \\
\text { Other form of reporting to TK } \\
\text { Reported in annual report ministry } \\
\text { Don't know }\end{array}$ \\
\hline $\begin{array}{l}\text { When Tweede Kamer is informed on such changes, } \\
\text { has there been a debate and what was the main } \\
\text { issue in that debate }\end{array}$ & $\begin{array}{l}\text { Yes, operational costs } \\
\text { Yes, program costs } \\
\text { Yes, both } \\
\text { No } \\
\text { Not applicable } \\
\text { Don't know }\end{array}$ \\
\hline $\begin{array}{l}\text { How would you characterise intermediate reports of } \\
\text { this ZBO }\end{array}$ & $\begin{array}{l}\text { Strict focus on compliance } \\
\text { Focus on expenditures/expenses } \\
\text { Focus on performance } \\
\text { Expenditures and policy } \\
\text { Expenditures and performance } \\
\text { No arrangements } \\
\text { Not applicable } \\
\text { Don't know }\end{array}$ \\
\hline $\begin{array}{l}\text { Does the 'parent' ministry separately control } \\
\text { program budgets and how does it control them } \\
\text { (income transfers only) }\end{array}$ & Open end question \\
\hline
\end{tabular}




\begin{tabular}{|c|c|}
\hline $\begin{array}{l}\text { What is the frequency on controlling program } \\
\text { budgets }\end{array}$ & $\begin{array}{l}\text { More frequent than monthly } \\
\text { Monthly } \\
\text { Quarterly } \\
\text { Semi annually } \\
\text { Annually } \\
\text { Regularly } \\
\text { Incidentally } \\
\text { Don't know }\end{array}$ \\
\hline \multicolumn{2}{|l|}{ Annual reports } \\
\hline $\begin{array}{l}\text { Is the approval/determination of annual reports of } \\
\text { the ZBO separately reported to Tweede Kamer }\end{array}$ & $\begin{array}{l}\text { Yes, in annual report of parent ministry } \\
\text { Yes, in letter accompanying annual report ZBO } \\
\text { Yes, otherwise } \\
\text { No } \\
\text { Don't know }\end{array}$ \\
\hline $\begin{array}{l}\text { Has the approval/determination of annual reports } \\
\text { led to a debate in Tweede Kamer }\end{array}$ & $\begin{array}{l}\text { Yes, operational costs } \\
\text { Yes, program costs } \\
\text { Yes, on allocating profits } \\
\text { Yes, on performance } \\
\text { Yes, other theme } \\
\text { No } \\
\text { Not applicable }\end{array}$ \\
\hline $\begin{array}{l}\text { What arrangements presently exist on allocating net } \\
\text { income }\end{array}$ & $\begin{array}{l}\text { Decision by minister } \\
\text { Standardised agreement, including reducing fees } \\
\text { Standardised agreement, including payback to } \\
\text { ministry } \\
\text { Proposal by ZBO } \\
\text { No arrangements } \\
\text { Don't know }\end{array}$ \\
\hline \multicolumn{2}{|l|}{$\begin{array}{l}\text { Would the management of the ZBO like to provide } \\
\text { more information to Parliament than the annual } \\
\text { report? Please explain why. (ZBO only). }\end{array}$} \\
\hline $\begin{array}{l}\text { How would you like to provide that information to } \\
\text { Parliament and what is ideally the role of the Board } \\
\text { in providing that information (ZBO only) }\end{array}$ & Open end question \\
\hline \multicolumn{2}{|l|}{ Evaluation } \\
\hline When was the last evaluation on this ZBO realised & $\begin{array}{l}\text { Fiscal } 2007 \\
\text { Fiscal } 2006 \\
\text { Before fiscal } 2006 \\
\text { Not at all } \\
\text { Don't know }\end{array}$ \\
\hline How was Tweede Kamer informed on this evaluation & $\begin{array}{l}\text { Verbally } \\
\text { Written in separate document } \\
\text { Written in budget or annual report } \\
\text { Not } \\
\text { Not applicable } \\
\text { Don't know }\end{array}$ \\
\hline How did Tweede Kamer respond to this evaluation & Open end question \\
\hline \multicolumn{2}{|l|}{ Responsibility accounting } \\
\hline $\begin{array}{l}\text { Does the ZBO's budget include revenues to be } \\
\text { realised and what is the basis for these revenues? }\end{array}$ & $\begin{array}{l}\text { Yes based on pay as you go funding } \\
\text { Yes, based on expected sales } \\
\text { No, government funding } \\
\text { Don't know }\end{array}$ \\
\hline $\begin{array}{l}\text { Are estimated costs based on outputs and are these } \\
\text { outputs homogeneous }\end{array}$ & $\begin{array}{l}\text { Yes, homogeneous } \\
\text { Yes, heterogeneous } \\
\text { No, but homogeneous } \\
\text { No, heterogeneous } \\
\text { Don't know }\end{array}$ \\
\hline
\end{tabular}




\begin{tabular}{|l|l|}
\hline $\begin{array}{l}\text { Which mandate has the management of the ZBO on } \\
\text { investment decisions }\end{array}$ & $\begin{array}{l}\text { Full degrees of freedom } \\
\text { To a specified level of investments } \\
\text { Within an approved plan } \\
\text { Is included in the full budget } \\
\text { Owner is responsible } \\
\text { Not applicable } \\
\text { Don't know }\end{array}$ \\
\hline $\begin{array}{l}\text { To what extent is management of the ZBO able to } \\
\text { control operational accounts receivable }\end{array}$ & $\begin{array}{l}\text { Depending on parent ministry } \\
\text { Direct claims } \\
\text { Accounts receivable are mainly contributions or pay } \\
\text { as you go based receivables } \\
\text { Don't know }\end{array}$ \\
\hline $\begin{array}{l}\text { Which restrictions exist with respect to (parts of) } \\
\text { budgets for ZBO's management }\end{array}$ & $\begin{array}{l}\text { Strict compliance } \\
\text { Separated in staff cost and other operational costs } \\
\text { Deviation within specified margins allowed } \\
\text { Full budget responsibility } \\
\text { No arrangements } \\
\text { Don't know }\end{array}$ \\
\hline $\begin{array}{l}\text { Which kind of activities have to be reported in } \\
\text { advance to the 'parent' ministry }\end{array}$ & $\begin{array}{l}\text { Investments, new projects, new commissioners, } \\
\text { material developments in production volume, other } \\
\text { issues, no arrangements have been made (multiple } \\
\text { answers possible) }\end{array}$ \\
\hline $\begin{array}{l}\text { Is this ZBO subject to using the Treasury for cash } \\
\text { management (article 45 cW 2001) }\end{array}$ & \begin{tabular}{l} 
Yes/No \\
\hline Are other arrangements made on cash management
\end{tabular} \\
\hline
\end{tabular}




\section{Appendix 5: Questionnaire politicians}

These questions were used for the interviews with politicians. All questions are open ended.

1. ZBOs have different legal forms and characteristics. Which criteria do you use to hold the minister to account for his actions towards a ZBO, and what part of the minister's responsibility would you consider to be the most important part. Would you elaborate on this from the perspectives of ownership and commission on the one hand and policy development/policy execution on the other?

2. Do you think that you have sufficient information available to monitor the activities and performance of a ZBO and eventually intervene in policy execution?

3. Do you include in your debates on the ministry's budget proposals the data available on the budgets of ZBOs and are there in your opinion gaps in the information provision on ZBOs. Could you elaborate on the question when in your opinion budgets of ZBOs are really becoming a political topic and would that be on operational costs or on program costs?

4. Do you study annual reports of ZBOs and has that led to asking questions to the minister who can be held accountable?

5. I now present you two schemes with a general classification of ZBOs on a few dimensions. Given this classification would you consider to focus on the topics included in these schemes or are other classifications more important to you? (make reference to schemes)

6. Are, apart from the debates on ministry's budgets and annual reports, other occasions that you would like to use to discuss operations of ZBOs with the minister?

7. MinBZK has in her letter of April 1, 2008, provided information on the proposed exceptions in the application of KZBO for individual ZBOs. These exceptions include 'vernietiging $\left(25^{*}\right)$, non civil servant staff $\left(15^{*}\right)$, approving ZBOs policy rules $\left(7^{*}\right)$, creation of egalisation reserve $\left(4^{*}\right)$, right to appoint the ZBO's board $\left(4^{*}\right)$ and right to determine fees $\left(3^{*}\right)$. Would you reflect on these exceptions in general, and more specifically on the issues of the egalisation reserve and the right to determine fees.?

8. The three major Market Authorities are all funded differently. To what extent do you consider this consistent to the general idea that oversight on markets is to be considered a public task? 
9. Before kZBO was applicable, some entities at arm's length (e.g. Police regions and State Forestry SBB) were also regarded as ZBOs. Are there, in your opinion sufficient control tools available to Tweede Kamer to monitor such entities that are no longer regarded as ZBOs?

10. Local governments are supposed by law to prepare a separate section in their budget documents and annual reports in which they focus on the political and financial risks that exist with respect to associated and affiliated parties of local government. Would you think a similar arrangement on State level, particularly on ZBOs, would be useful to you as a MP?

11. Government Agencies are separately included and disclosed in ministries' budgets. Does this presentation contribute to the possibilities you have to control Government Agencies. What is your opinion on the fact that actually, budgets of government funded Agencies are actually authorised twice?

12. Do you think it is worth considering to submit intermediate changes in the budgets of ZBOs to Parliament and why would you think so. Please note that in case of Government Agencies, such a rule does not exist (section $11.5 \mathrm{CW}$ 2001) 


\section{Appendix 6: Questionnaire Gerritsen Committee}

Starting point for these questions is the letter of the minister BZK on the proposed application of kZBO and the debate on that letter in Tweede Kamer (Parliament 2008ad; Parliament 2008ae)

\section{A. Some practical issues}

1. In the Gerritsen Committee report is besides following the official statements in kZBO and the motives for creating ZBOs, no further differentiation on ZBOs made. Did the Committee consider more differentiation, or did the assignment to the Committee only allow for an assessment of ZBOs as was done

2. The Committee regularly refers in its texts to 'Aanwijzingen'. Apparently, these instructions are still relevant, despite of the introduction of kZBO. What were the reasons for the Committee to refer so specifically to 'Aanwijzingen'?

3. In the letter of the minister BZK, a number of 144 clusters of ZBOs is mentioned. The Committee mentioned 153 a few months before. Who ultimately decided to include 144 clusters and what reasons can be given for this choice

4. The Committee's report specifically mentions 'organisations that are part of central government' ( $p$ 30. This is a noticeable statement, given the legal status of many ZBOs (e.g. foundations) but also with respect to debates on accountability and consolidation that are usually held under accounting standards. What did the Committee want to express through this statement?

B. Authority attributed to the minister.

1. Role of Supervising Board. In order to allow for ministerial responsibility, a Supervising Board should not have a position somewhere in between the minister and the ZBO. The Committee indicates that in some cases a Supervising Board has authority that should be in the hands of the minister. Can you give specific examples and would it not be logical to have a Supervising Board, given the arm's length relationship between minister and ZBO. On the other hand, Advisory Boards that still do exist are not mentioned at all in the Committee's report. Can you elaborate on these issues?

2. General reserve/general equity. Despite the statements of the Committee, in 4 cases no general reserve for operations will be allowed by ministries. At what level was the discussion on this issue held and did either the minister of FIN or BZK intervene?

3. Authority to reverse decisions 'vernietigingsbevoegdheid' in the Cultural Sector. An exception is made for 'vernietigingsbevoegdheid' in the cultural sector, i.e. the minister is not allowed to decide on individual applications to the respective art 
funds. At the same time, most notably in a debate in Parliament on September 3, 2008, MP's state that they have, as politicians, no opinion on (the contents) of arts. Despite of that, the debate on the 4year redistribution of budgets to the arts sector results in debates on decisions in individual or regional cases. How would you explain this contradiction and what does it mean for the motivation given for the vernietigingsrecht?

4. Appointment/Dismissal of the Board. In 4 cases, despite the advise by the Committee, an exemption is made on article 12 kZBO (on appointments of Boards). This concerns 4 ZBOs. Three of these ZBOs have a quasi-judicial position in the system of central government. This specific position does not lead to a statement by the Committee to make an exception, whereas in the ultimate proposals by the respective individual 'parent' ministries, this argument actually is given. Why did the Committee not allow for a general exception with respect to this matter, and in the end the exceptions are likely to be granted?

C. Planning \& Control

1. Change of date on submitting annual report. Can you explain what arguments were given that required to make exceptions of the proposed standardisation of the reporting date and why in the end in most cases the proposed standardisation was accepted. There is now still only one exception. Would you also comment on the fact that essentially three ministries claimed for exceptions. What were their arguments and isn't there a bit of an inconsistency in allowing only one exception?

2. Information provision. In the Committee's report and in the debate in Parliament in September 2008 attention is drawn to the issue of information provision. In the debate in Parliament a link is made towards information provision on Government Agencies. What is generally missing is that there is no debate on what (financial) information should be provided towards Tweede Kamer. Unlike the Government Agency case, there is no arrangement between Parliament and ministers to disclose full sales and costs of ZBOs. Furthermore, no attention is given to the remarks of NCA on the absence of information on the financial position of ZBOs (equity). Can you give an opinion why these issues are not addressed?

3. Staff. Several MPs asked information on the proposed reduction of ZBO staff by 1800 FTEs. The interviews I have done during this study at least give the impression that minBZK is strongly focusing on the staff numbers in central government. But, when one of the arguments for creating ZBOs is that creating entities at arm's length gives more leeway for management to use resources more flexibly, a question is whether the strong focus on staff numbers is appropriate. Basically, the division between the ministry and the entity at arm's length comes down to the degrees of freedom for management to operate the 
entity and the ministry as commissioner is supposed to address issues on the tasks to be assigned to the entity. What is your opinion on the issue of Staff control?

D. Miscellaneous

1. Merger of IBGoep and CFI. One of the arguments used not to rearrange the domain of ZBOs fundamentally is the level of transactions costs that may result from a large scale rearrangement. Ultimately, one of the more important and large ZBOs is in the process of merging with a Government Agency. What has been the role of the Committee in the debate on this merger?

2. Double function/possible conflict of interest NZA. Unlike NMa and AFM, NZA has two main tasks: market authority on the one hand and decision maker on maximum fees in the health/ care sector on the other. In a debate between minister and Tweede Kamer (07 May 2008), it is argued that the minister VWS has the power to give general instructions without affecting the impartiality of NZA. Theoretically, that might be the case, but there may be a conflict of interest between regulating and issuing instructions. NZA is the exception in the domain of the large Market regulating authorities. To what extent has this exception been discussed within the Committee? 


\section{Appendix 7: List of interviewees}

\begin{tabular}{|c|c|c|}
\hline ZBO-case & Organisation & Official interviewed \\
\hline Cfv & CFV & director \\
\hline Cfv & minVrom/Topzo & Head monitoring department \\
\hline Cfv & $\begin{array}{l}\text { minVrom/ DG } \\
\text { WWI }\end{array}$ & Member policy advising staff \\
\hline SVB & SVB & Head secretary to the board \\
\hline UWV & UWV & $\begin{array}{l}\text { Member of Board } \\
\text { Head secretary to the board } \\
\text { CFO }\end{array}$ \\
\hline UWV/SVB & $\operatorname{minszW}$ & $\begin{array}{l}\text { Director and staff member commissioning and monitoring } \\
\text { directorate }\end{array}$ \\
\hline CVZ & CVZ & Controller \\
\hline CVZ & minWVS & 2 staff members commissioning and monitoring directorate \\
\hline NMa & NMa & $\begin{array}{l}2 \text { staff members strategic consultants to the board } \\
\text { Controller }\end{array}$ \\
\hline NMa & $\min E Z$ & staff member policy directorate \\
\hline NZA & NZA & Controller \\
\hline NZA & minWVS & $\begin{array}{l}\text { Staff member secretary to the board } \\
\text { staff member policy directorate }\end{array}$ \\
\hline AFM & AFM & $\begin{array}{l}\text { Controller } \\
\text { Head department organisation development }\end{array}$ \\
\hline AFM & $\operatorname{minFin}$ & Head and staff member commissioning directorate \\
\hline NAK & NAK & Legal counsel to the board \\
\hline NAK & $\min L N V$ & Staff member commissioning directorate \\
\hline VF/PF & VF/PF & Director \\
\hline VF/PF & $\operatorname{minOCW}$ & Staff member commissioning and monitoring directorate \\
\hline BKVB & BKVB & Deputy director \\
\hline BKVB & $\operatorname{minOCW}$ & Staff member commissioning directorate \\
\hline RRbDen Haag & RvR & $\begin{array}{l}\text { Director } \\
\text { Controller }\end{array}$ \\
\hline $\begin{array}{l}\text { RRb Den Haag } \\
\text { Politicians }\end{array}$ & minJUS & $\begin{array}{l}\text { Head of unit in commissioning and monitoring directorate } \\
\text { Former MP SGP } \\
\text { MP PvdA } \\
\text { MP VVD }\end{array}$ \\
\hline $\begin{array}{l}\text { Gerritsen } \\
\text { committee }\end{array}$ & $\min B Z K$ & Secretary to the committee \\
\hline
\end{tabular}




\section{Appendix 8: Relevant Parliamentary documents on ZBOs}

Specification of documents submitted to Parliament with respect to the ZBOs studied. The documents were found on https://zoek.officielebekendmakingen.nl/zoeken; an official website of the State on which Parliamentary documents can be found.

Documents were searched for in the period cover September 1st, 2006 till July 1st, 2009. This covers all documents with respect to fiscal 2007 and 2008 . Key search words were on the one hand 'begroting ZBOx' and 'jaarverslag ZBOx' on the other. In some cases more general words were required to find relevant documents. This is indicated in the specifications below. The total number of documents found is mentioned for each separate ZBO. This form of search results in overlap in documents which were found in both queries. Within the documents, the pdf search function is used, but now only on the simple word ZBOx or similar. The same document is only studied once.

Criteria to list a document are twofold: 1 . must be submitted to 'Tweede Kamer' and 2. must concern operations rather than policy issues. 


\section{CVZ}

$\mathrm{N}=248$ documents on 'begroting CVZ' in text $\mathrm{N}=101$ documents on 'jaarverslag CVZ' in text

\begin{tabular}{|c|c|c|}
\hline Document regarding CVZ & Relevance operations & $\begin{array}{l}\text { \# remarks by } \\
\text { MPs }\end{array}$ \\
\hline \multicolumn{3}{|l|}{ Fiscal 2006} \\
\hline 30885XVI_2 2 $2^{\text {nd }}$ supplement 2006 & $\mathrm{y}$ & 0 \\
\hline $30885 \mathrm{XVI} 32^{\text {nd }}$ supplement 2006 & $\mathrm{Y}$ & 1 \\
\hline 31031XVI_1 Annual report 2006 VWS & $\mathrm{y}$ & 0 \\
\hline 31031XVI_5 Annual report 2006 VWS & $\mathrm{Y}$ & 1 \\
\hline \multicolumn{3}{|l|}{ Fiscal 2007} \\
\hline 30800XVI-2 Budget 2007 Notes & $y$ & 0 \\
\hline 30800XVI-27 Budget 2007: Questions & $y$ & 4 \\
\hline 30800XVI-117 Budget 2007: reply minister & $\mathrm{Y}$ & 0 \\
\hline Proceedings 20062007 31-2033-2068 & $\mathrm{Y}$ & 1 \\
\hline 31061XVI_1 $1^{\text {st }}$ supplement 2007 & $\mathrm{Y}$ & 0 \\
\hline 31061XVI_4 $1^{\text {st }}$ supplement 2007 & $\mathrm{Y}$ & 2 \\
\hline $31290 X V I 22^{\text {nd }}$ supplement 2007 & $\mathrm{Y}$ & 0 \\
\hline 31444XVI_1 Annual report 2007 & $y$ & 0 \\
\hline 31444XVI_4 Annual report & $\mathrm{y}$ & 1 \\
\hline $25268 \_45$ ZBOs & $\mathrm{Y}$ & 0 \\
\hline 25268_59 ZBOs Proceedings & $\mathrm{y}$ & 3 \\
\hline 25268 63 ZBOs & $\mathrm{Y}$ & 0 \\
\hline 31249_6 Change ZVW Protocol & $\mathrm{Y}$ & 1 \\
\hline 30918_3; 30918_6; 30918_8; 30918_13 Change ZVW & $\mathrm{Y}$ & 1 \\
\hline 31201_3 Organisation of government & $\mathrm{Y}$ & 0 \\
\hline \multicolumn{3}{|l|}{ Fiscal 2008} \\
\hline 31200XVI_2 Budget 2008 Notes & $\mathrm{Y}$ & 0 \\
\hline 31474XVI_2 $1^{\text {st }}$ supplement 2008 Notes & $\mathrm{Y}$ & 0 \\
\hline 3792XVI_2 2 $2^{\text {nd }}$ supplement 2008 Notes & $\mathrm{Y}$ & 0 \\
\hline $31792 \_42^{\text {nd }}$ supplement, questions & $\mathrm{Y}$ & 1 \\
\hline 31924XVI_2 Annual 2008 Notes & $\mathrm{Y}$ & 0 \\
\hline 31924XVI 5 Annual 2008 questions & $\mathrm{Y}$ & 1 \\
\hline 31924XVI_6 Annual 2008 Questions & $\mathrm{Y}$ & 1 \\
\hline 25268_70 ZBOS & $\mathrm{Y}$ & 0 \\
\hline \multicolumn{3}{|l|}{ Fiscal 2009} \\
\hline 31700XVI_2 budget 2009 notes & $\mathrm{y}$ & 0 \\
\hline $31700 X V I 23$ budget 2009 questions & $\mathrm{Y}$ & 2 \\
\hline 31965XVI_2 $1^{\text {st }}$ supplement 2009 & $\mathrm{Y}$ & 0 \\
\hline Proceedings20082009 1415-1452 & $\mathrm{Y}$ & 1 \\
\hline Proceedings20082009 4031-4051 & $\mathrm{Y}$ & 1 \\
\hline 31950 3 Law on modification to kZBO & $\mathrm{Y}$ & 0 \\
\hline
\end{tabular}




\section{RvR}

$\mathrm{N}=248$ documents on 'begroting raad rechtsbijstand' in text $\mathrm{N}=103$ documents on 'jaarverslag raad rechtsbijstand' in text

\begin{tabular}{|c|c|c|}
\hline Document regarding RvR & $\begin{array}{l}\text { Relevance } \\
\text { operations } \\
\end{array}$ & \# remarks by MPs \\
\hline \multicolumn{3}{|l|}{ Fiscal 2006} \\
\hline 30885VI_2. $2^{\text {nd }}$ supplement 2006 Notes & $\mathrm{y}$ & 0 \\
\hline 30885VI_6. 2 ${ }^{\text {nd }}$ supplement 2006 Questions & $\mathrm{y}$ & 1 \\
\hline 31031VI_1: Annual report fiscal 2006 & $\mathrm{y}$ & 4 \\
\hline $\begin{array}{l}\text { 30436_6. Changes in law on legal aid; protocol of } \\
\text { debate }\end{array}$ & $\mathrm{Y}$ & 1 \\
\hline \multicolumn{3}{|l|}{ Fiscal 2007} \\
\hline 30800 VI_2: Budget 2007 Notes & $\mathrm{y}$ & 0 \\
\hline 30800VI_99: protocol & $\mathrm{N}$ & 1 \\
\hline 30800VI_111 protocol & $\mathrm{N}$ & 1 \\
\hline 31061: $1^{\text {st }}$ supplement 2007 notes & $\mathrm{Y}$ & 0 \\
\hline 31061VI_2: $1^{\text {st }}$ supplement minJUS & $\mathrm{Y}$ & 0 \\
\hline 31061VI_3 1st supplement 2007 & $\mathrm{Y}$ & 0 \\
\hline 31290VI_2: $2^{\text {nd }}$ supplement to budget 2007 & $\mathrm{y}$ & 0 \\
\hline 31290VI_3: $2^{\text {nd }}$ supplement to budget 2007: Protocol & $\mathrm{Y}$ & 1 \\
\hline 31444VI_1: Annual report fiscal 2007 & $\mathrm{y}$ & 0 \\
\hline 31444VI_4: Annual report fiscal 2007; notes & $\mathrm{y}$ & 0 \\
\hline 31444VI_6: Annual report fiscal 2007; questions & $\mathrm{y}$ & 2 \\
\hline $\begin{array}{l}\text { 30492_3: Report on development of staff of } \\
\text { Government }\end{array}$ & $y$ & 0 \\
\hline 31201_3 Memorandum employability & $y$ & 0 \\
\hline Proceedings 20062007_2011-2032 & $\mathrm{N}$ & 1 \\
\hline Proceedings 20062007_2094-2110 & $\mathrm{N}$ & 1 \\
\hline Proceedings 20062007_5420-5428 & $\mathrm{n}$ & 0 \\
\hline Proceedings 20062007_5431-5440 & $\mathrm{n}$ & 0 \\
\hline 30800VI_138: monitoring report legal aid & $y$ & 0 \\
\hline \multicolumn{3}{|l|}{ Fiscal 2008} \\
\hline 31200 Budgetmemorandum 2008, appendix & $\mathrm{n}$ & 0 \\
\hline 31200VI_2 Budget 2008 & $\mathrm{y}$ & 0 \\
\hline 31200VI_13 Budget 2008 & $\mathrm{y}$ & 0 \\
\hline 31200VI_86 Budget 2008; protocol & $\mathrm{Y}$ & 2 \\
\hline Proceedings 20072008_2061-2072 & $\mathrm{y}$ & 0 \\
\hline 31200VI_108 Budget 2008; questions & $\mathrm{Y}$ & 0 \\
\hline 31200VI_123 Budget 2008; questions & $\mathrm{Y}$ & 0 \\
\hline 31200VI_123 Budget 2008; questions & $\mathrm{Y}$ & 1 \\
\hline 31474_1: $1^{\text {st }}$ supplement 2008 & $\mathrm{y}$ & 0 \\
\hline 31474VI_1: $1^{\text {st }}$ supplement 2008 & $\mathrm{y}$ & 0 \\
\hline 31474VI_3: $1^{\text {st }}$ supplement 2008: questions & $\mathrm{Y}$ & 0 \\
\hline 31200VI_123 Budget 2008; questions & $\mathrm{Y}$ & 0 \\
\hline 31792_1: $2^{\text {nd }}$ supplement 2008: general overview & $\mathrm{y}$ & 0 \\
\hline 31792VI_2: $2^{\text {nd }}$ supplement notes & $\mathrm{y}$ & 0 \\
\hline 31792VI_3: $2^{\text {nd }}$ supplement 2008 questions & $\mathrm{Y}$ & 3 \\
\hline 31924VI_4: Annual report 2008: notes & $\mathrm{y}$ & 0 \\
\hline 25268_63: overview adaption to kZBO & $\mathrm{y}$ & 0 \\
\hline 31753_1 Legal aid & $\mathrm{Y}$ & 0 \\
\hline \multicolumn{3}{|l|}{ Fiscal 2009} \\
\hline 31700VI_2: Budget 2009; notes & $\mathrm{y}$ & 0 \\
\hline 31700VI_7: Budget 2009; monitor legal aid & $\mathrm{y}$ & 0 \\
\hline
\end{tabular}




\begin{tabular}{|l|l|l|}
\hline Document regarding RvR & $\begin{array}{l}\text { Relevance } \\
\text { operations }\end{array}$ & \# remarks by MPs \\
\hline 31700VI_10: Budget 2009;questions & y & 2 \\
\hline 31753_10-Legal aid & Y & 1 \\
\hline 31835_3: Law on merger of RvRs into one ZBO & y & 0 \\
\hline $\begin{array}{l}\text { 31835_8: Law on merger of RvRs into one ZBO: } \\
\text { Protocol }\end{array}$ & Y & 3 \\
\hline Proceedings 20082009_1373-1415 & & \\
\hline Proceedings 20082009_1459-1492 & y & 1 \\
\hline 31700VI_87: Budget 2009; letter by minister & y & 1 \\
\hline 31965_1. 1st Supplement 2009 & y & 0 \\
\hline 31965VI_2. 1st Supplement 2009: notes & y & 0 \\
\hline 31965VI_2. 1st Supplement 2009 & y & 0 \\
\hline
\end{tabular}




\section{SVB}

$\mathrm{N}=269$ documents on 'begroting SVB' in text

$\mathrm{N}=180$ documents on 'jaarverslag SVB' in text

$\mathrm{N}=31$ documents on SUWI/SVB (26448 SVB)

\begin{tabular}{|c|c|c|}
\hline Document regarding SVB & $\begin{array}{l}\text { Relevance } \\
\text { operations }\end{array}$ & $\begin{array}{l}\text { \# remarks by } \\
\text { MPs }\end{array}$ \\
\hline \multicolumn{3}{|l|}{ Fiscal 2006} \\
\hline 30885XV_SZW2: $2^{\text {nd }}$ supplement 2006 notes & $\mathrm{y}$ & 0 \\
\hline 30885VI_2Jus: $2^{\text {nd }}$ supplement & $\mathrm{y}$ & 0 \\
\hline 31031_XVI_1 Annual report 2006 & $\mathrm{y}$ & 0 \\
\hline 31031VI_2 Annual report JUS 2006 notes & $\mathrm{y}$ & 0 \\
\hline 31031XVI_1 Annual reportVWS 2006 notes & $\mathrm{y}$ & 0 \\
\hline 31031XV_1 Annual reportSZW 2006 notes & $\mathrm{y}$ & 0 \\
\hline 31031XV_8 Annual report SZW 2006, questions & $\mathrm{y}$ & 2 \\
\hline 26448_294 Suwi Quarterly report Q2 & $\mathrm{y}$ & 0 \\
\hline 26448_296 Suwi Quarterly report, protocol & $\mathrm{y}$ & 1 \\
\hline 26448_309 Suwi Quarterly report Q3 & $\mathrm{y}$ & 0 \\
\hline 26448_331 Suwi Quarterly report; Q4 2006 & $\mathrm{y}$ & 0 \\
\hline \multicolumn{3}{|l|}{ Fiscal 2007} \\
\hline 30800VI_2 Budget Justice2007,notes & $\mathrm{y}$ & 0 \\
\hline 30800XV_2 Budget SZW2007 notes & $\mathrm{y}$ & 0 \\
\hline 30800XV_9 Budget SZW2007, questions & $\mathrm{Y}$ & 1 \\
\hline 31061XV_2; $1^{\text {st }}$ supplement 2007 SZW notes & $\mathrm{y}$ & 0 \\
\hline 31290XI_2nd supplement to budget 2007 VROM & $\mathrm{y}$ & 0 \\
\hline $31290 X V \_2^{\text {nd }}$ supplement to budget 2007 SZW & $\mathrm{y}$ & 0 \\
\hline 31444XV_1 Annual report SZW 2007 & $\mathrm{y}$ & 0 \\
\hline 31444XI_1 Annual report VROM 2007 & $\mathrm{y}$ & 0 \\
\hline 31444XVI_3 Annual report VWS 2007 & $\mathrm{y}$ & 0 \\
\hline 26448_305 SUWI & $\mathrm{y}$ & 0 \\
\hline 26448_315 SUWI & $\mathrm{y}$ & 0 \\
\hline 26448_326 SUWI Protocol & $\mathrm{y}$ & 0 \\
\hline 26448_337 SUWI Q1 2007 & $\mathrm{y}$ & 0 \\
\hline 26448_338 SUWI & $\mathrm{y}$ & 0 \\
\hline 26448_338_Report SVBTien2006 by IWI & $\mathrm{y}$ & 0 \\
\hline 26448_343 SUWI q2 2007 & $\mathrm{y}$ & 0 \\
\hline 26448_350 SUWI Quarterly Q3 2007 & $\mathrm{y}$ & 0 \\
\hline 26448_365: SUWI: annual reports 2007 & $\mathrm{Y}$ & 0 \\
\hline 30545/26448_32 SUWI Protocol & $\mathrm{y}$ & 1 \\
\hline 30545/26448_32 WWB/SUWI; Protocol & $\mathrm{Y}$ & 3 \\
\hline $\begin{array}{l}\text { 30492_3: Report on development of staff of Government (Lof } \\
\text { der Eenvoud) }\end{array}$ & $\mathrm{Y}$ & 0 \\
\hline 31201_3 Government employability memorandum & $\mathrm{Y}$ & 0 \\
\hline Proceedings 20062007_1161-1188 & $\mathrm{Y}$ & 1 \\
\hline Proceedings 20062007_1371-1376 & $\mathrm{y}$ & 0 \\
\hline Proceedings 20062007_1294-1342 & $\mathrm{y}$ & 0 \\
\hline \multicolumn{3}{|l|}{ Fiscal 2008} \\
\hline 31200_3_Appendix to Budget memorandum 2008 & $\mathrm{y}$ & 0 \\
\hline 31200XI_2VROM_budget 2008 notes & $\mathrm{y}$ & 0 \\
\hline 31200XVIII_2WWI_budget 2008 notes & $\mathrm{y}$ & 0 \\
\hline 31200XVI_2VWS_budget 2008 notes & $\mathrm{y}$ & 0 \\
\hline 31200XVII_2JG_budget 2008 notes & $\mathrm{Y}$ & 0 \\
\hline 31200XV_2SZW_budget 2008r notes & $\mathrm{Y}$ & 0 \\
\hline 31200XVII_5_Budget2008_JG; Questions & $\mathrm{Y}$ & 1 \\
\hline
\end{tabular}




\begin{tabular}{|c|c|c|}
\hline Document regarding SVB & $\begin{array}{l}\text { Relevance } \\
\text { operations }\end{array}$ & $\begin{array}{l}\text { \# remarks by } \\
\text { MPs }\end{array}$ \\
\hline 31200XV_9_Budget2008_SZW; Questions & Y & 3 \\
\hline $\begin{array}{l}\text { 31200VIII_137_Budget OCW2008: providing books for } \\
\text { secondary education }\end{array}$ & $\mathrm{y}$ & 0 \\
\hline $31474 X V I 1^{\text {st }}$ supplement 2008 VWS & $y$ & 0 \\
\hline 31474XV 1st supplement 2008 SZW & $\mathrm{y}$ & 0 \\
\hline 31474XVII_3 $1^{\text {st }}$ supplement to budget $2008 \mathrm{JG}$ & $\mathrm{Y}$ & 1 \\
\hline 31792XV_2 2 $2^{\text {nd }}$ supplement 2008 SZW & $\mathrm{y}$ & 0 \\
\hline 31924XV_1Annual report 2008 SZW & $y$ & 0 \\
\hline 31924XVII_Annual report $2008 \mathrm{JG}$ & $\mathrm{Y}$ & 0 \\
\hline 31924VIII_Annual report 2008 OCW & $\mathrm{Y}$ & 0 \\
\hline 31924XVIII_Annual report 2008 WWI & $\mathrm{y}$ & 0 \\
\hline 31924XV_6Annual report 2008 SZW questions & $\mathrm{Y}$ & 1 \\
\hline $26448 \quad 355$ & $y$ & 0 \\
\hline 26448_363_performance information SUWI. & $\mathrm{Y}$ & 1 \\
\hline 26448_376: SUWI T1 reports 2008 & $\mathrm{y}$ & 0 \\
\hline 26448_378 SUWI & $y$ & 0 \\
\hline 26448_388: SUWI T2 reports 2008 & $\mathrm{y}$ & 0 \\
\hline 26448 397_SUWI2008 annual reports. & $y$ & 0 \\
\hline 26448_397 Appendix letter of assessment annual report & $\mathrm{y}$ & 0 \\
\hline 31325_6: provision of books in secondary education & $\mathrm{y}$ & 0 \\
\hline 31924XV_13Annual report 2008 SZW motion & $\mathrm{Y}$ & 1 \\
\hline 31924XV_14Annual report 2008 SZW motion & $\mathrm{Y}$ & 1 \\
\hline 25268 63: implementation kZBO & $\mathrm{Y}$ & 1 \\
\hline 31514_2 Proposed change on SUWI law & $\mathrm{y}$ & 0 \\
\hline 31514_2 Proposed change on SUWI law notes & $\mathrm{y}$ & 0 \\
\hline 20454_95_War victims/PUR & $y$ & 2 \\
\hline $\begin{array}{l}31586 \text { : change of regulations on reclaim of incorrectly paid } \\
\text { or fraudulent benefits }\end{array}$ & $y$ & 0 \\
\hline Proceedings 20072008-2073-2095 & $\mathrm{Y}$ & 0 \\
\hline Proceedings 20072008_2169-2172 & $\mathrm{Y}$ & 1 \\
\hline Proceedings 20072008-2629-2654 & $\mathrm{Y}$ & 1 \\
\hline Proceedings $20072008-2742-2756$ & $\mathrm{Y}$ & 1 \\
\hline Proceedings 20072008-3558-3565 & $\mathrm{Y}$ & 1 \\
\hline Proceedings 20072008-4172-4188 & $\mathrm{Y}$ & 1 \\
\hline $\begin{array}{l}2009 D 26367 / 31924 X V I \_5 \text { Questions on VWS annual report } \\
2008\end{array}$ & $\dot{Y}$ & 1 \\
\hline \multicolumn{3}{|l|}{ Fiscal 2009} \\
\hline 31700XVI_2_Budget2009 VWS & $\mathrm{y}$ & 0 \\
\hline 31700XV_2_Budget2009 SZW & $\mathrm{y}$ & 0 \\
\hline 31700XVII____Budget2009 JG & $y$ & 0 \\
\hline 31700XVIII_2_Budget2009 WWI & $\mathrm{y}$ & 0 \\
\hline $31700 X V 11$ Budget2009 SZW: questions & $y$ & 2 \\
\hline 31700XVI_23_Budget2009 VWS: questions & $\mathrm{y}$ & 1 \\
\hline 31700VIII_32_Budget2009 OCW: questions & $\mathrm{y}$ & 1 \\
\hline 31700XV_21_Budget2009 SZW: questions & $\mathrm{y}$ & 3 \\
\hline 31965XV_1 1 st supplement 2009 SZW & $\mathrm{y}$ & 0 \\
\hline 26448_390: SUWI budgets 2009 & $\mathrm{y}$ & 0 \\
\hline 26448_406 T1 2009 report & $\mathrm{y}$ & 0 \\
\hline 31772_6. Changes in child benefits: questions & $\mathrm{Y}$ & 1 \\
\hline Proceedings 20082009-2606-2620 & $y$ & 0 \\
\hline Proceedings 20082009 5085-5152 & $\mathrm{Y}$ & 1 \\
\hline Proceedings $200820095507-5581$ & $\mathrm{Y}$ & 1 \\
\hline Proceedings 20082009 5583-5664 & $\mathrm{Y}$ & 1 \\
\hline Proceedings 20082009 5895-5947 & $\mathrm{Y}$ & 1 \\
\hline
\end{tabular}




\section{UWV}

$\mathrm{N}=651$ documents containing ' begroting UWV' in text

$\mathrm{N}=388$ documents containing ' jaarverslag UWV' in text

$\mathrm{N}=125$ documents on SUWI (26448).

service and kZBO issues. Remarks of different MPs on same subject are counted as one remark.

\begin{tabular}{|c|c|c|}
\hline Document regarding UWV & $\begin{array}{l}\text { Relevance } \\
\text { operations }\end{array}$ & \# remarks by MPs \\
\hline \multicolumn{3}{|l|}{ Fiscal 2006} \\
\hline 30885XV_2 2 $2^{\text {nd }}$ supplement to budget 2006 & $\mathrm{Y}$ & 0 \\
\hline 31031_XIV_2 Annual report 2006 & $\bar{Y}$ & 0 \\
\hline 31031XV_7 Annual 2006 Questions & $\mathrm{Y}$ & 1 \\
\hline 31031XV_8 Annual 2006, questions & $\mathrm{Y}$ & 5 \\
\hline 31031XV_10 & $\mathrm{Y}$ & 1 \\
\hline 31031XV_11 & $\mathrm{Y}$ & 0 \\
\hline 26448_288 SUWI & $\mathrm{Y}$ & 0 \\
\hline 26448_290 SUWI Evaluation & $\mathrm{N}$ & 0 \\
\hline 26448_294 Q2-2006 reports (12 ${ }^{\text {th }}$ report) & $\mathrm{y}$ & 0 \\
\hline 26448_296_Protocol & $y$ & 8 \\
\hline 26448_297 SUWI Letter & $\mathrm{Y}$ & 0 \\
\hline 26448_300 SUWI Motion & $\mathrm{Y}$ & 1 \\
\hline 26448_304 SUWI & $\bar{Y}$ & 0 \\
\hline 26448_306 SUWI & $\mathrm{Y}$ & 0 \\
\hline 26448_307 SUWI letter & $\mathrm{Y}$ & 0 \\
\hline 26448_309 Q3-2006 & $\mathrm{Y}$ & 0 \\
\hline 26448_310 SUWI & $\mathrm{Y}$ & 0 \\
\hline 26448_311SUWI & $\mathrm{Y}$ & 0 \\
\hline 26448_312 SUWI & $\bar{Y}$ & 0 \\
\hline 26448_314 SUWI & $\mathrm{Y}$ & 0 \\
\hline 26448_331 Q4-2006 13 ${ }^{\text {th }}$ report & $y$ & 0 \\
\hline Proceedings20062007-766-769 & $y$ & 1 \\
\hline 17050_329 Fraud and improper use of benefits & $\mathrm{Y}$ & 0 \\
\hline Proceedings20062007-1705-1709 & $\mathrm{Y}$ & 1 \\
\hline Proceedings20062007 Appendix 501 & $\mathrm{Y}$ & 1 \\
\hline Fiscal 2007 & $\begin{array}{l}\text { Relevance } \\
\text { operations }\end{array}$ & \# remarks by MPs \\
\hline 30800XV_2 Budget 2007 Notes & $\mathrm{Y}$ & 0 \\
\hline 30800XV_9 Budget 2007 Protocol & $\mathrm{Y}$ & 3 \\
\hline 30800XV_44 Budget 2007 Motion & $\mathrm{Y}$ & 1 \\
\hline 30800XV_56 Budget 2007 Letter & $\mathrm{Y}$ & 1 \\
\hline 31061XV_2 $1^{\text {st }}$ supplement to Budget 2007 & $\mathrm{Y}$ & 0 \\
\hline 31061XV_4 1 $1^{\text {st }}$ supplement to Budget 2007; questions & $\mathrm{Y}$ & 1 \\
\hline 31290XV_2 2 $2^{\text {nd }}$ supplement to budget 2007 & $y$ & 0 \\
\hline 31290XV_3 $2^{\text {nd }}$ supplement to budget 2007 & $\mathrm{Y}$ & 1 \\
\hline 31444XV_1 Annual report 2007 minSZW & $\mathrm{Y}$ & 0 \\
\hline 31444XV_6 Annual 2007, Questions & $\bar{Y}$ & 3 \\
\hline 31444XV_7 Annual 2007, Questions & $\mathrm{Y}$ & 1 \\
\hline 30545/26448_32 SUWI-reports & $\mathrm{y}$ & 4 \\
\hline 26448_315 SUWI & $\mathrm{Y}$ & 0 \\
\hline 26448_318 & $\mathrm{Y}$ & 2 \\
\hline 26448_321 Motion & $\mathrm{Y}$ & 1 \\
\hline 26448_322 Motion & $\mathrm{Y}$ & 1 \\
\hline 26448_324 SUWI Protocol & $\mathrm{Y}$ & 1 \\
\hline
\end{tabular}




\begin{tabular}{|c|c|c|}
\hline Document regarding UWV & $\begin{array}{l}\text { Relevance } \\
\text { operations }\end{array}$ & \# remarks by MPs \\
\hline 26448_326 SUWI Protocol & $\mathrm{y}$ & 13 \\
\hline 26448_328 SUWI & $\mathrm{y}$ & 0 \\
\hline 26448_329 SUWI & $\mathrm{Y}$ & 5 \\
\hline 26448_333 SUWI Questions (Walvis) & $\mathrm{y}$ & 1 \\
\hline 26448_335 SUWI & $\mathrm{Y}$ & 1 \\
\hline 26448_337 SUWI A1-2007 report & $\mathrm{Y}$ & 0 \\
\hline 26448_342 SUWI & $\mathrm{Y}$ & 0 \\
\hline 26448_343 SUWI Q $2200714^{\text {th }}$ report & $\mathrm{Y}$ & 0 \\
\hline 26448_346 SUWI/WALVIS & $\mathrm{Y}$ & 0 \\
\hline 26448_350 SUWI Q3 2007 & $\mathrm{y}$ & 0 \\
\hline $31066 \_8$ & $y$ & 4 \\
\hline Proceedings20062007-1161-1181 & $\mathrm{y}$ & 5 \\
\hline Proceedings20062007-1294-1342 & $\mathrm{Y}$ & 2 \\
\hline Proceedings20062007-1371-1376 & $y$ & 0 \\
\hline 30942_3 Organisation Civil service & $\mathrm{Y}$ & 0 \\
\hline Proceedings20062007-2263-2266 & $\mathrm{Y}$ & 1 \\
\hline Proceedings20062007-2614-2618 & $\mathrm{y}$ & 2 \\
\hline 30970_6 Law on data provision & $\mathrm{Y}$ & 1 \\
\hline 29461_34 Re-integration & $\mathrm{Y}$ & 1 \\
\hline 29461_35 Re-integration & $\mathrm{Y}$ & 1 \\
\hline 29461_37 Re-integration & $\mathrm{Y}$ & 0 \\
\hline 29461_40 Re-integration & $\mathrm{Y}$ & 1 \\
\hline 31066_9 Walvis AO & $\mathrm{Y}$ & 2 \\
\hline 17050_340 Fraud and improper use of benefits & $\mathrm{y}$ & 0 \\
\hline Proceedings20062007-5021-5024 & $\mathrm{Y}$ & 1 \\
\hline Proceedings20072008-2023-2029 & $\mathrm{Y}$ & $\frac{1}{1}$ \\
\hline Proceedings $20072008-2629-2654$ & $\mathrm{y}$ & 1 \\
\hline Fiscal 2008 & $\begin{array}{l}\text { Relevance } \\
\text { operations }\end{array}$ & \# remarks by MPs \\
\hline 31200XV_2 Budget 2008 & $\mathrm{Y}$ & 0 \\
\hline 31200XV_9 Budget 2008 Questions & $\mathrm{Y}$ & 6 \\
\hline 31200XV_30 Budget 2008 Motion & $\mathrm{Y}$ & 1 \\
\hline 31200XV_31 Budget 2008 Motion & $\mathrm{Y}$ & 1 \\
\hline 31200XV_36 Budget 2008 Motion & $\mathrm{Y}$ & 1 \\
\hline 31200XV_59 Budget 2008 Letter & $\mathrm{Y}$ & 0 \\
\hline 31200XV_62 Budget 2008 Protocol & $\mathrm{y}$ & 1 \\
\hline $31200 X X_{1} 65$ Budget 2008 reply on motions & $\mathrm{y}$ & 0 \\
\hline 31200XV_72 Budget 2008 Protocol & $\mathrm{Y}$ & 2 \\
\hline $31474 X V$ _2. $1^{\text {st }}$ supplement to budget 2008 & $\mathrm{Y}$ & 0 \\
\hline $31474 X V \_61^{\text {st }}$ supplement, questions & $\mathrm{Y}$ & 2 \\
\hline $31792 X V \_22^{\text {nd }}$ supplement to budget 2008 Notes & $\mathrm{y}$ & 0 \\
\hline 31792_4 2 $2^{\text {nd }}$ supplement, questions & $\mathrm{Y}$ & 1 \\
\hline 31924XV_1 Annual 2008 SZW & $\mathrm{Y}$ & 0 \\
\hline 31924XV_6 Annual 2008 Questions & $\mathrm{Y}$ & 1 \\
\hline 31924XV_13 Annual 2008 & $\mathrm{Y}$ & 1 \\
\hline 31924_14 Annual 2008 & $\mathrm{Y}$ & 1 \\
\hline 26448_347 SUWI & $\mathrm{Y}$ & 0 \\
\hline 26448_353 SUWI/WALVIS & $\mathrm{Y}$ & 0 \\
\hline 26448_355 SUWI & $\mathrm{Y}$ & 0 \\
\hline 26448_357 SUWI Protocol & $\mathrm{y}$ & 2 \\
\hline 26448_362 SUWI & $\mathrm{Y}$ & 0 \\
\hline 26448-363 SUWI & $\mathrm{Y}$ & 0 \\
\hline 26448_365 SUWI & $\mathrm{Y}$ & 0 \\
\hline 26448_368 SUWI/WALVIS & $\mathrm{Y}$ & 0 \\
\hline 26448_369 SUWI & $y$ & 0 \\
\hline 26448_370 SUWI & $\mathrm{n}$ & 0 \\
\hline 26448_371 SUWI & $\mathrm{Y}$ & 0 \\
\hline 26448_376 SUWI & $\mathrm{Y}$ & 0 \\
\hline 26448_379 SUWI & $\mathrm{Y}$ & 3 \\
\hline 26448_380 SUWI & $\mathrm{Y}$ & 0 \\
\hline
\end{tabular}




\begin{tabular}{|c|c|c|}
\hline Document regarding UWV & $\begin{array}{l}\text { Relevance } \\
\text { operations }\end{array}$ & \# remarks by MPs \\
\hline 26448_383 SUWI & $\mathrm{Y}$ & 0 \\
\hline 26448_384 SUWI & $\mathrm{N}$ & 0 \\
\hline 26448_386 SUWI & $\mathrm{Y}$ & 1 \\
\hline 26448_387 SUWI/WALVIS & $\mathrm{Y}$ & 0 \\
\hline 26448_388 SUWI & $\mathrm{Y}$ & 0 \\
\hline 26448_389 SUWI & $\mathrm{Y}$ & 0 \\
\hline 26448_397 SUWI & $\mathrm{y}$ & 0 \\
\hline 31514_2 and 3. Change of SUWI law & $\mathrm{Y}$ & 0 \\
\hline 31514_7 Change of SUWI law & $\mathrm{Y}$ & 0 \\
\hline 31514-14 Change of SUWI law & $\mathrm{Y}$ & 0 \\
\hline 31514-16 Change of SUWI law & $\mathrm{Y}$ & 1 \\
\hline 31514_22 Change of SUWI law & $\mathrm{Y}$ & 1 \\
\hline 31514_23 Change of SUWI law & $\mathrm{Y}$ & 1 \\
\hline 28719_43 Re-integration & $\mathrm{y}$ & 0 \\
\hline 28719_44 Re-integration & $\mathrm{Y}$ & 3 \\
\hline 28719_56 Re-integration & $\mathrm{Y}$ & 0 \\
\hline 28719_57 Re-integration & $\mathrm{Y}$ & 4 \\
\hline 28719_59 Re-integration & $\mathrm{Y}$ & 0 \\
\hline 28179_60 Re-integration & $\mathrm{Y}$ & 0 \\
\hline 31201_3 Civil service & $\mathrm{Y}$ & 0 \\
\hline 25268_63 kZBO & $\mathrm{Y}$ & 0 \\
\hline 31224_26 Participation youngsters & $\mathrm{Y}$ & 0 \\
\hline 31224_28 Participation youngsters. & $\mathrm{Y}$ & 1 \\
\hline 29362_142 Modernising government. & $\mathrm{Y}$ & 1 \\
\hline 31749 Unemployment youngsters & $\mathrm{N}$ & 0 \\
\hline 31586_Restructuring personal debts & $\mathrm{Y}$ & 0 \\
\hline Proceedings 20072008_6041-6054 & $\mathrm{y}$ & 1 \\
\hline Proceedings20082009-1239-1255 & $\mathrm{Y}$ & 5 \\
\hline Proceedings20082009-1279-1289 & $\mathrm{Y}$ & 0 \\
\hline 26448_397 SUWI unnumbered: & $\mathrm{Y}$ & 0 \\
\hline 26448_397 SUWI unnumbered: & $\mathrm{y}$ & 0 \\
\hline 26448_397 SUWI unnumbered: & $y$ & 0 \\
\hline 26448_397 SUWI unnumbered: & $\mathrm{y}$ & 0 \\
\hline 26448_397 SUWI unnumbered: & $\mathrm{y}$ & 0 \\
\hline Fiscal 2009 & $\begin{array}{l}\text { Relevance } \\
\text { operations }\end{array}$ & \# remarks by MPs \\
\hline 31700XV_2 Budget 2009 Notes & $\mathrm{Y}$ & 0 \\
\hline 31700XV_12 Budget 2009, questions & $\mathrm{Y}$ & 10 \\
\hline 31700XV_29/44 Budget 2009 Amendement & $\mathrm{Y}$ & 1 \\
\hline 31700XV_51 Budget 2009 Protocol & $\mathrm{Y}$ & 2 \\
\hline 31965 1 $11^{\text {st }}$ supplement to budget 2009 & $\mathrm{y}$ & 0 \\
\hline 26448_390 SUWI & $\mathrm{y}$ & 0 \\
\hline 26448_392 SUWI & $\mathrm{Y}$ & 2 \\
\hline 26448_394 SUWI & $\mathrm{Y}$ & 4 \\
\hline 26448_396 SUWI motion & $\mathrm{Y}$ & 1 \\
\hline 26448_397 SUWI unnumbered & $\mathrm{y}$ & 0 \\
\hline 26448_400 SUWI & $\mathrm{Y}$ & 0 \\
\hline 26448-404 SUWI letter & $\mathrm{Y}$ & 0 \\
\hline 26448_405 SUWI Protocol & $\mathrm{Y}$ & 1 \\
\hline 26448 406 SUWI T 1 report 2009 & $\mathrm{y}$ & 0 \\
\hline Appendix to proceedings nr 2328 and 233920082009 & $\mathrm{Y}$ & 1 \\
\hline
\end{tabular}




\section{FBKVB}

$\mathrm{N}=82$ documents containing ' begroting beeldende kunst' in text $\mathrm{N}=8$ documents containing ' begroting kunstenfondsen' in text $\mathrm{N}=41$ documents containing ' begroting cultuurfondsen' in text $\mathrm{N}=6$ documents containing ' begroting fonds BKVB' in text.

$\mathrm{N}=50$ documents containing ' jaarverslag beeldende kunst' in text $\mathrm{N}=8$ documents containing ' jaarverslag kunstenfondsen in text $\mathrm{N}=27$ documents containing ' jaarverslag cultuurfondsen' in text. $\mathrm{N}=3$ documents containing ' jaarverslag fonds BKVB' in text.

\begin{tabular}{|c|c|c|}
\hline Document regarding FBKVB & $\begin{array}{l}\text { Relevance } \\
\text { operations }\end{array}$ & $\begin{array}{l}\text { \# remarks by } \\
\text { MPs }\end{array}$ \\
\hline \multicolumn{3}{|l|}{ Fiscal 2006} \\
\hline 31031_VIII_1 Annual report 2006 & $\mathrm{~N}$ & 0 \\
\hline \multicolumn{3}{|l|}{ Fiscal 2007} \\
\hline 30800VIII_2 Budget 2007 Notes & $\mathrm{N}$ & 0 \\
\hline 30800VIII_8 Letter & $\mathrm{Y}$ & 0 \\
\hline 30800VIII_35 Letter & $\mathrm{N}$ & 0 \\
\hline 31444VIII_1 Annual report 2007 & $y$ & 0 \\
\hline 31444VIII_8 Questions & $\mathrm{N}$ & 0 \\
\hline Proceedings20062007 Question 1405 & $\mathrm{Y}$ & 1 \\
\hline 30847_5 Law on arts policy & $\mathrm{Y}$ & 1 \\
\hline 30847_13 & $\mathrm{Y}$ & 1 \\
\hline Proceedings20062007_3493-3511 & $\mathrm{Y}$ & 1 \\
\hline Proceedings20062007_3513-3529 & $y$ & 0 \\
\hline 28989_56 Memorandum Culture & $\mathrm{Y}$ & 2 \\
\hline 28989_57 Memorandum Culture_Letter & $\mathrm{Y}$ & 0 \\
\hline 31201_3 Trendnota arbeidszaken & $\mathrm{Y}$ & 0 \\
\hline \multicolumn{3}{|l|}{ Fiscal 2008} \\
\hline 31200VIII_2 Budget 2008 Notes & $\mathrm{N}$ & 0 \\
\hline 31200VIII_31 Budget 2008 Questions & $\mathrm{N}$ & 0 \\
\hline 31200VIII_135 Budget 2008 questions & $\mathrm{N}$ & 0 \\
\hline 31924VIII_1 Annual report 2008 & $\mathrm{y}$ & 0 \\
\hline 25268_63 ZBOs & $\mathrm{Y}$ & 0 \\
\hline 28989_76 Art policy & $y$ & 2 \\
\hline 25434_40 support film industry & $\mathrm{Y}$ & 0 \\
\hline 25434_42 & $\mathrm{y}$ & 0 \\
\hline 31482_15 art subsidies 2009-2012 & $\mathrm{N}$ & 0 \\
\hline 31482_18 art subsidies $2009-2012$ & $\mathrm{y}$ & 1 \\
\hline \multicolumn{3}{|l|}{ Fiscal 2009} \\
\hline 31700VIII_1 Budget 2009 Notes & $\mathrm{N}$ & 0 \\
\hline 31700VIII_13 Budget 2009 questions & $\mathrm{N}$ & 0 \\
\hline 31700VIII_30 Budget 2009 & $\mathrm{Y}$ & 1 \\
\hline 31700VIII_61 & $\mathrm{Y}$ & 1 \\
\hline 31700VIII_134 & $\mathrm{N}$ & 0 \\
\hline OCW key data 2004-2008 & $\mathrm{n}$ & 0 \\
\hline Proceedings 18808 & $\mathrm{Y}$ & 1 \\
\hline
\end{tabular}




\section{$\mathrm{VF} / \mathrm{PF}$}

$\mathrm{N}=101$ documents containing ' begroting participatiefonds' in text.

$\mathrm{N}=57$ documents containing ' jaarverslag participatiefonds' in text.

$\mathrm{N}=33$ documents containing ' begroting vervaningsfonds' in text.

$\mathrm{N}=25$ documents containing ' jaarverslag vervangingsfonds' in text

\begin{tabular}{|l|l|l|}
\hline Document regarding Vf/Pf & Relevance operations & \# remarks by MPs \\
\hline Fiscal 2005 & & \\
\hline 30800VIII_67_Annual reports pf/vf & y & 0 \\
\hline Fiscal 2006 & & \\
\hline 31031VIII_1. Annual report 2006 OCW & y & 0 \\
\hline 31031_1A: Appendix to Annual report State & y & 0 \\
\hline 31031VIII_1. Annual report 2006 OCW & y & 0 \\
\hline 31200VIII_27. Annual reports Pf/Vf & y & 0 \\
\hline 30885VIII_3_Questions 2nd supplement to budget 2006 & y & 1 \\
\hline 30800VIII_153. Annual reports Pf/Vf & y & 0 \\
\hline Fiscal 2007 & & \\
\hline 30800VIII_2 Budget 2007 OCW notes & y & 0 \\
\hline 30800VIII_85. Evaluation funding of secondary schools & y & 0 \\
\hline 31061_11 1st supplement 2006 & y & 0 \\
\hline 31061VIII_3: 1st supplement budget OCW2007. Questions & y & 1 \\
\hline 31290VIII_2.2nd supplement to budget 2007 & y & 0 \\
\hline 31200VIII_180: announcement annual reports Pf/Vf 2007 & y & 0 \\
\hline 31444VIII_8: Annual report 0CW, questions & y & 0 \\
\hline 31700VIII_4_Annual reports Pf/Vf & y & 0 \\
\hline 31201_3: Trendnota arbeidszaken overheid & y & 0 \\
\hline Fiscal 2008 & & \\
\hline 31200 Appendix to budgetmemorandum 2008 & n & 0 \\
\hline 31200VIII_2 Budget OCW 2008 notes & y & 0 \\
\hline 31200VIII_31: Budget OCW 2008 Questions & y & 0 \\
\hline 31200VIII_47: Employability in education & y & 0 \\
\hline 31200VIII_85: Budget OCW 2008: Questions & y & 0 \\
\hline 31792VIII_2nd supplement 2008 & y & 0 \\
\hline 31924VIII_Annual report OCW & y & 0 \\
\hline 31700VIII_199 announcement annual reports pf vf & y & 0 \\
\hline 25286_63 Letter implementation kZBO & y & 0 \\
\hline Proceedings 20072008_2887-2896 & y & 1 \\
\hline Proceedings 20072008_2688-2708 & y & 1 \\
\hline Proceedings 20072008_2887-2896 & y & 0 \\
\hline 31700VIII_2: Budget2009 notes & y & 0 \\
\hline 31965VIII_2 1st supplement 2009 & y & 0 \\
\hline & & \\
\hline
\end{tabular}




\section{AFM}

$\mathrm{N}=207$ documents containing ' begroting AFM' in text

$\mathrm{N}=169$ documents containing ' jaarverslag AFM' in text

References to motions and promises by minister in the ministry's budget documents/annual reports not included. Debates on problem ABN/AMRO \& Fortis Bank (sale to foreign banks in 2007/2008) not included.

Key issue: increase in monitoring costs

\begin{tabular}{|c|c|c|}
\hline Document regarding AFM & $\begin{array}{l}\text { Relevance } \\
\text { operations }\end{array}$ & \# remarks by MPs \\
\hline \multicolumn{3}{|l|}{ Fiscal 2006} \\
\hline 30885IXB_2 2 $2^{\text {nd }}$ supplement 2006 Notes & $\mathrm{Y}$ & 0 \\
\hline 30885IXB_4 $2^{\text {nd }}$ supplement 2006 Questions & $\mathrm{Y}$ & 3 \\
\hline 31031IXB_1 Annual 2006 notes & $\mathrm{Y}$ & 0 \\
\hline 31031IXB_4 Annual 2006 Notes & $\mathrm{Y}$ & 0 \\
\hline 31031IXB_7 Annual 2006 Questions & $\mathrm{Y}$ & 1 \\
\hline 31031IXB_8 Annual 2006 Proceedings & $\mathrm{Y}$ & 1 \\
\hline 30800IXB_36 Annual report AFM & $\mathrm{Y}$ & 0 \\
\hline 30413_53 Pensionplan legislation & $\mathrm{Y}$ & 1 \\
\hline $\begin{array}{l}\text { 30413_62 Pension plan legislation, Protocol } \\
\text { (also Proceedings } 20062007 \text { 79-100) }\end{array}$ & $\mathrm{Y}$ & 3 \\
\hline 30413_79 Pensionplan legislation, Motion & $\mathrm{Y}$ & 1 \\
\hline 30413 88 Pensionplan legislation. Letter & $\mathrm{N}$ & 0 \\
\hline Proceedings20062007 439-469 & $\mathrm{Y}$ & 1 \\
\hline Proceedings20062007 511-530 & Y & 1 \\
\hline Proceedings20062007 595-599 Appendix & $\mathrm{Y}$ & 1 \\
\hline \multicolumn{3}{|l|}{ Fiscal 2007} \\
\hline 30800IXB_2 Budget 2007 Notes & $\mathrm{Y}$ & 0 \\
\hline 30800IXB_4 Budget 2007 Questions & $\mathrm{Y}$ & 1 \\
\hline 30800IXB_27 Budget 2007 protocol & $\mathrm{Y}$ & 1 \\
\hline 31061IXB_2 $1^{\text {st }}$ supplement 2007 Notes & $\mathrm{N}$ & 0 \\
\hline 31290IXB_2 2 $2^{\text {nd }}$ supplement 2007 Notes & $\mathrm{Y}$ & 0 \\
\hline 31290IXB_2 2 ${ }^{\text {nd }}$ supplement 2007 Questions & $\mathrm{y}$ & 1 \\
\hline 31444IXB_1 Annual report 2007 & $\mathrm{Y}$ & 0 \\
\hline 31444IXB_5 Annual report 2007 & $\mathrm{Y}$ & 3 \\
\hline 31444IXB_8 Annual report 2007 & $\mathrm{Y}$ & 2 \\
\hline 31444XV_1 Annual report 2007 & $\mathrm{Y}$ & 0 \\
\hline 31200IXB_20 Annual report 2007 AFM & $\mathrm{Y}$ & 0 \\
\hline 31200IXB_34 Annual report 2007 AFM, questions & $\mathrm{Y}$ & 24 \\
\hline 30942_3 Organisation Civil service & $\mathrm{Y}$ & 0 \\
\hline 27831 23 Framework for monitoring services & $\mathrm{Y}$ & 0 \\
\hline 29507_45 Law on financial services & $\mathrm{Y}$ & 1 \\
\hline 30928_8 Civil code; consumer protection & $\mathrm{Y}$ & 2 \\
\hline 30419_22 Mergers & $\mathrm{Y}$ & 1 \\
\hline 30598_2 Evaluation of money exchange offices & $\mathrm{Y}$ & 1 \\
\hline 31123_1 Liability of monitoring Authorities & $\mathrm{Y}$ & 0 \\
\hline 28122_23 Reform monitoring financial institutions & $\mathrm{Y}$ & 0 \\
\hline 28122_25 Reform monitoring financial institutions & $\mathrm{y}$ & 3 \\
\hline 31270_3 Adaption of Accounting institutions legislation & $\mathrm{Y}$ & 0 \\
\hline Proceedings20062007 4287-4301 & $\mathrm{Y}$ & 1 \\
\hline \multicolumn{3}{|l|}{ Fiscal 2008} \\
\hline 31200_11 BudgetMemorandum 2008 Motion & $\mathrm{N}$ & 1 \\
\hline
\end{tabular}




\begin{tabular}{|c|c|c|}
\hline Document regarding AFM & $\begin{array}{l}\text { Relevance } \\
\text { operations }\end{array}$ & \# remarks by MPs \\
\hline 31200IXB_2 Budget 2008 Notes & $\mathrm{Y}$ & 0 \\
\hline 31200IXB_8 Budget 2008 Letter & $\mathrm{Y}$ & 0 \\
\hline 31200XIII_4 Budget 2008 Questions & $\mathrm{N}$ & 1 \\
\hline 31200XIII_10 Budget 2008 Letter & $\mathrm{Y}$ & 1 \\
\hline 31474IXB_2 $1^{\text {st }}$ supplement 2008 & $\mathrm{Y}$ & 0 \\
\hline 31792IXB_2 2 $2^{\text {nd }}$ supplement 2008 & $\mathrm{Y}$ & 0 \\
\hline 31792IXB_3 $2^{\text {nd }}$ supplement 2008 & $\mathrm{Y}$ & 1 \\
\hline 31924IXB_1 Annual report 2008 & $\mathrm{Y}$ & 0 \\
\hline 31924IXB_4 Annual report 2008 & $\mathrm{Y}$ & 0 \\
\hline 31924IXB_7 Annual report 2008 & $\mathrm{Y}$ & 1 \\
\hline 31700IXB_24 and appendix: Annual report AFM & $\mathrm{Y}$ & 0 \\
\hline 31924XV_1 Annual report & $\mathrm{Y}$ & 0 \\
\hline 31201_3 Civil service & $\mathrm{Y}$ & 0 \\
\hline 22112_712. Proposals EU & $\mathrm{Y}$ & 0 \\
\hline 22112_787. Proposals EU & $\mathrm{Y}$ & 0 \\
\hline $25268 \_56$ kZBO & $\mathrm{Y}$ & 1 \\
\hline 25268_63 kZBO & $\mathrm{Y}$ & 0 \\
\hline 28122_29 Restructuring monitoring financial sector & $\mathrm{Y}$ & 1 \\
\hline 29911_16 Organised crime & $\mathrm{N}$ & 0 \\
\hline 30413_119 Pension plan legislation & $\mathrm{Y}$ & 1 \\
\hline 31052_18 ABN-AMRO sale & $\mathrm{N}$ & 0 \\
\hline 31083_10 Corporate governance & $\mathrm{Y}$ & 0 \\
\hline $\begin{array}{l}\text { 31093_6_Implementation EU regulations } \\
\text { (also: 31093_7 and proceedings } 200720086072-6088 \text { ) }\end{array}$ & $\mathrm{Y}$ & 4 \\
\hline $\begin{array}{l}\text { 31093_8 Implementation EU regulations, change in } \\
\text { legislation }\end{array}$ & $\mathrm{Y}$ & 0 \\
\hline 31371_8 Financial crisis & $\mathrm{Y}$ & 1 \\
\hline 31477_5 Money laundering Questions & $\mathrm{Y}$ & 1 \\
\hline Proceedings20082009 614-620 & $\mathrm{Y}$ & 1 \\
\hline Proceedings20072008 733-745 & $\mathrm{Y}$ & 2 \\
\hline Proceedigs20072009 6693-6706 & $\mathrm{Y}$ & 2 \\
\hline Appendix to proceedings20082009_1049 & $\mathrm{Y}$ & 1 \\
\hline \multicolumn{3}{|l|}{ Fiscal 2009} \\
\hline 31700IXB_2 Budget 2009 Notes & $\mathrm{Y}$ & 0 \\
\hline 31965IXB_2 1 $1^{\text {st }}$ supplement 2009 & $\mathrm{Y}$ & 0 \\
\hline 31965IXB_3 1 $1^{\text {st }}$ supplement 2009 & $\mathrm{Y}$ & 1 \\
\hline 22712_874 EU proposals & $\mathrm{Y}$ & 0 \\
\hline 27562_33 Urban development & $\mathrm{Y}$ & 1 \\
\hline 29507_85 Law on financial services & $\mathrm{N}$ & 0 \\
\hline 31070_24. Coalition agreement reviewed & $\mathrm{Y}$ & 0 \\
\hline 31892_3 Cross border payments & $\mathrm{Y}$ & 0 \\
\hline 31904_6Energy markets & $\mathrm{Y}$ & 1 \\
\hline Proceedings20082009 6299-6395 & $\mathrm{N}$ & 1 \\
\hline Proceedings20082009 6397-6440 & $\mathrm{Y}$ & 1 \\
\hline Proceedings20082009 7975-8087 & $\mathrm{Y}$ & 1 \\
\hline Proceedings20082009 Appendix 2333 & $\mathrm{Y}$ & 1 \\
\hline Proceedings20082009 Appendix 3052 & $\mathrm{~N}$ & 1 \\
\hline Not numbered: report on reorganisation civil service & $\mathrm{Y}$ & 0 \\
\hline
\end{tabular}




\section{CFV}

46 documents containing ' begroting CFV' in text.

37 documents containing ' jaarverslag CFV' in text.

References to promises of minister to Parliament as mentioned in budget documents and annual reports are not included in the list below.

\begin{tabular}{|c|c|c|}
\hline Document regarding CFV & $\begin{array}{l}\text { Relevance } \\
\text { operations }\end{array}$ & $\begin{array}{l}\text { \# remarks by } \\
\text { MPs }\end{array}$ \\
\hline \multicolumn{3}{|l|}{ Fiscal 2006} \\
\hline 31031_XI_1 Annual report 2006 & $\mathrm{Y}$ & 0 \\
\hline 29453_110 Housing associations & $\mathrm{Y}$ & 0 \\
\hline \multicolumn{3}{|l|}{ Fiscal 2007} \\
\hline 30800XI_2 budget 2007 Notes & $\mathrm{Y}$ & 0 \\
\hline 30995_33 Improving housing & $\mathrm{N}$ & 0 \\
\hline 31444XI_1 Annual 2007 & $\mathrm{Y}$ & 0 \\
\hline Proceedings20072008: 2319-2337 & $\mathrm{N}$ & 3 \\
\hline \multicolumn{3}{|l|}{ Fiscal 2008} \\
\hline 31200XVIII_2 budget 2008 notes & $\mathrm{Y}$ & 0 \\
\hline 31200_39 Questions to budget memorandum & $\mathrm{N}$ & 0 \\
\hline 31474XVIII_5 $1^{\text {st }}$ supplement 2008 Questions & $\mathrm{N}$ & 1 \\
\hline 31924_XVIII_3 Annual report 2008 & $\mathrm{~N}$ & 0 \\
\hline 31205_9 Changes in Tax laws & $\mathrm{N}$ & 0 \\
\hline 29453_68 Housing associations & $\mathrm{N}$ & 0 \\
\hline 29453_71 Housing associations & $\mathrm{Y}$ & 1 \\
\hline 29453_80 Housing associations & $\mathrm{N}$ & 0 \\
\hline 29453_86 Housing associations & $\mathrm{Y}$ & 1 \\
\hline 29453_89 Housing associations & $\mathrm{Y}$ & 1 \\
\hline 29453_96 Housing associations & $\mathrm{N}$ & 0 \\
\hline 30995_42 Improving housing & $\mathrm{N}$ & 1 \\
\hline 30995_45 Improving housing & $\mathrm{y}$ & 2 \\
\hline 30995_46 Improving housing & $\bar{Y}$ & 1 \\
\hline 30995_59 Improving housing Protocol & $\mathrm{y}$ & 4 \\
\hline 30995_61 Improving housing. Protocol & $\mathrm{Y}$ & 1 \\
\hline 30995_68 Improving housing & $\mathrm{Y}$ & 0 \\
\hline 25268_63 kZBO & $\mathrm{Y}$ & 0 \\
\hline Proceedings20072008, Appendix 3444 & $\mathrm{Y}$ & 1 \\
\hline \multicolumn{3}{|l|}{ Fiscal 2009} \\
\hline 31700XVIII_2 Budget 2009 notes & $\mathrm{Y}$ & 0 \\
\hline 29453_100 Housing associations & $\mathrm{Y}$ & 1 \\
\hline 29453_115 Housing associations & $\bar{Y}$ & 2 \\
\hline Proceedings20082009 7447-7524 & $\mathrm{N}$ & 1 \\
\hline Proceedings 20082009 Appendix 1748 & $\mathrm{Y}$ & 1 \\
\hline
\end{tabular}




\section{NAK}

$\mathrm{N}=25$ documents containing ' begroting NAK' in text

$\mathrm{N}=46$ documents containing ' begroting keuringsdienst' in text

$\mathrm{N}=12$ documents containing ' jaarverslag NAK' in text

$\mathrm{N}=18$ documents containing ' jaarverslag ' keuringsdienst' in text

\begin{tabular}{|l|l|l|}
\hline Document regarding NAK & $\begin{array}{l}\text { Relevance } \\
\text { operations }\end{array}$ & $\begin{array}{l}\text { \# remarks by } \\
\text { MPs }\end{array}$ \\
\hline Fiscal 2006 & & \\
\hline 31031_XIV_1 Annual report 2006 & Y & 0 \\
\hline Fiscal 2007 & & \\
\hline 30800XIV_2 Budget 2008 & N & 0 \\
\hline 30800XIV_33 Budget 2008 Letter & Y & 0 \\
\hline 30800XIV_103 Budget 2008 Letter & Y & 0 \\
\hline 30800XIV_124 Motion & Y & 1 \\
\hline 30800XIV_133 & Y & 0 \\
\hline 30800XIV_140 Protocol & Y & 2 \\
\hline 31061XIV_2 1st supplement to budget 2007 & Y & 0 \\
\hline 31290XIV_2 2nd supplement to budget 2007 & Y & 0 \\
\hline 31444XIV_3 Annual 2007 Notes & Y & 0 \\
\hline 31444XIV_8 Annual 2007, questions & Y & 1 \\
\hline Proceedings 20062007_5122-5124 & Y & 0 \\
\hline 30942_3 Letter minBZK & Y & 0 \\
\hline 31201_3 Letter minBZK & Y & 0 \\
\hline Fiscal 2008 & & \\
\hline 31200XIV_2 Budget 2008 Notes & Y & 0 \\
\hline 31200XIV_158 Budget 2008 Letter & Y & 0 \\
\hline 31200XIV_178 Budget 2008 Letter & Y & 0 \\
\hline 31200XIV_181 Budget 2008 Letter & Y & 0 \\
\hline 31200XIV_206 Budget 2008 Protocol & Y & 2 \\
\hline 31924XIV_3. Annual report 2006 Notes & $\mathrm{N}$ & 0 \\
\hline 25268_63 kZBO & $\mathrm{N}$ & 0 \\
\hline 31809_3. Adaption minLNV legislation to kZBO & $\mathrm{N}$ & 0 \\
\hline Fiscal 2009 & & \\
\hline 31700XIV_2 Budget 2009 Notes & $\mathrm{Y}$ & 0 \\
\hline 31700XIV_4 Budget 2009 Letter & $\mathrm{Y}$ & 0 \\
\hline 31700XIV_8 Budget 2009 Letter & $\mathrm{Y}$ & 1 \\
\hline 31700XIV_16 Budget 2009 Letter & Y & 0 \\
\hline 31700XIV_153 & $\mathrm{Y}$ & 7 \\
\hline & & \\
\hline
\end{tabular}




\section{NMa}

$\mathrm{N}=406$ documents containing ' begroting nma' in text $\mathrm{N}=240$ documents containing ' jaarverslag nma' in text Neglecting case specific decisions of nma

Regular debates on postal market, cure and care market and the energy market and NMa's role in monitoring.

\begin{tabular}{|c|c|c|}
\hline Document regarding $\mathrm{NMa}$ & $\begin{array}{l}\text { Relevance } \\
\text { operations }\end{array}$ & $\begin{array}{l}\text { \# remarks by } \\
\text { MPs }\end{array}$ \\
\hline \multicolumn{3}{|l|}{ Fiscal 2006} \\
\hline $30885 \_12^{\text {nd }}$ supplement 2006 & $\mathrm{~N}$ & 0 \\
\hline 30885XIII_2 2 $2^{\text {nd }}$ supplement 2006 Notes & $\mathrm{y}$ & 0 \\
\hline 30885XIII_3 $2^{\text {nd }}$ supplement 2006 & $\mathrm{Y}$ & 3 \\
\hline 30885XII_5 2 $2^{\text {nd }}$ supplement 2006 & $\mathrm{Y}$ & 1 \\
\hline 31031_XIII_1 Annual report 2006 & $\mathrm{Y}$ & 0 \\
\hline 31031_XIII_4 Annual report 2006 & $\mathrm{Y}$ & 0 \\
\hline 31031_XIII_6 Annual report 2006 & $\mathrm{Y}$ & 2 \\
\hline 31031_XIII_8 Annual report 2006 & $\mathrm{Y}$ & 2 \\
\hline 31031XVI_5 Annual report 2006 & $\mathrm{Y}$ & 1 \\
\hline 30800 XIII_50 Annual report nma & $\mathrm{Y}$ & 0 \\
\hline 27659_80 Licensing care providers & $\mathrm{N}$ & 0 \\
\hline 28244_115 Fraud in building and construction & $\mathrm{Y}$ & 1 \\
\hline 29689_114 Restructuring Care & $\mathrm{N}$ & 0 \\
\hline 30595_5 Housing rents policy & $\mathrm{N}$ & 1 \\
\hline 30595_6 Housing rents policy & $\mathrm{N}$ & 0 \\
\hline 30601_5 Modernising waterboards & $\mathrm{Y}$ & 1 \\
\hline 30601_6 Modernising waterboards & $\mathrm{Y}$ & 0 \\
\hline 30913_3 Monitoring Pilot services & $\mathrm{Y}$ & 0 \\
\hline Proceedings20052006 6547-6564 & $\mathrm{Y}$ & 0 \\
\hline Proceedings20062007 501-530 & $\mathrm{Y}$ & 1 \\
\hline Proceedings20062007 973-1000 & $\mathrm{Y}$ & 1 \\
\hline \multicolumn{3}{|l|}{ Fiscal 2007} \\
\hline 30800XIII_2 Budget 2007 Notes & $\mathrm{Y}$ & 0 \\
\hline 30800VI_13 Budget2007 & $\mathrm{N}$ & 0 \\
\hline 30800VIII_38 Budget2007 & $\mathrm{Y}$ & 1 \\
\hline 30800VIII_12 Budget 2007 questions & $\mathrm{Y}$ & 3 \\
\hline 30800XVI_27 Budget 2007 & $\mathrm{~N}$ & 0 \\
\hline 30800A_9 Budget2007 & $\mathrm{Y}$ & 0 \\
\hline 31061XIII_2 1st supplement 2007 & $\mathrm{Y}$ & 0 \\
\hline 31061XIII_3 1 $1^{\text {st }}$ supplement 2007 & $\mathrm{Y}$ & 3 \\
\hline 31290_1 $2^{\text {nd }}$ supplement 2007 & $\mathrm{~N}$ & 0 \\
\hline 31290_XIII_2 2 $2^{\text {nd }}$ supplement 2007 & $\mathrm{Y}$ & 0 \\
\hline 31290_XIII_3 2 nd supplement 2007 & $\mathrm{~N}$ & 1 \\
\hline 31200XIII_51 annual report nma & $\mathrm{Y}$ & 0 \\
\hline 31444XIII_1 Annual report & $\mathrm{Y}$ & 0 \\
\hline 31444XIII_9 Annual report 2007 & $\mathrm{Y}$ & 2 \\
\hline 31444XIII_16 Annual report 2007 & $\mathrm{Y}$ & 1 \\
\hline 21501_135 EU summit & $\mathrm{Y}$ & 1 \\
\hline $\begin{array}{l}22112 \text { 499 EU regulations } \\
\text { (also 22112_508) }\end{array}$ & $\mathrm{Y}$ & 0 \\
\hline 22112-578 EU regulations & $\mathrm{Y}$ & 0 \\
\hline 27831_23 Vision on monitoring & $\mathrm{y}$ & 0 \\
\hline 29515-197 Reduction bureaucracy costs & $\mathrm{Y}$ & 1 \\
\hline
\end{tabular}




\begin{tabular}{|c|c|c|}
\hline Document regarding NMa & $\begin{array}{l}\text { Relevance } \\
\text { operations }\end{array}$ & $\begin{array}{l}\text { \# remarks by } \\
\text { MPs }\end{array}$ \\
\hline 30891_4 Cabinet formation & $\mathrm{N}$ & 0 \\
\hline 30895_9 Water supply & $\mathrm{Y}$ & 2 \\
\hline 31055_2 Monitoring on competition & $\mathrm{Y}$ & 0 \\
\hline 31055_3 Monitoring on competition & $\mathrm{Y}$ & 4 \\
\hline 31055_4 Monitoring on competition; 31055_5 & $\mathrm{Y}$ & 9 \\
\hline 31123_1 Liability of monitoring Authorities & $\mathrm{Y}$ & 0 \\
\hline 31201_3 Civil service & $\mathrm{Y}$ & 0 \\
\hline Proceedings20062007 2157-2186 & $\mathrm{N}$ & 1 \\
\hline Proceedings20062007 3397-3412 & $\mathrm{Y}$ & 2 \\
\hline Proceedings20062007 3529-3550 & $\mathrm{Y}$ & 1 \\
\hline Proceedings20062007 Appendix 1586 & $\mathrm{Y}$ & 1 \\
\hline Proceedings20062007 Appendix 2511 & $\mathrm{Y}$ & 1 \\
\hline Proceedings20072008 848-872 & $\mathrm{Y}$ & 1 \\
\hline Proceedings20072008 987-995 & $\mathrm{Y}$ & 2 \\
\hline \multicolumn{3}{|l|}{ Fiscal 2008} \\
\hline 31200_6 Opposition's budget proposal & $\mathrm{N}$ & 1 \\
\hline 31200_11 budget 2008 & $\mathrm{~N}$ & 1 \\
\hline 31200XIII_2 Budget2008 Notes & $\mathrm{Y}$ & 0 \\
\hline 31200XIII_4 Budget2008 & $\mathrm{Y}$ & 5 \\
\hline 31200XIII_21 Budget 2008 & $\mathrm{Y}$ & 1 \\
\hline 31200XIII_58 Budget 2008 & $\mathrm{Y}$ & 5 \\
\hline 31200VIII_201 Budget 2008 & $\mathrm{Y}$ & 0 \\
\hline 31200XII_2 Budget 2008 & $\mathrm{Y}$ & 0 \\
\hline 31200A_94 budget 2008 & $\mathrm{Y}$ & 0 \\
\hline 31474_2 1st supplement 2008 & $\mathrm{Y}$ & 0 \\
\hline 31474XIII_2 1st supplement 2008 & $\mathrm{Y}$ & 0 \\
\hline 31792_1 $2^{\text {nd }}$ supplement 2008 & $\mathrm{Y}$ & 0 \\
\hline 31792XIII_2 2 nd supplement 2008 & $\mathrm{Y}$ & 0 \\
\hline 31792XIII_3 2 nd supplement 2008 & $\mathrm{Y}$ & 4 \\
\hline 31700XIII_55 Annual report nma & $\mathrm{Y}$ & 0 \\
\hline 31924XIII_1 Annual report & $\mathrm{Y}$ & 0 \\
\hline 31924_7 $1^{\text {st }}$ supplement 2009 & $\mathrm{Y}$ & 4 \\
\hline 24036_349 competition policy & $\mathrm{Y}$ & 0 \\
\hline 24036_350 Competition policy & $\mathrm{Y}$ & 1 \\
\hline 25268_53 kZBO & $\mathrm{Y}$ & 0 \\
\hline 25268_63 kZBO & $\mathrm{Y}$ & 0 \\
\hline 29247_75 Immediate care provision & $\mathrm{Y}$ & 0 \\
\hline $29247 \_78$ Immediate care provision & $\mathrm{Y}$ & 1 \\
\hline 29515_272 Reduction of bureaucracy & $\mathrm{Y}$ & 0 \\
\hline 29842_33 Sustainable agriculture & $\mathrm{Y}$ & 1 \\
\hline 29842_18 Sustainable agriculture & $\mathrm{Y}$ & 1 \\
\hline 30895_44 Water supply & $\mathrm{Y}$ & 1 \\
\hline 31325_5 Providing educational books & $\mathrm{Y}$ & 1 \\
\hline 31325_6 Providing educational books & $\mathrm{Y}$ & 0 \\
\hline 31354_3 Tendering by government affiliated entities & $\mathrm{Y}$ & 0 \\
\hline 31354_6 Tendering by government affiliated entities & $\mathrm{Y}$ & 0 \\
\hline 31388_2 Fraud indications & $\mathrm{N}$ & 0 \\
\hline 31388_3 Fraud indications & $\mathrm{Y}$ & 1 \\
\hline 31579 Law on services (internal EU market) & $\mathrm{Y}$ & 1 \\
\hline Proceedings20072008 4102-4107 & $\mathrm{Y}$ & 1 \\
\hline $\begin{array}{l}\text { Proceedings20072008 5255-5256 } \\
\text { Proceedings20072008 5256-5274 } \\
\text { Proceedings20072008 5281-5286 }\end{array}$ & $\mathrm{Y}$ & 1 \\
\hline $\begin{array}{l}\text { Proceedings20082009 933-959 } \\
\text { Proceedings20082009 1126-1141 }\end{array}$ & $\mathrm{Y}$ & 1 \\
\hline \multicolumn{3}{|l|}{ Fiscal 2009} \\
\hline 31700XIII_2 Budget2009 & $\mathrm{Y}$ & 0 \\
\hline
\end{tabular}




\begin{tabular}{|l|l|l|}
\hline Document regarding NMa & $\begin{array}{l}\text { Relevance } \\
\text { operations }\end{array}$ & $\begin{array}{l}\text { \# remarks by } \\
\text { MPs }\end{array}$ \\
\hline 31700XIII_7 Budget2009 & Y & 4 \\
\hline 31700XIII_18 Budget2009 Amendment & Y & 1 \\
\hline $\begin{array}{l}\text { 31700XIII32 Budget2009 Motion } \\
\text { Proceedings20082009 1063-1096 }\end{array}$ & Y & 1 \\
\hline 31700XVI_122 Budget 2009 & & 0 \\
\hline 31965_11st supplement 2009 & Y & 0 \\
\hline 31965_31st supplement 2009 & Y & 1 \\
\hline 22122_855 EU Regulations & Y & 1 \\
\hline 24095_235 Communication Frequencies & Y & 0 \\
\hline $\begin{array}{l}\text { 30536_98 Liberalisation postal market Motion } \\
\text { Proceedings20082009 5085-5152 }\end{array}$ & $\mathrm{Y}$ & 1 \\
\hline 31892_3 Cross border payments & $\mathrm{Y}$ & \\
\hline 31901_5 Fees energy infrastructure & & 0 \\
\hline Proceedings20082009 3809-3911 & $\mathrm{Y}$ & 7 \\
\hline Proceedings20082009 4757-4802 & $\mathrm{Y}$ & 0 \\
\hline Proceedings20082009 4757-4802 & $\mathrm{N}$ & 1 \\
\hline Proceedings20082009 4931-5020 & $\mathrm{Y}$ & 1 \\
\hline Proceedings20082009 6698-6725 & $\mathrm{Y}$ & 1 \\
\hline
\end{tabular}




\section{NZA}

$\mathrm{N}=391$ documents containing ' begroting nza' in text

$\mathrm{N}=145$ documents containing ' jaarverslag nza' in text

$\mathrm{N}=17$ documents containing ' begroting ctz' in text

$\mathrm{N}=11$ documents containing ' jaarverslag ctz' in text

No reference to particular research activities of NZA

\begin{tabular}{|c|c|c|}
\hline Document regarding NZA & $\begin{array}{l}\text { Relevance } \\
\text { operations }\end{array}$ & \# remarks by MPs \\
\hline \multicolumn{3}{|l|}{ Fiscal 2006} \\
\hline 31031_XVI_1_Annual report 2006 & $\mathrm{Y}$ & 0 \\
\hline 31031XVI_5 Annual 2006 questions & $\bar{Y}$ & 2 \\
\hline 31031XVI_6 Annual 2006 questions & $\mathrm{Y}$ & 1 \\
\hline 30800XVI_34 Budget2007 Questions regarding 2006 & $\mathrm{Y}$ & 1 \\
\hline 25268_45 kZBO & $\mathrm{Y}$ & 0 \\
\hline 30831_3 VWS legislation 2006 & $\mathrm{Y}$ & 0 \\
\hline \multicolumn{3}{|l|}{ Fiscal 2007} \\
\hline 30800XVI_2 Budget 2007 & $\mathrm{Y}$ & 0 \\
\hline 30800XVI_18 Budget 2007 Instruction & $\mathrm{Y}$ & 0 \\
\hline 30800XVI_27 Budget 2007 questions & $\mathrm{Y}$ & 3 \\
\hline 30800XVI_129 Budget 2007 Instruction & $\mathrm{Y}$ & 0 \\
\hline 30800XVI_139 Budget 2007 Instruction & $\mathrm{Y}$ & 0 \\
\hline 31061XVI_2 1 ${ }^{\text {st }}$ supplement 2007 & $\mathrm{Y}$ & 0 \\
\hline 31061XVI_4 $1^{\text {st }}$ supplement 2007 & $\mathrm{Y}$ & 2 \\
\hline 31444XVI_1-3 Annual 2007 & $\mathrm{Y}$ & 0 \\
\hline 25268-70 kZBO Annual 2007 & $\mathrm{Y}$ & 0 \\
\hline 27831_23 Framework Monitoring policies & $\mathrm{Y}$ & 0 \\
\hline $\begin{array}{l}\text { 29248_39 DBCs Motion } \\
\text { Proceedings20062007 5078-5079 }\end{array}$ & $\mathrm{Y}$ & 1 \\
\hline 29515_181 reducing bureaucracy & $\mathrm{Y}$ & 0 \\
\hline 29689_154 Restructuring Health sector Instruction & $\mathrm{y}$ & 0 \\
\hline 30918_3 Health insurance policy & $\mathrm{Y}$ & 0 \\
\hline $\begin{array}{l}\text { 31200XVI_50 Budget } 2008 \text { Motion } \\
\text { 31200XVI_82 adapted motion } \\
\text { 31200XVI_83 adapted motion } \\
\text { Proceedings20072008 1773-1802 } \\
\text { Proceedings20072008 2037-2052 }\end{array}$ & $\mathrm{Y}$ & 1 \\
\hline $\begin{array}{l}\text { 31200XVI_72 Budget 2008, policy } \\
\text { Proceedings20072008 1741-1874 }\end{array}$ & $\mathrm{Y}$ & 1 \\
\hline 31201_3 Civil service & $\mathrm{Y}$ & 0 \\
\hline Proceedings20072008 2177-2180 & $\mathrm{Y}$ & 1 \\
\hline Proceedings 20072008 Appendix 932 & $\mathrm{Y}$ & 1 \\
\hline \multicolumn{3}{|l|}{ Fiscal 2008} \\
\hline 31200XVI_2 Budget 2008 & $\mathrm{Y}$ & 0 \\
\hline 31200XVI_13 Budget 2008 & $\mathrm{Y}$ & 1 \\
\hline 31200XIII_4 Budget 2008 & $\mathrm{Y}$ & 1 \\
\hline 31200XIII_145 Budget 2008, Motion & $\mathrm{Y}$ & 1 \\
\hline 31924XVI_3 Annual 2008 & $\mathrm{Y}$ & 0 \\
\hline 31924XVI_5 Annual 2008 & $\mathrm{Y}$ & 2 \\
\hline 31924XVI_6 Annual 2008 & $\mathrm{Y}$ & 1 \\
\hline $\begin{array}{l}\text { 24036_350 Competition policy } \\
\text { 31700XIII_7 Budget2009 }\end{array}$ & $\mathrm{Y}$ & 1 \\
\hline 25268_59 kZBO & $\mathrm{Y}$ & 2 \\
\hline 25268_63 kZBO & $\mathrm{Y}$ & 0 \\
\hline
\end{tabular}




\begin{tabular}{|c|c|c|}
\hline Document regarding NZA & $\begin{array}{l}\text { Relevance } \\
\text { operations }\end{array}$ & \# remarks by MPs \\
\hline 26631_250 Modernising care & $\mathrm{Y}$ & 1 \\
\hline 26631_274 Modernising care Instruction & $y$ & 0 \\
\hline 27295_110 General hospitals & $\mathrm{Y}$ & 0 \\
\hline 29247_78 Immediate care & $\mathrm{Y}$ & 1 \\
\hline 29247_81 Immediate care Instruction & $\mathrm{Y}$ & 0 \\
\hline $\begin{array}{l}\text { 29477_59 Motion } \\
\text { 29477_60 Motion } \\
\text { Proceedings20072008 7612-7613 }\end{array}$ & $\mathrm{Y}$ & 2 \\
\hline $\begin{array}{l}\text { 29689_237 Motion } \\
\text { Proceedings20082009 3292_3295 }\end{array}$ & $\mathrm{Y}$ & 1 \\
\hline 30597 Future care & $\mathrm{Y}$ & 0 \\
\hline $\begin{array}{l}\text { 31016_14 Motion } \\
\text { Proceedings20072008 4102-4107 }\end{array}$ & $\mathrm{Y}$ & 1 \\
\hline 31420_7 Merger health institutions & $\mathrm{Y}$ & 2 \\
\hline Proceedings20072008 5256-5274 & $\mathrm{Y}$ & 1 \\
\hline \multicolumn{3}{|l|}{ Fiscal 2009} \\
\hline 31700XVI_2 Budget 2009 & $\mathrm{Y}$ & 0 \\
\hline 31700XVI_160 Budget 2009 Instruction & $\mathrm{Y}$ & 0 \\
\hline 31950_3 adaption to kZBO & $\mathrm{Y}$ & 0 \\
\hline Proceedings20082009 3809-3911 & $\mathrm{Y}$ & 1 \\
\hline Proceedings20082009 4931-5018 & $\mathrm{Y}$ & 1 \\
\hline Proceedings20082009 Appendix 2261 & $\mathrm{Y}$ & 1 \\
\hline
\end{tabular}




\section{Appendix 9: Responsibility centre assessment}

The table below shows for each of the ZBOs in the case study characteristics that have lead to a classification under the responsibility centre model. I have made a separation between ex ante (e.a.) known data and what has been found in interviews and documents ex post (e.p.). As a result changes in classification are disclosed.

Table A - 4: Ex ante and ex post assessment of responsibility centre types for ZBOs studied.

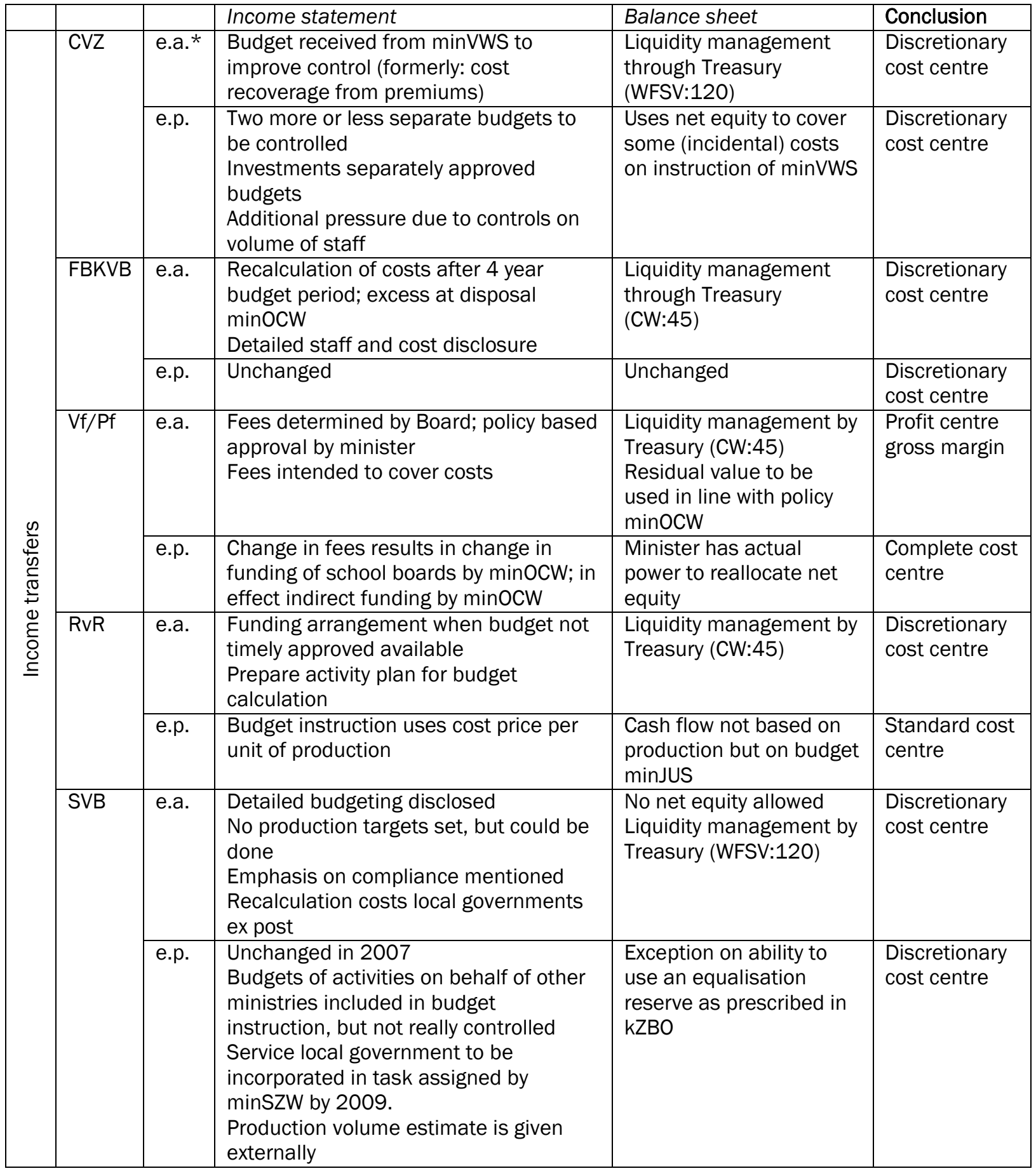




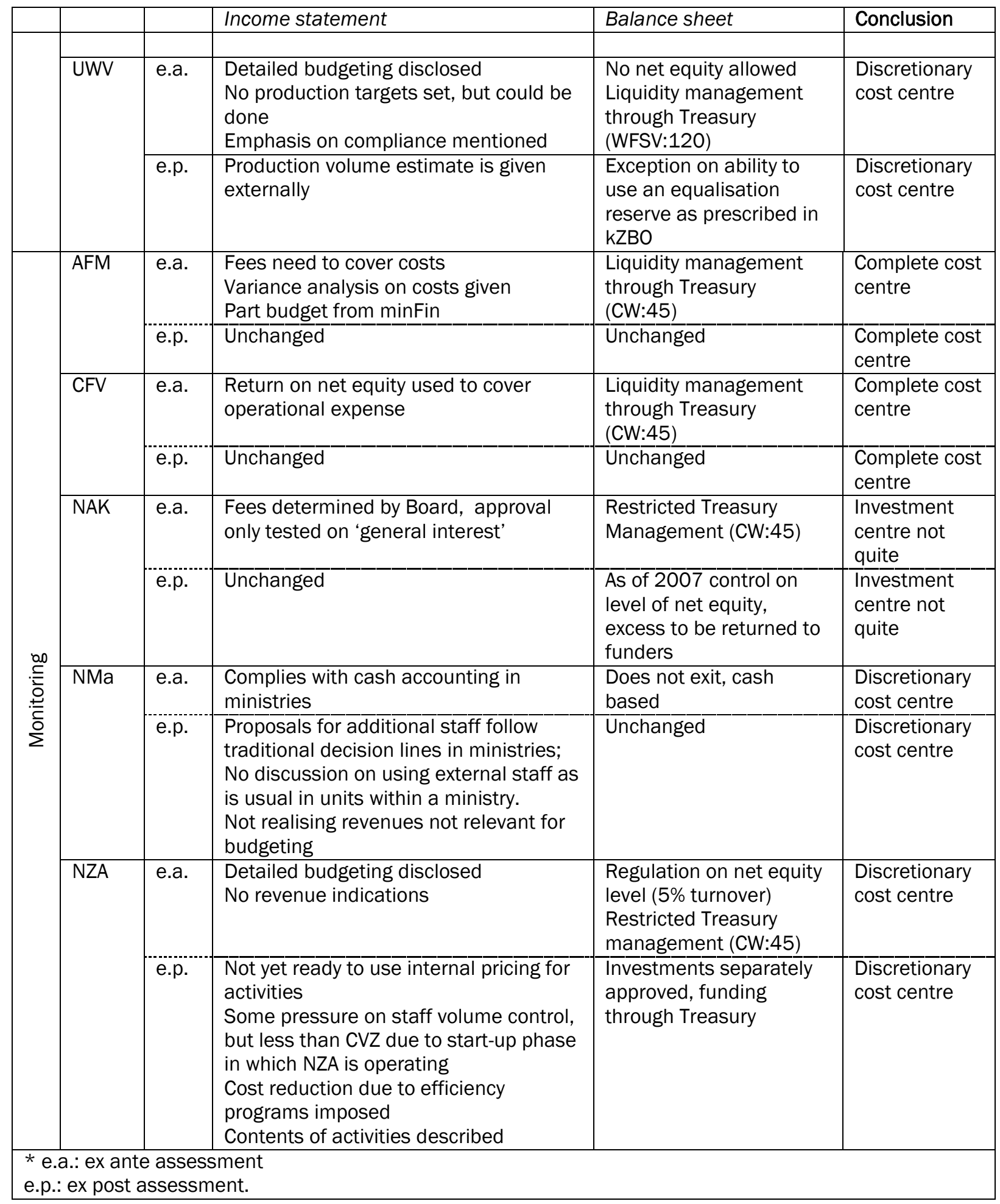


Appendix 10: Comparative overview of actual mismatches.

Table A - 5: Comparative overview of formal and actual legal impact on autonomy for income transfer ZBOs

\begin{tabular}{|c|c|c|c|c|c|c|c|c|c|c|c|c|c|c|c|c|}
\hline & Type & Authority issue & $\begin{array}{l}\text { Authority } \\
\text { Group }\end{array}$ & $\begin{array}{l}\text { reference } \\
\text { kZBO }\end{array}$ & CVZ & & RvR & & SVB & & UWV & & FBKI & & $\mathrm{Vf} / \mathrm{P}$ & \\
\hline & & & & & 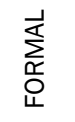 & 咅 & $\underset{\substack{\mathbb{1} \\
\text { 난 }}}{\stackrel{1}{⿺}}$ & 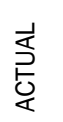 & 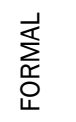 & 崖 & 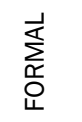 & 站 & 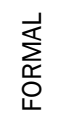 & 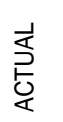 & 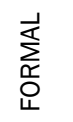 & 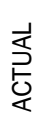 \\
\hline 1 & $X^{*}$ & $\begin{array}{l}\text { Not appointing civil } \\
\text { servant in board }\end{array}$ & Normative & 9 & 0 & 0 & 0 & 0 & $\downarrow$ & 0 & $\downarrow$ & 0 & 0 & 0 & 0 & 0 \\
\hline 2 & 0 & Appointment of staff & Normative & $\begin{array}{l}\text { kZBO:15 } \\
\text { (PLA) }\end{array}$ & $\downarrow$ & 0 & $\uparrow$ & $\uparrow$ & $\uparrow$ & $\uparrow$ & $\uparrow$ & $\uparrow$ & 0 & 0 & 0 & 0 \\
\hline 3 & $\mathrm{X}$ & $\begin{array}{l}\text { Requirement of data } \\
\text { protection }\end{array}$ & Normative & 41 & $\uparrow$ & 0 & 0 & 0 & 0 & 0 & 0 & 0 & 0 & $\uparrow$ & $\uparrow$ & $\uparrow$ \\
\hline 4 & $\mathrm{X}$ & $\begin{array}{l}\text { Appointment based on } \\
\text { gender and or cultural } \\
\text { background }\end{array}$ & Normative & not included & $\downarrow$ & $\downarrow$ & 0 & 0 & 0 & 0 & 0 & 0 & 0 & 0 & 0 & 0 \\
\hline 5 & $P$ & $\begin{array}{l}\text { Submit annual report to } \\
\text { Parliament }\end{array}$ & Information & 18 & $\uparrow$ & $\uparrow$ & $\uparrow$ & $\uparrow$ & $\downarrow$ & $\downarrow$ & $\downarrow$ & $\downarrow$ & $\uparrow$ & $\uparrow$ & $\downarrow$ & $\downarrow$ \\
\hline 6 & $\mathrm{~N}$ & $\begin{array}{l}\text { Frequency of } \\
\text { intermediate reports set } \\
\text { in legislation }\end{array}$ & Information & none & 0 & 0 & $\downarrow$ & $\downarrow$ & $\downarrow$ & $\downarrow$ & $\downarrow$ & $\downarrow$ & 0 & 0 & 0 & 0 \\
\hline 7 & $\mathrm{~N}$ & General right of inquiry & Information & 20 & 0 & 0 & 0 & 0 & 0 & 0 & 0 & 0 & 0 & 0 & 0 & 0 \\
\hline 8 & $P$ & $\begin{array}{l}\text { Approval of statement } \\
\text { of accounts }\end{array}$ & Information & 34 & 0 & 0 & $\downarrow$ & $\downarrow$ & 0 & 0 & 0 & 0 & $\uparrow$ & $\uparrow$ & $\uparrow$ & $\uparrow$ \\
\hline 9 & $\mathrm{~N}$ & $\begin{array}{l}\text { Use separate accounts } \\
\text { for activities }\end{array}$ & Information & 38 & 0 & 0 & 0 & 0 & 0 & 0 & 0 & 0 & 0 & 0 & 0 & 0 \\
\hline 10 & $\mathrm{~N}$ & $\begin{array}{l}\text { Board discusses directly } \\
\text { with Parliament }\end{array}$ & Information & none & 0 & 0 & 0 & 0 & 0 & 0 & 0 & 0 & 0 & 0 & 0 & 0 \\
\hline 11 & $\mathrm{~N}$ & Multiple bodies & Governance & 7 & 0 & 0 & 0 & 0 & 0 & $\downarrow$ & 0 & $\downarrow$ & 0 & 0 & $\uparrow$ & $\uparrow$ \\
\hline 12 & $\mathrm{M}$ & $\begin{array}{l}\text { Ex ante approval of } \\
\text { mandates }\end{array}$ & Governance & 8 & $\downarrow$ & 0 & $\downarrow$ & $\downarrow$ & $\uparrow$ & $\uparrow$ & $\uparrow$ & 0 & 0 & 0 & 0 & 0 \\
\hline 13 & $\mathrm{~N}$ & $\begin{array}{l}\text { (re)appointment of } \\
\text { board }\end{array}$ & Governance & kZBO:12 & 0 & 0 & 0 & 0 & 0 & 0 & 0 & 0 & 0 & 0 & 0 & 0 \\
\hline 14 & $\mathrm{~N}$ & secondary jobs & Governance & kZBO:13 & 0 & 0 & 0 & 0 & 0 & 0 & 0 & 0 & 0 & 0 & 0 & 0 \\
\hline
\end{tabular}




\begin{tabular}{|c|c|c|c|c|c|c|c|c|c|c|c|c|c|c|c|c|}
\hline & Type & Authority issue & $\begin{array}{l}\text { Authority } \\
\text { Group }\end{array}$ & $\begin{array}{l}\text { reference } \\
\text { kZBO }\end{array}$ & CVZ & & RvR & & SVB & & UWV & & FBK & & $\mathrm{Vf} / \mathrm{P}$ & \\
\hline & & & & & 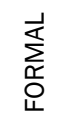 & $\frac{\vec{S}}{\stackrel{5}{L}}$ & 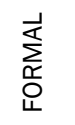 & 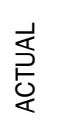 & 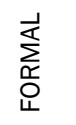 & 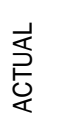 & 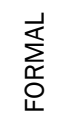 & 崖 & 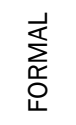 & 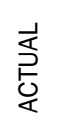 & 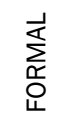 & 岁 \\
\hline 15 & $\mathrm{~N}$ & $\begin{array}{l}\text { Decision on and } \\
\text { disclosure of } \\
\text { remuneration }\end{array}$ & Governance & $\begin{array}{l}\text { kZBO:14; } \\
\text { WOPT:6 }\end{array}$ & 0 & 0 & 0 & 0 & 0 & 0 & 0 & 0 & 0 & 0 & 0 & 0 \\
\hline 16 & $X$ & $\begin{array}{l}\text { Annulling of ZBO } \\
\text { decisions }\end{array}$ & Governance & 22 & 0 & 0 & $\uparrow$ & 0 & 0 & 0 & 0 & 0 & 0 & 0 & 0 & 0 \\
\hline 17 & $X$ & $\begin{array}{l}\text { Intervention in case of } \\
\text { negligence }\end{array}$ & Governance & 23 & $\uparrow$ & 0 & 0 & 0 & 0 & 0 & 0 & 0 & 0 & 0 & $\uparrow$ & $\uparrow$ \\
\hline 18 & 0 & $\begin{array}{l}\text { Asset related } \\
\text { transactions: borrowing } \\
\text { and lending }\end{array}$ & Governance & $32 d$ & 0 & 0 & 0 & 0 & 0 & 0 & 0 & 0 & 0 & 0 & 0 & 0 \\
\hline 19 & 0 & $\begin{array}{l}\text { Asset related } \\
\text { transactions: others }\end{array}$ & Governance & $32 a-c, e, f$ & 0 & 0 & $\downarrow$ & 0 & $\downarrow$ & $\downarrow$ & $\downarrow$ & $\downarrow$ & 0 & $\uparrow$ & 0 & 0 \\
\hline 20 & $X$ & $\begin{array}{l}\text { Asset related } \\
\text { transactions: } \\
\text { bankruptcy }\end{array}$ & Governance & $32 g$ & 0 & 0 & 0 & 0 & $\downarrow$ & 0 & $\downarrow$ & 0 & 0 & 0 & 0 & 0 \\
\hline 21 & $X$ & $\begin{array}{l}\text { Asset related } \\
\text { transactions: } \\
\text { dissolvement }\end{array}$ & Governance & none & 0 & 0 & 0 & 0 & 0 & 0 & 0 & 0 & $\downarrow$ & 0 & $\downarrow$ & 0 \\
\hline 22 & $\mathrm{~N}$ & $\begin{array}{l}\text { Frequency of meetings } \\
\text { board and minister }\end{array}$ & Cyclical & none & 0 & $\uparrow$ & 0 & $\uparrow$ & 0 & 0 & 0 & $\downarrow$ & 0 & $\uparrow$ & 0 & $\uparrow$ \\
\hline 23 & $\mathrm{P}$ & Approval of fees & Cyclical & 17 & 0 & 0 & 0 & 0 & $\uparrow$ & $\uparrow$ & $\uparrow$ & 0 & 0 & 0 & 0 & 0 \\
\hline 24 & $\mathrm{P}$ & $\begin{array}{l}\text { Rules on structure of } \\
\text { budget }\end{array}$ & Cyclical & 27,28 & 0 & 0 & 0 & 0 & 0 & 0 & 0 & 0 & 0 & 0 & $\uparrow$ & $\uparrow$ \\
\hline 25 & $\mathrm{P}$ & Approval of budget & Cyclical & 29 & $\downarrow$ & $\downarrow$ & $\downarrow$ & $\downarrow$ & $\downarrow$ & $\downarrow$ & $\downarrow$ & $\downarrow$ & $\uparrow$ & $\uparrow$ & $\uparrow$ & 0 \\
\hline 26 & $\mathrm{P}$ & Submit multiyear plan & Cyclical & none & $\downarrow$ & $\downarrow$ & 0 & 0 & $\downarrow$ & $\downarrow$ & $\downarrow$ & $\downarrow$ & 0 & 0 & 0 & 0 \\
\hline 27 & $P$ & $\begin{array}{l}\text { Creating equalisation } \\
\text { reserve }\end{array}$ & Cyclical & 33 & $\downarrow$ & $\downarrow$ & 0 & $\downarrow$ & $\downarrow$ & $\downarrow$ & $\downarrow$ & $\downarrow$ & 0 & 0 & $\uparrow$ & 0 \\
\hline 28 & 0 & Audit protocol & Cyclical & none & $\downarrow$ & $\downarrow$ & $\downarrow$ & $\downarrow$ & 0 & 0 & 0 & 0 & $\downarrow$ & $\downarrow$ & 0 & 0 \\
\hline
\end{tabular}


Table A - 6: Overview of expected and actual impact on economic autonomy of income transfer ZBOs

\begin{tabular}{|c|c|c|c|c|c|c|c|c|c|c|c|c|c|c|c|c|}
\hline & Type & & $\begin{array}{l}\text { Exepected } \\
\text { level }\end{array}$ & Indicator type & \multicolumn{2}{|c|}{ CVZ } & \multicolumn{2}{|c|}{ RvR } & \multicolumn{2}{|c|}{ SVB } & \multicolumn{2}{|c|}{ UWV } & \multicolumn{2}{|c|}{ FBKVB } & \multicolumn{2}{|c|}{ Vf/Pf } \\
\hline & & & & & 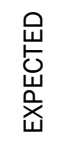 & $\begin{array}{l}\frac{1}{S} \\
\frac{5}{2}\end{array}$ & $\begin{array}{l}\text { 岁 } \\
\text { ü } \\
\text { 离 }\end{array}$ & $\begin{array}{l}\vec{S} \\
\stackrel{5}{2} \\
\stackrel{0}{4}\end{array}$ & $\begin{array}{l}\text { 嵌 } \\
\text { 㟧 } \\
\text { 离 }\end{array}$ & 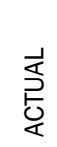 & $\begin{array}{l}\text { 岀 } \\
\text { 岀 } \\
\text { 离 }\end{array}$ & $\begin{array}{l}\frac{1}{5} \\
\frac{2}{2}\end{array}$ & 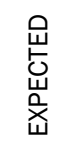 & 荥 & $\begin{array}{l}\stackrel{0}{\breve{y}} \\
\text { ü } \\
\text { 离 }\end{array}$ & 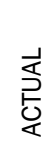 \\
\hline \multicolumn{17}{|c|}{ MARKET DIMENSION } \\
\hline 1 & $0 *$ & Production type & Mass & $\mathrm{G} * *$ & 0 & $\downarrow$ & 0 & 0 & 0 & 0 & 0 & 0 & 0 & $\uparrow$ & 0 & 0 \\
\hline 2 & $\mathrm{M}$ & $\begin{array}{l}\text { \% Funding largest demand } \\
\text { initiator ( } 2007, \text { annual } \\
\text { report) }\end{array}$ & 100 & G & 0 & 0 & 0 & 0 & 0 & 0 & 0 & 0 & 0 & 0 & $\uparrow$ & $\uparrow$ \\
\hline 3 & $\mathrm{M}$ & Type of funding charges & $\begin{array}{l}\text { not } \\
\text { applicable }\end{array}$ & $\mathrm{G}$ & 0 & 0 & 0 & 0 & 0 & 0 & 0 & 0 & 0 & 0 & 0 & 0 \\
\hline 4 & $\mathrm{M}$ & Budget funding & $\begin{array}{l}\text { activity } \\
\text { based }\end{array}$ & M & 0 & $\downarrow$ & 0 & $\downarrow$ & 0 & $\downarrow$ & 0 & $\downarrow$ & 0 & 0 & 0 & 0 \\
\hline 5 & M & Commissioning & request & $\mathrm{M}$ & 0 & 0 & 0 & 0 & 0 & 0 & 0 & 0 & 0 & 0 & 0 & 0 \\
\hline 6 & $\mathrm{M}$ & Competitors & none & $\mathrm{M}$ & 0 & 0 & 0 & 0 & 0 & $\uparrow$ & 0 & 0 & 0 & 0 & $\uparrow$ & $\downarrow$ \\
\hline 7 & 0 & Production form & $\begin{array}{l}\text { contract } \\
\text { provision }\end{array}$ & G & 0 & 0 & 0 & 0 & 0 & 0 & 0 & 0 & 0 & $\uparrow$ & 0 & $\uparrow$ \\
\hline \multicolumn{17}{|c|}{ PLANNING \& CONTROL DIMENSION } \\
\hline 8 & 0 & $\%$ fixed assets & $<10 \%$ & $\mathrm{G}$ & 0 & 0 & 0 & 0 & 0 & 0 & 0 & 0 & 0 & 0 & 0 & 0 \\
\hline 9 & $P$ & $\begin{array}{l}\text { Budget disclosure } \\
\text { operating costs in } \\
\text { ministry's budgets }\end{array}$ & line item & $\mathrm{P}$ & 0 & $\uparrow$ & 0 & 0 & 0 & $\uparrow$ & 0 & $\uparrow$ & 0 & $\uparrow$ & 0 & $\uparrow$ \\
\hline 10 & $\mathrm{P}$ & Responsibility centre type & $\begin{array}{l}\text { standard } \\
\text { cost } \\
\text { centre }\end{array}$ & M & 0 & $\downarrow$ & 0 & $\downarrow$ & 0 & $\downarrow$ & 0 & $\downarrow$ & 0 & $\downarrow$ & 0 & $\uparrow$ \\
\hline 11 & $P$ & $\begin{array}{l}\text { Approval of budget } \\
\text { document mentioned to } \\
\text { Parliament by minister }\end{array}$ & Yes & $P$ & 0 & $\uparrow$ & 0 & $\uparrow$ & 0 & 0 & 0 & 0 & 0 & $\uparrow$ & 0 & $\uparrow$ \\
\hline 12 & $\mathrm{P}$ & $\begin{array}{l}\text { Approval of fees mentioned } \\
\text { to Parliament by minister }\end{array}$ & $\begin{array}{l}\text { not } \\
\text { applicable }\end{array}$ & $P$ & 0 & 0 & 0 & 0 & 0 & 0 & 0 & 0 & 0 & 0 & 0 & $\uparrow$ \\
\hline 13 & $P$ & $\begin{array}{l}\text { Approval of annual report } \\
\text { mentioned to Parliament by } \\
\text { minister }\end{array}$ & Yes & $P$ & 0 & $\uparrow$ & 0 & $\uparrow$ & 0 & $\downarrow$ & 0 & $\downarrow$ & 0 & $\uparrow$ & 0 & $\downarrow$ \\
\hline
\end{tabular}




\begin{tabular}{|c|c|c|c|c|c|c|c|c|c|c|c|c|c|c|c|c|}
\hline \multirow[b]{2}{*}{14} & \multirow{2}{*}{$\begin{array}{l}\text { Type } \\
\text { P }\end{array}$} & \multirow[b]{2}{*}{$\begin{array}{l}\text { Frequency of reporting by } \\
\text { minister to Parliament }\end{array}$} & \multirow{2}{*}{$\begin{array}{l}\text { Exepected } \\
\text { level } \\
\text { Yearly }\end{array}$} & \multirow{2}{*}{$\begin{array}{l}\text { Indicator type } \\
\text { P }\end{array}$} & \multicolumn{2}{|c|}{ CVZ } & \multicolumn{2}{|c|}{ RvR } & \multicolumn{2}{|c|}{ SVB } & \multicolumn{2}{|c|}{ UWV } & \multicolumn{2}{|c|}{ FBKVB } & \multicolumn{2}{|c|}{ Vf/Pf } \\
\hline & & & & & 0 & $\downarrow$ & 0 & $\downarrow$ & 0 & $\downarrow$ & 0 & $\downarrow$ & 0 & 0 & 0 & 0 \\
\hline 15 & 0 & $\begin{array}{l}\text { Performance indicators } \\
\text { reported to Parliament in } \\
\text { ministries' budget } \\
\text { documents }\end{array}$ & Output & $\mathrm{P}$ & 0 & $\uparrow$ & 0 & 0 & 0 & 0 & 0 & 0 & 0 & $\uparrow$ & 0 & $\uparrow$ \\
\hline 16 & 0 & $\begin{array}{l}\text { Performance indicators } \\
\text { reported to Parliament in } \\
\text { ZBO Annual reports }\end{array}$ & Output & $\mathrm{P}$ & 0 & 0 & 0 & $\uparrow$ & 0 & 0 & 0 & 0 & 0 & $\uparrow$ & 0 & 0 \\
\hline 17 & $P$ & $\begin{array}{l}\text { Frequency of reporting to } \\
\text { Minister }\end{array}$ & $\begin{array}{l}\text { Parliament } \\
\text { 's } \\
\text { frequency }\end{array}$ & $\mathrm{M}$ & 0 & $\downarrow$ & 0 & 0 & 0 & 0 & 0 & 0 & $\uparrow$ & $\uparrow$ & $\uparrow$ & $\downarrow$ \\
\hline 18 & 0 & $\begin{array}{l}\text { Number of documents } \\
\text { submitted to Parliament } \\
\text { regarding operations of } \\
\text { ZBO }\end{array}$ & 0 & $\mathrm{P}$ & 0 & $\downarrow$ & 0 & $\downarrow$ & 0 & $\downarrow$ & 0 & $\downarrow$ & 0 & $\downarrow$ & 0 & $\downarrow$ \\
\hline 19 & $P$ & $\begin{array}{l}\text { Budget instruction by } \\
\text { Minister-Principal }\end{array}$ & Yes & $\mathrm{M}$ & 0 & $\uparrow$ & 0 & 0 & 0 & 0 & 0 & 0 & 0 & $\uparrow$ & 0 & $\uparrow$ \\
\hline
\end{tabular}


Table A - 7: Comparative overview of impact on formal and actual legal on autonomy of monitoring ZBOs

\begin{tabular}{|c|c|c|c|c|c|c|c|c|c|c|c|c|c|c|}
\hline & Type & Authority issue & $\begin{array}{l}\text { Authority } \\
\text { Group }\end{array}$ & $\begin{array}{l}\text { reference } \\
\text { kZBO }\end{array}$ & \multicolumn{2}{|c|}{ AFM } & \multicolumn{2}{|c|}{ CFV } & \multicolumn{2}{|c|}{ NAK } & \multicolumn{2}{|c|}{ NMa } & \multicolumn{2}{|c|}{ NZA } \\
\hline & & & & & 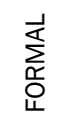 & 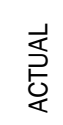 & 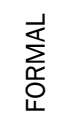 & 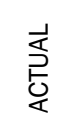 & 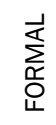 & $\begin{array}{l}\vec{S} \\
\stackrel{2}{D} \\
\stackrel{0}{<}\end{array}$ & 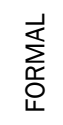 & $\begin{array}{l}\vec{S} \\
\stackrel{2}{D} \\
\stackrel{2}{4}\end{array}$ & 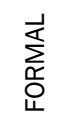 & $\begin{array}{l}\vec{S} \\
\stackrel{2}{2}\end{array}$ \\
\hline 1 & $X^{*}$ & Not appointing civil servant in board & Normative & 9 & 0 & 0 & 0 & 0 & 0 & 0 & 0 & 0 & 0 & 0 \\
\hline 2 & 0 & Appointment of staff & Normative & $\begin{array}{l}\text { kZBO:15 } \\
\text { (PLA) }\end{array}$ & 0 & 0 & 0 & 0 & 0 & 0 & 0 & 0 & 0 & 0 \\
\hline 3 & $\mathrm{X}$ & Requirement of data protection & Normative & 41 & 0 & 0 & $\uparrow$ & 0 & 0 & 0 & 0 & 0 & 0 & 0 \\
\hline 4 & $x$ & $\begin{array}{l}\text { Appointment based on gender and or } \\
\text { cultural background }\end{array}$ & Normative & not included & 0 & 0 & 0 & 0 & 0 & 0 & 0 & 0 & 0 & 0 \\
\hline 5 & $\mathrm{P}$ & Submit annual report to Parliament & Information & 18 & 0 & 0 & $\uparrow$ & 0 & 0 & $\uparrow$ & $\downarrow$ & $\downarrow$ & $\downarrow$ & $\uparrow$ \\
\hline 6 & $\mathrm{~N}$ & $\begin{array}{l}\text { Frequency of intermediate reports set } \\
\text { in legislation }\end{array}$ & Information & none & 0 & 0 & 0 & 0 & 0 & 0 & 0 & 0 & 0 & 0 \\
\hline 7 & $\mathrm{~N}$ & General right of inquiry & Information & 20 & 0 & 0 & 0 & 0 & 0 & 0 & 0 & 0 & 0 & 0 \\
\hline 8 & $P$ & Approval of statement of accounts & Information & 34 & $\uparrow$ & $\uparrow$ & $\uparrow$ & 0 & 0 & 0 & $\downarrow$ & $\downarrow$ & 0 & 0 \\
\hline 9 & $\mathrm{~N}$ & Use separate accounts for activities & Information & 38 & $\downarrow$ & $\downarrow$ & 0 & 0 & 0 & 0 & 0 & 0 & 0 & 0 \\
\hline 10 & $\mathrm{~N}$ & $\begin{array}{l}\text { Board discusses directly with } \\
\text { Parliament }\end{array}$ & Information & none & 0 & 0 & 0 & 0 & 0 & 0 & 0 & $\uparrow$ & 0 & 0 \\
\hline 11 & $\mathrm{~N}$ & Multiple bodies & Governance & 7 & $\uparrow$ & $\uparrow$ & $\uparrow$ & $\uparrow$ & $\uparrow$ & $\uparrow$ & 0 & 0 & 0 & 0 \\
\hline 12 & $\mathrm{M}$ & Ex ante approval of mandates & Governance & 8 & 0 & 0 & 0 & 0 & $\downarrow$ & $\downarrow$ & 0 & 0 & 0 & 0 \\
\hline 13 & $\mathrm{~N}$ & (re)appointment of board & Governance & kZBO:12 & $\downarrow$ & $\downarrow$ & 0 & 0 & $\downarrow$ & $\downarrow$ & 0 & 0 & 0 & 0 \\
\hline 14 & $\mathrm{~N}$ & secondary jobs & Governance & kZBO:13 & $\downarrow$ & $\downarrow$ & $\uparrow$ & $\uparrow$ & 0 & 0 & 0 & 0 & $\downarrow$ & $\downarrow$ \\
\hline 15 & $\mathrm{~N}$ & $\begin{array}{l}\text { Decision on and disclosure of } \\
\text { remuneration }\end{array}$ & Governance & $\begin{array}{l}\text { kZBO:14; } \\
\text { WOPT:6 }\end{array}$ & 0 & $\downarrow$ & $\uparrow$ & $\uparrow$ & 0 & $\uparrow$ & 0 & 0 & 0 & 0 \\
\hline 16 & $\mathrm{X}$ & Annulling of ZBO decisions & Governance & 22 & $\uparrow$ & 0 & $\uparrow$ & 0 & 0 & 0 & $\uparrow$ & 0 & $\uparrow$ & 0 \\
\hline 17 & $X$ & Intervention in case of negligence & Governance & 23 & 0 & 0 & 0 & 0 & $\uparrow$ & 0 & 0 & 0 & 0 & 0 \\
\hline 18 & 0 & $\begin{array}{l}\text { Asset related transactions: borrowing } \\
\text { and lending }\end{array}$ & Governance & $32 d$ & 0 & 0 & 0 & 0 & $\uparrow$ & $\uparrow$ & $\downarrow$ & $\downarrow$ & 0 & 0 \\
\hline 19 & 0 & Asset related transactions: others & Governance & $32 a-c, e, f$ & 0 & 0 & 0 & 0 & 0 & 0 & 0 & 0 & 0 & 0 \\
\hline 20 & $x$ & $\begin{array}{l}\text { Asset related transactions: } \\
\text { bankruptcy }\end{array}$ & Governance & $32 g$ & $\downarrow$ & 0 & 0 & 0 & 0 & 0 & 0 & 0 & 0 & 0 \\
\hline 21 & $\mathrm{X}$ & Asset related transactions: & Governance & none & $\downarrow$ & 0 & 0 & 0 & 0 & 0 & 0 & 0 & 0 & 0 \\
\hline
\end{tabular}




\begin{tabular}{|c|c|c|c|c|c|c|c|c|c|c|c|c|c|c|}
\hline & Type & Authority issue & $\begin{array}{l}\text { Authority } \\
\text { Group }\end{array}$ & $\begin{array}{l}\text { reference } \\
\text { kZBO }\end{array}$ & \multicolumn{2}{|c|}{ AFM } & \multicolumn{2}{|c|}{ CFV } & \multicolumn{2}{|c|}{ NAK } & \multicolumn{2}{|c|}{ NMa } & \multicolumn{2}{|c|}{ NZA } \\
\hline & & & & & 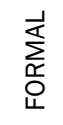 & 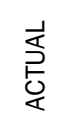 & 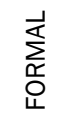 & $\frac{\vec{S}}{\overrightarrow{5}}$ & 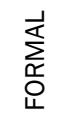 & $\begin{array}{l}\vec{S} \\
\stackrel{5}{D}\end{array}$ & 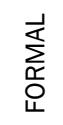 & 眆 & 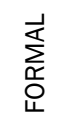 & 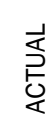 \\
\hline & & dissolvement & & & & & & & & & & & & \\
\hline 22 & $\mathrm{~N}$ & $\begin{array}{l}\text { Frequency of meetings board and } \\
\text { minister }\end{array}$ & Cyclical & none & 0 & $\uparrow$ & 0 & 0 & 0 & $\uparrow$ & 0 & $\downarrow$ & 0 & 0 \\
\hline 23 & $\mathrm{P}$ & Approval of fees & Cyclical & 17 & $\downarrow$ & $\downarrow$ & $\uparrow$ & 0 & 0 & 0 & 0 & 0 & 0 & 0 \\
\hline 24 & $\mathrm{P}$ & Rules on structure of budget & Cyclical & 27,28 & 0 & $\uparrow$ & $\uparrow$ & 0 & $\uparrow$ & $\uparrow$ & 0 & 0 & 0 & 0 \\
\hline 25 & $\mathrm{P}$ & Approval of budget & Cyclical & 29 & $\uparrow$ & $\uparrow$ & 0 & 0 & $\uparrow$ & 0 & $\downarrow$ & 0 & $\downarrow$ & $\downarrow$ \\
\hline 26 & $\mathrm{P}$ & Submit multiyear plan & Cyclical & none & 0 & $\downarrow$ & 0 & 0 & 0 & 0 & 0 & 0 & $\downarrow$ & $\downarrow$ \\
\hline 27 & $\mathrm{P}$ & Creating equalisation reserve & Cyclical & 33 & $\downarrow$ & $\downarrow$ & $\uparrow$ & 0 & 0 & 0 & $\downarrow$ & $\downarrow$ & $\downarrow$ & $\downarrow$ \\
\hline 28 & 0 & Audit protocol & Cyclical & none & 0 & 0 & 0 & 0 & 0 & 0 & 0 & 0 & 0 & $\downarrow$ \\
\hline
\end{tabular}


Table A - 8: Overview of expected and actual impact on economic autonomy of monitoring ZBOs

\begin{tabular}{|c|c|c|c|c|c|c|c|c|c|c|c|c|c|c|}
\hline & Type & & $\begin{array}{l}\text { Exepected } \\
\text { level }\end{array}$ & $\begin{array}{l}\text { Indicator } \\
\text { type }\end{array}$ & AFI & & $\mathrm{CF}$ & & NAK & & NM & & NZA & \\
\hline & & & & & 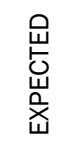 & 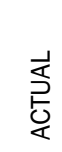 & $\begin{array}{l}\text { 岂 } \\
\text { u् } \\
\text { 嵌 }\end{array}$ & $\frac{\vec{T}}{\overrightarrow{2}}$ & 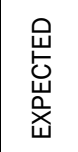 & $\begin{array}{l}\vec{T} \\
\vec{z} \\
\text { 定 }\end{array}$ & 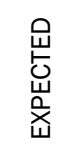 & 汖 & 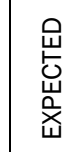 & 文 \\
\hline MAF & ET DIME & SION & & & & & & & & & & & & \\
\hline 1 & O* & Production type & Individual & $G^{* *}$ & 0 & $\uparrow$ & 0 & $\uparrow$ & $\uparrow$ & $\uparrow$ & 0 & 0 & 0 & 0 \\
\hline 2 & $M$ & $\begin{array}{l}\text { \% Funding largest demand } \\
\text { initiator (2007, annual report) }\end{array}$ & 100 & $G$ & 0 & 0 & 0 & 0 & $\uparrow$ & $\uparrow$ & 0 & 0 & 0 & 0 \\
\hline 4 & $M$ & Budget funding & lump sum & $\mathrm{M}$ & 0 & 0 & 0 & 0 & 0 & 0 & 0 & 0 & 0 & 0 \\
\hline 5 & $M$ & Commissioning & state & $M$ & 0 & 0 & 0 & 0 & $\uparrow$ & $\uparrow$ & 0 & 0 & 0 & 0 \\
\hline 6 & $M$ & Competitors & none & M & 0 & 0 & 0 & 0 & $\uparrow$ & $\downarrow$ & 0 & 0 & 0 & 0 \\
\hline 7 & 0 & Production form & $\begin{array}{l}\text { contract } \\
\text { provision }\end{array}$ & G & 0 & 0 & 0 & 0 & $\uparrow$ & $\uparrow$ & 0 & 0 & 0 & 0 \\
\hline 8 & 0 & $\%$ fixed assets & $<10 \%$ & $\mathrm{G}$ & 0 & 0 & 0 & 0 & 0 & $\uparrow \uparrow$ & 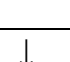 & $\downarrow$ & 0 & 0 \\
\hline 12 & $P$ & $\begin{array}{l}\text { Approval of fees mentioned to } \\
\text { Parliament by minister }\end{array}$ & not applicable & $P$ & 0 & $\uparrow$ & 0 & $\uparrow$ & 0 & $\uparrow$ & 0 & 0 & 0 & 0 \\
\hline 13 & $P$ & $\begin{array}{l}\text { Approval of annual report } \\
\text { mentioned to Parliament by } \\
\text { minister }\end{array}$ & Yes & $P$ & $\uparrow$ & 0 & 0 & $\uparrow$ & 0 & $\uparrow$ & 0 & $\downarrow$ & 0 & $\uparrow$ \\
\hline 14 & $P$ & $\begin{array}{l}\text { Frequency of reporting by } \\
\text { minister to Parliament }\end{array}$ & Yearly & $P$ & 0 & $\downarrow$ & 0 & $\uparrow$ & 0 & $\uparrow$ & 0 & $\downarrow$ & 0 & $\uparrow$ \\
\hline
\end{tabular}




\begin{tabular}{|c|c|c|c|c|c|c|c|c|c|c|c|c|c|c|}
\hline 15 & 0 & $\begin{array}{l}\text { Performance indicators } \\
\text { reported to Parliament in } \\
\text { ministries' budget documents }\end{array}$ & Throughput & $\mathrm{P}$ & 0 & $\uparrow$ & 0 & $\uparrow$ & 0 & $\uparrow$ & 0 & $\uparrow$ & 0 & $\uparrow$ \\
\hline 16 & 0 & $\begin{array}{l}\text { Performance indicators } \\
\text { reported to Parliament in ZBO } \\
\text { Annual reports }\end{array}$ & Throughput & $\mathrm{P}$ & 0 & 0 & 0 & $\uparrow$ & 0 & $\uparrow$ & 0 & 0 & 0 & $\uparrow$ \\
\hline 17 & $P$ & $\begin{array}{l}\text { Frequency of reporting to } \\
\text { Minister }\end{array}$ & Yearly & M & 0 & $\downarrow$ & 0 & $\downarrow$ & 0 & 0 & 0 & $\downarrow$ & 0 & $\downarrow$ \\
\hline 18 & 0 & $\begin{array}{l}\text { Number of documents } \\
\text { submitted to Parliament } \\
\text { regarding operations of ZBO }\end{array}$ & 0 & $\mathrm{P}$ & 0 & $\downarrow$ & 0 & 0 & 0 & $\downarrow$ & 0 & $\downarrow$ & 0 & $\downarrow$ \\
\hline 19 & $P$ & $\begin{array}{l}\text { Budget instruction by Minister- } \\
\text { Principal }\end{array}$ & No & $M$ & 0 & 0 & $\downarrow$ & $\uparrow$ & 0 & 0 & 0 & 0 & 0 & $\downarrow$ \\
\hline
\end{tabular}




\section{Appendix 11: Instructions on attributing authority.}

Table 20.1: instructions affecting autonomy of ZBOs in 'Aanwijzingen' and 'kZBO'

\begin{tabular}{|c|c|c|c|c|c|c|c|c|c|c|}
\hline & $\mathrm{Clnr}$ & $\begin{array}{l}\text { Classifi- } \\
\text { cation }\end{array}$ & $\begin{array}{l}\text { Article } x \\
\text { AW1996 }\end{array}$ & Applicability & $\begin{array}{l}\text { Option (O) or } \\
\text { compulsory (C) }\end{array}$ & $\begin{array}{l}\text { Impact on } \\
\text { autonomy }\end{array}$ & $\begin{array}{l}\text { Art x } \\
\text { AW2008 }\end{array}$ & $\begin{array}{l}\text { Applica- } \\
\text { bility }\end{array}$ & $\begin{array}{l}\text { Art } x \\
\text { kZBO }\end{array}$ & Applicability \\
\hline $\begin{array}{l}\text { Conditions for issuing } \\
\text { operational instructions by } \\
\text { ZBO }\end{array}$ & 4 & $\mathrm{~N}$ & $124 f$ & All & 0 & Yes & $124 c$ & All & & \\
\hline Task description & 4 & $\mathrm{~N}$ & $124 g$ & All & C & Yes & $\begin{array}{l}124 d .2 . \\
2\end{array}$ & All & & \\
\hline Structure of board & 2 & 0 & $124 \mathrm{i} .1$ & PLA & C & Yes & $124 \mathrm{e} .1$ & PLA & & \\
\hline $\begin{array}{l}\text { Appointment of members of } \\
\text { interest groups }\end{array}$ & 2 & 0 & $124 i .3$ & All & 0 & Yes & 124.e.2. & PLA & & \\
\hline $\begin{array}{l}\text { Appointment in governance } \\
\text { structures other than Board }\end{array}$ & 2 & 0 & $124 \mathrm{i} .4$ & All & C & Yes & 124 e.3 & PLA & & \\
\hline $\begin{array}{l}\text { Law must include relation and } \\
\text { authority attributed to minister } \\
\text { and board }\end{array}$ & 2 & 0 & $\begin{array}{l}124 I .1 / 1 \\
24 I .2\end{array}$ & All & $\mathrm{C}$ & Yes & & & & \\
\hline $\begin{array}{l}\text { Approval by minister of other } \\
\text { authoritative decisions by ZBO }\end{array}$ & 4 & $\mathrm{~N}$ & 1241.5 & All & 0 & Yes & & & & \\
\hline $\begin{array}{l}\text { Change of legislation when } \\
\text { insufficient authority appears } \\
\text { to be attributed to minister }\end{array}$ & 4 & $\mathrm{~N}$ & 1241.7 & All & C & Yes & & & & \\
\hline $\begin{array}{l}\text { Including funding method in } \\
\text { the law }\end{array}$ & 1 & C & $\begin{array}{l}124 n \cdot 1 / . \\
2\end{array}$ & PLA & C & Yes & $\begin{array}{l}124 d .2 . \\
3\end{array}$ & & & \\
\hline $\begin{array}{l}\text { Requirement that ZBO-case } \\
\text { law determines financial } \\
\text { oversight }\end{array}$ & 3 & I & 1240.2 & PLA & $\mathrm{C}$ & Yes & & & & \\
\hline $\begin{array}{l}\text { Specifications of annual report } \\
\text { included in ZBO-case law }\end{array}$ & 3 & $\mathrm{I}$ & 124s.2 & PLA & 0 & Yes & & & & \\
\hline $\begin{array}{l}\text { Arrangement on transfer of } \\
\text { assets and liabilities to new } \\
\text { legal entity }\end{array}$ & 4 & $\mathrm{~N}$ & $124 v$ & All? & 0 & Yes & $124 \mathrm{~h}$ & All & & \\
\hline $\begin{array}{l}\text { Arrangement on transfer of } \\
\text { legal disputes }\end{array}$ & 4 & $\mathrm{~N}$ & $124 w$ & PLA & 0 & Yes & $124 \mathrm{i}$ & All & & \\
\hline
\end{tabular}




\begin{tabular}{|c|c|c|c|c|c|c|c|c|c|c|}
\hline & $\mathrm{Clnr}$ & $\begin{array}{l}\text { Classifi- } \\
\text { cation }\end{array}$ & $\begin{array}{l}\text { Article } x \\
\text { AW1996 }\end{array}$ & Applicability & $\begin{array}{l}\text { Option (O) or } \\
\text { compulsory }(\mathrm{C})\end{array}$ & $\begin{array}{l}\text { Impact on } \\
\text { autonomy }\end{array}$ & $\begin{array}{l}\text { Art } x \\
\text { AW2008 }\end{array}$ & $\begin{array}{l}\text { Applica- } \\
\text { bility }\end{array}$ & $\begin{array}{l}\text { Art } x \\
\text { kZBO }\end{array}$ & Applicability \\
\hline $\begin{array}{l}\text { Defining relationship between } \\
\text { different bodies in governance } \\
\text { structure }\end{array}$ & 2 & 0 & $124 j$ & PLA & $\mathrm{C}$ & Yes & $124 f$ & $\begin{array}{l}\text { All } \\
\text { (extended } \\
\text { examples) }\end{array}$ & 7 & All \\
\hline $\begin{array}{l}\text { Ex ante approval by minister } \\
\text { for mandates within the ZBO }\end{array}$ & 2 & 0 & & & C & Yes & & & 8 & All \\
\hline $\begin{array}{l}\text { Prohibition to appoint civil } \\
\text { servants in board }\end{array}$ & 4 & $\mathrm{~N}$ & $124 \mathrm{i} .2$ & All & C & Yes & & & 9 & All \\
\hline $\begin{array}{l}\text { Approval of internal } \\
\text { governance statute by } \\
\text { minister }\end{array}$ & 2 & 0 & 1241.4 & PLA & C & Yes & & & 11 & PLA \\
\hline $\begin{array}{l}\text { (re)appointment and dismissal } \\
\text { of board }\end{array}$ & 2 & 0 & $124 \mathrm{i} .1$ & PLA & C & Yes & Not & & 12 & PLA \\
\hline $\begin{array}{l}\text { Arrangement on secondary } \\
\text { jobs of Board members }\end{array}$ & 2 & 0 & & & C & Yes & & & 13 & PLA \\
\hline $\begin{array}{l}\text { Arrangement on appointing } \\
\text { staff }\end{array}$ & 4 & $\mathrm{~N}$ & $124 u$ & PLA & 0 & Yes & & & 15 & PLA \\
\hline $\begin{array}{l}\text { Staff ZBO is subordinated to } \\
\text { board, not minister }\end{array}$ & 4 & $\mathrm{~N}$ & & & C & Yes & & & 16 & PLA \\
\hline Approval of fees by minister & 1 & C & 1241.3 & All & C & Yes & & & 17 & All \\
\hline $\begin{array}{l}\text { ZBO submits annual report to } \\
\text { minister }\end{array}$ & 3 & I & 124s.1 & All & C & Yes & & & 18 & All \\
\hline $\begin{array}{l}\text { General right of inquiry for } \\
\text { minister }\end{array}$ & 3 & I & $124 t$ & All & C & Yes & & & 20 & All \\
\hline $\begin{array}{l}\text { Minister decides on general } \\
\text { instructions on tasks and } \\
\text { other limitatively listed issues }\end{array}$ & 4 & $\mathrm{~N}$ & $\begin{array}{l}1241.5 a / \\
b\end{array}$ & All & 0 & Yes & & & 21 & $\begin{array}{l}\text { All, not } \\
\text { limited }\end{array}$ \\
\hline $\begin{array}{l}\text { Approval, suspension or } \\
\text { reversal of ZBO-decisions }\end{array}$ & 2 & 0 & $1241.5 c$ & All & 0 & Yes & & & 22 & $\begin{array}{l}\text { All, only } \\
\text { reversal }\end{array}$ \\
\hline $\begin{array}{l}\text { Intervention by minister in } \\
\text { case of negligence }\end{array}$ & 2 & 0 & $124 \mathrm{~m}$ & All & 0 & Yes & & & 23 & $\begin{array}{l}\text { All + inform } \\
\text { Parliament }\end{array}$ \\
\hline $\begin{array}{l}\text { Consent with budget and } \\
\text { multiyear forecast by minister }\end{array}$ & 1 & C & 1241.4 & PLA & C & Yes & & & $\begin{array}{l}29: \\
\text { approve } \\
\text { ment } \\
\text { except } \\
\text { multi } \\
\text { annual } \\
\text { forecast }\end{array}$ & All \\
\hline
\end{tabular}




\begin{tabular}{|c|c|c|c|c|c|c|c|c|c|c|}
\hline & $\mathrm{Clnr}$ & $\begin{array}{l}\text { Classifi- } \\
\text { cation }\end{array}$ & $\begin{array}{l}\text { Article } x \\
\text { AW1996 }\end{array}$ & Applicability & $\begin{array}{l}\text { Option (O) or } \\
\text { compulsory }(\mathrm{C})\end{array}$ & $\begin{array}{l}\text { Impact on } \\
\text { autonomy }\end{array}$ & $\begin{array}{l}\text { Art x } \\
\text { AW2008 }\end{array}$ & $\begin{array}{l}\text { Applica- } \\
\text { bility }\end{array}$ & $\begin{array}{l}\text { Art x } \\
\text { kZBO }\end{array}$ & Applicability \\
\hline $\begin{array}{l}\text { Report on substantial } \\
\text { differences between budget } \\
\text { and actual expenditures }\end{array}$ & 1 & C & & & $\mathrm{C}$ & Yes & & & 30 & All \\
\hline $\begin{array}{l}\text { Requirement that ZBO-case } \\
\text { law determines ministerial } \\
\text { consent to private law based } \\
\text { decisions (e.g. statutes, lease, } \\
\text { borrowing) }\end{array}$ & 2 & $\mathrm{O}$ & 1240.3 & PLA & 0 & Yes & & & $\begin{array}{l}32, \\
\text { limitative } \\
\text { list, }\end{array}$ & All \\
\hline Creating equalisation reserve & 1 & $\mathrm{C}$ & & & $\mathrm{C}$ & Yes & & & 33 & All \\
\hline $\begin{array}{l}\text { Requirement of statement of } \\
\text { accounts }\end{array}$ & 3 & I & $124 p .1$ & PLA & $\mathrm{C}$ & Yes & & & 34 & All \\
\hline $\begin{array}{l}\text { Minister can set rules on } \\
\text { structure statement of } \\
\text { accounts and auditing }\end{array}$ & 3 & I & 124 p. 2 & PLA & 0 & Yes & & & $35[\mathrm{C}]$ & All \\
\hline $\begin{array}{l}\text { Requirement to separate } \\
\text { accounts for ZBO activities } \\
\text { and non-ZBO activities }\end{array}$ & 3 & I & & & $\mathrm{C}$ & Yes & & & 38 & PLB \\
\hline $\begin{array}{l}\text { Requirement for data } \\
\text { protection }\end{array}$ & 4 & $\mathrm{~N}$ & & & 0 & Yes & & & 41 & All \\
\hline $\begin{array}{l}\text { Decide upon ZBOs to be } \\
\text { subject to kZBO }\end{array}$ & 4 & $\mathrm{~N}$ & & & $\mathrm{C}$ & Yes & & & 42 & All \\
\hline $\begin{array}{l}\text { Board ZBO decides upon the } \\
\text { budget }\end{array}$ & 1 & $\mathrm{C}$ & 1240.1 & PLA & $\mathrm{C}$ & Yes & & & $\begin{array}{l}26, \text { by } \\
\text { implicati } \\
\text { on } 29 \\
\end{array}$ & All \\
\hline $\begin{array}{l}\text { Minister can set rules on } \\
\text { structure of budget, }\end{array}$ & 1 & $\mathrm{C}$ & 124 p. 2 & PLA & 0 & Yes & & & $\begin{array}{l}27[\mathrm{C}] \\
28[\mathrm{C}]\end{array}$ & All \\
\hline Applicability of rules for PLBs & 4 & $\mathrm{~N}$ & & & C & Yes & & & $36 ; 37$ & PLB \\
\hline Attribution of legal status & 4 & $\mathrm{~N}$ & $124 b$ & All & $\mathrm{C}$ & No & Not & & & \\
\hline Contents explanatory notes & 4 & $\mathrm{~N}$ & $124 d$ & All & $\mathrm{C}$ & No & $124 a$ & All & & \\
\hline $\begin{array}{l}\text { Wording attribution of legal } \\
\text { status }\end{array}$ & 4 & $\mathrm{~N}$ & $124 h$ & PLA & $\mathrm{C}$ & No & $\begin{array}{l}124 d .1 / \\
124.2 .1\end{array}$ & All & & \\
\hline $\begin{array}{l}\text { Wording creating internal } \\
\text { governance statute }\end{array}$ & 4 & $\mathrm{~N}$ & $124 \mathrm{k}$ & PLA & $\mathrm{C}$ & No & & & & \\
\hline $\begin{array}{l}\text { Prohibition for minister to give } \\
\text { case based instructions }\end{array}$ & 4 & $\mathrm{~N}$ & $124 I .6$ & All & $\mathrm{C}$ & No & $124 g$ & All & & \\
\hline $\begin{array}{l}\text { Including funding method in } \\
\text { explanatory notes }\end{array}$ & 4 & $\mathrm{~N}$ & $124 n .3$ & All & $\mathrm{C}$ & No & & & & \\
\hline
\end{tabular}




\begin{tabular}{|c|c|c|c|c|c|c|c|c|c|c|}
\hline & $\mathrm{Clnr}$ & $\begin{array}{l}\text { Classifi- } \\
\text { cation }\end{array}$ & $\begin{array}{l}\text { Article } x \\
\text { AW1996 }\end{array}$ & Applicability & $\begin{array}{l}\text { Option (0) or } \\
\text { compulsory (C) }\end{array}$ & $\begin{array}{l}\text { Impact on } \\
\text { autonomy }\end{array}$ & $\begin{array}{l}\text { Art x } \\
\text { AW2008 }\end{array}$ & $\begin{array}{l}\text { Applica- } \\
\text { bility }\end{array}$ & $\begin{array}{l}\text { Art } x \\
\text { kZBO }\end{array}$ & Applicability \\
\hline $\begin{array}{l}\text { Board meetings publicly } \\
\text { accessible based on } \\
\text { regulations in the ZBO-case } \\
\text { law }\end{array}$ & 3 & I & $124 r$ & PLA & $\mathrm{C}$ & No & & & & \\
\hline Procedure to consult NCA & 4 & $\mathrm{~N}$ & $124 \times .2$ & All & C & No & & & & \\
\hline $\begin{array}{l}\text { Exclusion of universities and } \\
\text { high schools }\end{array}$ & 4 & $\mathrm{~N}$ & $124 z$ & PLA & C & No & & & & \\
\hline Formal legisItative issues & 4 & $\mathrm{~N}$ & & & C & No & & & $43-46$ & None \\
\hline Definition & 4 & $\mathrm{~N}$ & $124 a$ & All & C & No & Not & & 1 & All \\
\hline Transition arrangements & 4 & $\mathrm{~N}$ & & & C & No & & & 2 & All \\
\hline Reason for using ZBO & 4 & $\mathrm{~N}$ & $124 c$ & All & C & No & Not & & 3 & All \\
\hline Creating a ZBO & 4 & $\mathrm{~N}$ & $124 \mathrm{e}$ & All & C & No & $124 b$ & All & 4 & All \\
\hline $\begin{array}{l}\text { Requirement to inform } \\
\text { Parliament on intended } \\
\text { proposal to create ZBO }\end{array}$ & 3 & I & & & C & No & & & 5 & All \\
\hline $\begin{array}{l}\text { Procedure to consult minBZK, } \\
\text { minFin }\end{array}$ & 4 & $\mathrm{~N}$ & $124 x .1$ & All & C & No & $124 j$ & All & 6 & All \\
\hline $\begin{array}{l}\text { Defining applicability of } \\
\text { section of kZBO }\end{array}$ & 4 & $\mathrm{~N}$ & & & C & No & & & 10 & PLA \\
\hline $\begin{array}{l}\text { Minister decides on } \\
\text { remuneration of Board }\end{array}$ & 2 & 0 & & & C & No & & & 14 & PLA \\
\hline $\begin{array}{l}\text { ZBO monitors quality of } \\
\text { operations and reports in } \\
\text { annual report }\end{array}$ & 3 & I & & & C & No & & & 19 & All \\
\hline $\begin{array}{l}\text { Applicability of financial } \\
\text { monitoring section }\end{array}$ & 4 & $\mathrm{~N}$ & & & C & No & & & 24 & PLA \\
\hline Evaluation of kZBO & 2 & 0 & & & C & No & & & 39.1 & All \\
\hline $\begin{array}{l}\text { Public ZBO-register prepared } \\
\text { by minBZK }\end{array}$ & 4 & $\mathrm{~N}$ & & & $\mathrm{C}$ & No & & & 40 & All \\
\hline $\begin{array}{l}\text { Requirement on evaluation of } \\
\text { ZBO operations }\end{array}$ & 3 & I & $124 i j$ & All & C & No & & & 39.1 & All \\
\hline $\begin{array}{l}\text { Schedule for submitting } \\
\text { budget to minister }\end{array}$ & 1 & C & & & C & No & & & $25+26$ & All \\
\hline $\begin{array}{l}\text { (discontinued after 1-12- } \\
2000 \text { ) }\end{array}$ & & & $124 q$ & & & & & & & \\
\hline
\end{tabular}




\section{Curriculum Vitae.}

Johan A.M. de Kruijf was born in Drunen (Netherlands) in 1961. He studied public administration at the University of Twente (1982-1988) and later business economics at the University of Amsterdam (1995-1998). In his professional life he has been working in the public sector as of 1988 on both national as local level of government. In 1997 he started a line of career in the Dutch Social Security industry at one of the predecessors of UWV. As of 1999 he was able to return to the University of Twente as a part time assistant professor in public financial management. The combination of being a practitioner as well as an academic ultimately resulted in the research topic for this PhD thesis. Several papers on the theme of this thesis have been published so far, next to some papers on public sector accounting as well as financial management and autonomisation in local governments. 